\title{
ipen
}

INSTITUTO DE PESQUISAS ENERGÉTICAS E NUCLEARES Autarquia Associada à Universidade de São Paulo

\section{ARTICULAÇÃO DO SISTEMA DE INOVAÇÃO NO MUNICÍPIO DE SOROCABA. UM ESTUDO COM BASE NA EXPERIÊNCIA NACIONAL DE AMBIENTES DE INOVAÇÃO E NOS PÓLOS FRANCESES DE COMPETITIVIDADE.}

DEVANILDO DAMIÃO DA SILVA

Tese apresentada como parte dos requisitos para obtenção do grau de Doutor em Ciências na área de Tecnologia Nuclear - Aplicações.

Orientadora: Profa. Dra. Désirée Moraes Zouain Co-orientador: Prof. Dr. Guilherme Ary Plonski

SÃO PAULO 
INSTITUTO DE PESQUISAS ENERGÉTICAS E NUCLEARES Autarquia Associada à Universidade de São Paulo

\author{
ARTICULAÇÃO DO SISTEMA DE INOVAÇÃO \\ NO MUNICÍPIO DE SOROCABA. UM ESTUDO COM BASE NA \\ EXPERIÊNCIA NACIONAL DE AMBIENTES DE INOVAÇÃO E NOS \\ PÓLOS FRANCESES DE COMPETITIVIDADE.
}

DEVANILDO DAMIÃO DA SILVA

Tese apresentada como parte dos requisitos para obtenção do grau de Doutor em Ciências na área de Tecnologia Nuclear - Aplicações.

Orientadora: Profa. Dra. Désirée Moraes Zouain Co-orientador: Prof. Dr. Guilherme Ary Plonski

SÃO PAULO 2009 


\title{
AGRADECIMENTOS
}

\author{
A DEUS pela vida. \\ Aos pais: José e Inácia pelo amor. \\ A esposa Simone pela compreensão e carinho. \\ Ao pequeno David Ricardo pela alegria.
}

Aos demais familiares (irmaõs, cunhados e sobrinhos) pelo alicerce.

A orientadora Profa. Dra. Désirée M. Zouain pelo conhecimento, dedicação e oportunidade.

Ao Prof. Dr. Plonski pela sabedoria e articulação.

Aos amigos, em especial Carlos Alberto Graça, José Roberto Machado, Danilo Dupas e Mauro Catharino pela constante interação.

Aos participantes da banca (Dr. Rodolgo Politano, Dr. Paschoal, Dr. Martinho, Dr. Alberto).

Aos amigos da FAMOSP (Ormando, Cleberson e Mário), Impacta (Fructuoso, Valderes e Dalmolin) e Unifig (Carlos Gios, Gimenes, Joara, Gabarrone, Dagmar, Osmar) obrigado pelo apoio.

Aos amigos do grupo de pesquisa da USP (Renata, Vagner, Paulo, Luciana) pela ajuda na construção de pensamentos.

Ao Prefeito, Secretários e amigos de Sorocaba (Daniel, Carlos, Roberto e Nelson) pela oportunidade de conhecer e estudar essa cidade. 
Ao Consulado da França em São Paulo, em especial ao Dr. Michel Brunet, pelo apoio para a pesquisa de campo na França.

Ao Consulado Brasileiro na França, em especial à Sra. Diana Porto pela boa vontade e disposição em ajudar-me.

Aos membros dos Pólos Franceses estudados pela cordialidade e espírito de pesquisa.

Aos responsáveis pelos Parques Tecnológicos no Brasil pelo apreço ao trabalho científico.

Aos Prof. Dr. Vahan Agopyan e Prof. Dr. Marco Antonio Raupp pela gentileza na apreciação da proposta.

Aos membros do Pólo de Desenvolvimento e Inovação de Sorocaba, da Secretaria de Desenvolvimento de Sorocaba, do Núcleo de Política e Gestão Tecnológica da USP, do Instituto de Pesquisas Energéticas e Nucleares (Letícia, Rita, Barroso, Ilze) muito obrigado.

Aos demais entrevistados e aqueles que colaboraram nas entrevistas, agradeço a valiosa cooperação. 


\section{EPÍGRAFE}

Posso todas as coisas naquele que me fortalece. 


\title{
ARTICULAÇÃO DO SISTEMA DE INOVAÇÃO NO MUNICÍPIO DE SOROCABA. UM ESTUDO COM BASE NA EXPERIÊNCIA NACIONAL DE AMBIENTES DE INOVAÇÃO E NOS PÓLOS FRANCESES DE COMPETITIVIDADE.
}

\author{
DEVANILDO DAMIÃO DA SILVA
}

\begin{abstract}
RESUMO
Esta pesquisa investiga a relação entre o setor público, o setor privado, universidades e centros de pesquisa, com vistas ao incremento da competitividade, com base na situação do município de Sorocaba, no Estado de São Paulo. A hipótese inicial de pesquisa é que a interação entre os diferentes atores locais e os benefícios dela decorrentes são ampliados por meio da oferta de ambientes propícios à geração de conhecimento, tecnologia e inovação. A base teórica do estudo é alicerçada na escola neo-schumpeteriana e nos estudos dos sistemas nacionais e locais de inovação, recebendo uma importante contribuição de trabalhos desenvolvidos por renomados pesquisadores para analisar o tema Sistema de Inovação no Brasil. Simultaneamente é desenvolvido um profundo estudo das condições locais de Sorocaba, agregando pesquisa na literatura e pesquisa in loco, o que leva à caracterização da condição do sistema local de inovação em Sorocaba. Na perspectiva da pesquisa de campo opta-se, utilizando como critério a relevância da experiência, pelo desenvolvimento de um estudo de caso com foco nos Pólos Franceses de Competitividade. Em paralelo, com o objetivo de estabelecer uma referência local, são estudadas experiências nacionais em ambientes de inovação. A análise desses elementos permite definir dois conjuntos de informações: as demandas relacionadas às condições do Município de Sorocaba e os fatores prioritários em relação às experiências analisadas no Brasil e na França. Evidencia-se a fragilidade para tratamento dessas questões, considerando a utilização de um único instrumento, sendo proposto um sistema de inovação local com a utilização de vários instrumentos articulados, adequados às características locais do Município de Sorocaba.
\end{abstract}




\title{
ARTICULATION OF THE INNOVATION SYSTEM \\ IN SOROCABA CITY: A STUDY BASED ON THE BRAZILIAN \\ EXPERIENCE OF INNOVATION HABITATS AND FRENCH \\ COMPETITIVE CLUSTERS
}

\author{
DEVANILDO DAMIÃO
}

\begin{abstract}
This research investigates the relationship among public sector, private sector, universities and research centers, aiming to increase the companies competitiveness, focus on the case of the Sorocaba city, in State of São Paulo. The research hypothesis is that the local players' interaction and its resulting benefits are extended through the provision of an appropriate environment to the generation of knowledge, technology and innovation. The theoretical basis of the study is rooted in neo-Schumpeterian school, and the studies of local and national systems of innovation, receiving a major contribution to work of renowned researchers to examine the theme of Innovation System in Brazil. At the same time it is developed a deep study of local conditions of Sorocaba, by searching in the literature and performing a field research, which leads to the characterization of the condition of the local system of innovation in Sorocaba. In choosing primary research perspective, using as criterion the relevance of experience, it is developed a case study with focus on French Competitive Clusters. In parallel with the objective of establishing a local reference, are considered national experiences in innovation habitat. The analysis of these elements define two sets of information: the demand related to the conditions of the city of Sorocaba and the key factors examined considering the experiences in Brazil and France. Considering the use of a single instrument there is a weakness for the treatment of these issues, therefore it is proposed the articulation of a local innovation system, composed by several instruments dimensioned, adequate to the characteristics of the Sorocaba city.
\end{abstract}




\section{SUMÁRIO}

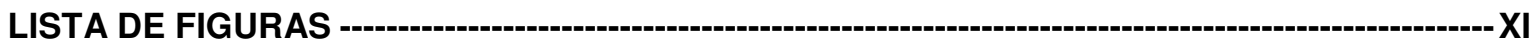

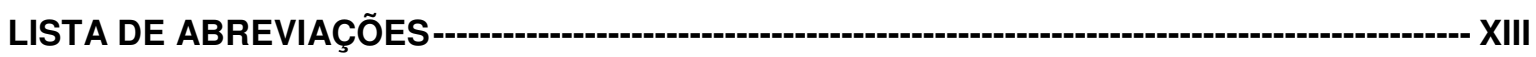

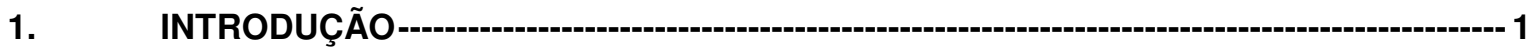

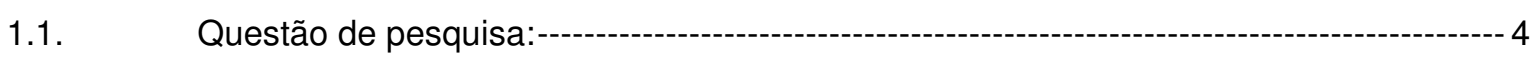

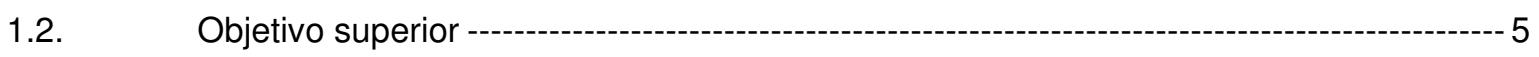

1.2.1. Objetivos Específicos: ---------------------------------------------------------------------- 5

1.3. Contribuições originais---

1.4. Apresentação da Estrutura do Trabalho ---

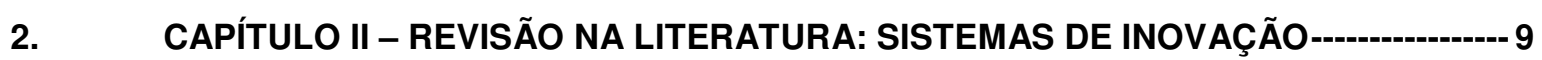

2.1. Sistemas de Inovação --

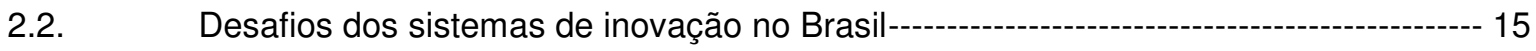

2.3. Considerações Preliminares -- 22

3. CAPÍTULO III - REVISÃO DA LITERATURA: AMBIENTES DE INOVAÇÃO--------- 24

3.1. Considerações sobre os Ambientes de Inovação-------

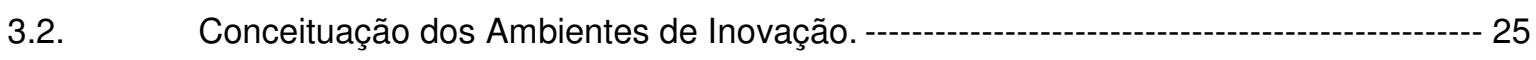

3.3. Parques Tecnológicos -- 30

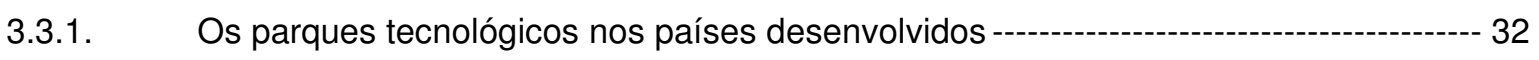

3.3.2. Os parques tecnológicos nos países em desenvolvimento. O caso brasileiro---------- 35

3.3.3. Conjunto de Atividades mais presentes em Parques Tecnológicos e Científicos. ----- 42

3.3.4. Fatores básicos para projetos de Parques Tecnológicos. - -

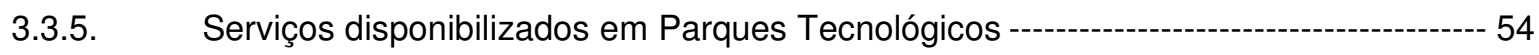

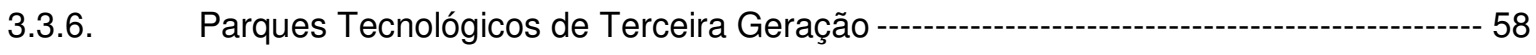

3.4. APLs - Arranjos Produtivos Locais -

3.5. Considerações Preliminares --

4. CAPÍTULO IV - REVISÃO DA LITERATURA. ESTUDO DAS CONDIÇÕES DE

SOROCABA----1.-- 71

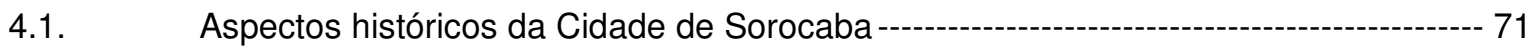

4.2. Caracterização da cidade---.-- 73

4.3. Aspectos relacionados à conurbação e importância para os Municípios vizinhos. ---- 75

4.4. Indicadores Sociais de Sorocaba -

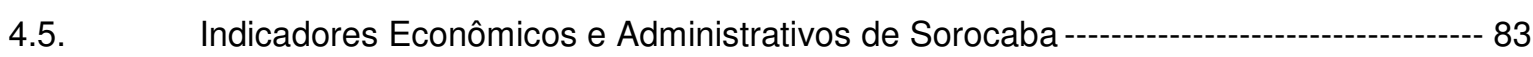

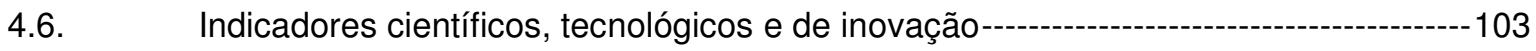

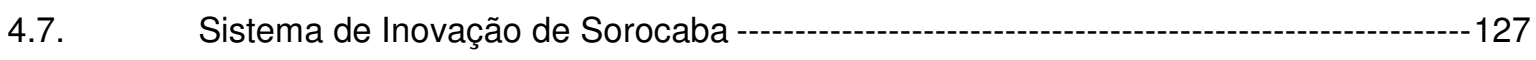

4.8. Considerações preliminares--

5. CAPÍTULO V - CONSIDERAÇÕES METODOLÓGICAS E O ESTUDO DE CASO ---131

5.1 Considerações metodológicas--

5.2 Estudo de caso - 135

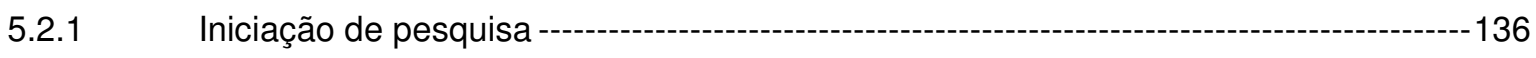


5.2.2 Seleção dos casos---- 141

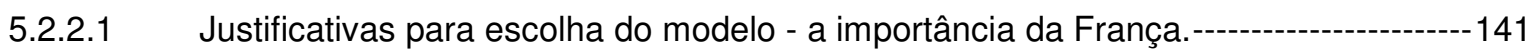

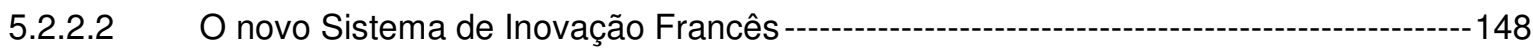

5.2.2.3 Pólos de competitividade---------

5.2.3 Desenvolvimento de Protocolos e Instrumentos. -

5.3 Considerações -

$6 . \quad$ CAPÍTULO V I - RESULTADOS E ANÁLISES-

6.1 Porto Digital----

6.2 A Fundação CERTI (Centros de Referência em Tecnologias Inovadoras) ---------------165

6.3 O Parque Científico e Tecnológico TECNOPUC - -

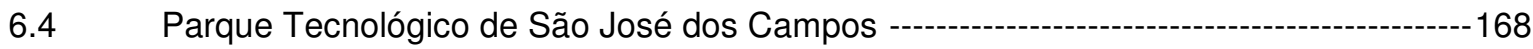

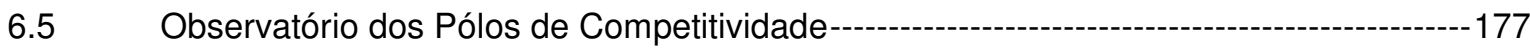

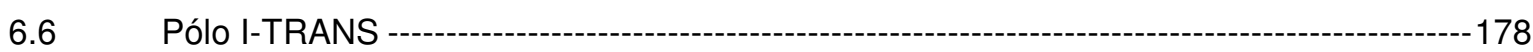

6.7 Medicen Paris Région--- 180

6.8 Cap Digital Paris Région --

6.9 ASTech Paris Région --- 183

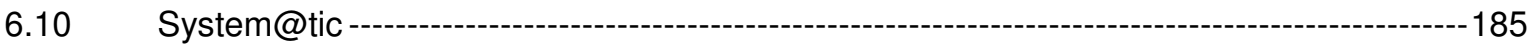

6.11 Análise --- 192

7. CAPÍTULO VII - PROPOSIÇÃO DE UMA ESTRUTURA CONCEITUAL DE AMBIENTE DE INOVAÇÃO PARA O MUNICÍPIO DE SOROCABA. -

7.1. Proposta de sistema de Inovação de Sorocaba--

8. CAPÍTULO VIII - CONCLUSÕES E RECOMENDAÇÕES --

APÊNDICE A - QUESTIONÁRIO DE PESQUISA -

APÊNDICE B - RELATÓRIO DE PESQUISA NA FRANÇA --:--:-

APÊNDICE C - RELATÓRIOS DAS VISITAS NACIONAIS-

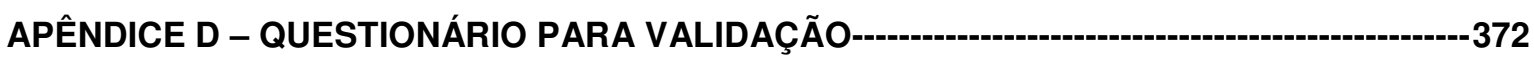

APÊNDICE E- CARACTERÍSTICAS DE SOROCABA--

GLOSSÁRIO - -

REFERÊNCIAS BIBLIOGRÁFICAS -- 


\section{LISTA DE TABELAS}

Tabela 2.1 panorama sobre a inovação nas empresas a partir da pintec.

Tabela 2.2 - gastos de p\&d privados - uma comparação entre brasil, outros países e ocde. ------ 18

Tabela 2.3 - governança nas políticas de inovação. ----------- 21

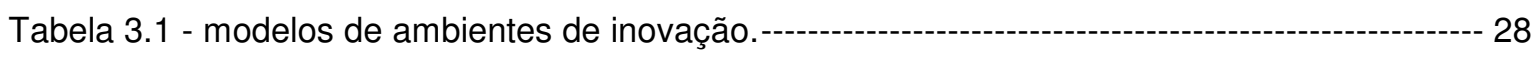

Tabela 3.2 - parques tecnológicos no mundo: modelos ---

Tabela 3.3 - número de parques tecnológicos no brasil. --

Tabela 3.4 - parques tecnológicos no brasil: natureza das atividades das empresas residentes -- 37

Tabela 3.5 - parques tecnológicos no brasil: número de empresas residentes---------------------- 37

Tabela 3.6 - parques tecnológicos do estado de são paulo ---

Tabela 3.7 - parques tecnológicos no mundo: período de fundação ----------------------------- 39

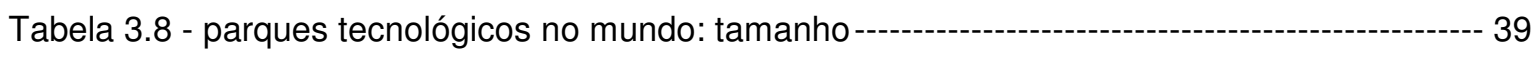

Tabela 3.9 - parques tecnológicos no mundo: área construída------- 40

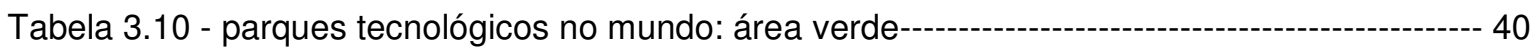

Tabela 3.11 - parques tecnológicos no mundo: natureza das atividades das empresas residentes

Tabela 3.12 - crescimento dos parques tecnológicos: principais restrições ------------------------ 44

Tabela 3.13 - empresas residentes em parques tecnológicos: elementos de localização ----------- 45

Tabela 3.14 - empresas residentes em parques tecnológicos: atributos mais valorizados ---------- 46

Tabela 3.15 - projeto de parques tecnológicos: projetos especialistas e generalistas (exemplos) 51

Tabela 3.16 - projeto de parques tecnológicos: sustentabilidade dos projetos (exemplos)---------- 53

Tabela 3.17 - projeto de parques tecnológicos: avaliação dos impactos (exemplos) ---------------- 56

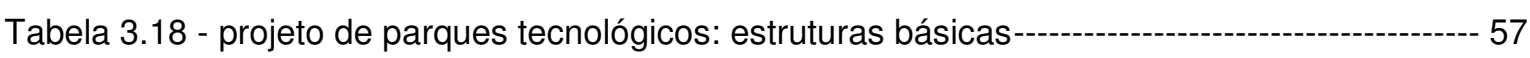

Tabela 3.19 - projeto de parques tecnológicos: estruturas complementares--------------------------- 58

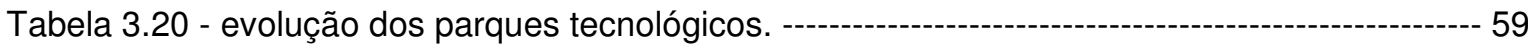

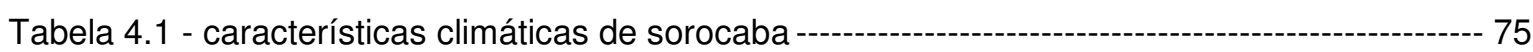

Tabela 4.2 - densidade demográfica dos principais municípios do entorno de sorocaba. ---------- 76

Tabela 4.3 - dados gerais da cidade de sorocaba e da ra de sorocaba. ---

Tabela 4.4 - participação de setores da indústria na região administrativa de sorocaba. ----------- 80

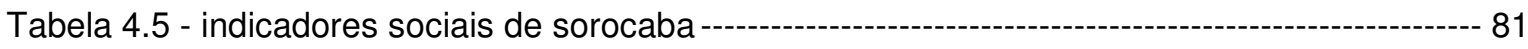

Tabela 4.6 -índices do mercado de trabalho de sorocaba. -

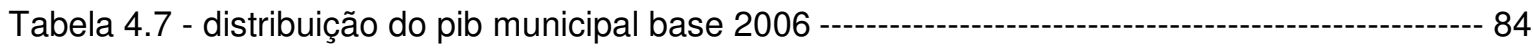

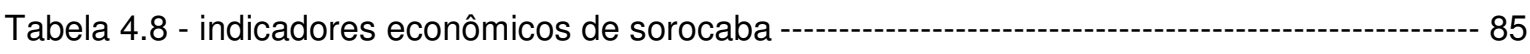

Tabela 4.9 - transferência de impostos para sorocaba.-- 86

Tabela 4.10 - valor adicionado fiscal da indústria --- 87

Tabela 4.11 - principais empresas de sorocaba ---o- 90

Tabela 4.12 - principais segmentos da indústria sorocabana. ---

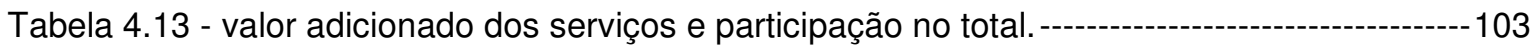

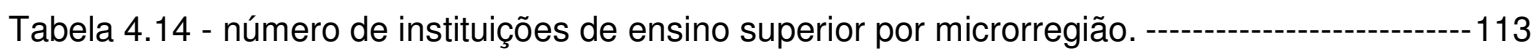


Tabela 4.15 - principais projetos desenvolvidos em instituições de c\&t em sorocaba.

Tabela 4.16 - instituições de p\&d das ciências físicas e naturais, por município - estado de são paulo, 2002.

Tabela 4.17 - cursos de aprendizagem industrial, técnicos e tecnológicos - microrregiões do estado de são paulo, 2003

Tabela 4.18 - cálculos de coeficiente locacional para atividades em sorocaba.----------------------126

Tabela 5.1- vantagens e desvantagens dos métodos racionalistas e de estudo de caso. ---------132

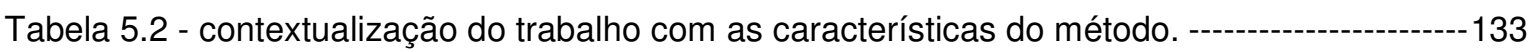

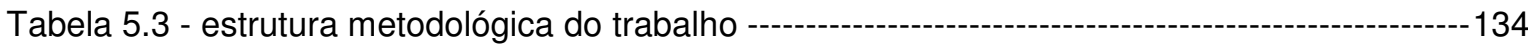

Tabela 5.4 - contextualização da pesquisa ---

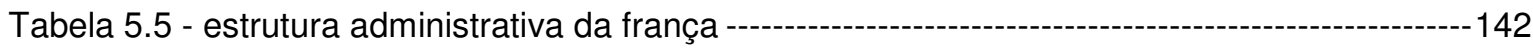

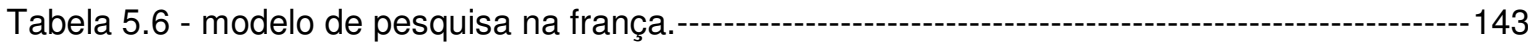

Tabela 5.7 - objetivos, ações e organização do programa para a pesquisa. ---

Tabela 5.8 - o novo sistema de inovação francês. ---

Tabela 5.9 - classificação de intensidade tecnológica. --

Tabela 5.10 - classificação dos setores da indústria brasileira, segundo intensidade tecnológica.

Tabela 5.11 - pólos pesquisados no estudo de caso ---

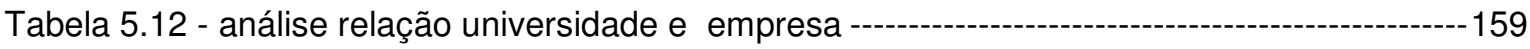

Tabela 6.1 - ambientes de inovação - experiências nacionais estudadas--------------------------163

Tabela 6.4.1 - resultados das entrevistas dos ambientes de inovação nacionais. -----------------172

Tabela 6.4.2 - dados cadastrais das experiências francesas selecionadas para as entrevistas. -176

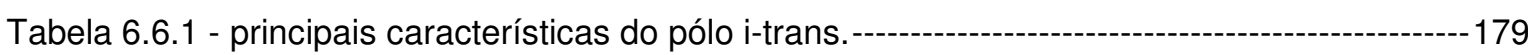

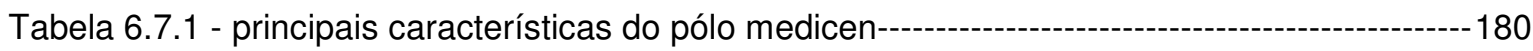

Tabela 6.8.1 - principais características do pólo cap digital ---------------------------------------182

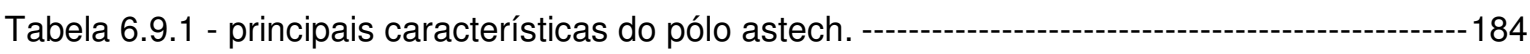

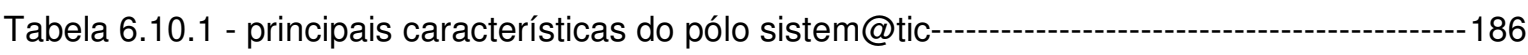

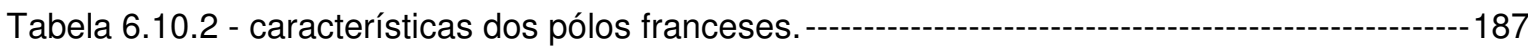

Tabela 6.11.1 - análise pontos fortes e pontos de melhorias dos ambientes de inovação pesquisados.

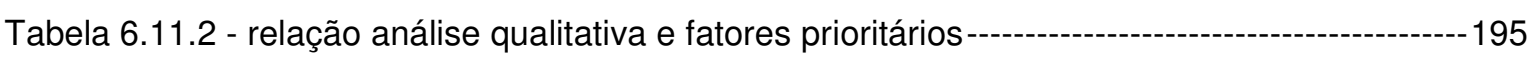

Tabela 7.1- características do sistema de inovação de sorocaba----- 


\section{LISTA DE FIGURAS}

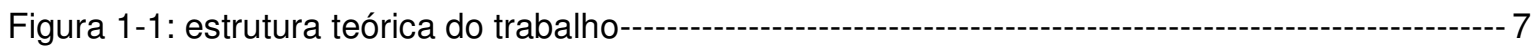

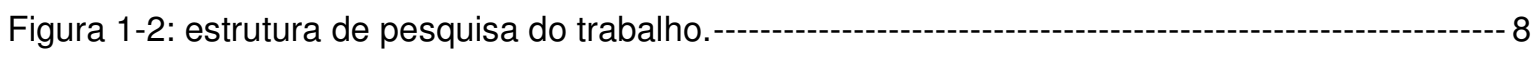

Figura 2-1: sistema de inovação: referências analíticas. - -

Figura 2-2: características em abordagens de sistema de inovação. ------------------------- 13

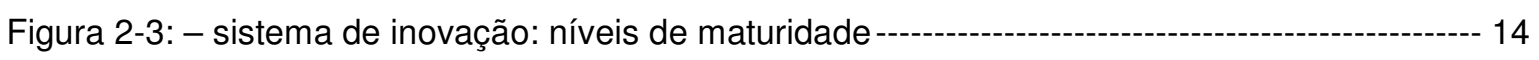

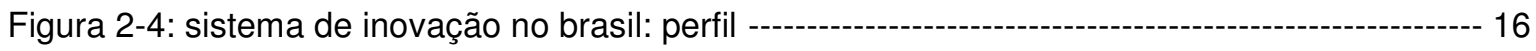

Figura 2-5: percentuais de empresa industriais que implementaram inovações no período de 1998

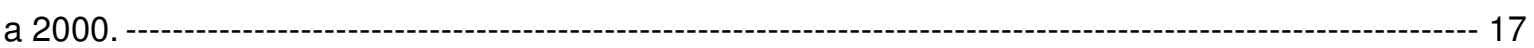

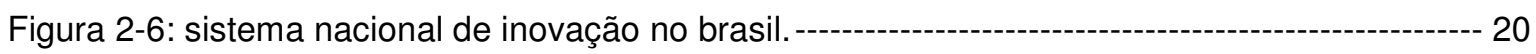

Figura 3-1: fatores que estimulam o desenvolvimento dos ambientes de inovação. ----------------- 24

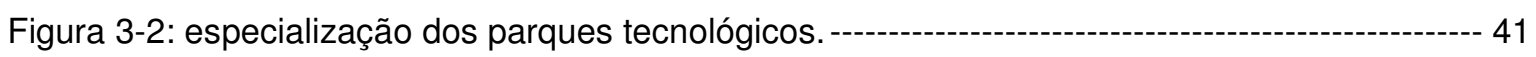

Figura 3-3: projetos de parques tecnológicos: modelos dos eixos estratégicos ---------------------- 49

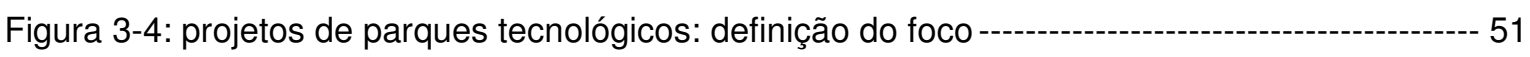

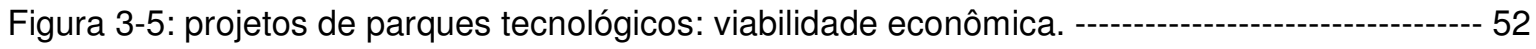

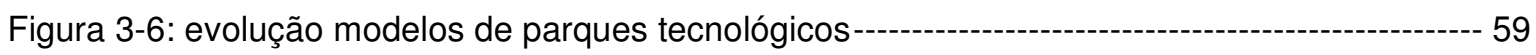

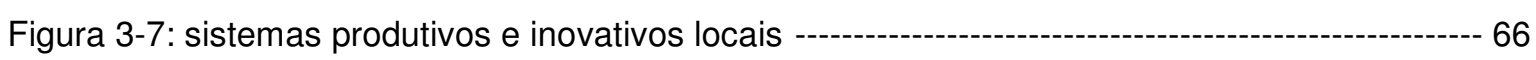

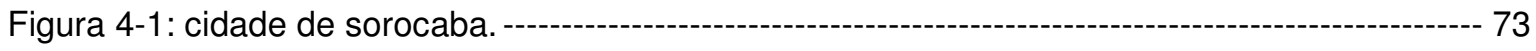

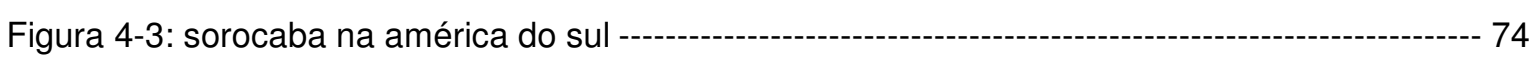

Figura 4-3: distribuição do pib - regiões administrativas do estado de são paulo - 2005. --------- 78

Figura 4-4: distribuição de riqueza da região administrativa de sorocaba.-------------------------- 79

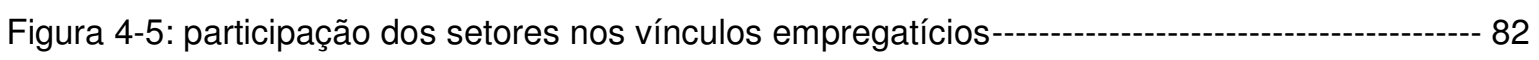

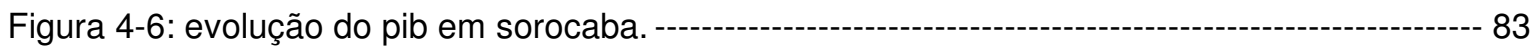

Figura 4-7: distribuição do valor adicionado de sorocaba. --------------------------------------------- 87

Figura 4-8: número de mestres e doutores atuando nas ies de sorocaba. ---

Figura 4-9: número de patentes por 100 mil habitantes - microrregiões do estado de são paulo, 1999-2001. --------107

Figura 4-10: especialização tecnológica* - microrregiões do estado de são paulo, 1999-2001. --108 Figura 4-11:: especialização tecnológica em informática - microrregiões do estado de são paulo, 1999-2001.

Figura 4-12: especialização tecnológica internacional* - microrregiões do estado de são paulo, 1992-2001.

Figura 4-13: especialização comercial internacional ${ }^{*}$ - microrregiões do estado de são paulo, 1998-

2002.----------------------------------------------------------------------------------------111

Figura 4-14: especialização científica* - microrregiões do estado de são paulo, 1999. ------------112 
Figura 4-15: número de estabelecimentos de ensino profissional (nível técnico e tecnológico) microrregiões do estado de são paulo, 2002. -

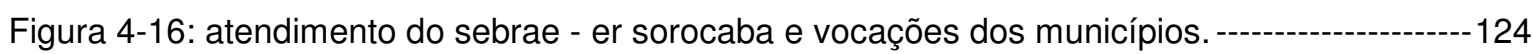

Figura 4-17: coeficiente locacional das atividades selecionadas de sorocaba.----------------------127

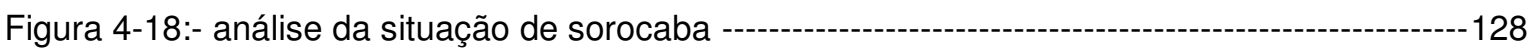

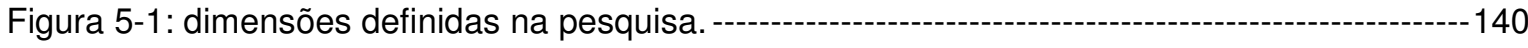

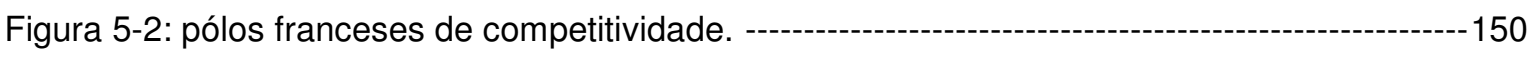

Figura 5-3: estrutura conceitual da governança. ---

Figura 5-4: mecanismos presentes na relação universidade e empresa. ----------------------------160

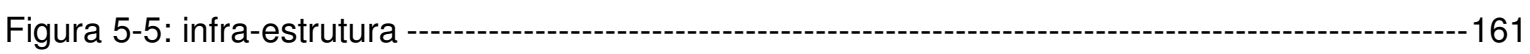

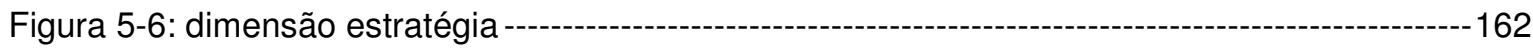

Figura 6.4-1: estrutura do parque tecnológico de são josé dos campos.---------------------------170

Figura 6.5-1: école nationale superieure des mines de paris. ---

Figura 6.7-1: escritório médicen paris. --- 180

Figura 6.8-1: pólo cap digital.----------181

Figura 6.9-1: chambre regionale de commerce et d'industrie, lille - france ---

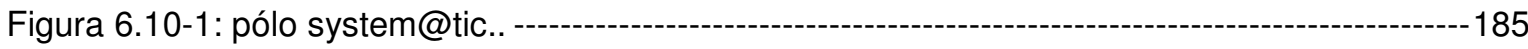

Figura 7-1: estrutura conceitual para a articulação do sistema local de inovação. ----------------197

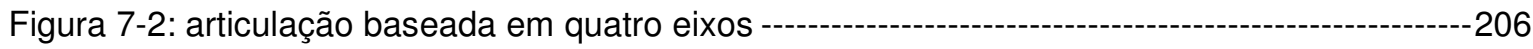

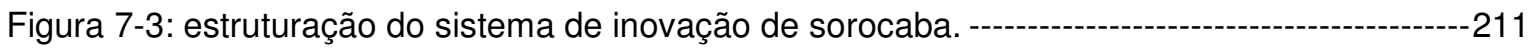




\section{LISTA DE ABREVIAÇÕES}

\begin{tabular}{|c|c|}
\hline CIFRE & Convenção Industrial de Formação para a Pesquisa (tradução) \\
\hline CNAE & Classificação Nacional de Atividades Econômicas \\
\hline $\mathrm{CPqD}$ & Centro de Pesquisa e Desenvolvimento em Telecomunicações \\
\hline C\&T\&I & Ciência, Tecnologia e Inovação \\
\hline DAESP & Departamento Aeroviário do Estado de São Paulo \\
\hline IASP & International Association of Science Parks \\
\hline IBGE & Instituto Brasileiro de Geografia e Estatística \\
\hline $\mathrm{IDH}$ & Índice de Desenvolvimento Humano \\
\hline IES & Instituições de Ensino Superior \\
\hline IPEN & Instituto de Pesquisas Energéticas e Nucleares \\
\hline INEP & Instituto Nacional de Estudos e Pesquisas Educacionais \\
\hline OCDE & Organização para a Cooperação e Desenvolvimento Econômico \\
\hline ONU & Organização das Nações Unidas \\
\hline$P \& D$ & Pesquisa e Desenvolvimento \\
\hline PAEP & Pesquisa da Atividade Econômica Paulista \\
\hline PDTI & Programa de Desenvolvimento Tecnológico e Industrial \\
\hline $\mathrm{PI}$ & Propriedade Intelectual \\
\hline PIB & Produto Interno Bruto \\
\hline PINTEC & Pesquisa de Inovação Tecnológica \\
\hline PME & Pequena e Média Empresa \\
\hline PT & Parque Tecnológico \\
\hline RA & Região Administrativa \\
\hline RAIS & Relação Anual de Informações Sociais \\
\hline $\mathrm{RM}$ & Região Metropolitana \\
\hline SEADE & Fundação Sistema Estadual de Análise de Dados \\
\hline SEBRAE & Serviço Brasileiro de Apoio as Micro e Pequenas Empresas \\
\hline SEDE & Secretaria de Desenvolvimento Econômico \\
\hline STP & Science and Technology Park \\
\hline USPTO & United States Patent and Trademark Office \\
\hline VA & Valor Adicionado \\
\hline VAF & Valor Adicionado Fiscal \\
\hline
\end{tabular}




\section{INTRODUÇÃO}

A capacidade de apropriar, desenvolver e transformar o conhecimento em produtos e processos inovadores representa um elemento fundamental para a competitividade das organizações e, também, para o desenvolvimento dos sistemas socioeconômicos (OCDE, 2004).

No entanto, a atividade inovativa compreende um processo de natureza complexa, da qual participam diferentes atores, em relações dinâmicas marcadas pelas especificidades contextuais, e, sobretudo, pelas incertezas. De acordo com Schumpeter (1982), a atividade inovadora rompe o fluxo circular estacionário e promove o crescimento de seu meio, levando outras empresas a inovarem em um processo de imitação.

Para lidar com essa questão, existe uma base teórica bem definida relacionada aos conceitos de "Sistema Inovação", que, tradicionalmente, considera as características e especificidades dos agentes que nele interagem a fim de estabelecer condições favoráveis à atividade inovativa. $\mathrm{Na}$ análise dos sistemas de inovação emerge uma literatura (EDQUIST, 2004. BORRÁS, 2004) que considera como componentes da sua formação as organizações, instituições e articulações.

A despeito do escopo da análise, que pode variar entre aglomerações produtivas com incipientes vínculos de articulação e cooperação, arranjos produtivos mais especializados e até mesmo os sistemas nacionais, constata-se que o objetivo básico das pesquisas ancoradas nesse referencial são 0 conhecimento e a intervenção sobre os elementos capazes de fomentar as atividades inovadoras nas empresas, considerados os atores (motores) da inovação.

Com a finalidade de melhorar as condições de conhecimento e intervenção sobre os elementos, considera-se importante desenvolver estudos descritivos para mapeamento das organizações e análises dos arcabouços institucionais sob a perspectiva de diferentes sistemas de inovação. Todavia, 
estes não se mostram totalmente efetivos, visto que não apontam os fatores determinantes para o desenvolvimento das inovações.

De outra forma, a articulação e a interação são condições relevantes para o sucesso de sistemas de inovação em diversos níveis. Sousa (2005) afirma que a palavra chave do conceito de sistema de inovação é interação, que se verifica entre empresas e instituições de pesquisa e de apoio, bem como na organização social para promover a inovação e o desenvolvimento econômico.

Vargas (2002) aprofunda esse tema e define que o aprendizado tecnológico e a capacitação produtiva não podem ser explicados unicamente numa perspectiva interna de empresa ou setor, mas, sobretudo, emergem das interações que são estabelecidas entre os atores e organizações que formam o sistema.

Portanto, é reconhecida como fundamental a interação. Entretanto somente o reconhecimento da importância das interações não é suficiente, uma vez que derivam questões de como fazê-la ou mesmo de como replicá-la.

Uma alternativa é atuar sobre os fatores de influência para o desenvolvimento de interações, em especial, os ambientes. Nesse contexto, convém citar Feldman e Florida (1994) que destacam o papel do ambiente no processo inovador, e Vargas (2002), que destaca a importância da proximidade para a disseminação do conhecimento tácito, ou seja, a geografia apresenta um papel central no processo inovador.

Uma análise mais aprofundada permite observar que, na década de 80, os modelos de inovação regionalizados ganharam destaque, inicialmente, com o renascimento da teoria dos distritos industriais italianos, e, posteriormente, com as teorias dos meios inovadores dos sistemas locais de produção (França), dos sistemas regionais de inovação, dos ${ }^{1}$ clusters territoriais e das regiões de aprendizagem (learning regions) ou do conhecimento (knowledge regions), de base anglo-saxônica e também inspiradas em casos específicos de sucesso, sendo que o mais notório foi, sem dúvida, o Sillicon Valley, nos Estados Unidos da América.

1 Clusters são redes de empresas independentes, instituições de produção do conhecimento (universidades, institutos de pesquisa, firmas provedoras de tecnologia) com organizações (ex. provedores de serviços técnicos) e clientes, ligados numa cadeia de produção que cria e agrega valor. O conceito de cluster vai além de um simples aglomerado de empresas, visto que capta o intercâmbio e compartilhamento do conhecimento. 
No cerne dessa literatura, estavam as vantagens advindas das condições locais positivas (mão-de-obra, logística) e a valorização dos conhecimentos mais densos. A densidade é função da complexidade de transmissão, sendo que alguns conhecimentos não são replicáveis fora do contexto e também não permitem uma codificação eficaz; sendo assim, a distância é a variável chave para a sua disseminação, enfatizando o papel central da proximidade como determinante a fim de garantir a competitividade.

Essa intensidade de elementos e interações apresenta impactos nas áreas de influências. Nesse sentido, o estudo dos sistemas de inovação constituise em referência para as políticas públicas, para 0 desenvolvimento socioeconômico, para a requalificação dos espaços urbanísticos e para a competitividade territorial, além de subsidiar o planejamento estratégico dos agentes envolvidos diretamente nessas atividades.

No contexto brasileiro, para ampliar a condição de análise, uma das alternativas é comparar a sua performance com a dos outros países. No Brasil a principal fonte de Pesquisa \& Desenvolvimento (P\&D) (mais de 50\%) ocorre por meio da compra de máquinas e equipamentos, sendo que nos países mais desenvolvidos, a principal fonte de P\&D são as atividades realizadas internamente nas empresas. (TIGRE, 2006)

Com maior especificidade, os resultados no país, medidos pela PINTEC $^{2}$, Pesquisa de Inovação Tecnológica (2005), demonstram uma postura reativa das empresas alicerçada em processos de difusão tecnológica com a finalidade de não perder mercado para as concorrentes. Também demonstram um moderado esforço inovativo, medido pelos investimentos em P\&D pelas empresas (TIGRE, 2006).

De acordo com Gonçalves (2007), uma possível explicação deve-se ao processo de industrialização tardia, que levou à adoção de políticas de substituição de importações. Tal processo foi desfavorável à atividade

\footnotetext{
2 PINTEC - Pesquisa de Inovação Tecnológica, realizada pelo Instituto Brasileiro de Geografia e Estatística (IBGE): "A PINTEC tem por objetivo a construção de indicadores setoriais nacionais e, no caso da indústria, também regionais, das atividades de inovação tecnológica das empresas brasileiras, comparáveis com as informações de outros países. O foco da pesquisa é sobre os fatores que influenciam o comportamento inovador das empresas, sobre as estratégias adotadas, os esforços empreendidos, os incentivos, os obstáculos e os resultados da inovação. Os resultados agregados da pesquisa permitirão: às empresas avaliar o seu desempenho em relação às médias setoriais; às entidades de classe analisar a conduta tecnológica dos setores; e aos governos desenvolver e avaliar políticas nacionais e regionais.”. Disponível em: http://www.pintec.ibge.gov.br. Acesso em 05/03/2009.
} 
tecnológica, dada a maior facilidade de "conseguir coisas prontas", disponíveis no mercado mundial de tecnologias.

Essa opção pela busca em adquirir coisas prontas não favoreceu a interação dos atores no país, configurando um sistema de inovação desarticulado, justificado pelos seguintes fatores: I) pela perspectiva dos resultados modestos no tocante a empresas inovativa; II) esforço reduzido das entidades privadas em P\&D; III) e pouca articulação entre os atores, sendo nítida a concentração da infra-estrutura, atividades e gastos em pesquisa e desenvolvimento pelo setor público.

Reforçando esse cenário, observa-se 0 descolamento entre as produções científicas e tecnológicas, visto que de acordo com os resultados nos últimos anos, o Brasil apresenta produção científica de quase 1,5\% do volume mundial e somente $0,1 \%$ da produção tecnológica, considerando as bases de artigos indexados no ISI - Instituto para informação Científica- e nas patentes depositadas na USPTO - escritório de patentes do USA. (ALBUQUEQUE et al, 2005).

No caso específico do Município de Sorocaba, definido para estudo, a partir de uma demanda da Secretaria de Desenvolvimento Econômico de Sorocaba para o grupo de pesquisa do CNPq, liderado pela Profa. Dra. Désirée M. Zouain, o mencionado contexto permite tomar como premissa que o Município reproduz as mesmas características destacadas no sistema nacional de inovação. Todavia, existe a hipótese a ser investigada de que a cidade reflete outra situação, possibilidade existente em países com sistemas de inovação heterogêneos.

Desse modo, a presente pesquisa investiga as condições para o desenvolvimento de uma estrutura conceitual de ambiente de inovação, que contemple as condições sócio-econômicas e tecnológicas locais, considerando aspectos de sustentabilidade.

A seguir são apresentadas as questões de pesquisa do trabalho.

\subsection{Questão de pesquisa:}

- Como estimular a interação entre o setor público, o setor privado e a universidade /centros de pesquisa, com vistas ao incremento da competitividade, considerando a experiência de um modelo desenvolvido num país com um sistema de inovação articulado e alicerçado em dinâmicas 
espontâneas versus o caso do Município de Sorocaba, localizado em um país caracterizado por um sistema de inovação heterogêneo com base numa dinâmica planejada?

\subsection{Objetivo superior}

- Estudar em profundidade a articulação de ambientes para o incremento da competitividade baseados no conhecimento e na inovação e propor o desenvolvimento de uma estrutura, considerando referências externas, adequada às condições locais em Sorocaba.

\subsubsection{Objetivos Específicos:}

- Estudar e caracterizar as condições locais do Município de Sorocaba e levantar suas bases científicas, tecnológicas e econômicas;

- Estudar os Pólos de competitividade da França (sistema de inovação articulado), modelo este selecionado por este pesquisador dentre outras experiências internacionais, com foco em variáveis específicas, verificando os pontos passíveis de serem aplicados à realidade local, no Brasil, levando em consideração as lacunas existentes em sistemas de inovação pouco articulados;

- Estruturar conceitualmente um ambiente de inovação em Sorocaba.

\subsection{Contribuições originais}

As principais contribuições do trabalho situam-se na realização de estudos que analisam um modelo de política de apoio ao desenvolvimento e à inovação aplicado a um país desenvolvido com um sistema de inovação articulado (França), confrontando esses estudos com uma situação local brasileira, caracterizada por um sistema de inovação (des)articulado.

É enriquecido com uma proposição original de uma estrutura de estímulo à competitividade e à inovação considerando o mapeamento das condições locais para uma região que não possui referências anteriores de estudos desta natureza (no caso, Sorocaba). 


\subsection{Apresentação da Estrutura do Trabalho}

O estudo apresenta uma característica multidisciplinar, não permitindo o seu enquadramento em uma única área do conhecimento. O tema inovação e, conseqüentemente, as suas vertentes de sistema de inovação e ambientes de inovação são abrangentes, podendo ser citados em diferentes áreas do conhecimento, como as ciências sociais aplicadas, em disciplinas de Economia e Administração; também no corpo das Engenharias com enfoque da engenharia de produção, ou em áreas relacionadas ao Urbanismo, a Geografia Espacial e mesmo Políticas Públicas.

Desta forma, o trabalho está estruturado em duas partes principais. A primeira de característica teórica (Figura 1-1) envolve a revisão bibliográfica, revisão documental e fundamentação teórica. No capítulo inicial são apresentados os principais conceitos sobre a base conceitual utilizada, a qual versa sobre os sistemas de inovação. A análise da literatura permite determinar os principais elementos relacionados na literatura tais como: i) o posicionamento do sistema de inovação brasileiro, com base numa perspectiva de comparação com dados desagregados por país; ii) os principais elementos constituintes de um sistema de inovação, iii) os critérios para análise do sistema de inovação do Brasil e iv) a importância relacionado aos ambientes e proximidade.

No Capítulo III são priorizadas as informações relacionadas aos ambientes de inovação, com enfoque relacionado aos parques tecnológicos, considerados na literatura especializada como o modelo mais evoluído de ambientes inovativos; também é analisada a literatura referente aos Arranjos Produtivos Locais e seus variantes.

O Capítulo IV apresenta um diagnóstico da cidade de Sorocaba com base na utilização de diversos indicadores, tais como: econômicos, científicotecnológicos, sociais, perfil histórico e principais equipamentos e serviços disponibilizados. 
Capitulo II - Sistema de Inovação

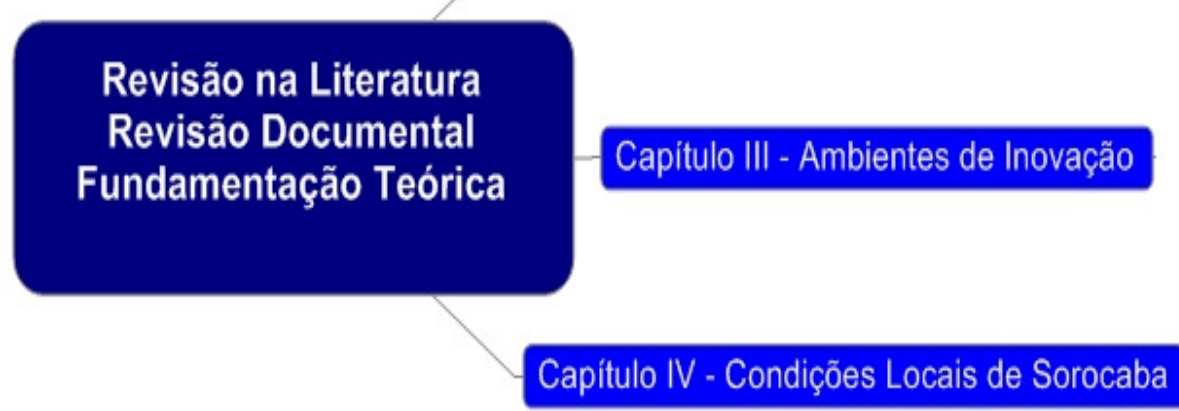

Figura 1-1: Estrutura Teórica do Trabalho

Na segunda parte, a qual trata do Desenvolvimento de pesquisa do trabalho (Figura 1-2), inicialmente no Capítulo $V$ é apresenta a estrutura metodológica, incluindo o estudo de caso, identificação das variáveis estudadas, a metodologia de seleção dos casos estudados, o porquê do caso dos pólos franceses serem privilegiados e os elementos relacionados ao estudo de caso desenvolvido nos pólos de inovação na França, desenvolvido com base nas dimensões de infra-estrutura, governança, estratégia e relação universidadeempresa. Nesse capítulo também são apresentadas a estrutura das visitas de controle executadas em alguns dos principais parques tecnológicos do Brasil.

O Capítulo VI são apresentados e analisados os resultados do estudo de caso, com base na estrutura analítica qualitativa utilizada.

O Capítulo VII desenvolve com base nas informações dos capítulos anteriores a proposição de articulação de um sistema de inovação para o Município de Sorocaba, considerando as características da região e a análise das experiências pesquisadas. 


\section{Capitulo V - Estudo de Caso}

\section{Pesquisa de Campo \\ Metodologia}

Capitulo VI - Resultados e Análise

Capítulo VII - Proposição de um sistema de inovação

Figura 1-2: Estrutura de pesquisa do Trabalho.

No capítulo final são apresentadas as conclusões e considerações da presente tese. 


\section{CAPÍTULO II - REVISÃO NA LITERATURA: SISTEMAS DE INOVAÇÃO}

\subsection{Sistemas de Inovação}

As abordagens iniciais sobre Sistema de Inovação foram desenvolvidas numa perspectiva nacional, na década de 80 de forma simultânea na Europa e nos Estados Unidos. Dentre os acadêmicos de destaque estão: Freeman, Lundvall, Nelson e também o IKE group (grupo de pesquisa da Universidade de Alborg/Dinamarca), com a participação de Esben Sloth Andersen e Gert Willumsen. (LUNDVALL, 2007).

Freeman (1995) conceituou o sistema nacional de inovação como uma construção institucional, podendo ser planejada ou espontânea, ou seja, produto de uma ação consciente ou um somatório de decisões descentralizadas e desarticuladas que impulsionam o progresso tecnológico em economias capitalistas complexas (FREEMAN, 1987; NELSON, 1993).

O nível de desagregação de análise dos sistemas nacionais de Inovação tradicionalmente ocorre entre países, servindo como referência para análises comparativas. Todavia não é a única abordagem, uma vez que a visão sistêmica da inovação apresenta variações podendo deslocar o foco das políticas, colocando como elemento principal a interação entre as instituições, observando os processos interativos na criação e na difusão e aplicação do conhecimento (OCDE, 2004).

Dessa forma, o sistema de inovação, visto como conjunto de componentes econômicos e institucionais que interage para o desenvolvimento de produtos e processos, pode ser abordado a partir de diferentes perspectivas e finalidades, como sugere Edquist (2004). Em relação às perspectivas de análise, o enfoque pode ser espacial ou geográfico, considerando-se o sistema a partir de uma área específica, como o espaço nacional, regional ou mesmo local (ASHEIM E ISAKSEN, 2002); ou, ainda, um enfoque setorial, em que são tratados produtos e/ou processos específicos em um sistema (MALERBA, 2003), conforme representados na Figura 2-1 
A escola denominada Evolucionista ou Neo-schumpeteriana identifica a atividade inovativa como um processo de natureza evolucionário, que ocorre a partir da conjugação de fatores econômicos e institucionais. A abordagem evolucionária enfatiza a importância da variedade e da diversidade tecnológicas e das formas em que a variedade se traduz em oportunidades e resultados tecnológicos (OCDE, 2004). Vargas (2002) destaca:

"A busca de uma explicação endógena para o processo de transformação do conhecimento aplicado em sistemas econômicos representa o principal desafio do esforço de teorização evolucionário. Sob vários aspectos, o desenvolvimento de explicação evolucionária para o processo de mudança tecnológica reflete o desconforto em relação ao referencial teórico ortodoxo, onde, tradicionalmente, o processo de criação e acumulação dos conhecimentos se encontra fora do escopo de análise dos modelos".

Como características da abordagem evolucionista podem ser citadas: I) a aceitação do desequilíbrio como elemento comum da dinâmica econômica, dado que existem estímulos para que os atores provoquem mudanças; II) a racionalidade com incerteza, visto a impossibilidade de conhecer todos os aspectos sob determinado tema e a maneira fragmentada que os problemas se apresentam; III) a busca e seleção de novas tecnologias, responsável pela introdução de dessas tecnologias e o aprimoramento dos processos (ALMEIDA, 2003).

Borrás (2004), ao estudar o sistema de inovação europeu, observa que o mesmo é essencialmente formado por dois elementos: I) uma estrutura de produção, relacionada à indústria e à dinâmica produtiva; II) um conjunto de instituições (arcabouço institucional) socioeconômicas e políticas numa determinada localidade. É importante frisar que na visão de Borrás (2004) as instituições possuem três funções genéricas na economia: reduzir incertezas, gerenciar conflitos e operações e prover incentivos. Também, aprofunda o estudo das instituições, segregando-as em dois grupos, um conjunto de instituições formais composto por regras e arranjos organizacionais e uma parte informal construída pelas interações dos atores que geram regras implícitas.

De acordo com Edquist (2004), as organizações básicas que compõem os sistemas de inovação são as empresas, consideradas o lócus da atividade inovativa; as organizações científicas e tecnológicas, responsáveis pelo 
desenvolvimento do conhecimento básico e também pela formação de recursos humanos; as organizações de fomento, em suas mais diversas configurações; o capital empreendedor (venture capital, seed money, business angels) e o poder público constituído.

As instituições, por sua vez, representam as normas, diretrizes, regulamentos e os procedimentos formais e informais vigentes no contexto das operações do sistema de inovação. Já as chamadas interações entre os atores, referem-se ao conjunto dos relacionamentos inerentes ao processo inovativo, que podem ser de mercado (quando envolvem relações de compra e venda), extra mercado (quando não envolvem relações diretas de compra e venda) e, ainda, entre as organizacionais de apoio ou institucionais.

No último sentido, ganham destaque as especificidades locais, como a natureza e o perfil das organizações, entendidas como atores do processo de inovação; as características das interações entre os elementos que compõem os subsistemas de inovação; as instituições, que suportam e norteiam as interações inerentes às atividades inovativa.

No que tange à relação finalidade, a análise do sistema de inovação pode centrar-se nos resultados e implicações relacionadas ao sistema, em termos, por exemplo, da criação da geração de produto, emprego e renda, ou, ainda, nos elementos determinantes dos sistemas de inovação, que constituem os condicionantes do seu desempenho.

A análise dos determinantes dos sistemas de inovação é, tradicionalmente, a perspectiva mais relevante para a pesquisa, como também para as políticas públicas, que buscam o desenvolvimento socioeconômico por meio da dinamização da atividade inovativa. Isso ocorre, sobretudo, pelo reconhecimento de que atividade inovativa, especialmente nas áreas de fronteira do conhecimento, é um processo de complexidade crescente, de natureza multidisciplinar, que dependem de políticas sistêmicas e cooperação.

Nessa perspectiva de análise, são consideradas as atividades do sistema de inovação e as suas funções (representadas pelos subconjuntos de atividades básicas operadas pelos atores do sistema) que se constituem em elementos interdependentes e característicos da eficácia e qualidade dos sistemas (BORRAS, 2004). Entre as atividades básicas do sistema, destacam-se: a pesquisa científica e tecnológica; o desenvolvimento de processos e de 
produtos; além da formação de recursos humanos (LIU e WHITE, 2000). Já, entre as funções básicas do sistema, destacam-se a produção, difusão e exploração das inovações.

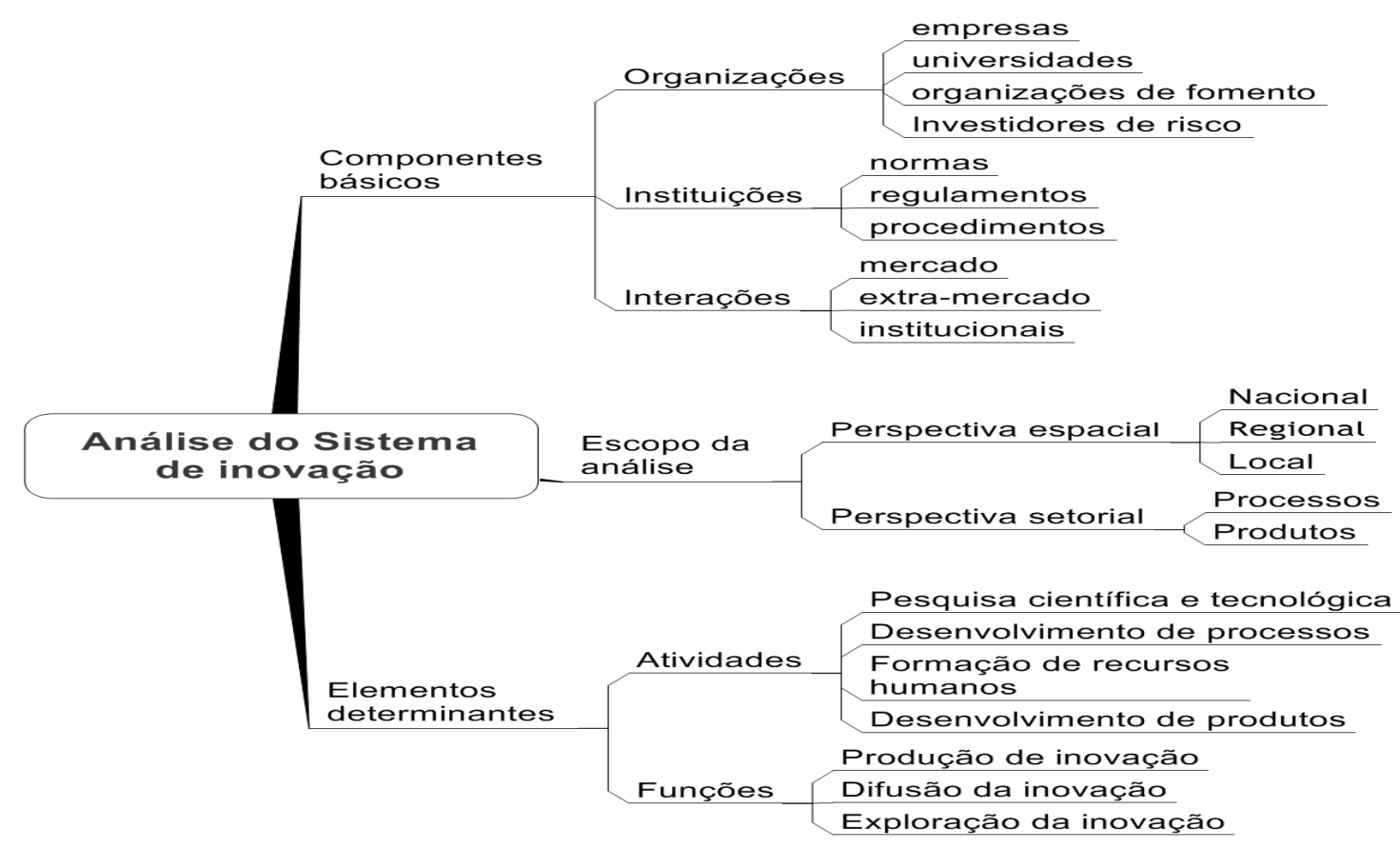

Figura 2-1: Sistema de inovação: referências analíticas. Elaborado a partir de Edquist (2001).

Edquist (2004), em suas análises sobre sistemas de inovação, aponta nove características comuns nas abordagens, sendo as mesmas apresentadas na Figura 2-2. 


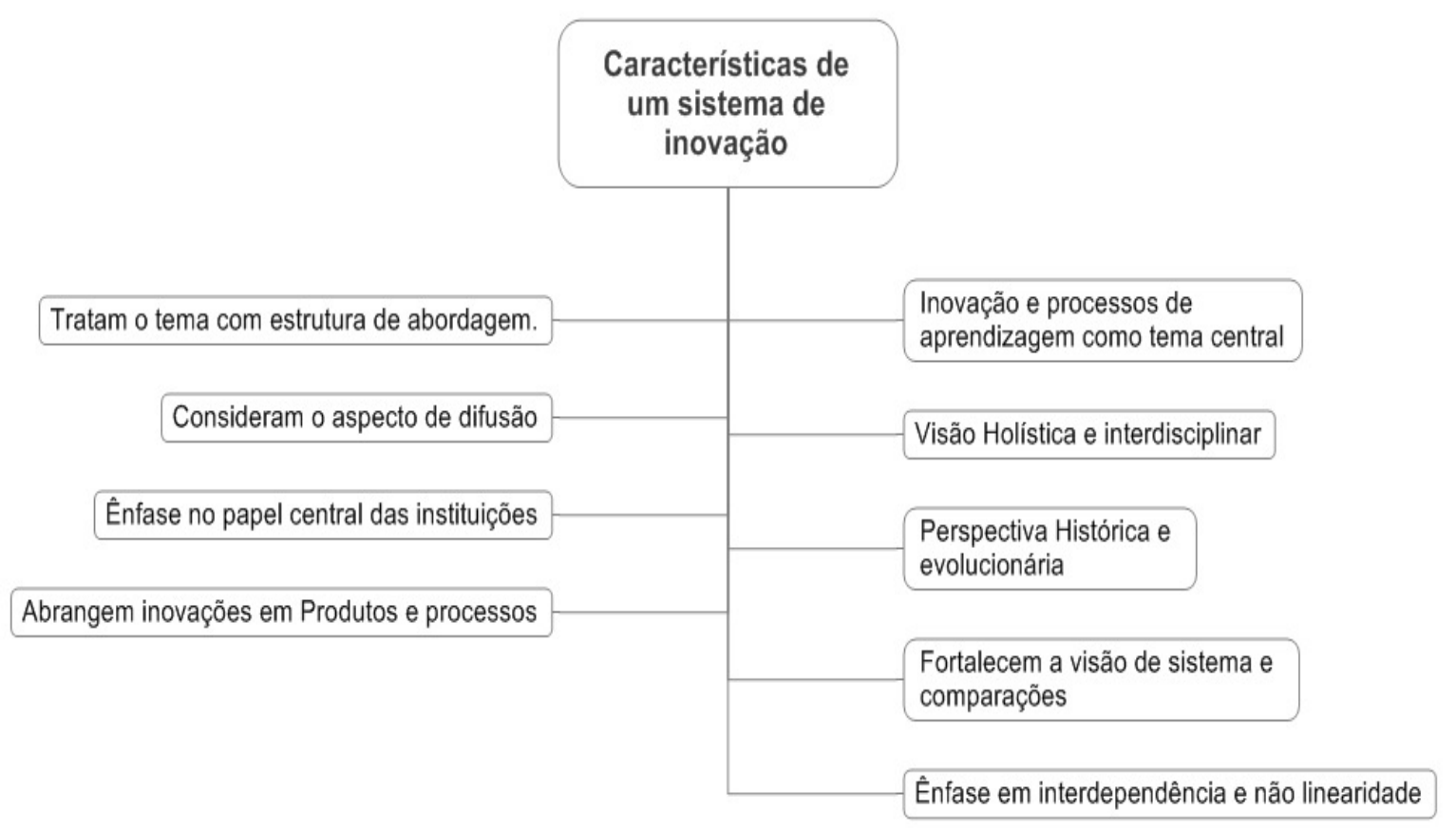

Figura 2-2: Características em abordagens de sistema de inovação.

Fonte: Elaborado a partir de Edquist (2004)

A presença da abordagem evolucionária é evidenciada pelo processo contínuo de inovação e aprendizagem que ocorre entre os agentes. No que tange à visão sistêmica, esta se consolida nos aspectos da não linearidade e interdependência entre os atores, como também nas abordagens das relações de causa e efeito, apresentando um aspecto não científico. Nas análises sobre sistemas de inovação, também prevalece uma visão baseada nos aspectos de difusão tecnológica e uma ênfase no papel das instituições a fim de determinar os diferentes níveis de sucesso dos países.

Partindo-se desse referencial, os sistemas de inovação podem ser analisados com base nos seus níveis de maturidade, que são representados pelo nível de articulação entre os componentes do sistema e pela importância da atividade inovadora para o dinamismo econômico (NELSON, 1993). Assim, quanto maior dinamismo da relação entre os subsistemas científico e tecnológico, financeiro, educacional e sistema produtivo, maior o nível de articulação do sistema; quanto maior a participação dos produtos de base intensivos em tecnologia na produção, maior a importância da atividade inovadora para o dinamismo econômico. 
De acordo com Albuquerque et al (2005), os sistemas de inovação podem ser classificados como: maduros, se os níveis de articulação dos agentes do sistema e a importância da produção intensiva em tecnologia são elevados, conforme ocorre nos Estados Unidos; incipiente, quando tanto a articulação do sistema e a participação da produção intensiva em tecnologia são pouco expressivas, como os países mais pobres do mundo.

Entre esses extremos, existem os sistemas de inovação em processo de catching up, isto é, que se encontram em processo de amadurecimento acelerado e consolidação do dinamismo econômico sustentável baseado na atividade inovativa, ou seja, ampliam a sua infra-estrutura científica e concentram seu desenvolvimento científico em disciplinas-chave, especialmente naquelas que são fontes de desenvolvimento industrial; como exemplos há a Coréia do Sul e Taiwan (AMSDEN, 2001). Ainda entre esses extremos (sistemas maduros e incipientes), há também os países heterogêneos, cujos sistemas são marcados pelo baixo dinamismo em razão da desarticulação entre os componentes, apesar da existência de elementos básicos de infra-estrutura, tais como: Brasil, Índia, México, África do Sul, Rússia e Malásia. Nos sistemas heterogêneos, a importância da atividade inovativa para o dinamismo econômico também é, geralmente, limitada (vide Figura 2-3).

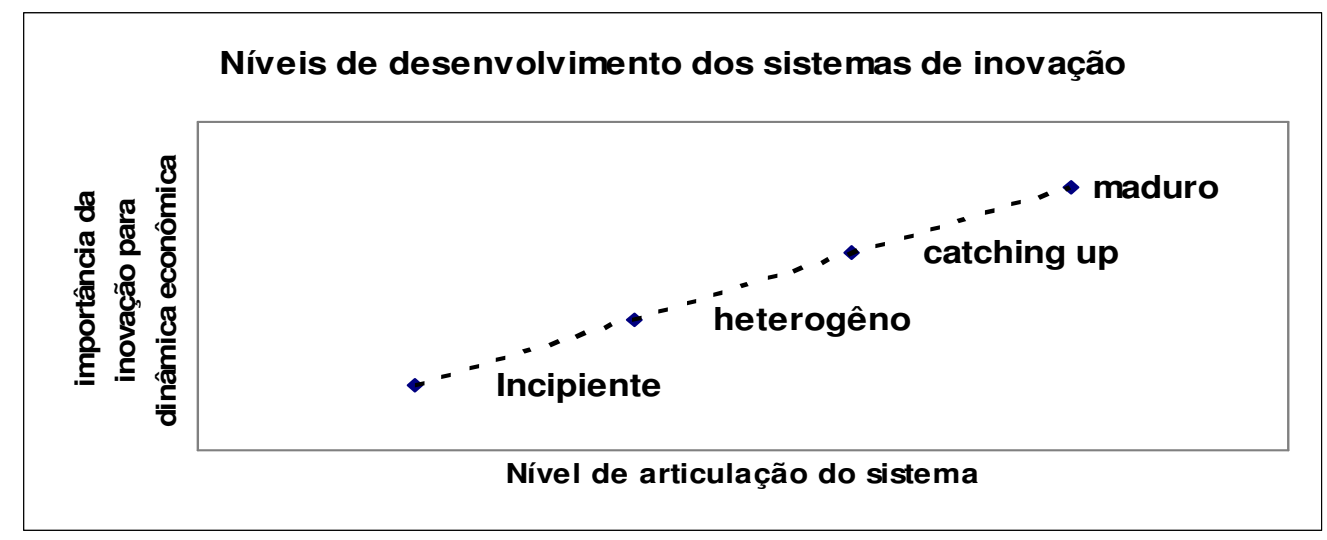

Figura 2-3: - Sistema de inovação: níveis de maturidade Elaborado a partir de Albuquerque et al (2005) 


\subsection{Desafios dos sistemas de inovação no Brasil}

Em estudo comparativo entre países (Brasil, México, África do Sul e Índia) com sistemas de inovação caracterizados como heterogêneos (imaturos), Albuquerque (2003), baseando-se nos estudos da produção científica e tecnológica, listou as principais similaridades: I) as dinâmicas de interação não possibilitam uma conexão adequada entre ciência e tecnologia que permitam uma produção de ciência e tecnologia; II) os investimentos estrangeiros e firmas estatais apresentam forte participação na produção tecnológica; III) há uma tendência para a concentração regional das atividades tecnológicas; IV) existem conexões parciais em alguns segmentos nesses países indicando que algumas ilhas de eficiências estão presentes.

Numa análise mais profunda em relação aos resultados no Brasil, convém observar, na Tabela 2.1, os dados de duas amostras da PINTEC sobre a inovação no país. Observa-se, a priori, que houve uma melhoria na taxa de inovação das empresas quando comparados os resultados da amostra PINTEC de $2000(31,50 \%)$ com os de 2003 , alcançando o percentual de $33,30 \%$.

Tabela 2.1 Panorama sobre a inovação nas empresas a partir da PINTEC.

\begin{tabular}{l|c|c}
\hline & $\begin{array}{l}\text { PINTEC } \\
\mathbf{2 0 0 0}\end{array}$ & $\begin{array}{l}\text { PINTEC } \\
\mathbf{2 0 0 3}\end{array}$ \\
\hline Taxa de inovação & $31,50 \%$ & $33,30 \%$ \\
\hline № Total de Empresas & 72.005 & 84.262 \\
\hline № de Empresas Inovadoras & 22.698 & 28.036 \\
\hline Inovação de Processos P/ merc. Interno & $4,10 \%$ & $2,70 \%$ \\
\hline Inovação de Produtos P/ merc. Interno & $2,80 \%$ & $1,20 \%$ \\
\hline Inovadoras com atividades inovativas & $84,40 \%$ & $73,50 \%$ \\
\hline Inovadoras com alta importação P\&D & & \\
interna & $24,20 \%$ & $17,20 \%$ \\
\hline Inovadoras com P\&D interna. & 7.412 & 4.941 \\
\hline P\%D Interna (em R $\$$ bi de 2003) & 5,8 & 5,1 \\
\hline P\%D Interna Média (em R\$ bi de 2003) & 0,8 & 1 \\
\hline Intensidade Tecnológica & $0,64 \%$ & $0,53 \%$ \\
\hline
\end{tabular}

Fonte: PINTEC - IBGE

Os números relativos ao desenvolvimento de pesquisa \& desenvolvimento (P\&D) internamente nas empresas continuam abaixo dos 
patamares dos países mais desenvolvidos, apresentando um cenário de pouco desenvolvimento. Observa-se que o maior percentual deve-se às atividades de aquisição de máquinas e equipamentos.

Esse panorama, no Brasil, reflete um sistema de inovação marcado pelo baixo nível de interação entre o processo produtivo e a atividade científica e tecnológica, sobretudo pelo fato do desenvolvimento da atividade econômica ocorrer, historicamente, a partir da difusão tecnológica, isto é, pela transferência de tecnologias consolidadas no mercado internacional (CASSIOLATO E LASTRES, 2000).

Tal característica provavelmente é resultante das dificuldades do processo de industrialização via substituição de importações, que resultaram em fragilidades setoriais em suas estruturas produtivas e heterogeneidades entre as suas firmas industriais (GONÇALVES, 2007). Sem o papel indutor do Estado no processo, os avanços são de natureza incremental, obtendo-se, desse modo, uma relação de dependência com as nações mais desenvolvidas criadoras de mudanças radicais.

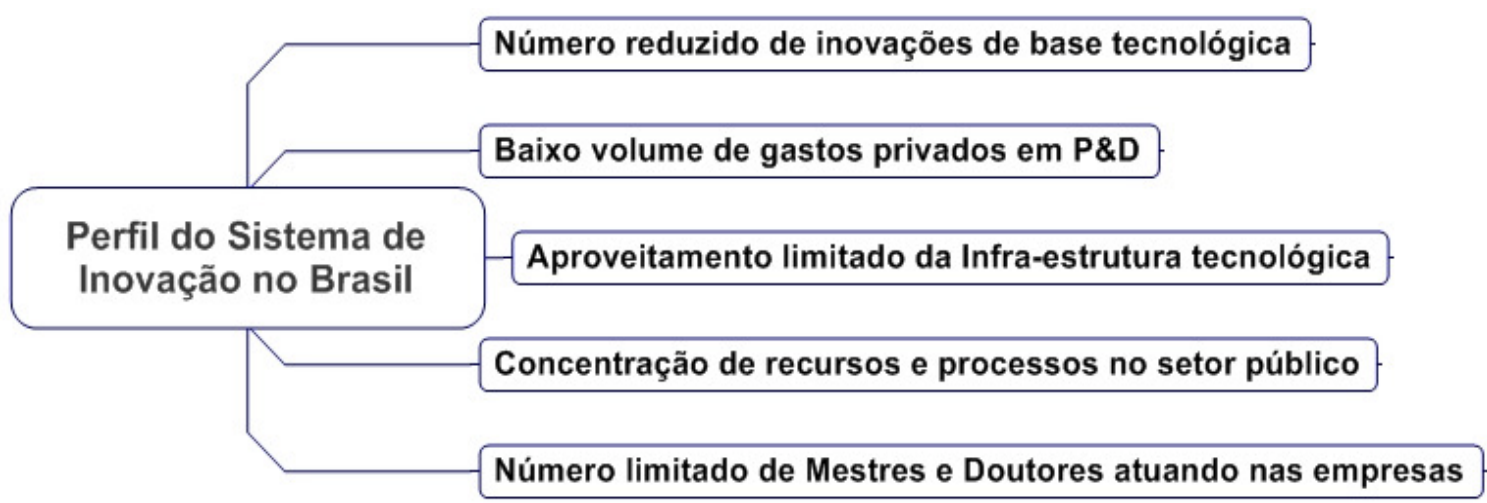

Figura 2-4: Sistema de inovação no Brasil: perfil

Elaborado a partir de Cassiolato e Lastres (2000) e Suzigan et al (2004)

Nesse contexto, podem ser observadas as principais características do sistema de inovação brasileiro, que são apresentados na Figura 2-4 e comentados a seguir:

I) Número relativamente pequeno de inovação de base tecnológica, sendo que, a partir dos anos 90 , a estrutura do país migrou de linhas de produtos e componentes de alto nível tecnológico para setores ancorados em vantagens competitivas com base em recursos naturais (TIGRE, 2006). 
Na Figura 2-5 é exibido o percentual de empresas brasileiras que implementaram inovações em comparação com as européias. O trabalho de Viotti, Baessa e Koeller (2005) foi realizado com base nas estatísticas da EUROSTAT $^{3}$ e IBGE. Observa-se que as empresas brasileiras apresentam desempenho superior somente em relação à Grécia.

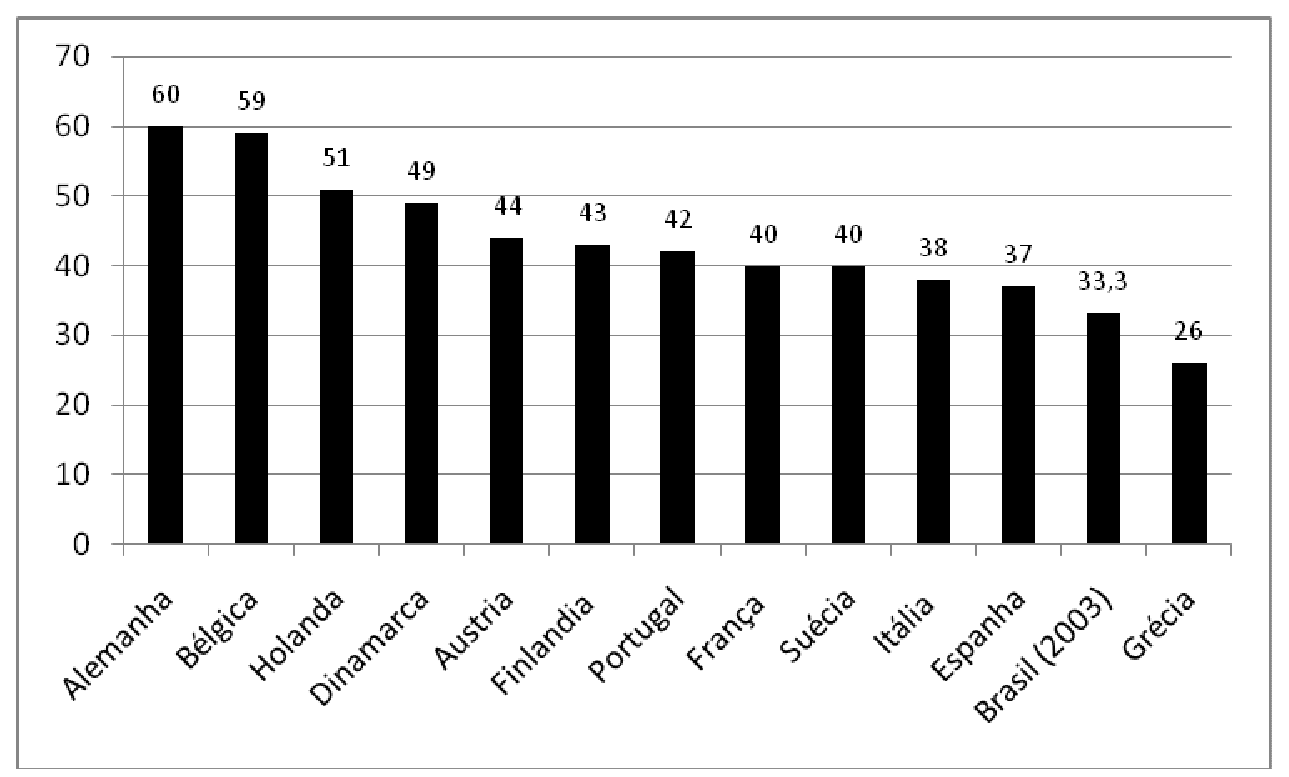

Figura 2-5: Percentuais de empresa industriais que implementaram inovações no período de 1998 a 2000. Fonte: desenvolvido a partir de Viotti, Baessa e Koeller (2005)

II) Baixo nível de investimentos do setor produtivo em atividades de pesquisa e desenvolvimento, na economia brasileira predominam os processos de difusão de tecnologia, na qual a maior parte das inovações é de natureza incremental, sendo nova para a empresa, não para o mercado. Configura-se como processo de imitação para se equiparar a um competidor mais avançado. Mais da metade dos gastos das empresas brasileiras em atividades de P\&D referem-se à compra de ativos tangíveis (máquinas e equipamentos). Para efeito de análise nos países da União Européia, esse percentual é de 10 a 20\%, sendo que os gastos concentram-se em atividades internas de P\&D (ARBACHE, 2005);

III) Aproveitamento limitado da infra-estrutura científica e tecnológica disponível. Existe um distanciamento entre as bases científicas e tecnológicas do país e das empresas; a base existente é subutilizada;

${ }^{3}$ Comissão Européia de serviços estatísticos para a União Européia. 
IV) Concentração da infra-estrutura, atividades e gastos em pesquisa e desenvolvimento pelo setor público, o qual responde por grande parte dos investimentos de P\&D no país. Os investimentos em P\&D por empresas privadas são bastante reduzidos quando comparados aos padrões internacionais (Tabela 2.2). Um dos fatores deve-se ao fato das multinacionais desenvolverem as suas atividades de P\&D nas suas matrizes, sendo emblemático o caso da indústria farmacêutica. No tocante aos termos nacionais para efeito de comparação, os países da OCDE apresentam um gasto privado de mais de $60 \%$ no total dos gastos de P\&D; os EUA, por sua vez, estão próximos de $70 \%$, enquanto que no Brasil o percentual não alcança $40 \%$.

Tabela 2.2 - Gastos de P\&D privados - uma comparação entre Brasil, outros países e OCDE.

\begin{tabular}{l|c|c}
\hline \multicolumn{1}{c|}{ País } & Relação PIB/P\&D & $\begin{array}{c}\text { \% Participação } \\
\text { privada }\end{array}$ \\
\hline OCDE & 2,3 & 64 \\
\hline USA & 2,7 & 72 \\
\hline Brasil (2001) & 1,1 & 36 \\
\hline Coréia do Sul & 2,7 & 72 \\
\hline França & 2,2 & 53 \\
\hline
\end{tabular}

Fonte: Adaptado de Silva, Campanário, Rovai e Costa (2006)

V) Número reduzido de mestres e doutores atuando nas empresas, sendo que a maior parte dos especialistas continua na academia, não existindo nas mesmas uma cultura de contratação de pessoas altamente qualificadas. Esse quadro acentua-se nas MPE.

Observadas as características gerais do sistema de inovação no Brasil, a literatura aponta uma série de desafios relacionados ao chamado processo de catching up, revelando a natureza estrutural das fragilidades do sistema e sugerindo a necessidade de abordagens sistêmicas para as questões (QUADROS et al, 2000).

$\mathrm{Na}$ tangente a tais desafios, pode-se destacar a heterogeneidade da estrutura produtiva; a densidade tecnológica da produção; a capacitação do setor produtivo; o perfil das interações entre as Instituições Científicas e Tecnológicas 
(ICT) e o setor produtivo; a estrutura de financiamento e o processo de coordenação entre as ações públicas e privadas.

A desarticulação entre o sistema científico e tecnológico e o sistema financeiro é representada pela escassez dos mecanismos e estruturas de financiamento adequadas às especificidades e características desses projetos. Sobretudo em relação aos riscos inerentes às atividades inovadoras, ou seja, a desarticulação entre o sistema financeiro e a atividade inovativa implica em limitações aos chamados capital semente, capital de risco, entre outros mecanismos e sistemas de financiamento presentes no mercado de capitais nos países com sistemas inovadores maduros (SALLES FILHO, 2004).

A articulação entre os agentes públicos e privados também representa um elemento importante para a qualidade dos sistemas de inovação, sobretudo pela orientação e coordenação das ações entre os atores que compõem o sistema inovação. No caso dos países em desenvolvimento, a (des) articulação entre os agentes públicos e privados configura-se em uma questão crítica, tendo em vista o contexto de escassez de recursos; necessidades de políticas públicas que atinjam objetivos socioeconômicos abrangentes e a importância relativa do setor público para as atividades científicas e tecnológicas (SIQUEIRA, 2003).

$\mathrm{Na}$ Figura 2-6, é apresentado o Sistema Nacional de Inovação brasileiro, sendo possível identificar como principais características: I) a existência de uma forte estrutura de organizações de apoio à inovação, com organizações acadêmicas, organizações de fomento e financiamento, instituições de pesquisa e ensino; como também a existência de organizações para o desenvolvimento inovador, dentre outros; II) a abordagem interministerial com a presença de núcleos representativos de diversos ministérios; III) o relacionamento com os governos estaduais e seus sistemas de inovação; IV) a presença do tecido empresarial por meio das empresas. 


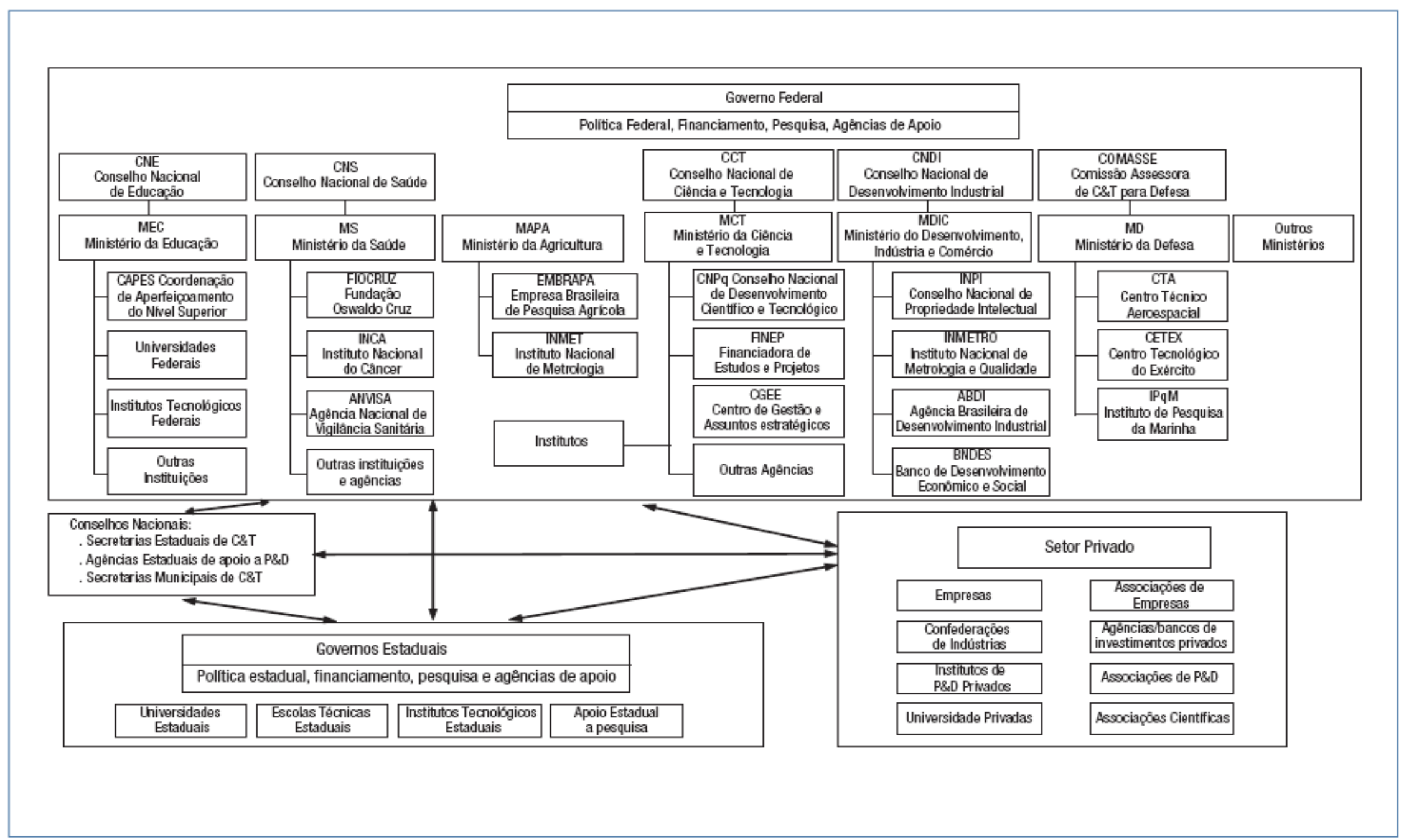

Figura 2-6: Sistema Nacional de Inovação no Brasil. Fonte: Estudo: Conhecimento e Inovação para a Competitividade, 2008. Banco Internacional para reconstrução e desenvolvimento / Banco Mundial 2009. http://siteresources.worldbank.org. Acesso 12/12/2008. 
Relacionado aos processos de governança, considerando como referência as fases de coordenação das políticas de inovação dos países de referência estudados na pesquisa (MOBIT, 2007) observam-se diferenças.

Variando de uma realidade de pouca concentração no Brasil, caracterizada pela distribuição por uma série de ministérios, agências, institutos de pesquisa e bancos públicos pouco articulados e com objetivos específicos ou até mesmo divergentes, para a realidade dos demais países que apresentam concentração em uma ou duas organizações (Tabela 2.3).

Tabela 2.3 - Governança nas Políticas de Inovação.

\begin{tabular}{|c|c|c|c|c|c|}
\hline Pa ís es & Coordenação & Elaboração & Implementação & Gerenciamento & Avaliação \\
\hline EUA & $\begin{array}{l}\text { Descentralizada } \\
\text { Presidência+ } \\
\text { Legislativo }\end{array}$ & $\begin{array}{l}\text { Presidência + } \\
\text { Legislativo }\end{array}$ & Agências & Agências & Agências \\
\hline França & Ministério & Ministério & Agências & Agências & Agências \\
\hline Japão & $1^{\circ}$ Ministro & $\begin{array}{l}1^{\circ} \text { Ministro + } \\
\text { Meti }\end{array}$ & $\begin{array}{l}\text { Ministérios + } \\
\text { agências }\end{array}$ & $\begin{array}{l}\text { Ministérios + } \\
\text { agências }\end{array}$ & $\begin{array}{l}\text { Ministérios + } \\
\text { agências }\end{array}$ \\
\hline Finlândia & $\begin{array}{l}\text { Agências }+1^{\circ} \\
\text { Ministro }\end{array}$ & $\begin{array}{l}\text { Agências + 1o } \\
\text { Ministro }\end{array}$ & Agências & Agências & Agências \\
\hline Reino Unido & $\begin{array}{l}1^{\circ} \text { Ministro + } \\
\text { DTI } \\
\text { (departamento } \\
\text { comércio e } \\
\text { indústria). }\end{array}$ & $\begin{array}{l}\text { 10 Ministro + } \\
\text { Ministério } \\
\text { DTI/ } \\
\text { BERR } \\
\text { Tesouro }\end{array}$ & $\overline{\mathrm{DTI}}$ & DTI & $\begin{array}{l}1^{\circ} \text { Ministro + } \\
\text { DTI } \\
+ \text { Tesouro }\end{array}$ \\
\hline Irlanda & $\begin{array}{l}\text { Agências + } 1^{\circ} \\
\text { Ministro }\end{array}$ & Ministério & Agências & Agências & Agências \\
\hline Canadá & $\begin{array}{lr}\text { Agências } & + \\
\text { Ministério } & \text { da } \\
\text { Indústria } & \\
\text { Canada } & \end{array}$ & $\begin{array}{l}\text { 10 Ministro + } \\
\text { Ministério da } \\
\text { Indústria } \\
\text { Canada }\end{array}$ & Agências & Agências & $\begin{array}{l}\text { Agências + } \\
\text { Industry } \\
\text { Canada }\end{array}$ \\
\hline Brasil & $\begin{array}{l}\text { Fragmentada: } \\
\text { MDIC, ABDI, } \\
\text { MCT/ } \\
\text { Finep, BNDES }\end{array}$ & $\begin{array}{l}\text { MDIC, ABDI, } \\
\text { MCT, } \\
\text { BNDES, } \\
\text { Câmara de } \\
\text { Política } \\
\text { Econômica }\end{array}$ & $\begin{array}{l}\text { Fragmentada: } \\
\text { MDIC, MCT, } \\
\text { Finep, } \\
\text { BNDES }\end{array}$ & Descordenado & $\begin{array}{l}\text { Precária e } \\
\text { fragmentada: } \\
\text { ABDI, MCT, } \\
\text { MDIC, } \\
\text { MPOG, } \\
\text { IPEA }\end{array}$ \\
\hline
\end{tabular}

Fonte: Mobilização Brasileira pela InovaçãoTecnológica - MOBIT (2007) 


\subsection{Considerações Preliminares}

A interação entre as bases científicas e tecnológicas representa um importante fator para fortalecer e qualificar os sistemas de inovação dos diferentes países. O conhecimento encontra-se no centro do desenvolvimento desses sistemas, sendo o insumo principal para a geração de novas tecnologias.

A análise da teoria oferece que os sistemas possuem diferentes estágios de evolução, aferidos principalmente pela interação entre as atividades científicas e tecnológicas. Uma proxy para dimensionar esse cenário encontra-se na performance desses países em termos de inovações nas empresas, patentes desenvolvidas e publicações científicas.

O sistema de inovação brasileiro é caracterizado por algumas debilidades que são comprovadas no que se refere a sua performance quando comparado a sistemas mais avançados. Dentre tais debilidades, encontra-se a desarticulação entre as bases científicas e tecnológicas, evidenciando um cenário de pouca interação entre academia e empresas; pouco gasto para com P\&D nas empresas privadas; número limitado de mestres e doutores atuando nas empresas, sobretudo nas MPE, e subutilização da infra-estrutura disponível.

O Brasil, que se caracteriza por possuir um sistema de inovação tido como imaturo (heterogêneo), vem obtendo avanços nos últimos anos nesta temática, com o fortalecimento dos organismos de planejamento e gestão. Todavia, algumas deficiências são notadas na articulação intra-organismos, levando a um quadro de sobreposição de responsabilidades e ações na execução das políticas.

Outro aspecto identificável é a dificuldade de coordenação de políticas entre os diferentes níveis de governo, constatando-se que no nível municipal, apesar de previsto no modelo do sistema nacional, não existem competências que possibilitem a interface com as ações envolvidas em articulações federal e estadual.

Por fim, a pouca participação da iniciativa privada nas atividades de P\&D constitui-se num desafio de raízes históricas a ser superado, não se subestimando o papel indutor de políticas governamentais no processo de incentivo à interação; todavia a articulação com as empresas deve ser iniciada numa perspectiva local. 
Considerando essa conjuntura, sugere-se o desenvolvimento de iniciativas a partir de uma perspectiva local (municipal), diagnosticando as suas características no que diz respeito à organização das suas bases científicas, tecnológicas e econômicas, mapeando as iniciativas em esferas estaduais e federais que são aplicáveis, evidenciando, assim, uma estrutura aplicável a essas características e contexto.

A priorização das iniciativas acarreta a análise dos ambientes de inovação no capítulo III, envolvendo inicialmente a análise da teoria sobre Arranjos Produtivos Locais, e posteriormente destacando os parques tecnológicos (terminologias assemelhadas) que são considerados os instrumentos mais evoluídos no tocante à articulação entre os atores da academia, tecido empresarial e poder público. 


\section{CAPÍTULO III - REVISÃO DA LITERATURA: AMBIENTES DE INOVAÇÃO}

\subsection{Considerações sobre os Ambientes de Inovação}

As idéias seminais de Schumpeter (1961) apontavam para a inovação como fruto somente da ação individual de um "empreendedor"; na sua busca permanente de diferenciação, objetivando a obtenção de vantagens competitivas que proporcionavam lucros de monopólio, mesmo que temporários (POSSAS, 2002). Todavia, com o passar dos anos, verificou-se que essas idéias não eram suficientes para fazer frente a complexidade do tema; sendo assim o aprofundamento dos estudo fortaleceu a idéia de que a inovação envolvia outras variáveis, e que derivava de um conjunto de atores ligados ao setor produtivo e ao meio local, envolvendo diferentes agentes.

Nesse contexto, especula-se que um dos determinantes para o seu desenvolvimento é o ambiente, (considerado como o local e o contexto na qual a ação é desenvolvida) e o seu impacto que pode ser propício ou impeditivo para o desenvolvimento da inovação. Os fatores que confluem para essa visão, estão apresentados na Figura 3-1:

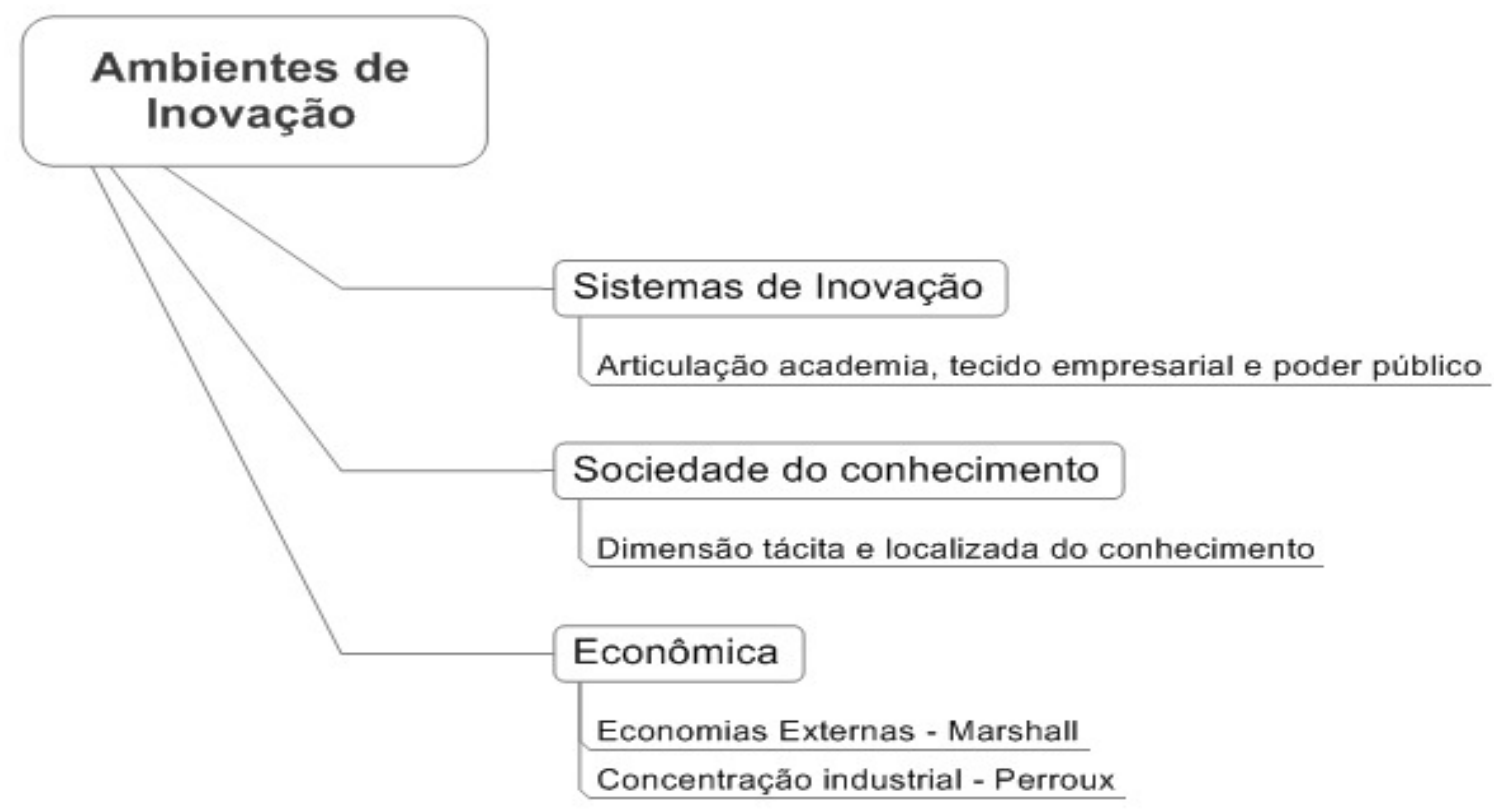

Figura 3-1: Fatores que estimulam o desenvolvimento dos ambientes de inovação. 
Inicialmente, são observados os elementos relacionados ao sistema de inovação, os quais foram detalhados no capítulo 1, podendo-se destacar: a necessidade de articulação entre os diferentes atores.

No tocante à sociedade do conhecimento o pressuposto é que a interação entre os atores é capaz de impulsionar o desenvolvimento das atividades inovadoras intensivas em tecnologia, porque a proximidade física facilita a transmissão do conhecimento e estimula a sinergia, o que resulta em incrementos na eficiência e na eficácia das atividades.

É importante observar a relação da distância com o custo de transmissão de conhecimentos tácitos e explícitos. Por definição pode-se considerar conhecimentos explícitos aqueles caracterizados em responder o que fazer e como fazer, sendo que são passíveis de serem armazenados e retransmitidos em mídias; desta forma, o seu custo tem pouca variação em relação a distância.

Em contrapartida, o conhecimento tácito provém de experiências, capacitações e aprendizado interativo dos indivíduos, não possibilitando a sua descrição de forma convencional e está ligado à resolução de problemas sem soluções evidentes. Portanto, fortemente ligado ao indivíduo e a sua reprodução é onerosa para a organização.

A outra vertente está relacionada às economias externas, as quais foram estudadas inicialmente por Marshall (TIGRE, 2006) como fator de sucesso nos distritos industriais. Esses fatores externos envolviam:

- Concentração de recursos humanos qualificados;

- Infra-estrutura física;

- Capacidade produtiva.

As regiões, portanto, diferenciavam-se pela oferta ou escassez desses elementos, sendo que as empresas individualmente procuravam ser mais competitivas com base nesses fatores encontrados em determinados locais.

\subsection{Conceituação dos Ambientes de Inovação.}

Os ambientes de inovação, também conhecidos como habitat de inovação, são ambientes diferenciados, que podem ser organizados por instituições 
públicas ou privadas e se caracterizam por garantir condições favoráveis para desenvolvimento de produtos e processos de base tecnológica. Nesse sentido, atendem à necessidade de minimizar os diversos riscos associados às iniciativas inovadoras e maximizar os resultados desses processos constituindo-se em um elemento importante dos sistemas de inovação (ZOUAIN, 2003).

Outra definição considera que um habitat de inovação (ou ambiente de inovação) é um espaço que reúne condições propícias ao desenvolvimento de atividades e processos tecnológicos com finalidades econômicas, ou seja, é uma área delimitada, podendo ser contígua ou não, que agrega condições diferenciadas para o desenvolvimento de produtos e processos produtivos de natureza inovadora (ZOUAIN, DAMIÃO E CATHARINO, 2006).

Apesar dos primeiros habitats de inovação serem organizados a partir da década de 50, a difusão desses empreendimentos ocorreu de forma mais evidente a partir dos anos 80, na América do Norte e na Europa, com consolidação dos processos característicos da economia do conhecimento e dos princípios e pesquisas no campo dos sistemas de inovação. Também contribuiu para o desenvolvimento dessas experiências, a ênfase no desenvolvimento de políticas de locais, em razão da evolução dos acordos e tratados internacionais, como a Organização Mundial do Comércio (OMC), e a conseqüente diminuição dos níveis de independência das políticas nacionais.

Nos países em desenvolvimento, entre os quais o Brasil, a organização dos ambientes de inovação se intensificou a partir do final da década de $90 \mathrm{com}$ as mudanças nas diretrizes de políticas públicas. Todavia, os sistemas de inovação desses países, apesar dos esforços recentes de governo, ainda caracterizam-se por serem pouco articulados, afetando o processo de organização desses ambientes, os quais demandam uma intensa articulação entre os atores.

O elemento crítico, que configura e distingue os habitats de inovação de outros arranjos, como os distritos industriais, por exemplo, é que nesse ambiente o desenvolvimento dos produtos e processos é necessariamente estruturado a partir do conhecimento de base científica. Nesse sentido, os habitats de inovação têm como condição fundamental os recursos de base científica e tecnológica que dão 
suporte ao desenvolvimento das inovações. Por esse motivo, também se pode chamar tais arranjos de habitats de inovação de base tecnológica.

O desenvolvimento de produtos e processos a partir da aplicação de conhecimentos científicos tem grande potencial de benefícios socioeconômicos (geração de riqueza) e de resultados econômicos (lucros). No entanto, a complexidade das atividades, as incertezas em relação aos resultados e as condições necessárias em termos de recursos implicam riscos elevados para essas operações. Diante disso, os habitats de inovação, ao reunirem condições diferenciadas, justificam-se como formas de minimizar riscos e de maximizar o potencial de sucesso econômico da aplicação do conhecimento científico.

Considera-se a existência de uma grande diversidade de habitats de inovação, organizados no contexto do próprio desenvolvimento científico e da aplicação desses conhecimentos à atividade econômica.

A literatura apresenta os temas e termos referentes aos ambientes de inovação de forma indiscriminada, sendo difícil um consenso sobre os elementos de taxonomia e caracterização dos mesmos (FIGLIOLI, 2007) (KANG, 2004). Na Tabela 3.1, busca-se, com base em trabalhos anteriores, contribuir para essa discussão.

No decorrer do trabalho serão apresentados três modelos de ambientes de inovação, que foram definidos com base em três critérios: i) aproximação com a base científica e tecnológica: envolvendo os parques tecnológicos e científicos considerados como a forma mais evoluída de ambientes de inovação (ZOUAIN, DAMIÃO e CATHARINO, 2006); ii) proximidade com o tecido empresarial: relacionado aos conceitos sobre arranjos produtivos locais e; iii) estudo de referência na articulação entre academia e empresas: com o estudo de caso sobre os pólos de competitividade da França. 
Tabela 3.1 - Modelos de ambientes de Inovação.

\begin{tabular}{|c|c|c|c|c|c|c|}
\hline Ambiente & Atividades & Atores & Localização & Governança & Ativos & Referências \\
\hline $\begin{array}{l}\text { Parques } \\
\text { Tecnológicos } \\
\text { E Científicos }\end{array}$ & $\begin{array}{l}\text { Estímulo à } \\
\text { geração de } \\
\text { tecnologias, } \\
\text { desenvolvimento } \\
\text { de novas } \\
\text { empresas } \\
\text { tecnológicas, } \\
\text { oferecimento de } \\
\text { serviços de alto } \\
\text { valor agregado }\end{array}$ & $\begin{array}{l}\text { Academia } \\
\text { Poder Público } \\
\text { Empresas. }\end{array}$ & $\begin{array}{l}\text { Tradicionalmente } \\
\text { em áreas } \\
\text { contíguas. }\end{array}$ & $\begin{array}{lr}\text { Pode variar entre } \\
\text { os atores de } \\
\text { acordo com a } \\
\text { formatação dos } \\
\text { projetos } & \text { e } \\
\text { propriedade } & \text { das } \\
\text { áreas. } & \end{array}$ & $\begin{array}{l}\text { Incubadoras, } \\
\text { Centros de } \\
\text { pesquisa, centros } \\
\text { de formação, } \\
\text { condomínios de } \\
\text { empresas, } \\
\text { laboratórios. }\end{array}$ & Tagus Parks \\
\hline Pólo de Inovação & $\begin{array}{l}\text { Desenvolvimento } \\
\text { de inovações. } \\
\text { Serviços técnicos } \\
\text { especializados }\end{array}$ & $\begin{array}{l}\text { Academia } \\
\text { Poder Público } \\
\text { Empresas. }\end{array}$ & $\begin{array}{l}\text { Desenvolve-se a } \\
\text { partir de um } \\
\text { Núcleo. }\end{array}$ & $\begin{array}{ll}\text { Participação } & \text { do } \\
\text { poder público }\end{array}$ & $\begin{array}{ll}\text { Centros } & \text { de } \\
\text { pesquisa; } & \\
\text { Empresas. } & \end{array}$ & $\begin{array}{l}\text { Pólo de alta } \\
\text { tecnologia } \\
\text { (Campinas) }\end{array}$ \\
\hline Tecnopóle & $\begin{array}{l}\text { Atividades de } \\
\text { formação e apoio } \\
\text { ao } \\
\text { desenvolvimento } \\
\text { de inovações nas } \\
\text { empresas. }\end{array}$ & $\begin{array}{l}\text { Academia } \\
\text { Poder Público } \\
\text { Empresas. }\end{array}$ & $\begin{array}{l}\text { Espalhada pela } \\
\text { região }\end{array}$ & $\begin{array}{lr}\text { Geralmente } & \text { do } \\
\text { poder público } \\
\text { local, ram } \\
\text { oferecimento de } \\
\text { extenalidades } \\
\text { positivas. }\end{array}$ & $\begin{array}{l}\text { Parques } \\
\text { tecnológicos } \\
\text { Incubadoras } \\
\text { Laboratórios }\end{array}$ & Sophia antipolis \\
\hline
\end{tabular}




\begin{tabular}{|c|c|c|c|c|c|c|}
\hline Ambiente & Atividades & Atores & Localização & Governança & Ativos & Referências \\
\hline $\begin{array}{l}\text { Incubadoras de } \\
\text { base tecnológica }\end{array}$ & $\begin{array}{l}\text { Formação de } \\
\text { empresas } \\
\text { iniciantes }\end{array}$ & $\begin{array}{l}\text { Universidade } \\
\text { Poder público } \\
\text { MPEs }\end{array}$ & $\begin{array}{l}\text { Internamente ou } \\
\text { próximas das } \\
\text { Universidades }\end{array}$ & $\begin{array}{l}\text { Núcleo gestor } \\
\text { com participação } \\
\text { e apoio de órgãos } \\
\text { como o SEBRAE. }\end{array}$ & $\begin{array}{l}\text { Estrutura } \\
\text { administrativa e } \\
\text { tecnológica de } \\
\text { apoio. }\end{array}$ & $\begin{array}{l}\text { Cietec - SP } \\
\text { CIATEC } \\
\text { Campinas. }\end{array}$ \\
\hline $\begin{array}{l}\text { Arranjos } \\
\text { Produtivos Locais } \\
\text { e variantes. }\end{array}$ & $\begin{array}{ll}\text { Melhorias } & \text { de } \\
\text { condições } & \\
\text { produtivas } & \text { de } \\
\text { determinado } & \\
\text { segmento } & \\
\text { produtivo } & \end{array}$ & $\begin{array}{l}\text { Empresas } \\
\text { entidades } \\
\text { representativas } \\
\text { Poder publico } \\
\text { Entidades de apoio. }\end{array}$ & $\begin{array}{lr}\text { Abertos } & \mathrm{e} \\
\text { espalhados } & \text { por } \\
\text { localidades. } & \end{array}$ & $\begin{array}{l}\text { Entidades } \\
\text { representativas } \\
\text { com apoio de } \\
\text { entidades } \\
\text { governamentais }\end{array}$ & $\begin{array}{l}\text { Empresas } \\
\text { Institutos. } \\
\text { Laboratórios }\end{array}$ & $\begin{array}{ll}\text { Cerâmica de } & \text { de } \\
\text { Santa Gertrudes. } \\
\text { Calçadista de } \\
\text { Birigui. }\end{array}$ \\
\hline $\begin{array}{l}\text { Pólos de } \\
\text { Competitividade }\end{array}$ & $\begin{array}{l}\text { Estímulo à } \\
\text { geração de } \\
\text { tecnologias. } \\
\text { Projetos } \\
\text { desenvolvidos } \\
\text { com interação } \\
\text { entre empresas e } \\
\text { academia. }\end{array}$ & $\begin{array}{l}\text { Universidade, Poder } \\
\text { Público, MPEs e } \\
\text { grandes empresas, } \\
\text { aglomerações de atu } \\
\text { ação colaborativa em } \\
\text { nível regional/ } \\
\text { nacional/internacional }\end{array}$ & $\begin{array}{ll}\text { Limitado } & \text { de } \\
\text { acordo com as } \\
\text { vocações } \\
\text { regionais. }\end{array}$ & $\begin{array}{l}\text { Estrutura própria } \\
\text { de Gestão. }\end{array}$ & $\begin{array}{lr}\text { Grandes } & \\
\text { empresas } & \\
\text { Universidades } & \\
\text { Centros r de } \\
\text { pesquisa } & \text { e } \\
\text { laboratórios } & \end{array}$ & $\begin{array}{l}\text { Pólos Franceses } \\
\text { de } \\
\text { Competitividade }\end{array}$ \\
\hline $\begin{array}{l}\text { Distritos } \\
\text { Industriais } \\
\text { (não } \\
\text { ambientes dẽo } \\
\text { inovação, } \\
\text { utilizado } \\
\text { somente como } \\
\text { referência) }\end{array}$ & $\begin{array}{l}\text { Atividades } \\
\text { Produtivas }\end{array}$ & $\begin{array}{l}\text { Empresas } \\
\text { Poder Público }\end{array}$ & $\begin{array}{lr}\text { Abertos } & \text { e } \\
\text { espalhados } & \text { por } \\
\text { localidades, } & \\
\text { limitados } & \text { de } \\
\text { acordo } & \text { com } \\
\text { áreas } & \text { de } \\
\text { incentivos. } & \end{array}$ & Poder Público. & $\begin{array}{l}\text { Empresas } \\
\text { Entidades } \\
\text { Patronais } \\
\text { sindicais. }\end{array}$ & São Bernardo \\
\hline
\end{tabular}

Fonte: Elaborado a partir de Figlioli (2007), Zouain (2003), Graça (2007). 


\subsection{Parques Tecnológicos}

Os Parques Tecnológicos (também identificados como parques científicos) representam as formas mais elaboradas de habitats de inovação, sendo tradicionalmente considerados instrumentos dos sistemas locais de inovação, com potencial para influenciar as dinâmicas econômicas nas regiões que compõem a sua área de influência (ZOUAIN, DAMIÃO e CATHARINO, 2006).

Os parques tecnológicos oferecem e/ou organizam um conjunto diversificado de instrumentos, processos e projetos que envolvem os agentes relacionados ao processo de inovação de base tecnológica, que são as empresas (inovadoras), as instituições científicas e tecnológicas, como também as políticas públicas de promoção das atividades inovadoras. Nesse sentido, os parques tecnológicos são habitats de inovação (isto é, uma área delimitada que agrega condições diferenciadas para o desenvolvimento de produtos e processos produtivos de natureza inovadora, como foi mencionado), apresentando, ao menos, três características básicas que os qualifica e os distingue:

- Disponibilidade de recursos para o desenvolvimento de produtos e/ou processo de natureza inovadora a partir da aplicação de conhecimento de natureza científica e tecnológica, o que é expresso por infra-estrutura (de instalações, equipamentos e serviços tecnológicos) e recursos humanos de natureza científica e tecnológica;

- Disponibilidade de formas, instrumentos e serviços diversificados que constituam um ambiente de inovação empresarial diferenciado, representado pelos processos facilitadores de interação entre os agentes do processo de inovação, da difusão do conhecimento e das informações relevantes para tais atividades;

Capacidade e potencial para influenciar a dinâmica econômica de sua área de influência representada pelo potencial de atração de investimentos derivados dos processos tecnológicos; geração de produto, renda e emprego qualificados; desenvolvimento da cultura e ações empreendedoras, entre outros efeitos de animação local. 
De acordo com os dados da ASPP $^{4}$ (Associação Internacional de Parques Científicos/Tecnológicos) (2007), os parques científicos e tecnológicos têm sido criados desde a década de 1950, com curva de crescimento acentuada a partir da década de 1980. Especialmente, foram nos anos de 1986, 1992 e 2001 em que mais parques foram criados. Percebe-se que no século XXI esta tendência está ainda mais forte, já que concentra $26 \%$ dos parques criados nestes últimos 56 anos.

A maioria dos parques é urbana (66\%), especialmente os europeus, ou semi-urbanos $(27 \%)$, ou seja, que estão a menos de 25 quilômetros de uma cidade. Em $36 \%$ dos casos localizam-se dentro ou nas redondezas de universidades e em $53 \%$ a localização é independente da proximidade com universidades. Entretanto, há parcerias com a universidade em diferentes graus, com o compartilhamento de grupos de pesquisas e conhecimentos.

Em relação à proximidade com aglomerados industriais, ocorre em $65 \%$ dos casos, mas, aparentemente, não é fator crítico para o sucesso dos parques, embora possa exercer uma influência positiva.

O tempo decorrente do início do planejamento até sua efetiva criação é de um a treze anos, com média em 3,4 anos. Ainda de acordo com a pesquisa da IASP (ibid), os principais fatores que afetam o seu desenvolvimento estão relacionados às políticas públicas, sendo eles:

- Apoio do setor público,

- Regulamentações,

- Turbulências sócio-políticas e econômicas, e

- Tributação.

A pesquisa da IASP também identificou os fatores de sucesso para a implantação dos parques tecnológicos, que são imagem/prestígio, localização, ligação com universidades, apoio institucional e demanda local.

Em relação às iniciativas brasileiras, Vedovello, Judice e Maculan (2006) relacionam como dificuldades o longo prazo de desenvolvimento e maturação, o elevado custo de implantação e dificuldades em conciliar múltiplos

\footnotetext{
${ }^{4}$ International Association of Science Parks. Possui mais de 109 parques associados e 146 membros em 72 países, sendo 350 membros associados no total.
} 
objetivos colocados nesse tipo de projeto por stakeholders (partes interessadas) variados.

\subsubsection{Os parques tecnológicos nos países desenvolvidos}

As experiências pioneiras de organização de Parques Tecnológicos ocorreram nos Estados Unidos, no final da $2^{\text {a }}$ Guerra, visando à promoção do desenvolvimento de produtos e processos intensivos em tecnologia a partir da interação empresas e centros de pesquisa das universidades. Entre elas, destacou-se o chamado "Vale do silício", que tem como origem as ações empreendidas pela Universidade de Stanford, para o desenvolvimento da atividade econômica local, através concessão de áreas, espaços para o desenvolvimento de negócios inovadores, na década de 50. Essa experiência deu origem ao chamado modelo californiano.

O modelo californiano, cujas características estão expostas na Tabela 3.2 são tipicamente organizações vinculadas às universidades e aos setores de alta tecnologia, voltados ao processo de comercialização de tecnologia por novas empresas (spin-offs). Entre as especificidades desse modelo, destaca-se a natureza do processo de coordenação e tomada de decisões, que é fortemente descentralizada (mercado).

A partir dos anos 80 , o movimento de parques ganhou impulso, quando se evidenciaram as limitações em relação à eficácia das políticas econômicas tradicionais, assim como ao momento em que a inovação se consolidou como forma dominante de competição entre os países desenvolvidos. Diante disso, ocorreu um amplo processo de reestruturação econômica, que se manifestou através da reforma do Estado e do esforço para o desenvolvimento de novas estruturas de desenvolvimento econômico, ancorado na inovação tecnológica.

Desse modo, considerados como uma alternativa viável para promoção do desenvolvimento econômico baseados em processos inovativos, novos parques tecnológicos foram criados, principalmente, na Europa. Devido a isso, surgiu uma série de experiências bastante diversificadas no que se refere aos formatos e características dos parques, em razão do processo de adequação da configuração desses habitats de inovação às diferentes dinâmicas econômicas e 
tecnológicas existentes nos diferentes espaços. Posteriormente, essas experiências foram agrupadas pelos especialistas na forma de modelos, com o intuito de organizar as referências, sendo atualmente reconhecidos pela literatura (ZOUAIN, 2003) os modelos Inglês, Mediterrâneo e Escandinavo (vide a Tabela $3.2)$.

A Inglaterra, pioneira na implantação dos parques tecnológicos na Europa, juntamente com os países do Mediterrâneo e o do Norte Europeu, apresenta, como principal característica do seu modelo, a forte participação das Universidades, através de atividades de pesquisa e desenvolvimento e infraestrutura. O modelo Mediterrâneo (França, Espanha, e Portugal) distinguiu-se pela maciça presença de agentes governamentais, grandes empresas em conjunto com universidades, constituindo empreendimentos com grandes áreas de extensão. Já o modelo Escandinavo, organizado no norte europeu, caracteriza-se por possuir empreendimentos de pequena a média extensão, promovidos com a participação de universidades, organizações públicas e iniciativa privada e autoridades públicas locais.

Os investimentos em Parques Tecnológicos nos países desenvolvidos têm se mostrado recompensador na proporção de três por um, de acordo com dados da ANPROTEC (2008); as empresas instaladas geram em média U $\$ 3,00$ de receita anual para cada $\bigcup \$ 1,00$ investido na implantação do Parque.

Tabela 3.2 - Parques tecnológicos no mundo: modelos

\begin{tabular}{|c|c|c|c|c|}
\hline 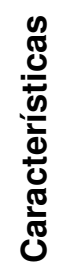 & $\begin{array}{c}\text { Modelo } \\
\text { Californiano }\end{array}$ & $\begin{array}{l}\text { Modelo } \\
\text { Britânico }\end{array}$ & $\begin{array}{c}\text { Modelo } \\
\text { Norte-Europeu }\end{array}$ & $\begin{array}{c}\text { Modelo } \\
\text { Mediterrâneo }\end{array}$ \\
\hline 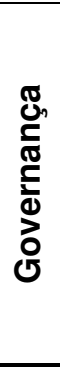 & $\begin{array}{l}\text { São } \\
\text { promovidas, ou muito } \\
\text { vinculadas, } \\
\text { Universidades }\end{array}$ & \begin{tabular}{|l|} 
Caracterizado como \\
"Science Park" com \\
participação ativa das \\
universidades
\end{tabular} & $\begin{array}{l}\text { Projetos promovidos } \\
\text { com participação de } \\
\text { Universidades, } \\
\text { organizações públicas } \\
\text { (na maioria das vezes } \\
\text { as municipalidades) e } \\
\text { iniciativa privada }\end{array}$ & $\begin{array}{l}\text { Parques são } \\
\text { geralmente por } \\
\text { promovidos públicas } \\
\text { entidades } \\
\text { (principalmente } \\
\text { municipalidades, } \\
\text { organizações } \\
\text { governamentais } \\
\text { regionais) }\end{array}$ \\
\hline
\end{tabular}




\begin{tabular}{|c|c|c|c|c|}
\hline 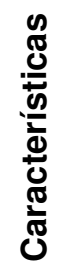 & $\begin{array}{c}\text { Modelo } \\
\text { Californiano }\end{array}$ & $\begin{array}{l}\text { Modelo } \\
\text { Britânico }\end{array}$ & $\begin{array}{c}\text { Modelo } \\
\text { Norte-Europeu }\end{array}$ & $\begin{array}{c}\text { Modelo } \\
\text { Mediterrâneo }\end{array}$ \\
\hline 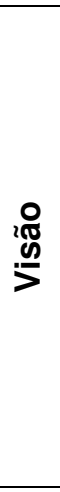 & $\begin{array}{|lr|}\text { São ligadas a setores } \\
\text { tecnológicos de ponta, } \\
\text { emergentes er de } \\
\text { altíssimo } & \text { valor } \\
\text { agregado } & \end{array}$ & 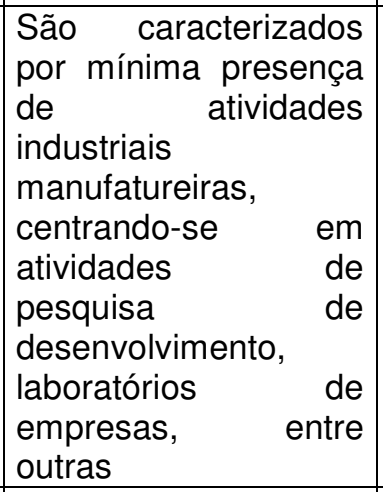 & 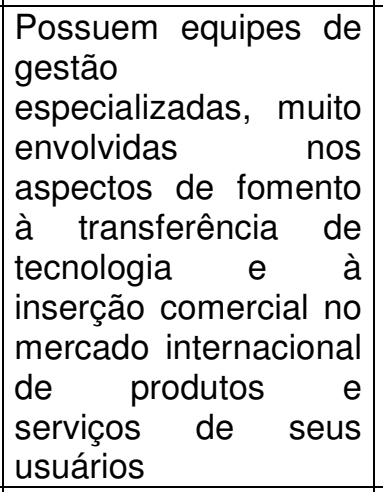 & \begin{tabular}{|l}
\multicolumn{2}{|l|}{ São concebidos como } \\
instrumentos de \\
desenvolvimento \\
regional
\end{tabular} \\
\hline 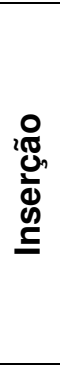 & $\begin{array}{|lr|}\text { Aproveitam, } & \text { ao } \\
\text { máximo, a capacidade } \\
\text { de atração da região, } \\
\text { bem como o r valor } \\
\text { comercial } & \text { das } \\
\text { pesquisas } & \\
\text { desenvolvidas rr } & \text { pelas } \\
\text { Universidades, } & \text { na } \\
\text { criação de empresas } \\
\end{array}$ & $\begin{array}{l}\text { Pouca inserção na } \\
\text { economia local }\end{array}$ & $\begin{array}{l}\text { O foco do projeto é o } \\
\text { mercado externo }\end{array}$ & $\begin{array}{l}\text { Forte inserção na } \\
\text { economia local. Estão } \\
\text { relacionados à } \\
\text { ocupação de grandes } \\
\text { áreas de extensão. }\end{array}$ \\
\hline$\frac{\frac{0}{0}}{\frac{0}{2}}$ & $\begin{array}{|lrr|}\text { Trata-se de } & \text { um } \\
\text { fenômeno } & \\
\text { espontâneo, ou } & \text { seja, } \\
\text { não } & \text { há } & \text { um } \\
\text { planejamento inicial; } \\
\text { não existem intenções } \\
\text { prévias de renstituir- } \\
\text { se em um elemento } \\
\text { de desenvolvimento } \\
\text { regional } \\
\end{array}$ & $\begin{array}{l}\text { Desenvolvimento de } \\
\text { laboratórios e centros } \\
\text { de P\&D }\end{array}$ & \begin{tabular}{|l|} 
Oferta reduzida de \\
áreas, enfatizando-se \\
o oferecimento de \\
edifícios (para venda, \\
aluguel ou leasing)
\end{tabular} & $\begin{array}{l}\text { Estão relacionados à } \\
\text { ocupação de grandes } \\
\text { áreas de extensão }\end{array}$ \\
\hline 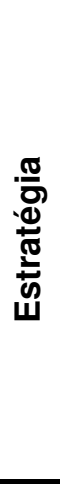 & 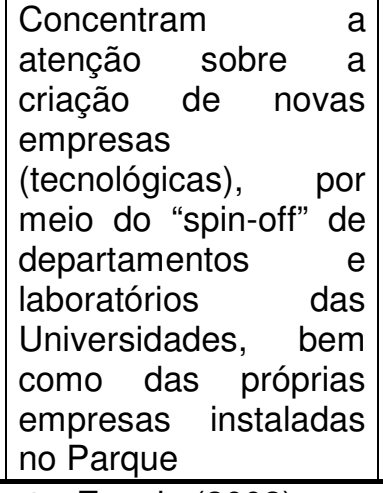 & \begin{tabular}{|lr} 
As incubadoras & de \\
empresas & são \\
consideradas & \\
elementos & \\
importantes & nos \\
Parques &
\end{tabular} & \begin{tabular}{|l} 
Voltado \\
exportação
\end{tabular} & $\begin{array}{ll}\text { Focados } & \text { no } \\
\text { desenvolvimento } & \\
\text { regional } & \end{array}$ \\
\hline
\end{tabular}

Fonte: Zouain (2003) 
3.3.2. Os parques tecnológicos nos países em desenvolvimento. O caso brasileiro

Nos países em desenvolvimento, o movimento de parques ganhou impulso a partir da década de 90, no contexto da reforma do estado, processo de integração dos mercados e da consolidação da inovação como forma dominante de concorrência internacional. Assim, tais países passaram a adequar os modelos adotados nos Estados Unidos e Europa às suas características e ao perfil dos seus desafios, particularmente à necessidade de desenvolvimento socioeconômico e atualização tecnológica (catching up). Dentre as experiências em países em desenvolvimento, destaca-se, na região de Bangalore, o Silicon Valley da Índia, onde há elevada densidade tecnológica, institutos, centros de pesquisa e parques tecnológicos com empresas especializadas em tecnologia da comunicação e software.

No Brasil, o movimento de Parques Tecnológicos teve início na década de 80. Como iniciativas pioneiras podem-se citar: Movimento da Fundação Parque Tecnológico da Paraíba (PARQTEC); Companhia de Desenvolvimento do Pólo de Alta Tecnologia de Campinas CIATEC, em Campinas (SP); o Parque de Software de Curitiba (PR); o Parque de Desenvolvimento Tecnológico, PADETEC, da Universidade Federal do Ceará; a Fundação Parque de Alta Tecnologia de São Carlos - ParqTec (SP).

A dinâmica acelerada do movimento de parques tecnológicos no Brasil nos últimos anos, ainda não aparece nas estatísticas dos organismos internacionais mais recentes.

De acordo com o estudo da ANPROTEC 2008 (Tabela 3.3) no Brasil atualmente existem 74 parques tecnológicos em diferentes estágios de evolução, 25 deles em operação e os demais em processo de implantação ou em fase de planejamento. O número de empresas ultrapassa 500 empresas de tecnologia instaladas, gerando cerca de 47.000 postos de trabalho. 
Tabela 3.3 - Número de parques tecnológicos no Brasil.

\begin{tabular}{l|l}
\hline Estágio & Número \\
\hline Operação & 22 \\
\hline Projeto & 32 \\
\hline Implantação & 19 \\
\hline
\end{tabular}

Fonte: Portfólio - Anprotec 2008

A região sudeste conta com o maior número de iniciativa, 35 empreendimentos, seguida pela região Sul, com 23; no Nordeste, 07; CentroOeste, 5 no Norte $4.83 \%$ dos parques tecnológicos apresentam uma ligação formal com a instituição de pesquisa e 17\%, ligações informais. Considerando a natureza jurídica dos parques, $58 \%$ são privados, $34 \%$ públicos e $8 \%$ de outras modalidades (ANPROTEC, 2008).

O grande número de parques em projeto revela a evolução no número de empreendimentos após o ano de 2005, sendo registrados 49 novos empreendimentos.

Referente à distribuição regional, verifica-se uma predominância das regiões com bases científicas e tecnológicas mais evoluídas. No Sul e Sudeste concentram-se $78 \%$ das novas iniciativas, com o sul apresentando 23 e o sudeste 35 do total, perfazendo $47 \%$.

Utilizando a base de dados da ANPROTEC de 2005 (Tabela 3.4), observa-se que as atividades de Tecnologias de informação e comunicação (TIC) foram responsáveis por $78 \%$ dos negócios desenvolvidos nos parques tecnológicos, em 2005, seguido da biotecnologia e eletrônica (44\%), meio ambiente e energia $(41 \%)$, novos materiais (37\%), agronegócios $(30 \%)$, e outras atividades (44\%). No que se refere à natureza da atividade, $54 \%$ foram classificadas no setor de serviços, $42 \%$ no setor industrial, e $4 \%$ em outras categorias. 
Tabela 3.4 - Parques tecnológicos no Brasil: natureza das atividades das empresas residentes

\begin{tabular}{|c|c|c|c|c|c|c|c|c|c|c|c|}
\hline $\begin{array}{l}\text { Empresas residentes em } \\
\text { parques tecnológicos }\end{array}$ & 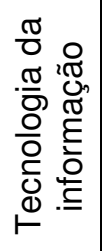 & $\begin{array}{l}: \frac{\pi}{0} \\
\frac{0}{0} \\
\frac{\overline{0}}{0} \\
\frac{\Phi}{0} \\
.00 \\
\frac{0}{0}\end{array}$ & 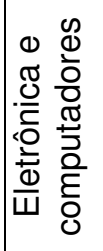 & 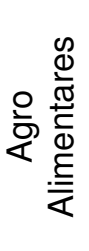 & 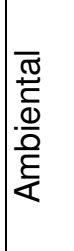 & 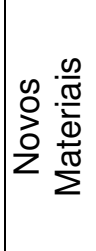 & $\begin{array}{l}\frac{\pi}{0} \\
\frac{\pi}{\omega} \\
\frac{5}{\omega}\end{array}$ & 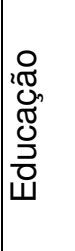 & $\begin{array}{l}\frac{\pi}{0} \\
\frac{0}{0} \\
\frac{0}{0} \\
d \\
\frac{0}{0} \\
\frac{0}{\pi} \\
\frac{\pi}{Z}\end{array}$ & 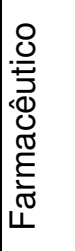 & 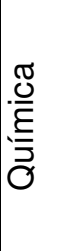 \\
\hline $\begin{array}{l}\text { Participação por natureza de } \\
\text { atividade }(\%)\end{array}$ & 82 & 81 & 75 & 35 & 52 & 46 & 41 & 52 & 41 & 44 & 49 \\
\hline
\end{tabular}

Fonte: ANPROTEC (2005)

No que diz respeito ao número de empresas reunidas (nos parques em atividade por ocasião da pesquisa da Anprotec em 2005), 62\% possuíam até 10 empresas instaladas; $30 \%$, entre 11 e 50 ; e $8 \%$, mais de 51 empresas (Tabela 3.5). Os principais critérios para seleção de empresas para os Parques Tecnológicos brasileiros eram: a viabilidade econômica (77\%); aplicação de novas tecnologias (75\%); interação com universidades (71\%); perfis de empreendedores (69\%); potencial para rápido crescimento (59\%); empregos criados (54\%).

Tabela 3.5 - Parques tecnológicos no Brasil: número de empresas residentes

\begin{tabular}{|c|c|c|c|c|c|c|c|c|}
\hline $\begin{array}{l}\text { Empresas residentes em } \\
\text { parques tecnológicos }\end{array}$ & 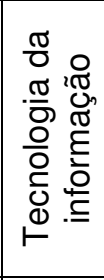 & $\begin{array}{l}\frac{\pi}{0} \\
\frac{0}{0} \\
\frac{0}{0} \\
\frac{\Phi}{0} \\
. \frac{0}{0}\end{array}$ & 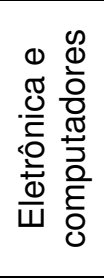 & 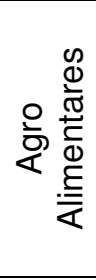 & 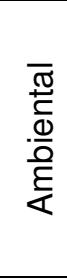 & 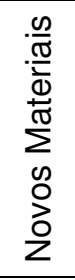 & $\begin{array}{l}\frac{\pi}{0} \\
\frac{0}{0} \\
\frac{5}{4}\end{array}$ & 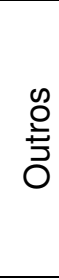 \\
\hline Participação por natureza de atividade (\%) & 78 & 44 & 44 & 30 & 41 & 37 & 41 & 44 \\
\hline
\end{tabular}

Elaborado a partir do anuário da Anprotec (2005)

No Estado de São Paulo existe um Programa específico de Apoio aos Parques Tecnológicos com 14 iniciativas, das quais seis estão pré-credenciadas, ou seja, cumpriram requisitos técnicos estabelecidos pela Secretaria de Desenvolvimento do estado de São Paulo, a saber na Tabela 3.6: 
Tabela 3.6 - Parques Tecnológicos do Estado de São Paulo

\begin{tabular}{|c|c|c|}
\hline Cidade & Iniciativas & Situação \\
\hline São José dos Campos & 01 & Pré-credenciado \\
\hline São Paulo & 02 & \\
\hline Guarulhos & 01 & \\
\hline São Carlos (Parq TEC) & 02 & Pré-credenciado \\
\hline Campinas (Unicamp) & 01 & Pré-credenciado \\
\hline Ribeirão Preto & 01 & \\
\hline Araçatuba & 01 & \\
\hline Santos & 01 & \\
\hline Americana & 01 & \\
\hline São José do Rio Preto & 01 & Pré-credenciado \\
\hline Piracicaba & 01 & Pré-credenciado \\
\hline Sorocaba & 01 & Pré-credenciado \\
\hline
\end{tabular}

Fonte: Secretaria de Desenvolvimento do estado de São Paulo.

A pesquisa da ANPROTEC (2008) sugere um perfil dos parques Tecnológicos no Brasil com alguns dados interessantes:

- a influência das políticas públicas, enfatizando que em geral os parques estão relacionados com programas formais de desenvolvimento regional;

- o papel desempenhado pelo empreendedorismo, materializado no grande número de incubadoras existentes nos parques tecnológicos;

- gestão e governança: observa-se uma situação não uniforme, sendo que muitos projetos são liderados por iniciativas individuais de "visionários"; outro tipo de governança advém de projetos de incubadoras de empresas e núcleos de transferência de tecnologias;

- considerando as empresas âncoras que são de fundamental importância nesse tipo de projeto, observa-se a presença positiva de empresas estatais, podendo se citada, por exemplo, a Petrobrás no Rio de Janeiro.

- Perfil dos parques tecnológicos

De acordo com dados organizados pela International Association of Science Parks (IASP), entidade que representa o movimento internacional de parques científicos e tecnológicos, o perfil dos parques tecnológicos, no mundo, 
segundo a pesquisa realizada em 2007, apresenta as seguintes características: empreendimentos organizados nos anos 90, que ocupavam áreas de pequeno e médio porte e que abrigavam, em sua maioria, empresas do setor de serviços, nas atividades de tecnologia da informação, eletrônica e biotecnologia.

Os dados em relação ao período de criação dos parques tecnológicos (Tabela 3.7 sugerem, ainda, o vigor atual do movimento sustentado, sobretudo, pelos países em desenvolvimento. Visto que, apesar da maior parte dos empreendimentos existentes em 2007 terem sido criados durante a década de 80 (34\%), cerca de $1 / 4$ dos parques foram organizados no início da presente década (vide Tabela 3.7).

Tabela 3.7 - Parques tecnológicos no mundo: período de fundação

\begin{tabular}{c|c|c|c|c|c|c}
\hline \multicolumn{1}{c|}{ Períodos } & $\begin{array}{c}\text { até 1979 + } \\
\text { NA }\end{array}$ & 1980 a 1985 & 1986 a 1989 & 1990 a 1999 & 2000 a 2006 & Total \\
\hline $\begin{array}{l}\text { Criação dos } \\
\text { parques } \\
\text { tecnológicos (\%) }\end{array}$ & $(2)+(3)$ & 11 & 23 & 17 & 26 & 100 \\
\hline
\end{tabular}

Fonte: Elaborado a partir de relatório da IASP (2007)

Já a concentração de empreendimentos de pequeno e médio porte (72\%), pode ser explicada pelo fato de que a infra-estrutura de ciência e tecnologia, geralmente, localiza-se em regiões adensadas, onde a oferta de espaços é mais limitada, especialmente nos países em desenvolvimento. Por outro lado, os dados da IASP (vide Tabela 3.8) revelam que cerca de $1 / 4$ dos parques ocupam áreas superiores a 600 mil metros quadrados, sendo classificados como grandes ou muito grandes, o que sugere a diversidade de modelos existentes para esses habitats de inovação.

Tabela 3.8 - Parques tecnológicos no mundo: tamanho

\begin{tabular}{c|c|c|c|c|c|c}
\hline Porte & $\begin{array}{c}\text { Pequenos } \\
(\text { até 200 mil } \\
\left.\mathrm{m}^{2}\right)\end{array}$ & $\begin{array}{c}\text { Médios } \\
(\mathrm{de} 201 \mathrm{a} \\
\left.600 \mathrm{mil} \mathrm{m}^{2}\right)\end{array}$ & $\begin{array}{c}\text { Grandes } \\
(\mathrm{de} 600 \mathrm{a} \text { um } \\
\left.\text { milhão } \mathrm{m}^{2}\right)\end{array}$ & $\begin{array}{c}\text { Muito grandes } \\
(\text { mais de um } \\
\left.\text { milhão } \mathrm{m}^{2}\right)\end{array}$ & $\begin{array}{c}\text { Sem } \\
\text { informação }\end{array}$ & Total \\
\hline Empreendimentos (\%) & 40 & 27 & 10 & 19 & 4 & 100 \\
\hline
\end{tabular}

Fonte: Elaborado a partir de relatório da IASP (2007) 
Em termos de área construída, os dados da IASP (2007) apontam para quase metade dos empreendimentos que conta com uma área construída superior a 40 mil metros quadrados, considerando as edificações pertencentes ao parque e dos participantes e/ou instituições residentes. Os empreendimentos tidos como pequenos (até 15 mil metros quadrados) representam cerca de $30 \%$, enquanto os muito grandes, $35 \%$ conforme apresentado na Tabela 3.9).

Tabela 3.9 - Parques tecnológicos no mundo: área construída

\begin{tabular}{|c|c|c|c|c|c|c|}
\hline Área construída & $\begin{array}{c}\text { Até } \\
15 \mathrm{mil} \mathrm{m}^{2}\end{array}$ & $\begin{array}{c}15 \text { a } 40 \text { mil } \\
\mathrm{m}^{2}\end{array}$ & $\begin{array}{c}40 \text { a } 80 \text { mil } \\
m^{2}\end{array}$ & $\begin{array}{l}\text { Maior do que } \\
80 \mathrm{mil} \mathrm{m}^{2}\end{array}$ & $\begin{array}{c}\text { Sem } \\
\text { informação }\end{array}$ & Total \\
\hline $\begin{array}{l}\text { Empreendimentos } \\
(\%)\end{array}$ & 16 & 25 & 17 & 36 & 6 & 100 \\
\hline
\end{tabular}

Fonte:Elaborado a partir de relatório da IASP (2007)

As áreas verdes, por sua vez, representam entre 15 e $30 \%$ para cerca de metade dos parques tecnológicos que compõem a amostra da pesquisa da IASP (Tabela 3.10). Contudo, enquanto os projetos que operam com espaços verdes classificados como grandes (maior que $50 \%$ da área total do empreendimento) representaram apenas $5 \%$, os com área verde inferior a $15 \%$ representam $20 \%$, o que, de certo modo, pode ser explicado pela natureza urbana de uma parte importante dos empreendimentos.

Tabela 3.10 - Parques tecnológicos no mundo: área verde

\begin{tabular}{c|c|c|c|c|c|c}
\hline Área verde & < que 15\% & de 15 e 30\% & de 31 e 50\% & > que 50\% & Sem informação & Total \\
\hline $\begin{array}{c}\text { Empreendimentos } \\
(\%)\end{array}$ & 22 & 29 & 19 & 21 & 9 & 100 \\
\hline
\end{tabular}

Fonte: Elaborado a partir de relatório da IASP (2007)

Em relação à natureza das atividades desenvolvidas, torna-se importante diferir os empreendimentos especializados dos generalistas. A pesquisa da IASP aponta três modelos de parques quanto à especialização:

- Generalistas, parques que admitem empresas de qualquer setor tecnológico;

- Especialistas, são parques especializados num único setor, ou limitados a alguns setores; 
- Semi-especialistas são parques que favorecem determinados setores tecnológicos, mas admitem algumas empresas de outros setores.

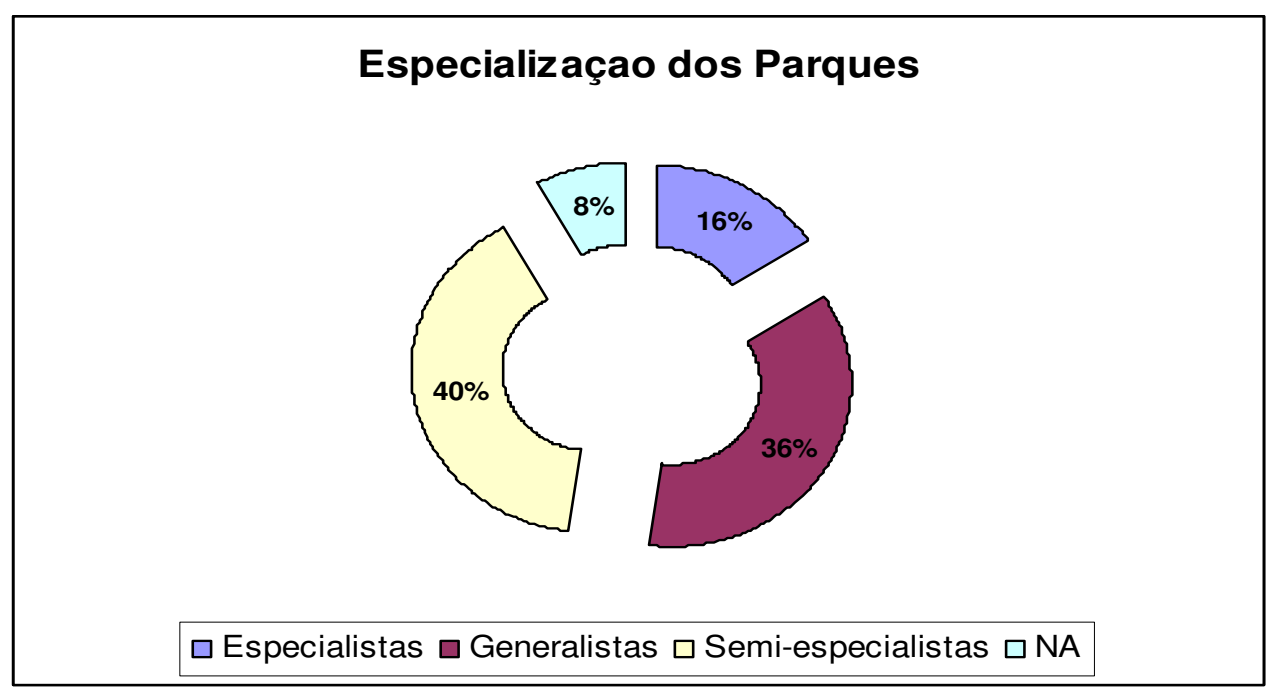

Figura 3-2: Especialização dos parques tecnológicos. Fonte: IASP (2007)

A tecnologia da informação está presente em aproximadamente 1/4 dos parques tecnológicos, enquanto as de biotecnologia e eletrônica representam cerca de 1/5 das atividades. As iniciativas de base agro-alimentar e ambiental, quando consideradas em conjunto, também se encontravam presentes em 1/5 dos empreendimentos pesquisados, conforme pode ser visto na Tabela 3.11.

Tabela 3.11 - Parques tecnológicos no mundo: natureza das atividades das empresas residentes

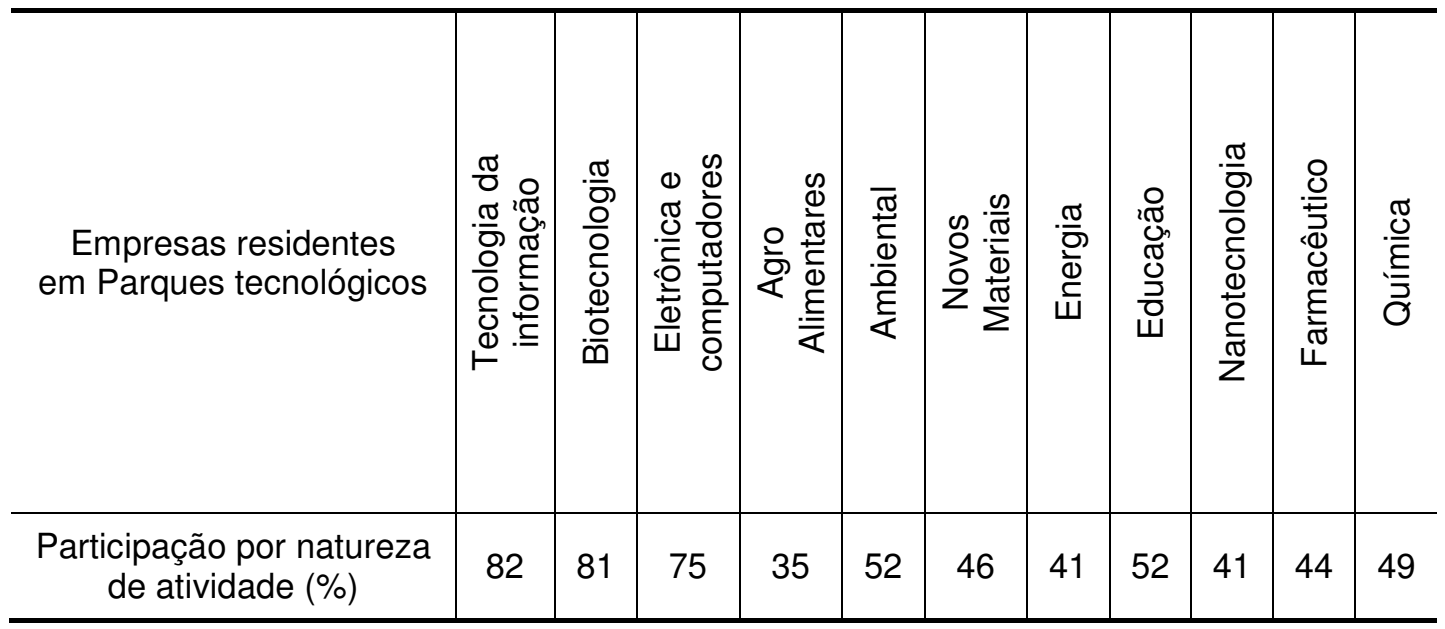

Fonte: Elaborado a partir de relatório da IASP (2007) 
3.3.3. Conjunto de Atividades mais presentes em Parques Tecnológicos e Científicos.

Apesar de os Parques Tecnológicos apresentarem características bastante heterogêneas, segundo foi mencionado, esses habitats contam com alguns elementos constitutivos comuns (disponibilidade de recursos de base tecnológica, ambiente diferenciado com condições de estimular a inovação no setor privado e capacidade de influenciar a dinâmica econômica).

Também o objetivo de promover o desenvolvimento de produtos e processo, tendo como base o conhecimento científico e o tecnológico. Por isso, é encontrado nos parques tecnológicos um conjunto de atividades tradicionais, entre as quais se destacam as ações de estímulo à geração de tecnologias, as ações de fomento para o desenvolvimento de novas empresas tecnológicas, a oferta de serviços de alto valor agregado, mecanismos facilitadores de interação entre os atores envolvidos no processo de inovação.

- Estímulo à geração de tecnologias: é o conjunto das ações voltadas ao desenvolvimento de conhecimento e da tecnologia. Nos parques tecnológicos, a estratégia mais comum para estimular o desenvolvimento tecnológico é a cooperação, representada pela interação entre universidades, instituições de pesquisa e empresas;

- Desenvolvimento de novas empresas de tecnologia: ações voltadas ao desenvolvimento do espírito e das ações empreendedoras. Em geral, nos parques tecnológicos, tais ações estão articuladas aos projetos de incubação de empresas de base tecnológica a partir dos quais o desenvolvimento de negócios inovadores é estimulado;

- Serviços de alto valor agregado: agrega o conjunto da infra-estrutura disponibilizada pelo parque a fim de facilitar o processo de desenvolvimento de produtos e processos inovadores, como também, promover o crescimento desses negócios. Os serviços de alto valor agregados reúnem, além espaços e instalações diferenciados em termos de qualidade, serviços de apoio, como assessorias, consultoria em marketing, comunicação, finanças e outros; 
- Interação entre os atores: é o conjunto de ações e de mecanismos facilitadores do processo de interação entre os agentes do parque. Além de dar suporte à estratégia para o desenvolvimento da tecnologia (como foi mencionado), a interação com outros atores como investidores, autoridades públicas, entre outros, caracterizam o ambiente diferenciado dos parques tecnológicos.

- Grupos de interesse

Considerando a configuração e os objetivos básicos dos parques tecnológicos, existem, pelo menos, três grupos de interesse (stakeholders), cujas necessidades são atendidas através das atividades básicas mencionadas anteriormente. São eles: as instituições de ciência e tecnologia; as empresas que procuraram desenvolver os produtos e processos a partir da infra-estrutura de ciência e tecnologia; os agentes públicos.

- Instituições de ciência e tecnologia: o interesse básico é o acesso diferenciado aos recursos que podem ser obtidos a partir da interação com as empresas. Tais recursos geralmente são de ordem financeira, representados pelos resultados econômicos das pesquisas; recursos de infra-estrutura, que são fornecidos pelo acesso à infra-estrutura tecnológica das empresas; no acesso à informação, através do conhecimento das necessidades do mercado ou necessidade industriais, que consegue, por exemplo, definir novas diretrizes para o processo de pesquisa.

- Empresas inovadoras: o interesse básico é o de minimizar os custos e os riscos para o desenvolvimento de produtos e processos de base tecnológica e maximizar a oportunidade e os retornos dos projetos. Nesse contexto, o interesse das empresas está voltado ao acesso à infra-estrutura de ciência e tecnologia representada por laboratórios e equipamentos; ao acesso à mãode-obra qualificada, presente nas instituições de ensino e pesquisa; ao acesso aos programas e pesquisas em desenvolvimento para avaliação do potencial de mercado, como também a outros elementos que configuram o diferencial do habitat de inovação: vantagens tributárias, financiamento de investimentos, acesso ao mercado etc. 
- Agentes públicos: o objetivo geral é a promoção do desenvolvimento socioeconômico (especialmente local) a partir do estímulo às atividades econômicas de base tecnológica. Pode-se considerar que esses interesses são atendidos através do processo de criação de novos empreendimentos e redução do êxodo de empresas; criação de postos de trabalho e redução da evasão de talentos; redefinição das atividades econômicas e inserção da produção local em níveis nacional e/ou internacional; revitalização de áreas degrada; geração de renda e tributos.

- Fatores de atratividade e desafios dos projetos

O sucesso dos parques tecnológicos está diretamente relacionado ao sucesso das empresas residentes neles. O nível de atratividade de um parque tecnológico influi na condição da oferta de empresas qualificadas com maior potencial de desenvolvimento.

Considerando essa visão, foram desenvolvidas pesquisas pela AURP para captar a opinião das empresas residentes em parques tecnológicos com 0 objetivo de evidenciar os principais fatores mais importantes que restringem 0 crescimento e os principais elementos que atraem as empresas para os parques tecnológicos. Nas Tabela 3.12 e Tabela 3.13 encontram-se os resultados mais significativos desse estudo.

Relacionado às restrições ao crescimento, a maioria dos respondentes avalia que os principais fatores estão relacionados a limitações ao desenvolvimento do parque tecnológico (investimentos) e a disponibilidade de capital de risco para as empresas. Fica evidente a preocupação com os instrumentos que possibilitam o crescimento destas no ambiente do parque.

Outros fatores que aparecem com maior freqüência relacionam-se à disponibilidade de terras (área total) e espaços (área produtiva).

Tabela 3.12 - Crescimento dos parques tecnológicos: principais restrições

\begin{tabular}{l|c}
\hline Restrições ao crescimento dos parques & Freqüência de respostas (\%) \\
\hline Possibilidade de desenvolvimento & 51 \\
\hline Disponibilidade de capital de risco & 50 \\
\hline
\end{tabular}




\begin{tabular}{l|c}
\hline Restrições ao crescimento dos parques & Freqüência de respostas (\%) \\
\hline Outros & 28 \\
\hline Disponibilidade de espaço & 24 \\
\hline Disponibilidade de terras & 20 \\
\hline Cultura empreendedora & 16 \\
\hline Acesso para Universidade & 12 \\
\hline Falta de liderança na comunidade & 12 \\
\hline
\end{tabular}

Fonte: AURP, University Research Park Profile (2003)

Os dados expostos na Tabela 3.13 dizem respeito à atratividade do parque tecnológico em relação à localização, ou seja, os fatores que conduzem as empresas para se instalarem no local. Destacando-se mais, aparece a imagem do local, permitindo inferir que o prestígio desfrutado exerce grande influência na escolha. Outro fator profundamente observado envolve a relação localização do parque e a origem do fundador da empresa. Também surgem elementos relacionados à infra-estrutura, tais como transportes e comunicação e as condições diferenciadas em termos de locação do espaço.

Tabela 3.13 - Empresas residentes em parques tecnológicos: elementos de localização

\begin{tabular}{|c|c|c|c|c|}
\hline Elementos de decisão de localização & 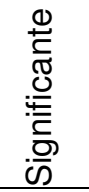 & $\begin{array}{l}\frac{0}{0} \\
\frac{\pi}{\overline{0}} \\
\frac{0}{2} \\
\Sigma\end{array}$ & 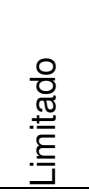 & 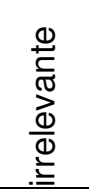 \\
\hline Imagem do local & $39 \%$ & $13 \%$ & $40 \%$ & $8 \%$ \\
\hline Salas para expansão & $20 \%$ & $24 \%$ & $40 \%$ & $15 \%$ \\
\hline Transporte e comunicação & $23 \%$ & $20 \%$ & $35 \%$ & $20 \%$ \\
\hline Custo do espaço & $23 \%$ & $20 \%$ & $35 \%$ & $20 \%$ \\
\hline Local de origem do fundador empresa & $30 \%$ & $14 \%$ & $20 \%$ & $33 \%$ \\
\hline Serviços disponíveis & $11 \%$ & $22 \%$ & $33 \%$ & $30 \%$ \\
\hline mão-de-obra & $12 \%$ & $24 \%$ & $30 \%$ & $34 \%$ \\
\hline Acesso para mercados e clientes & $20 \%$ & $30 \%$ & $22 \%$ & $38 \%$ \\
\hline Outras empresas estabelecidas na área & $17 \%$ & $10 \%$ & $22 \%$ & $54 \%$ \\
\hline Acesso para universidades/centros de pesquisa & $17 \%$ & $20 \%$ & $13 \%$ & $50 \%$ \\
\hline
\end{tabular}

Fonte: AURP, University Research Park Profile (2003) 
A pesquisa realizada pela AURP (Tabela 3.14) avalia os elementos mais valorizados pelas empresas residentes em parques tecnológicos. $O$ elemento mais significativo também está ligado ao prestígio alcançado por empresas localizadas em um parque tecnológico. O acesso aos espaços comuns aparece em segundo lugar, visto que facilita a interação entre as empresas. Quase no mesmo nível de valorização estão as facilidades propiciadas pelos serviços disponibilizados. Outros fatores lembrados são os potenciais de expansão, oportunidade propiciada pela localização e a atmosfera social.

Tabela 3.14 - Empresas residentes em parques tecnológicos: atributos mais valorizados

\begin{tabular}{|c|c|c|c|c|}
\hline $\begin{array}{l}\text { Atributos mais valorizados pelas } \\
\text { empresas }\end{array}$ & 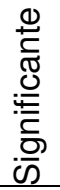 & $\begin{array}{l}\frac{0}{0} \\
\frac{\pi}{0} \\
\frac{0}{0} \\
\frac{0}{2}\end{array}$ & 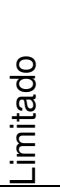 & 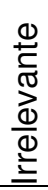 \\
\hline Qualidade dos serviços & 18 & 32 & 30 & 10 \\
\hline Prestígio localização & 20 & 28 & 30 & 20 \\
\hline Acesso para espaços comuns & 19 & 28 & 28 & 30 \\
\hline Oportunidade na região & 5 & 35 & 22 & 60 \\
\hline Potencial de expansão & 10 & 32 & 16 & 22 \\
\hline Comunidade e atmosfera social & 5 & 33 & 31 & 38 \\
\hline Secretaria/serviço de suporte & 3 & 7 & 32 & 62 \\
\hline Gerenciamento/Orientação & 3 & 7 & 31 & 62 \\
\hline
\end{tabular}

Para definir os principais desafios dos projetos, foram analisados os fatores que com maior incidência prejudicam o sucesso dos parques tecnológicos, baseando-se nas experiências internacionais. A pesquisa da Association of University Research Parks (AURP) verificou que os fatores encontravam-se tanto no âmbito interno dos projetos quanto em elementos externos. Todavia, não devem ser repetidos, transformando-se em fatores críticos de sucesso aos novos projetos. A seguir, eles são destacados:

- Definição de uma governança com papéis e funções claras sem conflito de interesses; 
- Planejamento estratégico, que direcione as ações do projeto numa perspectiva de longo prazo do projeto com visão e missão consistentes;

- Marketing do projeto, considerando a visibilidade do mesmo e plano de atração de empresas;

- Planejamento financeiro do parque, com a visão do ciclo de desenvolvimento dele, com previsão de fontes de receitas e desembolsos;

- Desenvolvimento de parcerias adequadas;

- Organização dos espaços, prevendo o crescimento do parque.

Relacionada aos fatores externos, a disponibilidade de recursos para investimentos é fator de grande importância. A pesquisa realizada pela AURP em parques americanos e canadenses identificou que o descompasso entre a oferta de recursos de fundos de desenvolvimento (development funding) ao parque tecnológico e capital de risco (venture capital) para as empresas é um grande obstáculo ao desenvolvimento dos mesmos.

Considera-se que a demanda para o crescimento dos parques tecnológicos é determinada pela disposição das empresas em adquirir e/ou ampliar seus espaços. Esse fato, por sua vez, é influenciado pela disponibilidade de recursos disponíveis para investimento das empresas. Considerando o momento de consolidação da demanda das empresas para ampliação dos seus espaços, a equipe gestora do parque tecnológico também necessitará de recursos para utilizar na ampliação do projeto.

Portanto, cabe aos gestores de parques tecnológicos dimensionarem e preverem tais oscilações no ciclo de capitais, revendo ações a fim de obter vantagens no tocante a esses momentos. Em mercados como o brasileiro, no qual a oferta de recursos para investimento em sua maior parte é de origem pública, o gestor deve planejar estrategicamente o crescimento dos parques e alinhá-los com a oferta das fontes de recursos. Também não devem ser utilizados critérios políticos, visto que a contrapartida do apoio público aos parques (sem o qual não teriam sido criados) é de uma freqüente e excessiva "dependência" política, com um prejudicial cerceamento da liberdade de gestão com critérios empresariais. 
- Diretrizes para elaboração de projetos

A natureza dos grupos de interesse (instituições de ciência e tecnologia, empresas inovadoras e agentes públicos) associada ao perfil das atividades empreendidas (desenvolvimento de produtos e processos a partir de base tecnológica) caracterizam os projetos dos parques tecnológicos como de natureza complexa. A seguir, são apresentados alguns dos itens mais importantes dos projetos de parques tecnológicos, que são objeto de decisão, além de críticos para o sucesso dos habitats de inovação.

\subsubsection{Fatores básicos para projetos de Parques Tecnológicos.}

A seguir, são especificados de acordo com a visão do autor, tendo como base uma extensa revisão na literatura e experiências de, os fatores básicos para projetos de parques tecnológicos:

- Suporte das autoridades locais, regionais ou nacionais - apoio dos representantes de governo, a fim de incentivar o projeto e prover melhorias na infra-estrutura do local;

- Presença de instituições de pesquisa e universidades - a base de C\&T é condição básica para o desenvolvimento de parques tecnológicos;

- Sistema de incentivos (creditícios e tributários) - definição de condições diferenciadas para o desenvolvimento dos parques tecnológicos, permitindo atrair empresas e investidores;

- Espaços para aglomeração de empresas de base tecnológica - oferta de espaços para as empresas desenvolverem as atividades;

- Infra - estrutura básica (transporte, telecomunicações, energia e outros) condições favoráveis e atrativas para receber os proprietários e funcionários das empresas do parque tecnológico;

- Qualidade ambiental e boa imagem urbanística - os projetos de parques tecnológicos devem estar em harmonia com os preceitos de desenvolvimento sustentável, sendo a construção condizente com empresas de base tecnológica; 
- Capacidade de absorção de conhecimento aplicado e de inovação - presença de empresas com capacidade de prover parcerias e aplicar os conhecimentos gerados;

- Foco de mercado - definição da estratégia para atuação, podendo ser interno ou baseado em exportações.

\section{- Decisões Estratégicas}

As decisões estratégicas são os conjuntos de definições que têm efeito sobre todo o projeto, tomadas pelos mais prestigiados membros do mesmo. $\mathrm{O}$ modelo proposto por Sanz (apresentado no seminário internacional da Associação Brasileira das Empresas Inovadoras - ANPROTEC, em 2006) organiza as decisões estratégicas em sete níveis, facilitando o planejamento e organização.

As decisões definem: a característica do parque (urbano ou não urbano), tipos de empresas a serem privilegiadas (nascentes ou maduras); grau de especialização do parque (especialista ou generalista); objetivo de mercado (local ou exportação); trabalho em redes (ocasional ou estratégico) e o modelo de gestão (aberto ao mercado ou institucional) (Figura 3-3).
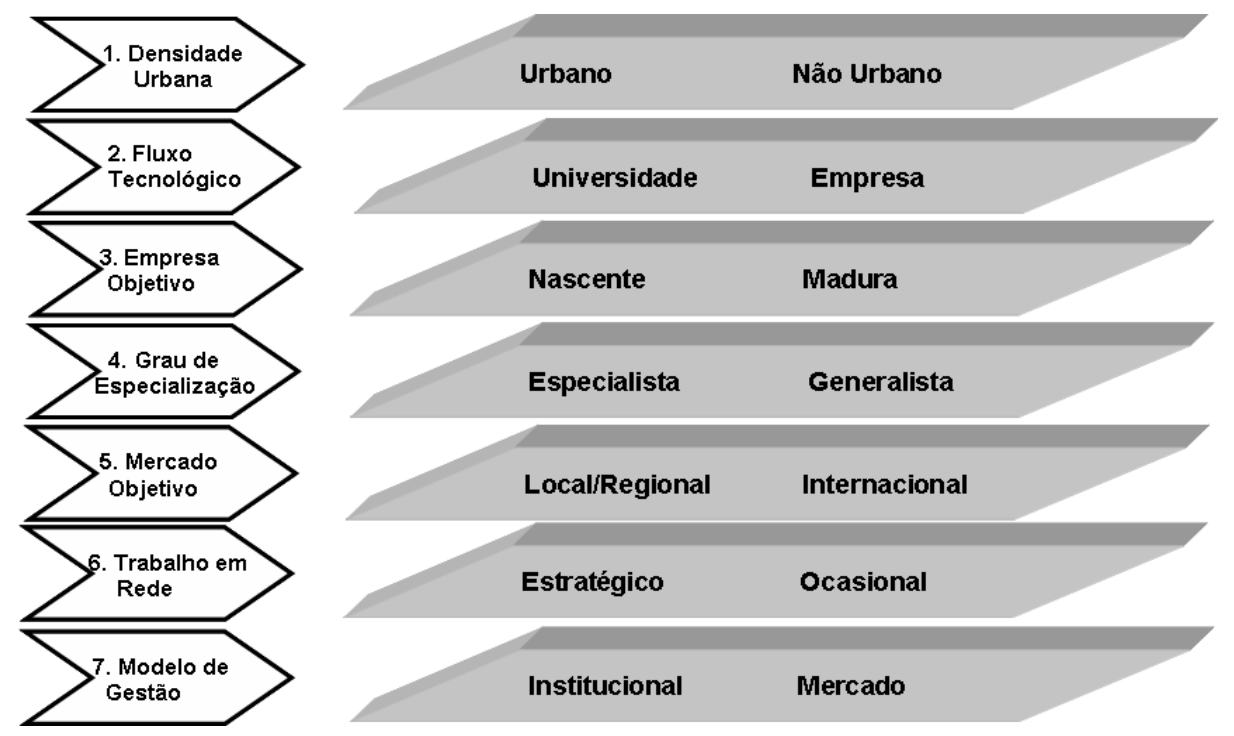

Figura 3-3: Projetos de parques tecnológicos: Modelos dos Eixos estratégicos Elaborado a partir de Sanz (2006) 
As decisões são as bases para o desenvolvimento das parcerias, definição do local, tipo de mercado, modelo de gestão e características dos potenciais parceiros.

- Foco do projeto

O foco do projeto do parque tecnológico deve ser entendido como o conjunto de atividades econômicas e plataformas tecnológicas que serão privilegiadas pelo habitat de inovação. A decisão sobre o foco do projeto é crítica, uma vez que condiciona tanto as especificações operacionais (definição de formas, equipamentos e infra-estrutura) quanto às especificações estratégicas (atores relevantes e a forma de interação com o habitat) do projeto.

A definição do foco do projeto costuma ser precedida de uma análise de vocação econômica, de uma análise de vocação tecnológica, proporcionando ao desenvolvimento do habitat. Há, também, uma avaliação das dinâmicas urbanas dos espaços de influência. A análise de vocação econômica precisa sugerir as atividades econômicas prioritárias em relação à necessidade e potencial ao desenvolvimento de produtos e processos de base tecnológica; a análise de vocação tecnológica deve apontar as plataformas e linhas de pesquisa científica e tecnológica com maior potencial de desenvolvimento de produtos e processos inovadores; já a análise das dinâmicas urbanas necessita, por sua vez, estabelecer prioridade para os efeitos de animação do ponto de vista do interesse social.

Além das perspectivas econômicas, tecnológicas e urbanas (Figura 3-4), também é recomendável que a definição do foco do projeto seja elaborada levando-se em conta as diretrizes econômicas das diferentes esferas de poder (município, estado, região e país), sobretudo no que se refere às perspectivas de médio e longo prazo. A justificativa é que a organização de um ambiente diferenciado para o desenvolvimento dos produtos e processos tecnológicos (que representa um dos elementos constitutivos dos parques tecnológicos) ocorre devido à facilidade de articulação dos interesses dos agentes relevantes ao sucesso dessas atividades. 


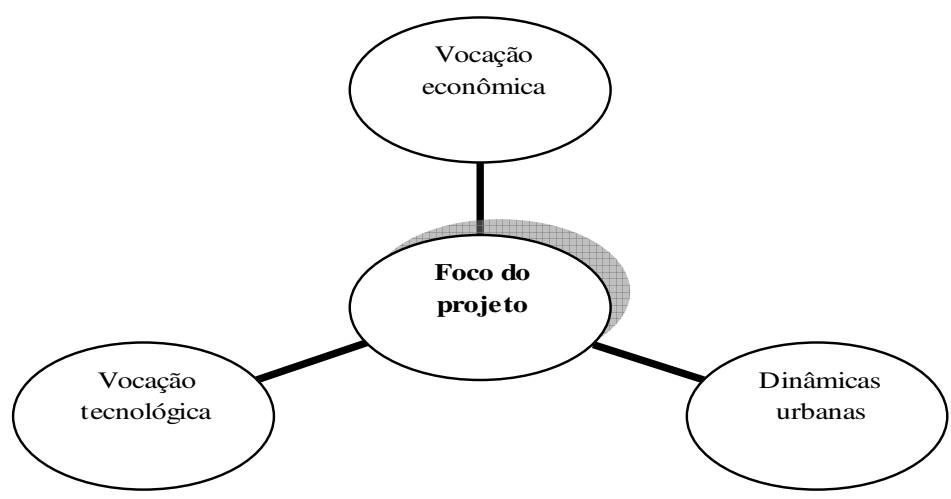

Figura 3-4: Projetos de parques tecnológicos: definição do foco

O foco dos projetos pode ser estabelecido tendo como referência os modelos generalista ou especialista (ver os exemplos na Tabela 3.15).

O modelo generalista é marcado pelo desenvolvimento de atividades de pesquisa e outros diversificados, enquanto o especialista se concentra em um número mínimo de atividades. A maior parte dos projetos é generalista porque o modelo possibilita rápido desenvolvimento do habitat, oferece mais flexibilidade, maiores efeitos multiplicadores em curto prazo evitando a ocorrência de truncamentos em determinadas trajetórias tecnológicas. Os projetos especialistas, entretanto, possuem melhores condições de criar ambientes diferenciados para o desenvolvimento de produtos e processos de base técnica maximizando o potencial de sucesso dos negócios elaborados em uma determinada plataforma tecnológica.

Tabela 3.15 - Projeto de parques tecnológicos: projetos especialistas e generalistas (exemplos)

\begin{tabular}{l|l}
\hline Projetos com foco especialista & Projetos com foco generalista \\
\hline Agroparc (França) & Parco Scientifico e tecnologico della Sicilia (Itália) \\
\hline Agri-biotech Park (Índia) & Quebec Metro High Tech Park (Canadá) \\
\hline Sindicate Mixte Du Technopole Alimentec & Khorasan Science and Technology Park (Irã) \\
(França) & \\
\hline
\end{tabular}

Fonte: IASP (2004) 
- Sustentabilidade econômica

Assim como a definição do foco do projeto do parque tecnológico, as decisões em relação às estratégias de auto-sustentação são críticas para garantir a condição de viabilidade econômica do empreendimento, como também as condições de longo prazo para retorno dos investimentos e consecução dos objetivos do habitat.

As decisões ligadas à estratégia de viabilidade econômica dos empreendimentos envolvem a especificação das origens e fontes de recursos para cobertura das despesas correntes, que estão relacionadas à manutenção da infra-estrutura e serviços do parque tecnológico, além do financiamento dos investimentos. O projeto de viabilidade prevê ainda a especificação de objetivos e metas em relação à composição dos recursos e à construção de cenários a fim de orientar a tomada de decisões para gestão financeira, em curto prazo (Figura 3-5).

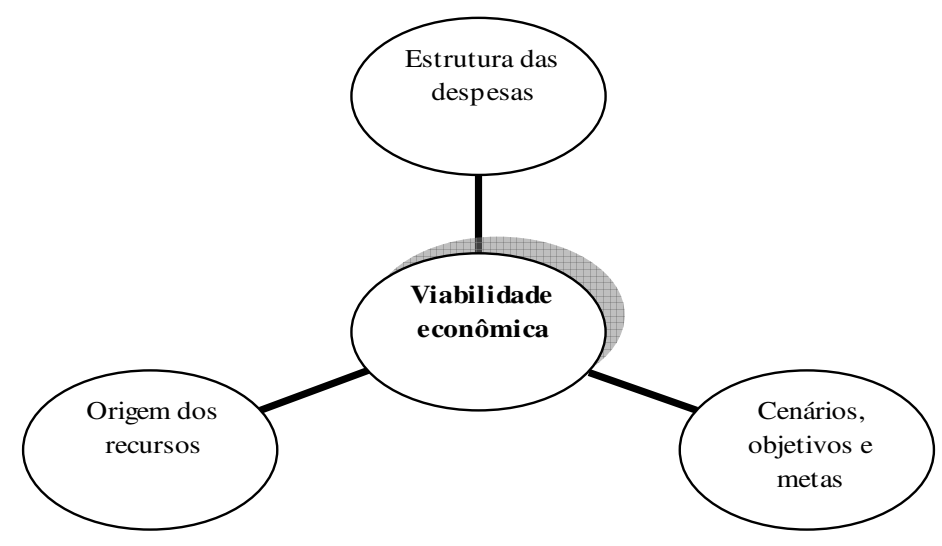

Figura 3-5: Projetos de parques tecnológicos: viabilidade econômica.

A experiência internacional indica a existência de três fontes básicas de recursos, que são as receitas próprias, as receitas com patentes e participação nos resultados e o financiamento de gastos com custeio e investimentos a partir de fundos públicos. As receitas próprias são aquelas geradas pela concessão do espaço envolvendo receita com os aluguéis e outras comerciais diversas. As receitas com patentes e participação nos resultados compreendem uma receita 
associada ao sucesso econômico dos processos e produtos desenvolvidos no contexto do habitat de inovação. Já os fundos públicos, por sua vez, são representados pelo apoio dos agentes públicos ou mesmo da política pública através do fomento das atividades de base tecnológica.

As experiências internacionais sugerem que, à medida que os parques tecnológicos se consolidam com habitats de inovação, a importância relativa dos fundos públicos para as despesas correntes e investimentos tende a diminuir, enquanto as receitas relacionadas ao sucesso econômico das atividades tendem a aumentar. $\mathrm{Na}$ fase de maturação dos empreendimentos, as receitas próprias e os fundos públicos apresentam a tendência de serem as principais fontes de recursos dos parques tecnológicos. Cumpre destacar que os negócios de natureza eminentemente imobiliária através da compra e venda de áreas nos parques tecnológicos representaram, historicamente, uma fonte de recursos importante à realização de investimentos em muitos parques dos Estados Unidos e também da Europa.

$\mathrm{Na}$ Tabela 3.16 são apresentados dados sobre as sobre as receitas próprias dos parques tecnológicos. A participação relativamente pequena das referidas receitas dos parques tecnológicos, no Brasil, pode ser explicada pela fase de maturação desses empreendimentos no país, em comparação àqueles tradicionais e consolidados, anteriormente referenciados.

Tabela 3.16 - Projeto de parques tecnológicos: sustentabilidade dos projetos (exemplos)

\begin{tabular}{l|l}
\hline \multicolumn{1}{c|}{ Parque } & Estratégias de auto sustentação \\
\hline PADETEC (CE) & Receita própria (9,9\%) \\
\hline Londrina Tecnópolis (PR) & Receita própria (50,0\%) \\
\hline Porto Digital (PE) & Receita própria (50,0\%) \\
\hline Parque Tecnológico do Rio de Janeiro (RJ) & Receita própria (40,0\%) \\
\hline Kyriat Weizmann Science Park (Israel) & Auto-sustentável \\
\hline Taguspark S.A. (Portugal) & Auto-sustentável \\
\hline Parque Tecnológico de Andalucia (Espanha) & Auto-sustentável \\
\hline
\end{tabular}

Fonte: Elaborado a partir de Zouain (2003) 


\subsubsection{Serviços disponibilizados em Parques Tecnológicos}

Os projetos de parques tecnológicos envolvem empresas em diferentes estágios de desenvolvimento, desde a geração das idéias até empresas com maturidade no mercado. Esses estágios serão os direcionadores dos serviços que estarão disponibilizados. Os serviços oferecidos pelos parques tecnológicos às empresas que estão sob a sua área de influência são classificados como básicos e estratégicos. Os serviços básicos representam os de infra-estrutura e apoio, como segurança, limpeza, informação e manutenção. Os estratégicos constituem o ambiente diferenciado para o desenvolvimento de produtos e processos de base tecnológica.

- Treinamento: É desejável que um Parque Tecnológico proporcione cursos para a elaboração de Planos de Negócios aos seus associados, com recursos e pessoal próprio, bem como a contratação de consultores. Os temas focais presentes na atuação do Centro abrangem: estratégias, políticas, gestão e integração empresarial; gestão ambiental; inovação, produtividade e qualidade (metrologia, normalização e certificação) para a competitividade; investimento e promoção de tecnologia; núcleo de informações gerenciais - informações tecnológicas e sobre políticas governamentais, contratação e comercialização de tecnologia.

- Transferência de tecnologia: A universidade (tradicionalmente) não desenvolve tecnologias, mas gera resultados de pesquisas. Sendo assim, a universidade, normalmente oferece à indústria a transferência de conhecimento, mais do que a transferência de tecnologia. A principal implicação disso, é que, em vários casos, independente da qualidade da pesquisa, a indústria atribui pequeno valor de retorno a tais resultados, que se deve ao fato de que, para transformar conhecimento em tecnologia, a indústria precisa incorrer em significativos custos de desenvolvimento. Torna-se necessário, portanto, encontrar formas a fim de que as universidades consigam desenvolver tecnologias por meio de pesquisas, obtendo retornos financeiros com a propriedade intelectual dos resultados destas pesquisas. É função de um Parque Tecnológico providenciar o serviço necessário para implementar este processo de transferência de tecnologia. 
- Pesquisa cooperativa: disponibilidade de desenvolvimento de pesquisas em conjunto com os pesquisadores da instituição de C\&T e I, possibilitando o acesso aos laboratórios de pesquisa das instituições apoiadoras.

- Espaços diferenciados para Compartilhamento: existência de espaços para interação entre as empresas para trocas de conhecimento, de tecnologia e definição de arranjos e parcerias.

- Bolsões para negociação de serviços entre empresas do parque - acesso ao mercado das empresas residentes no parque, assim como empresas parceiras do projeto.

- Preparação para realizar atividades de comércio exterior: por meio da melhoria da capacitação tecnológica, da potencialização de fatores produtivos e de vantagens competitivas em escalas nacionais e internacionais.

- Eventos e divulgação: Promoção de eventos e visitas que aumentem o prestígio do parque tecnológico e das empresas residentes, além disso, os residentes gozam de ambientes diferenciados para promoverem os seus produtos.

- Acesso a financiamentos e investidores: maior possibilidade de acesso aos canais e fundos de investimentos para aplicação em empresas de base tecnológica.

- Impactos e desempenho dos Parques Tecnológicos

Quando ocorre a instalação de um Parque Tecnológico, a região absorve uma série de resultados ou impactos provenientes de suas atividades. Baseando-se nesse contexto, torna-se importante 0 desenvolvimento de indicadores que avaliam os resultados da iniciativa, tendo em vista a diversidade dos interesses normalmente associados aos projetos dos parques tecnológicos, como as instituições de ensino e pesquisa (ICT), empresas e a política pública.

Deve-se ressaltar ainda que é difícil avaliar com precisão os impactos de um Parque (principalmente caso a sua instalação seja muito recente). $\mathrm{Na}$ 
Tabela 3.17 são apresentados alguns empreendimentos nacionais e internacionais e seus principais impactos.

Tabela 3.17 - Projeto de parques tecnológicos: avaliação dos impactos (exemplos)

\begin{tabular}{l|l}
\hline \multicolumn{1}{c|}{ Parque } & \multicolumn{1}{c}{ Impactos/efeitos } \\
\hline $\begin{array}{l}\text { Pólo de Informática de São Leopoldo } \\
\text { (RS) }\end{array}$ & $\begin{array}{l}\text { Postos de trabalho qualificados. } \\
\text { Movimento comercial. }\end{array}$ \\
\hline PADETEC (CE) & $\begin{array}{l}\text { Número de empresas de base tecnológica. } \\
\text { Aproveitamento das riquezas locais. }\end{array}$ \\
\hline Londrina Tecnópolis (PR) & Crescimento regional \\
\hline Porto Digital (PE) & $\begin{array}{l}\text { Oferta de cursos de especialização. } \\
\text { Criação de novas empresas }\end{array}$ \\
\hline $\begin{array}{l}\text { Parque Tecnológico do Rio de Janeiro } \\
\text { (RJ) }\end{array}$ & $\begin{array}{l}\text { Valorização da vocação tecnológica no RJ. } \\
\text { Recuperação de área pública degradada. }\end{array}$ \\
\hline Kyriat Weizmann Science Park (Israel) & $\begin{array}{l}\text { Porcentagens de sucesso das empresas no } \\
\text { mercado. } \\
\text { Benefícios para a economia do país. }\end{array}$ \\
\hline Taguspark S.A. (Portugal) & $\begin{array}{l}\text { Total de postos de trabalho. } \\
\text { Número de empresas criadas. }\end{array}$ \\
\hline Parque Tecnológico de Andalucia & $\begin{array}{l}\text { Valorização imobiliária da região. } \\
\text { aumento de atividade econômica. }\end{array}$ \\
\hline
\end{tabular}

Fonte: Elaborado a partir de Zouain (2003)

\section{- Estruturação dos Parques Tecnológicos}

Os Parques Tecnológicos apresentam estruturas diferenciadas quanto a sua composição em razão das características locais que são as condicionantes dos projetos. Todavia, a análise das experiências mundiais possibilita as mesmas em dois grupos principais: as estruturas essenciais, que são encontradas na maioria dos Parques (Tabela 3.18) e as estruturas opcionais, que são as que estão presentes somente em alguns Parques (Tabela 3.19).

A seguir, são exemplificadas as estruturas essenciais e suas características de função, estrutura, serviços e indicadores de sucesso. A composição básica envolve as incubadoras de empresas, que são ambientes para a transformação das idéias em produtos com valor no mercado. Condomínios de empresas, formados por aquelas que passaram pelo processo de incubação e outras empresas que pretendem desfrutar das condições diferenciadas do parque tecnológico. Os núcleos de gestão, que gerenciam as atividades do parque tecnológico, e os Centros de pesquisa cooperativa que promovem a articulação entre a academia e a iniciativa privada. 
Tabela 3.18 - Projeto de parques tecnológicos: estruturas básicas

\begin{tabular}{|c|c|c|c|c|}
\hline Item & Núcleo & Incubadora & $\begin{array}{c}\text { Condomínio de } \\
\text { empresas }\end{array}$ & $\begin{array}{c}\text { Centro de pesquisa } \\
\text { cooperativa }\end{array}$ \\
\hline Função & $\begin{array}{l}\text { estimular a } \\
\text { interação } \\
\text { universidade- } \\
\text { empresa; } \\
\text { promover a } \\
\text { transferência de } \\
\text { tecnologia; } \\
\text { selecionar as } \\
\text { empresas que } \\
\text { desejam se instalar. }\end{array}$ & $\begin{array}{l}\text { agregar empresas } \\
\text { em estágio de } \\
\text { iniciação de } \\
\text { negócios; } \\
\text { propiciar ambiente } \\
\text { adequado à } \\
\text { inovação. }\end{array}$ & $\begin{array}{l}\text { Receber } \\
\text { empresas de } \\
\text { base tecnológica } \\
\text { prédios e } \\
\text { módulos. }\end{array}$ & $\begin{array}{l}\text { promover a } \\
\text { aproximação entre as } \\
\text { atividades de P\&D e } \\
\text { suas aplicações no } \\
\text { setor produtivo. }\end{array}$ \\
\hline Estrutura & $\begin{array}{l}\text { física: conta com } \\
\text { auditório, salas de } \\
\text { reunião, áreas de } \\
\text { exposição, serviços } \\
\text { de escritório e } \\
\text { comunicações, } \\
\text { secretaria e gestão } \\
\text { de núcle. } \\
\text { pessoal: conta com } \\
\text { uma equipe de } \\
\text { gestão. }\end{array}$ & $\begin{array}{l}\text { conta com um } \\
\text { gerente ou } \\
\text { coordenador que } \\
\text { se reporta à } \\
\text { coordenação } \\
\text { executiva do } \\
\text { parque; } \\
\text { pequena infra- } \\
\text { estrutura de } \\
\text { secretaria e } \\
\text { recepção. }\end{array}$ & $\begin{array}{l}\text { conta com um } \\
\text { gerente ou } \\
\text { coordenador que } \\
\text { se reporta à } \\
\text { coordenação } \\
\text { executiva do } \\
\text { parque; } \\
\text { pequena infra- } \\
\text { estrutura de } \\
\text { secretaria e } \\
\text { recepção. }\end{array}$ & $\begin{array}{l}\text { empresas, centros de } \\
\text { P\&D e instituições do } \\
\text { governo. }\end{array}$ \\
\hline Serviços & $\begin{array}{l}\text { promover a infra- } \\
\text { estrutura dos } \\
\text { serviços básicos, } \\
\text { limpeza, etc.; } \\
\text { promover cursos e } \\
\text { treinamento, } \\
\text { empreendedorismo. }\end{array}$ & $\begin{array}{l}\text { todos os serviços } \\
\text { e suporte são } \\
\text { fornecidos por } \\
\text { contratos firmados } \\
\text { por núcleo. }\end{array}$ & $\begin{array}{l}\text { todos os serviços } \\
\text { e suporte são } \\
\text { fornecidos por } \\
\text { contratos } \\
\text { firmados por } \\
\text { núcleo. }\end{array}$ & $\begin{array}{l}\text { realizar pesquisas; } \\
\text { adaptar tecnologias } \\
\text { prestar serviços } \\
\text { tecnológicos; } \\
\text { industrializar produtos } \\
\text { e processos. }\end{array}$ \\
\hline $\begin{array}{l}\text { Indicadores } \\
\text { de sucesso }\end{array}$ & $\begin{array}{l}\text { número de patentes } \\
\text { depositadas no } \\
\text { INPI ou USPTO; } \\
\text { número de } \\
\text { empresas } \\
\text { graduadas. }\end{array}$ & $\begin{array}{l}\text { relatórios } \\
\text { indicando número } \\
\text { de empresas } \\
\text { graduadas. }\end{array}$ & $\begin{array}{l}\text { número de } \\
\text { empresas } \\
\text { residentes; } \\
\text { valor dos } \\
\text { negócios } \\
\text { realizados. }\end{array}$ & $\begin{array}{l}\text { número projetos } \\
\text { realizados. }\end{array}$ \\
\hline
\end{tabular}

Fonte: Zouain, Damião e Catharino, 2006

No contexto das estruturas complementares (

Tabela 3.19), destaca-se a importância da presença de empresas âncoras, que são grandes empresas, capazes de ativar o desenvolvimento de uma cadeia de outras empresas menores no seu entorno. O conceito de empresa júnior também é relevante porque possibilita desenvolver a cultura empreendedora nos indivíduos oriundos da academia. A presença de órgãos e agências de fomento proporciona, pelo lado das empresas, maior acesso aos financiamentos e, pelo lado dos órgãos de fomento, uma melhor visualização dos 
projetos apoiados. Os centros de serviços e formação têm como objetivo melhorar as condições de gestão das estruturas do parque tecnológico.

Tabela 3.19 - Projeto de parques tecnológicos: estruturas complementares

\begin{tabular}{|c|c|c|c|c|}
\hline Item & Empresa júnior & Empresa âncora & $\begin{array}{l}\text { Agências de } \\
\text { fomento } \quad \text { e } \\
\text { órgãos de C\&T }\end{array}$ & $\begin{array}{l}\text { Centros de serviços e } \\
\text { formação empresarial }\end{array}$ \\
\hline 趂 & $\begin{array}{l}\text { Estimular e fortalecer o } \\
\text { empreendedorismo } \\
\text { entre os acadêmicos. }\end{array}$ & $\begin{array}{l}\text { As empresas } \\
\text { âncoras são } \\
\text { constituídas de } \\
\text { corporações de } \\
\text { grande porte, } \\
\text { trazendo } \\
\text { credibilidade } \\
\text { para o } \\
\text { empreendimento. }\end{array}$ & $\begin{array}{l}\text { Financiamento } \\
\text { de projetos } \\
\text { relacionados ao } \\
\text { Parque e } \\
\text { empresas nele } \\
\text { residentes. }\end{array}$ & $\begin{array}{l}\text { Abrigar atividades de } \\
\text { apoio à relação centro } \\
\text { de pesquisa-empresa; } \\
\text { desenvolver gestão à } \\
\text { comunidade do } \\
\text { Parque. }\end{array}$ \\
\hline 离 & $\begin{array}{l}\text { Corporação de } \\
\text { pequeno porte }\end{array}$ & $\begin{array}{l}\text { Corporação de } \\
\text { grande porte }\end{array}$ & $\begin{array}{l}\text { Espaço ocupado } \\
\text { por escritórios }\end{array}$ & Unidade \\
\hline 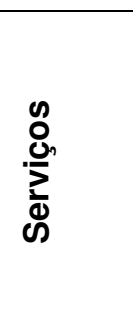 & $\begin{array}{l}\text { Estrutura física e } \\
\text { serviços, articulação, } \\
\text { suporte de } \\
\text { professores. }\end{array}$ & $\begin{array}{l}\text { Agentes } \\
\text { financeiros e } \\
\text { investidores de } \\
\text { risco, empresas } \\
\text { fornecedoras de } \\
\text { serviços } \\
\text { especializados. }\end{array}$ & $\begin{array}{l}\text { Ações de } \\
\text { incentivo } \\
\text { financeiros, } \\
\text { proteção à } \\
\text { propriedade } \\
\text { intelectual. }\end{array}$ & $\begin{array}{l}\text { Contratador e } \\
\text { prestador de serviços } \\
\text { nas áreas de: gestão } \\
\text { empresarial; gestão de } \\
\text { qualidade, formação e } \\
\text { treinamento; promoção } \\
\text { de cursos e eventos; } \\
\text { empreendedorismo. }\end{array}$ \\
\hline 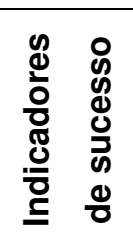 & $\begin{array}{l}\text { Parcerias com } \\
\text { entidades privadas, } \\
\text { número de projetos } \\
\text { desenvolvidos, alunos } \\
\text { participantes. }\end{array}$ & $\begin{array}{l}\text { Valor dos } \\
\text { negócios } \\
\text { realizados }\end{array}$ & $\begin{array}{l}\text { Número de } \\
\text { projetos } \\
\text { financiados e } \\
\text { ações de } \\
\text { incentivo. }\end{array}$ & $\begin{array}{l}\text { Eventos promocionais; } \\
\text { número de cursos e } \\
\text { treinamentos; número } \\
\text { de participantes } \\
\text { treinados. }\end{array}$ \\
\hline
\end{tabular}

Fonte: Zouain, Damião e Catharino, 2006

\subsubsection{Parques Tecnológicos de Terceira Geração}

No decorrer dos anos, os conceitos e projetos de Parques tecnológicos têm alterado os seus objetos e impacto na sociedade, podendo ser identificadas três gerações de parques tecnológicos com base na relevância e performance da sua atuação para a sociedade (Figura 3-6). 
Figura 1: Evolução da performance / relevância das três geraçöes |

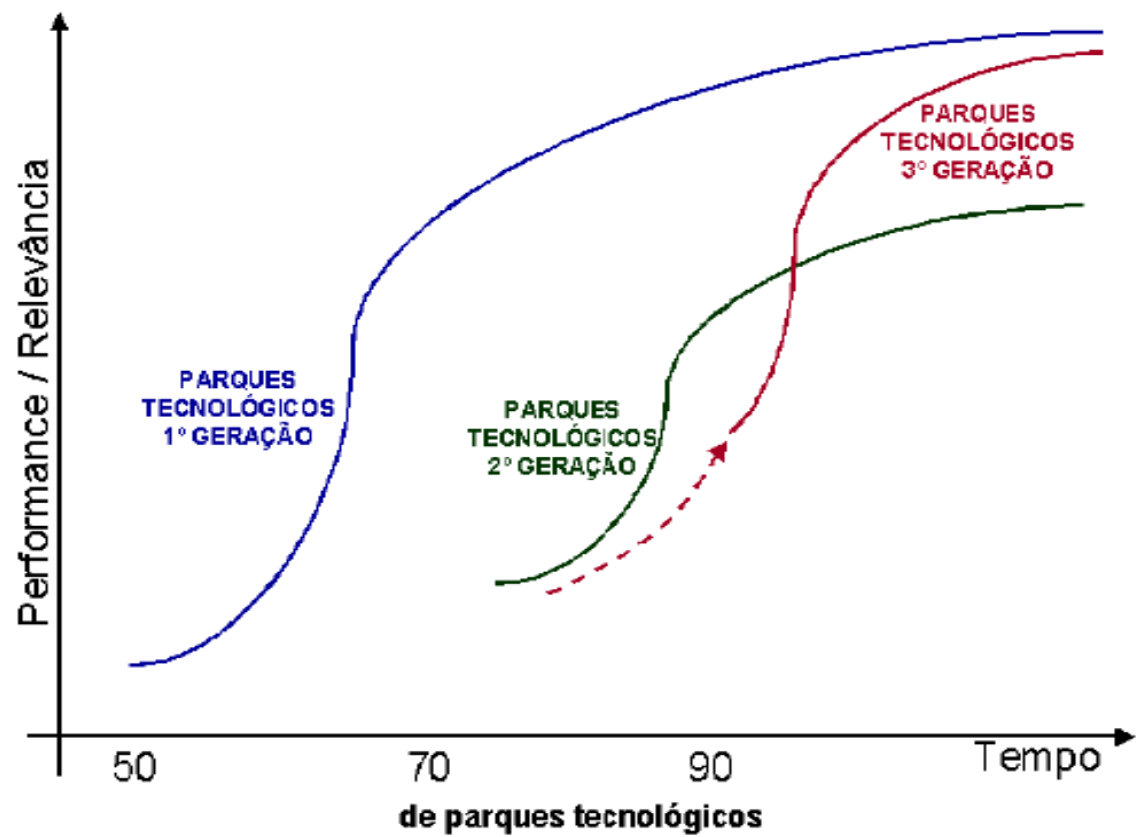

Figura 3-6: Evolução modelos de Parques Tecnológicos

Fonte: Apresentação Guilherme A. Plonski - Seminário Projeto Fapesp Guarulhos - 2008

O principal elemento de determinação da evolução dos parques tecnológicos é a sua relevância para a sociedade local, sendo que atualmente é considerado um elemento de políticas públicas.

Apresenta-se na Tabela 3.20 a evolução dos parques tecnológicos, migrando de uma perspectiva de isolamento para uma intensa conectividade, findando na influência do direcionamento econômico do município.

Tabela 3.20 - Evolução dos Parques Tecnológicos.

\begin{tabular}{l|l|l}
\hline $\begin{array}{c}\text { Início (1960) } \\
\text { Isolamento de espaço } \\
\text { físico }\end{array}$ & \multicolumn{1}{|c}{\begin{tabular}{c}
\multicolumn{1}{c|}{ 1990: } \\
Conectividade
\end{tabular}} & $\begin{array}{c}\text { 2000 em diante: } \\
\text { Direção econômica para a } \\
\text { região }\end{array}$ \\
\hline $\begin{array}{l}\text { Foco no recrutamento } \\
\text { industrial }\end{array}$ & $\begin{array}{l}\text { Organizações-âncora com } \\
\text { pesquisa e desenvolvimento com } \\
\text { alinhamento no foco da indústria }\end{array}$ & $\begin{array}{l}\text { Desenvolvimento contínuo, } \\
\text { incluindo comércio e residências }\end{array}$ \\
\hline $\begin{array}{l}\text { Baixa ligação das } \\
\text { empresas incubadas } \\
\text { com universidades }\end{array}$ & $\begin{array}{l}\text { Centros de Inovação e Incubadoras } \\
\text { Tecnológicas tornam-se mais } \\
\text { comuns }\end{array}$ & Menos foco no recrutamento \\
\hline $\begin{array}{l}\text { Baixa disponibilidade } \\
\text { para assistência aos } \\
\text { negócios }\end{array}$ & $\begin{array}{l}\text { Facilidades para acomodar } \\
\text { pequenas empresas }\end{array}$ & $\begin{array}{l}\text { Planejamento formal para } \\
\text { comercialização de tecnologia }\end{array}$ \\
\hline & $\begin{array}{l}\text { Suporte para empreendedores em } \\
\text { início de atividade }\end{array}$ & $\begin{array}{l}\text { Aumento no foco e } \\
\text { aprofundamento de suporte às }\end{array}$ \\
\hline
\end{tabular}




\begin{tabular}{c|c|c}
\hline $\begin{array}{c}\text { Início (1960) } \\
\begin{array}{c}\text { Isolamento de espaço } \\
\text { físico }\end{array}\end{array}$ & $\begin{array}{c}\text { 1990: } \\
\text { Conectividade }\end{array}$ & $\begin{array}{c}\text { Direção econ diante: } \\
\text { regiãomica para a }\end{array}$ \\
\hline & & empresas iniciantes \\
\hline & & $\begin{array}{c}\text { Maior interesse das empresas } \\
\text { incubadas em firmar parceria } \\
\text { com universidades }\end{array}$ \\
\hline
\end{tabular}

Fonte: Adaptado de Battelle, 2007

A evolução de gerações também foi caracterizada por uma maior aproximação com a base científica e tecnológica. Para Allen (2007), um relacionamento ativo, efetivo, com diversidade e processo "ganha-ganha" entre os atores (organizações - mercado - universidade - entorno) é provavelmente a principal característica de um parque tecnológico de terceira geração.

Como aspectos da terceira geração dos parques tecnológicos, diferenciando-se da primeira e segunda gerações, destacam-se: ênfase maior no suporte à incubação de empresas e ao empreendedorismo e menos no recrutamento, encorajando a criação de um ambiente de inovação e empreendedorismo, e também:;

- O aparecimento de cluster de especialização, na qual a região ao competir no desenvolvimento de tecnologias, diferencia-se das demais, e assim cultiva e sustenta áreas especializadas de expertise;

- Aproximação maior com as universidades e identificação com o desenvolvimento econômico da região;

- As empresas incubadas dos parques tecnológicos apontam como forte motivo de adesão a facilidade de aproximação com a força de trabalho qualificada dos estudantes das universidades; $\mathrm{e}$

- Facilidade de acesso aos laboratórios de pesquisa e à transferência de tecnologia das universidades e comercialização.

Reforça-se que além desses aspectos, os parques tecnológicos de terceira geração apresentam como atrativos:

- Estão sendo desenvolvidos em áreas urbanas como um componente de revitalização da comunidade; 
- Apresentam ênfase maior na sustentabilidade como um princípio de atenção para o equilíbrio entre o desenvolvimento do negócio e a proteção ao meio ambiente; $\mathrm{e}$

- Ocorre o estabelecimento de parcerias internacionais, com atração de empresas incubadas de outras regiões e países.

Segundo pesquisa realizada pelo Battelle (2007) com 134 parques tecnológicos dos Estados Unidos, são desafios para os parques tecnológicos os seguintes aspectos:

- Enquanto os pesquisadores dos parques tecnológicos lidam com a comercialização de novas tecnologias pela promoção de relacionamentos entre pesquisadores e organizações, a inovação no mercado não acontece facilmente. $O$ desafio é providenciar assistência para tornar mais fácil o processo de comercialização.

- Diminuir as barreiras culturais entre a Academia e as comunidades de negócios, facilitando uma real parceria. Os parques podem atuar como um intermediário que entende ambas as culturas, para facilitar processos de inovação integrados e esforços de colaboração entre os atores.

- Continuar a integração entre universidades e empresas incubadas.

- Atenção à competitividade global, além de retenção de conhecimento das operações locais, frente às empresas internacionais.

Os desafios apresentados anteriormente também servem como oportunidades no desenvolvimento dos parques tecnológicos. Como oportunidades, os parques tecnológicos da terceira geração apresentam:

- Aprofundamento da parceria com indústria, serviços educacionais e instituições médicas, resultando em aumento de expertise;

- Financiamento e assistência para comercialização de tecnologia e de propriedade intelectual;

- Retenção, atração e desenvolvimento de talentos, pelo estabelecimento de treinamentos avançados, facilitando a parceria com instituições de ensino ofertantes de conhecimento técnico; 
- Foco no networking - rede de relacionamentos - entre as empresas incubadas, pois na Economia do Conhecimento o espaço físico não é fundamental, como nos parques tecnológicos de primeira e segunda geração;

- Segurança e garantia no acesso a informações em um ambiente de desenvolvimento de tecnologia;

- Revitalização da comunidade, não somente como alocação de empresas, mas com melhorias no entorno social;

- Facilidade no monitoramento dos impactos dos Parques Tecnológicos;

- Estimular o crescimento das pequenas empresas, pela criação do valor adicionado aos negócios, por intermédio da assistência das instituições no seu desenvolvimento;

- Ampliação do uso do espaço, para além da alocação das empresas incubadas, possibilitando a instalação de lojas, restaurantes e residências no mesmo espaço físico.

Em síntese, os parques tecnológicos da nova geração apresentam como elementos-chave:

- Transformação da descoberta em aplicação;

- Desenvolvimento de talentos;

- Comercialização de tecnologia;

- A integração entre governo, educação superior e interesses do mercado.

$\mathrm{Na}$ pesquisa realizada por Allen (2007) descreveu-se quatro modelos de parques tecnológicos, que serviram como estímulo para discussão de um cenário de sucesso de um parque tecnológico de terceira geração, explicitados a seguir:

Orientado por aliança:

- Dois ou mais parceiros gerenciam para o desenvolvimento e o crescimento do parque;

- Há um objetivo comum de desenvolvimento econômico baseado na transferência de conhecimento e inovação; 
- Apoio público para desenvolvimento de infra-estrutura;

- A organização é criada para desenvolver, gerenciar e atingir objetivos estratégicos.

Orientação para Universidade:

- O parque tecnológico é fisicamente integrado no campus da Universidade;

- Mais de $40 \%$ das empresas incubadas estão em início de atividades;

- Um número significante de acadêmicos participa como diretores, mentores, parceiros etc.;

- Empreendedorismo é assunto central no currículo acadêmico;

- A Universidade provê a incubadora de negócios para as próprias incubadas em início de atividades e também da economia local.

Orientação para empresa:

- A empresa-âncora tem papel fundamental na administração;

- Isto atrai outras empresas incubadas, algumas delas fazem parte da cadeia de valor da empresa-âncora;

- Há cooperação para inovação entre a âncora e as outras incubadas;

- O foco de pesquisa é fortemente influenciado pelos produtos e serviços da empresa-âncora;

Orientação para o cluster:

- Um cluster (aglomeração de empresas) em um único setor, geograficamente co-alocado;

- Uma parceria que providencia suporte às empresas do cluster;

- Associação com os criadores de conhecimento das próprias empresas, não compulsoriamente da Universidade ou de políticas públicas;

- Oportunidades de marketing para suporte ao desenvolvimento econômico.

Allen (2007), estudando o modelo de Manchester, aponta que existem certos pontos em comum em diversos modelos de maturidade de parques tecnológicos: 
- Ser um player (ator) global, mas com raízes locais. As empresas incubadas dos parques tecnológicos de terceira geração não precisam atuar apenas localmente, mas devem inserir-se no mercado internacional, ampliando o paradigma de pensar no mercado regional e começar a pensar e atuar internacionalmente;

- Orientar-se ao cuidado com as pessoas e meio ambiente, para além de sua comunidade. O desenvolvimento de tecnologias deve estar alinhado à atenção ao meio ambiente e à qualidade de vida das pessoas que vivem na comunidade;

- A alta qualificação da equipe, especialmente a capacidade de liderança do Chief Executive Officer (CEO);

- Os parques tecnológicos de $3^{a}$ geração são parte das atividades da Universidade. Isto implica em influências no currículo acadêmico e atividades de pesquisa.

- Ser parte de uma multiplicidade de network - rede de relacionamentos engajando-se com organizações regionais, nacionais e internacionais.

- Foco nas necessidades das empresas incubadas. O espaço físico deve merecer atenção assim como uma estrutura de suporte ao desenvolvimento de um ambiente de negócios às empresas incubadas. 


\subsection{APLs - Arranjos Produtivos Locais}

Esta análise tem como objetivo referenciar o estudo presente no Capítulo IV, o qual tem como objetivo determinar aglomerações existentes no Município de Sorocaba.

Particularmente, no caso brasileiro, o estudo das aglomerações geográficas e setoriais, a utilização do termo APLs tem sido amplamente utilizada. A dificuldade de caracterização do fenômeno dos APLs acentua os debates sobre o conceito, não existindo um consenso sobre o termo mais adequado a ser utilizado, tendo em vista que essa denominação tem sido aplicada a uma grande diversidade de experiências em vários tipos de atividades (IPEA, 2006)

Os APLs, arranjos produtivos locais, são definidos pela Redesist (2007) como aglomerações territoriais de agentes econômicos, políticos e sociais - com foco em um conjunto específico de atividades econômicas - que apresentam vínculos mesmo que incipientes.

Em Cassiolato \& Szapiro (2002) e Graça (2007), Arranjos Produtivos Locais (APLs), correspondem a aglomerações de empresas de determinada cadeia produtiva localizadas em um mesmo território. Essas aglomerações apresentam algum grau de especialização produtiva em um ou mais elos da cadeia, e mantêm algum vínculo de articulação, interação, cooperação e aprendizagem entre si e com outros atores locais tais como instituições governamentais, associações empresariais, instituições de crédito, ensino e pesquisa voltadas à introdução de novos produtos e processos.

Essa definição é bem próxima da conceituação de clusters definida por Porter (1989) para os clusters "um agrupamento geograficamente concentrado de empresas inter-relacionadas e instituições correlatas numa determinada área, vinculadas por elementos comuns e complementares". Desta forma, Porter (1989), enfatiza que a presença dos agrupamentos proporciona vantagens competitivas com a utilização das externalidades positivas, residindo na localização das unidades de negócios. 
Essas definições bastante abrangentes são limitadas na perspectiva de colocar critérios para identificação dos arranjos, sendo que não considera a natureza e intensidade das interações das empresas.

Para diferenciar os APLs mais maduros, ou seja, em estágios mais evoluídos de interação, a mesma Redesist os identificam como SLPs - sistemas produtivos e inovativos locais - a variável de diferenciação é representada pela variável interação entre os agentes, que objetiva a cooperação e aprendizagem. (CASSIOLATO E LASTRES, 2003) (Figura 3-7).

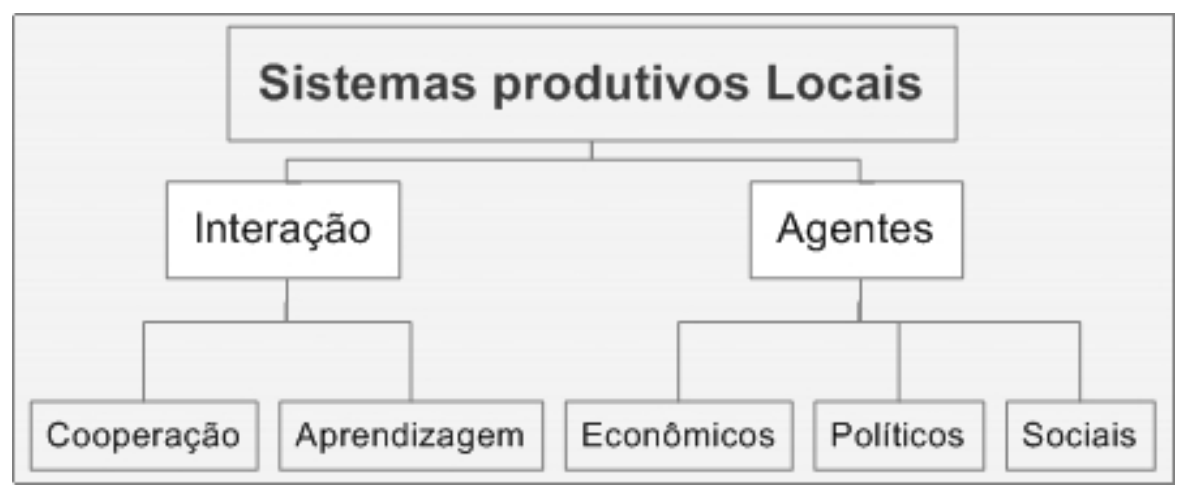

Figura 3-7: Sistemas Produtivos e Inovativos Locais

Mesmo considerando os méritos nessas definições, observa-se que são pouco instrumentais, na perspectiva de oferecer subsídios para investimentos públicos. As aglomerações são favoráveis para o estabelecimento de políticas públicas, todavia, o investimento público é limitado e precisa de critérios para priorização dos recursos.

O trabalho de Suzigan et al (2004), participando de grupos de apoio no contexto da política industrial, teve como objetivo oferecer metodologias que mitigassem a subjetividade subjacente a esses elementos.

O foco dos estudos centrou-se na identificação, delimitação e caracterização dos sistemas produtivos locais. Para tal, foi desenvolvida uma metodologia que teve como alicerces os coeficientes de Gini locacional e de um índice de especialização, o quociente locacional ( $Q L)$, combinados com variáveis de controle e filtros, os mesmo foram desenvolvidos a partir da base de dados da RAIS/MTE. 
A metodologia possui como etapas:

i) Definir preliminarmente no espaço os sistemas locais de produção com base em base secundárias de dados consiste na análise com base em indicadores de concentração das principais atividades presentes em determinadas localidades;

ii) Por meio da observação direta com visitas in loco, investigar o nível de interação entre esses elementos, fazer trabalho de campo, coletando informações sobre as relações existentes entre as empresas em determinada localidade. 


\subsection{Considerações Preliminares}

A revisão bibliográfica sobre os arranjos produtivos locais e os parques tecnológicos, tem como objetivo subsidiar as pesquisas presentes no Capítulo IV que trata das condições locais de Sorocaba e também o estudo de caso no Capítulo V que trata do tema dos Parques Tecnológicos

Os APLs e suas variantes se constituem em elementos fundamentais de análises para a determinação das concentrações setoriais em espaços determinados. A sua análise permite observar a dinâmica de determinada atividade e as diferentes etapas (elos) de um sistema produtivo.

Os sistemas produtivos variam de acordo com o tipo de setor a ser explorado, podendo desenvolver atividades tradicionais ou considerados inovativas sendo sensível aos níveis de intensidade tecnológica destas, a diagnose de um arranjo permite observar as suas principais forças e debilidades, sendo um importante instrumento para a tomada de decisões.

A constituição pode ser planejada, mas geralmente é expontânea com o intuito de aproveitar as externalidades positivas de determinadas regiões, e a sua maturidade varia de acordo com o nível de articulação entre os atores.

A base científica e tecnológica não é fator determinante para caracterizar um arranjo produtivo e quando presente em arranjos mais articulados contribui para as fases de identificação e desenvolvimento de soluções produtivas, um papel de desenvolvimento tecnológico.

Em outra vertente, a década de 50 marcou o início no Mundo e de forma mais acentuada no Brasil (última década) do processo de iniciativas e adoção de políticas para o desenvolvimento de parques tecnológicos (e terminologias assemelhadas) para promover a articulação entre os meios empresariais, acadêmicos e de políticas públicas.

Esses ambientes, considerados a forma mais evoluída de ambientes inovativos, proporcionam, dentre outras vantagens, 0 desenvolvimento tecnológico pela aplicação de conhecimentos por meio da aproximação entre os atores oriundos da academia, poder público e empresas. O objetivo principal é aumentar a competitividade das empresas situadas nessas áreas de influência do ambiente inovativo. Esses instrumentos vêm sendo amplamente utilizado por 
países que buscam de forma acelerada reduzir o hiato existente com países desenvolvidos, recebendo a terminologia de países com sistema de inovação catching up.

É importante frisar que os parques tecnológicos e científicos apresentam diferenciação em relação aos estágios de evolução, tomando como variável a interação entre universidades, empresas e poder público. A primeira geração de parques tinha como principal característica a atração de empresas, posteriormente evoluiu com a finalidade de maior interação com o ambiente acadêmico e finalmente na $3^{a}$ geração privilegiou-se o envolvimento com as políticas públicas, dado os impactos que apresentam para as suas áreas de influência.

Também, pode-se afirmar que cada projeto de parque tecnológico é singular nas suas características, pois advém de impactos contextuais e condicionais da sua formação, legitimando as diferentes formas e modelos existentes.

$\mathrm{Na}$ análise dos fatores críticos para o desenvolvimento desses ambientes, sobressai-se a necessidade de existência de base científica e tecnológica, de base produtiva e apoio do poder público. Inicialmente a necessidade de uma base científica e tecnológica, implica na articulação com instituições de ensino, de formação, de fomento e de qualificação, aliados a presença de institutos de pesquisa e agentes de certificação.

A outra vertente relacionada a base produtiva (vocação de determinada área) será o diferencial na definição da necessidade e tipo de especialização do parque. Cabe ao agente público promover por meio de políticas públicas a animação do processo, atuando como indutor no processo.

No processo de implementação desses ambientes, algumas variáveis são de extrema importância, e passíveis de investigação mais aprofundada, tais como o modelo de Governança em operação, o qual envolve a definição das linhas de decisão e responsabilidade, além de questões de financiamento, de coordenação e de papéis de atores, sobretudo do poder público em suas diferentes esferas de atuação. 
A análise da infra-estrutura permite descrever os ativos presentes no ambiente investigado e os aspectos relacionados à existência de externalidades positivas e também a base existente para a gestão do conhecimento.

As estratégias indicam como as ações serão desenvolvidas, indicando a orientação do ambiente inovativo, e especialmente a forma de operação, resultando no conhecimento de como alcançar resultados em relação a internacionalização e atração de empresas.

Por fim, as relações entre universidade-empresas são observadas sob o prisma de como são tratadas as relações, quais os mecanismos de indução e características da interação.

Os elementos listados não esgotam o rol de características passíveis de serem investigadas, mas, possibilitam informações primordiais para referenciar pesquisas aprofundadas em ambientes inovativos específicos.

Os benefícios advindos da implantação de um Parque tecnológico passam invariavelmente pelo filtro da sua especialização, caracterizando a sua condição de um importante instrumento para o desenvolvimento de um sistema de inovação local que não exclui a necessidade de outras iniciativas. 


\section{CAPÍTULO IV - REVISÃO DA LITERATURA. ESTUDO DAS CONDIÇÕES DE SOROCABA}

Considerando os objetivos desta pesquisa, faz-se necessário conhecer e caracterizar o local alvo dos estudos em diversos aspectos, envolvendo a vocação, características e potencialidades entre outros. Para validar metodologicamente de forma específica essa etapa do trabalho, convém citar Mattar (1996) que considera esse tipo de pesquisa que se utiliza de base de dados bibliográficos e documentais como pesquisa descritiva, dado que o seu objetivo é descrever as características do objeto. Há dois tipos básicos de pesquisas descritivas: levantamentos de campo e estudo de campo, embora a distinção entre um e outro não seja precisa, a diferença básica está na amplitude e na profundidade.

Considerando a presente pesquisa, observa-se que a necessidade de profundidade e amplitude no tocante ao desenvolvimento do perfil de Sorocaba é limitada, caracterizando um levantamento de campo. O estudo foca a análise da cidade de Sorocaba, envolvendo o mapeamento da sua base científicotecnológica, a configuração do seu sistema de inovação, além de uma análise econômica e administrativa. (Detalhes complementares relacionados a infraestrutura são apresentados no Apêndice E).

\subsection{Aspectos históricos da Cidade de Sorocaba}

Esse breve relato histórico da cidade de Sorocaba foi baseado em análise da literatura histórica da cidade, com consulta a livros, manuais e Internet.

A chegada do capitão Baltazar Fernandes em 1654 foi um importante marco, considerando que ele se mudou para a região com a família e escravaria e fundou um povoado, ao qual deu o nome de Sorocaba que na linguagem TupiGuarani significa "Terra Rasgada", ou "Terra que se abre" ao desenvolvimento. 
Para desenvolver a região, ele doou uma grande gleba de terras à ordem dos beneditinos de Parnaíba, colocando como condição, a construção de um convento e uma escola, que funcionaria como centro gerador de cultura (Almeida apud STRAFORINI, 2001), como incentivo para o povoamento da região.

O comércio de índios era a principal fonte de renda, esse panorama começou a ser alterado a partir do século XVII quando foi substituído por outra atividade comercial, a saber: as feiras de muares.

O Coronel gaúcho Cristóvão Pereira de Abreu conduziu a primeira tropa que passou pelas ruas no ano de 1733, é importante ressaltar que ele foi um dos fundadores do Rio Grande do Sul. Coube a Pereira de Abreu fazer a história e inaugurar um ciclo, o do Tropeirismo.

Devido a sua posição estratégica, a cidade tornou-se passagem obrigatória para os Tropeiros, compondo um eixo econômico entre o Norte, o Nordeste e o Sul. A cidade ganhou com o fluxo de tropeiros uma Feira de Muares, onde brasileiros de todos os Estados reuniam-se para comprar e vender animais.

A dinâmica comercial proporcionou também o desenvolvimento da indústria caseira, baseado na confecção de facas, facões, redes, doces e objetos de couro para montaria.

Todavia, o desenvolvimento do Município teve outro fato relevante, com a inauguração da Estrada de Ferro Sorocabana a partir de 1875. Aproveitando-se desse contexto, as Indústrias têxteis de origem inglesa instalaram-se na cidade e tornaram-na conhecida como a Manchester Paulista.

A estrada de ferro foi fundamental para o desenvolvimento, espalhando o progresso e aumentando a densidade populacional e o logo o pequeno vilarejo dobrou seu espaço, multiplicou sua população, passou a cidade, chegou a município e acabou investida na condição de Comarca.

Com a mudança de cenário na indústria têxtil a partir da década de 70, ocasionou o declínio da indústria e fez com que a cidade buscasse novos caminhos e, então Sorocaba diversificou o seu parque Industrial. (MATEUS, 2006). 


\subsection{Caracterização da cidade}

Sorocaba é um dos mais importantes municípios do Estado de São Paulo, localizado na região sudoeste do Estado, próxima à capital (87 quilômetros de distância de São Paulo). Seus limites geográficos são ao norte com Porto Feliz; ao sul com Votorantim; ao leste com Mairinque; ao nordeste com Itu; ao oeste com Araçoiaba da Serra; ao sudoeste com Salto de Pirapora e a Noroeste com Iperó (Figura 4-1).

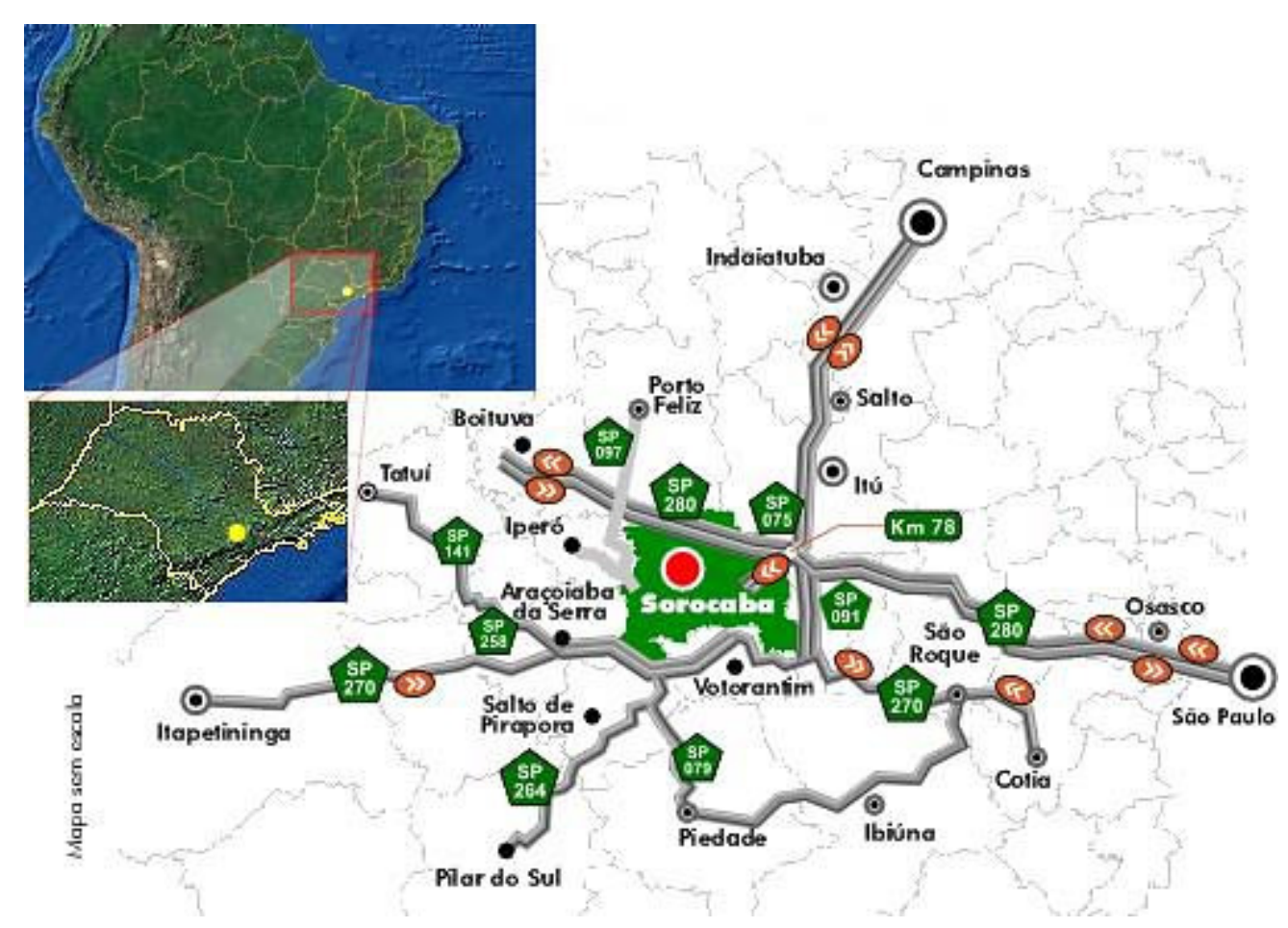

Figura 4-1: Cidade de Sorocaba.

Fonte: PUC - Sorocaba. Disponível em: http:/www.sorocaba.pucsp.br. Acesso 01/03/2008.

Sorocaba tem uma localização privilegiada, não somente no aspecto local com a sua proximidade com a região metropolitana de São Paulo, mas, sobretudo em relação ao MERCOSUL, o Mercado Comum do Cone Sul, bloco comercial da América Latina, que já tem como parceiros Brasil, Argentina, Uruguai, Paraguai e mais recentemente Venezuela, cujo PIB soma mais de $R \$ 2$ trilhões. (vide na Figura 4-2 a situação geográfica de Sorocaba na América do Sul) 


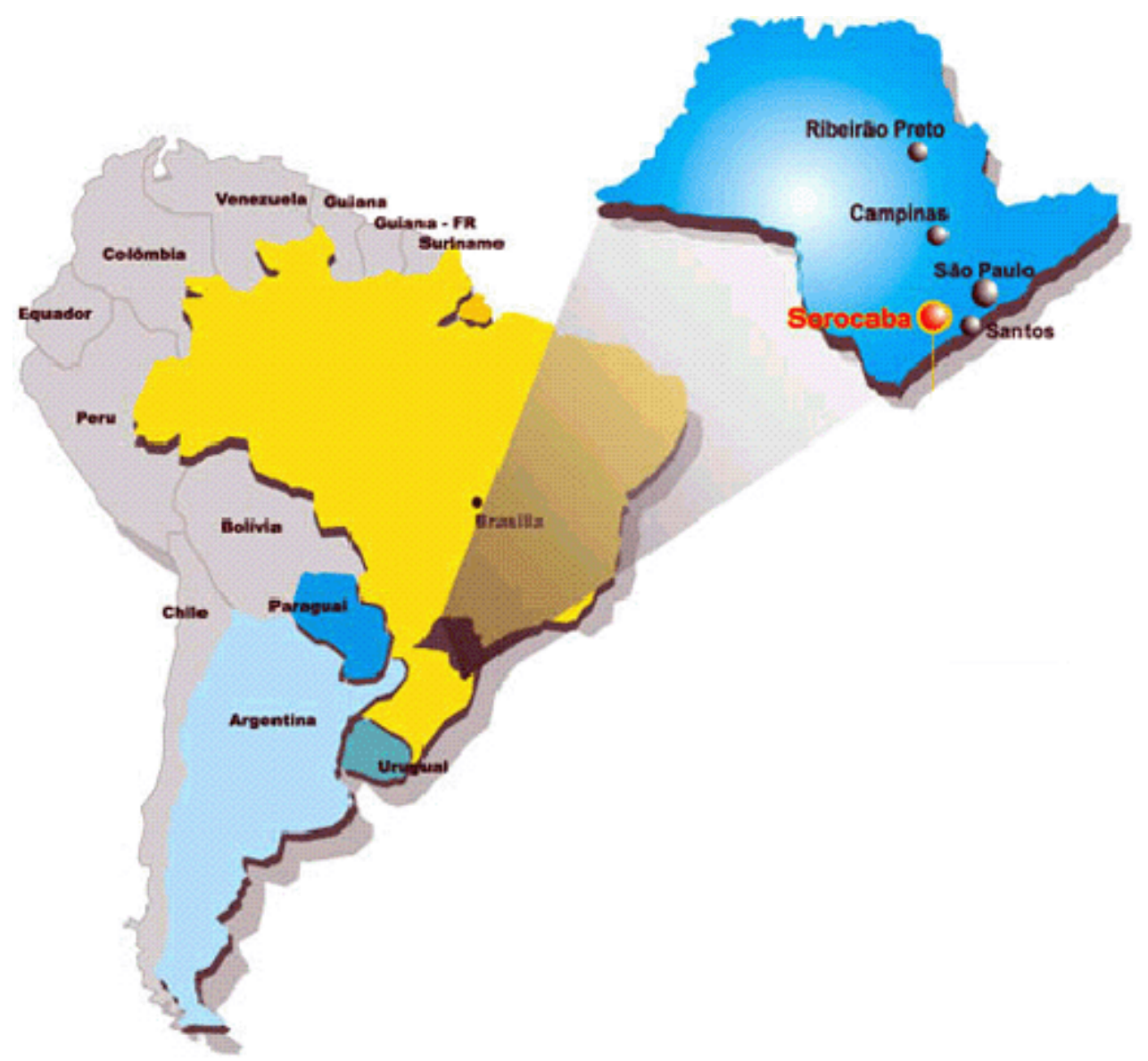

Figura 4-2: Sorocaba na América do Sul

Fonte: Disponível: http://br.geocities.com/radioatividadefm/mapa2.gif. Acesso em 16 de abril de 2008.

O município de Sorocaba tem impacto nos aspectos sócio-cultural e econômico em relação ao seu entorno, a RA - Região Administrativa de Sorocaba, região esta que conta com municípios com forte tradição histórica, outros se notabilizam por um rico folclore, outros formam um parque industrial expressivo. Também alguns representam a forte vocação agrícola, fato que torna a agricultura regional igualmente expressiva, por exemplo: a cidade de Itararé.

No aspecto tecnológico, destaca-se a proximidade com a cidade de Iperó (a 15 quilômetros de distância) na qual está localizado um dos mais avançados centros de tecnologia de ponta desenvolvidos no país, o Centro Experimental Aramar - Pólo de Desenvolvimento Nuclear.

A cidade está localizada a uma altitude de 601 metros, apresentando uma boa intensidade de ventos, as suas coordenadas apresentam latitude 


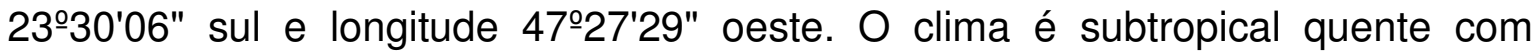
inverno não muito seco, sem histórico de catástrofes naturais.

$\mathrm{Na}$ Tabela 4.1 são apresentadas as características climáticas de Sorocaba:

Tabela 4.1 - Características climáticas de Sorocaba

\begin{tabular}{l|l}
\hline \multicolumn{1}{c|}{ Elementos } & \multicolumn{1}{c}{ Características } \\
\hline Vento & Ventos alísios sudoeste \\
\hline Chuvas & $\begin{array}{l}\text { A média climatológica no período de } 1998 \text { a 2008 tomando-se por base os } \\
\text { meses de janeiro de todo o período foi de } 226 \mathrm{~mm} .\end{array}$ \\
\hline Temperatura & $\begin{array}{l}\text { Média climatológica no período de 1998 a 2008 (base os meses de janeiro de } \\
\text { todo o período) - mínima de 17,9 e máxima de 27,3 - temperatura "Celsius" }\end{array}$ \\
\hline Tufão & $\begin{array}{l}\text { Não há histórico de tufões que tenham atingido o Município em toda a sua } \\
\text { existência. }\end{array}$ \\
\hline Raio/Trovão & $\begin{array}{l}\text { Densidade raios (raios/km².ano) - 2,789 raios } \\
\text { Número de raios/ano - 1879 } \\
\text { O Brasil recebe anualmente } 50 \text { milhões de raios e São Paulo apresenta o o } \\
\text { número de dois milhões, não aparecendo como um dos estados com maior } \\
\text { intensidade de eletricidade atmosférica no país. A cidade de Sorocaba quando } \\
\text { comparada com outros municípios do Estado, encontra-se na 366a posição, e } \\
\text { no país está classificado na posição 1701. }\end{array}$ \\
\hline Clima & $\begin{array}{l}\text { De acordo com a classificação KOEPPEN }{ }^{6} \text {, o clima é caracterizado como Cfa, } \\
\text { ou seja, Subtropical quente com inverno não muito seco, possuindo uma faixa } \\
\text { mais ao norte com características de clima tipo "Cwa" (mês mais seco com } \\
\text { chuva acumulada menor de 30 mm). }\end{array}$ \\
\hline
\end{tabular}

Fonte: Disponível em http://www.inpe.br/ranking e http://koeppen-geiger.vu-wien.ac.at. Acesso: 17 de abril de 2008.

\subsection{Aspectos relacionados à conurbação e importância para os Municípios vizinhos.}

Na região está presente o fator conhecido como de conurbação, Meyer (2000) destaca:

"É historicamente reconhecido que a origem das metrópoles modernas foi em grande medida um movimento de agregação, e a palavra conurbação traduz do ponto de vista semântico a ação de reunir em um todo diversos núcleos e cidades pela unificação das suas malhas urbanas, respeitando uma hierarquia funcional. Em suma, a metrópole é acima de tudo a expressão de um processo de articulação e não de desarticulação do território urbanizado"

\footnotetext{
5 Dados obtidos: http://www.inpe.br/ranking/Ranking_Municipios_Geral_2005-2006.pdf. Acesso: 17 de abril de 2008.

${ }^{6} \mathrm{http}: / /$ koeppen-geiger.vu-wien.ac.at
} 
Portanto, refere-se a uma extensa área urbana surgida do encontro ou junção da área urbana de duas ou mais cidades Ao longo do tempo os seus limites geográficos perdem-se em virtude do seu crescimento horizontal. Em geral, esse processo dá origem à formação de regiões metropolitanas.

O fenômeno metropolitano é mais amplo do que suas efetivas delimitações legais. No caso da concentração urbana de Sorocaba, assim como outras áreas em seu entorno, as áreas urbanas são hoje interdependentes economicamente e formam uma rede metropolitana integrada de fato, com funções produtivas complementares.

O Governo do Estado de São Paulo, por meio da EMPLASA, não definiu ainda qual será o limite da Região Metropolitana de Sorocaba (que inclui os municípios de Alumínio, Araçoiaba da Serra, Cabreúva, Capela do Alto, Iperó, Itu, Mairinque, Piedade, Porto Feliz, Salto, Salto de Pirapora, Sarapuí, São Roque e Votorantim). Essa região se encontra em um estado de pré-metropolização, podendo vir a ser elevada à categoria de região metropolitana nos próximos anos.

Os dezoito principais municípios no entorno de Sorocaba, segundo dados da Fundação SEADE de 2006, contam com uma população de aproximadamente 1.467 .000 (um milhão, quatrocentos e sessenta e sete mil) habitantes, distribuídos por uma área de 6.271 (seis mil, duzentos e setenta e um) quilômetros quadrados, perfazendo uma densidade demográfica de 233 (duzentos e trinta e três) habitantes por quilômetro quadrado (vide Tabela 4.2)

Tabela 4.2 - Densidade Demográfica dos Principais Municípios do Entorno de Sorocaba.

\begin{tabular}{l|c|c|c}
\hline \multicolumn{1}{c|}{ Município } & População & Área $\mathbf{( k m}^{\mathbf{2}}$ ) & $\begin{array}{c}\text { Densidade Demográfica } \\
\text { (habitantes } \mathbf{k m}^{2} \text { ) }\end{array}$ \\
\hline Boituva & 43.079 & 249 & 173,71 \\
\hline Capela do Alto & 16.853 & 143 & 117,85 \\
\hline Sarapuí & 8.654 & 342 & 25,30 \\
\hline Cabreúva & 41.406 & 267 & 155,08 \\
\hline Alumínio & 16.549 & 95 & 174,20 \\
\hline Araçariguama & 13.621 & 138 & 98,70 \\
\hline Araçoiaba da Serra & 23.643 & 283 & 83,54 \\
\hline Ibiúna & 74.895 & 1088 & 68,84 \\
\hline
\end{tabular}




\begin{tabular}{l|c|c|c}
\hline \multicolumn{1}{c|}{ Município } & População & Área $\mathbf{( k m}^{\mathbf{2}}$ ) & $\begin{array}{c}\text { Densidade Demográfica } \\
\text { (habitantes/km }{ }^{2} \text { ) }\end{array}$ \\
\hline Iperó & 22.734 & 165 & 137,78 \\
\hline Itu & 154.303 & 642 & 240,35 \\
\hline Mairinque & 47.400 & 214 & 221,50 \\
\hline Piedade & 54.288 & 729 & 74,47 \\
\hline Porto Feliz & 50.450 & 569 & 88,66 \\
\hline Salto de Pirapora & 42.361 & 255 & 166,12 \\
\hline Salto & 106.562 & 160 & 666,01 \\
\hline São Roque & 72.663 & 313 & 232,15 \\
\hline Sorocaba & 572.479 & 443 & $1.292,23$ \\
\hline Votorantim & 105.349 & 177 & 595,19 \\
\hline TOTAL & 1.467 .269 & 6.271 & 233,98 \\
\hline
\end{tabular}

Fonte: Fundação Seade. Disponível em: http://www.seade.gov.br. Acesso em 10 de janeiro de 2008.

Os números demonstram a elevada densidade demográfica dessa região. Pode-se destacar que a maior distância entre as localidades citadas não ultrapassa 50 (cinqüenta) quilômetros do município sede da região de Sorocaba, evidenciando o efeito de conurbação.

Além disso, este agrupamento de municípios apresenta uma elevada diversidade de suas atividades, grande especialização e integração sócioeconômica, graças à ligação entre esses municípios à Capital e outras regiões do Estado de São Paulo. Feita por importantes rodovias, tais como a Rodovia Presidente Castello Branco, a Rodovia Raposo Tavares e a Rodovia Senador José Ermírio de Moraes.

Outro recorte pode ser realizado, tendo como base as regiões administrativas, sendo pertinente apresentar um panorama das dinâmicas das divisões regionais no Estado de São Paulo (Figura 4-3). A Região Metropolitana de São Paulo (RMSP), responde por mais da metade do PIB total do Estado (50,3\%). No interior, a maior Região Administrativa é a de Campinas com 17,3\%, seguida pelas de São José dos Campos 6,7\%, a RA de Sorocaba corresponde a $5,6 \%$ e Santos $3,5 \%$, que formam o entorno da RMSP e delimita a área de maior 
desenvolvimento econômico do Estado, responsável pela geração de mais de $83 \%$ do PIB estadual.

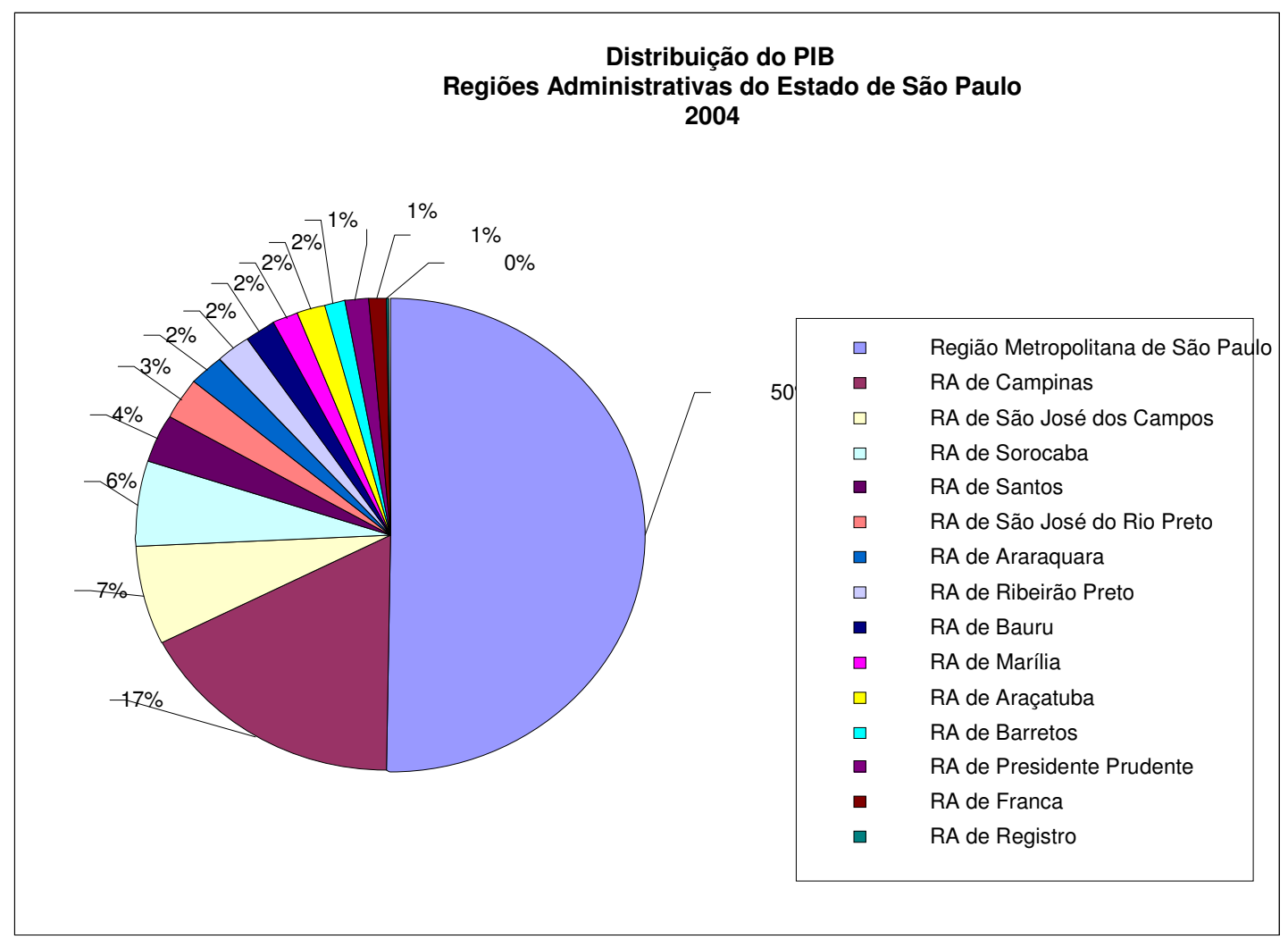

Figura 4-3: Distribuição do PIB - Regiões Administrativas do Estado de São Paulo - 2005. Fonte: Seade, 2005. Estudo do PIB dos municípios paulistas em 2005.

No que tange a população, a Região Administrativa de Sorocaba apresenta a terceira área de concentração da população paulista, com um total de 2.776.343 (dois milhões e setecentos e setenta e seis mil e trezentos e quarenta e três) habitantes. Entre os anos de 2000 e 2002, verificou-se uma taxa de crescimento de $2,0 \%$ ao ano, a maior entre as regiões paulistas.

Tabela 4.3 são apresentados alguns indicadores do município de Sorocaba comparativamente com a RA - Região Administrativa de Sorocaba obtidos a partir de pesquisa da Fundação SEADE. Destaca-se que a população residente na cidade de Sorocaba corresponde a 20,62\% da população da região administrativa de Sorocaba e $1,41 \%$ da população do Estado de São Paulo. Na mesma Tabela são apresentados dados relativos ao crescimento da população, 
sendo que a cidade de Sorocaba apresenta taxa acima da região administrativa de Sorocaba e também do Estado de São Paulo.

Tabela 4.3 - Dados gerais da cidade de Sorocaba e da RA de Sorocaba.

\begin{tabular}{|c|c|c|c|c|}
\hline Item & Ano & Sorocaba & $\begin{array}{l}\text { RA } \\
\text { Sorocaba }\end{array}$ & $\begin{array}{l}\text { Estado São } \\
\text { Paulo }\end{array}$ \\
\hline Área (em km2) & 2009 & 449,12 & 41.077 & 248.600 \\
\hline População & 2008 & 586.680 & 2.776 .343 & 40.484 .029 \\
\hline Grau de Urbanização (em \%) & 2005 & 98,82 & 85,01 & 93,65 \\
\hline Densidade Demográfica (habitantes/km2) & 2008 & $1.306,29$ & 66,39 & 160,7 \\
\hline $\begin{array}{l}\text { Taxa Geométrica de Crescimento Anual da } \\
\text { População - 2000/2005(Eem \% a.a.) }\end{array}$ & 2008 & 2,22 & 2,05 & 1,56 \\
\hline População com Menos de 15 Anos (em \%) & 2008 & 22,45 & 25,61 & 24,43 \\
\hline População com Mais de 60 Anos (em \%) & 2008 & 9,84 & 9,35 & 9,57 \\
\hline Taxa de Natalidade (por mil habitantes) & 2007 & 13,91 & 15,54 & 15,5 \\
\hline $\begin{array}{l}\text { Taxa de Fecundidade Geral (por mil } \\
\text { mulheres entre } 15 \text { e } 49 \text { anos) }\end{array}$ & 2007 & 47,49 & 55,56 & 53,86 \\
\hline
\end{tabular}

Fonte: Perfil Municipal. Disponível em:

www.seade.gov.br/produtos/perfil. Acesso em 15 de março de 2009.

No tocante à localização, a Região Administrativa de Sorocaba na parte Sudoeste do Estado de São Paulo é rota de passagem para os estados do sul e centro-oeste do país. Compreende uma área de 79 (setenta e nove) municípios, e é uma das maiores geradoras da receita paulista.

Referente ao aspecto econômico, a região tem a seguinte distribuição da geração de riqueza entre os segmentos (Figura 4-4).

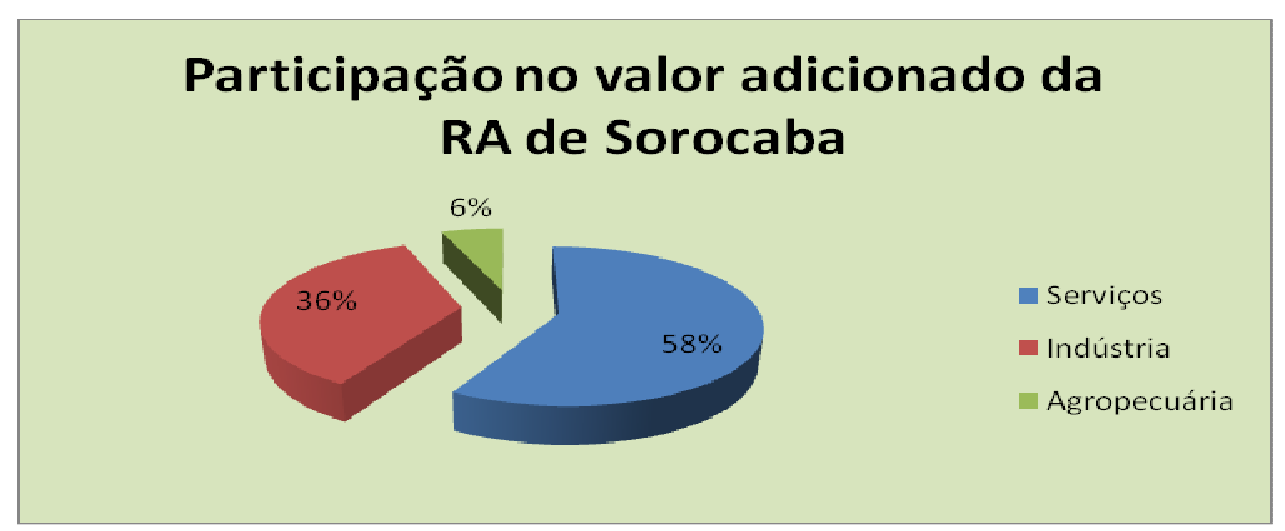

Figura 4-4: Distribuição de riqueza da Região administrativa de Sorocaba. Fonte: www.seade.gov.br. Acesso em 15 de dezembro de 2007. 
A economia da RA está fortemente estruturada nas suas indústrias, contando com diversos segmentos, além do tradicional têxtil. Segundo dados do SEADE do ano de 2007, a indústria, em termos de produção de riqueza, representava $36 \%$ do valor adicionado gerado e respondia por mais de 184 mil empregos, destacando-se a metalurgia básica, sobretudo de materiais não ferrosos como o alumínio que corresponde a cerca de $10 \%$ do valor adicionado da região. Também a fabricação de minerais não-metálicos ligada à indústria extrativa (principalmente do calcário) e fabricação de cimento e cal. Cabe ressaltar que a indústria da madeira está concentrada na região sendo altamente representativa no Estado.

Tabela 4.4 - Participação de setores da indústria na região administrativa de Sorocaba.

\begin{tabular}{l|l|l}
\hline \multicolumn{1}{c|}{ Indústria } & Valor adicionado - VA & \multicolumn{1}{c}{ Empregos } \\
\hline Metalurgia básica & $12,33 \%$ & + de $8 \mathrm{mil}$ \\
\hline Montadoras e autopeças & $16,6 \%$ & + de $8 \mathrm{mil}$ \\
\hline Alimentos e bebidas & $25,8 \%$ & $17 \mathrm{mil}$ \\
\hline Químico & $9,0 \%$ & $4,8 \mathrm{mil}$ \\
\hline Têxtil & 4 & $8,5 \mathrm{mil}$ \\
\hline
\end{tabular}

Fonte: Seade, base de dados 2005. Disponível em: http://www.seade.gov.br.

Acesso em: 20/11/2008.

Como evidenciado na Tabela 4.4, a terceira maior participação, em valor adicionado (VA), é da metalurgia básica, que representa $12,33 \%$ do $\mathrm{VA}^{7}$ e ocupa mais de oito mil pessoas. Destacam-se em primeiro lugar os segmentos

\footnotetext{
7. A expressão Valor Adicionado à qual se refere a Constituição Federal de 1988, artigo 158, parágrafo único, inciso I, para atender ao disposto no inciso I, do artigo 161, foi definida pelo parágrafo $1^{\circ}$, do artigo $3^{\circ}$, da Lei Complementar 63/90, que não são todas as prestações de serviço que compõem o Valor Adicionado, que irão compor a base de tributação, mas somente as que constituem fatos geradores do ICMS, e neste caso, participam apenas os serviços de transporte intermunicipal e interestadual e de comunicações. O VAF é um índice calculado anualmente pelo Estado, usado para apurar o valor a ser creditado para cada Município referente ao repasse de receitas advindas do ICMS (imposto estadual) e IPI Exportação (imposto da União, que corresponde a 10\% do valor total arrecadado pela União, que compõem o Fundo de Exportação).
} 
industriais de alimentos e bebidas, com $24 \%$ do VA industrial da região e 17 mil empregados; montadoras e autopeças (16,6\% do VA e 8,7 mil ocupados); e produtos químicos ( $9 \%$ do VA e 4,8 mil pessoas ocupadas). A indústria têxtil, que originalmente tinha maior representatividade na região, passou a responder por cerca de $4 \%$ do VA da região e ocupar 8,5 mil pessoas, indicando o crescimento e a diversificação da indústria da região de Sorocaba.

\subsection{Indicadores Sociais de Sorocaba}

Para uma melhor distinção dos dados sociais de Sorocaba, os principais indicadores serão apresentados comparativamente com a cidade de São Paulo, a cidade mais rica do País. Como pode ser observado na Tabela 4.5, a cidade apresenta indicadores bem similares a São Paulo em relação à média de estudo da população e desenvolvimento humano. Quando se trata do número de leitos em hospitais e infra-estrutura urbana adequada, observa-se uma condição mais favorável.

$\mathrm{Na}$ Tabela 4.5 é apresentado o IDH, Índice de Desenvolvimento Humano, criado pela Organização das Nações Unidas em 1991, que é um indicador que resulta da análise de três dimensões: longevidade, educação e renda. O IDH de Sorocaba é de 0,828, sendo que valores acima de 0,800 indicam alto desenvolvimento humano.

Tabela 4.5 - Indicadores sociais de Sorocaba

\begin{tabular}{l|l|l}
\hline \multicolumn{1}{c|}{ Indicadores sociais } & Sorocaba & \multicolumn{1}{c}{ São } \\
Paulo
\end{tabular}


- Mercado de Trabalho de Sorocaba

Os principais índices do mercado de trabalho da cidade de Sorocaba comparativamente com o município de São Paulo com base no ano de 2007 estão demonstrados na Tabela 4.6 e Figura 4-5.

Tabela 4.6 -Índices do Mercado de Trabalho de Sorocaba.

\begin{tabular}{l|l|l}
\hline Mercado de trabalho & Sorocaba & São Paulo \\
\hline Rendimento médio no total de empregos ocupados (em reais - 2005) & 1290,59 & 1655,29 \\
\hline $\begin{array}{l}\text { Participação dos empregados ocupados da agropecuária no total de } \\
\text { empregos ocupados }\end{array}$ & $0,23 \%$ & $0,11 \%$ \\
\hline $\begin{array}{l}\text { Participação dos empregados ocupados da indústria no total de } \\
\text { empregos ocupados }\end{array}$ & $35,5 \%$ & $14,05 \%$ \\
\hline $\begin{array}{l}\text { Participação dos empregados ocupados da construção civil no total de } \\
\text { empregos ocupados }\end{array}$ & $4,79 \%$ & $4,62 \%$ \\
\hline $\begin{array}{l}\text { Participação dos empregados ocupados do comércio no total de } \\
\text { empregos ocupados }\end{array}$ & $22,18 \%$ & $17,59 \%$ \\
\hline $\begin{array}{l}\text { Participação dos empregados ocupados dos serviços no total de } \\
\text { empregos ocupados }\end{array}$ & $37,46 \%$ & $63,47 \%$ \\
\hline
\end{tabular}

Fonte: Base de dados SEADE. Tabulação própria, 2007.

Disponível em: www.seade.gov.br/projetos/fiesp/. Acesso em 15 de dezembro de 2007.

Diferentemente da cidade de São Paulo, na qual o setor de serviços isoladamente é o maior empregador, em Sorocaba, existe um equilíbrio entre os setores de serviços e a indústria, que na ocupação das pessoas em Sorocaba.

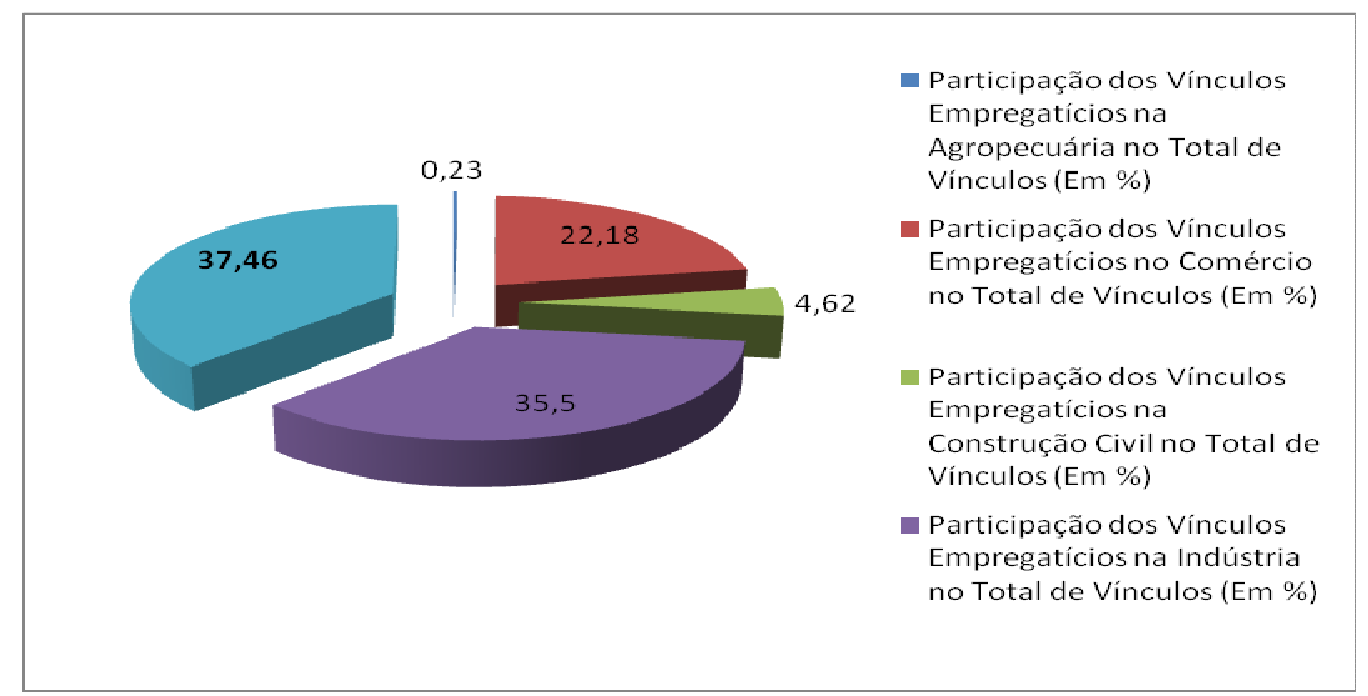

Figura 4-5: Participação dos setores nos vínculos empregatícios

Fonte: Base de dados SEADE, 2007. Disponível em: www.seade.gov.br/projetos/fiesp/. Acesso em 15 de dezembro de 2007. 


\subsection{Indicadores Econômicos e Administrativos de Sorocaba}

O Município de Sorocaba apresenta um dos maiores PIB (Produto Interno Bruto) do País, sobretudo quando considerado os municípios que não são capitais do seu estado. Esse indicador vem aumentando progressivamente a sua representação (aumentou 32\% desde 2003), de acordo com o IBGE, o valor superou 10 bilhões de dólares em 2006, precisamente $R \$$ 10.162.976,00 (Figura 4-6).

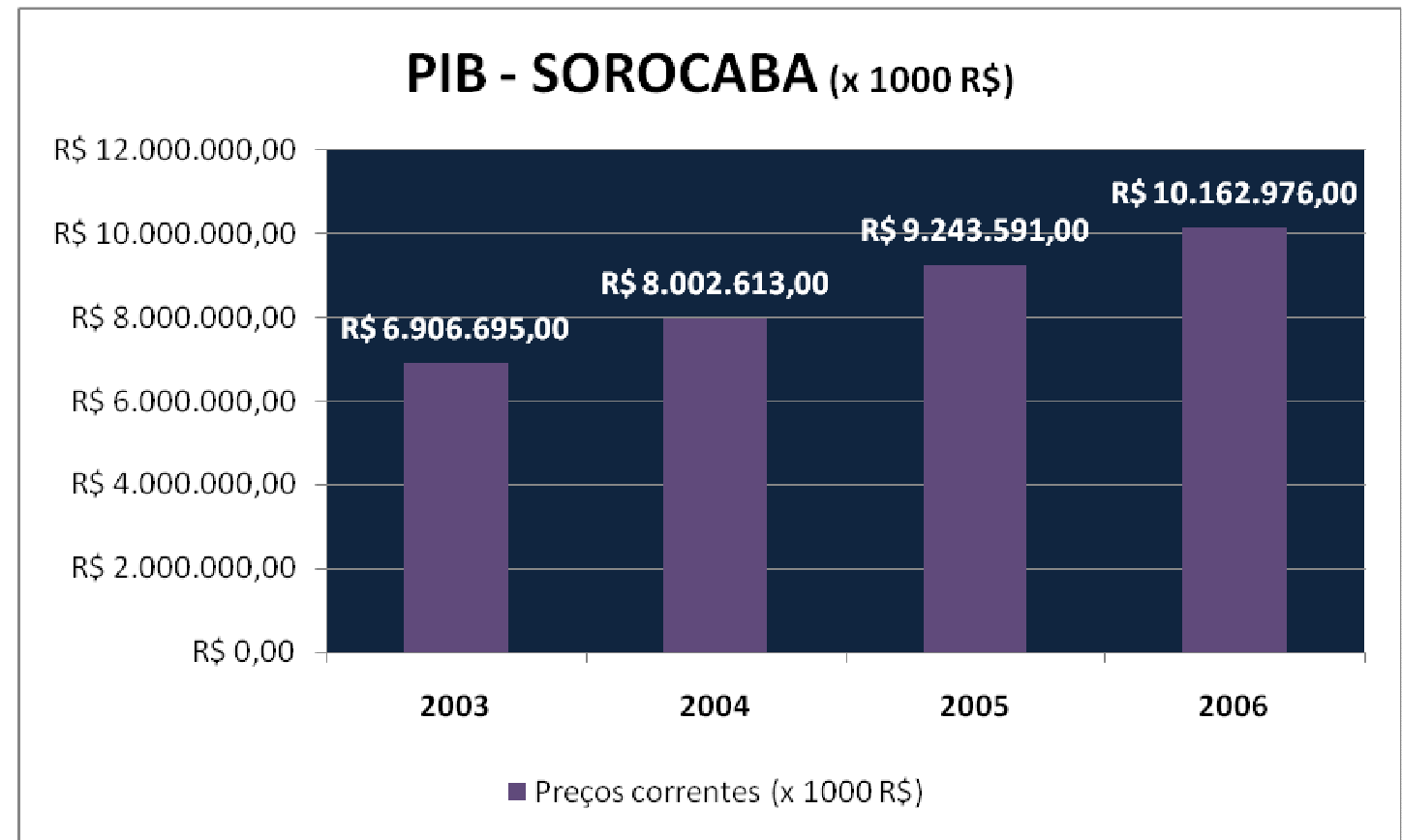

Figura 4-6: Evolução do PIB em Sorocaba.

Fundação SEADE, 2006. Disponível em: www.seade.gov.br/projetos/fiesp/. Acesso em 02 de dezembro de 2008

Sorocaba está na $31^{\circ}$ posição no Brasil em relação a geração de riqueza (participação de $0,43 \%$ ), sendo responsável pelo desenvolvimento dos municípios localizados no seu entorno. No estado, localiza-se entre os doze municípios com maior potencial econômico e produtivo do Estado de São Paulo (Tabela 4.7). 
Tabela 4.7 - Distribuição do PIB Municipal base 2006

\begin{tabular}{|c|c|c|c|}
\hline Municípios & $\begin{array}{c}\text { PIB (em milhões de } \\
\text { reais) }\end{array}$ & $\begin{array}{l}\text { PIB per capita } \\
\text { (em reais) }\end{array}$ & $\begin{array}{c}\text { Participação } \\
\%\end{array}$ \\
\hline ESTADO DE SÃO PAULO & 802551691 & 19548 & \\
\hline São Paulo & 282852338 & 25675 & 35,24 \\
\hline Guarulhos & 25663706 & 19999 & 3,19 \\
\hline Barueri & 25483663 & 95966 & 3,17 \\
\hline Campinas & 23624853 & 22300 & 2,94 \\
\hline São Bernardo do Campo & 20572084 & 25590 & 2,56 \\
\hline Osasco & 17796629 & 24892 & 2,21 \\
\hline Santos & 16128535 & 38550 & 2,00 \\
\hline São José dos Campos & 15530132 & 25419 & 1,93 \\
\hline Santo André & 11674559 & 17341 & 1,45 \\
\hline Jundiaí & 11294335 & 32397 & 1,40 \\
\hline Ribeirão Preto & 11270937 & 20139 & 1,40 \\
\hline Sorocaba & 10162976 & 17581 & 1,26 \\
\hline
\end{tabular}

Fonte: Adaptado de Fundação Seade; Instituto Brasileiro de Geografia e Estatística - IBGE - 2006.

O Município de Sorocaba encontra-se no seleto grupo de cidades altamente relevantes para a economia paulista. Para entender esse fenômeno, convém ressaltar que o Estado de São Paulo é reconhecido pela intensa concentração das atividades econômicas em poucos municípios. Por exemplo, em 2006: a capital respondeu por 35,24\% do PIB do Estado e os sete maiores municípios foram responsáveis pela geração de mais de $50 \%$ das riquezas. De outra perspectiva, 58\% do PIB paulista, em 2006, foi gerado pelas doze maiores economias municipais. Essa característica reproduz-se em termos geográficos. Os seis maiores municípios paulistas, responsáveis por 50\% do PIB estadual (vide Tabela 4.7), localizam-se num raio de 100 quilômetros em torno da capital. Seis deles pertencem à RMSP - São Paulo, Guarulhos, São Bernardo do Campo, Barueri, Santo André e Osasco - e os outros cinco localizam-se em seu entorno São José dos Campos, Santos, Jundiaí, Campinas, Sorocaba, sendo que o único município mais distante é Ribeirão Preto.

Cabe ressaltar que essa aglutinação espacial do PIB paulista reflete, principalmente, a concentração da atividade industrial - essas localidades respondem por cerca de $50 \%$ do VA da indústria paulista - e das atividades 
terciárias tributárias à industrial - 58\% do VA do setor de serviços do Estado também foi gerado por esse grupo de municípios.

Considerando de forma específica o segmento industrial, de acordo com dados do IBGE de 2006, Sorocaba está na 38ª colocação dentre todos os municípios do País, apresentando um PIB industrial de 2.876,612 bilhões que corresponde a $0,49 \%$ do total do País.

O IBGE modificou a sua metodologia para cálculo do PIB, com o objetivo de dar maior consistência de acordo com os parâmetros internacionais. Essa alteração posicionou o setor de serviços, e não a indústria, como o mais significativo na economia de Sorocaba, todavia, é importante destacar que não houve uma desindustrialização de Sorocaba, mas sim, um processo de maior precisão dos dados com a utilização a base da CNAE - Classificação Nacional das atividades Econômicas. Assim, vários serviços prestados internamente as empresas que estão em Sorocaba que eram contabilizados como da indústria, foram contabilizados como serviços.

Tabela 4.8 - Indicadores Econômicos de Sorocaba

\begin{tabular}{l|l|l}
\hline \multicolumn{1}{c|}{ Indicadores econômicos } & \multicolumn{1}{c}{ Sorocaba } & \multicolumn{1}{c}{$\begin{array}{c}\text { São Paulo } \\
\text { (Município) }\end{array}$} \\
\hline $\begin{array}{l}\text { Produto Interno Bruto - PIB (em milhões de reais } \\
\text { correntes - 2008) }\end{array}$ & 10.162976 & 282.852338 \\
\hline Valor adicionado da indústria no PIB (2006) & $28,30 \%$ & $19,24 \%$ \\
\hline Valor adicionado dos serviços no PIB (2006) & $53,20 \%$ & $64,05 \%$ \\
\hline Valor adicionado da adm. Pública no PIB (2006) & $6,81 \%$ & $5,50 \%$ \\
\hline Valor adicionado da Agropecuária no PIB (2006) & $0,009 \%$ & $0,03 \%$ \\
\hline PIB per capita (em reais correntes - 2006) & $17.581,00$ & 25675,00 \\
\hline Agências bancárias & 56 & 1966 \\
\hline Número de habitantes por automóvel & 3,6 & 2,85 \\
\hline Valor as exportações (2006) & 1.055 .761 .794 & 7.151 .803 .246 \\
\hline Valor das Importações (2006) & 1.187 .519 .550 & 6.479 .361 .528 \\
\hline Fonte: Fundaça SEADE, 2006. DisponIVel
\end{tabular}

Fonte: Fundação SEADE, 2006. Disponível em: www.seade.gov.br/projetos/fiesp/. Acesso em 15 de dezembro de 2009 
Convém destacar o PIB per capita de $R \$ 17.581,00$, inferior ante $R \$$ 25.675,00 do Município de São Paulo, mas bastante superior ao do Brasil de $\mathrm{R} \$$ $12.688,00$.

Com relação aos dados de repasse de arrecadação do Estado de São Paulo para Sorocaba, são apresentados na Tabela 4.9 os valores relacionados aos anos de 2004 a 2007, evidenciando um crescimento de mais de $40 \%$ no período.

Tabela 4.9 - Transferência de impostos para Sorocaba.

\begin{tabular}{c|c|c|c|c|c}
\hline Ano & ICMS(**) & IPVA & $\begin{array}{c}\text { Fund. Exp- } \\
\text { IPI(**) }\end{array}$ & Comp. $\left(^{*}\right)$ & Total \\
\hline 2007 & $176.297 .606,86$ & $51.558 .082,98$ & $1.792 .256,63$ & $18.480,07$ & $229.666 .426,54$ \\
\hline 2006 & $159.847 .431,82$ & $41.949 .991,34$ & $1.471 .175,12$ & $19.305,90$ & $203.287 .904,18$ \\
\hline 2005 & $135.383 .110,23$ & $34.361 .435,10$ & $1.280 .699,50$ & $15.930,05$ & $171.041 .174,88$ \\
\hline 2004 & $122.836 .515,17$ & $29.362 .443,05$ & $1.123 .096,18$ & $14.822,19$ & $153.336 .876,59$ \\
\hline
\end{tabular}

Fonte: Secretaria da Fazenda do Estado de São Paulo.

(Valores expressos em Reais)

$\left({ }^{*}\right) \quad$ Compensação Financeira sobre Exploração de Gás, Energia Elétrica, Óleo Bruto, Xisto Betuminoso de acordo com a Lei 7.990 de 28/12/89

$\left({ }^{* *}\right) \quad$ Até fevereiro/2007, valores com desconto de $15 \%$ referente à transferência para o FUNDEF, de acordo com a Lei 9.424 de 24/12/1996. No período de março a dezembro de 2007, montantes com desconto de $16,66 \%$; e a partir de janeiro/2008, valores com desconto de $18,33 \%$ referente à transferência para o FUNDEB, de acordo com a Lei 11.494 de 20/06/2007.

- A Força da Indústria - Indicadores Industriais

Em Sorocaba, a principal atividade econômica é o setor de serviços; todavia, merece destaque a informação que grande parte dos serviços são desenvolvidos internamente ou para as indústrias.

A indústria é responsável por $32 \%$ do Valor adicionado do Município (Figura 4-7), sendo que ela é a principal demandante dos serviços. Para efeito de comparação, é importante comentar que no ano de 2006 a atividade industrial da cidade de São Paulo foi responsável por $23,10 \%$ do valor adicionado total do município. 


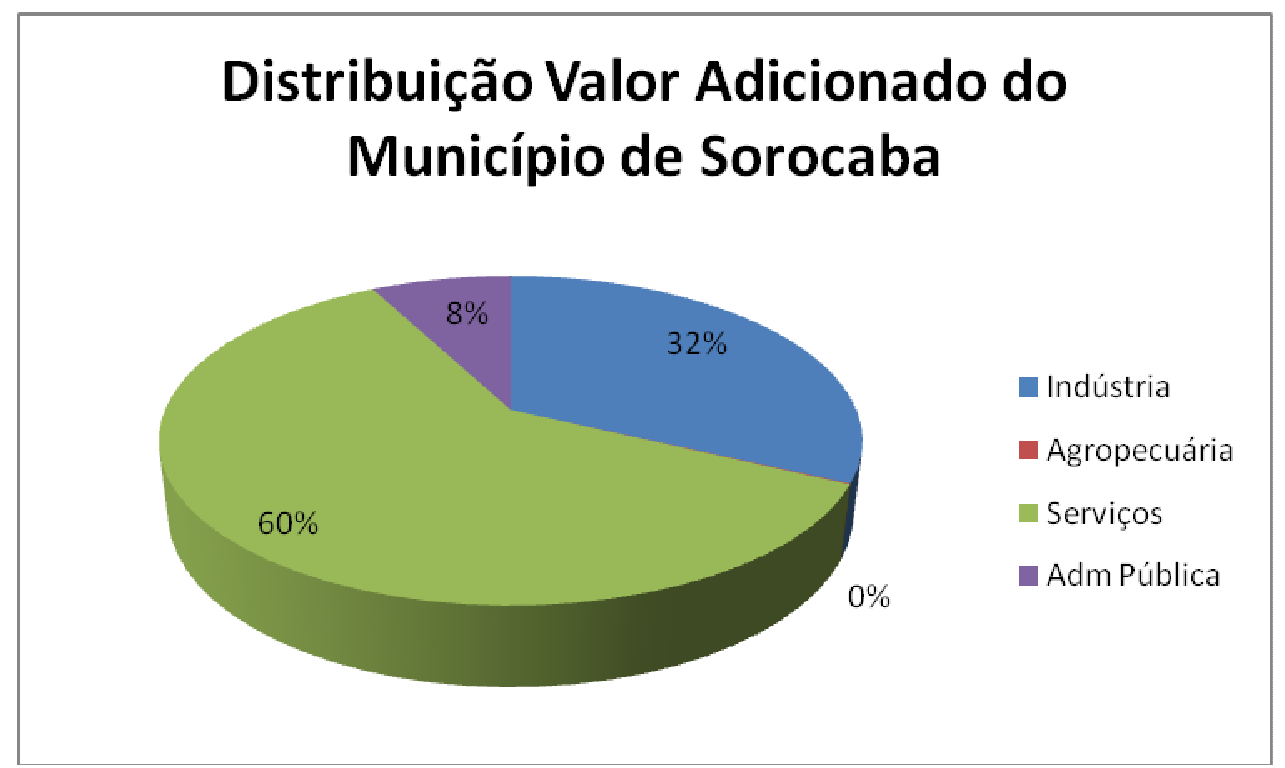

Figura 4-7: Distribuição do Valor adicionado de Sorocaba.

Fonte: Fundação SEADE, 2006. Disponível em: www.seade.gov.br. Acesso em 02/12/2008.

A cidade de Sorocaba atualmente tem um perfil industrial bastante diversificado, que compreende do tradicional setor de fiação e tecelagem até componentes aeronáuticos, com inclusão de empresas do ramo eletroeletrônico, telecomunicações, siderurgia e metalurgia pesada, autopeças, metal-mecânico, químico, farmacêutico, papel e celulose, e de alimentos.

Considerando a referência do valor adicionado fiscal, são apresentadas na Tabela 4.10 as principais atividades industriais com destaque para a indústria de auto-peças e transporte corresponde a $30 \%$ do valor adicionado gerado.

Tabela 4.10 - Valor Adicionado Fiscal da Indústria

\begin{tabular}{l|r}
\multicolumn{1}{c|}{ Atividades } & \multicolumn{1}{c}{ Valores } \\
\hline Valor Adicionado Fiscal da Indústria - Produtos de Metal (Em reais de 2007) & 296.687 .080 \\
\hline Valor Adicionado Fiscal da Indústria - Máquinas e Equipamentos (Em reais de & 580.350 .884 \\
$2007)$ & 129.778 .700 \\
\hline $\begin{array}{l}\text { Valor Adicionado Fiscal da Indústria - Equipamentos Médicos, Óticos, de } \\
\text { Automação e Precisão (R\$ de 2007) }\end{array}$ & 1.296 .386 .228 \\
\hline Valor Adicionado Fiscal da Indústria - Material de Transporte - Montadoras e \\
Autopeças (Em reais de 2007) & 355.164 .371 \\
\hline Valor Adicionado Fiscal da Indústria - Produtos Químicos (Em reais de 2007)
\end{tabular}




\begin{tabular}{l|c}
\multicolumn{1}{c|}{ Atividades } & Valores \\
\hline Valor Adicionado Fiscal da Indústria - Produtos de Plástico (Em reais de 2007) & 156.416 .107 \\
\hline Valor Adicionado Fiscal da Indústria - Produtos Alimentícios (Em reais de 2007) & 178.272 .379 \\
\hline Valor Adicionado Fiscal da Indústria - Bebidas (Em reais de 2007) & 137.133 .484 \\
\hline Valor Adicionado Fiscal da Indústria - Diversas (Em reais de 2007) & 119.966 .073 \\
\hline Valor Adicionado Fiscal da Indústria - Total (Em reais de 2007) & 4.228 .071 .448 \\
\hline
\end{tabular}

Fonte: Fundação SEADE, 2006. Disponível em: www.seade.gov.br. Acesso em 02/12/2008.

A indústria de máquinas e equipamentos, que é importante vetor de inovação pela aquisição de tecnologias incorporadas, responde por $14 \%$ do valor adicionado fiscal do Município.

Sorocaba também abriga inúmeras empresas metalúrgicas, sendo um dos mais importantes centros do Estado na fabricação de implementos para telecomunicações, desde transistores até antenas parabólicas. Na fabricação de equipamentos para geração de energia eólica, as duas principais indústrias encontram-se instaladas na região.

No município de Sorocaba, existe uma divergência em relação aos dados sobre o número de indústrias instaladas o IBGE computa no seu último levantamento de 2006 o número de 1836, envolvendo as indústrias extrativa e de transformação, enquanto que a Fundação SEADE com base no levantamento da RAIS, indica 1263 estabelecimentos industriais.

A Zona Industrial dispõe de uma área construída de aproximadamente 25 milhões de metros quadrados, distribuídos em torno da Rodovia José Ermírio de Moraes (Castelinho). No entanto, ainda existem muitas áreas disponíveis para a implantação de empresas, com rede de energia elétrica, telefone, água tratada, coleta de esgoto e aterro sanitário para a deposição do lixo e resíduos industriais. O serviço de transporte coletivo integrado, com tarifa única, faz a ligação da zona industrial com a zona urbana do município. 
- Principais Empresas

Dentre as principais indústrias instaladas na região que concentram suas atividades na Zona Industrial de Sorocaba, podemos destacar (Tabela 4.11):

- Metalac S/A

- ZF do Brasil LTDA

- Telcon S/A

- Grupo Splice

- Draktel optical fibre S/A

- Jaraguá equipamentos industriais

- Unimetal ind. e com. e empreendimentos

- Metso Minerals Brasil

- Andrew do Brasil LTDA

- Kyocera do Brasil componentes industriais LTDA

- Nipro Medical LTDA 
Tabela 4.11 - Principais empresas de Sorocaba

\begin{tabular}{|c|c|c|}
\hline Empresa & Produtos & Posição no mercado \\
\hline $\begin{array}{l}\text { METALAC S.A é uma empresa subsidiária } \\
\text { do grupo Precision Castparts Corp., com sede } \\
\text { em Portland, Oregon, Estados Unidos da } \\
\text { América (EUA). } \\
\text { A METALAC S/A está localizada à Avenida } \\
\text { Itavuvu no } 4690 \text {. }\end{array}$ & $\begin{array}{l}\text { Parafusos de biela, parafusos de cabeçote, } \\
\text { mancal, pinos de freio, entre muitos outros. No } \\
\text { Brasil, é o principal fornecedor de parafusos } \\
\text { com sextavado interno, por intermédio da sua } \\
\text { linha de fabricação com a marca TELLEP. } \\
\text { Desenvolve e produz equipamentos eletrônicos } \\
\text { voltados à fixação, como torquímetros digitais, } \\
\text { máquinas de Torque-Tensão, e outros } \\
\text { fabricados sob encomenda. }\end{array}$ & $\begin{array}{l}\text { Iniciou operação em } 1953 \text { e tem continuamente } \\
\text { realizado planos de investimento visando se } \\
\text { adiantar às crescentes necessidades dos } \\
\text { clientes com relação ao aumento de capacidade } \\
\text { de produção, melhoria de qualidade e } \\
\text { produtividade, além de se manter atualizada } \\
\text { com o melhor da tecnologia em fixação. } \\
\text { A empresa é líder na fabricação de fixadores de } \\
\text { alta resistência no Brasil, com alto grau de } \\
\text { tecnologia em sua linha de produtos e excelente } \\
\text { gerenciamento de processos de manufatura. É } \\
\text { um importante fornecedor de itens para } \\
\text { aplicações críticas na indústria automotiva. }\end{array}$ \\
\hline
\end{tabular}




\begin{tabular}{|c|c|c|}
\hline Empresa & Produtos & Posição no mercado \\
\hline $\begin{array}{l}\text { ZF DO BRASIL LTDA é uma empresa do } \\
\text { Grupo alemão Zahnradfabrik Friedrichshafen e } \\
\text { está em Sorocaba desde } 1981 \text { quando } \\
\text { inaugurou seu no complexo industrial para } \\
\text { produzir eixos e transmissões para máquinas } \\
\text { agrícolas. }\end{array}$ & $\begin{array}{l}\text { Fabrica transmissões para veículos comerciais; } \\
\text { sistemas de direção, sistemas de embreagens, } \\
\text { amortecedores e componentes de chassis para } \\
\text { veículos comerciais e de passeio; além de eixos } \\
\text { e transmissões para máquinas agrícolas e } \\
\text { reversores marítimos. }\end{array}$ & $\begin{array}{l}\text { Presente no País há mais de } 40 \text { anos, a ZF } \\
\text { América do Sul conta com mais de } 4.000 \\
\text { colaboradores e possui unidades em Sorocaba } \\
\text { (SP), São Bernardo do Campo (SP), Araraquara } \\
\text { (SP), Belo Horizonte (MG) e San Francisco } \\
\text { (Argentina) }\end{array}$ \\
\hline $\begin{array}{l}\text { Em 2001, a ZF Lemförder do Brasil foi } \\
\text { inaugurada no complexo industrial de Sorocaba } \\
\text { para fabricar componentes de chassis e } \\
\text { suspensão. } \\
\text { A ZF do Brasil está localizada à Avenida Conde } \\
\text { Zeppelin no } 1935 \text {. }\end{array}$ & $\begin{array}{l}\text { Conta com uma rede de mais de } 150 \\
\text { concessionários da marca ZF operando em toda } \\
\text { a América Latina. }\end{array}$ & $\begin{array}{l}\text { A empresa realiza investimentos para oferecer } \\
\text { componentes e sistemas de padrão de } \\
\text { qualidade internacional que atendam aos mais } \\
\text { exigentes mercados do mundo. Possui hoje } \\
\text { uma ampla participação no MERCosUL, } \\
\text { fornecendo para quase todas as montadoras } \\
\text { instaladas. }\end{array}$ \\
\hline
\end{tabular}




\begin{tabular}{c|c|c}
\hline \multicolumn{1}{c|}{ Empresa } & Produtos & \multicolumn{1}{c}{ Posição no mercado } \\
\hline $\begin{array}{l}\text { TELCON S.A, fundada em 1987, está } \\
\text { localizada na cidade de Sorocaba e iniciou suas } \\
\text { atividades na fabricação de cabos metálicos } \\
\text { para redes telefônicas externas. Em 1993, } \\
\text { introduziu a linha de cabos de fibras ópticas. Já } \\
\text { no ano de 2000, a TELCON se associou à } \\
\text { Draka Holding, atualmente Draka Comteq. }\end{array}$ & $\begin{array}{l}\text { Fios telefônicos, cabos metálicos e cabos } \\
\text { A TELCON S.A está localizada à Rua Chicri }\end{array}$ & $\begin{array}{l}\text { A Telcon dispõe de modernas instalações, } \\
\text { projetadas para o desenvolvimento e produção } \\
\text { de fios e cabos, seguindo os mais avançados } \\
\text { padrões de tecnologia. }\end{array}$ \\
Maluf no 121. & & $\begin{array}{l}\text { A empresa busca sempre desenvolver, } \\
\text { produzir e comercializar produtos, baseando-se } \\
\text { no mais alto grau de tecnologia e qualidade, a } \\
\text { fim de criar um excelente relacionamento com } \\
\text { seus clientes, tendo como missão ser um dos } \\
\text { líderes do mercado de telecomunicações. }\end{array}$ \\
\end{tabular}




\begin{tabular}{|c|c|c|}
\hline Empresa & Produtos & Posição no mercado \\
\hline $\begin{array}{l}\text { GRUPO SPLICE iniciou suas atividades em } \\
\text { 1962, com a constituição da Companhia Rede } \\
\text { Telefônica Sorocabana, como concessionária } \\
\text { de telefonia fixa em Sorocaba/SP. } \\
\text { Atualmente, o Grupo conta com cinco } \\
\text { empresas: Splice Controle de Tráfego, Splice } \\
\text { Empreendimentos, BRVias, Banco Credibel e } \\
\text { Facens. }\end{array}$ & $\begin{array}{l}\text { Com capital } 100 \% \text { nacional, atua em } \\
\text { diferentes setores produtivos, como tecnologia, } \\
\text { infra-estrutura, construção civil e setor } \\
\text { financeiro. }\end{array}$ & $\begin{array}{l}\text { Desde sua criação, o Grupo Splice mostrou } \\
\text { agilidade para se adaptar às mudanças } \\
\text { ocorridas no mercado e suas operações são } \\
\text { unidas pela excelência nos serviços prestados, } \\
\text { nos produtos oferecidos e pela experiência, } \\
\text { expertise e qualificação de seus colaboradores. } \\
\text { Além de sua performance empresarial, o } \\
\text { Grupo é, também, mantenedor da Faculdade de } \\
\text { Engenharia de Sorocaba - FACENS, centro de } \\
\text { excelência educacional sem fins lucrativos. }\end{array}$ \\
\hline
\end{tabular}




\begin{tabular}{|c|c|c|}
\hline Empresa & Produtos & Posição no mercado \\
\hline $\begin{array}{l}\text { JARAGUÁ EQUIPAMENTOS NDUSTRIAIS } \\
\text { faz parte do Grupo Garcia, possui três unidades } \\
\text { fabris e está presente no cenário da indústria } \\
\text { brasileira como uma fábrica que produz fábricas. } \\
\text { A Jaraguá está localizada à Avenida Jaraguá } \\
\text { o } 300 \text {. }\end{array}$ & $\begin{array}{l}\text { Na unidade de Sorocaba, a Jaraguá } \\
\text { desenvolve projetos em regime "Turn Key", } \\
\text { para os setores de petróleo, petroquímica e } \\
\text { química. }\end{array}$ & $\begin{array}{l}\text { No ano de } 1992 \text { iniciou parcerias com } \\
\text { empresas de tecnologia americanas, italianas, } \\
\text { norueguesas e alemãs. Hoje, a Jaraguá tem } \\
\text { clientes pertencentes a setores de óleo e gás, } \\
\text { petroquímico e químico. } \\
\text { Conta com tecnologia de ponta, obtida por } \\
\text { meio de pesquisas e desenvolvimento, e } \\
\text { também com acordos e parcerias firmadas com } \\
\text { empresas líderes em vários segmentos do } \\
\text { mundo corporativo. } \\
\text { A Jaraguá foi qualificada como a principal } \\
\text { fornecedora de equipamentos para a Petrobrás, } \\
\text { dentro do programa de qualidade realizado pela } \\
\text { Estatal. }\end{array}$ \\
\hline
\end{tabular}




\begin{tabular}{|c|c|c|}
\hline Empresa & Produtos & Posição no mercado \\
\hline $\begin{array}{l}\text { UNIMETAL INDÚSTRIA E COMÉRCIO } \\
\text { foi fundada em 1984, na cidade de Sorocaba, } \\
\text { para realizar o beneficiamento de finos de } \\
\text { coque verde de petróleo. Atualmente, faz parte } \\
\text { do Grupo Universal e possui } 6 \text { unidades de } \\
\text { negócio no País. } \\
\text { A UNIMETAL-Sorocaba localiza-se à Av. } \\
\text { Dr. Antonio de Souza Neto no } 362 \text {. }\end{array}$ & $\begin{array}{l}\text { É uma empresa especializada em agregar } \\
\text { valor ao coque verde de petróleo, } \\
\text { transformando-o desde um carburante de baixo } \\
\text { carbono até um grafite sintético de alta pureza, } \\
\text { testado e aprovado inclusive na Europa. }\end{array}$ & $\begin{array}{l}\text { A UNIMETAL tem posição de destaque } \\
\text { onde atua e movimenta grandes volumes, } \\
\text { sendo qualificada a manusear e processar seus } \\
\text { produtos carbonosos e minerais em unidades } \\
\text { próprias. } \\
\text { Em } 2001 \text { implementou o Sistema de Gestão } \\
\text { Integrado (SGI) que engloba as certificações } \\
\text { referentes ao Sistema de Gestão da Qualidade } \\
\text { (ISO 9001), Meio Ambiente (ISO 14001), Saúde } \\
\text { e Segurança do Trabalho (OHSAS 18001) e } \\
\text { Responsabilidade Social (SA 8000). }\end{array}$ \\
\hline
\end{tabular}




\begin{tabular}{|c|c|c|}
\hline Empresa & Produtos & Posição no mercado \\
\hline $\begin{array}{l}\text { METSO MINERALS - BRASIL, pertence à } \\
\text { Metso Minerals cuja matriz localiza-se em } \\
\text { Helsinque (Finlândia) e possui parques fabris, } \\
\text { escritórios de vendas e serviços e distribuidores } \\
\text { em mais de } 100 \text { países. } \\
\text { A Metso Minerals é uma das áreas de } \\
\text { negócios da Corporação Metso, que está listada } \\
\text { nas bolsas de valores de Helsinque e Nova } \\
\text { lorque. } \\
\text { A Metso possui três unidades em Sorocaba: } \\
\text { a Fábrica de Equipamentos, construída em } \\
\text { 1969; a Fundição, fundada em 1979; e a } \\
\text { Fábrica de Produtos de Desgaste, construída } \\
\text { em 2005. Conta com cerca de } 1.300 \\
\text { profissionais empregados nestas unidades. }\end{array}$ & $\begin{array}{l}\text { As principais linhas de negócios da Metso } \\
\text { Minerals são: Construção: ofertar de } \\
\text { equipamentos e soluções que abrangem a } \\
\text { totalidade dos processos de agregados. } \\
\text { Mineração: soluções para produção de } \\
\text { concentrado de minerais. Reciclagem: a Metso } \\
\text { Minerals é a líder global de mercado em } \\
\text { reciclagem de metal e oferece uma ampla gama } \\
\text { de sistemas para fragmentação, compactação e } \\
\text { separação de praticamente todo tipo de sucata } \\
\text { metálica. } \\
\text { Em sua linha de produção são fabricados: } \\
\text { britadores cônicos e de mandíbulas, peneiras, } \\
\text { conjuntos móveis de britagem, entre outros. E a } \\
\text { produção de fundidos destina-se à fabricação } \\
\text { de peças de desgaste e reposição para } \\
\text { britagem, moagem, mineração e terraplanagem. }\end{array}$ & $\begin{array}{l}\text { No Brasil, a experiência em pesquisas e } \\
\text { projetos, faz da unidade da Metso Minerals local } \\
\text { a mais importante fabricante de equipamentos } \\
\text { de britagem e processamento de minérios da } \\
\text { América Latina. } \\
\text { Seus produtos e engenharia estão } \\
\text { presentes desde pedreiras de pequeno porte } \\
\text { até grandes obras como usinas hidrelétricas, } \\
\text { grandes minerações, estradas, ferrovias e } \\
\text { aeroportos. A Metso Minerals Brasil projeta, } \\
\text { fornece e instala plantas completas de britagem, } \\
\text { moagem, transporte e estocagem de granéis } \\
\text { sólidos, processamento de minerais e } \\
\text { piroprocessamento. }\end{array}$ \\
\hline
\end{tabular}




\begin{tabular}{|c|c|c|}
\hline Empresa & Produtos & Posição no mercado \\
\hline $\begin{array}{l}\text { ANDREW DO BRASIL LTDA pertence ao } \\
\text { Andrew Corporation, de origem norte- } \\
\text { americana, atua mundialmente no mercado de } \\
\text { equipamentos de telecomunicações. } \\
\text { Em sua unidade de Sorocaba, localizada à } \\
\text { Avenida Camilo Julio no } 1256 \text {, emprega cerca } \\
\text { de } 500 \text { funcionários. }\end{array}$ & $\begin{array}{l}\text { Produz e comercializa antenas, cabos de } \\
\text { transmissão, dispositivos para pressurização, } \\
\text { acessórios para linhas de telecomunicações, } \\
\text { filtros e combinadores, amplificadores em torre } \\
\text { e soluções para atenuações de sinais, testes e } \\
\text { medição de equipamentos. peças e } \\
\text { equipamentos relacionados e sistemas } \\
\text { distributivos de comunicação. }\end{array}$ & $\begin{array}{l}\text { A Andrew do Brasil fabrica e fornece } \\
\text { equipamentos e soluções inovadoras para o } \\
\text { mercado latino-americano de infra-estrutura de } \\
\text { telecomunicações. } \\
\text { A Andrew Corporation tem mais de } 60 \text { anos } \\
\text { de experiência e possui fábricas em } 35 \text { países. } \\
\text { Todas fábricas são certificadas em Sistema } \\
\text { de Gestão da Qualidade (ISO 9001-2000) e a } \\
\text { Unidade do Brasil conta também com a } \\
\text { certificação ISO } 14001 \text {. }\end{array}$ \\
\hline
\end{tabular}




\begin{tabular}{|c|c|c|}
\hline Empresa & Produtos & Posição no mercado \\
\hline $\begin{array}{l}\text { KYOCERA DO BRASIL COMPONENTES } \\
\text { INDUSTRIAIS LTDA é uma das subsidiárias do } \\
\text { grupo Kyocera Corporation, empresa com sede } \\
\text { em Kyoto, Japão. } \\
\text { A KYOCERA YASHICA DO BRASIL tem } \\
\text { sua matriz em Sorocaba à Rua Yashica no } 65 \text {. }\end{array}$ & $\begin{array}{l}\text { Ferramentas de corte e serviços de injeção } \\
\text { plástica. }\end{array}$ & $\begin{array}{l}\text { A partir de 2007, como parte da sua } \\
\text { estratégia global, a Kyocera Yashica altera a } \\
\text { razão social para "Kyocera do Brasil } \\
\text { Componentes Industriais Ltda", descontinuando } \\
\text { a comercialização de câmaras fotográficas da } \\
\text { marca Yashica no Brasil, e passando a investir } \\
\text { na comercialização de ferramentas de corte e } \\
\text { serviços de injeção plástica. } \\
\text { Buscando sempre a satisfação do cliente, a } \\
\text { Kyocera promove a "Gestão Participativa por } \\
\text { Todos os Funcionários", para melhorar a } \\
\text { capacidade de execução e realização para } \\
\text { assegurar esta satisfação. } \\
\text { Atualmente, possui as certificações ISO } \\
\text { 9001-2000 e ISO } 14001 .\end{array}$ \\
\hline
\end{tabular}




\begin{tabular}{|c|c|c|}
\hline Empresa & Produtos & Posição no mercado \\
\hline $\begin{array}{l}\text { NIPRO MEDICAL LTDA foi a primeira } \\
\text { unidade fabril da NIPRO CORPORATION no } \\
\text { continente americano. Ela foi constituída no } \\
\text { Brasil em } 15 \text { de agosto de 1995, inicialmente } \\
\text { com a comercialização de produtos importados. } \\
\text { Em } 1997 \text { teve início a fabricação de produtos no } \\
\text { Brasil. } \\
\text { Em 2006, a NIPRO adquiriu uma unidade } \\
\text { de produtos cardiopulmonares que funcionava } \\
\text { em São Paulo. E em } 2008 \text { essa linha de } \\
\text { produção foi transferida para a planta em } \\
\text { Sorocaba, que passou a produzir também } \\
\text { oxigenadores e acessórios utilizados em } \\
\text { cirurgias cardíacas. } \\
\text { A fábrica da NIPRO localiza-se na Avenida } \\
\text { Marginal à Rodovia Senador José Ermírio de } \\
\text { Moraes, km 2,5, Sorocaba/SP. }\end{array}$ & $\begin{array}{l}\text { A NIPRO trabalha com diversas linhas de } \\
\text { produtos, entre eles, Linha Hemodiálise, Linha } \\
\text { Cárdio, Linha Medical (com produtos como } \\
\text { agulhas e cateteres), Linha Endovascular (com } \\
\text { produtos para intervenções minimamente } \\
\text { invasivas, como fio guia) e Serviço Técnico } \\
\text { (para manutenções preventivas e corretivas em } \\
\text { equipamentos de hemodiálise e máquinas de } \\
\text { circulação extracorpórea). } \\
\text { A NIPRO atua também prestando serviço de } \\
\text { esterilização a óxido de etileno, contagem } \\
\text { microbiológica e outros. }\end{array}$ & $\begin{array}{l}\text { A NIPRO CORPORATION foi estabelecida } \\
\text { em 1954, em Kyoto no Japão. O objetivo do } \\
\text { grupo sempre foi o de buscar uma melhor } \\
\text { qualidade de vida para as pessoas, com } \\
\text { produtos inovadores e confiáveis. } \\
\text { Atualmente, a empresa está dividida em três } \\
\text { áreas principais: Médica, Farmacêutica e Vidros } \\
\text { \& Materiais. São cinco fábricas no mundo, } \\
\text { sendo duas no Japão, uma na Tailândia, uma } \\
\text { na China e uma no Brasil. } \\
\text { No Brasil, a NIPRO possui cerca de } 350 \\
\underline{\text { colaboradores e nas áreas de produtos como }} \\
\underline{\text { agulha AVF (para hemodiálise) e oxigenadores }} \\
\underline{\text { para cirurgia cardíaca), a empresa é líder de }} \\
\underline{\text { mercado. }}\end{array}$ \\
\hline
\end{tabular}




\section{Toyota Motor Company Ltda}

Além das empresas mencionadas, convém mencionar a decisão de instalação da planta da Toyota em Sorocaba. O processo decisório foi bastante concorrido, sendo que outras grandes cidades do país articularam esforços para sediar a Montadora.

Na planta de Sorocaba, prevista para iniciar as atividades em 2011, estão previstas a criação de cerca de 2 mil empregos diretos e 10 mil indiretos considerando a política da empresa de desenvolver fornecedores sistêmicos.

Os impactos da presença da Toyota já estão sendo sentidos, levando a uma necessidade de qualificação de mão-de-obra, por meio do alinhamento do processo de formação de recursos humanos. Outro aspecto, está relacionado as externalidades positivas com efeitos sobre os setores de prestação de serviços, comércio e lazer.

Para efeito de análise, com base na cidade de Indaiatuba que sedia uma Planta da Toyota é possível estimar os seus efeitos do crescimento econômico, de 2002 a 2005 o PIB do estado de São Paulo cresceu aproximadamente 40 \%, enquanto que o PIB de Indaiatuba cresceu $112 \%$.

Outro aspecto positivo da presença da Toyota está relacionado ao seu Sistema de Gestão, o Toyotismo é uma referência nas cátedras de administração de e engenharia de produção, desta forma é plausível aproveitar da sua presença para adquirir know-how para melhorias em Sorocaba. 
- Principais Segmentos

O Parque Industrial de Sorocaba concentra suas atividades em vinte setores principais, entre os quais o segmento de fabricação de máquinas e equipamentos. É importante ressaltar que em vários setores a produção local é a principal responsável pelo abastecimento do mercado brasileiro. (Tabela 4.12)

Tabela 4.12 - Principais segmentos da Indústria Sorocabana.

\begin{tabular}{|c|c|c|c|}
\hline & $\begin{array}{c}\text { № de } \\
\text { estabelecimentos } \\
\text { da indústria }\end{array}$ & $\begin{array}{c}\text { № de } \\
\text { empregos } \\
\text { na indústria }\end{array}$ & $\begin{array}{c}\text { Participação } \\
\%\end{array}$ \\
\hline $\begin{array}{l}\text { Fabricação de produtos de metal - exclusive } \\
\text { máquinas e equipamentos }\end{array}$ & 219 & 6023 & 2,18 \\
\hline Fabricação de máquinas e equipamentos & 135 & 6902 & 2,34 \\
\hline Confecção de artigos de vestuário e acessórios & 117 & 4795 & 0,96 \\
\hline Fabricação de produtos alimentícios e bebidas & 102 & 2284 & 0,67 \\
\hline Fabricação de produtos de minerais não metálicos & 81 & 2923 & 1,74 \\
\hline Edição, impressão e reprodução de gravações & 79 & 512 & 1,26 \\
\hline Fabricação de móveis e indústrias diversas & 72 & 2275 & 1,13 \\
\hline $\begin{array}{l}\text { Fabricação de artigos de borracha e de material } \\
\text { plástico }\end{array}$ & 69 & 3232 & 1,33 \\
\hline Fabricação de produtos químicos & 42 & 2753 & 1,12 \\
\hline Fabricação de produtos têxteis & 34 & 2132 & 0,97 \\
\hline $\begin{array}{l}\text { Fabricação de montagem de veículos } \\
\text { automotores, reboques e carrocerias }\end{array}$ & 34 & 9607 & 1,98 \\
\hline Metalúrgica básica & 30 & 1921 & 1,69 \\
\hline $\begin{array}{l}\text { Fabricação de máquinas, aparelhos e materiais } \\
\text { elétricos }\end{array}$ & 27 & 2299 & 1,34 \\
\hline Fabricação de produtos de madeira & 16 & 217 & 0,90 \\
\hline $\begin{array}{l}\text { Fabricação de equipamentos de instrumentação } \\
\text { médico-hospitalar }\end{array}$ & 16 & 874 & 1,47 \\
\hline Fabricação de celulose, papel e produtos de papel & 14 & 510 & 0,98 \\
\hline Fabricação de outros equipamentos de transporte & 14 & 423 & 3,65 \\
\hline $\begin{array}{l}\text { Fabricação de material eletrônico e aparelhos de } \\
\text { comunicações }\end{array}$ & 8 & 515 & 1,06 \\
\hline $\begin{array}{l}\text { Preparação de couros e fabricação de artefatos de } \\
\text { couro }\end{array}$ & 4 & 15 & 0,11 \\
\hline Reciclagem & 3 & 44 & 0,66 \\
\hline $\begin{array}{l}\text { Fabricação de máquinas para escritório e } \\
\text { equipamentos de informática }\end{array}$ & 2 & $\mathrm{X}$ & 0,72 \\
\hline Fabricação de produtos de fumo & - & - & - \\
\hline $\begin{array}{l}\text { Fabricação de coque, refino de petróleo e } \\
\text { combustíveis nucleares }\end{array}$ & - & - & - \\
\hline Total da indústria de transformação & 1118 & 52457 & \\
\hline
\end{tabular}

Fonte: Fundação Seade. Disponível em: HTTP://www.seade.gov.br - Acesso em 15/11/2007.

- Indicadores Serviços

A dinâmica da economia mundial evidencia o crescimento do setor de serviços. Em Sorocaba, a força da indústria e o dinamismo do comércio impulsionam 
o movimento crescente do setor responsável atualmente por 3.793 estabelecimentos que respondem pela geração de quase $40 \%$ dos empregos diretos, totalizando de acordo com dados do SEADE, o número de 52194 em 2006, afora a ocupação de autônomos e profissionais liberais.

Para fomentar empreendimentos no setor de prestação de serviços, a Prefeitura de Sorocaba garante incentivos como a redução escalonada das contribuições e a diminuição das exigências para a abertura e formalização das empresas, garantindo assim o aumento de receita no setor.

Com base nos principais Municípios geradores de valor adicionado do estado torna-se possível fazer uma análise. Primeiramente, o foco vai para o Município de São Paulo (Tabela 4.13). Percebe-se uma concentração do VA dos serviços, responsável por $3 / 4$ do total dos valores adicionados totais. Numa análise com maior nível de desagregação, observa-se que eles são em parte destinados às empresas, aos consumidores finais e para as atividades de intermediação financeira.

Alguns municípios apresentam uma concentração de valores adicionados em serviços devido as atividades de logística e intermediação financeira. Em 2006, o Município de Barueri apareceu como o segundo município em importância no VA dos serviços, superando o Município de Guarulhos. Ao se analisar o Município de Osasco, que aparece como quinto valor adicionado, constata-se que a sua participação é impactada pelo setor financeiro, devido à presença da sede de uma grande instituição financeira em seu território,

No tocante a Campinas e São Bernardo do Campo que ocupam, respectivamente, a quarta e sexta posições no ranking, destacam-se pela grande diversidade das atividades terciárias em seus territórios, mas com forte presença de serviços voltados às empresas, especialmente industriais e também de intermediação financeira e de administração pública.

Um aspecto de importância é que a distribuição do valor adicionado nos serviços pelos municípios paulistas coincide, em aspectos gerais, com a da indústria. Isso porque aquele setor, por ter grande parte de sua demanda ligada à indústria segue a dinâmica territorial semelhante a esta. (Tabela 4.13) 
Tabela 4.13 - Valor Adicionado dos Serviços e Participação no Total.

\begin{tabular}{l|c|c}
\hline \multicolumn{1}{c|}{ Município } & $\begin{array}{c}\text { Valores } \\
\text { (em milhões } \\
\text { de R\$) }\end{array}$ & $\%$ \\
\hline São Paulo & $181.192,94$ & 76,89 \\
\hline Barueri & $17.504,84$ & 83,89 \\
\hline Guarulhos & $14.301,24$ & 67,44 \\
\hline Campinas & $12.958,35$ & 73,17 \\
\hline Osasco & $12.890,63$ & 85,49 \\
\hline São Bernardo do Campo & $9.397,13$ & 56,3 \\
\hline Ribeirão Preto & $7.959,25$ & 80,18 \\
\hline São José dos Campos & $6.717,01$ & 50,4 \\
\hline Santos & $6.511,44$ & 75,69 \\
\hline Santo André & $6.443,38$ & 63,96 \\
\hline Jundiaí & $6.199,50$ & 64,76 \\
\hline Sorocaba & $5.407,51$ & 65,22 \\
\hline
\end{tabular}

Fonte: Fundação Seade - Base 2006

Disponível em www.seade.gov.br. Acesso em 15/11/2007

\subsection{Indicadores científicos, tecnológicos e de inovação}

Nas últimas décadas, os indicadores científicos, tecnológicos e de inovação vêm ganhando importância crescente como instrumentos para análise da geração de conhecimento e inovação e das suas relações com o desenvolvimento econômico e social dos países.

O ativo que proporciona o desenvolvimento de rotinas de C\&T\&I é o conhecimento. Os conhecimentos são, em alguns aspectos, codificados, todavia, a sua grande maioria, encontra-se na forma tácita. Para a medição dos seus resultados são analisados: i) vertente do conhecimento não codificado, enfocando as competências; ii) vertente codificada, com enfoque nos registros de propriedade industrial; e os registros de publicações científicas.

O Brasil tem despendido um esforço considerável para ampliar a geração de conhecimento, referenciado no sistema de pós-graduação (formação de mestres 
de doutores) e ancorado principalmente nas universidades públicas federais e estaduais.

Todavia, essa opção não propicia, quando isolada, aumento da competitividade para o país, visto as necessidades de apropriação e utilização do conhecimento gerado, ou seja, a transformação de conhecimento em riqueza.

A articulação e estruturação de ambientes sinérgicos têm sido a resposta de países mais desenvolvidos. Para desenvolver e articular esses ambientes são concebidos diferentes modelos. No caso dos parques tecnológicos, por exemplo, vertentes mais tradicionais como a inglesa e a americana prevêem que eles surjam de uma base científico-tecnológica local, representada por instituições de ensino, as quais são a base para atração de empresas. A dinâmica desse movimento de interação proporciona um alinhamento entre as atividades da academia e das empresas, alavancando a competitividade regional.

No contexto específico da cidade de Sorocaba, observa-se que a mesma está fortemente alicerçada nas áreas de humanas, distanciada das principais atividades empresariais desenvolvidas na região. Para uma análise mais profunda da situação do Município em termos do potencial científico e tecnológico, um importante indicador consiste no número de mestres e doutores atuando na região.

Desta forma, foi realizada uma pesquisa na cidade de Sorocaba, junto às Instituições de Ensino Superior de Sorocaba - IES que apontou a existência de 336 mestres e 338 doutores (vide Figura 4-8). Esses números com base unicamente na perspectiva das IES podem ser considerados uma aproximação do número total de mestres e doutores de Sorocaba, pois na cidade, não são notados grandes institutos de pesquisa e profissionais com alta especialização atuando nas empresas. Os dados relativos apontam para a proporção de um doutor para cada 1736 habitantes, mesmo considerando como limitação a atividade de professores em mais de uma instituição. 


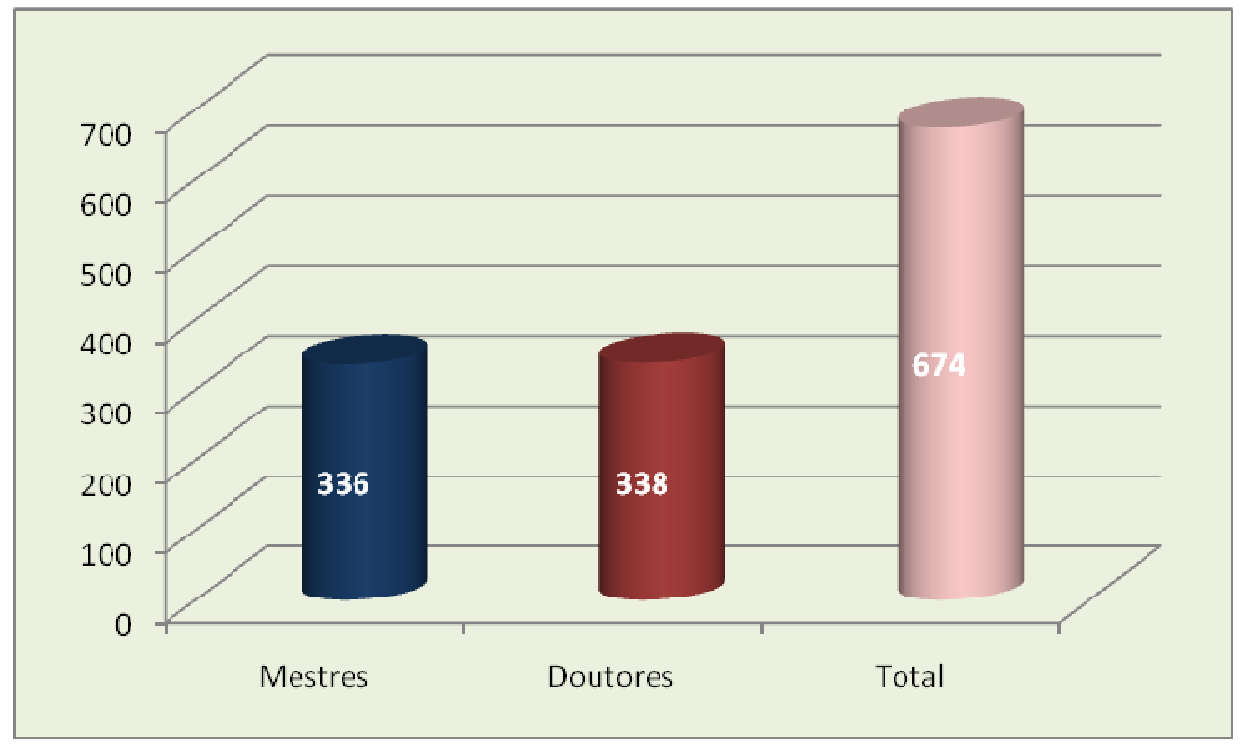

Figura 4-8: Número de mestres e doutores atuando nas IES de Sorocaba. Fonte: Pesquisa de campo junto as Instituições de Ensino de Sorocaba Pólo de Desenvolvimento e Inovação. Maio/2009.

Os dados relacionados ao perfil científico e tecnológico da população apontam para a predominância de formação técnica, sendo identificadas lacunas na formação tecnológica, que nos últimos anos vem sendo amenizada pela chegada de grandes instituições de ensino, tais como A Universidade Federal de São Carlos e a Universidade Estadual Paulista - UNESP.

Para se obter uma referência do potencial científico e tecnológico da região de Sorocaba são apresentadas, a seguir, informações de indicadores tecnológicos referenciados no Estado de São Paulo. É importante observar que os indicadores referem-se, na sua maioria, à microrregião de Sorocaba (conta com 15 municípios limítrofes a Sorocaba), a qual envolve a cidade de Sorocaba e outros municípios no seu entorno.

Considerando os indicadores de inovação no país, a principal pesquisa realizada é a PINTEC - Pesquisa Industrial de Inovação Tecnológica, conduzida pelo IBGE - Instituto Brasileiro de Geografia e Estatística - com o apoio da Financiadora de Estudos e Projetos - FINEP e do Ministério da Ciência e Tecnologia - MCT. A pesquisa tem por finalidade construir indicadores nacionais e regionais das atividades de inovação tecnológica desenvolvidas nas empresas industriais brasileiras com dez ou mais pessoas ocupadas. 
A referida pesquisa evidencia aumentos significativos no número de empresas inovadoras na indústria, tomando como base o período de 2003 a 2005. Assim, o número de empresas inovadoras na indústria aumentou 8,4\%, em números absolutos de 28.036 para 30.377 , todavia, não alterou a participação delas no total das empresas industriais (33,4\%).

O Estado de São Paulo é o local de maior aglomeração de empresas inovadoras 35,3\%, sendo também reconhecido pelo esforço em inovação, com percentuais acima de $50 \%$. Considerando o faturamento das empresas, nota-se uma tendência a gastar mais com inovação, atingindo indicadores próximos a padrões internacionais de $3 \%$.

Todavia, são identificados fatores inibidores tradicionais, tais como, elevados custos, riscos econômicos excessivos e escassez de fontes de financiamento.

Refinando o mapeamento da capacitação em C\&T no Estado, a distribuição aponta um grau bastante elevado de concentração nas regiões mais industrializadas; provavelmente devido a uma vertente logística que aponta para uma distribuição ao longo dos eixos das principais rodovias do Estado de São Paulo e no entorno de áreas metropolitanas (especialmente nas microrregiões ${ }^{8}$ de São Paulo e de Campinas) e de outras regiões com forte concentração de instituições acadêmicas.

No caso específico da microrregião de Sorocaba que reflete o panorama da cidade de Sorocaba, a densidade tecnológica em alguns segmentos é baixa, explicada em parte, pela base de C\&T\&I incipiente em determinados domínios.

Esse fato é determinante para que Sorocaba, ao contrário de São Paulo, apresente alta concentração de ocupações técnicas (nível de especialização médio), todavia baixa concentração de ocupações ligadas a C\&T\&I com especialização superior. Para uma análise mais pormenorizada das ocupações técnicas, segue um panorama das regiões que apresentam maior densidade relativa de ocupações técnicas pelo total de empregos com base na metodologia de Suzigan et al, (2006),

\footnotetext{
${ }^{8}$ Microrregião é, de acordo com a Constituição brasileira de 1988, um agrupamento de municípios limítrofes. Sua finalidade é integrar a organização, o planejamento e a execução de funções públicas de interesse comum, definidas por lei complementar estadual.
} 
em São José dos Campos há 43,1 de ocupações técnicas para cada 1.000 empregos, na cidade de Campinas 35,3 Sorocaba apresenta 32,2 de ocupações, Piedade 32, Osasco 31,9 e Jundiaí 31,3.

Nas ocupações operacionais, a densidade é mais elevada nas regiões de São Carlos (155), São José dos Campos $(107,3)$, Guarulhos $(87,1)$ e Sorocaba (86). A microrregião de São Paulo, pelo esvaziamento das unidades produtivas, apresenta reduzida densidade tanto nas ocupações técnicas $(28,3)$ como nas ocupações operacionais $(42,6)$.

\section{Números de Patentes}

$\mathrm{Na}$ academia discute-se a viabilidade de utilizar o número de patentes como indicador de intensidade tecnológica. No presente trabalho, são consideradas as limitações oriundas de uma análise baseada unicamente nesse indicador, todavia, a sua utilização permite uma boa aproximação. A microrregião de São Paulo é a mais importante quando comparada as outras tanto em números absolutos (com 5.105 patentes, ou $61 \%$ do total) como em termos de patentes per capita (com cerca de 40 patentes por 100 mil habitantes) (Figura 4-9).

O resultado da microrregião de Sorocaba está situado na faixa de 12 a 15 patentes por 100 mil habitantes. É importante frisar que esse resultado é fruto do dinamismo das empresas que estão no seu entorno, compensando a pequena presença da academia nesse indicador.

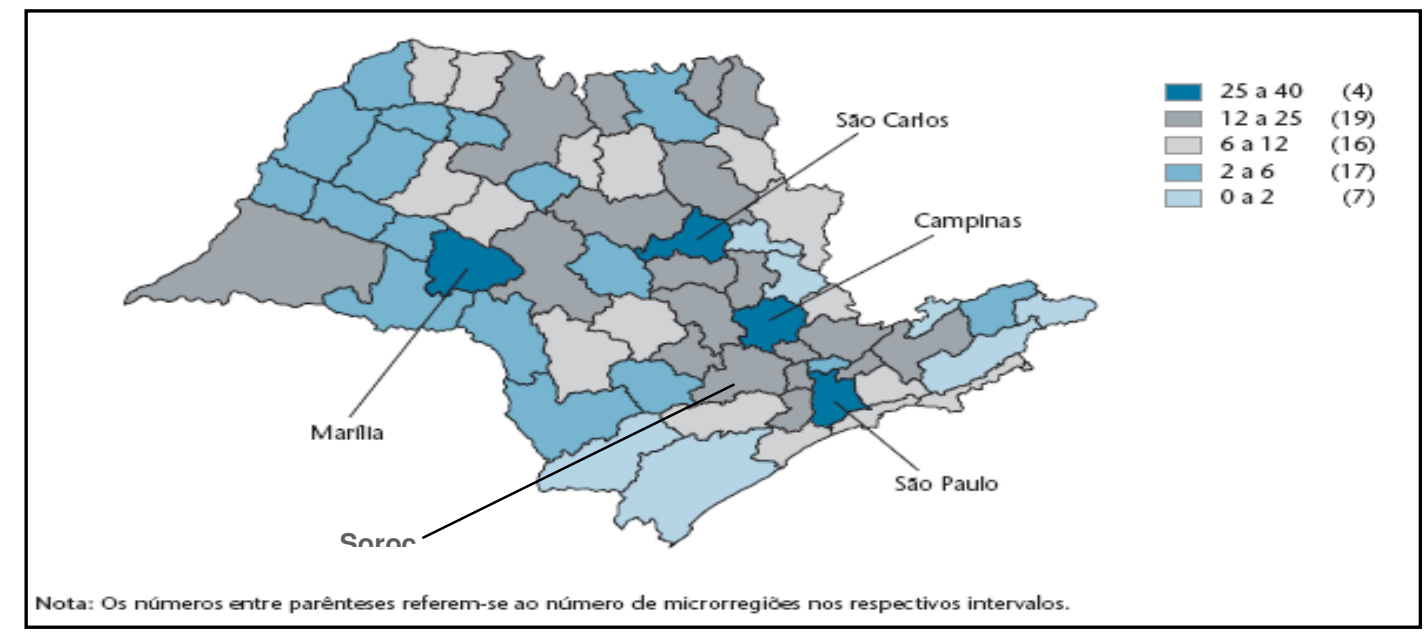

Figura 4-9: Número de patentes por 100 mil habitantes - Microrregiões do Estado de São Paulo, 1999-2001. Fonte: FAPESP - Indicadores de ciência, tecnologia e inovação em São Paulo, 2004 
- Especialização Tecnológica

Quando considerados os domínios tecnológicos, a química fina aparece como o principal domínio na maior parte das microrregiões do Estado de São Paulo (17), especialmente na região centro-oeste do Estado. O domínio procedimentos/química de base/metalurgia prevalece em quinze microrregiões.

Tomando os casos das microrregiões com maior densidade tecnológica, verifica-se que a cidade de São Paulo apresenta elevada especialização nos subdomínios tecnológicos de tratamento de superfícies, química macromolecular e engenharia médica. A cidade de São Carlos apresenta atividades de patenteamento que revelam especialização principalmente em óptica e química macromolecular. Campinas, por outro lado, tem maior concentração de atividades de inovação nas áreas de meio ambiente, química orgânica, audiovisual e informática.

A microrregião de Sorocaba, com base na dinâmica das empresas na região, evidencia os domínios relacionados a procedimentos químicos de base metalúrgica. (Figura 4-10).

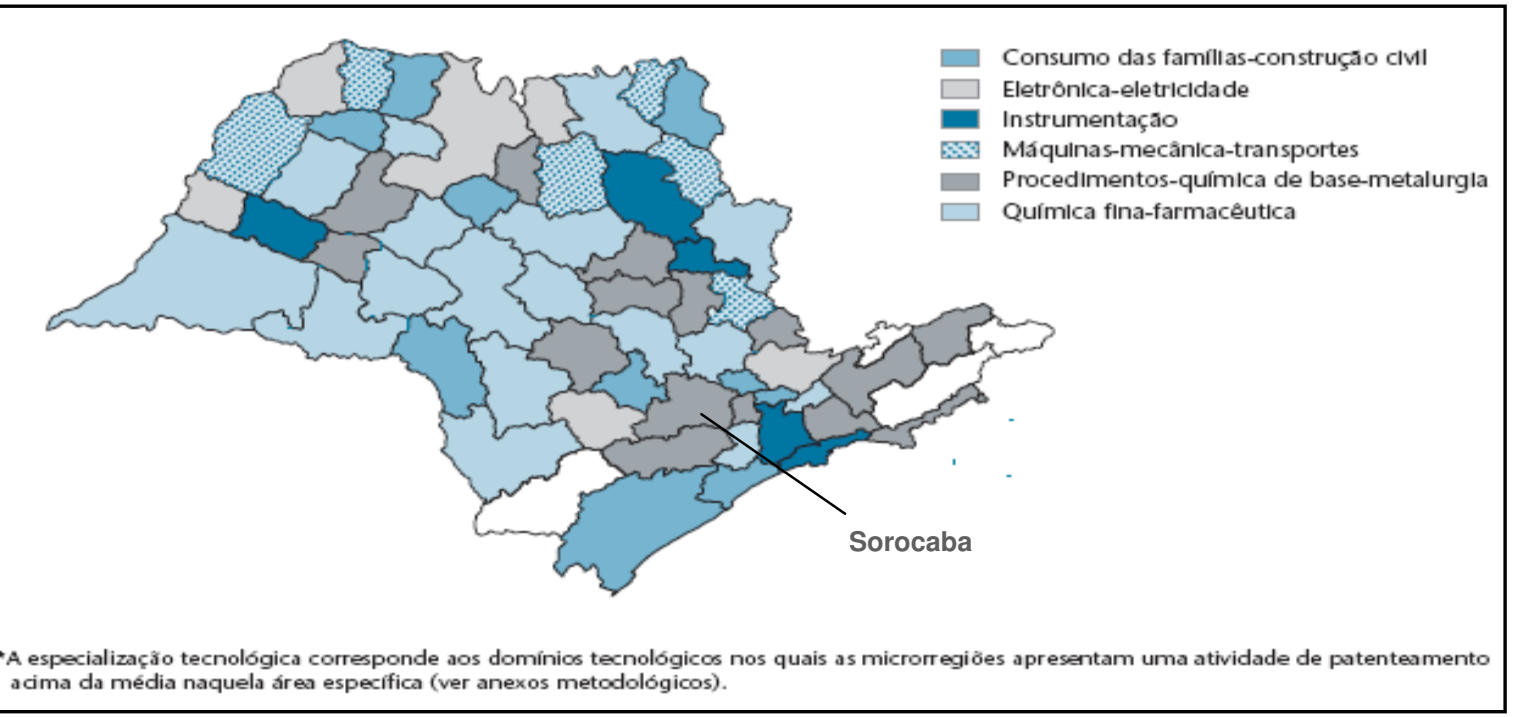

Figura 4-10: Especialização tecnológica* - Microrregiões do Estado de São Paulo, 1999-2001.

Fonte: FAPESP - Indicadores de ciência, tecnologia e inovação em São Paulo, 2004

Considerando as solicitações de Patentes e Modelos de utilidade originadas a partir de instituições de Sorocaba, foi solicitada uma tabulação especial junto ao Institutito Nacional de Propriedade Industrial em 2009, que apresentou entre 
2004 e 2009 o número de 115 solicitações, sendo 69 de solicitação de patentes, 44 de modelos de utilidade e 02 de constetação.

$\mathrm{Na}$ Figura 4-11 observa-se que em patentes relacionadas ao setor de informática destaca-se como estrategicamente importante Campinas (21 patentes), impactada positivamente pela presença do CPqD - Fundação CPqD Centro de Pesquisa e Desenvolvimento em Telecomunicações que é um dos mais conceituados pólos de tecnologia do mundo em telecomunicações e tecnologia da informação, além das microrregiões de Sorocaba e Osasco.

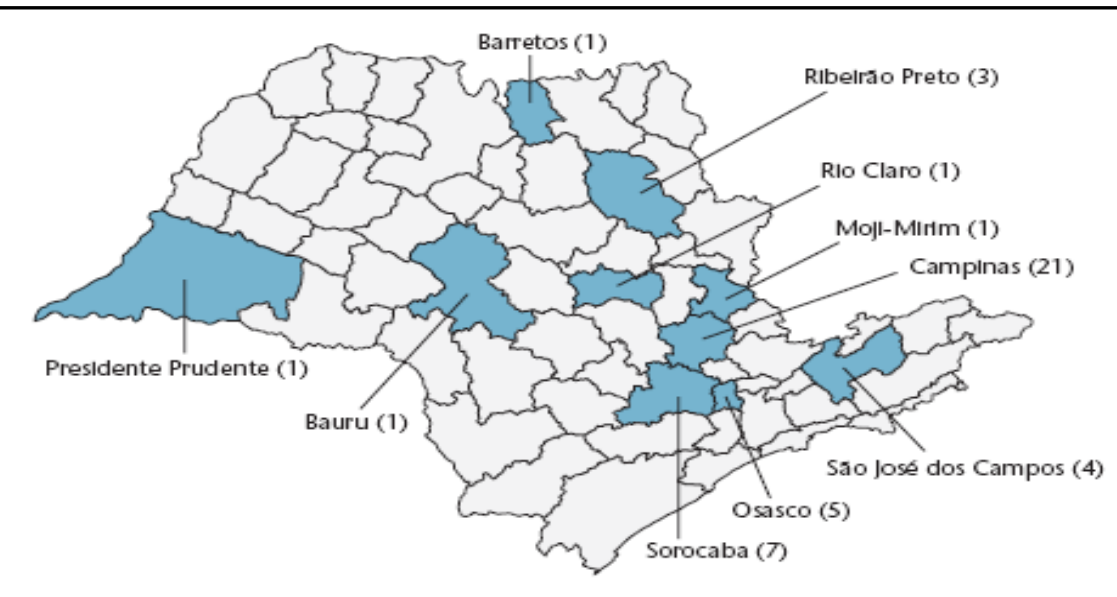

Nota: Os números entre parênteses referem-se ao total de patentes da microrregiăo no domínio tecnológico selecionado.

Figura 4-11:: Especialização tecnológica em informática - Microrregiões do Estado de São Paulo, 1999-2001.

Fonte: FAPESP - Indicadores de ciência, tecnologia e inovação em São Paulo, 2004

- Especialização Tecnológica Internacional

Os dados de patentes registradas no Escritório de Patentes dos Estados Unidos da América (USPTO - United States Patent and Trademark Office) servem como indicador de especialização tecnológica internacional. Confirmando uma característica do Sistema Nacional de Inovação, constata-se que apenas 18 das 63 microrregiões do Estado de São Paulo tiveram patentes registradas no exterior, sobretudo nos domínios tecnológicos de Consumo das famílias e máquinasmecânica-transportes.

Algumas das microrregiões que se destacam na especialização internacional em seus respectivos domínios tecnológicos são aquelas nas quais se 
observa a presença de algumas importantes empresas inovadoras. Esse é o caso, por exemplo, das microrregiões de Marília (município de Pompéia), no domínio Transportes; de Araraquara (município de Matão), Mogi-Mirim (município de MogiGuaçu), Campinas (município de Santa Bárbara D’Oeste) e São Paulo (município de São Caetano do Sul), no domínio Máquinas-ferramentas; de Sorocaba (município de Itu) e Osasco, no domínio Telecomunicações; de São Paulo (município de Diadema), Sorocaba e São José dos Campos, em Tecnologias de Instrumentação; e de Osasco (município de Cajamar) e São Paulo, na área de Química fina (Figura 4-12).

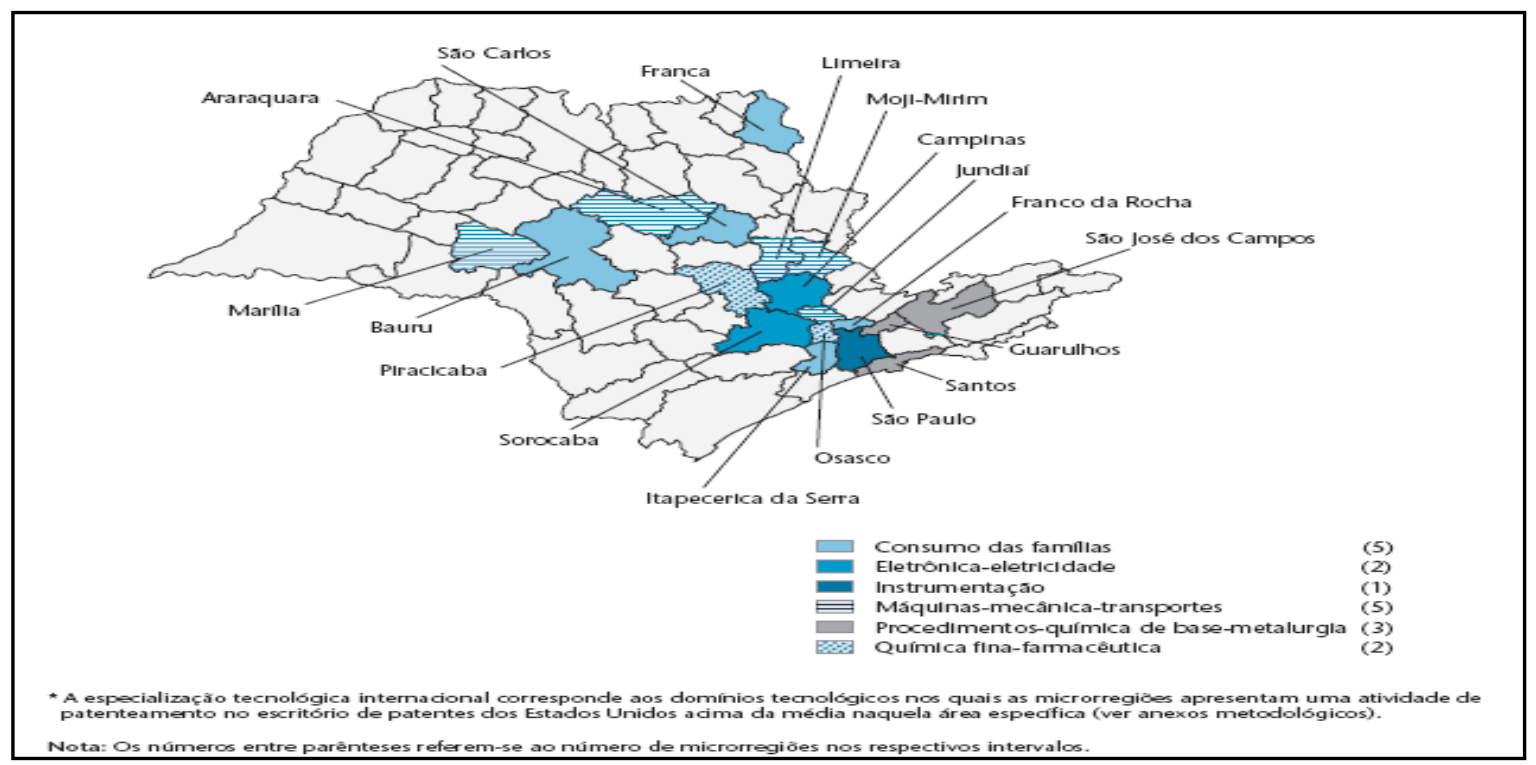

Figura 4-12: Especialização tecnológica internacional* - Microrregiões do Estado de São Paulo, 19922001. Fonte: FAPESP - Indicadores de ciência, tecnologia e inovação em São Paulo, 2004

A microrregião de Campinas destaca-se também pelas patentes internacionais na área de Informática e, nesse caso, o dinamismo tecnológico é mais abrangente do que aquele representado pela presença de uma ou algumas empresas inovadoras. Reflete a forte especialização regional nessa área, concentrando grande número de empresas dos vários segmentos da cadeia produtiva, de instituições de ensino e pesquisa e de laboratórios e centros de pesquisa especializados. 
- Marcas

Dentro do contexto de um mundo globalizado e de alta competitividade, a divulgação da marca torna-se cada vez mais um ativo-chave. O Brasil ainda produz resultados modestos nesse segmento, fato que fica evidente numa análise regional.

Verifica-se que somente 21 das 63 microrregiões do Estado de São Paulo apresentam atividade de registro de marcas nos Estados Unidos. A maior parte (oito microrregiões) concentra-se em bens de consumo das famílias. Nesse campo, destacam-se os esforços comerciais de empresas de Sorocaba, em jogos, brinquedos e artigos esportivos, conforme apresentado na Figura 4-13.

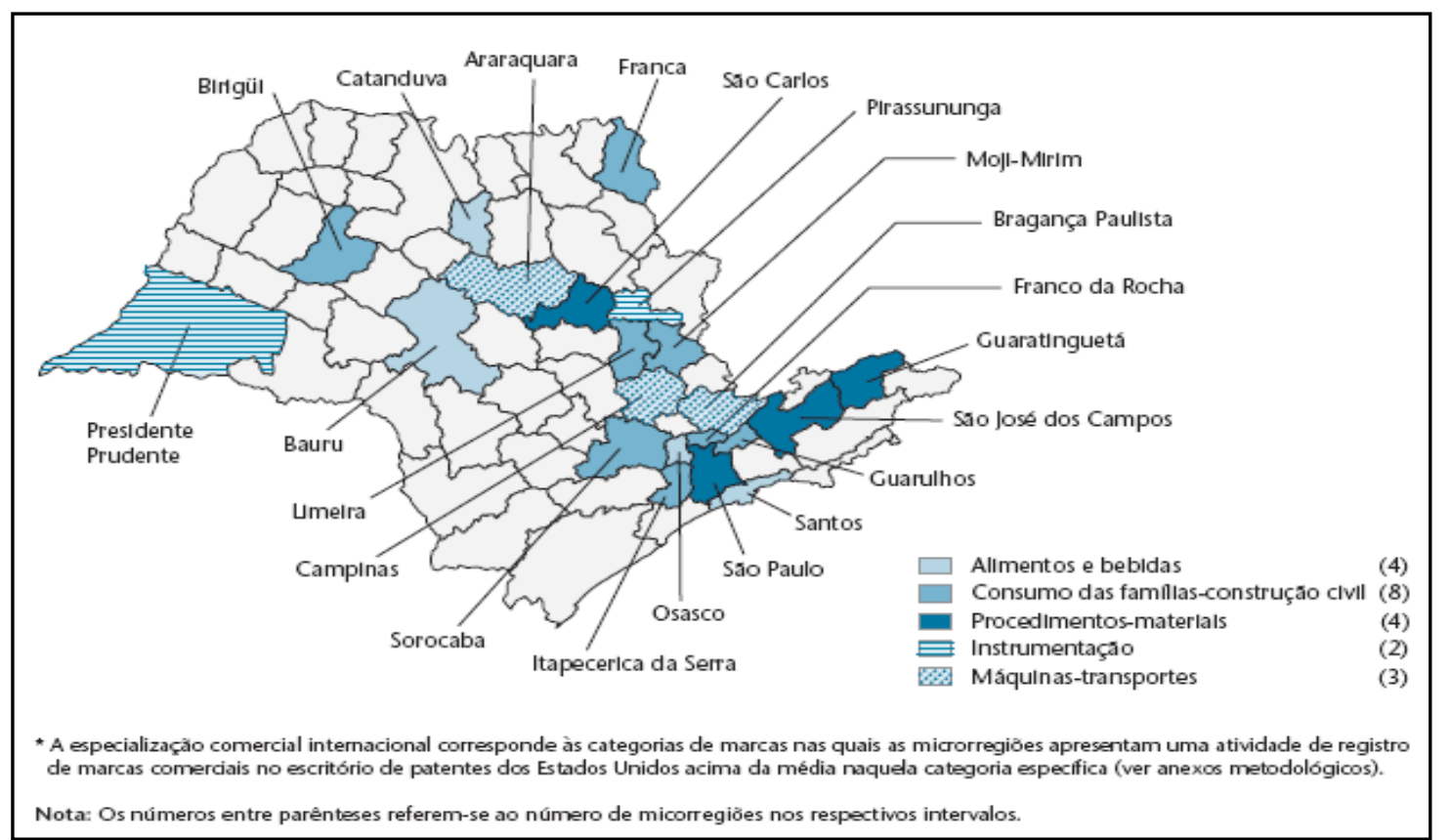

Figura 4-13: Especialização comercial internacional ${ }^{\star}$ - Microrregiões do Estado de São Paulo, 19982002. Fonte: FAPESP - Indicadores de ciência, tecnologia e inovação em São Paulo, 2004.

- Especialização Científica

A produção científica do Estado de São Paulo é caracterizada por fenômeno de concentração em determinadas regiões. Este fato justifica-se pela concentração nessas áreas dos principais institutos de pesquisa e instituições de ensino, não somente do Estado, como do País. 
No Brasil, aproximadamente $80 \%$ dos resultados decorrentes da produção científica concentram-se nas microrregiões de São Paulo (49\%), Campinas (18\%), São Carlos (9\%) e Ribeirão Preto (6\%). Os campos de Ciências Biológicas e Agrárias são os mais concentrados, seguidos em ordem decrescente de número de microrregiões, Exatas, Saúde, Engenharias e Humanas.

A microrregião de Sorocaba apresenta uma forte concentração nas áreas de humanas, coerente com a sua base atual de Ciência e tecnologia (Figura 4-14).

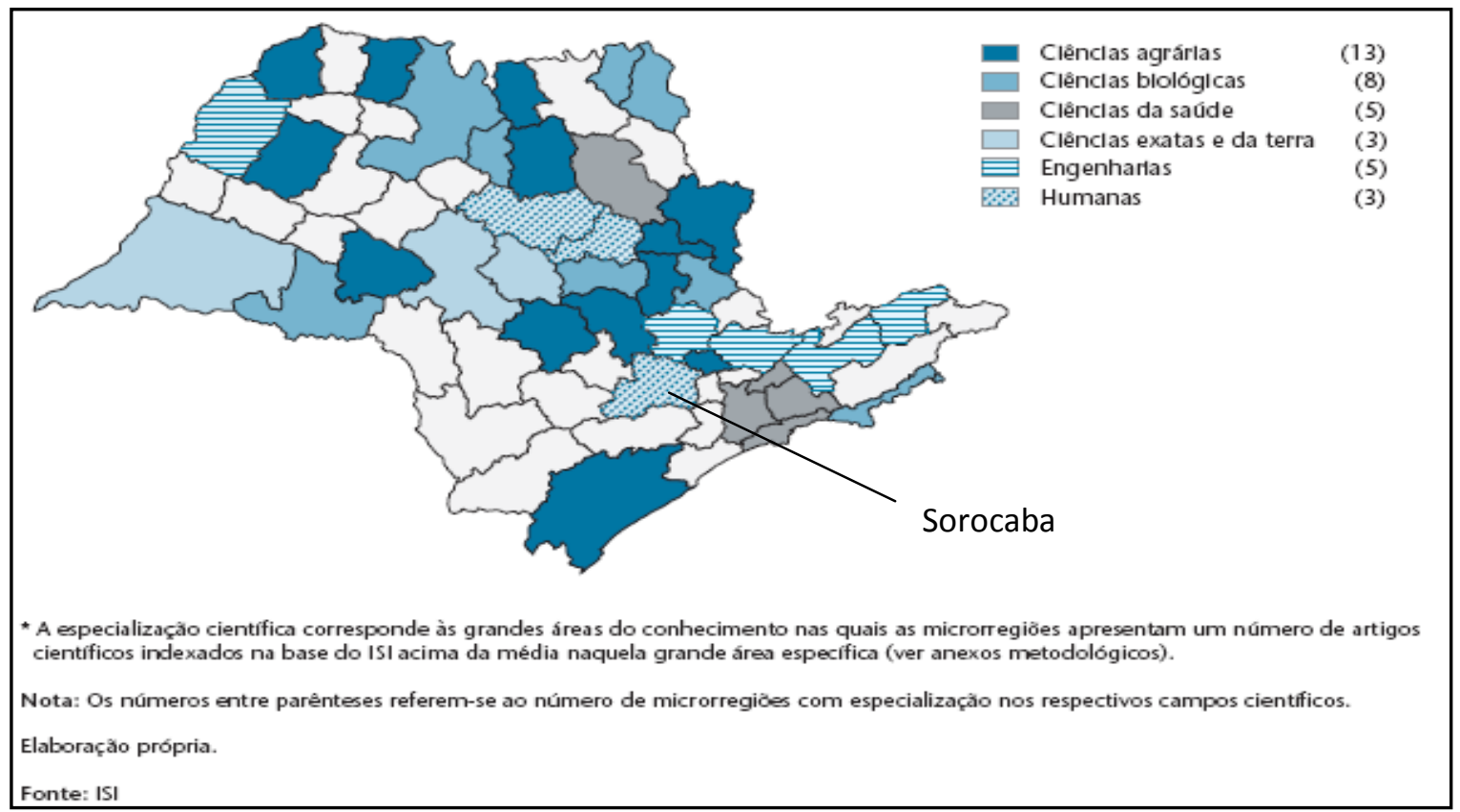

Figura 4-14: Especialização científica* - Microrregiões do Estado de São Paulo, 1999.

Fonte: FAPESP - Indicadores de ciência, tecnologia e inovação em São Paulo, 2004 - a partir do ISI Institute for Scientific Information.

- Universidades

A oferta em relação ao ensino superior tem aumentado nos últimos anos em Sorocaba. Existem hoje na cidade de Sorocaba mais de 50 cursos superiores, oferecidos por diversas IES (Entidades de Ensino Superior), destacando-se cinco grandes universidades: Universidade de Sorocaba (UNISO), Universidade Estadual Paulista (UNESP), Universidade Federal de São Carlos (UFSCar), Pontifícia Universidade Católica (PUC), Universidade Paulista (UNIP) e também por outras 
Instituições de Ensino Superior como: Faculdades Anhanguera, SENAC, FATEC dentre outras.

$\mathrm{Na}$ Tabela 4.14 é apresentada a densidade de Faculdades por regiões no Estado de São Paulo, apontando que Sorocaba assemelha-se a outros municípios como Santos, Bauru, Piracicaba, São José do Rio Preto e Ribeirão Preto, sendo que os três últimos estão presentes no Sistema Paulista de Parques Tecnológicos ${ }^{9}$. Englobando as áreas de Exatas, Humanas e Saúde, os cursos incluem: medicina, tecnologia, engenharia ambiental, engenharia de controle e automação, comércio exterior, ciências da computação, direito, turismo, análise de sistemas, processamento de dados e técnicos em saúde.

Tabela 4.14 - Número de instituições de ensino superior por microrregião.

\begin{tabular}{l|c}
\hline \multicolumn{1}{c|}{ Região } & Número de estabelecimentos (faixa) \\
\hline São Paulo & 23 a 250 \\
\hline Campinas & 23 a 250 \\
\hline Santos & 13 a 23 \\
\hline Ribeirão Preto & 13 a 23 \\
\hline Piracicaba & 13 a 23 \\
\hline São José do Rio Preto & 13 a 23 \\
\hline Bauru & 13 a 23 \\
\hline Sorocaba & 7 a 13 \\
\hline
\end{tabular}

Fonte: Adaptado de FAPESP - Indicadores de ciência, tecnologia e inovação em São Paulo, 2004.

A seguir, uma breve apresentação das principais instituições de ensino superior localizadas em Sorocaba:

FACENS - A Associação Cultural de Renovação Tecnológica Sorocabana - ACRTS, no início de 1976, solicitou ao Ministério da Educação e Cultura (MEC) um pedido para instalação da Faculdade de Engenharia de Sorocaba - FACENS, na cidade de Sorocaba. Em outubro de 1976, foi publicada a autorização para a implantação de seus primeiros cursos. A FACENS organizou seu primeiro vestibular em janeiro de 1977 para os cursos de Engenharia Civil e Engenharia Elétrica.

9 O Sistema Paulista de Parques Tecnológicos foi instituído por meio do Decreto do Governo do Estado de São Paulo n. 50.504 de 6 de fevereiro de 2006, com a finalidade de ser um instrumento articulador de Parques Tecnológicos no Estado de São Paulo, tendo por objetivo fomentar, impulsionar e apoiar as iniciativas de criação e implantação dos parques. 
Em 1978, foi iniciada a construção do campus universitário da Faculdade criada para suprir uma lacuna no Ensino Superior de Sorocaba. Em 03 de junho de 1980, a FACENS foi reconhecida pelo MEC. A construção do campus foi concluída em 1984 com a implantação dos prédios de Engenharia Civil e Elétrica, laboratórios para esses cursos e o ginásio de esportes.

Em anos mais recentes, a FACENS recebeu autorização para ministrar os cursos de Engenharia da Computação (1998) e de Engenharia Mecânica (2001), atendendo assim, à crescente demanda por tais profissionais na Região. Por este mesmo motivo passou a oferecer, no final da década de 90, cursos de Especialização e Pós-Graduação lato sensu.

A FACENS está localizada na Rodovia Senador José Ermírio de Moraes, 1425 (Castelinho quilômetro 1,5) e é mantida pela ACRTS (Associação Cultural de Renovação Tecnológica Sorocabana), uma entidade de Utilidade Pública Federal sem fins lucrativos e certificada como filantrópica pelo Conselho Nacional de Assistência Social, e concede inúmeras bolsas de estudos aos seus alunos que apresentam carência sócio-econômica comprovada e investe todo o seu resultado em prol da Faculdade.

FATEC - SOROCABA - A Faculdade de Tecnologia de Sorocaba foi criada em maio de 1970, pelo então Governador do Estado de São Paulo, Dr. Roberto Costa de Abreu Sodré. A partir do Decreto de 22/9/1971, a FATEC-SO, ficou subordinada ao Centro Estadual de Educação Tecnológica de São Paulo, atualmente Centro Estadual de Educação Tecnológica "Paula Souza".

Com o crescimento do Parque Industrial de Sorocaba, o mercado de trabalho necessitava de novos profissionais qualificados, quando a FATEC-SO criou os cursos superiores de Tecnologia de Projetos, Processos de Produção, Processamento de Dados e Manutenção e Operação de Aparelhos MédicoHospitalares.

Entre os anos de 2005 e 2007, a FATEC-SO formou cerca de 800 estudantes divididos entre as áreas de processos de produção, projetos, processamento de dados e saúde. No corpo docente da Fatec Sorocaba existem atualmente 17 doutores e 40 mestres, perfazendo aproximadamente $70 \%$ do quadro. 
Universidade Federal de São Carlos - A UFSCar apresenta grande produção científica e consolida-se como uma das maiores instituições do país na área de engenharia. Fundada em 1968, a Universidade Federal de São Carlos (UFSCar) foi por muito tempo, a única instituição federal de ensino superior localizada no interior do Estado de São Paulo.

A Universidade possui três campi: São Carlos/SP, Araras/SP e Sorocaba/SP. O campus da UFSCar em Sorocaba localiza-se na Rodovia João Leme dos Santos (SP-264) KM 110 e conta com cerca de 700 mil metros quadrados. O campus de Sorocaba oferece: 10 salas de aula; 12 salas de aula provisórias; 3 laboratórios de informática; 1 suporte de informática; 49 salas de professores; e 16 laboratórios; 1 laboratório de pesquisa para os alunos; Restaurante Universitário e Biblioteca.

Além desses espaços o campus de Sorocaba da UFSCar conta com laboratórios de pesquisa oriundos de projetos aprovados junto a Financiadora de Estudos e Projetos (FINEP).

A unidade de Sorocaba está em desenvolvimento, com a previsão de incorporação de cursos identificados com a dinâmica econômica local, tais como, cursos de Ciências Econômicas e Ciências da Computação. Assim, a UFSCar terá sete cursos na cidade de Sorocaba, oferecendo mais de 700 vagas. Atualmente, o campus de Sorocaba da UFSCar possui corpo docente composto por 100 professores doutores (74\%) e 35 professores mestres (26\%).

Universidade de Sorocaba - A UNISO é uma Universidade comunitária, regional, cuja primeira semente foi a Faculdade de Filosofia Ciências e Letras de Sorocaba, criada em 1951 e que começou a funcionar efetivamente em 1954. Com dois cursos, Pedagogia e Letras Neolatinas e apenas 27 alunos.

Atualmente, a UNISO conta com três campi: a Cidade Universitária, inaugurada em 1999 e localizada na Rodovia Raposo Tavares km 92,5; o Trujillo, onde foi implantada a Faculdade de Filosofia, Ciências e Letras, em 1954; e o Seminário, desde 1994; além de uma unidade avançada localizada em Tietê/SP, implantada em 2003. 
Possui 34 cursos de graduação, além de cursos de extensão e pósgraduação lato sensu e stricto sensu. Conta com cerca de dez mil alunos provenientes de 70 cidades, localizadas num raio de 100 quilômetros ao redor de Sorocaba.

Universidade Estadual Paulista - UNESP - O Campus de Sorocaba, inicialmente criado como "Unidade Diferenciada de Sorocaba/lperó", foi instituído em reunião do Conselho Universitário da UNESP no dia 29 de agosto de 2002, como parte do plano de expansão de vagas proposta pelo Prof. Dr. José Carlos Souza Trindade, Reitor da UNESP na época.

O seu modelo, diferentemente das outras Unidades da UNESP, nasceu de uma parceria entre a Prefeitura Municipal de Sorocaba, o Governo do Estado de São Paulo e a UNESP. Neste modelo, a Prefeitura de Sorocaba é a responsável por toda a infra-estrutura necessária para o Campus, desde o terreno onde está localizada a Unidade, até a construção das salas de aula, salas da administração e biblioteca, dos laboratórios dos Cursos aqui implantados, além dos encargos relativos.

A Unidade de Sorocaba/Iperó conta hoje com dois Cursos de Graduação: Engenharia de Controle e Automação e Engenharia Ambiental, com cerca de 500 alunos nas duas turmas semestrais de cada curso. Oferece, ainda, o programa de Pós-Graduação com cursos de mestrado e doutorado. Isto somente foi possível graças à integração do Campus ao Programa Institucional da UNESP, conhecido como POSMAT, que já contava com os Campi de Bauru, Presidente Prudente, Araraquara, Botucatu e Ilha Solteira. As Linhas de Pesquisas Existentes são:

- GASI - Grupo de Automação e Sistemas Integráveis

- GPM - Grupo de Plasmas e Materiais

- GEA - Grupo de Estudos Ambientais

O corpo docente possui 27 doutores e 23 outros profissionais divididos entre Mestre, Especialistas e Graduados.

Pontifícia Universidade Católica - PUC - A Pontifícia Universidade Católica de São Paulo é uma instituição sexagenária. Nesse período, firmou-se como fonte inovadora de políticas pedagógicas e de reflexões teóricas atreladas à pesquisa. 
Advoga o pioneirismo, em termos nacionais, na adoção de práticas democráticas de gestão e deliberação, com práticas modernas como em 1980, quando se tornou a primeira universidade a eleger seu Reitor pelo voto direto de professores, alunos e funcionários, iniciativa que se tornou referência para as instituições de ensino superior do País.

O campus da Pontifícia Universidade Católica de Sorocaba conta hoje com três cursos de graduação: Biologia, Enfermagem e Medicina. Oferece, ainda, o programa de Pós-Graduação stricto sensu e lato sensu, além da residência médica que constitui uma modalidade de ensino de pós-graduação, destinada a médicos, sob a forma de cursos de especialização.

- Projetos apoiados por agências de fomento

Foi efetuado um levantamento interno de dados em 2008 pela Secretaria de Desenvolvimento Econômico de Sorocaba, junto às Instituições de Ensino Superior locais com a participação do autor, pertinente aos principais projetos desenvolvidos e também ao órgão financiador do projeto. A UNISO atualmente é a instituição com mais projetos no município de Sorocaba, contando com projetos financiados por agências de fomento à pesquisa como a FAPESP - Fundação de Amparo à Pesquisa do Estado de São Paulo e o CNPq - Conselho Nacional de Desenvolvimento Científico e Tecnológico.

A UNESP-Sorocaba também apresenta uma dedicação à pesquisa, contando inclusive com a participação de um fundo da própria universidade.

Na Tabela 4.15 são apresentados os principais projetos. 
Tabela 4.15 - Principais projetos desenvolvidos em instituições de C\&T em Sorocaba.

\begin{tabular}{|c|c|c|c|c|}
\hline Instituição & Projeto & Linhas de Pesquisa & $\begin{array}{c}\text { Agência } \\
\text { Financiadora }\end{array}$ & Informações \\
\hline \multirow[t]{2}{*}{$\begin{array}{l}\text { Universidade } \\
\text { Estadual } \\
\text { Paulista Júlio } \\
\text { de Mesquita } \\
\text { Filho - UNESP } \\
\text { Unidade: } \\
\text { Unidade } \\
\text { Diferenciada de } \\
\text { Sorocaba/lperó }\end{array}$} & $\begin{array}{l}\text { Grupo de Estudos } \\
\text { Ambientais }\end{array}$ & $\begin{array}{l}\text { Análise de traços e } \\
\text { química ambiental; } \\
\text { Física ambiental e } \\
\text { poluição do ar; } \\
\text { Geoprocessamento } \\
\text { aplicado à análise } \\
\text { ambiental; Geoquímica } \\
\text { de Superfície, Ambiental } \\
\text { e Isotópica; Hidrologia, } \\
\text { Recursos Hídricos e } \\
\text { Gestão Ambiental; } \\
\text { Manejo e conservação } \\
\text { do solo e da água; } \\
\text { Resíduos sólidos } \\
\text { urbanos com ênfase em } \\
\text { plásticos e matéria } \\
\text { orgânica; Tratamento } \\
\text { matemático para } \\
\text { problemas ambientais. }\end{array}$ & $\begin{array}{l}\text { FAPESP, } \\
\text { FUNDUNESP, } \\
\text { CAPES e CNPq }\end{array}$ & $\begin{array}{l}\text { Prof. Dr. } \\
\text { André } \\
\text { Henrique } \\
\text { Rosa }\end{array}$ \\
\hline & $\begin{array}{l}\text { Grupo de Plasmas } \\
\text { e Materiais }\end{array}$ & $\begin{array}{l}\text { Modificação de } \\
\text { Superfícies; } \\
\text { Caracterização de } \\
\text { Materiais; } \\
\text { Caracterização dos } \\
\text { Plasmas } \\
\end{array}$ & FAPESP & $\begin{array}{l}\text { Prof. Dr. } \\
\text { José Roberto } \\
\text { Bortoleto }\end{array}$ \\
\hline \multirow[t]{3}{*}{$\begin{array}{l}\text { UNISO - } \\
\text { Universidade de } \\
\text { Sorocaba }\end{array}$} & $\begin{array}{l}\text { Competências e } \\
\text { Práticas Sociais }\end{array}$ & $\begin{array}{l}\text { O Trabalho Como } \\
\text { Organizador e } \\
\text { Estruturador das } \\
\text { Reformas Educacionais } \\
\text { Brasileiras no Ensino } \\
\text { Médio e na Educação } \\
\text { Profissional de Nível } \\
\text { Técnico e sua } \\
\text { Concretização nas } \\
\text { Instituições Escolares } \\
\text { nos primeiros Anos do } \\
\text { Século XXI } \\
\end{array}$ & $\begin{array}{l}\text { Fundação de } \\
\text { Amparo à } \\
\text { Pesquisa do } \\
\text { Estado de São } \\
\text { Paulo - FAPESP }\end{array}$ & $\begin{array}{l}\text { Prof. Dr. } \\
\text { Celso João } \\
\text { Ferretti e } \\
\text { Prof. Dr. } \\
\text { João dos } \\
\text { Reis }\end{array}$ \\
\hline & $\begin{array}{l}\text { Formação da } \\
\text { Educação Escolar } \\
\text { em Sorocaba }\end{array}$ & $\begin{array}{l}\text { A formação do processo } \\
\text { da educação escolar em } \\
\text { Sorocaba }\end{array}$ & $\begin{array}{l}\text { Universidade de } \\
\text { Sorocaba }\end{array}$ & $\begin{array}{l}\text { Prof. Dr. } \\
\text { Jorge Luis } \\
\text { Cammarano } \\
\text { González }\end{array}$ \\
\hline & $\begin{array}{l}\text { A Performance } \\
\text { Econômica das } \\
\text { Regiões: Estudo } \\
\text { Comparado da } \\
\text { Competitividade } \\
\text { Regional Brasileira }\end{array}$ & $\begin{array}{l}\text { Emprego e Mercado de } \\
\text { Trabalho na Região de } \\
\text { Sorocaba; Inovações e } \\
\text { Desenvolvimento } \\
\text { Regional }\end{array}$ & $\begin{array}{l}\text { CNPq Conselho } \\
\text { Nacional de } \\
\text { Desenvolvimento } \\
\text { Científico e } \\
\text { Tecnológico }\end{array}$ & $\begin{array}{l}\text { Prof. Dr. } \\
\text { Aurílio Sérgio } \\
\text { da Costa } \\
\text { Caiado }\end{array}$ \\
\hline
\end{tabular}




\begin{tabular}{|c|c|c|c|c|}
\hline Instituição & Projeto & Linhas de Pesquisa & $\begin{array}{c}\text { Agência } \\
\text { Financiadora }\end{array}$ & Informações \\
\hline & $\begin{array}{l}\text { Acordos de } \\
\text { Cooperação } \\
\text { Verticais, } \\
\text { Respostas } \\
\text { Ambientais e } \\
\text { Logística das } \\
\text { Empresas } \\
\text { Industriais em } \\
\text { Sorocaba-SP }\end{array}$ & $\begin{array}{l}\text { A Rotatividade dos } \\
\text { Trabalhadores nas } \\
\text { Empresas Metalúrgicas } \\
\text { de Sorocaba entre } 1999 \\
\text { e } 2003\end{array}$ & $\begin{array}{l}\text { Fundação de } \\
\text { Amparo à } \\
\text { Pesquisa do } \\
\text { Estado de São } \\
\text { Paulo - FAPESP }\end{array}$ & $\begin{array}{l}\text { Prof. Dr. } \\
\text { Manuel } \\
\text { Antonio } \\
\text { Munguia } \\
\text { Payès }\end{array}$ \\
\hline & $\begin{array}{l}\text { Desenvolvimento } \\
\text { Regional }\end{array}$ & $\begin{array}{l}\text { Competitividade } \\
\text { Regional e das } \\
\text { Organizações }\end{array}$ & $\begin{array}{l}\text { Universidade de } \\
\text { Sorocaba }\end{array}$ & $\begin{array}{l}\text { Prof. Dr. } \\
\text { Manuel } \\
\text { Antonio } \\
\text { Munguía } \\
\text { Payés }\end{array}$ \\
\hline & $\begin{array}{l}\text { Grupo de Estudos } \\
\text { e Pesquisas em } \\
\text { Ética e Direitos } \\
\text { Humanos da } \\
\text { Universidade de } \\
\text { Sorocaba }\end{array}$ & $\begin{array}{l}\text { Direitos Humanos: } \\
\text { Proteção e Efetivação; } \\
\text { Ética e Direitos } \\
\text { Humanos na } \\
\text { Administração Pública }\end{array}$ & $\begin{array}{l}\text { Universidade de } \\
\text { Sorocaba }\end{array}$ & $\begin{array}{l}\text { Prof. Dr. } \\
\text { Domenico } \\
\text { Antonio } \\
\text { Landulfo }\end{array}$ \\
\hline
\end{tabular}

Fonte: Zouain, Damião, (2008) - Termo de Referência do Município de Sorocaba.

- Institutos de Pesquisa

No Estado de São Paulo existem 67 instituições de Pesquisa e Desenvolvimento das Ciências Físicas e Naturais, empregando cerca de 4.300 pessoas (Tabela 4.16).

A distribuição regional desses estabelecimentos mostra forte concentração nos municípios de: São Paulo, onde estão sediadas 20 instituições que empregam 1.747 pessoas; Campinas, com 11 instituições e 1.347 pessoas empregadas.

Nota-se também o elevado tamanho médio das instituições de pesquisa da região de Campinas, explicado pela presença, na região, de importantes centros de pesquisa de âmbito nacional, como o CPqD, o Centro de Pesquisas Renato Archer (CENPRA) e a Associação Brasileira de Tecnologia de Luz Síncrotron (ABTLUS). Além de São Paulo e Campinas, destacam-se também os municípios de Piracicaba, que possui seis estabelecimentos de pesquisa com 142 empregados, e São Carlos, com cinco estabelecimentos e 305 profissionais. A cidade de Sorocaba conta atualmente com um Instituto de Pesquisa, o FIT (Flextronics Instituto de 
Tecnologia) ${ }^{10}$ e com uma unidade do IBAMA (Instituto Brasileiro do Meio Ambiente e dos Recursos Naturais Renováveis) ${ }^{11}$. No entanto, devido a sua posição proximidade com São Paulo e Campinas, pode utilizar os locais onde estão presentes mais de $70 \%$ dos institutos do Estado.

Tabela 4.16 - Instituições de P\&D das Ciências Físicas e Naturais, por município - Estado de São Paulo, 2002.

\begin{tabular}{|c|c|c|c|}
\hline Município & $\begin{array}{c}\mathbf{N}^{\circ} \text { de } \\
\text { estabelecimentos }\end{array}$ & $\begin{array}{c}\mathrm{N}^{\circ} \mathrm{de} \\
\text { empregados }\end{array}$ & $\begin{array}{l}\text { Tamanho médio } \\
\text { dos estabelecimentos } \\
\text { (em } \mathrm{n}^{\circ} \text { de empregados) }\end{array}$ \\
\hline São Paulo & 20 & 1747 & 87 \\
\hline Campinas & 11 & 1347 & 122 \\
\hline Piracicaba & 6 & 142 & 26 \\
\hline São Carlos & 5 & 305 & 61 \\
\hline Barueri & 2 & 331 & 166 \\
\hline Jaguariúna & 1 & 159 & 159 \\
\hline São Bernardo co Campo & 1 & 79 & 79 \\
\hline Jaboticabal & 1 & 38 & 38 \\
\hline Araçoiaba da Serra & 1 & 25 & 25 \\
\hline Bebedouro & 1 & 24 & 24 \\
\hline Americana & 1 & 13 & 13 \\
\hline Hortolândia & 1 & 12 & 12 \\
\hline São José dos Campos & 1 & 11 & 11 \\
\hline Nazaré Paulista & 1 & 11 & 11 \\
\hline Suzano & 1 & 8 & 8 \\
\hline Paulínia & 1 & 6 & 6 \\
\hline
\end{tabular}

${ }^{10}$ FIT (Flextronics Instituto de Tecnologia) é um Instituto de Pesquisa e Desenvolvimento constituído como uma organização da sociedade civil de direito privado sem fins lucrativos. Localizado na cidade de Sorocaba, Estado de São Paulo, possui em suas instalações laboratórios e infra-estrutura para atuar em pesquisa e desenvolvimento, se dedicando a gerar conhecimento e soluções que atendam à realidade de negócio de seus clientes, bem como à capacitação profissional de seus colaboradores, contribuindo assim para o aumento da competitividade tecnológica do país. O FIT é credenciado pelo CATI (Comitê da Área de Tecnologia da Informação e Comunicação) do Ministério da Ciência e Tecnologia através da portaria 022/4, sendo por isso também habilitado a desenvolver projetos no âmbito da legislação de informática. Disponível em: http://www.fittecnologia.org.br/Pages/GetToKnow.aspx. Acesso em 10/04/2008.

${ }^{11}$ Fonte: IBCT. Disponível em: http://prossigas.ibict.br/servlet/sigp1. Acesso em 10/05/2009. 


\begin{tabular}{|c|c|c|c|}
\hline Município & $\begin{array}{c}\mathbf{N}^{\circ} \mathrm{de} \\
\text { estabelecimentos }\end{array}$ & $\begin{array}{c}\mathrm{N}^{\circ} \mathrm{de} \\
\text { empregados }\end{array}$ & $\begin{array}{c}\text { Tamanho médio } \\
\text { dos estabelecimentos } \\
\text { (em } \mathrm{n}^{\circ} \text { de empregados) }\end{array}$ \\
\hline Holambra & 1 & 5 & 5 \\
\hline Ilha Solteira & 1 & 4 & 4 \\
\hline Mogi das Cruzes & 1 & 4 & 4 \\
\hline Brotas & 1 & 3 & 3 \\
\hline Iperó & 1 & 3 & 3 \\
\hline Ibiúna & 1 & 2 & 2 \\
\hline Araras & 1 & 1 & 1 \\
\hline Catanduva & 1 & 1 & 1 \\
\hline Jundiaí & 1 & 1 & 1 \\
\hline Mairiporã & 1 & 1 & 1 \\
\hline Sorocaba & 1 & 1 & 1 \\
\hline Araraquara & 1 & 0 & 0 \\
\hline Total & 67 & 4284 & 64 \\
\hline
\end{tabular}

Fonte: Bases Estatísticas RAIS/CAGED (2007). Disponível em

https://sgt.caged.gov.br. Acesso em 20/08/2008

- Formação Técnica

A microrregião de Sorocaba é privilegiada pela oferta de cursos de formação técnica. Dispõe de unidade da Faculdade de Tecnologia (FATEC); do SENAI (Serviço Nacional de Aprendizagem Industrial) com diversos cursos voltados para as aplicações industriais; e do SENAC (Serviço Nacional de Aprendizagem Comercial) com cursos direcionados ao comércio e prestação de serviços (Figura 4-15).

Além desses, são encontrados ainda dois colégios técnicos e três institutos de ensino superior, alguns públicos outros particulares, que oferecem cursos profissionalizantes que atendem às necessidades de geração de mão-de-obra qualificada e apta a oferecer trabalho em algumas áreas específicas. 


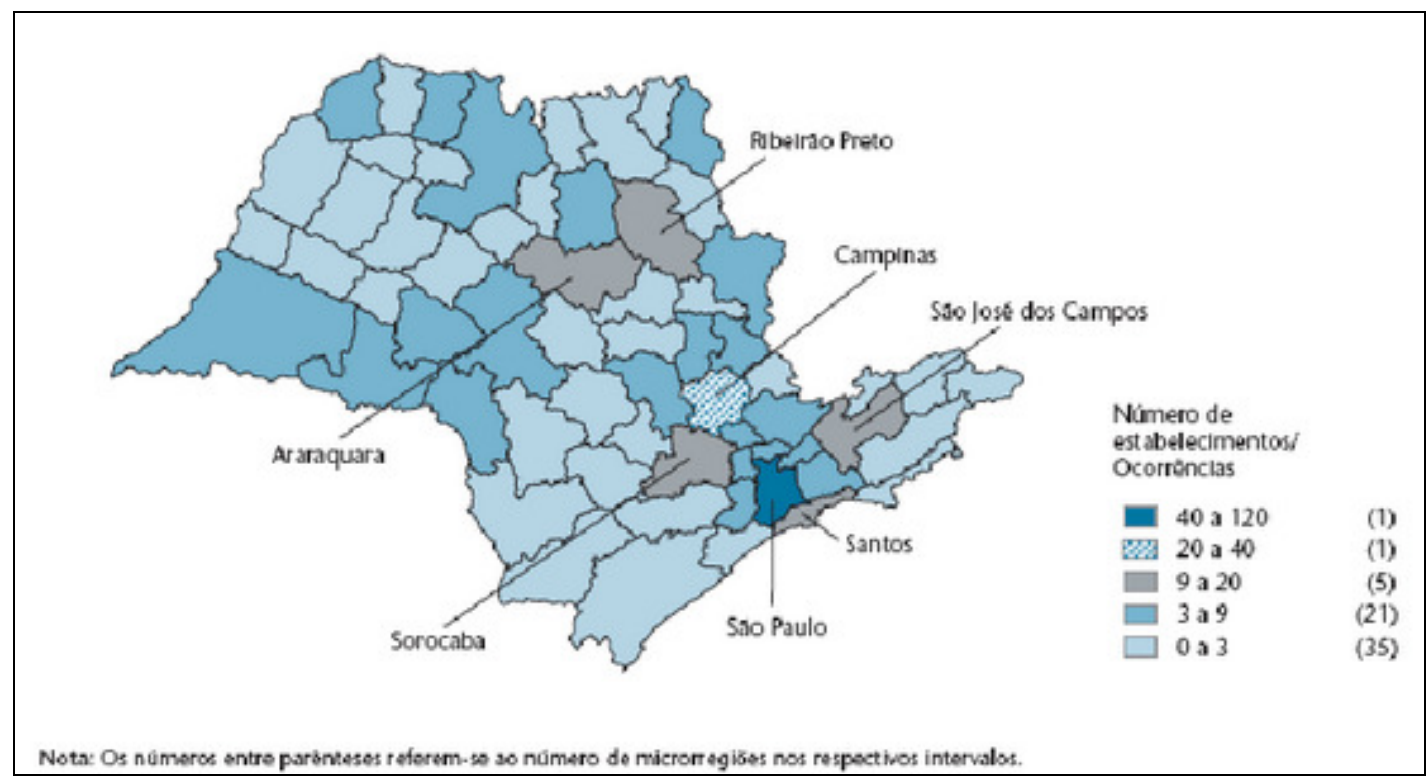

Figura 4-15: Número de estabelecimentos de ensino profissional (nível técnico e tecnológico) Microrregiões do Estado de São Paulo, 2002.

Fonte: FAPESP - Indicadores de ciência, tecnologia e inovação em São Paulo, 2004.

Como ressaltado anteriormente, Sorocaba apresenta uma boa oferta de formação técnica, com a relação de um curso por 72.000 habitantes; em relação a vagas tecnológicas a razão é 2.386 habitantes por vaga (Tabela 4.17).

Tabela 4.17 - Cursos de aprendizagem industrial, técnicos e tecnológicos - Microrregiões do Estado de São Paulo, 2003

\begin{tabular}{|c|c|c|c|c|}
\hline \multirow{2}{*}{ Microrregião } & \multirow{2}{*}{$\begin{array}{l}\text { No de cursos de } \\
\text { aprendizagem } \\
\text { industrial }\end{array}$} & \multirow{2}{*}{$\begin{array}{l}\text { No de } \\
\text { cursos } \\
\text { técnicos }\end{array}$} & \multicolumn{2}{|c|}{$\begin{array}{c}\text { Cursos } \\
\text { tecnológicos }\end{array}$} \\
\hline & & & $\begin{array}{l}\text { № de } \\
\text { cursos }\end{array}$ & Vagas \\
\hline São Paulo & 46 & 62 & 23 & 1400 \\
\hline Campinas & 17 & 20 & 3 & 160 \\
\hline São José dos Campos & 11 & 11 & 0 & 0 \\
\hline Sorocaba & 8 & 8 & 2 & 240 \\
\hline Limeira & 8 & 8 & 0 & 0 \\
\hline Santos & 7 & 8 & 4 & 280 \\
\hline Ribeirão Preto & 12 & 7 & 0 & 0 \\
\hline Marília & 3 & 5 & 0 & 0 \\
\hline Jundiaí & 6 & 4 & 1 & 80 \\
\hline São Carlos & 5 & 4 & 0 & 0 \\
\hline Jaú & 4 & 4 & 6 & 150 \\
\hline
\end{tabular}




\begin{tabular}{l|l|l|l|l}
\hline Microrregião & $\begin{array}{c}\text { No de cursos de } \\
\text { aprendizagem } \\
\text { industrial }\end{array}$ & $\begin{array}{c}\text { No de } \\
\text { cursos } \\
\text { técnicos }\end{array}$ & $\begin{array}{c}\text { Cursos } \\
\text { tecnológicos }\end{array}$ \\
\cline { 4 - 6 } & $\begin{array}{c}\text { No de } \\
\text { cursos }\end{array}$ & Vagas \\
\hline Franca & 3 & 4 & 0 & 0 \\
\hline Assis & 0 & 4 & 0 & 0 \\
\hline São João da Boa Vista & 0 & 4 & 0 & 0 \\
\hline Bauru & 8 & 3 & 0 & 0 \\
\hline Piracicaba & 8 & 3 & 0 & 0 \\
\hline Araraquara & 5 & 3 & 0 & 0 \\
\hline Outras & 43 & 56 & 7 & 360 \\
\hline Total & 194 & 218 & 46 & 2670 \\
\hline
\end{tabular}

Fonte: Dados institucionais dos sistemas Centro Estadual de Educação Tecnológica Paula Souza (CEETEPS), Centro Federal de Educação Tecnológica de São Paulo (CEFET) e Serviço Nacional de Aprendizagem Industrial (SENAI), 2003.

Outro suporte ao desenvolvimento industrial, comercial e agrícola do município é dado pelo Serviço de Apoio às Micro e Pequenas Empresas (SEBRAE), Serviço Nacional de Aprendizagem do Transporte (SEST-SENAT) e Serviço Nacional de Aprendizagem Rural (SENAR), que também oferecem cursos sobre esses temas.

- Outros agentes - SEBRAE-SP

O SEBRAE-SP é uma sociedade civil, sem fins lucrativos, que tem o objetivo de promover a competitividade e o desenvolvimento sustentável dos empreendimentos de micro e pequeno porte.

O SEBRAE-SP atua em Sorocaba por meio de um Escritório Regional (ER) é parceiro da Prefeitura de Sorocaba em diversas iniciativas. O ER Sorocaba atende 28 municípios e ajuda a promover a capacitação profissional do micro, pequeno e médio empresário (Figura 4-16).

De acordo com dados obtidos em entrevista (2008) com os gerentes Carlos Alberto Freitas e Eduardo B. Frud do ER (Escritório Regional) SEBRAE de Sorocaba, em 2007 foram efetuados 15.000 atendimentos, envolvendo atendimentos individuais, atendimentos coletivos, incubadora de empresas e iniciação empresarial.

O Sistema SEBRAE busca criar, por vários mecanismos (capacitação, mobilização, disseminação do empreendedorismo e do associativismo, entre outros) um ambiente favorável a sustentabilidade e crescimento dos pequenos negócios. 
Esse ambiente visa articular ações por menor carga tributária, menos burocracia, acesso ao crédito, à tecnologia e ao conhecimento.
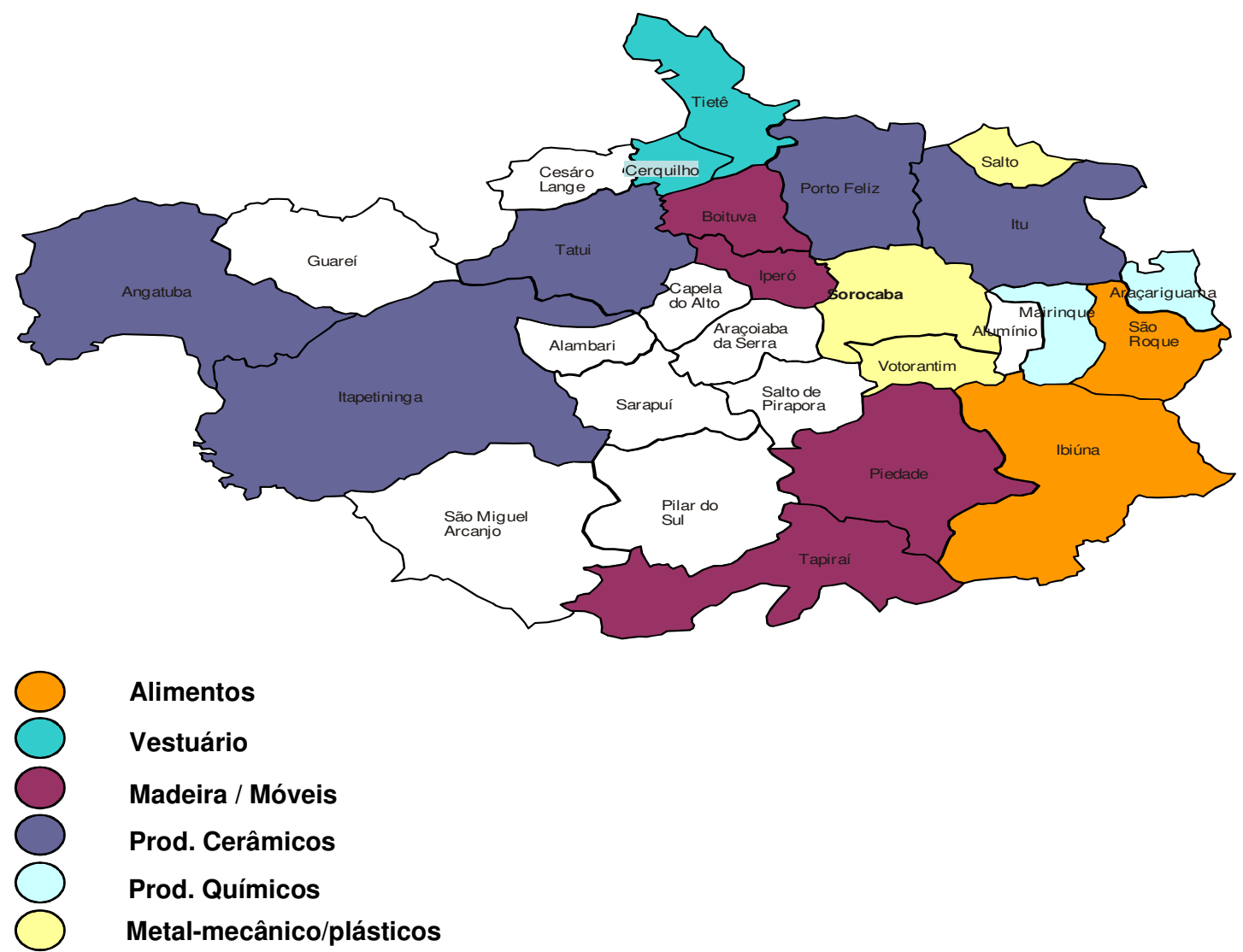

Figura 4-16: Atendimento do SEBRAE - ER Sorocaba e vocações dos municípios.

Fonte: Apresentação de Carlos Albeto Freitas - Gerente Regional do SEBRAE - ER Sorocaba, 2008.

A presença de um ER em Sorocaba permite uma maior aproximação com as demandas locais e sinergia com o empreendedor local. Existe a previsão da instalação de um posto avançado de atendimento do SEBRAE-SP nas instalações do PODI.

- Aglomerações setoriais em Sorocaba

Uma importante indústria no Município é a de componentes para produção de energia eólica, que se encontra concentrada em Sorocaba. É importante frisar que essa indústria é altamente sensível ao desenvolvimento tecnológico, sobretudo design e novos materiais. 
No contexto da análise das atividades econômicas desenvolvidas no município de Sorocaba, a identificação de aglomerações industriais é importante para direcionamento de atividades de planejamento. No aspecto prático existe uma percepção das principais aglomerações, que carece de dados mais conclusivos sob a extensão e importância das mesmas.

Nessa perspectiva, a utilização da metodologia do quociente locacional é indicada, sendo uma medida de especialização econômica que permite comparar a concentração de determinada base econômica num determinado espaço em relação a essa mesma atividade econômica num espaço maior de referência. Serve, por exemplo, para comparar a atividade econômica de um município em relação ao estado, ou do estado em relação ao país.

A variável base para o cálculo do coeficiente locacional pode ser a riqueza, o número de estabelecimentos ou o emprego. Para finalidade do presente trabalho, buscou-se utilizar a base empregos, visto a disponibilidade de dados por meio da Relação Anual de Informações Sociais (RAIS).

As variáveis base para o cálculo são de acordo com Haddad (1989):

$E_{i j} \quad=$ emprego/pib ..no setor $\mathrm{i}$ da região $\mathrm{j}$
$E_{\bullet j}=\sum_{i} E_{i j} \quad=$ emprego/pib ...em todas os setores da região $\mathrm{j}$
$E_{i \bullet}=\sum_{j} E_{i j} \quad=$ emprego/pib no setor $\mathrm{i}$ de todas as regiões.
$E_{\bullet \bullet}=\sum_{i} \sum_{j} E_{i j} \quad=$ Emprego/pib em todos os setores em todas as regiões.

Resultando na fórmula

$$
Q L_{i j}=\frac{E_{i j} / E_{\bullet j}}{E i_{\bullet} / E_{\bullet \bullet}} \frac{\geq}{<}
$$


Um QL > 1 significa que a participação relativa do setor $(x)$ no município de Sorocaba que está sendo analisado é mais elevada do que a participação relativa deste mesmo no setor na média do estado de São Paulo. Portanto, a região analisada apresenta um grau de especialização neste setor, em relação à média do estado. Quanto maior QL de determinado setor, maior será o grau de especialização da região analisada neste setor frente à base de referência utilizada.

A seguir na Tabela 4.18 e Figura 4-17 são apresentados os valores calculados para algumas atividades:

Tabela 4.18 - Cálculos de coeficiente locacional para atividades em Sorocaba.

\begin{tabular}{|c|c|c|}
\hline Atividades & CNAES & Coeficiente Locacional \\
\hline Plásticos e Borracha & 22 & 1,2725 \\
\hline Produtos Químicos & 20 & 0,5018 \\
\hline \multirow[t]{6}{*}{ Metal-Mecânico } & 24 & \multirow[t]{6}{*}{2,4267} \\
\hline & 25 & \\
\hline & 28 & \\
\hline & 29 & \\
\hline & 30 & \\
\hline & 33 & \\
\hline Têxtil & 13 & 1,3212 \\
\hline Alimentícios e Bebidas & $\begin{array}{l}10 \\
11\end{array}$ & 0,5211 \\
\hline
\end{tabular}

Fonte: Bases Estatísticas RAIS/CAGED (2007). Disponível em https://sgt.caged.gov.br. Acesso em 20/08/2008.

O complexo metal-mecânico responde por mais de $17 \%$ do total de empregos em Sorocaba (RAIS, 2007), enquanto que nesse segmento no estado de São Paulo apresenta pouco mais de 7\%. O coeficiente locacional de 2,4267 é significativo evidenciando a importância do segmento metal-mecânico para o Município. 


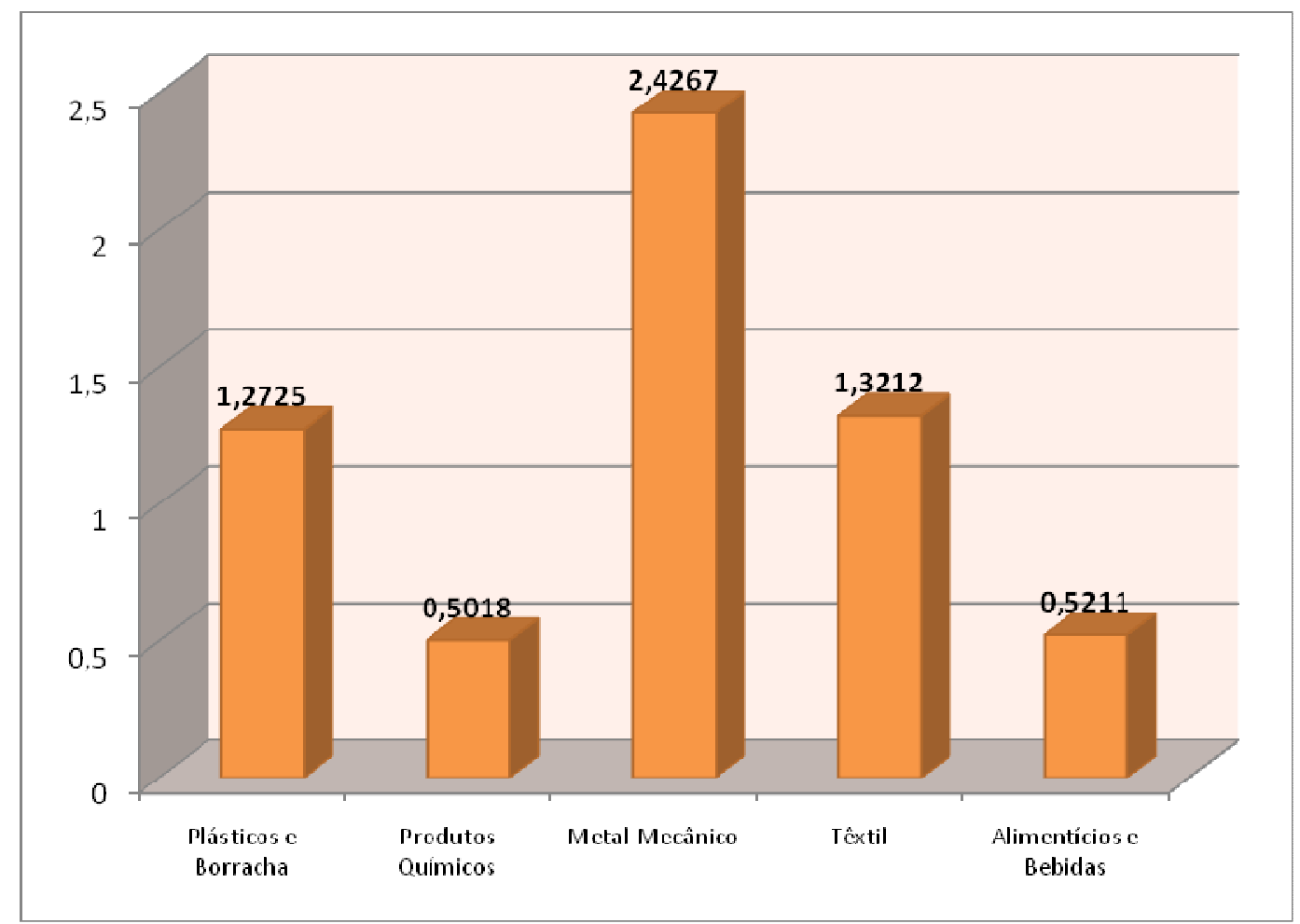

Figura 4-17: Coeficiente Locacional das atividades selecionadas de Sorocaba.

\subsection{Sistema de Inovação de Sorocaba}

Para o desenvolvimento do Perfil de Sorocaba, utilizou-se do referencial de estudos desenvolvidos e as analises do pesquisador nas suas visitas e interações na cidade. Como referencial analítico considerou-se as variáveis de análise comparativa de performance dos sistemas de inovação, sendo: instituições, organizações e interações (BORRÁs, 2004) (Figura 4-18).

Observou-se que as características são similares ao contexto do país. Constatou-se na perspectiva dos resultados, a baixa produção de inovações de base tecnológica, tomado como referência o número de patentes geradas no Município. 


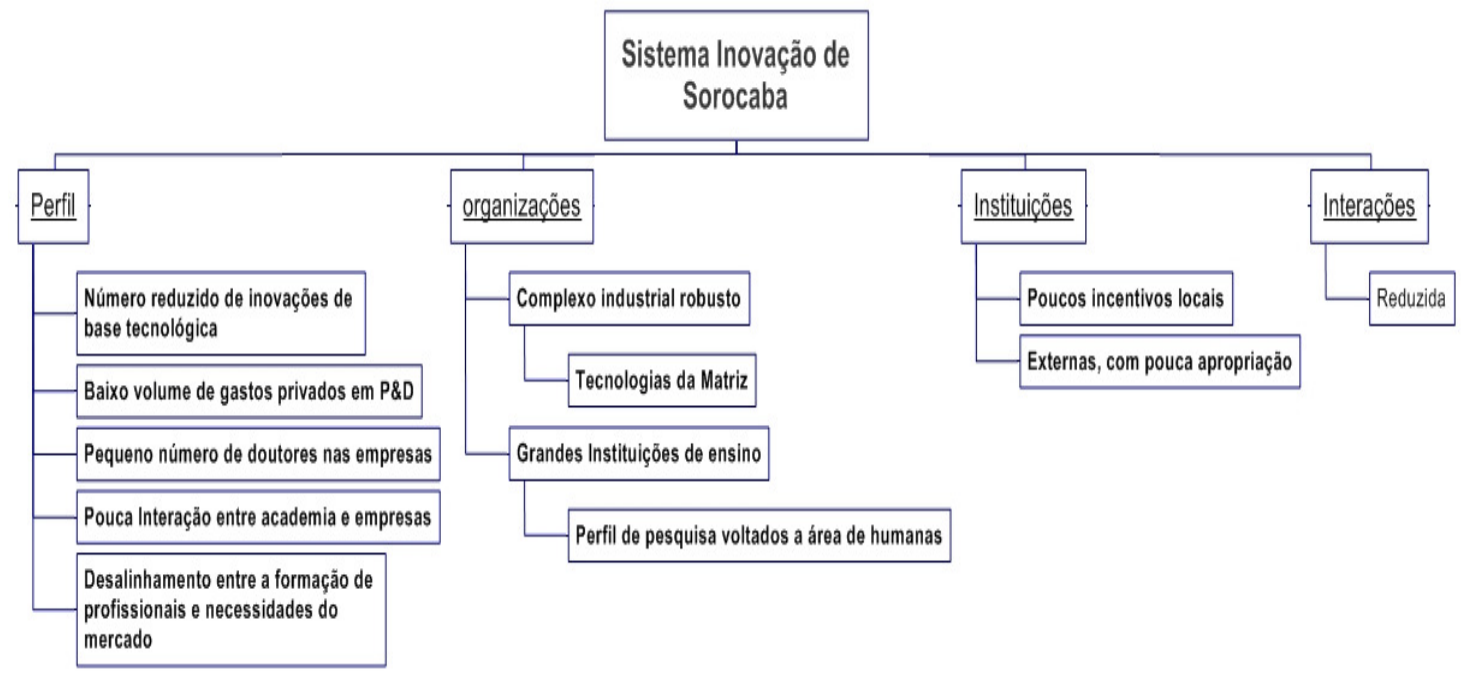

Figura 4-18:- Análise da situação de Sorocaba

A desarticulação entre ciência e tecnologia é observada no baixo número de publicações científicas e patentes internacionais, agravado pela pouca interação entre os cursos de formação superior e as principais atividades econômicas da cidade.

Relacionado aos gastos privados em P\&D, observam-se pouco investimentos desse tipo, sendo que na sua maioria, as empresas desconhecem os incentivos oferecidos pelos organismos de apoio públicos para investimentos. Outro aspecto importante está relacionado a concentração de empresas multi-nacionais que concentram as etapas de Pesquisa e Desenvolvimento nas suas matrizes.

Com relação aos profissionais qualificados (mestres e doutores) verificouse que a grande maioria encontra-se atuando na academia, principalmente nas Universidades. A falta de doutores nas empresas talvez seja um fator que tenha peso na realidade de pouca interação da academia com as empresas em Sorocaba.

Considerando a formação de profissionais e as necessidades do mercado, a realidade apontou para um desalinhamento, sendo que existe uma demanda por profissionais de engenharia no mercado, todavia, a principal vertente de formação local na da academia está na área de humanas.

Relacionado as organizações, pode-se observar a presença de grandes empresas no Município, sobretudo do segmento metal-mecânico. Essas empresas 
na sua maioria são multinacionais e aproveitam as boas condições locais de mão-deobra e logística. Todavia, a concentração de suas atividades de Pesquisa e Desenvolvimento estão concentradas nas suas matrizes.

No que tange as organizações de ensino, observa-se que existem grandes instituições como um Campus da Universidade Federal de São Carlos, a UNESP e outras instituições provadas como a FACENS e a UNISO. Também, é facilmente identificável que há uma carência de instituições de pesquisa na região.

Não é observada no Município uma atuação constante dos organismos de fomento, certificação, metrologia e de propriedade intelectual.

\subsection{Considerações preliminares}

Sorocaba é uma das principais cidades do estado de São Paulo com expressivos resultados econômicos, com um PIB superior a $R \$ 10$ bilhões, colocando-a entre as 32 maiores cidades do país em termos de riqueza.

A cidade é altamente relevante para o desenvolvimento dos municípios vizinhos influenciando nas dinâmicas locais.

Grande parte dessas riquezas deve-se à presença de grandes empresas no Município (nacionais e internacionais) que aproveitam das externalidades positivas da área, atuando principalmente em setores ligados à atividade metalmecânica, mais especificamente relacionado a auto-peças e máquinas pesadas. Nos últimos anos, empresas de segmentos de alta intensidade tecnológica como aeronáutica e energia consolidaram posições em Sorocaba.

Os fatores de atratividade envolvem a logística privilegiada, a mão-de-obra capacitada, (sobretudo técnica), a estruturação de uma dinâmica de serviços para os habitantes da região e a atuação do poder público local.

Nos últimos anos, dado o aumento de competição entre as empresas em nível global, tornou-se notória a necessidade de apropriação de conhecimentos para inovar, sobretudo em setores intensivos em tecnologia. Para tal, pressupõe-se uma intensa articulação com a base científica e tecnológica local.

Os resultados de ciência e tecnologia da cidade apresentam resultados modestos, visto que se observam poucas produções tecnológicas de patenteamento. 
No que tange à produção científica, os resultados não refletem a dinâmica do Estado de São Paulo que possui produção científica com patamares próximos a países considerados expoentes nesse aspecto. Uma possível explicação para esse fator consiste na falta de instituições âncoras com o adensamento necessário para promover o círculo virtuoso de pesquisa, ensino e extensão.

Outra característica refere-se ao perfil de formação nos diversos cursos oferecidos por instituições de ensino superior no município; existe uma predominância de cursos relacionados às áreas de humanas, com pouca formação de profissionais nas áreas de exatas que, normalmente, são demandados na maioria das empresas locais.

As observações in loco deste pesquisador permitiram evidenciar um cenário de pouca interação e articulação entre academia e empresas; a formação em nível superior é, de certo modo, descolada das necessidades das empresas.

Essa dinâmica observada evidenciou a necessidade de novas ações para manter e incrementar a competitividade da região, com o desenvolvimento de instrumentos adequados. 


\section{CAPÍTULO V - CONSIDERAÇÕES METODOLÓGICAS E O ESTUDO DE CASO}

\subsection{Considerações metodológicas}

O trabalho científico é caracterizado pela utilização de métodos e procedimentos adequados. Vários acadêmicos, dentre os quais Bêrni (2002), enfatizam que as ciências necessitam de métodos científicos e procedimentos adequados para obtenção, observação, tratamento de dados e análise de dados.

Esses métodos e procedimentos tornam-se requisitos para a validação do conhecimento gerado pela pesquisa, pois o pesquisador deve mostrar expertise sobre o tema abordado e também métodos para inserção do seu trabalho no processo de produção coletiva do conhecimento. Tal preocupação favorece o diálogo com aqueles que se interessam pela mesma temática, além de permitir a cumulatividade e aplicabilidade dos resultados. (ALVES-MAZZOTTI, 2006).

Especificamente, de acordo com as características do presente estudo, o método científico oferece dois tipos de abordagens principais: (i) o método racionalista, o qual tem como foco a abordagem quantitativa, com utilização de métodos variados, tais como: otimização, simulação, pesquisas (surveys) e experimentação, sendo validado por meio de procedimentos matemáticos (MEREDITH, 1998) e (ii) a abordagem interpretativa, com característica qualitativa, centrado na profundidade do fenômeno estudado, buscando explicações sobre as causas dos fenômenos e o seu desenvolvimento (HART, 1998)

Não são raros na literatura os registros de autores que advogam uma supremacia das metodologias racionalistas (quantitativas). Todavia uma análise mais detalhada evidenciará que eles servem aos objetivos de pesquisa e às características dos dados coletados. Portanto, não existe uma supremacia, pois estão sujeitos a um conjunto de vantagens e desvantagens em cada abordagem, as quais são apresentadas na Tabela 5.1. 
Tabela 5.1-Vantagens e desvantagens dos métodos racionalistas e de estudo de caso.

\begin{tabular}{l|l|l}
\hline \multicolumn{1}{c|}{ Vantagens } & \multicolumn{1}{c}{ Desvantagens } \\
\hline Racionalista & Precisão & Dificuldades amostra \\
\hline & Confiabilidade & Dados triviais \\
\hline & Procedimentos padronizados & Modelo limitado \\
\hline & Testabilidade & Pouca explicação variâncias \\
\hline Estudo de Caso & Relevância & Restrições variáveis \\
\hline & Entendimento & Resultado pobre \\
\hline & Profundidade Exploratória & Acesso e tempo \\
\hline & & Falta de controle \\
\hline & & $\begin{array}{l}\text { Não familiaridade com } \\
\text { procedimentos }\end{array}$ \\
\hline
\end{tabular}

Fonte: Adaptado de Meredith (1998)

Considerando essas características, entende-se que o ponto crucial para a definição do método são os objetivos de cada pesquisa. Para responder questões com alto nível de profundidade, nas quais fica evidente a relevância do objeto a ser estudado (organizações, instituições, eventos e outros) a literatura sugere que o estudo de caso é o mais adequado (YIN, 1994, VOSS, TSIKRIKTSIS, FROHLICH, 2002). Nesse método, o pesquisador observa diretamente e a partir daí, utiliza a sua lógica para dedução ou inferir relacionamentos. As questões são explanatórias do tipo "como" e "por que", sendo propícias para a geração e extensão de teorias (MEREDITH, 1998, VOSS, TSIKRIKTSIS, FROHLICH, 2002).

No campo das definições da metodologia de estudo de caso, convém citar Creswell (1994), que define como a exploração de um sistema que apresenta limites evidenciados nos tempo e na profundidade, tomando como base a obtenção de dados de fontes relacionadas ao contexto. Definição parecida a de outro pesquisador na área, Yin (1984), que define como uma pesquisa empírica que investiga um fenômeno contemporâneo em seu contexto natural, em situações em que as fronteiras entre o contexto e o fenômeno não são claramente evidentes, utilizando múltiplas fontes de evidência. Patton (1990) define o estudo de caso como uma abordagem qualitativa específica para coletar, organizar e analisar os dados com o 
propósito de prover a informação de características compreensivas, sistemáticas e profundas.

Portanto, são enfatizados os elementos de relevância, entendimento e profundidade. No contexto do presente trabalho, considerando que as vantagens do método, o método definido é o estudo de caso, considerando as características de relevância, entendimento do caso e profundidade exploratória (Tabela 5.2).

Tabela 5.2 - contextualização do trabalho com as características do método.

\begin{tabular}{l|l}
\hline Vantagens & Contexto do trabalho \\
\hline Relevância & $\begin{array}{l}\text { Estudo dos Pólos Franceses. Os casos podem ser } \\
\text { caracterizados como reveladores. }\end{array}$ \\
\hline Entendimento & $\begin{array}{l}\text { Entendimentos de como as variáveis definidas na pesquisa se } \\
\text { comportam. }\end{array}$ \\
\hline $\begin{array}{l}\text { Profundidade } \\
\text { Exploratória }\end{array}$ & $\begin{array}{l}\text { Diferentes métodos para coleta de dados e análise, permitindo a } \\
\text { adequação para o desenvolvimento de um modelo nacional }\end{array}$ \\
\hline
\end{tabular}

A Metodologia utilizada no trabalho está apresentada na Figura 5-1, a qual envolve o estudo de caso, a análise de bases secundárias para traçar um perfil do Município e a posterior estruturação de um sistema de inovação local. 
Tabela 5.3 - Estrutura Metodológica do Trabalho

\begin{tabular}{|c|c|c|c|c|c|c|c|}
\hline \multirow[b]{2}{*}{ 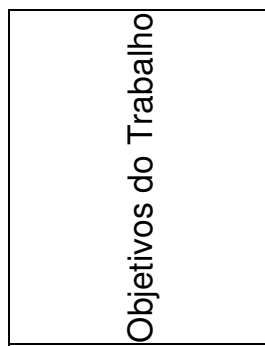 } & \multirow{2}{*}{ 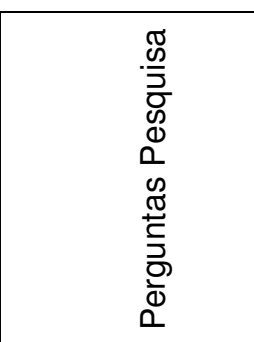 } & \multirow{2}{*}{$\begin{array}{l}\frac{\pi}{2} \\
\frac{0}{0} \\
\frac{0}{0} \\
\frac{0}{0} \\
\frac{0}{2}\end{array}$} & \multicolumn{3}{|c|}{$\begin{array}{l}\text { Método de Coleta de } \\
\text { Informações }\end{array}$} & \multicolumn{2}{|c|}{ Método de Análise } \\
\hline & & & 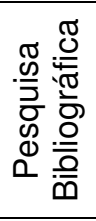 & 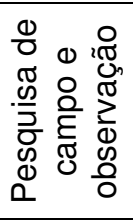 & 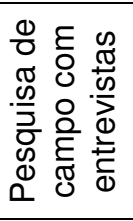 & 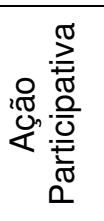 & 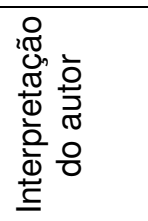 \\
\hline $\begin{array}{l}\text { 1. Revisão na } \\
\text { Literatura }\end{array}$ & $\begin{array}{l}1.1 \text { Como está } \\
\text { caracterizado o } \\
\text { sistema de } \\
\text { inovação no } \\
\text { Brasil? }\end{array}$ & 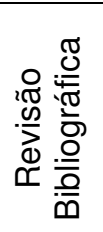 & & & & & \\
\hline \multirow[t]{2}{*}{$\begin{array}{l}\text { 2. Análise } \\
\text { Experiências } \\
\text { Nacionais. }\end{array}$} & $\begin{array}{l}\text { 2.1 Como estão } \\
\text { caracterizados } \\
\text { os ambientes } \\
\text { de inovação } \\
\text { presentes no } \\
\text { País. }\end{array}$ & 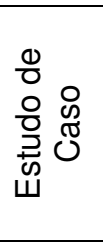 & & & & & \\
\hline & $\begin{array}{l}\text { 2.2 Como são } \\
\text { os aspectos de } \\
\text { governança, } \\
\text { estratégia, } \\
\text { infra-estrutura e } \\
\text { relação } \\
\text { universidade - } \\
\text { empresas? }\end{array}$ & 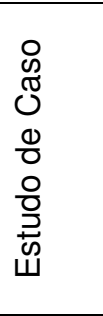 & & & & & \\
\hline $\begin{array}{l}\text { 3. Pólo de } \\
\text { competitividade } \\
\text { Francês. }\end{array}$ & $\begin{array}{l}.1 \text { Como são } \\
\text { os aspectos de } \\
\text { governança, } \\
\text { estratégia, } \\
\text { infra-estrutura e } \\
\text { relação } \\
\text { universidade- } \\
\text { empresas? }\end{array}$ & 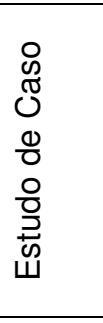 & & & & & \\
\hline $\begin{array}{l}\text { 4. Análise } \\
\text { vocação da } \\
\text { região? }\end{array}$ & $\begin{array}{l}4.1 \text { Quais os } \\
\text { elementos e } \\
\text { características } \\
\text { do perfil } \\
\text { científico } \\
\text { tecnológico e } \\
\text { econômico da } \\
\text { região? }\end{array}$ & 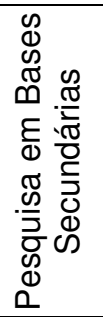 & & & & & \\
\hline $\begin{array}{l}\text { 5. Estrutura de } \\
\text { competitividade } \\
\text { para a região } \\
\text { de Sorocaba. }\end{array}$ & $\begin{array}{l}5.1 \text { Como deve } \\
\text { ser estruturado } \\
\text { o modelo para } \\
\text { desenvolver a } \\
\text { inovação e } \\
\text { competitividade } \\
\text { para a região? }\end{array}$ & 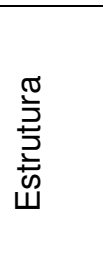 & & & & & \\
\hline
\end{tabular}




\subsection{Estudo de caso}

Observa-se que o estudo de caso apresenta complexidades para o seu desenvolvimento. Nessa perspectiva, pode-se citar o trabalho de Yin (1993) que visa sistematizar as etapas para o desenvolvimento do estudo de caso, a saber:

$1^{1}$ e etapa - Envolve:

i) escolha do referencial teórico sobre o qual se pretende trabalhar;

ii) a seleção dos casos $\mathrm{e}$;

iii) o desenvolvimento de protocolos para a coleta de dados.

$2^{\mathrm{a}}$ etapa - condução do estudo de caso, envolvendo:

i) coleta e análise de dados; e

ii) relatório do caso.

$3^{\underline{a}}$ etapa - análise dos dados obtidos à luz da teoria selecionada.

Outra referência é encontrada no trabalho de Eisenhardt (1989) com roteiro de procedimentos para a construção de teorias a partir do estudo de caso, esse roteiro envolve oito etapas, as quais são apresentadas a seguir:

1. Iniciar a pesquisa, definindo a questão de pesquisa e caso possível com o desenvolvimento de um construto preliminar.

2. Seleção de caso, selecionando amostragem com ênfase teórica, não quantitativa

3. Desenvolver protocolos e instrumentos, envolvendo diversos métodos de coleta de dados.

4. Entrar em campo, desenvolvendo os processos de coleta e análises simultaneamente.

5. Analisar dados, analisando-os dentro do contexto do caso.

6. Refinar as hipóteses, buscando evidências dos "por ques" e "comos".

7. Desdobrar literatura, resolvendo os conflitos com a literatura

8. Fechar a pesquisa, com a saturação e objetivos definidos.

Considerando esses fundamentos teóricos, apresenta-se, a seguir, a fundamentação da presente pesquisa (Tabela 5.2). 
Tabela 5.4 - Contextualização da pesquisa

\begin{tabular}{l|l}
\multicolumn{1}{c|}{ Sistematização de YIN } & \multicolumn{1}{c}{ Contextualização } \\
\hline $\begin{array}{l}\text { 1. Escolha do referencial teórico sobre o qual } \\
\text { pretende-se trabalhar }\end{array}$ & $\begin{array}{l}\text { Sistema de Inovação, ambientes de } \\
\text { Inovação. }\end{array}$ \\
\hline $\begin{array}{l}\text { 2. Seleção dos casos } \\
\begin{array}{l}\text { 3. Desenvolvimento do Protocolo para a } \\
\text { coleta de dados }\end{array}\end{array}$ & $\begin{array}{l}\text { Pólos franceses (05 Pólos) } \\
\text { estruturada. }\end{array}$ \\
\hline $\begin{array}{l}\text { 4. Coleta e análise de dados } \\
\text { 5. Análise dos dados sob a luz da teoria } \\
\text { selecionada }\end{array}$ & Paris 09/2008 \\
\hline
\end{tabular}

Fonte: YIN, R. K. Case Study Research, Beverly Hills :Sage publications, 1994

Para o desenvolvimento do presente estudo de caso, foram considerados os elementos destacados no trabalho de Yin (1994) e Eisenhardt (1989), os quais são apresentados e contextualizados para o presente trabalho.

\subsubsection{Iniciação de pesquisa}

O ponto de partida para o trabalho é a questão de pesquisa; no presente trabalho busca-se como desenvolver um instrumento de desenvolvimento econômico e social para a região de Sorocaba que possibilite a interação entre o setor público, privado e base de ciência e tecnologia?

Para o desenvolvimento da pesquisa, ela foi desdobrada em objetivos específicos, sendo que o objetivo descrito a seguir está diretamente relacionado com o estudo de caso: analisar o modelo conceitual do instrumento de desenvolvimento, identificando e caracterizando estruturas cuja temática de atuação envolva atividades próximas (similares) a atividades econômicas de Sorocaba.

Para tornar a análise objetiva, faz-se necessário, a partir da literatura, definir as principais dimensões a serem analisadas no estudo, ou seja, o construto de referência para o desenvolvimento do questionário da pesquisa. No levantamento bibliográfico realizado, não se obteve êxito na definição das dimensões a serem estudadas. 
Foi identificada a necessidade um trabalho de característica exploratória, para estruturar as dimensões a partir da análise da literatura nacional e internacional envolvendo ambientes de inovação, tais como, incubadoras, parques tecnológicos (científicos), pólos de inovação e clusters.

Assim, foi feito um levantamento dos temas apresentados na IASP (International Association of Science Parks) a partir do ano de 2004, conjuntamente com os temas estruturantes do Seminário da ANPROTEC (Associação Nacional de Entidades Promotoras de Empreendimentos Inovadores):

1. XXV IASP World Conference on Science \& Technology Parks 2008 (Johannesburg, Gauteng, South Africa

\section{Sessões Plenárias}

- Empreendedorismo como uma ferramenta-chave em economias do conhecimento - papel dos Parques Científicos e Tecnológicos.

- Desenvolvimento rápido das economias na economia global - parques científicos e tecnológicos como veículos.

- Inovação e cultura de negócios nos países m relação ao desenvolvimento e sucessos dos Parques Científicos e Tecnológicos.

- Cidades e seus parques científicos - crescimento economias locais.

- Medidas de impacto para Parques Científicos e Tecnológicos.

\section{Sessões Paralelas}

- Parcerias e colaboração para acelerar a integração na cadeia de valor.

- Políticas que dirigem a inovação.

- Explorando os novos horizontes Parques Científicos e Tecnológicos.

- Construindo capacidade local para desenvolver Parques Científicos e Tecnológicos.

- Staffing de Parques Científicos e Tecnológicos.

- Projetando Parques Científicos e Tecnológicos- fazendo as grandes escolhas.

2. XXIV IASP World Conference 2007 (Barcelona - Spain)

\section{Sessões Paralelas}

- Construindo para Inovação

- Desenvolvendo Ambientes criativos para o crescimento dos seus crescimentos.

- Empreendedorismo Global e Parques Científicos e Tecnológicos

- Promovendo as Companhias Globais.

\section{Sessões Plenárias}

- Entendimento, fortalecimento e gerenciando "criatividade".

- A geografia da criatividade. 
- Parques Científicos e Tecnológicos ajudando companhias a atrair e reter talentos globais.

- Profissionais criativos: perfil, necessidades e expectativas.

- Parques Científicos e Tecnológicos servindo companhias criativas e pessoas criativas.

\section{XXII IASP World Conference 2005 (Beijing - China)}

\section{Sessões Plenárias}

- Parques Científicos e recursos humanos: atraindo, treinando e retendo talentos.

- O ambiente humano para desenvolver tecnologia e estimular inovação

- Suportando pequenas e médias empresas companhias para competir na economia global

- O posicionamento dos Parques Científicos no networking de inovação.

\section{Sessões Paralelas}

- Incubação: Experiência chinesa e mundial.

- Emprendedorismo internacional.

- Parques Científicos na região da Ásia-Pacífico.

- Relacionamento entre Parques Científicos e universidades.

- Comercialização de tecnologia: do laboratório para o mercado.

- Financiamento de PMEs de alta tecnologia e start-ups.

- Tecnologia e conhecimento para melhorar serviços dos Parques Científicos.

- Estudo de viabilidade e planos de negócios para novos projetos de Parques Científicos.

\section{XXI IASP World Conference 2004 (Bergamo - Italy) Sessões Plenárias}

- O que são "regiões atrativas" atrativas hoje? Elementos de atratividade na economia global.

- Critério de localização corporativa na economia do conhecimento: como as companhias escolhem onde se localizar?

- O que estão fazendo os Parques Científicos e Tecnológicos para atair investimentos?

- Atratividade regional e trabalhadores do conhecimento.

\section{Sessões Paralelas}

- Atratividade dos Parques Científicos e Tecnológicos por meio dos serviços de valor adicionado.

- O que faz uma região atrativa hoje?

- Parcerias para envolver a atratividade regional

- Atratividade dos Parques Científicos e Tecnológicos por meio do gerenciamento em estado real.

- Políticas para envolver atratividade regional: estudo de casos.

- Capital social, clusters e atratividade regional

- Atratividade dos Parques Científicos e Tecnológicos por meio da comunicação e marketing.

- O papel da incubação de negócios na atratividade regional. 
As sessões evidenciam temas como a necessidade da atratividade do ambiente de inovação, a sua importância para o desenvolvimento regional, o empreendedorismo, a formação de recursos humanos e também aspectos relacionados a gestão envolvendo mercados e aspectos financeiros.

Em relação aos seminários da ANPROTEC, os temas são fixos, sendo mais relacionados às incubadoras, não sendo desdobrados em temas específicos:

5. XVI Seminário nacional de Parques Tecnológicos e incubadoras de empresas - 2007

- Cultura do Empreendedorismo e Inovação;

- Promoção de Empreendimentos orientados para o uso intensivo de tecnologias;

- Promoção de Empreendimentos orientados para o desenvolvimento local e setorial;

- Habitats de Inovação Sustentáveis.

- Cultura empreendedora;

- Criação e planejamento de incubadoras de empresas;

- Processo de incubação;

- Infra-estrutura e serviços oferecidos pela incubadora;

- Gestão da incubadora.

- Arranjos e atuação em redes

- Avaliação da incubadora

- Políticas públicas

Considerando esse referencial os temas mais presentes nesses eventos foram: gestão econômica financeira, articulação/networking, transferência tecnológica, relacionamento entre universidades e empresas, estratégias, políticas, infra-estrutura e recursos humanos.

Essa coleta de material resultou num conjunto de dimensões que deveriam ser priorizadas; para tal, foi utilizada uma técnica referenciada na Metodologia Delphi (WRIGHT e GIOVINAZZO, 2000), comumente utilizada para prospecção e que tem como principais características: a reunião de um grupo de especialistas, o anonimato dos respondentes, o tratamento estatístico das respostas e a realização de mais de uma rodada para a busca do consenso nas respostas.

Um questionário estruturado com base nas dimensões encontradas no mapeamento dos eventos foi enviado aos especialistas, membros do grupo de pesquisa registrado no Diretório do CNPq (Gestão da inovação com ênfase em 
ambientes de inovação), solicitando que indicassem o grau de importância de cada dimensão selecionada na literatura e na análise dos eventos, com base numa escala de três pontos.

As respostas da primeira rodada foram tabuladas estatisticamente e reenviadas aos mesmos respondentes, com os resultados da rodada anterior em destaque. Os resultados da segunda rodada possibilitaram definir as dimensões com base num consenso de $80 \%$ em relação às questões consideradas muito importantes. A opinião dos especialistas aponta para as seguintes dimensões: governança, relação universidade/empresa, infra-estrutura e estratégia.

- Governança - considerando o contexto e os objetivos desta pesquisa, a governança foi tratada com base em três pilares: articulação (definição/caracterização dos atores: públicos e privados, nacionais e internacionais; métodos de articulação (agências, associações, redes etc.); política (locais/regionais que impactam a sociedade, relacionadas a ambientes de inovação; métodos e/ou ferramentas para implementação das políticas - modelos de financiamento e atração); coordenação (modelo da organização)

- Relação universidade-empresa - no contexto do projeto, a relação universidade-empresa foi tratada nas seguintes perspectivas: composição da base de ciência e tecnologia, estruturas de apoio e mecanismos de financiamento.

- Infra-estrutura - envolve a estrutura logística do pólo, a composição dos seus ativos, os serviços oferecidos em relação a gestão e conhecimentos.

- $\quad$ Estratégia - relacionado à estratégia de operação do Pólo, à estratégia de internacionalização e à estratégia de atração de empresas.

Assim, com base nessas dimensões foram selecionadas para 0 presente trabalho, as seguintes dimensões: Governança, relacionamento entre universidades-empresas, Políticas e Estratégias e Infra-estrutura (Figura 5-1).

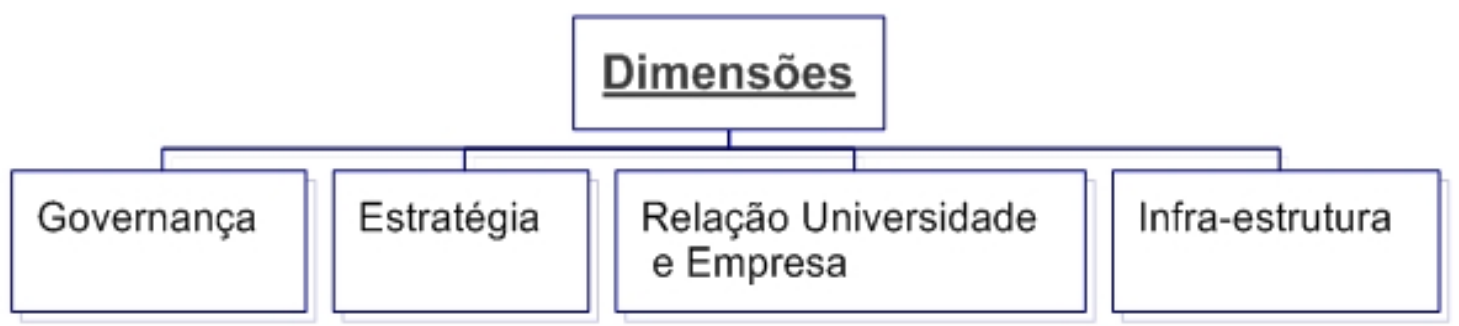

Figura 5-1: Dimensões definidas na pesquisa. 


\subsubsection{Seleção dos casos}

A Revisão bibliográfica e as condições locais evidenciaram que o modelo mais adequado de ambiente de inovação para servir como referência para o estudo são os Pólos de Competividade Franceses, os quais foram considerados os parâmetros específicos do objeto de estudo, ou seja, as unidades de análise.

Desta forma, o estudo de caso teve como objeto de estudo os Pólos de Competitividade situados na França, sendo esses instrumentos criados para desenvolver atividades inovativas por meio da aproximação de atores das iniciativas públicas e privadas. Nesse modelo, a governança é do governo francês que determinou a criação por meio de sua política industrial (2004) com o objetivo de estimular a economia francesa e reforçar a competitividade de suas empresas.

\subsubsection{Justificativas para escolha do modelo - a importância da} França.

A França com cerca de 63 milhões de habitantes é um dos países europeus mais populosos ao lado da Alemanha ( 82,5 milhões de habitantes) e da Grã-Bretanha (60 milhões de habitantes), com densidade média de 110,7 hab./ $\mathrm{km}^{2}$ na metrópole e $80 \%$ da sua população é urbana. No que tange ao tamanho da sua economia, figura entre as dez maiores economias mundiais, com um PIB de 2,04 trilhões de dólares em 2007.

O país possui três níveis de coletividades territoriais de pleno exercício: a comuna, o departamento e a região. A descentralização, isto é, a transferência de atribuições do Estado para as coletividades territoriais, é bem recente, somente tomou impulso no início dos anos 80 e uma nova etapa da descentralização foi iniciada com a adoção da emenda constitucional (que modifica a Constituição francesa) de 28 de março de 2003 e da lei de 13 de agosto de 2004. 
Tabela 5.5 - estrutura administrativa da França

\begin{tabular}{|c|c|c|c|}
\hline Coletividades & Característica & Funções & Governança \\
\hline $\begin{array}{l}\text { Estado } \\
\text { (1) }\end{array}$ & $\begin{array}{l}\text { República democrática semi } \\
\text { presidencialista }\end{array}$ & $\begin{array}{l}\text { Preside o conselho de } \\
\text { ministros }\end{array}$ & $\begin{array}{l}\text { Presidente eleito } \\
\text { pelo sufrágio } \\
\text { universal }\end{array}$ \\
\hline $\begin{array}{l}\text { Comuna } \\
(36.778)\end{array}$ & $\begin{array}{l}\text { Constitui a menor e a mais } \\
\text { antiga divisão administrativa } \\
\text { francesa. }\end{array}$ & $\begin{array}{l}\text { Educação, } \\
\text { Urbanismo, } \\
\text { Ação social, } \\
\text { Manutenção da rede } \\
\text { viária comunal; } \\
\text { Coleta do lixo } \\
\text { doméstico, } \\
\text { saneamento; } \\
\text { Transporte, } \\
\text { Ação econômica; } \\
\text { Cultura }\end{array}$ & $\begin{array}{l}\text { A comuna é gerida } \\
\text { por um conselho } \\
\text { municipal, eleito a } \\
\text { cada } 6 \text { anos pelo } \\
\text { sufrágio universal } \\
\text { direto. }\end{array}$ \\
\hline $\begin{array}{l}\text { Departamento } \\
(100)\end{array}$ & $\begin{array}{l}\text { Somente é reconhecido como } \\
\text { coletividade local autônoma em } \\
1871, \text { com um órgão deliberador } \\
\text { e um executivo eleito. Todavia, } \\
\text { somente em } 1982 \text { consegue se } \\
\text { libertar totalmente da tutela do } \\
\text { Estado para se tornar uma } \\
\text { coletividade territorial de pleno } \\
\text { exercício }\end{array}$ & $\begin{array}{l}\text { Ação sanitária e } \\
\text { social: } \\
\text { Equipamentos e } \\
\text { transportes: } \\
\text { Educação: }\end{array}$ & $\begin{array}{l}\text { Gerido por um } \\
\text { conselho geral } \\
\text { cujos membros, os } \\
\text { conselheiros gerais, } \\
\text { são representantes } \\
\text { eleitos por meio de } \\
\text { sufrágio universal } \\
\text { por seis anos }\end{array}$ \\
\hline $\begin{array}{l}\text { Região } \\
\text { (26) }\end{array}$ & $\begin{array}{l}\text { Uma estrutura recente na } \\
\text { administração local francesa, } \\
\text { passou a coletividade territorial } \\
\text { em } \\
\text { conseqüência das leis de } \\
\text { descentralização dos anos } \\
\text { 1980. Sua existência foi } \\
\text { consagrada pela revisão } \\
\text { constitucional de } 28 \text { de março } \\
\text { de } 2003 \text { : a partir de então, ela é } \\
\text { mencionada na Constituição } \\
\text { francesa como coletividade } \\
\text { territorial da mesma forma que a } \\
\text { comuna e o departamento. }\end{array}$ & $\begin{array}{l}\text { Educação e formação } \\
\text { profissional: } \\
\text { Desenvolvimento } \\
\text { econômico: } \\
\text { Ordenamento do } \\
\text { território e } \\
\text { planejamento: }\end{array}$ & $\begin{array}{l}\text { Os conselheiros } \\
\text { regionais foram } \\
\text { eleitos pela primeira } \\
\text { vez pelo sufrágio } \\
\text { universal em março } \\
\text { de } 1986 . \\
\text { Seu mandato é de } \\
\text { seis anos. }\end{array}$ \\
\hline
\end{tabular}

Fonte:Projeto Eurobrasil 2000 (2006)

No aspecto científico-tecnológico é um dos países fundadores da OCDE (Organização para a Cooperação e Desenvolvimento Econômico), organização considerada de referência mundial na produção de trabalhos e indicadores de C\&T\&I, posicionando-se como segunda potência européia, situando-se ligeiramente acima do Reino Unido, e abaixo da Alemanha.

No diz respeito ao aspecto de relações com o Brasil, são identificados diversos acordos de cooperação nos mais diversos segmentos da sociedade como defesa, cultura e ciência e tecnologia, dentre outros. 
Além disso, é uma referência para o modelo da Lei de Inovação Tecnológica - LIT (Lei Federal n. .10 .973 de 02.12.2004) de 2004 que foi baseada na Lei n. 99-587 sobre Inovação e Pesquisa Francesa de 1999.

Destacam-se os preceitos que estabelecem os procedimentos legais da relação público-privada, além de criar mecanismos que estimulem a inovação tecnológica no ambiente universitário. A sua estrutura compõe quatro seções:

i) Tratam da mobilidade dos pesquisadores em direção à indústria e às empresas;

ii) Cooperação entre estabelecimento de pesquisa do setor público e empresas;

iii) Quadro geral fiscal para empresas inovadoras;

iv) Quadro geral jurídico para empresas inovadoras.

No Brasil, a Lei de Inovação Tecnológica do Brasil também está orientada para: a criação de um ambiente propício a parcerias estratégicas entre universidades, institutos tecnológicos e empresas; ao estímulo à participação de instituições de ciência e tecnologia no processo de inovação; e o incentivo à inovação na empresa.

A comparação do conteúdo da lei francesa indica que a esta influenciou decisivamente o projeto de Lei de Inovação Tecnológica do Brasil. (MATIAS-PEREIRA, KRUGLIANSKAS, 2005).

A história da França evidencia uma região com grandes avanços científicos e tecnológicos, induzidos em grande parte pelo Estado. Essa característica está relacionada ao desenvolvimento de grandes projetos do governo.

Na Tabela 5.6 é apresentada a estrutura baseada no desenvolvimento de organismos de estudos, pesquisa e desenvolvimento para suportar os projetos dos diferentes segmentos.

Tabela 5.6 - Modelo de Pesquisa na França.

\begin{tabular}{c|l|l}
\hline \multicolumn{1}{c|}{ Setor } & \multicolumn{1}{|c}{ Descrição } & \multicolumn{1}{c}{ Suporte } \\
\hline Aeronáutica & $\begin{array}{l}\text { Plano Concorde, seguido de Airbus em parceria } \\
\text { européia }\end{array}$ & $\begin{array}{l}\text { ONERA : Bureau } \\
\text { Nacional de Estudo e de } \\
\text { Pesquisa Aeronáutica. }\end{array}$ \\
\hline Energia & $\begin{array}{l}\text { Plano nuclear com o CEA e EDF e a criação de uma } \\
\text { indústria de energia nuclear. }\end{array}$ & $\begin{array}{l}\text { CEA : Centro de } \\
\text { Estudos Atômicos }\end{array}$ \\
\hline
\end{tabular}




\begin{tabular}{l|l|l}
\hline \multicolumn{1}{c|}{ Setor } & \multicolumn{1}{c}{ Descrição } & \multicolumn{1}{c}{ Suporte } \\
\hline Defesa & $\begin{array}{l}\text { Programa de defesa na área nuclear; Programa AIR } \\
\text { com o desenvolvimento de aviões militares: Mirage, } \\
\text { Rafale; } \\
\text { Programa TERRE, com o desenvolvimento de } \\
\text { diferentes tanques AMX, LECLERC; } \\
\text { Programa MER, com o desenvolvimento de diferentes } \\
\text { submarinos: SNA, SNLE, bem como de porta-aviões. }\end{array}$ & \\
\hline Espacial & $\begin{array}{l}\text { Programas de lançamento, com ARIANE em evidência } \\
\text { e diversos programas de satélites dirigidos pelo CNES } \\
\text { que colaboraram para a criação de uma indústria } \\
\text { espacial. }\end{array}$ & $\begin{array}{l}\text { CNES : Centro Nacional } \\
\text { de Estudos Espaciais }\end{array}$ \\
\hline Saúde & $\begin{array}{l}\text { Plano de saúde que através de mecanismos de } \\
\text { reembolso de medicamentos pela saúde social, permitiu } \\
\text { a formação de grandes grupos farmacêuticos }\end{array}$ & $\begin{array}{l}\text { INSERM : Instituto } \\
\text { Nacional de Saúde e } \\
\text { Pesquisas Médicas. }\end{array}$ \\
\hline Informática & $\begin{array}{l}\text { Plano estratégico com a criação da BULL, empresa } \\
\text { pública }\end{array}$ & $\begin{array}{l}\text { INRIA : Instituto } \\
\text { Nacional de Pesquisa } \\
\text { em Informática } \\
\text { Aplicada. }\end{array}$ \\
\hline Telefonia & $\begin{array}{l}\text { Em1974 que permitiu à France Telecom, organismo } \\
\text { governamental, a criação de gigantes da telefonia como } \\
\text { ALCATEL }\end{array}$ & $\begin{array}{l}\text { CNET : Centro Nacional } \\
\text { de Estudo de } \\
\text { Telecomunicações }\end{array}$ \\
\hline
\end{tabular}

Fonte: Brunet (2007)

Após a segunda Guerra Mundial, a França buscou diminuir a intervenção do Estado nas atividades de pesquisa, tecnologia e inovação (LAREDO e MUSTAR, 2001). O objetivo era aproximar as estruturas de pesquisa e inovação das atividades produtivas com o objetivo de proporcionar maior competitividade ao país.

Considerando a evolução do sistema francês, pode-se citar as iniciativas que tiveram maior impacto (Brunet, 2007):

1979 - criação da ANVAR - Agência Nacional de Valorização da Pesquisa. No início, este organismo era destinado a apoiar a valorização dos resultados da pesquisa francesa. Rapidamente, a ANVAR se tornou uma agência de financiamento da pesquisa, primeiramente nos laboratórios, e depois nas empresas. A ANVAR financia projetos através de diferentes mecanismos de financiamento, seja na forma de subvenção, seja na forma de reembolsáveis em caso de sucesso. Também contribuiu amplamente com a gênese e o desenvolvimento de Micro, Pequenas e Médias Empresas tecnológicas (MPME).

1981 - criação de bolsas para doutores co-financiadas por empresas (bolsa CIFRE - é um instrumento na cooperação Universidade-Empresa. São destinadas aos Doutores que fazem suas teses de Doutorado em empresas, 
como funcionários das empresas orientados por um laboratório, sobre um tema de pesquisa escolhido pela empresa e pelo laboratório de comum acordo.

Anos 80 - apoio às incubadoras, diversas autoridades locais se conscientizam da importância da criação de empresas inovadoras para o desenvolvimento econômico, surgindo as incubadoras. A grande maioria das incubadoras são estruturas destinadas a hospedar as empresas em criação, de preferência tecnológicas. Elas fornecem: hospedagem flexível, modular e pouco onerosa; serviços comuns administrativos como telefone, copiadora, fax, bibliotecas, acesso internet. Em 1984, um edital da Comunidade Européia permitiu a criação dos $\mathrm{CEEI}$, estruturas equivalentes às incubadoras, mas que apresentam um acompanhamento pós-criação por especialistas, por meio de financiamento Europeu.

Anos 80 - Células de valorização - Essas células consistem em serviços internos das Universidades para desenvolver interface com as empresas, as principais atividades são de: i) detectar as tecnologias com resultados de pesquisa maduros para serem valorizados; ii) assegurar a proteção da propriedade intelectual; iii) fazer a interface com as empresas encarregadas de colocar no mercado a tecnologia considerada. Atualmente, todas as universidades dispõem de uma célula de valorização. Todas essas células se reúnem em uma rede, a Rede CURIE, que as permitem praticar trocas de experiências, de knowhow, de práticas, e compartilhar recursos entre elas.

A Lei de Inovação de 1999. Em 1999, a Lei de Inovação de pesquisa de 12 de julho revoluciona o quadro da inovação. Ela é constituída de quatro eixos principais: i) a mobilidade de pesquisadores públicos para atuar em empresas; ii) a colaboração entre a pesquisa pública e as empresas; iii) o quadro fiscal para as empresas inovadoras; iv) o quadro jurídico para as empresas inovadoras.

Também a partir desta Lei foram criadas estruturas e meios para incentivar a criação de empresas inovadoras, entre eles:

- A criação de empresas a partir da pesquisa:

- As pré-incubadoras vinculadas à pesquisa pública;

- Os fundos de capital semente ("amorçage");

- O concurso Nacional de apoio à criação de empresas de tecnologias inovadoras. 
- A parceria público/privada na pesquisa:

- As redes de pesquisa e de inovação tecnológica;

- Os centros nacionais de pesquisa tecnológica.

2003 - Lei das Jovens Empresas Inovadoras (JEI) - plano de incentivo à inovação foi elaborado para complementar os dispositivos da Lei e ações subseqüentes. Entre eles estão:

- Apoio à criação de empresas:

- Ensino do empreendedorismo;

- Incentivos fiscais para os Business Angels ${ }^{12}$, atraindo investidores para as jovens empresas inovadoras.

- Apoio ao P\&D na empresa:

- Novo crédito de imposto-pesquisa;

- Apoio à transferência de tecnologia:

- Prêmio pelo registro de patente e à parceria público/privada;

- Apoio à transferência de tecnologia nos estabelecimentos públicos;

- Uma melhor valoração da pesquisa pelas empresas;

- Jovens cientistas na empresa.

Lei de Programa para a Pesquisa 2006 - Aprovada em 2006, é uma lei de orientação da pesquisa. Ela é baseada em três princípios fundamentais: i) desenvolvimento equilibrado da pesquisa, envolvendo pesquisa fundamental, pesquisa aplicada para fins sociais (saúde, meio-ambiente, desenvolvimento sustentável, segurança) e pesquisa aplicada para fins econômicos (criação de riquezas e empregos); ii) desenvolvimento de interfaces e de cooperação entre os atores; iii) desenvolvimento baseado em uma estratégia global e de longo prazo. Seis objetivos estruturais são definidos, exibidos na Tabela 5.7.

${ }^{12}$ Business Angels - indivíduos, pessoa física, que investem ou emprestam recursos financeiros para um determinado negócio, geralmente resultante de inovação tecnológica incremental ou que tenha um mercado bem definido, tendo perspectiva de retorno do seu investimento a curto ou médio prazo. 
Tabela 5.7 - Objetivos, ações e organização do programa para a pesquisa.

\begin{tabular}{|c|c|c|}
\hline Objetivos & Ações & Estruturas/organizações \\
\hline $\begin{array}{l}\text { Fortalecer as capacidades do Estado em } \\
\text { termos de orientação estratégica e de } \\
\text { definição de prioridades }\end{array}$ & $\begin{array}{l}\text { Nova governança. } \\
\text { Articulação comum entre } \\
\text { políticos Nacionais, } \\
\text { Regionais e Europeus. } \\
\text { Fortalecimento da cultura } \\
\text { de projetos }\end{array}$ & $\begin{array}{l}\text { 1.1 - Criação de um Alto Conselho para Ciência e Tecnologia (HLST), organismo } \\
\text { independente consultivo e de orientação junto ao Governo. } \\
\text { 1.2 - Papel do Conselho Superior de Pesquisa e Tecnologia (CSRT) como } \\
\text { organismo de debate sobre a pesquisa. } \\
\text { 2.1-Criação de pólos de competitividade de dominio regional. } \\
\text { 2.2-Criação de Pólos de Pesquisa e Ensino Superior (PRES). } \\
\text { 3.1 - Criação da Agência Nacional de Pesquisa (ANR). Financiamento de projetos } \\
\text { de pesquisa fundamental e aplicada. } \\
\text { 3.2-Criação da Agência de Inovação Industrial (All). Financiamento de projetos de } \\
\text { inovação de grande envergadura sob a protecção de grandes empresas }\end{array}$ \\
\hline $\begin{array}{l}\text { Criar um sistema de avaliação da } \\
\text { pesquisa unificada, coerente, } \\
\text { transparente e reconhecido } \\
\text { internacionalmente }\end{array}$ & $\begin{array}{l}\text { Tornar simultanea, } \\
\text { sistemática, rápida } \\
\text { transparente e } \\
\text { homogênea a avaliação. }\end{array}$ & Criação da Agência de Avaliação da Pesquisa e de Ensino Superior (AERES) \\
\hline $\begin{array}{l}\text { Reunir as energias e facilitar as } \\
\text { cooperações entre os atores da } \\
\text { Pesquisa }\end{array}$ & Promover sinergias & $\begin{array}{l}\text { Criação de PRES: lógica de coordenação regional das atividades e cooperação } \\
\text { mútua dos recursos. } \\
\text { Criação de campus de pesquisa: lógica de projeto de aproximação das atividades. } \\
\text { Criação das RTRA: Redes Temáticas de Pesquisas Avançadas, para } \\
\text { acompanhar projetos de excelência científica sobre um determinado tema. } \\
\text { Criação da ANR: financiamento de projetos de pesquisa em parceria. } \\
\text { Otimização dos procedimentos administrativos. }\end{array}$ \\
\hline $\begin{array}{l}\text { Melhorar a atratividade e a evolução das } \\
\text { carreiras científicas. }\end{array}$ & & $\begin{array}{l}\text { Reforma das formações doutorais, } \\
\text { Atribuição das bolsas Descartes, bem como um observatório do emprego } \\
\text { científico que oferecerá aos estudantes melhor visibilidade com relação aos } \\
\text { segmentos científicos e seus mercados profissionais }\end{array}$ \\
\hline $\begin{array}{l}\text { Intensificar a dinâmica de inovação e } \\
\text { aproximar a pesquisa pública e a } \\
\text { pesquisa privada: inúmeras medidas } \\
\text { visando fortalecer as Jovens Empresas } \\
\text { Inovadoras, e para favorecer o } \\
\text { desenvolvimento da pesquisa privada. }\end{array}$ & & \\
\hline $\begin{array}{l}\text { Fortalecer a inserção do sistema francês } \\
\text { no espaço Europeu da Pesquisa }\end{array}$ & & \\
\hline
\end{tabular}

Fonte: Brunet (2007). 


\subsubsection{O novo Sistema de Inovação Francês}

A evolução da estrutura apresentada possibilitou o desenvolvimento de um novo sistema de inovação, cujas principais entidades estão vinculadas ao Ministério da Economia e Indústria com exceção do ANR vinculada ao Ministério de Pesquisa, e o DIACT. Na Tabela 5.8 são apresentadas as principais organizações e funções.

Tabela 5.8 - O novo sistema de Inovação Francês.

\begin{tabular}{|c|c|}
\hline $\begin{array}{l}\text { All - Agência de } \\
\text { Inovação } \\
\text { Industrial }\end{array}$ & $\begin{array}{l}\text { Apóia programas voltados à inovação industrial propostos pelas grandes } \\
\text { empresas para atividades que ultrapassam seus investimentos habituais } \\
\text { em P\&D, com o intuito de ajudá-las a atingir dimensão mundial (os projetos } \\
\text { financiados devem visar em seus business plan } 20 \% \text { do mercado mundial). } \\
\text { A All trabalha com dois objetivos: gerar emprego para profissionais } \\
\text { altamente qualificados e aumentar as exportações francesas }\end{array}$ \\
\hline $\begin{array}{l}\text { DGE - Direção } \\
\text { Geral das } \\
\text { Empresas do } \\
\text { Ministério da } \\
\text { Indústria }\end{array}$ & $\begin{array}{l}\text { Gere o FCE - Fundo de Competitividade das Empresas ("Fonds de } \\
\text { Compétitivité des Entreprises") que reúne em um fundo único os recursos } \\
\text { de diferentes ministérios voltados ao financiamento de projetos industriais } \\
\text { de pesquisa, principalmente os que se enquadram no programa europeu } \\
\text { EUREKA de incentivo a "clusters" europeus. }\end{array}$ \\
\hline OSEO- ANVAR & $\begin{array}{l}\text { Seu objetivo é promover e apoiar as empresas pequenas e médias no seu } \\
\text { desenvolvimento industrial e crescimento através de mecanismos de ajuda } \\
\text { à inovação, principalmente a inovação tecnológica. }\end{array}$ \\
\hline $\begin{array}{l}\text { ANR - Agência } \\
\text { Nacional de } \\
\text { Pesquisa }\end{array}$ & $\begin{array}{l}\text { Encarregada de apoiar o desenvolvimento de pesquisa fundamental e } \\
\text { aplicada, a parceria entre setores público e privado e de contribuir para a } \\
\text { transferência e aplicação dos resultados da pesquisa pública na esfera } \\
\text { produtiva e comercial }\end{array}$ \\
\hline DIACT & $\begin{array}{l}\text { Ligado ao Primeiro Ministro que tem como foco a concepção e operação } \\
\text { de políticas regionais e urbanas, foi um dos formuladores da política de } \\
\text { pólos, pensando no desenvolvimento local. É responsável, juntamente com } \\
\text { o Ministério da Indústria pela coordenação dos pólos de competitividade, } \\
\text { para os quais, através do programa planejamento do território } \\
\text { (“aménagement du territoire") contribui financiando projetos das empresas } \\
\text { participantes dos pólos. Atua fazendo análise de projetos, concebendo e } \\
\text { operando políticas regionais tradicionais, além de coordenar em conjunto } \\
\text { com a DGE o GTI onde faz a articulação do Fundo Ministerial Unificado } \\
\text { (720 M€ } 2006-2008 \text { ) }\end{array}$ \\
\hline
\end{tabular}

Fonte: Relatório MOBIT (2007)

Os Pólos de competitividade, estudados a seguir, apresentam-se como um importante catalisador dessas iniciativas.

\subsubsection{Pólos de competitividade}

O modelo francês de desenvolvimento tradicionalmente é baseado no policentrismo, ou seja, a idéia de que um território deve se organizar ao redor de vários pólos. 
Desta forma, foi criado o DATAR (Delegação para o Ordenamento do Território e da Ação Regional) em 1963 que se transformou no DIACT (Delegação Interministerial para o ordenamento e a competitividade dos territórios), ligado ao Ministério do Interior e do Ordenamento Territorial. Este órgão atua como fiador político e administrativo do "desenvolvimento em cascata" (teoria econômica inspirada nos pólos de desenvolvimento de François Perroux). (Projeto Eurobrasil 2000, 2006)

As premissas para o ordenamento são o aumento de competitividade da poderosa indústria que representa $80 \%$ do comércio exterior do país e ocupa o quinto lugar em nível mundial, e o aproveitamento das vantagens territoriais (as externalidades positivas) e que de forma contrária diminua o conjunto de danos (externalidades negativas).

Portanto, buscou-se reforçar a sua atratividade econômica e competitividade por meio de uma política em perspectivas territorial e industrial, sendo lançado em 2004, os pólos de competitividade, com o objetivo de estimular a economia francesa e reforçar a competitividade de suas empresas. (DARMON, 2006)

Podem-se definir os pólos de competitividade como um instrumento de política pública que objetiva evidenciar as competências de unidades públicas e privadas de pesquisa, centros de formação e know-how de empresas em um dado território, aproveitando as sinergias e promovendo o trabalho colaborativo. (LES PÓLES DE COMPETITIVITE, 2007).

O desenvolvimento dos pólos de competitividade na França é particularmente influenciado pela articulação do setor industrial de cada região, seu potencial de C\&T e ainda pela importância das aglomerações de empresas que a caracterizam.

O pressuposto é que a interação entre esses agentes é capaz de impulsionar o desenvolvimento das atividades inovadoras intensivas em tecnologia, porque a proximidade física facilita a transmissão do conhecimento e estimula a sinergia, o que resulta em incrementos na eficiência e na eficácia dessas atividades. (SUZIGAN et al, 2004 e AUDRETSCH \& THURIK, 2001)

Os pólos estão ancorados em quatro pressupostos: i) estratégia comum de desenvolvimento, ii) concentração em tecnologias com alto potencial de mercado, iii) visibilidade internacional e iv) sinergia de forças entre os atores. 
Atualmente existem na França 71 pólos de competitividade (Figura 5-2) sendo dezessete de abrangência mundial, ou seja, propícios para os mercados globalizados. Os pólos são temáticos e desenvolvidos a partir de domínios setoriais.

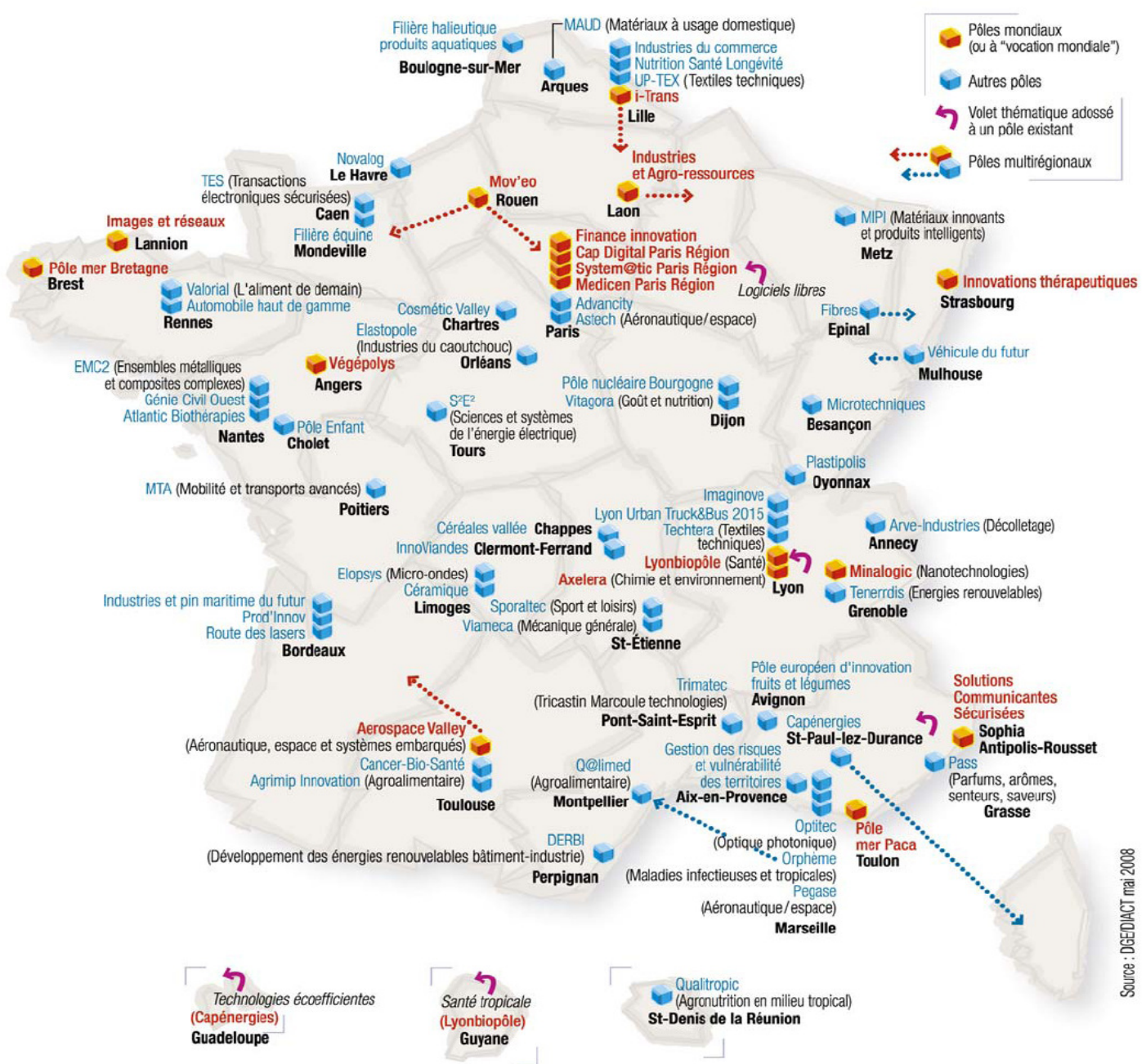

Figura 5-2: Pólos Franceses de Competitividade.

Fonte: http:// www.competitivite.gouv.fr. Acesso em: 14/11/2008.

O programa é interministerial, desenvolvido por meio de um grupo de trabalho (GTI - Groupe de Travail Interministérie) composto por agências (Oseo, ANR, All), Ministérios que contribuem para Fundo Único da Inovação - FUI (Indústria - a maior contribuição, Defesa, Interior / Planejamento Regional, Saúde, Agricultura, Infra-estrutura e Ministério da Pesquisa). O GTI é secretariado pela 
DGE (Ministério de Finanças e Indústria) e pela DIACT ("Délégation à l'Aménagement et à la Compétitivité des Territoires", Serviço do primeiro Ministro responsável pelo planejamento territorial).

Inicialmente, foram selecionados 67 pólos em julho de 2005, através de chamada de projetos que foram complementados como mais quatro pólos em 2008. Esses pólos receberão uma ajuda financeira de 1,5 bilhões de euros durante três anos, dos quais:

- 700 milhões de euros do Estado;

- 500 milhões de euros de agências públicas especializadas em inovação e pesquisa e de um estabelecimento público financeiro;

- 300 milhões de euros de isenções fiscais e redução de encargos sociais.

Essas verbas de ajuda são destinadas a financiar os trabalhos de pesquisa e desenvolvimento realizados pelas empresas em parceria com os centros de pesquisa, bem como outros aspectos não vinculados diretamente à inovação tecnológica, necessários ao desenvolvimento permanente dos pólos. Esses aspectos abrangem ações de segurança e de inteligência econômica, desenvolvimento da dimensão internacional dos pólos, melhoria da gestão dos recursos humanos (especialmente o apoio a grupos de empregadores), acesso às novas tecnologias de informação e de comunicação, melhoria das condições de vida das pessoas das empresas envolvidas.

\section{Definições dos Pólos estudados.}

Considerando o número de 71 pólos de competitividade na França, verificou-se a impossibilidade de desenvolver uma pesquisa com característica de censo, ou seja, envolvendo toda a população. Nessa perspectiva, o trabalho foi orientado para a definição de uma amostra com qualidade metodológica.

Considerando as proposições de Eisenhardt (1989) que estabelece de quatro a dez um bom número de casos, foi estabelecida a adoção de cinco pólos para estudo. Para a seleção da amostra foi estabelecido um critério intencional tendo como base os padrões de intensidade tecnológica das atividades econômicas desenvolvidas nos diferentes Pólos de Competitividade e a aderência à realidade local de Sorocaba. 
$\mathrm{Na}$ proposição de um Pólo de Desenvolvimento e Inovação em Sorocaba, pode-se aceitar como pressuposto que os pólos que desenvolvem atividades de maior intensidade tecnológica apresentam informações mais maduras tecnologicamente e são mais propícios às inovações.

De acordo com a OCDE, a variável intensidade tecnológica é derivada dos gastos em P\&D nos setores. Considerando o indicador de intensidade de $P \& D$ (gasto em P\&D/valor adicionado ou gasto em P\&D/produção). A classificação da OCDE considera quarto grupos principais de intensidade tecnológica (Tabela 5.9).

Tabela 5.9 - Classificação de Intensidade Tecnológica.

\begin{tabular}{l|l}
\hline $\begin{array}{l}\text { Intensidade } \\
\text { tecnológica }\end{array}$ & \multicolumn{1}{c}{$\bullet$ Setores } \\
\hline alta & $\begin{array}{l}\text { setores aeroespacial; farmacêutico; de informática; eletrônica e } \\
\text { telecomunicações; instrumentos. }\end{array}$ \\
\hline média-alta & $\begin{array}{l}\text { setores de material elétrico; veículos automotores; química, excluído o setor } \\
\text { farmacêutico; ferroviário e de equipamentos de transporte; máquinas e } \\
\text { equipamentos }\end{array}$ \\
\hline média-baixa & $\begin{array}{l}\text { setores de construção naval; borracha e produtos plásticos; coque, produtos } \\
\text { refinados de petróleo e de combustíveis nucleares; outros produtos não } \\
\text { metálicos; metalurgia básica e produtos metálicos }\end{array}$ \\
\hline baixa & $\begin{array}{l}\text { outros setores e de reciclagem, madeira, papel e celulose; editorial e gráfica; } \\
\text { alimentos, bebidas e fumo; têxtil e de confecção, couro e calçados. }\end{array}$ \\
\hline
\end{tabular}

Fonte: Furtado e Quadros (2005)

Os pesquisadores, Furtado e Quadros (2005) desenvolveram estudos para estabelecer padrões de intensidade tecnológica específicos para a indústria brasileira. Para tal, os autores utilizaram-se dos dados obtidos na Pesquisa nacional de Inovação (PINTEC), a qual foi desenvolvida de acordo com padrões internacionais da OCDE.

Os trabalhos utilizaram a mesma base metodológica (esforço); todavia existem diferenças, que são explicadas, na maioria, por estarem relacionadas às características dos investimentos e gastos nas indústrias de países desenvolvidos e países em desenvolvimento (emergentes). A classificação apontou algumas diferenças em relação ao padrão da OCDE, sobretudo as atividades farmacêuticas e também a atividade aeroespacial, pela impossibilidade de desagregação dos dados (Tabela 5.10). 
Tabela 5.10 - Classificação dos Setores da Indústria Brasileira, segundo Intensidade Tecnológica.

\begin{tabular}{l|l}
\hline$\bullet \quad$ Intensidade & \multicolumn{1}{c}{$\bullet$ Setores } \\
\hline Baixa & $\begin{array}{l}\text { Alimentos, Bebidas e Fumo; Têxtil, Confecção e Calçados; Madeira, Papel, } \\
\text { Celulose, Edição e Gráfica; Minerais } \\
\text { Não-Metálicos, Metalúrgica Básica, Produtos Metálicos, Móveis e Diversos }\end{array}$ \\
\hline Média-Baixa & Refino e Outros, Química, Borracha e Plástico, Farmacêutica \\
\hline Média-Alta & $\begin{array}{l}\text { Informática, Máquinas e Equipamentos, Instrumentos e Veículos } \\
\text { Automotores }\end{array}$ \\
\hline Alta Intensidade & Material e Máquinas Elétricas, Eletrônica e Outro Material de Transporte. \\
\hline
\end{tabular}

Fonte: Furtado e Quadros (2005)

Com base nos resultados, foram definidos os pólos a serem pesquisados, como critério para definição, utilizou da opção de escolha de pólos relacionados a setores classificados como de alta e média alta intensidade tecnológica.

Conforme, análise apresentada nesse trabalho, a cidade de Sorocaba apresenta a presença de uma forte indústria metal-mecânica, com fabricação de máquinas e equipamentos e a presença de montadoras de automóveis. Tornouse propício que os pólos pesquisados representem setores relacionados a esse contexto.

Também foram privilegiados os pólos franceses que estivessem voltados para mercados externos, não somente ao mercado interno da França. Os pólos selecionados são apresentados na Tabela 5.11.

Tabela 5.11 - Pólos pesquisados no estudo de caso

\begin{tabular}{l|l}
\hline Pólos & Setores \\
\hline Astech & Aeronáutica, Espaço e Sistemas Embarcados \\
\hline Médicen Paris & $\begin{array}{l}\text { Tecnologia de ponta (instrumentos), Novos } \\
\text { Medicamentos, Novas terapias genéticas, Moleculares e } \\
\text { celulares. }\end{array}$ \\
\hline System@tic & Tecnologia de informação e comunicação \\
\hline I-trans & Logística \\
\hline Cap-digital & Conteúdo digital \\
\hline
\end{tabular}




\subsubsection{Desenvolvimento de Protocolos e Instrumentos.}

A estratégia de estudo de caso, de acordo com Yin (2005) apresenta três propósitos principais, a saber: (i) exploratório, voltado a desbravar, desenvolver hipóteses, criar teorias; (ii) descritivo, na perspectiva de apresentar o fenômeno; (iii) causal ou explanatório, com foco nas relações de causa e efeito.

No presente trabalho, a ênfase está relacionada à descrição dos fenômenos, considerando a relevância do modelo de referência para posterior utilização como referência num novo modelo para a cidade de Sorocaba. Também corrobora a definição prévia do construto, que explicita as dimensões que serão observadas, servindo de referência para o desenvolvimento dos diferentes instrumentos de coleta de dados.

Para obtenção de dados, foram utilizados diferentes métodos, tais como: entrevistas, questionários e análise documental.

Para análise das dimensões do estudo foi elaborado um questionário (Apêndice A) estruturado para ser respondido por pessoas com funções diretivas nos Pólos escolhidos.

A seguir, são apresentadas as definições das dimensões.

\section{Governança:}

Em decorrência da relevância que o termo governança ganhou a partir de Williamson (1985), o conceito se ampliou ganhando destaque nos arranjos inter-organizacionais emergentes que se expandiram na parte final do século XX.

O termo governança é bastante abrangente e em virtude do caráter subjetivo das considerações acerca desse conceito, o termo governança incorporou diferentes significados ao longo do tempo tornando-se uma palavra pouco clara das intenções a que serve. E, quanto a esse processo de significação, a governança deve ser entendida como um construto e, portanto, não pode ser explicada por um único conceito, mas por intermédio de construções teóricas que envolvem vários campos do conhecimento.

No contexto específico dos ambientes de inovação, a noção de governança é utilizada para representar diversos elementos; convém citar Kysiak (2004), que baseado na realidade americana, observa que cada modelo de ambiente inovativo apresenta a natureza particular da parceria; quando os terrenos são propriedades de universidades públicas, favorecem o domínio 
público. Independente, do modelo escolhido, o financiamento e controle tendem a predominar na governança.

A governança, portanto, baliza-se por relações subjetivas entre atores (organizações de pesquisa, estado e iniciativa privada) reforçando a importância da clareza entre a distinção do "papel individual" construído coletivamente e a "função" específica atribuída a cada um no acordo que rege as ações de convívio nessa sociedade.

Nesse contexto, conforme sugere a literatura, a Governança pode ser realizada por meio de relações de mercado, de forma hierárquica ou por cooperação (RICHARDSON, 1972) (CASAROTTO, 2004).

Graça (2007) utilizou e aprimorou essa abordagem, na qual conceitua Governança também por formas de poder (mecanismos institucionais), que podem ser representadas pelo mercado, hierarquias e formas mistas de cooperação.

A maneira hierarquica tem como base a definição vertical de decisões e comando. A forma de cooperação tem como referência os modelos encontrados nos distritos italianos, com o desenvolvimento de redes condicionadas à importância dos atores na estrutura da cadeia produtiva (PIORE, SABEL,1984).

$\mathrm{Na}$ Governança de mercado a coordenação não é intencional (planejada), não existe um centro de poder estabelecendo metas e limites e, tampouco, impondo comportamento ao conjunto de atores. A Governança na condução das relações de mercado, considerando a inovação, envolve conceitos da microeconomia tradicional (GRAÇA, 2007).

Sob essa perspectiva, a literatura especializada tem dado bastante ênfase às práticas de governança notadamente nas relações entre empresas em cadeias produtivas e em arranjos produtivos locais (APL). De acordo com Furtado (2000), a cadeia privilegia os elementos verticais de comando, enquanto os arranjos produtivos priorizam os mecanismos de coordenação horizontais.

A idéia central a partir de Gereffi (1998), é que as cadeias têm estruturas de poder que determinam as políticas de toda a cadeia. Já os Arranjos correspondem a partes de uma cadeia produtiva, com a característica de serem competitivos e regionalmente instalados. Em geral, os APL se expandem em direção aos canais de distribuição e aos clientes, e depois em direção aos fabricantes de insumos e bens de capital. 
Não pode ser negado também o papel da governança privada, também chamada em certas ocasiões como de "empresa âncora", especificamente a existência de uma empresa líder que poderá exercer algum tipo de coordenação (atração) de caráter local.

Pode-se afirmar que a interação é a essência da governança, sendo que, considerando o contexto e os objetivos desta pesquisa (Estrutura conceitual da Governança.), a governança será tratada com base em três pilares (Figura 5-6): articulação (definição/caracterização dos atores: públicos e privados, nacionais e internacionais); métodos de articulação (agências, associações, redes etc.); política (locais/regionais que impactam a sociedade, relacionadas a ambientes de inovação); métodos e/ou ferramentas para implementação das políticas (modelos de financiamento e atração); coordenação (modelo da organização).

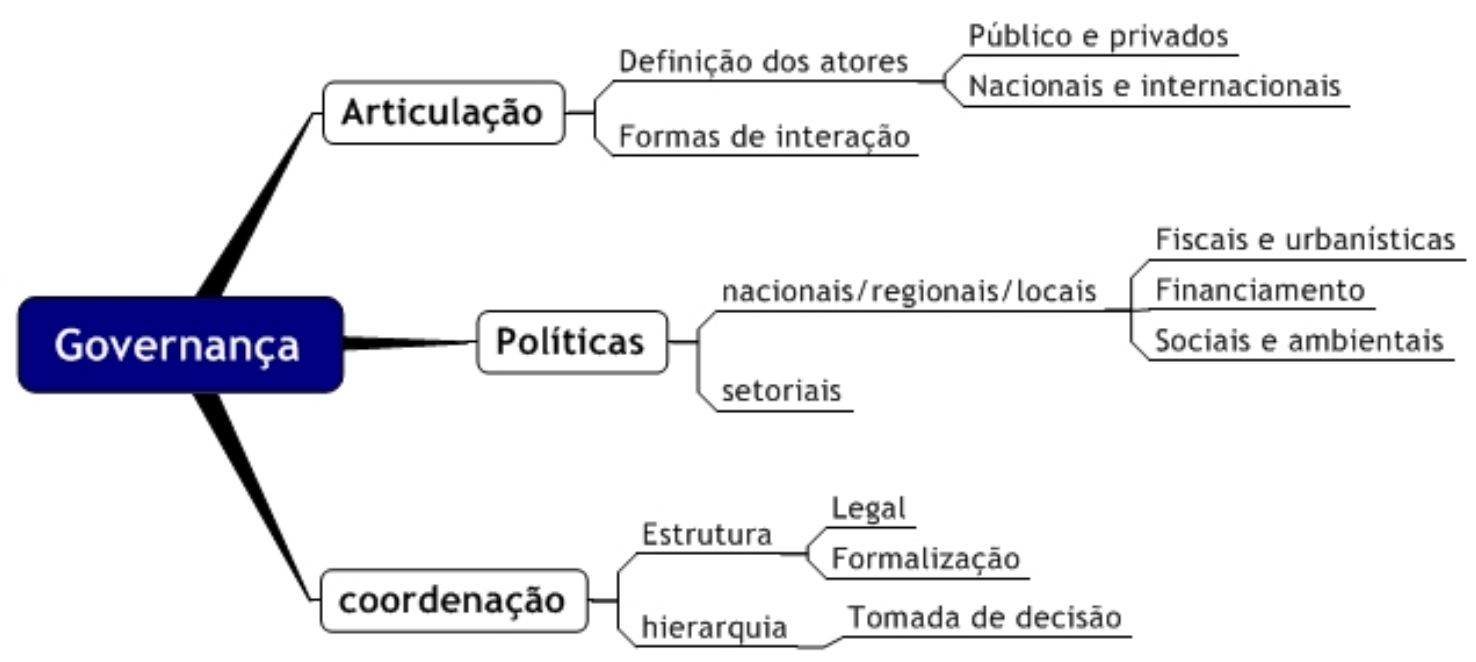

Figura 5-3: Estrutura conceitual da Governança.

Para fins desta pesquisa, define-se como:

\section{ARTICULAÇÃO:}

- DEFINIÇÃO DOS ATORES: identificação/caracterização dos atores públicos e privados envolvidos nas ações do Pólo (local, regional, nacional); identificação/caracterização dos atores internacionais;

- CARACTERÍSTICAS - estudo e caracterização das formas/procedimentos de articulação (como é realizada a articulação?) 


\section{POLÍTICA:}

- POLÍTICAS LOCAIS/REGIONAIS/NACIONAIS: estudo e caracterização das políticas locais e regionais em apoio às ações do Pólo e seus participantes e articuladores: políticas fiscais e urbanísticas (de atração); de financiamento; sociais; ambientais; de desenvolvimento local/regional.

- POLÍTICAS SETORIAIS: estudo e caracterização de políticas setoriais em apoio aos Pólos.

\section{COORDENAÇÃO:}

- ESTRUTURA: estudo e caracterização da estrutura legal/grau de formalização/organizacional da articulação;

- HIERARQUIA: estudo e caracterização do processo de tomada de decisão (estratégia) ${ }^{13}$.

\section{Relação Universidade - empresa:}

O advento da tecnologia da informação provocou um aumento substancial na capacidade de armazenamento e processamento de informação, trazendo como consequência uma maior dinâmica no fluxo de informações e comunicações para as organizações.

Essa dinâmica foi e continua sendo, instigadora de mudanças, sendo que essas se aceleraram nos últimos anos, levando a necessidade das organizações inovarem constantemente para manter-se competitivas. Para inovar, as organizações são dependentes do ativo conhecimento, pois, considerase que as nações, empresas e países melhor sucedidos são aqueles que melhor gerenciam esse ativo em todas as suas formas (OCDE, 2004) (FELDMAN, 1994)

Essa situação tem motivado investimentos em pesquisa, desenvolvimento, educação, treinamento e capacitação, com o objetivo de ampliar a possibilidade do desenvolvimento de inovações. A justificativa está ancorada nas respostas aos desafios competitivos, que sob a ótica de vários autores, entre eles (GILSING, 2000) dependem da inovação. A inovação, todavia, não ocorre de forma espontânea (SCHUMPETER,1982) pois, precisa de estímulos, interação e estrutura.

\footnotetext{
${ }^{13}$ Considera-se para fins desta pesquisa, que a caracterização do processo de tomada de decisão consiste no tratamento das informações obtidas com relação à hierarquia da tomada de decisão estratégica.
} 
Analisando o aspecto estrutural, considera-se que a base de ciência e engenharia existente é o um dos principais fatores para o desenvolvimento de atividades inovativas. Por sua vez, a base de ciência e engenharia é composta por diferentes elos como: treinamento técnico, sistema de universidades e pesquisa básica (OCDE, 2004). O sistema de universidades será abordado inicialmente para facilitar o entendimento da relação universidade-empresa.

Tradicionalmente, o sistema das universidades foi baseado em modelos lineares e distanciado de outros atores, com o seu papel bem definido e circunscrito para a geração de conhecimentos.

Todavia, a mudança econômica e a valorização dos ativos intangíveis alteraram esse panorama, nos EUA, no final do século XIX, ocorreu um aumento substancial dos vínculos formais e informais entre universidades e setor produtivo, as razões principais foram a modesta e insuficiente contribuição do financiamento público para a sua sustentação e também a rápida expansão das atividades de capacitação desenvolvidas pelas universidades para grandes empresas (MOVERY e ROSENBERG, 2005). Essas mudanças tiveram como referência o posicionamento do sistema de ensino da Alemanha com a reforma universitária de Humboldt e posterior desenvolvimento de um modelo bimodal na relação geração e aplicação do conhecimento.

Essa relação da geração do conhecimento e geração de riquezas continuou a ser explorada por acadêmicos que geraram modelos de interação envolvendo também o poder público como o triângulo de Sábato e o modelo da Hélice Tripla.

$\mathrm{Na}$ universidade observa-se um cenário de mudanças com a proposição de um novo contrato com a sociedade, participando de forma mais ativa do desenvolvimento econômico em contrapartida aos investimentos públicos. (DAGNINO, 2003).

No tocante às empresas, elas são consideradas o dínamo da inovação, representando o local no qual as inovações acontecem, todavia, cabe realçar que a propensão de uma empresa para inovar depende do aparecimento de oportunidades tecnológicas e da sua capacitação interna para identificá-las e explorá-las (OCDE, 2004).

Um dos desafios a ser confrontado diz respeito à mudança de paradigma que orienta a pesquisa acadêmica, o mérito científico, grande parte 
das pesquisas levam a uma transformação de tempo e dinheiro em conhecimento, com uma finalidade única: ser impresso em alguma publicação científica (PLONSKI, 1999).

Todavia, desenvolver e transformar o conhecimento em inovação obriga integrar ciência e tecnologia desenvolvida. Mas, para que as dinâmicas inovativas se estabeleçam é necessário, que as empresas possuam estrutura cognitiva para compreender e absorver as novas informações, ou seja, deter conhecimentos tácitos, até que finalmente a inovação se torna habitual e sua aceitação passa a ser uma questão de livre escolha, pois neste ponto, fala o mercado.

Não se pode negar que a relação universidade-empresa vem se tornando mais intensa nos últimos anos, com a celebração de acordos para atuação conjunta, ou seja, um aumento quantitativo de acordos e simultanemante, pode-se observar, uma melhoria qualitativa, sendo que os resultados são refletidos nos indicadores econômicos.(ETZKOWITZ, 1989). Também são mais nítidas as vantagens para ambos, conforme apresentado na Tabela 5.12

Tabela 5.12 - Análise relação universidade e empresa

\begin{tabular}{l|l}
\hline \multicolumn{1}{c|}{ Vantagens para a Universidade } & Vantagens para as Empresas \\
\hline $\begin{array}{l}\text { Maior possibilidade de apresentar os } \\
\text { resultados dos seus trabalhos para a } \\
\text { sociedade }\end{array}$ & $\begin{array}{l}\text { Alta competitividade e necessidade de } \\
\text { introduzir inovações de forma rápida }\end{array}$ \\
\hline $\begin{array}{l}\text { Melhor condição de financiamento para as } \\
\text { suas pesquisas }\end{array}$ & $\begin{array}{l}\text { Compartilhamento com a universidade de } \\
\text { riscos em pesquisas }\end{array}$ \\
\hline Maior exposição & Financiamentos e incentivos do governo \\
\hline
\end{tabular}

Salienta-se como relevante que existem variações na intensidade dos acordos e compromissos, sendo que as principais alterações na intensidade devem-se aos seguintes fatores: características setoriais, tecnologia, competitividade, setor de pesquisa público (RAPINI, 2007).

Em relação aos mecanismos de interação são observados instrumentos comuns, tais como: acordos de cooperação, criação de empresas para buscar capita de risco, estabelecimento de trabalhos de consultoria, realização de contratos de pesquisa cooperativa, implantação de parques 
tecnológicos e participação de professores nos conselhos das empresas e viceversa (BRISOLA et al, 1997),

No contexto da tese, a relação universidade-empresa será tratada nas seguintes perspectivas (Figura 5-4): composição da base de ciência e tecnologia, estruturas de apoio e mecanismos de financiamento.

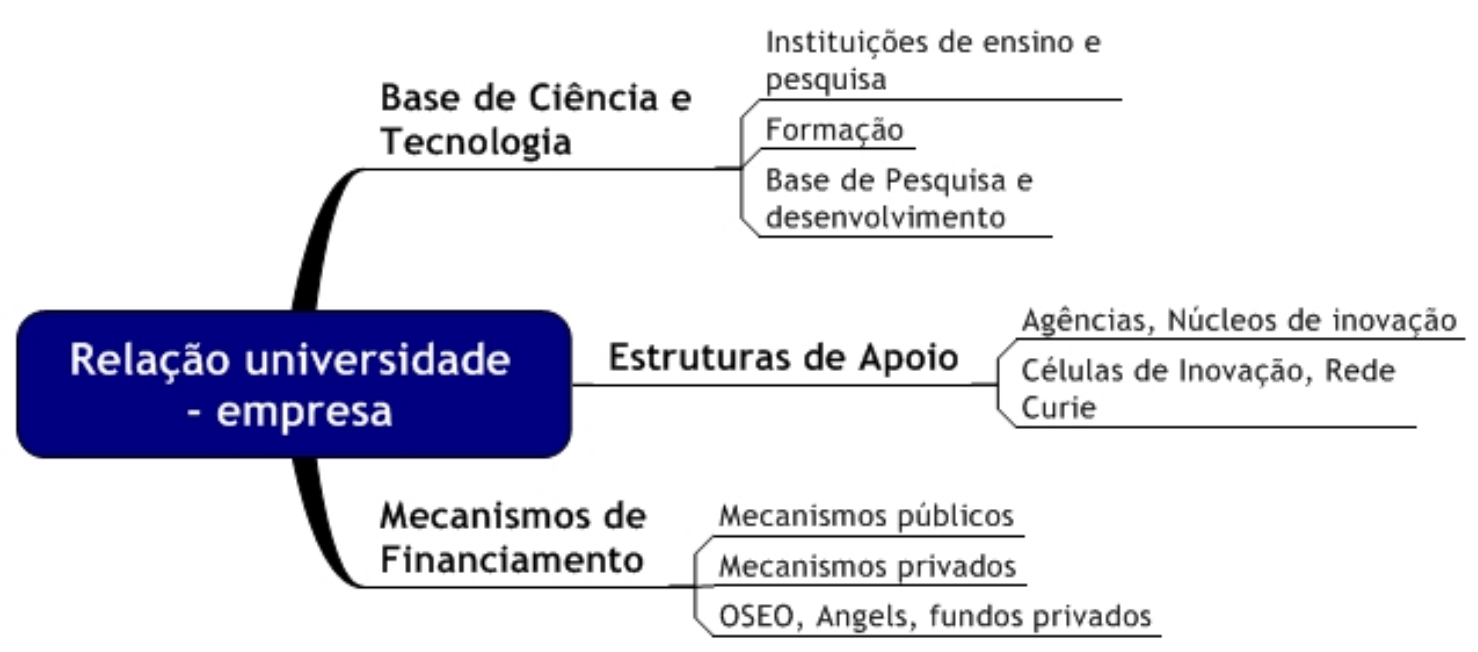

Figura 5-4: Mecanismos presentes na relação Universidade e Empresa.

\section{Infra-estrutura}

Considerando o desenvolvimento de ambientes de inovação, o papel da infra-estrutura envolve um conjunto de elementos que determinam a atratividade para os atores.

Porter (1989), estudando os clusters, considera que o fator de influência para a competitividade dos mesmos é determinada por um conjunto de condições favoráveis que prevalecem no ambiente local dos negócios: fatores de produção (oferta, custo, qualidade e especialização de insumos: matérias primas, trabalho qualificado, conhecimento especializado, capital, infra- estrutura física e de ciência e tecnologia, e estruturas de informação e de administração).

Nessa perspectiva, considera-se fundamental o conhecimento dos elementos de suporte do ambiente de inovação. Para tal, o questionário foi estrutura em duas perspectivas (Figura 5-5): 


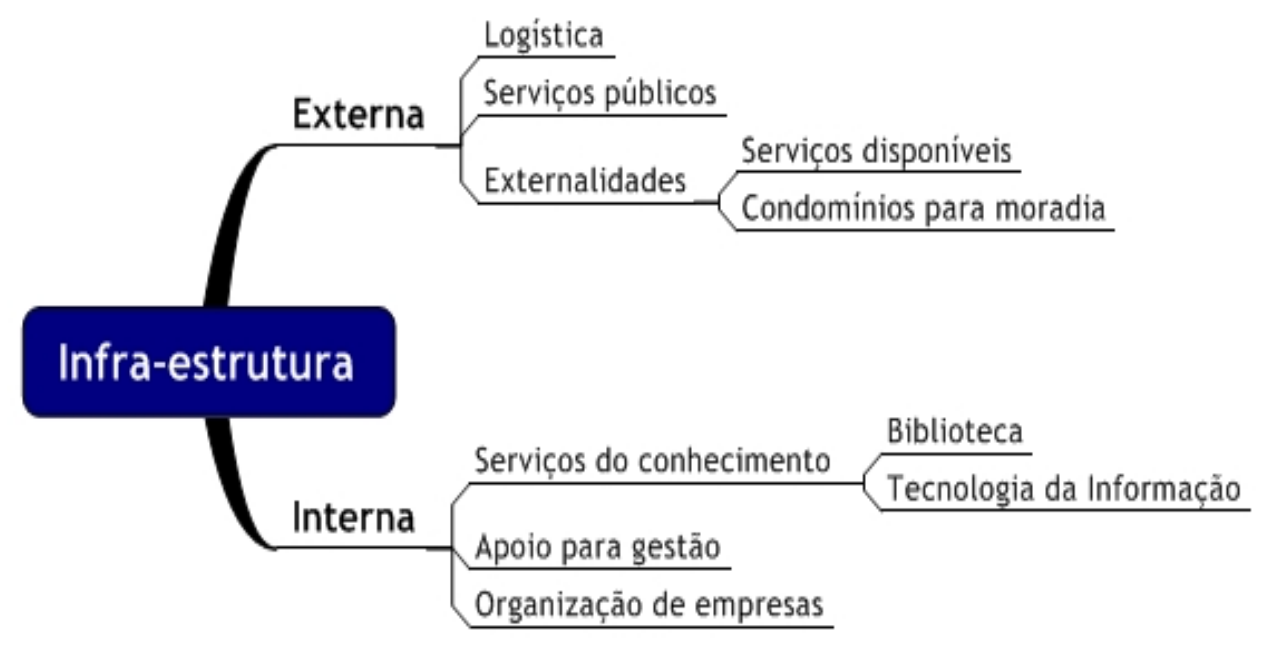

Figura 5-5: Infra-estrutura

i) externa, envolvendo a disponibilidade de serviços públicos básicos e tudo que se refere a disponibilidade logística local, considerando os meios de acesso como aeroportos, metrô e avenidas. Também os aspectos relacionados à dinâmica residencial e serviços de turismo, comércio e lazer.

ii) Interna, envolve os serviços disponibilizados pelas empresas e outros organismos presentes no Pólo, como exemplo pode-se citar as bibliotecas, base de dados, laboratórios de pesquisa e desenvolvimento, comunidades de prática. Outro aspecto pesquisado refere-se à estrutura de apoio a gestão das empresas, relacionado à formação, treinamentos e consultorias especializadas. Finalizando o aspecto relacionado à organização e estruturas de empresas, envolvendo as MPE e grandes empresas.

\section{Estratégia}

No presente contexto a estratégia refere-se ao conjunto de ações planificadas pelos competentes organismos de governança para desenvolvimento do Pólo, caracterizando-se como parte do planejamento para responder aos desafios.

Para estratificação do conjunto de estratégias, elas foram agrupadas em três eixos (Figura 5-6):

i) Estratégias de Internacionalização, relacionadas as ações de internacionalização envolvendo o comércio exterior, parcerias internacionais e organismos de representações. 
ii) Estratégia de Operação, o qual envolve a articulação dos atores para operação das atividades, ou seja, quem faz o que? E responde a quem? quais são as estruturas de coordenação, implementação, gerenciamento e controle.

iii) Estratégias de Atração de Empresas, como é desenvolvido o processo de atração de empresas? Existem organismos formais, é função específica de algumas pessoas no Pólo, ou existe uma articulação com outros organismos regionais..

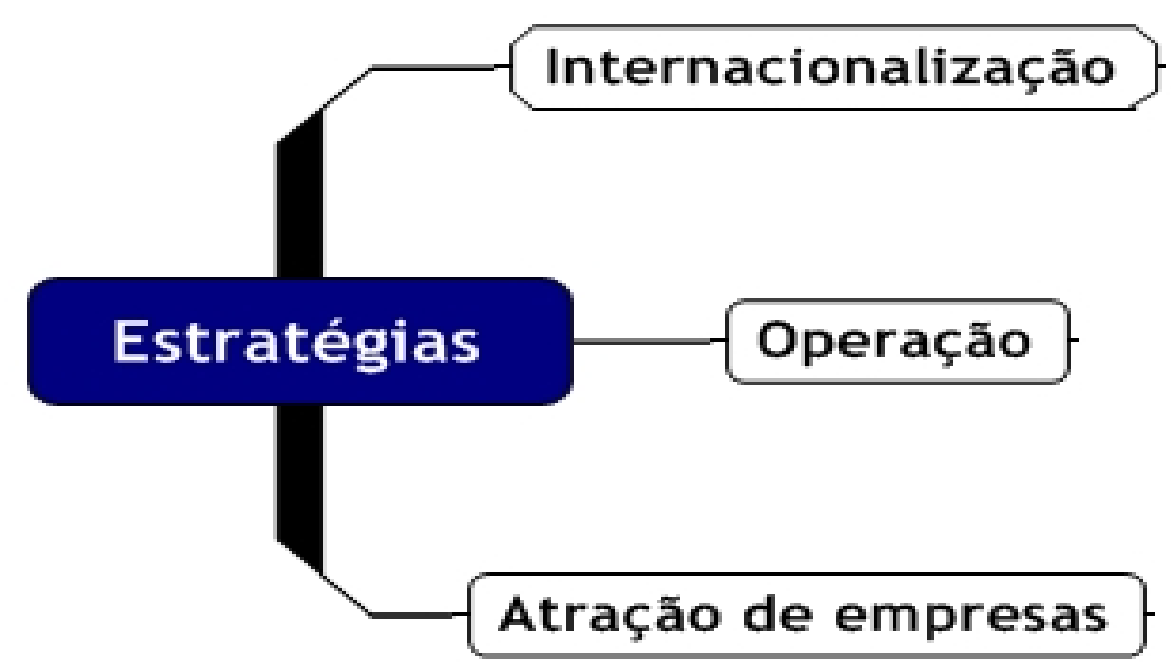

Figura 5-6: Dimensão Estratégia

Os protocolos de pesquisa foram validados pelo Dr. Michel Brunet, então Adido para Área de Ciência e Tecnologia do Consulado Francês em São Paulo.

\subsection{Considerações}

Para perseguir os resultados esperados do estudo de caso foi necessário o desenvolvimento de novos instrumentos adequados aos propósitos da pesquisa. A definição dos critérios para desenvolvimento do questionário de pesquisa foi referenciado nos principais eventos que tratam do tema ambiente de inovação.

No próximo capítulo serão apresentados os métodos de coleta das informações, resultados e análise dos mesmos. 


\section{CAPÍTULO V I-RESULTADOS e ANÁLISES}

\section{Coleta e apresentação das experiências}

Os processos de coleta e análise de dados foram desdobrados em duas etapas: i) processo de controle referencial, com o objetivo de analisar a situação de alguns dos principais parques tecnológicos e ambientes de inovação (e respectivas inserções nos sistemas locais de inovação) existentes no país; ii) estudo do caso, com a pesquisa de campo realizada na França visando aprofundar o conhecimento do modelo francês dos Pólos de Competitividade.

As experiências nacionais selecionadas, com base na indicação dos professores orientadores, tinham como propósito referenciar as iniciativas em desenvolvimento mais consolidadas no país, considerando as variáveis destacadas para o estudo.

Os levantamentos de dados e entrevistas presenciais ocorreram entre os meses de julho e agosto de 2008, ação esta apoiada pelos projetos FAPESP Programa de Políticas Públicas, sendo esses projetos coordenados pelos professores doutores orientadores da tese: Désirée Zouain e Guilherme Ary Plonski, ambos da Universidade de São Paulo, as informações foram complementadas com o estudo do caso do Parque Tecnológico de São José dos Campos que ocorreu no mês de Abril de 2009, foram estudados os seguintes Ambientes de Inovação (vide Tabela 6.1).

Tabela 6.1 - Ambientes de Inovação - experiências nacionais estudadas

\begin{tabular}{|c|c|}
\hline Organização & Entrevistados \\
\hline $\begin{array}{l}\text { Porto Digital } \\
\text { Recife }\end{array}$ & $\begin{array}{l}\text { Sr. Aurélio Molina (aumolina@portodigital.org) - Diretor de Inovação e } \\
\text { Competitividade Empresarial e Sr. Marcos Suassuna (tuloca@portodigital.org) - } \\
\text { Consultor Especial; }\end{array}$ \\
\hline $\begin{array}{l}\text { TECNOPUC } \\
\text { Porto Alegre }\end{array}$ & $\begin{array}{l}\text { Prof. Dr. Jorge Luís Nicolas Audy (audy@pucrs.br) - Pró-reitor de } \\
\text { Pesquisa e Pós-Graduação, Prof. Edemar de Paula (edemar.paula@pucrs.br) - } \\
\text { Gestor de Relacionamento, Sra. Gabriela Cardozo Ferreira - } \\
\text { Coordenadora INOVAPUC, Sr Vicente Zanella (vzanella@pucrs.br) - } \\
\text { Coordenador Acadêmico RAIAR, Sra. Marli Elizabeth Ritter dos Santos } \\
\text { (elizabeth.ritter@pucrs.br) - Coordenadora do Escritório de Transferência de }\end{array}$ \\
\hline
\end{tabular}




\begin{tabular}{|c|c|}
\hline \multirow[t]{2}{*}{ Organização } & Entrevistados \\
\hline & Tecnologia - ETT. \\
\hline $\begin{array}{l}\text { CERTI/Sapiens } \\
\text { Florianópolis }\end{array}$ & $\begin{array}{l}\text { Sr. José Eduardo Azevedo Fiates (jef@sapiensparque.com.br) - } \\
\text { Superintendente de Inovação da Fundação CERTI, Sr. Tony Chierighini } \\
\text { (tc@certi.org.br) - Gerente de Negócios da Incubadora CELTA e o Sr. } \\
\text { Leandro Carioni (Ic@sapiensparque.com.br) - Gerente Executivo do Sapiens } \\
\text { Parque. }\end{array}$ \\
\hline $\begin{array}{l}\text { Parque } \\
\text { Tecnológico } \\
\text { São José } \\
\text { Campos }\end{array}$ & $\begin{array}{l}\text { Dr. Marco Antonio Raupp (pqtecsjc_01@sjc.sp.gov.br) diretor do } \\
\text { Parque tecnológico de São José dos Campos. } \\
\text { Angela Tornelli (pqtecsjc_01@sjc.sp.gov.br) Secretaria de assuntos } \\
\text { estratégicos da Prefeitura Municipal de São José dos Campos. }\end{array}$ \\
\hline
\end{tabular}

A seguir, apresenta-se uma descrição das características de cada experiência; os relatórios completos das visitas encontram-se nos apêndices $B$ e C.

\subsection{Porto Digital}

Criado em julho de 2000, caracterizado como um projeto de desenvolvimento do sistema local de inovação, resultante de investimentos públicos e participação da iniciativa privada e universidades.

Está localizado no sítio histórico do Bairro do Recife, tem entre outros objetivos o de revitalizar uma área degradada e deprimida do Recife, importante para a cidade como legado cultural. O Porto Digital é considerado um Arranjo Produtivo de Tecnologia da Informação e Comunicação, com foco no desenvolvimento de software e, nos termos deste estudo, é caracterizado como "Parque Tecnológico aberto", com a estratégia de atrair e repovoar a região na qual está inserido com novas empresas inovadoras.

O objetivo macro do Porto Digital é produzir conhecimento localmente e exportar serviços de valor agregado para o mercado mundial. Para implantar o modelo de governança e os projetos estruturadores foi criado o Núcleo de Gestão do PORTO DIGITAL - NGPD.

Os recursos iniciais investidos no então projeto foram de $R \$ 33$ milhões advindos do Governo do Estado, fruto da privatização da CELPE - Companhia Energética de Pernambuco), destinados a criar a infra-estrutura e as condições necessárias para a implantação e operação do Porto Digital. Para implantação do 
Parque foram realizados diversos investimentos, entre eles, a recuperação de prédios e cabeamento com fibra ótica.

Em oito anos de operação, o Porto Digital já transferiu para o Bairro do Recife quatro mil postos de trabalho, atraindo dez empresas de outras regiões do país e quatro multinacionais, abrigando, ainda, quatro centros de tecnologia.

\subsection{A Fundação CERTI (Centros de Referência em Tecnologias Inovadoras)}

É uma instituição sem fins lucrativos, de pesquisa e desenvolvimento tecnológico, com foco na inovação em negócios, produtos e serviços no segmento de tecnologia da informação e coordena todas as atividades relacionadas aos Parques Tecnológicos em Florianópolis: incluindo ALFA, Sapiens e demais ativos.

A motivação para o estudo da Fundação CERTI está relacionada principalmente a dimensão de governança, dado que ela coordena as atividades de diferentes ambientes de inovação e, sobretudo a gestão que desenvolve no Parque Sapiens, inclusive envolvendo a questão imobiliária.

A Instituição foi criada em 1984, a partir do Laboratório de Metrologia do Departamento de Engenharia Mecânica da Universidade Federal de Santa Catarina (UFSC), com a participação de diversas empresas, incluindo empresas paulistas do setor mecânico e também dos governos federal e estadual.

A Fundação conta com duzentos profissionais especializados em universidades brasileiras e do exterior que possuem amplo know-how em suas áreas de atuação e desenvolvem projetos para grandes, médias e pequenas empresas. Os valores desses projetos variam de $R \$ 500$ mil a um milhão de reais, em média.

A sede da CERTI funciona desde 1990 em prédio próprio localizado no campus da UFSC; o trabalho da CERTI é realizado por intermédio de sete Centros, sendo cinco deles denominados CRIT - Centro de Referência em Tecnologias Inovadoras, com competências tecnológicas específicas e equipes de colaboradores próprios. Mais de 600 empresas e instituições de todo o Brasil beneficiam-se, anualmente, dos serviços tecnológicos, dos projetos de melhoria de processos, dos desenvolvimentos de produtos inovadores e dos empreendimentos tecnológicos desenvolvidos pelos Centros da Fundação CERTI.

Os cinco atuais CRIT são: CME - CRIT em Dispositivos Meca-OptoEletrônicos; CMI - CRIT em Soluções de Metrologia e Instrumentação; CPC - 
CRIT em Sistemas Produtivos Cooperativos; CAI - CRIT em Ambientes de Inovação; e CCD - CRIT em Soluções de Convergência Digital.

Os outros dois Centros da CERTI são: CIENCIA - Centro Incubador de Empreendimentos, Novos Conhecimentos e Idéias Avançadas e CELTA - Centro Empresarial para Laboração de Tecnologias Avançadas.

A Fundação também possui dois Institutos associados: um localizado em Manaus - Instituto CERTI Amazonas (ICA); e outro localizado em Brasília para atender projetos de convergência digital - Instituto Sapientia (IS); e um Laboratório - o LABelectron - que é mantido com acordos de cooperação técnicocientífica, baseados na Lei de Informática, com as empresas ALCATEL e MEGAFLEX SUL.

A motivação para o estudo do Parque Tecnológico Sapiens deve-se a sua condição de ser um ativo na perspectiva de do desenvolvimento regional de Florianópolis.

O Parque Tecnológico foi constituído como uma empresa com representação de diferentes atores entre os quais: a própria Fundação CERTI e o governo do Estado de Santa Catarina. Também é importante ressaltar que os projetos são estruturados com base na formatação de empresas de propósito Específicos - SPE. O Sapiens Parque possui 4,5 milhões $\mathrm{m}^{2}$ (445 hectares) de área, com o Potencial Máximo Construtivo = 1,2 milhões $\mathrm{m}^{2}$. Ele está dividido em grandes empreendimentos, dos quais alguns já estão em operação: Comunidade Sapiens, Roteiro Gastronômico, Escola Sapiens, Sapiens Circus, Quinta das Artes, Telecentro e Biblioteca SESI.

Sapiens em Números:

- Área total = 4,5 milhões m2 (445 hectares)

- Potencial Máximo Construtivo = 1,2 milhões m2

- TO (Taxa de Ocupação) = 11\%

- IA (Índice de Aproveitamento) = 25\%

- Horizonte de Implantação = 15 a 20 anos

- Arrecadação de Impostos na fase de implantação $=R \$ 1,1$ bilhão

- $\quad$ Capital da Sapiens Parque S.A. = R\$228.817.602,00

- Investimento em infra-estrutura (5 fases do projeto) $=\mathrm{R} \$ 417.189 .000,00$ 
- Investimento em edificações comerciais e empresariais $=\mathrm{R} \$$ $1.350 .000 .000,00$

- Investimento em Projetos nas Áreas Social e Ambiental $=R \$$ $150.000 .000,00$

- Investimento em Projetos Tecnológicos e Científicos $=\mathrm{R} \$ 250.000 .000,00$

- Investimentos relativos à infra-estrutura e projetos sociais no entorno do Sapiens Parque $=R \$ 150.000 .000,00$

- Investimento Total $(20$ anos $)=R \$ 2.317 .189 .000,00$

- Área Natural Preservada $=2.000 .000 \mathrm{~m}^{2}$ (mais de $50 \%$ total)

- Total de empregos diretos (nas 5 fases de implantação) = Cerca de 30 mil

\subsection{O Parque Científico e Tecnológico TECNOPUC}

Foi criado em agosto de 2003 pela Universidade PUCRS (Pontifícia Universidade Católica do Rio Grande do Sul), que é dirigida pelos irmãos maristas e cujo atual reitor, irmão Joaquim Clotet, acredita muito na relação Universidade Empresa e no empreendedorismo. A PUCRS tem mais de vinte e seis mil estudantes nos seus cinqüenta cursos de graduação, e mais de cinco mil estudantes divididos entre os cento e quinze cursos de pós-graduação lato-sensu e os quarenta e um cursos de pós-graduação strictu-sensu. Atualmente, a PUCRS é uma das primeiras colocadas no ranking de universidades privadas e grupos de pesquisa do país. A área total do TECNOPUC está em 5,4 hectares (ha) com uma área construída de dezoito mil metros quadrados que será dobrada com a construção do novo prédio que se encontra em obras.

Em meados da década de 90, ao realizar seu planejamento estratégico para os anos futuros, a PUCRS definiu que iniciaria um movimento importante em prol da ciência e da tecnologia e da busca por uma aproximação Universidade Empresa e que, entre outras metas, teria próximo ao ano de 2000 um total de mil mestres e doutores. Hoje esse número já foi ultrapassado e a Universidade conta com cerca de mil e oitocentos e cinqüenta professores, dentre os quais, $85 \%$ são mestres e doutores.

Assim surgiu o TECNOPUC que está diretamente ligado aos departamentos de pós-graduação da Universidade, e foi criado com o objetivo de interagir o conhecimento de base, desenvolvido a partir da pesquisa na 
Universidade - PUCRS, com o tecido empresarial que possui o mercado para vender o produto resultante da aplicação prática desse conhecimento.

Outro elemento indutor do processo foi o Porto Alegre Tecnópole, cuja equipe treinada por pesquisadores franceses, realizava projetos locais envolvendo a UFRS (Universidade Federal do Rio Grande do Sul), a UNISINOS (Universidade do Vale do Rio dos Sinos) e a PUCRS, nos quais identificavam necessidades das pequenas empresas e buscavam soluções em parceria com grupos das Universidades. O Porto Alegre Tecnópole está desativado, mas existe o interesse na região em reativá-lo, considerando as ações positivas geradas e o nível de articulação feita no passado que proporcionou o surgimento de casos de sucesso como, por exemplo, a instalação da Motorola P\&D no Brasil. Atualmente, a UFRS, a UNISINOS e a PUCRS não tem projetos em comum, nem parcerias.

O Modelo de governança do TECNOPUC está baseado no modelo californiano (capítulo 3) e são iniciativas promovidas, ou muito vinculadas, a Universidades.

A estrutura de governança do TECNOPUC é formada por um Comitê Gestor interno à Universidade do qual fazem parte os pró-reitores de Pesquisa e Pós-Graduação (Presidente), Extensão, Administração e Finanças, Procuradoria Jurídica e a Direção da Agência de Gestão Tecnológica.

O TECNOPUC tem uma grande infra-estrutura instalada no campus da PUCRS que abriga também estudantes de mestrado e doutorado do exterior.

No processo de desenvolvimento e expansão do Parque Tecnológico, realizou-se uma importante aproximação com os fabricantes de equipamentos de informática DELL Computadores do Brasil e HP (Hewlett-Packard Development Company), a qual propiciou o início da utilização da Lei de Informática e dos Fundos Setoriais de Ciência e Tecnologia para ampliação de material permanente no Parque.

São apresentados na Tabela 6.4.1 os resultados, com base numa redução qualitativa dos dados, os mesmos sestão estruturados de acordo com as dimensões da pesquisa.

\subsection{Parque Tecnológico de São José dos Campos}

Em março de 2006 começou a implantação do Parque Tecnológico de São José por meio de uma parceria entre a Prefeitura e o Governo do Estado. A 
área compreende cerca de um milhão de metros quadrados de terreno e 30 mil metros quadrados oriundos de uma empresa de tecnologia que saiu do município e foi adquirida pela prefeitura Municipal de São José dos Campos pelo valor de 6 milhões de dólares.

A área construída reúne instituições públicas e privadas que visam transformar conhecimento em riqueza por meio do desenvolvimento de inovações tecnológicas com foco no mercado.

Existe a previsão de que mais de US\$ 250 milhões serão investidos no Parque Tecnológico nos próximos anos, considerando os ativos que serão desenvolvidos no Parque Tecnológico de São José dos Campos.

Atualmente já estão implantados os Centros de Desenvolvimento de Tecnologias, Incubadora de Negócios, Arranjos Produtivos Locais, Faculdade de Tecnologia (Fatec), CECOMPI (Centro para a Competitividade e Inovação do Cone Leste Paulista) e Centro de Eventos.

A próxima etapa prevê a implantação de outros ativos, como os pequenos condomínios industriais, os campi da Unifesp (Universidade Federal de São Paulo), Unesp (Universidade Estadual de São Paulo) e Fatec, além de uma unidade do Senai.

Dentro do planejamento do Parque observa-se a definição de uma área denominada ZEPTEC - Zona Especial Proteção a Tecnologia com 12,5 milhões de metros quadrados no entorno do Parque Tecnológico, a qual privilegia a ocupação de atividades com potencial tecnológico de acordo com o planejamento estratégico desenvolvido para ocupação do Parque.

A Gestão do Parque é constituída de dois organismos, sendo um gestor imobiliário responsável pelas negociações envolvendo o espaço, a URBAM, que é um órgão da administração Pública. Em relação a entidade gestora, está sendo constituída a APTSJC, a Associação Parque Tecnológico de São José dos Campos, órgão responsável pela gestão dos ativos e também pela articulação externa. 


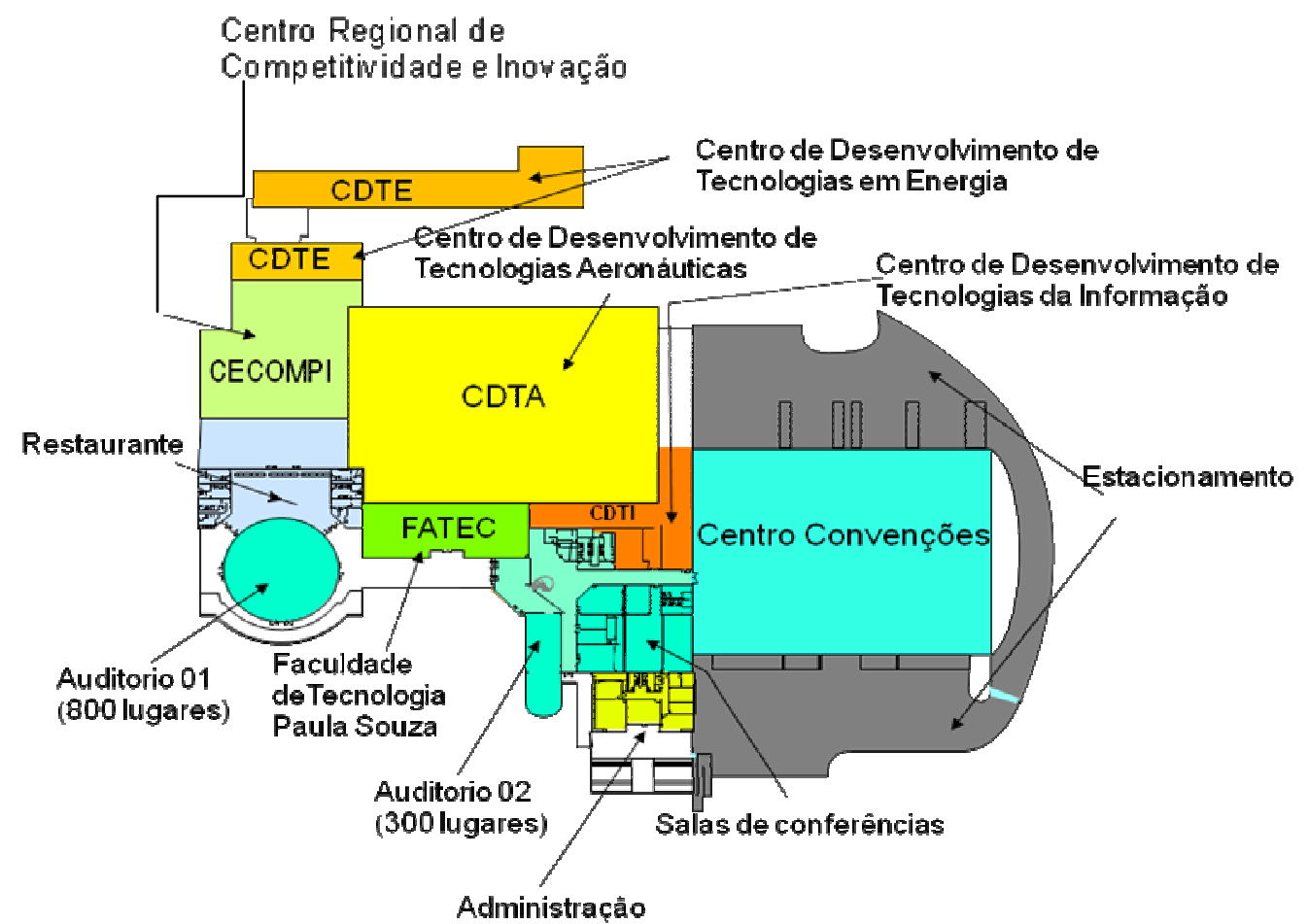

Figura 6.4-1: Estrutura do Parque Tecnológico de São José dos Campos. Fonte: Apresentação Marco A. Raupp. Visita Técnica em 28/05/2009.

Na Figura 6.4-1 estão expostos os principais ativos de formação do Parque Tecnológico, os quais estão descritos a seguir:

Os Centros de Desenvolvimento de Tecnologia possuem como objetivos de atuação a promoção de acordos, contratos ou convênios envolvendo empresa âncora, institutos de pesquisa e universidades, além do próprio Parque Tecnológico.

\section{Centro de Desenvolvimento de Tecnologia Aeronáutica - CDTA}

Em 1 de setembro de 2006 foi criado o CDTA que de acordo com a estimativa da direção receberá investimento no valor de US\$130 milhões nos próximos anos. Ele tem como objetivo manter a competitividade da indústria nacional gerando demandas de produtos e serviços, empregos e receitas de impostos. Instalado no Parque Tecnológico, o CDTA é resultado da vocação do município, operacionalizado por meio de um convênio entre a Prefeitura, o Instituto Tecnológico de Aeronáutica (ITA), o Instituto de Pesquisas Tecnológicas (IPT) e a Embraer.

\section{Centro de Desenvolvimento Tecnológico em Energia - CDTE}

Fruto de um acordo entre a Prefeitura e a Empresa VALE S. A, será instalado no Núcleo do Parque Tecnológico em uma área de 900 metros 
quadrados. A implantação do Centro também conta com a parceira do BNDES (Banco Nacional de Desenvolvimento Econômico e Social), do ITA e da Escola de Engenharia de São Carlos (USP).

No CDTE serão desenvolvidas atividades nas áreas de gaseificação de carvão térmico e de biomassa, além de pesquisas para a produção de turbinas a gás e motores pesados multicombustíveis. Em princípio, a VALE S. A irá investir cerca de US\$120 milhões, em um período de três anos.

\section{Incubadora de Negócios}

A incubadora é preliminar ao parque tecnológico dada que foi implantada em 2005, também não é uma incubadora de empresas sendo um local, no qual os empreendedores encontram apoio para desenvolver suas atividades e estruturar novos negócios que visam a inovação e inserção no mercado.

A incubadora oferece acesso à infra-estrutura operacional para desenvolver negócios com sucesso, além de serviços especializados de consultorias: gestão empresarial e orientação mercadológica. A incubadora não abriga empresas já formadas, mas sim projetos e idéias que possuem viabilidade técnica e potencial para vencer no mercado.

\section{CECOMPI}

É uma organização do terceiro setor, sem fins lucrativos tendo como figura jurídica a denominação de Organização Social. O CECOMPI (Centro Para a Competitividade e Inovação do Cone Leste Paulista) foi criado em outubro de 2004, sendo um organismo de articulação entre o Poder Público, Instituições de Ensino e Pesquisa e Iniciativa Privada. 
Tabela 6.4.1 - Resultados das entrevistas dos ambientes de Inovação Nacionais.

\begin{tabular}{|c|c|c|c|c|}
\hline Parques & Governança & Estratégia & Infra-estrutura & Universidade-Empresas \\
\hline TecnoPuc & $\begin{array}{l}\text { - A estrutura de governança do } \\
\text { TECNOPUC é formada por um } \\
\text { Comitê Gestor interno à } \\
\text { Universidade, do qual fazem parte } \\
\text { os pró-reitores de Pesquisa e Pós- } \\
\text { Graduação (Presidente), Extensão, } \\
\text { Administração e Finanças, } \\
\text { Procuradoria Jurídica e a Direção } \\
\text { da Agência de Gestão Tecnológica. } \\
\text { - O Modelo de governança do } \\
\text { TECNOPUC está baseado no } \\
\text { modelo californiano de Parques } \\
\text { Tecnológicos, os quais surgiram a } \\
\text { partir das Universidades. } \\
\text { - As Instituições funcionam como um } \\
\text { departamento da Universidade e } \\
\text { não têm personalidade jurídica. } \\
\text { - A gestão dos seus projetos é } \\
\text { realizada pelo meio da AGT } \\
\text { (Agência de Gestão Tecnológica) } \\
\text { que é um departamento mais } \\
\text { antigo que o próprio TECNOPUC. } \\
\text { - O TECNOPUC, bem como, a AGT, } \\
\text { a Incubadora RAIAR, o ETT } \\
\text { (Escritório de Transferência de } \\
\text { Tecnologia) e os outros organismos } \\
\text { associados ao funcionamento do } \\
\text { TECNOPUC estão subordinados à } \\
\text { pró-reitoria de pesquisa da PUCRS. }\end{array}$ & 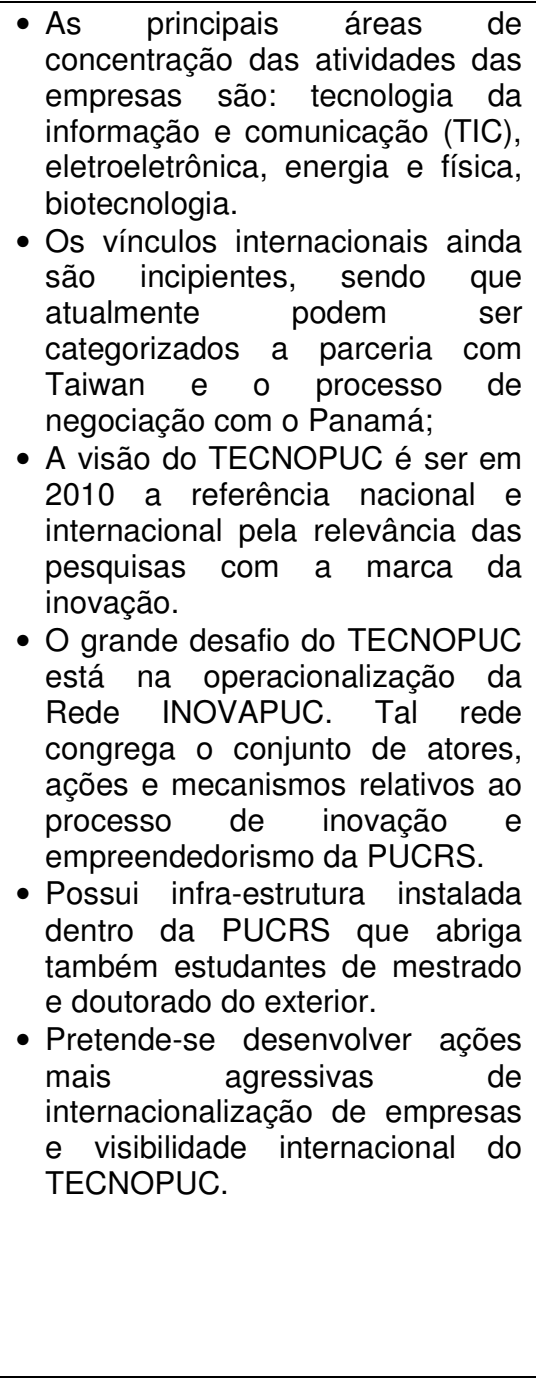 & 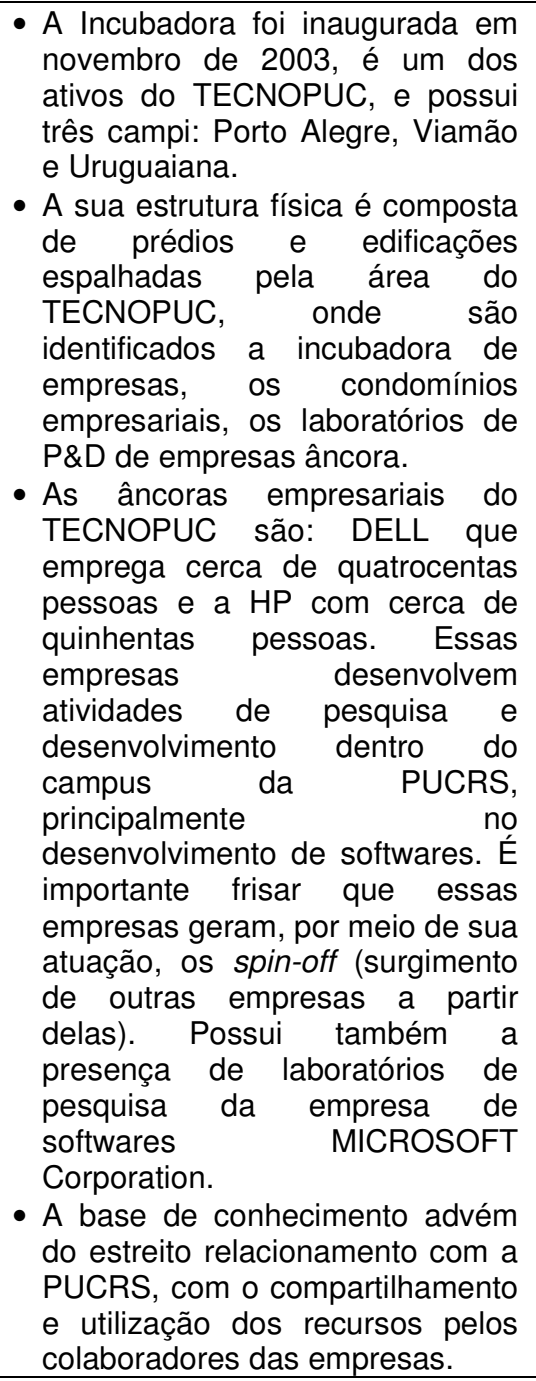 & $\begin{array}{l}\text { - O TECNOPUC está estruturado } \\
\text { no binômio, universidade- } \\
\text { empresas, contando com uma } \\
\text { grande universidade, dotada de } \\
\text { vários institutos e unidades } \\
\text { acadêmicas de pesquisa. } \\
\text { - A AGT é um departamento da } \\
\text { Pró-reitoria de Pós-Graduação da } \\
\text { PUCRS e é responsável por toda } \\
\text { interação universidade-empresas. } \\
\text { Conta com uma equipe de 13 } \\
\text { membros para atuação como elo } \\
\text { no processo dessa interação, } \\
\text { articulando as necessidades do } \\
\text { mercado com as competências } \\
\text { existentes na Universidade. } \\
\text { - ETT (Escritório de } \\
\text { Transferência de Tecnologia) está } \\
\text { ligado à Pró-Reitoria de pesquisa } \\
\text { e Pós-graduação e localiza-se no } \\
\text { Parque Tecnológico. Surgiu a } \\
\text { partir da necessidade de proteger } \\
\text { o patrimônio intelectual da } \\
\text { Universidade e de promover a } \\
\text { transferência dos resultados de } \\
\text { pesquisa ao setor produtivo. } \\
\text { Desenvolve registro da } \\
\text { propriedade intelectual, } \\
\text { transferência de tecnologia e } \\
\text { capacitação de recursos } \\
\text { humanos neste tema. } \\
\text { - A Universidade tem benefícios } \\
\text { indiretos gerados pela maior } \\
\text { atração de novos alunos } \\
\text { pagantes, pelas oportunidades } \\
\text { detectadas no TECNOPUC. }\end{array}$ \\
\hline
\end{tabular}




\begin{tabular}{|c|c|c|c|c|}
\hline Parques & Governança & Estratégia & infra-estrutura & Universidade-Empresas \\
\hline Porto Digital & 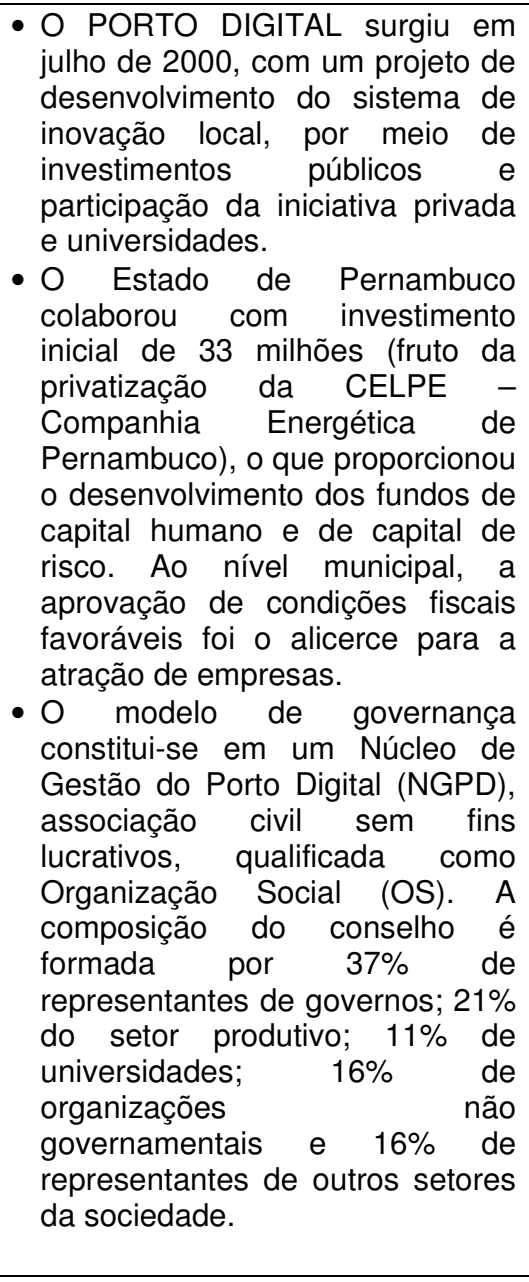 & 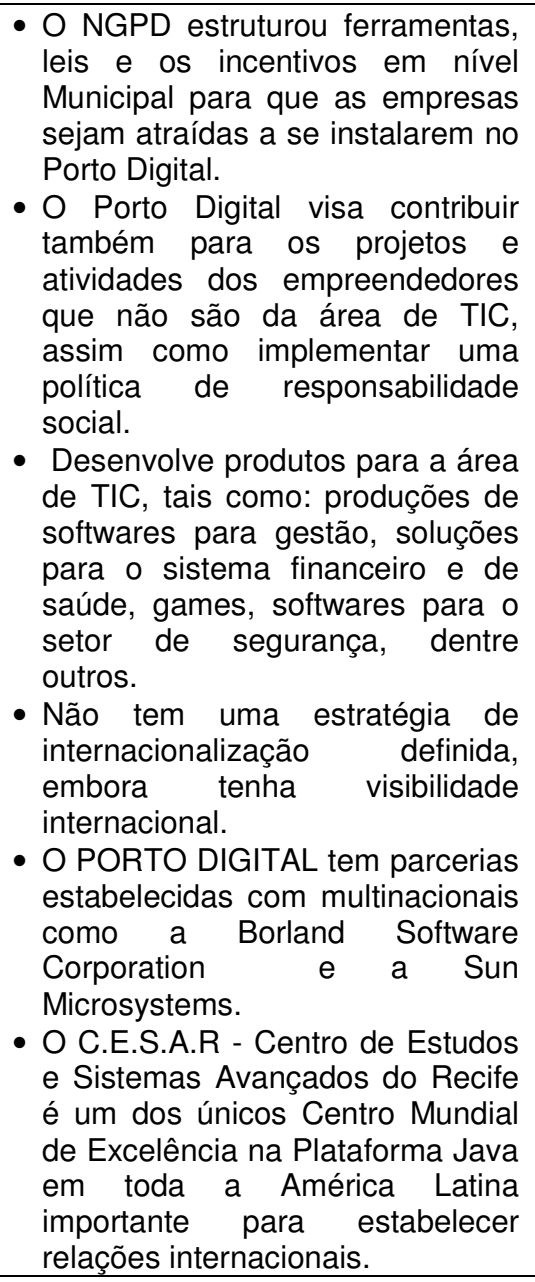 & $\begin{array}{l}\text { - O Porto Digital está situado no } \\
\text { sítio histórico do Bairro do Recife, } \\
\text { acrescentando ao projeto a } \\
\text { componente de revitalização e } \\
\text { requalificação urbana; foram } \\
\text { executadas obras civis de } \\
\text { recuperação de imóveis } \\
\text { históricos, importanteacervo } \\
\text { histórico e cultural da cidade. } \\
\text { - Números do Porto Digital: } 100 \\
\text { hectares; } 107 \text { organizações; 3,6 } \\
\text { mil empregos; } 8 \text { km de fibra ótica; } \\
26 \text { km de dutos. } \\
\text { - Ativos - O C.A.I.S. Centro de } \\
\text { Apoio de Integração e Suporte a } \\
\text { Empreendimentos de Tecnologia } \\
\text { da Informação e Comunicação } \\
\text { (TIC) do Porto Digital não é } \\
\text { apenas uma incubadora, pois } \\
\text { abriga também empresas já } \\
\text { consolidadas no mercado e que } \\
\text { permanecem no espaço para } \\
\text { usufruir do ambiente favorável. } \\
\text { - Elajá tem 07 anos e está } \\
\text { estruturada como um micro- } \\
\text { sistema local de inovação em } \\
\text { funcionamento no edifício sede do } \\
\text { Porto Digital. Reúne em um } \\
\text { mesmo ambiente físico um } \\
\text { conjunto diverso de organizações } \\
\text { e instituições que, articuladas, } \\
\text { promovem inovação } \\
\text { impulsionam negócios. }\end{array}$ & $\begin{array}{l}\text { - A base técnica do Porto Digital } \\
\text { está ancorada nas competências } \\
\text { desenvolvidas na Universidade } \\
\text { Federal de Pernambuco - UFPE. } \\
\text { - Possui o CESAR para promover a } \\
\text { transferência tecnológica entre } \\
\text { universidade, mercado e } \\
\text { sociedade; o CESAR é uma das } \\
\text { âncoras do Porto Digital, } \\
\text { associado ao Centro de } \\
\text { Informática da UFPE. } \\
\text { - Outro centro importante é o: } \\
\text { - CIN - Inovação, Excelência e } \\
\text { Criatividade fazem do Centro de } \\
\text { Informática da UFPE um dos } \\
\text { melhores centros acadêmicos de } \\
\text { informática da América Latina. O } \\
\text { CIN tem } 30 \text { anos de } \\
\text { funcionamento e oferece curso de } \\
\text { bacharelado em ciência da } \\
\text { computação, disponibilizando } 100 \\
\text { vagas por ano. Hoje atuam no } \\
\text { corpo docente do CIN } 46 \\
\text { doutores. Estão matriculados no } \\
\text { Centro cerca 123 alunos de } \\
\text { mestrado, } 65 \text { alunos de } \\
\text { doutorado e } 165 \text { de } \\
\text { especialização. Diversas } \\
\text { empresas do Porto Digital } \\
\text { nasceram a partir de projetos de } \\
\text { alunos do CIN. }\end{array}$ \\
\hline
\end{tabular}




\begin{tabular}{|c|c|c|c|c|}
\hline Parques & Governança & Estratégia & infra-estrutura & Universidade-Empresas \\
\hline $\begin{array}{l}\text { CERTI } \\
\text { Sapiens }\end{array}$ & $\begin{array}{l}\text { - A Fundação CERTI (Centros de } \\
\text { Referência em Tecnologias } \\
\text { Inovadoras) é uma instituição sem } \\
\text { fins lucrativos, de pesquisa e } \\
\text { desenvolvimento tecnológico, } \\
\text { com foco na inovação em } \\
\text { negócios, produtos e serviços no } \\
\text { segmento de tecnologia da } \\
\text { informação e coordena todas as } \\
\text { atividades relacionadas aos } \\
\text { Parques Tecnológicos em } \\
\text { Florianópolis: incluindo ALFA, } \\
\text { Sapiens e demais ativos. } \\
\text { - S Sapiens foi constituído como } \\
\text { uma empresa com representação } \\
\text { de diferentes atores, tendo como } \\
\text { principais entre os quais a própria } \\
\text { Fundação CERTI e o governo do } \\
\text { Estado de Santa Catarina. A sua } \\
\text { estrutura acionária apresenta - } \\
60 \% \text { propriedade da CODESC; a } \\
\text { Fundação CERTI - 6,5\% } \\
\text { (integralização do capital } \\
\text { intelectual); Sapientia 0,6\%. } \\
\text { - Também é importante ressaltar } \\
\text { que os projetos são estruturados } \\
\text { com base na formação de } \\
\text { sociedades de propósito } \\
\text { Específicos - SPE com definição } \\
\text { de governança específica para o } \\
\text { projeto.. } \\
\text { - Existe um acordo de acionista } \\
\text { favorável a favor da Fundação } \\
\text { CERTI - têm um forte poder de } \\
\text { veto (5 dos } 7 \text { membros do } \\
\text { Conselho de Administração). }\end{array}$ & $\begin{array}{l}\text { - Existe uma estratégia de } \\
\text { desenvolvimento tecnológico } \\
\text { regional em Florianópolis. } \\
\text { - A estratégia do Sapiens Parque } \\
\text { está ancorado eno } \\
\text { desenvolvimento de segmentos } \\
\text { com forte vocação em } \\
\text { Florianópolis como o turismo, a } \\
\text { tecnologia, o meio-ambiente e } \\
\text { serviços especializados. } \\
\text { - O Sapiens especificamente } \\
\text { encontra-se em fase de } \\
\text { desenvolvimento; as atividades } \\
\text { com maior relevância no } \\
\text { momento, , são relacionadas à } \\
\text { produção de filmes de animação } \\
\text { com a aplicação de TIC, } \\
\text { envolvendo o trabalho com } \\
\text { massas especiais. } \\
\text { - O processo de atração de } \\
\text { empresas ocorre por meio de } \\
\text { visitas e negociações no país e no } \\
\text { exterior. } \\
\text { - O tipo de empresas que estão } \\
\text { sendo atraídas em termos de } \\
\text { empresas âncora (como o caso } \\
\text { da Empresa SIEMENS do Brasil) } \\
\text { preferem estruturas maiores. } \\
\text { Estão tentando inclusive } \\
\text { desenvolver projetos mais } \\
\text { vultosos, incluindo negociação } \\
\text { com bancos privados que } \\
\text { pretendem instalar uma base } \\
\text { operacional no Parque, por } \\
\text { exemplo. } \\
\text { - As atividades desenvolvidas, } \\
\text { entre as quais a cinematrográfica } \\
\text { atraem produtoras internacionais. }\end{array}$ & $\begin{array}{l}\text { - Os ativos locais são: o Parque } \\
\text { Tecnológico Sapiens, a } \\
\text { incubadora CELTA (Centro } \\
\text { Empresarial para Laboração de } \\
\text { Tecnologias Avançadas), o } \\
\text { Parque Tecnológico Alfa e o } \\
\text { laboratório-escola LABelectron. } \\
\text { - O Parque Alpa abriga a grande } \\
\text { empresa nacional que surgiu a } \\
\text { partir de ambientes de inovação, } \\
\text { a BEMATEC que fatura } 250 \\
\text { milhões de reais/ano. } \\
\text { A Incubadora CELTA atualmente } \\
\text { instalado em um prédio com dez } \\
\text { mil e quinhentos metros } \\
\text { quadrados, distante } 4 \text { km do } \\
\text { campus da UFSC, mantém trinta } \\
\text { e oito empresas de base } \\
\text { tecnológica que geram } 785 \\
\text { empregos diretos e, no ano de } \\
\text { 2005, o faturamento das } \\
\text { incubadas alcançou } \\
\text { aproximadamente R } \$ 40 \text { milhões. } \\
\text { As áreas de interesse do CELTA, } \\
\text { a saber são: Instrumentação, } \\
\text { Telecomunicações, Automação, } \\
\text { Eletrônica, Mecaoptoeletrônica, } \\
\text { Microeletrônica, Informática ( } \\
\text { Incluindo hardware e software), } \\
\text { Mecânica de Precisão. } \\
\text { - O Sapiens Parque possui } 4,5 \\
\text { milhões m² (445 hectares) de } \\
\text { área, com o Potencial Máximo } \\
\text { Construtivo = 1,2 milhões m². } \\
\text { - A base de conhecimento do } \\
\text { Sapiens está ancorada nos } \\
\text { recursos da Universidade Federal } \\
\text { de Santa Catarina, utilizando os } \\
\text { recursos disponibilizados por ela. }\end{array}$ & $\begin{array}{l}\text { - A Fundação CERTI tem a sua } \\
\text { origem e manancial de capital } \\
\text { intelectual a Universidade Federal } \\
\text { de Santa Catarina. } \\
\text { - O CERTI possui sete Centros, } \\
\text { sendo cinco deles denominados } \\
\text { CRIT - Centro de Referência em } \\
\text { Tecnologias Inovadoras, Os cinco } \\
\text { atuais CRIT são: CME - CRIT em } \\
\text { Dispositivos Meca-Opto- } \\
\text { Eletrônicos; CMI - CRIT em } \\
\text { Soluções de Metrologia e } \\
\text { Instrumentação; CPC - CRIT em } \\
\text { Sistemas Produtivos } \\
\text { Cooperativos; CAI - CRIT em } \\
\text { Ambientes de Inovação; e CCD - } \\
\text { CRIT em Soluções de } \\
\text { Convergência Digital. } \\
\text { - Os outros dois Centros da CERTI } \\
\text { são: CIENCIA - Centro Incubador } \\
\text { de Empreendimentos, Novos } \\
\text { Conhecimentos e Idéias } \\
\text { Avançadas e CELTA S.A. que } \\
\text { está promovendo também } \\
\text { parcerias com universidades, } \\
\text { centros de pesquisa e } \\
\text { desenvolvimento, laboratórios e } \\
\text { outras organizações que busquem } \\
\text { um ambiente de inovação para } \\
\text { criar novas tecnologias e } \\
\text { conhecimentos. }\end{array}$ \\
\hline
\end{tabular}




\begin{tabular}{|c|c|c|c|c|}
\hline Parques & Governança & Estratégia & infra-estrutura & Universidade-Empresas \\
\hline $\begin{array}{l}\text { São José } \\
\text { dos Campos }\end{array}$ & $\begin{array}{l}\text { - A Prefeitura de São José dos } \\
\text { Campos pode ser considerada } \\
\text { como o principal elemento de } \\
\text { governança na instalação do } \\
\text { Parque Tecnológico de São José } \\
\text { dos Campos. } \\
\text { - Em março de } 2006 \text { começou a } \\
\text { implantação do Parque } \\
\text { Tecnológico de São José por } \\
\text { meio de uma parceria entre a } \\
\text { Prefeitura que estima-se que } \\
\text { investiu 30, } 6 \text { milhões de reais e o } \\
\text { Governo do Estado que investiu } 6 \\
\text { milhões. } \\
\text { - O Parque é uma PPP (parceria } \\
\text { público-privada), visto que } \\
\text { envolve atividades de agentes } \\
\text { públicos, em níveis federal, } \\
\text { estadual e municipal; e privados. } \\
\text { - Possui dois organismos de } \\
\text { gestão: a URBAM, que é um } \\
\text { órgão da administração Pública, } \\
\text { responsável pela parte imobiliária } \\
\text { e a APTSJC, a Associação } \\
\text { Parque Tecnológico de São José } \\
\text { dos Campos, órgão responsável } \\
\text { pela gestão dos ativos e também } \\
\text { pela articulação externa. } \\
\text { - A Incubadora de Negócios } \\
\text { sediada no Parque Tecnológico } \\
\text { de São José dos Campos, é } \\
\text { gerenciada pelo Cecompi, possui } \\
\text { como parceiros: Prefeitura e o } \\
\text { SEBRAE-SP. }\end{array}$ & $\begin{array}{l}\text { - A estratégia de atração de } \\
\text { empresas está baseada na } \\
\text { articulação com os centros de } \\
\text { tecnologia, que envolve parcerias } \\
\text { com grandes empresas como a } \\
\text { Embraer, a Petrobrás e a VALE S. } \\
\text { A. Estas empresas aplicam parte } \\
\text { do percentual das suas receitas } \\
\text { em atividades de Pesquisa e } \\
\text { desenvolvimento. } \\
\text { - Para financiamento das suas } \\
\text { atividades busca-se o patrocínio } \\
\text { dos principais agentes de fomento } \\
\text { do país e também dos bancos de } \\
\text { desenvolvimento. } \\
\text { - Em relação a internacionalização, } \\
\text { existe um movimento de atração } \\
\text { de empresas internacionais para } \\
\text { compor o Parque Tecnológico, } \\
\text { além de parcerias para o } \\
\text { desenvolvimento de pesquisas e } \\
\text { tecnologias. }\end{array}$ & $\begin{array}{l}\text { - Com o conceito de uma zona } \\
\text { especial, a ZEPTEC - área de } \\
12,5 \text { milhões de metros } \\
\text { quadrados. } \\
\text { - O Núcleo do Parque tecnológico } \\
\text { possuí área de } 1 \text { milhão de } \\
\text { metros quadrados e área } \\
\text { construída de } 30 \text { mil metros } \\
\text { quadrados. } \\
\text { - Atualmente já estão implantados } \\
\text { os Centros de Desenvolvimento } \\
\text { de Tecnologias, Incubadora de } \\
\text { Negócios, Arranjos Produtivos } \\
\text { Locais, Faculdade de Tecnologia } \\
\text { (Fatec), Cecompi (Centro para a } \\
\text { Competitividade e Inovação do } \\
\text { Cone Leste Paulista) e Centro de } \\
\text { Eventos. } \\
\text { - A próxima etapa prevê a } \\
\text { implantação de outros ativos, } \\
\text { como os pequenos condomínios } \\
\text { industriais, os campi da Unifesp } \\
\text { (Universidade Federal de São } \\
\text { Paulo), Unesp (Universidade } \\
\text { Estadual de São Paulo) e Fatec - } \\
\text { Faculdade de Tecnologia, além } \\
\text { de uma unidade do Senai - } \\
\text { Serviço nacional de } \\
\text { aprendizagem industrial. } \\
\text { - Centro de Inovação da Microsoft } \\
\text { (Microsoft Innovation Center) - } \\
\text { MIC, local onde é desenvolvido } \\
\text { um ecossistema de pesquisa } \\
\text { aplicada e desenvolvimento } \\
\text { tecnológico, envolvendo } \\
\text { companhias do mercado público e } \\
\text { privado, universidades e } \\
\text { empresas desenvolvedoras de } \\
\text { software. }\end{array}$ & $\begin{array}{l}\text { - Desenvolvimento de } \\
\text { plataformas científicas e } \\
\text { tecnológicas para estudo de } \\
\text { temas específicos com a } \\
\text { presença: Centro de } \\
\text { Desenvolvimento de Tecnologia } \\
\text { Aeronáutica - CDTA } \\
\text { envolvendo a participação da } \\
\text { Prefeitura, do Instituto } \\
\text { Tecnológico de Aeronáutica } \\
\text { (ITA), do Instituto de Pesquisas } \\
\text { Tecnológicas (IPT) e a } \\
\text { Embraer. } \\
\text { Centro de Desenvolvimento } \\
\text { Tecnológico em Energia - } \\
\text { CDTE conta com a parceira do } \\
\text { BNDES (Banco Nacional de } \\
\text { Desenvolvimento Econômico e } \\
\text { Social), do ITA e da Escola de } \\
\text { Engenharia de São Carlos } \\
\text { (USP). } \\
\text { Os projetos serão } \\
\text { desenvolvidos de acordo com } \\
\text { as leis de referência a saber: lei } \\
\text { de inovação (lei 10.973 Federal } \\
\text { de } 2 \text { de dezembro de } 2004 \\
\text { regulamentada pelo decreto } \\
5.563 \text { de } 11 \text { de outubro de } \\
2005 \text { ) e lei Paulista de inovação } \\
\text { (Lei complementar } 1049 \text { de } 19 \\
\text { de junho de } 2008 \text { ). }\end{array}$ \\
\hline
\end{tabular}


$\mathrm{Na}$ Tabela 6.4.2 são apresentadas as informações referentes às experiências selecionadas e estudadas durante a missão realizada na França para o desenvolvimento da pesquisa sobre Pólos de Competitividade (8 a 16 de setembro de 2008). As entrevistas presenciais foram realizadas com o apoio da Professora Doutora Désirée Zouain e a colaboração no agendamento do Dr. Michel Brunet, então Adido de Cooperação Técnico-Científica do Consulado da França em São Paulo. Além disso, para a marcação das entrevistas foi fundamental a colaboração da Embaixada do Brasil na França, por intermédio da representante Sra. Diana Porto e da equipe da UNIDO-França, sediada em Paris, sob a coordenação do Dr. Yves Darricaud.

Para a seleção das experiências utilizou-se dois critérios principais: i) relacionado ao perfil de atividade desenvolvida no Pólo, a qual deveria ter um perfil tecnológico de média a alta intensidade tecnológica; ii) disponibilidade de participar da pesquisa, com base na resposta ao questionário (Apêndice A) e agendamento prévio da entrevista.

Tabela 6.4.2 - Dados cadastrais das experiências francesas selecionadas para as entrevistas.

\begin{tabular}{|c|c|c|}
\hline Organização & Entrevistados & Local \\
\hline $\begin{array}{llr}\text { Observatório dos } & \text { Pólos de } \\
\text { competitividade } & \text { - École } \\
\text { Nationale Supérieure } & \text { des } \\
\text { Mines } & \text { de } & \text { Paris }\end{array}$ & $\begin{array}{l}\text { - Dr. Thierry Weil: thierry.weil@ensm - } \\
\text { p.fr } \\
\text { - e a aluna de doutorado Stéphanie } \\
\text { Fen Chong: } \\
\text { - stephanie.fen-chong@ensmp.fr }\end{array}$ & $\begin{array}{l}\text { - 60-62, Boulevard Saint } \\
\text { Michel } \\
75272 \text { Paris, França }\end{array}$ \\
\hline $\begin{array}{l}\text { Pólo de Competitividade à } \\
\text { vocação Mundial - Medicen } \\
\text { Paris Région }\end{array}$ & $\begin{array}{l}\text { Gerentes de projetos: } \\
\text { Céline Griener:cgriener@medicn.org } \\
\text { e Agnès De De Simone: } \\
\text { adesimone@medicen.org }\end{array}$ & $\begin{array}{l}6 \text { rue Alexandre Cabanel } \\
75015 \text { Paris, França }\end{array}$ \\
\hline $\begin{array}{l}\text { Pólo de Competitividade à } \\
\text { vocação Mundial - I-TRANS - } \\
\text { Pesquisa e formação no } \\
\text { domínio do transporte } \\
\text { ferroviário e de sistemas de } \\
\text { transportes trerrestres } \\
\text { inovadoras nas regiões Nord- } \\
\text { Pas de Calais e Picardie. }\end{array}$ & $\begin{array}{l}\text { Delegado Geral do Pólo } \\
\text { Jean-Pierre Provo } \\
\text { jean-pierre.provo@i-trans.org }\end{array}$ & $\begin{array}{l}\mathrm{CRCl}-\text { Chambre } \\
\text { Régionale de Commerce } \\
\text { et d'Industrie. } \\
\text { 2, Palais Bourse } 59000 . \\
\text { Lille, França }\end{array}$ \\
\hline $\begin{array}{l}\text { Pólo de Competitividade à } \\
\text { vocação Mundial Cap Digital } \\
\text { Paris Région }\end{array}$ & $\begin{array}{l}\text { Gerente de projetos } \\
\text { Eduardo Oliveira: } \\
\text { eduardo.oliveira@capdigital.com }\end{array}$ & $\begin{array}{l}\text { 5, Rue d'Uzes } 75002 \\
\text { Paris, França }\end{array}$ \\
\hline $\begin{array}{l}\text { Pólo de Competitividade à } \\
\text { vocação Mundial System@tic } \\
\text { Paris Région }\end{array}$ & $\begin{array}{l}\text { Presidente - Systems Design \& } \\
\text { Development Tools - Gérard Poirier } \\
\text { gerard.poirier@dassault_aviation.fr }\end{array}$ & $\begin{array}{l}\text { 78,Quai Macel Dassault } \\
\text { - St Cloud - França }\end{array}$ \\
\hline $\begin{array}{ll}\text { Pólo de } & \text { Competitividade } \\
\text { Aeroespacial } & \text { ASTech Paris } \\
\text { Région } & \end{array}$ & $\begin{array}{l}\text { Diretor Geral: Gérard Laruelle } \\
\text { gerard.laruelle@pole-astech.org } \\
\text { e o Vice Presidente Gérard Poirier } \\
\text { gerard.poirier@pole-astech.org }\end{array}$ & $\begin{array}{l}\text { Rue des Vertudadins, } \\
\text { 92190, Meudon, França }\end{array}$ \\
\hline
\end{tabular}




\subsection{Observatório dos Pólos de Competitividade}

É uma plataforma aberta liderada pela École Nationale Supérieure des Mines de Paris, a pedido da Associação das Regiões de França, que visa o intercâmbio de informações e debates abertos a todos os envolvidos na vida pólos de competitividade, atuando direta ou indiretamente.

A École Nationale Supérieure des Mines de Paris (Figura 6.5-1) foi fundada em 1783 com ênfase na mineração e na indústria de alta tecnologia, com ênfase nos aspectos de segurança dos trabalhadores e de planejamento econômico. Com o desenvolvimento econômico da região ela ampliou o seu escopo e hoje exibe competência nas áreas de engenharias e ciências econômicas e sociais.

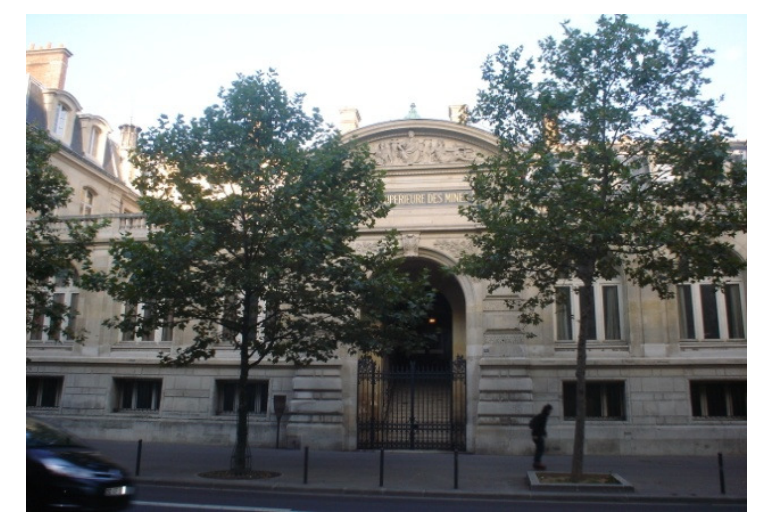

Figura 6.5-1: École Nationale Supérieure des Mines de Paris. Foto de autor tirada durante a entrevista técnica em 09/09/2009.

Os seus objetivos envolvem o aumento da interatividade entre os pólos e os atores das iniciativas pública, privada e acadêmica, servindo como uma plataforma que incentiva a disseminação dos conhecimentos entre os participantes.

No contexto do projeto de doutorado, a École Nationale Supérieure des Mines de Paris, foi selecionada baseado no fato que é a única instituição que desenvolveu um estudo com base científica para analisar os Pólos de Competitividade na França. 


\subsection{Pólo I-TRANS Pesquisa e formação no domínio do transporte ferroviário e de sistemas de transportes trerrestres inovadoras}

O I-TRANS é um Pólo à vocação mundial, reconhecido em 2005, com atuação nas regiões Nord-Pas-de-Calais e Picardie, tendo como objetivo desenvolver inteligência no setor de transportes.

O início do processo deriva da criação de uma associação em Valenciennes, que tinha como objetivo principal desenvolver soluções para o transporte ferroviário e automobilístico considerando a vocação da região (NordPas-de-Calais-Picardie) que concentra uma parcela significativa dos empregos nesses setores (250 mil empregos).

Com a instalação de dois importantes atores na região: a Agência Ferroviária Européia (AFE) em Valenciennes eda Organização Pública de Segurança Ferroviária em Amiens, a situação ficou favorável para o credenciamento como Pólo de Competitividade obtido por meio da associação Transports Terrestres Promotion (TTP) Northern France14, criada em 1991.

O Pólo de Competitividade reúne os principais atores da indústria, da pesquisa, e dos setores ferroviário, automobilístico, logístico e dos sistemas de transporte terrestres inovadores situados na região de abrangência do Pólo (Tabela 6.6.1).

Existem quatro domínios de atividade, os quais têm como objetivo o desenvolvimento sustentável:

- Transporte ferroviário - com foco na inter-operatividade (fazer com que um trem que opera (fabricado) na França possa operar em qualquer outra parte da Europa);

- Transporte automotivo - atuam em sistemas embarcados (usam as competências existentes localmente) - como no caso da Universidade de Compiegne.

- Logística - visam favorecer as trocas entre as plataformas logística-modais (transportes marítimos, ferroviários, automotivos); isso faz com que todos os contratos aduaneiros sejam facilitados (eles não autam sobre os aspectos de engenharia), atuando na otimização de processos;

\footnotetext{
${ }^{14}$ Associação, para gestão do Pólo de competitividade.
} 
- Sistemas de transporte inteligentes - promovem eventos, participações e articulações para divugar a cpacitação existente na região nesse setor.

O pólo quer ser o líder europeu em projetos, construção, manutenção, exploração de sistemas de transportes terrestres. Para isso investe amplamente em Pesquisa e Desenvolvimento com estimativa de 50 milhões de euros de investimentos até o final de 2010.

Tabela 6.6.1 - Principais características do Pólo I-TRANS.

\begin{tabular}{|c|c|}
\hline Setores & $\begin{array}{l}\text { Transporte ferroviário, automobilístico, logístico e sistemas de } \\
\text { transportes inteligentes. }\end{array}$ \\
\hline Regiões Principais & Norte da França (regiões Nord-Pas-de-Calais e Picardie) \\
\hline Número de Empresas & $\begin{array}{l}46 \text { empresas, envovendo dentre outras: Alstom Transport, AMKEY } \\
\text { Management, Arcelor Altlantique et Lorraine, Atos Worldline, } \\
\text { Bombardier Transport, Carbone lorraine, EGIS Mobilité, Faiveley } \\
\text { Transport, Federal Mogul, GECOM, Hutchinson, NFTlou, OUTREAU } \\
\text { Technologies, Railtech International, RATP, Renault, Saint Gobain } \\
\text { Sekurit, Siemens, SNCF, Direction de Lille, Valeo Embrayages, } \\
\text { Vistéon Systèmes Intérieurs, Vossloh Cogifer }\end{array}$ \\
\hline Centros de Pesquisa & $\begin{array}{l}\text { Organizações de pesquisa e desenvolvimento : } \\
\text { Centro Nacional de Pesquisa Científica(C.N.R.S.), CETIM (Centro } \\
\text { Técnico de Indústria Mecânica), CREPIM, (Centro de Pesquisa e } \\
\text { estudos sobre materiais), INERIS, Instituto Nacional de Pesquisa em } \\
\text { Transpostes (INRETS), INRIA (Instituto Nacional em Pesquisa } \\
\text { Ciência da Computação e controle), ONERA (Centro Francês de } \\
\text { Pesquisa Aeroespacial) e outros. } \\
6 \text { Estabelecimentos Educacionais. } \\
\text { Escola Central de Lill- e, ENSAIT (Escola Superior de Artes e } \\
\text { Indústria Textil), ENSAM (Escola Superior de artes), ENTE (Escola } \\
\text { Nacional de técnicas de equipamentos), ESC Lille (Escola de Lille), } \\
\text { ESIEE (Escola Superior de Engenharia). } \\
\text { Estabelecimentos Educacional e de Pesquisa. } \\
\text { Ecole des Mines de Douai, Ecole Supérieur de Chimie de Lille, ICAM, } \\
\text { Université d'Artois, Université Picardie Jules Verne, Université } \\
\text { Sciences et Technologies de Lille, UniversitéTechnologique de de } \\
\text { Compiègne, Université de Valenciennes Hainaut-Cambrésis }\end{array}$ \\
\hline Número de Empregos & $\begin{array}{l}\text { Total de } 290.829 \text { empregos, considerando os empregos nas } \\
\text { empresas envolvidas no Pólo. }\end{array}$ \\
\hline $\begin{array}{l}\text { Principais atividades nas } \\
\text { PME }\end{array}$ & $\begin{array}{l}\text { Extração de pedras para construção, construção de material } \\
\text { ferroviário rolante, engenharia e estudos técnicos, comércio de livros, } \\
\text { jornais e papelaria, organização de transportes internacionais. }\end{array}$ \\
\hline Projetos & $\begin{array}{l}53 \text { projetos credenciados: } 35 \text { projetos de inovação, } 15 \text { projetos de } \\
\text { pesquisa, } 2 \text { projetos de acompanhamento e um projeto global de } \\
\text { formação. }\end{array}$ \\
\hline
\end{tabular}




\subsection{Medicen Paris Région}

O Medicen Paris Région é um pólo de competitividade à vocação mundial, estruturado num arranjo que envolve os atores na área de saúde como hospitais, a indústria farmacêutica e as universidades e pequenas empresas de produtos médicos, contando com especialistas em ciências da vida e saúde.

Está localizado na região lle-de-France, uma região central da Europa, considerada uma das regiões do mundo com maior densidade em termos de pesquisa (estima-se 126.000 pessoas atuando com atividades de pesquisa). $\mathrm{Na}$ Figura 6.7-1 encontra-se uma foto do prédio onde está instalada a administração do Pólo.

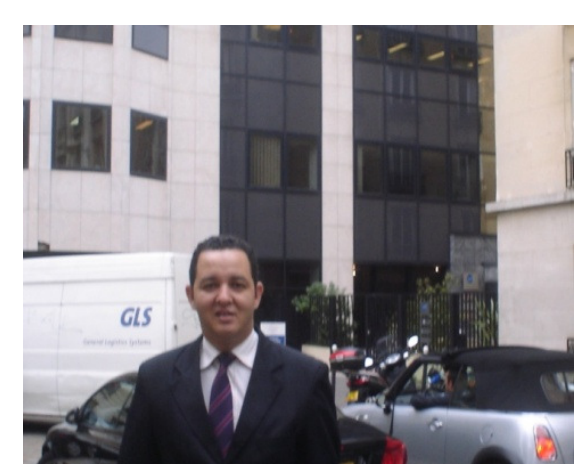

Figura 6.7-1: Escritório Médicen Paris. Foto de autor tirada durante a entrevista técnica em 12/09/2008.

O orçamento para custear a estrutura do Pólo custa cerca de um milhão de euros por anos, as atividades de Pesquisa e Desenvolvimento estão avaliadas em 260 milhões de euros por um período de três anos.

$\mathrm{Na}$ Tabela 6.7.1 são apresentados os dados das suas características, envolvendo inclusive os principais centros de pesquisa existente.

Tabela 6.7.1 - Principais características do Pólo Medicen

\begin{tabular}{l|l}
\hline Setores & $\begin{array}{l}\text { Oncologia, doenças do sistema nervoso, doenças infecciosas, terapias } \\
\text { moleculares e celulares, drogas farmacêuticas e imagens médicas. }\end{array}$ \\
\hline Regiões Principais & Ile de France \\
\hline Número de Empresas & $\begin{array}{l}\text { 99, envolvendo dentre outras: Novo Nordisk, Novartis, Philips Medical } \\
\text { Systems, Sanofi-Aventis, Servier, Siemens, Sun Microsystems, Zeiss, } \\
\text { Cap Gemini, Danone, General Electric Healthcare, GlaxoSmithKline, }\end{array}$ \\
\hline $\begin{array}{l}\text { Harrison Clinical Research, Chemunex, Denoyelle, Hamamatsu, } \\
\text { Medasys-Hitachi, Ipsen }\end{array}$ \\
\hline Centros de Pesquisa & $\begin{array}{l}\text { 20, envolvendo Centos de pesquisa e centros de formação, por exemplo, } \\
\text { Pasteur Institute, the Evry Génopole e o Atomic Energy Center (CEA) } \\
\text { biotechnologies labs. }\end{array}$ \\
\hline Número de Empregos & Total de 13.963 empregosenvolvendo as empresas associadas ao Pólo. \\
\hline
\end{tabular}




\begin{tabular}{l|l}
\hline $\begin{array}{l}\text { Principais atividades } \\
\text { das PMes }\end{array}$ & $\begin{array}{l}\text { Neurociência, Oncologia, Doenças infecciosas, Imagens biomédicas, } \\
\text { Medicina molecular e celular, ciências e tecnologias do medicamento. }\end{array}$ \\
\hline Projetos & $\begin{array}{l}\text { De Setembro de 2005 a Abril de 2007, o Pólo credenciou } 19 \text { projetos } \\
\text { colaborativos de Pesquisa e Desenvolvimento, dos quais } 18 \text { receberam } \\
\text { financiamento público. }\end{array}$ \\
\hline
\end{tabular}

\subsection{Cap Digital Paris Région}

O Cap Digital é um Pólo de vocação mundial que trabalha os setores de imagem e multimídia, com base em três eixos:

- desenvolvimento estratégico consistente com amplo plano de desenvolvimento de toda a região,

- fortes parcerias público-privadas;

- concentração de indústrias baseadas em alto nível de conhecimento.

O Cap Digital está localizado em Paris (Figura 6.8-1) e faz a interface entre as tecnologias digitais e seis setores estratégicos firmemente enraizados na região de Paris: conhecimentos em engenharia, patrimônio digital, imagens, sons e interatividade, videogames, educação digital e serviços e práticas. Apesar de recente, com cerca de dois anos e meio de atuação, o pólo já registra excelentes resultados: ao todo, são 330 membros - o que inclui mais de 270 pequenas e médias empresas, 20 grandes empresas, 37 instituições públicas, universidades, centros de pesquisa e centros de formação, entre outros - e 140 projetos credenciados (Tabela 6.8.1).

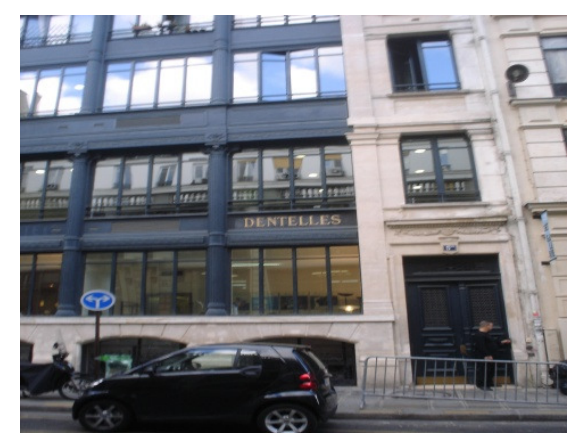

Figura 6.8-1: Pólo Cap Digital. Foto de autor tirada durante a entrevista técnica em 12 de Setembro de 2008.

A iniciativa já movimentou 213 milhões de euros em investimentos privados e 148 milhões em financiamento público. Existe bastante similaridade com a realidade nacional, entre elas: a característica das empresas, a maioria pequenas e médias, a subcapitalização (capital insuficiente por parte dessas empresas) e o grande potencial criativo e artístico. 
Tabela 6.8.1 - Principais características do PÓLO CAP DIGITAL

\begin{tabular}{|c|c|}
\hline Setores & Tecnologia de informação e comunicação e conteúdos digitais \\
\hline Regiões Principais & Ile de France \\
\hline Número de Empresas & $\begin{array}{l}\text { Total de } 250 \text { empresas, sendo mais de } 30 \text { empresas com } \\
\text { reputação global: Lagardère Interactive, Editis, France Télécom, } \\
\text { EADS, Thalès, TF1, Canal+, Sagem, Motorola, Eurodisney, } \\
\text { Europacorp, SFP, TSF. } \\
200 \text { pequenas e médias empresas altamente dinâmicas: } \\
\text { Attitude Studio, Akkana, Odile Jacob Multimédia, Sinequa, } \\
\text { Exalead, Pertimm, Eclair, Mac Gull Line, Mikros, Capital Games, } \\
\text { Silicon Sentier e inúmeras outras pequenas e médias empresas. }\end{array}$ \\
\hline Centros de Pesquisa & $\begin{array}{l}\text { Estão presentes nos Pólos } 50 \text { laboratórios de pesquisa como o } \\
\text { INA (Instituto Nacional de audio-visual), Escritório de } \\
\text { Documentação Francês, O IRCAM, (Instituto de pesquisa e } \\
\text { coordenação acústica/musical), BDIC (Biblioteca de } \\
\text { documentação internacional contemporânea), etc. }\end{array}$ \\
\hline Número de Empregos & $\begin{array}{l}\text { Total de } 169.399 \text { empregos envolvendo as empresas associadas } \\
\text { ao Pólo. }\end{array}$ \\
\hline Principais atividades & $\begin{array}{l}\text { Engenharia do conhecimento; } \\
\text { Patrimônio numérico } \\
\text { Educação numérica } \\
\text { Som, imagem e interatividade } \\
\text { Vídeo game } \\
\text { Serviços para utilização. }\end{array}$ \\
\hline Projetos & $\begin{array}{l}\text { Foram desenvolvidos } 16 \text { projetos de Pesquisa e Desenvolv } \\
\text { mento. }\end{array}$ \\
\hline
\end{tabular}




\subsection{ASTech Paris Région}

Considerando o domínio aeronáutico e espacial, a França é um dos líderes mundiais. Especificamente, a região de lle de France contribui para esta liderança nas áreas de aviação de negócios, transporte espacial, motor e equipamentos, graças a presença da indústria que é competitiva globalmente e seus parceiros.

Essa atividade intensiva em conhecimento foi desenvolvida com a presença de centros de excelência e centros de pesquisa que contribuam para desenvolvimento de toda a indústria francesa aeroespacial, fato que justifica a atuação do Pólo ASTech nessa região (Figura 6.9-1).

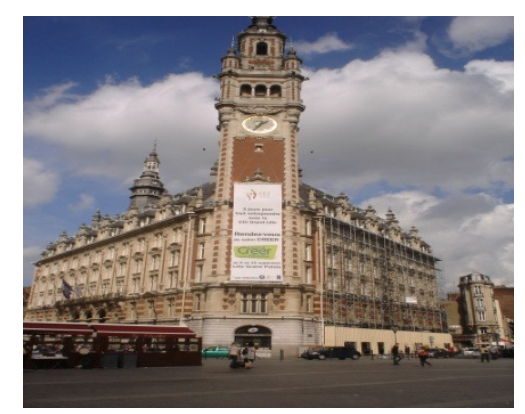

Figura 6.9-1: Chambre Régionale de Commerce et d'Industrie, Lille - France

O Pólo é complementar a outros Pólos que desenvolvem atividades no mesmo segmento industrial, como o AESE que abrange aviação comercial, satélites, estudos atmosféricos e sistemas embarcados e o Pégase da região Côte d'Azur (PACA) centrada em helicópteros. Além disso, o Paris ASTech Região tem uma Sistema de pólos complementares tecnologicamente 0 System@atic e o MOV'EO.

O Pólo tem duas missões principais, a primeira missão do pólo é prover projetos, por meio da articulação entre academia e iniciativa privada, a segunda é fortalecer o setor Aeroespacial na lle de France. Na Tabela 6.9.1 são apresentadas as principais características do Pólo. 
Tabela 6.9.1 - Principais Características do Pólo ASTech.

\begin{tabular}{l|l}
\hline Setores & $\begin{array}{l}\text { Aviação de negócios } \\
\text { Transporte espacial } \\
\text { Equipamentos e Motorização }\end{array}$ \\
\hline Regiões Principais & Ile de France \\
\hline Número de Empresas & Total de 60 empresas. \\
\hline Centros de Pesquisa & 15 centros de pesquisa e mais 20 centros de formação. \\
\hline Número de Empregos & 100.000 empregos na área de lle de France \\
\hline Principais atividades & $\begin{array}{l}\text { Propulsão } \\
\text { Materiais } \\
\text { Energia a bordo } \\
\text { Arquitetura de Veículos }\end{array}$ \\
\hline Projetos & $\begin{array}{l}\text { THERMELEC - Gerenciamento Térmico por Eletrônica } \\
\text { embarcada; } \\
\text { SEFORA }- \text { Acionador Elétrico Inteligente para Ambientes } \\
\text { severos. } \\
\text { REBECCA - Redução do ruído do motor de aeronaves por } \\
\text { conceitos avançados de tecnologia. } \\
\text { TOSCA - Tecnologias para operação de sistemas de injeção em } \\
\text { cadeias aeronaúticas. }\end{array}$ \\
\hline
\end{tabular}




\subsection{System@tic}

É um Pólo mundial, localizado na Região de lle de France (Figura 6.10-1), focado em sistemas eletrônicos complexos, com utilização no direcionamento, supervisão, regulação e controle de instalações sofisticadas. Abrange atividades de comércio, finanças, saúde, segurança, transporte e energia.

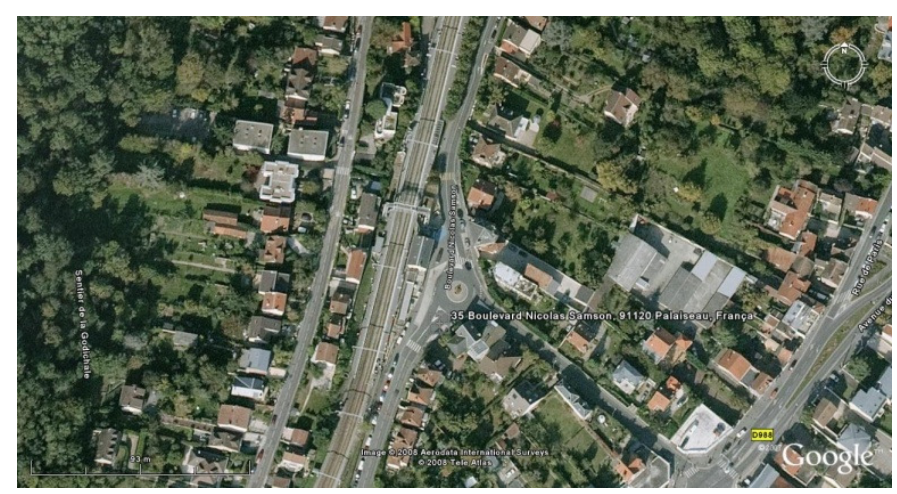

Figura 6.10-1: Pólo System@tic. Fonte: software google Earth. Acessada em 15/09/2008.

O Pólo posiciona-se como líder industrial nas áreas de soluções para conceitos, gestão e manutenção de sistemas computacionais complexos, em quatro mercados-alvo, descritos na seqüência:

- Telecomunicações;

- Automotiva e Transporte,

- Segurança e Defesa,

- Ferramentas de Projetos e desenvolvimento de sistemas.

Os seus objetivos principais do Pólo são:

- Desenvolver a atividade econômica e o emprego;

- Criar industriais e empresas de serviços: definir o objetivo de quinze com elevado potencial de crescimento por ano;

- Seleção de pesquisadores, atraindo especialmente os centros de $P$ \& $D$ empresas internacionais neste domínio: recrutamento objetivo de 4.000 cientistas por ano. 
Tabela 6.10.1 - Principais características do Pólo Sistem@tic

\begin{tabular}{|c|c|}
\hline Setores & $\begin{array}{l}\text { Controle de tecnologias-chave (óptica, eletrônica e software) e } \\
\text { sistemas complexos nos seguintes temas: } \\
\text { - Telecomunicações; } \\
\text { - } \quad \text { Automóveis e Transporte; } \\
\text { - Segurança e Defesa; } \\
\text { - } \quad \text { Ferramentas de desenho e desenvolvimento de sistemas; } \\
\text { - Software Livre }\end{array}$ \\
\hline Regiões Principais & lle de France \\
\hline Número de Empresas & $\begin{array}{l}\text { Total de } 180 \text { empresas, sendo } 100 \text { MPEs } \\
\text { Grandes empresas - Alcatel, Altis Semiconductor, Bull, Cegelec, } \\
\text { Dassault Avion, EADS, EDF, France Telecom, Motorola, Renault, } \\
\text { Sagem, Thales, Valeo. } \\
\text { MPEs - Adise SAS, Aevix, Amesim, Bertin Technologies, CAPS } \\
\text { Entreprise, CGG, CIMPA, Comsis, Cril Telecom Software SA, } \\
\text { Esterel Technology, ESI Group, Euraltech, GridXpert, Haption, } \\
\text { llog, Intercontrole, Kylia, M2M, N2soft, Newphenix, Ommic, } \\
\text { Picogiga SAS, Pyramis, Resonate, Samtech, Softeam, Trialog, } \\
\text { Trusted Logic, Vecsys, Virtools }\end{array}$ \\
\hline Centros de Pesquisa & $\begin{array}{l}134 \text { centros de pesquisa e mais } 44 \text { centros de formação. } \\
\text { CNES (Centro Nacional de Estudos Espaciais - Centro Pesquisa } \\
\text { Espaço), Ecole Centrale Paris, Polytechnique, INRIA (Instituto } \\
\text { Nacional Francês para pesquisa em ciências da Computação e } \\
\text { controle.), Supelec (Engenharia Elétrica e Ciência da } \\
\text { Computação), etc. }\end{array}$ \\
\hline Número de Empregos & $\begin{array}{l}\text { Total de } 706.270 \text { empregos na área de lle de France } \\
\text { considerando s empresas associadas. }\end{array}$ \\
\hline Principais atividades & $\begin{array}{l}\text { Sistemas embarcados } \\
\text { Infra-estrutura distribuída } \\
\text { Interface humana } \\
\text { Softwares } \\
\text { Eletrônica } \\
\text { Ótica }\end{array}$ \\
\hline Projetos & $\begin{array}{l}\text { Foram desenvolvidos } 93 \text { projetos, dentro de } 5 \text { atividades } \\
\text { principais distribuídas nos grupos de } \\
\text { Automotivo e Trabalho: } \\
\text { Segurança e Defesa; Projeto de software livre e aberto; } \\
\text { ferramentas, Telecomunicações. }\end{array}$ \\
\hline
\end{tabular}

O system@tic foi um dos primeiros pólos a ser criado, o mesmo conta atualmente com 101 projetos de pesquisa nos cinco grupos temáticos nos quais está organizado, com foco em inovações de ruptura que possam representar um referencial para as empresas em termos de mercado. 
Tabela 6.10.2 - Características dos Pólos Franceses.

\begin{tabular}{|c|c|c|c|c|}
\hline PÓLOS & Governança & Estratégia & Infra-estutura & Universidade-Empresas \\
\hline I--Trans & $\begin{array}{l}\text { - Figura jurídica de uma associação } \\
\text { sem fins lucrativos composta por } \\
\text { representantes de empresas e de } \\
\text { organismos de pesquisa. } \\
\text { - Falta Integração do Pólo nas } \\
\text { estratégias locais de inovação } \\
\text { - O Pólo é estruturado a partir de } \\
\text { associações, sendo que essas } \\
\text { prevêem a participação das } \\
\text { empresas associadas. } \\
\text { - Existe uma diferenciação da } \\
\text { participação das empresas, sendo } \\
\text { que as grandes empresas pelo fato } \\
\text { oferecer uma estrutura mais } \\
\text { adequada para Pesquisa e } \\
\text { Desenvolvimento tendem a exercer } \\
\text { seu poder de governança. } \\
\text { - Grandes empresas como âncoras, } \\
\text { tais como Alstom Transport, AMKEY } \\
\text { Management, Arcelor Altlantique et } \\
\text { lorraine, Atos Worldline, Bombardier } \\
\text { Transport. } \\
\text { - O Pólo funciona com uma estrutura } \\
\text { enxuta e tem o papel de articulador } \\
\text { e apoio para os associados, sendo } \\
\text { assim não desenvolveu uma } \\
\text { estrutura física para lidar com } \\
\text { determinadas funções e operações } \\
\text { para as empresas. }\end{array}$ & $\begin{array}{l}\text { - Desenvolve as ações por meio } \\
\text { de projetos. } \\
\text { - Dimensão internacional } \\
\text { participa de redes com outros } \\
\text { clusters no mundo. } \\
\text { - Visão de tornar a região como } \\
\text { referência mundial em } \\
\text { transportes } \\
\text { - Grupos específicos em temas } \\
\text { do conhecimento. } \\
\text { - Maior apoio as MPEs. } \\
\text { - A atração de empresas é pela } \\
\text { equipe de animação dentro do } \\
\text { conceito de aglomeração de } \\
\text { empresas existentes para } \\
\text { desenvolver projetos com a } \\
\text { base de C\&T. } \\
\text { - A estrutura de trabalho dos } \\
\text { Pólos são os projetos. } \\
\text { - }\end{array}$ & $\begin{array}{l}\text { - Localiza-se numa região com } \\
\text { vocação industrial, região que } \\
\text { abriga grandes empresas do } \\
\text { setor automobilístico, e de } \\
\text { logística. } \\
\text { - A região apresenta boas } \\
\text { condições em termos de } \\
\text { disponibilidade de serviços } \\
\text { públicos e condições de } \\
\text { moradias para os } \\
\text { empregados no Pólo. } \\
\text { - A base do conhecimento é } \\
\text { compartilhada no âmbito dos } \\
\text { projetos que são } \\
\text { desenvolvidos que envolvem } \\
\text { a disponibilização e } \\
\text { compartilhamento dos } \\
\text { recursos físicos e bases do } \\
\text { conhecimento. } \\
\text { - As equipes de trabalho } \\
\text { utilizam-se de escritórios } \\
\text { simples, com boa localização. }\end{array}$ & $\begin{array}{l}\text { - As entidades de pesquisas têm uma } \\
\text { participação importante: as Escolas, } \\
\text { Universidades que compõem o } \\
\text { agrupamento regional de pesquisa } \\
\text { cooperativa, a qual é uma estrutura } \\
\text { típica do caso de Lille, que permite o } \\
\text { alinhamento da pesquisa com o } \\
\text { desenvolvimento da indústria da } \\
\text { região. } \\
\text { - A estrutura para tratar dos assuntos } \\
\text { da relação Universidade-Empresa é o } \\
\text { SAIC - SERVICO DE ATIVIDADES } \\
\text { INDUSTRIAIS E COMERCIAIS, que } \\
\text { também não estão obtendo } \\
\text { aderências nos projetos dos Pólos. } \\
\text { - Não existe repercussão de um } \\
\text { instrumento ou mecanismo na } \\
\text { interação universidades-empresas. } \\
\text { - O mecanismo de bolsas CIFRE } \\
\text { (Convenção industrial de formação } \\
\text { pela pesquisa) é um bom mecanismo } \\
\text { na cooperação Universidade- } \\
\text { Empresa. Referem-se a Doutores que } \\
\text { fazem suas teses de Doutorado em } \\
\text { empresas, como funcionários da } \\
\text { empresa orientados por um organismo } \\
\text { de pesquisa, sobre um tema de } \\
\text { pesquisa escolhido em comum } \\
\text { acordo. }\end{array}$ \\
\hline
\end{tabular}




\begin{tabular}{|c|c|c|c|c|}
\hline PÓLOS & Governança & Estratégia & Infra-estutura & Universidade-Empresas \\
\hline Cap-Digital & $\begin{array}{l}\text { - Cap Digital é uma associação não } \\
\text { lucrativa, financiada em duas partes } \\
\text { nas quais, } 20 \% \text { são recursos } \\
\text { provenientes pelos membros e } 80 \% \\
\text { por representações de responsáveis } \\
\text { do estado e regionais: } \\
\text { - Pólos por meio da estrutura } \\
\text { hierárquica que prevê os diferentes } \\
\text { conselhos, com reuniões para } \\
\text { tomadas de decisões e estratégias. } \\
\text { O pólo digital pela característica da } \\
\text { atividade desenvolvida } \\
\text { - Grandes empresas como âncoras, } \\
\text { tais como France telecom e Motorola } \\
\text { SAS. } \\
\text { - Pouca integração do Pólo nas } \\
\text { estratégias locais de inovação } \\
\text { - O Pólo é estruturado a partir de } \\
\text { associações, sendo que essas } \\
\text { prevêem a participação das } \\
\text { empresas associadas. } \\
\text { - Existe uma diferenciação da } \\
\text { participação das empresas, sendo } \\
\text { que as grandes empresas pelo fato } \\
\text { oferecer uma estrutura mais } \\
\text { adequada para Pesquisa e } \\
\text { Desenvolvimento tendem a exercer } \\
\text { seu poder de governança. } \\
\text { - O Pólo funciona com uma estrutura } \\
\text { enxuta e tem o papel de articulador } \\
\text { e apoio para os associados, sendo } \\
\text { assim não desenvolveu uma } \\
\text { estrutura física para lidar com } \\
\text { determinadas funções e operações } \\
\text { para as empresas. }\end{array}$ & $\begin{array}{l}\text { - Focado no mercado } \\
\text { internacional estimado em } 300 \\
\text { bilhões de euros; } \\
\text { - atuar com agilidade e forte } \\
\text { interação com o mercado para } \\
\text { oferta de novos serviços, a } \\
\text { internet é uma plataforma para } \\
\text { vários serviços. } \\
\text { - Desenvolve as ações por meio } \\
\text { de projetos. } \\
\text { - A atração de empresas é pela } \\
\text { equipe de animação dentro do } \\
\text { conceito de aglomeração de } \\
\text { empresas existentes para } \\
\text { desenvolver projetos com a } \\
\text { base de C\&T. } \\
\text { - A estrutura de trabalho dos } \\
\text { Pólos são os projetos. }\end{array}$ & $\begin{array}{l}\text { - Situa-se numa região central } \\
\text { na lle de France, região que } \\
\text { abriga empresas de } \\
\text { diferentes portes, com uma } \\
\text { grande concentração de } \\
\text { empresas especializadas no } \\
\text { segmento multi-mídia, audio- } \\
\text { visual, efeitos especiais ou } \\
\text { video-gamos, empresas de } \\
\text { distribuição e edição, grupos } \\
\text { industriais e laboratórios de } \\
\text { pesquisas } \\
\text { - A base do conhecimento é } \\
\text { compartilhada no âmbito dos } \\
\text { projetos que são } \\
\text { desenvolvidos que envolvem } \\
\text { a disponibilização e } \\
\text { compartilhamento dos } \\
\text { recursos físicos e bases do } \\
\text { conhecimento. } \\
\text { - As equipes de trabalho } \\
\text { utilizam-se de escritórios } \\
\text { simples, com boa localização. } \\
\text { - }\end{array}$ & $\begin{array}{l}\text { - Estão presentes nos Pólos } 50 \\
\text { laboratórios de pesquisa como o INA } \\
\text { (Instituto Nacional de audio-visual), } \\
\text { Escritório de Documentação Francês, } \\
\text { o IRCAM, (Instituto de pesquisa e } \\
\text { coordenação acústica/musical)o, } \\
\text { BDIC (Biblioteca de documentação } \\
\text { internacional contemporânea). } \\
\text { - Falta participação do Pólo de } \\
\text { competitividade na orientação das } \\
\text { prioridades de pesquisa que serão } \\
\text { desenvolvidas na academia e } \\
\text { institutos. } \\
\text { - Não existe repercussão específica de } \\
\text { um instrumento ou mecanismo na } \\
\text { interação universidades-empresas. } \\
\text { - A estrutura para tratar dos assuntos } \\
\text { da relação Universidade-Empresa é o } \\
\text { SAIC - SERVICO DE ATIVIDADES } \\
\text { INDUSTRIAIS E COMERCIAIS, que } \\
\text { também não estão obtendo } \\
\text { aderências nos projetos dos Pólos. } \\
\text { - O mecanismo de bolsas CIFRE } \\
\text { (Conventions Industrielles de } \\
\text { Formation par la Recherche) faé um } \\
\text { bom mecanismo na cooperação } \\
\text { Universidade-Empresa. Referem-se a } \\
\text { Doutores que fazem suas teses de } \\
\text { Doutorado em empresas, como } \\
\text { funcionários da empresa orientados } \\
\text { por um organismo de pesquisa, sobre } \\
\text { um tema de pesquisa escolhido em } \\
\text { comum acordo. }\end{array}$ \\
\hline
\end{tabular}




\begin{tabular}{|c|c|c|c|c|}
\hline PÓLOS & Governança & Estratégia & Infra-estutura & Universidade-Empresas \\
\hline Medicen & $\begin{array}{l}\text { - Figura jurídica de uma associação } \\
\text { sem fins lucrativos composta por } \\
\text { representantes de empresas e de } \\
\text { organismos de pesquisa. } \\
\text { - No modelo de organização do pólo } \\
\text { de Competitividade Medicen } \\
\text { observa-se o domínio de uma } \\
\text { governança estruturada nas } \\
\text { empresas, as quais são privilegiadas } \\
\text { nas decisões de } \\
\text { representatividades. As empresas } \\
\text { são os atores que possuem maior } \\
\text { poder na escolha da estrutura de } \\
\text { administração dos Pólos. } \\
\text { - Grandes empresas como âncoras, } \\
\text { tais como Novartis, Philips Medical } \\
\text { Systems, Sanofi-Aventis, Servier, } \\
\text { Siemens. } \\
\text { - Pouca integração do Pólo nas } \\
\text { estratégias locais de inovação } \\
\text { - O Pólo é estruturado a partir de } \\
\text { associações, sendo que essas } \\
\text { prevêem a participação das } \\
\text { empresas associadas. } \\
\text { - Existe uma diferenciação da } \\
\text { participação das empresas, sendo } \\
\text { que as grandes empresas pelo fato } \\
\text { oferecer uma estrutura mais } \\
\text { adequada para Pesquisa e } \\
\text { Desenvolvimento tendem a exercer } \\
\text { seu poder de governança. } \\
\text { - O Pólo funciona com uma estrutura } \\
\text { enxuta e tem o papel de articulador } \\
\text { e apoio para os associados, sendo } \\
\text { assim não desenvolveu uma } \\
\text { estrutura física para lidar com } \\
\text { determinadas funções e operações } \\
\text { para as empresas. }\end{array}$ & $\begin{array}{l}\text { - O Pólo de competitividade tem } \\
\text { como prioridade trazer } \\
\text { competitividade a região e } \\
\text { atratividade internacional } \\
\text { considerando terapias } \\
\text { inovativas de alto nível, criando } \\
\text { ocupações de alta } \\
\text { especialização em ciências da } \\
\text { vida } \\
\text { - Desenvolve as ações por meio } \\
\text { de projetos. } \\
\text { - Fortalecer a indústria local, } \\
\text { formada por empresas de } \\
\text { inovação em biotecnologia e } \\
\text { empresas farmacêuticas, } \\
\text { serviços médicos, manufaturas } \\
\text { de provedores de serviços } \\
\text { afins, com a criação de } \\
\text { empregos qualificados. } \\
\text { - A atração de empresas é pela } \\
\text { equipe de animação dentro do } \\
\text { conceito de aglomeração de } \\
\text { empresas existentes para } \\
\text { desenvolver projetos com a } \\
\text { base de C\&T. } \\
\text { - A estrutura de trabalho dos } \\
\text { Pólos são os projetos. }\end{array}$ & $\begin{array}{l}\text { - Localizado numa região } \\
\text { central da Europa, a lle-de- } \\
\text { France é uma região líder na } \\
\text { Europa e a região no mundo } \\
\text { em termos de capacidade e } \\
\text { desenvolvimento de pesquisa } \\
\text { (estima-se } 126.000 \text { pessoas } \\
\text { atuando com atividades de } \\
\text { pesquisa). } \\
\text { - A base do conhecimento é } \\
\text { compartilhada no âmbito dos } \\
\text { projetos que são } \\
\text { desenvolvidos que envolvem } \\
\text { a disponibilização e } \\
\text { compartilhamento dos } \\
\text { recursos físicos e bases do } \\
\text { conhecimento. } \\
\text { - As equipes de trabalho } \\
\text { utilizam-se de escritórios } \\
\text { simples, com boa localização. } \\
\text { - }\end{array}$ & $\begin{array}{l}\text { - O pólo para articular a relação } \\
\text { universidade X empresa desenvolve e } \\
\text { organiza eventos, como almoços e } \\
\text { cafés para articular pesquisas, a } \\
\text { estratégia é mais dirigida a animação } \\
\text { de redes, outra estratégia é a } \\
\text { elaboração de comitês temáticos para } \\
\text { de envolver os projetos. } \\
\text { - Falta participação do Pólo de } \\
\text { competitividade na orientação das } \\
\text { prioridades de pesquisa que serão } \\
\text { desenvolvidas na academia e } \\
\text { institutos. } \\
\text { - Institutos como: CEA - Commissarait à } \\
\text { l'Energie Atomique, INSERM - Institut } \\
\text { National de la Santé et de la } \\
\text { Recheche Medicale, CNRS - Centre } \\
\text { National de la Recherche Scientifique, } \\
\text { Pasteur Institute, Curie Institute. } \\
\text { - A estrutura para tratar dos assuntos } \\
\text { da relação Universidade-Empresa é o } \\
\text { SAIC - Servico De Atividades } \\
\text { Industriais e Comerciais, que também } \\
\text { não estão obtendo aderências nos } \\
\text { projetos dos Pólos. } \\
\text { - O mecanismo de bolsas CIFRE } \\
\text { (Conventions Industrielles de } \\
\text { Formation par la Recherche) é um } \\
\text { bom mecanismo na cooperação } \\
\text { Universidade-Empresa. Referem-se a } \\
\text { Doutores que fazem suas teses de } \\
\text { Doutorado em empresas, como } \\
\text { funcionários da empresa orientados } \\
\text { por um organismo de pesquisa, sobre } \\
\text { um tema de pesquisa escolhido em } \\
\text { comum. }\end{array}$ \\
\hline
\end{tabular}




\begin{tabular}{|c|c|c|c|c|}
\hline PÓLOS & Governança & Estratégia & Infra-estutura & Universidade-Empresas \\
\hline ASTech & $\begin{array}{l}\text { - } \quad \text { A figura jurídica do Pólo é uma } \\
\text { associação que está estruturada } \\
\text { em colégios com diferentes } \\
\text { representações. } \\
\text { - Possui grandes empresa âncora a } \\
\text { Dassault e a EADS-Astrium. } \\
\text { - Pouca integração do Pólo nas } \\
\text { estratégias locais de inovação. } \\
\text { - O Pólo é estruturado a partir de } \\
\text { associações, sendo que essas } \\
\text { prevêem a participação das } \\
\text { empresas associadas. } \\
\text { Existe uma diferenciação da } \\
\text { participação das empresas, sendo } \\
\text { que as grandes empresas pelo } \\
\text { fato oferecer uma estrutura mais } \\
\text { adequada para Pesquisa e } \\
\text { Desenvolvimento tendem a } \\
\text { exercer seu poder de governança. } \\
\text { O Pólo funciona com uma } \\
\text { estrutura enxuta e tem o papel de } \\
\text { articulador e apoio para os } \\
\text { associados, sendo assim não } \\
\text { desenvolveu uma estrutura física } \\
\text { para lidar com determinadas } \\
\text { funções e operações para as } \\
\text { empresas }\end{array}$ & $\begin{array}{l}\text { - As atividades básicas do Pólo } \\
\text { estão relacionadas com o } \\
\text { desenvolvimento de projetos } \\
\text { - O Pólo tem duas missões } \\
\text { principais, a primeira missão do } \\
\text { pólo é prover projetos, por meio } \\
\text { da articulação entre academia } \\
\text { e iniciativa privada, a segunda } \\
\text { é fortalecer o setor } \\
\text { Aeroespacial na lle de France } \\
\text { - O Paris ASTech Região está } \\
\text { inserido num Sistema de pólos } \\
\text { complementares } \\
\text { tecnologicamente o } \\
\text { System@atic e o MOV'EO. } \\
\text { - Trabalha em escala global, fato } \\
\text { que demanda a inserção em } \\
\text { mercados internacionais. } \\
\text { - A atração de empresas é pela } \\
\text { equipe de animação dentro do } \\
\text { conceito de aglomeração de } \\
\text { empresas existentes para } \\
\text { desenvolver projetos com a } \\
\text { base de C\&T. } \\
\text { - A estrutura de trabalho dos } \\
\text { Pólos são os projetos. } \\
\text { Estratégias de operação da } \\
\text { equipe de animação com } \\
\text { papéis pouco definidos }\end{array}$ & $\begin{array}{l}\text { - A região da lle de France } \\
\text { contribui para esta liderança } \\
\text { nas áreas de aviação de } \\
\text { negócios, transporte espacial, } \\
\text { motor e equipamentos, } \\
\text { graças a presença da } \\
\text { indústria que é competitiva } \\
\text { globalmente e seus parceiros } \\
\text { - A base do conhecimento é } \\
\text { compartilhada no âmbito dos } \\
\text { projetos que são } \\
\text { desenvolvidos que envolvem } \\
\text { a disponibilização e } \\
\text { compartilhamento dos } \\
\text { recursos físicos e bases do } \\
\text { conhecimento. } \\
\text { - As equipes de trabalho } \\
\text { utilizam-se de escritórios } \\
\text { simples, com boa localização. }\end{array}$ & $\begin{array}{l}\text { - O pólo participa apenas da } \\
\text { negociação, na questão de buscar } \\
\text { parceiros para desenvolver os } \\
\text { projetos, ou seja, somente na } \\
\text { perspectiva da articulação, não atua } \\
\text { na questão de contratação. } \\
\text { - Falta participação do Pólo de } \\
\text { competitividade na orientação das } \\
\text { prioridades de pesquisa que serão } \\
\text { desenvolvidas na academia e } \\
\text { institutos. } \\
\text { - Cada um dos domínios temáticos dos } \\
\text { pólos é animado por técnicos } \\
\text { especializados (geralmente } \\
\text { professores). Eles atuam na } \\
\text { organização de reuniões periódicas } \\
\text { para discutir Road maps, discussão } \\
\text { dos projetos, gargalos de projetos - } \\
\text { essas atividades não são } \\
\text { formalizadas. } \\
\text { - A estrutura para tratar dos assuntos } \\
\text { da relação Universidade-Empresa é o } \\
\text { SAIC - SERVICO DE ATIVIDADES } \\
\text { INDUSTRIAIS E COMERCIAIS, que } \\
\text { também não estão obtendo } \\
\text { aderências nos projetos dos Pólos. } \\
\text { - O mecanismo de bolsas CIFRE } \\
\text { (Conventions Industrielles de } \\
\text { Formation par la Recherche) faé um } \\
\text { bom mecanismo na cooperação } \\
\text { Universidade-Empresa. Referem-se a } \\
\text { Doutores que fazem suas teses de } \\
\text { Doutorado em empresas, como } \\
\text { funcionários da empresa orientados } \\
\text { por um organismo de pesquisa, sobre } \\
\text { um tema de pesquisa escolhido em } \\
\text { comum acordo. }\end{array}$ \\
\hline
\end{tabular}




\begin{tabular}{|c|c|c|c|c|}
\hline PÓLOS & Governança & Estratégia & Infra-estrutura & Universidades-Empresa \\
\hline System@tic & $\begin{array}{l}\text { - A figura jurídica do Pólo é uma } \\
\text { associação que está estruturada } \\
\text { administrativamente em colégios } \\
\text { com diferentes representações } \\
\text { - O Pólo System@tic prevê em seu } \\
\text { estatuto que a presidência do } \\
\text { Pólo sempre será ocupada por } \\
\text { um industrial, fato que garante a } \\
\text { visão da indústria presente nas } \\
\text { decisões estratégicas. } \\
\text { - Pouca integração do Pólo nas } \\
\text { estratégias locais de inovação. } \\
\text { - O Pólo é estruturado a partir de } \\
\text { associações, sendo que essas } \\
\text { prevêem a participação das } \\
\text { empresas associadas. } \\
\text { - Existe uma diferenciação da } \\
\text { participação das empresas, sendo } \\
\text { que as grandes empresas pelo } \\
\text { fato oferecer uma estrutura mais } \\
\text { adequada para Pesquisa e e } \\
\text { Desenvolvimento tendem a a } \\
\text { exercer seu poder de governança. } \\
\text { - A estrutura operacional do Pólo é } \\
\text { desenvolvida pela Secretaria } \\
\text { Permanente, a qual é um grupo } \\
\text { formado por } 13 \text { profissionais com } \\
\text { um orçamento de } 1,7 \text { milhões de } \\
\text { Euros anuais, provenientes de } 40 \\
\text { \% do estado, 40\% de } \\
\text { coletividades territoriais e 20\% } \\
\text { dos membros da Associação. } \\
\text { - }\end{array}$ & $\begin{array}{l}\text { - Seleção de pesquisadores, } \\
\text { atraindo especialmente os centros } \\
\text { de P \& Dempresas internacionais } \\
\text { neste domínio: recrutamento } \\
\text { objetivo de } 4000 \text { cientistas por } \\
\text { ano } \\
\text { - O Pólo posiciona-se como líder } \\
\text { industrial nas áreas de soluções } \\
\text { para conceitos, gestão e } \\
\text { manutenção de sistemas } \\
\text { computacionais complexos } \\
\text { - O Pólo já está envolvido em redes } \\
\text { européias, tais como as } \\
\text { plataformas tecnológicas } \\
\text { européias (ARTEMIS eMobility, } \\
\text { etc.) e agregados EUREKA (ITEA } \\
\text { MEDEA +, etc.) Além disso, } \\
\text { alguns membros também estão } \\
\text { envolvidos em programas de \& \& } \\
\text { D da Comissão Européia } \\
\text { (Programa-Quadro de IDT). } \\
\text { - A estrutura de trabalho dos Pólos } \\
\text { são os projetos. } \\
\text { - A atração de empresas é pela } \\
\text { equipe de animação dentro do } \\
\text { conceito de aglomeração de } \\
\text { empresas existentes para } \\
\text { desenvolver projetos com a base } \\
\text { de C\&T. } \\
\text { - }\end{array}$ & $\begin{array}{l}\text { - A região é uma das mais } \\
\text { desenvolvidas na Europa e no } \\
\text { mundo, com cerca de região } \\
320 \text { o0 empregados (não } \\
\text { incluindo as atividades de P\&D do } \\
\text { setor público) que trabalham } \\
\text { neste campo na lle-de-França, a } \\
\text { região apresenta um perfil de } \\
\text { mão-de-obra altamente } \\
\text { qualificada e um potencial de } \\
\text { pesquisa de } 3000 \text { cientistas por } \\
\text { ano } \\
\text { - A base do conhecimento é } \\
\text { compartilhada no âmbito dos } \\
\text { projetos que são desenvolvidos } \\
\text { que envolvem a disponibilização e } \\
\text { compartilhamento dos recursos } \\
\text { físicos e bases do conhecimento. } \\
\text { - As equipes de trabalho utilizam-se } \\
\text { de escritórios simples, com boa } \\
\text { localização. }\end{array}$ & $\begin{array}{l}\text { - } 134 \text { centros de pesquisa e mais } \\
44 \text { centros de formação.CNES } \\
\text { (Centre National des Etudes } \\
\text { Spatiales - Space Research } \\
\text { Center), Ecole Centrale Paris, } \\
\text { Polytechnique, HEC, INRIA } \\
\text { (French National Institute for } \\
\text { Research in Computer Science } \\
\text { and Control), Supelec (Electrical } \\
\text { Engineering and Computer } \\
\text { Science), etc. } \\
\text { - Desenvolvimento de um programa } \\
\text { para previsão das competências } \\
\text { necessária para as empresas. } \\
\text { - Falta participação do Pólo de } \\
\text { competitividade na orientação das } \\
\text { prioridades de pesquisa que } \\
\text { serão desenvolvidas na academia } \\
\text { e institutos. } \\
\text { - A estrutura para tratar dos } \\
\text { assuntos da relação } \\
\text { Universidade-Empresa é o SAIC- } \\
\text { Servico De Atividades Industriais } \\
\text { e Comerciais, que não estão } \\
\text { obtendo aderências nos projetos } \\
\text { dos Pólos. } \\
\text { - O mecanismo de bolsas CIFRE } \\
\text { (Conventions Industrielles de } \\
\text { Formation par la Recherche) é um } \\
\text { bom mecanismo na cooperação } \\
\text { Universidade-Empresa. Referem- } \\
\text { se a Doutores que fazem suas } \\
\text { teses de Doutorado em } \\
\text { empresas, como funcionários da } \\
\text { empresa orientados por um } \\
\text { organismo de pesquisa. }\end{array}$ \\
\hline
\end{tabular}




\subsection{Análise}

Reforçando a constatação anterior, observa-se que as informações contidas na Tabela 6.10.2 evidenciam a existência de uma política comum para os Pólos, sendo que várias características são compartilhadas por eles. Na Tabela 6.11.1 é apresentada, de forma agregada, a análise dos ambientes de inovação visitados; a análise foi feita com base em duas perspectivas, os pontos fortes (PF) e principais pontos onde melhorias poderiam ser implementadas (PM). A análise teve como objetivo destacar os principais elementos relacionados aos critérios que permitiriam servir de referência para a proposição da estrutura de Inovação de Sorocaba.

A codificação está assim apresentada:

- PF ou PM

Pontos fortes ou Pontos de Melhoria

- Numeral

Sequência Numérica

- A ou B

Experiências Nacionais ou Pólos de competitividade.

- Numeral

Sequência Numérica 
Tabela 6.11.1 - Análise Pontos fortes e pontos de melhorias dos ambientes de inovação pesquisados.

\begin{tabular}{|c|c|c|c|}
\hline $\begin{array}{c}\text { Tabela } \\
\text { analítica }\end{array}$ & Dimensões & a.Experiências Nacionais & b.Pólos Franceses \\
\hline \multirow{2}{*}{ 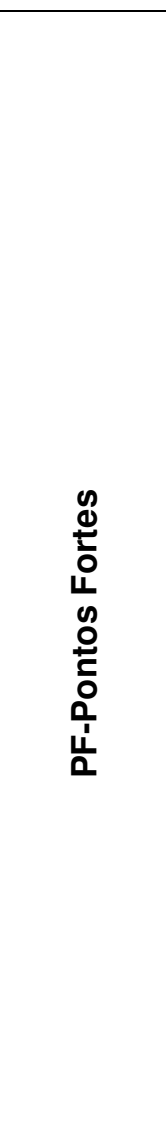 } & 1. Governança & $\begin{array}{l}\text { PF1a1-Modelos de gestão com flexibilidade para } \\
\text { interação com o mercado } \\
\text { PF1a2-Participação da academia na governança } \\
\text { PF1a3-Figura jurídica própria. } \\
\text { PF1a4-Poder público como indutor do Processo } \\
\text { PF1a5-Projetos estruturados como Sociedade de } \\
\text { Propósitos Específicos. }\end{array}$ & $\begin{array}{l}\text { PF1b1-Modelo de associação sem fins lucrativos com } \\
\text { representações de diferentes atores. } \\
\text { PF1b2-Estrutura com diferentes níveis de participação. } \\
\text { PF1b3-Estrutura de trabalho por meio de projetos. } \\
\text { PF1b4-Grandes empresas participando da gestão. }\end{array}$ \\
\hline & 3. Infra-estrutura & $\begin{array}{l}\text { PF3a1-Espaço para ativos de incubadoras empresas, } \\
\text { empresas e centros de pesquisa. } \\
\text { PF3a2-Escritórios para propriedade Intelectual e } \\
\text { internacionalização. } \\
\text { PF3a3-Localização com boa logística para acesso }\end{array}$ & $\begin{array}{l}\text { PF3b1- Presença de grandes empresas âncoras } \\
\text { PF3b2- Estrutura para formação de especialistas. } \\
\text { PF3b3-Necessidade de articulação de base de c\&T e } \\
\text { empresas para desenvolver projetos } \\
\text { PF3b4- Localização com boa logística para acesso }\end{array}$ \\
\hline
\end{tabular}




\begin{tabular}{|c|c|c|c|}
\hline $\begin{array}{c}\text { Tabela } \\
\text { analítica }\end{array}$ & Dimensões & a.Experiências Nacionais & b.Pólos Franceses \\
\hline \multirow{4}{*}{ 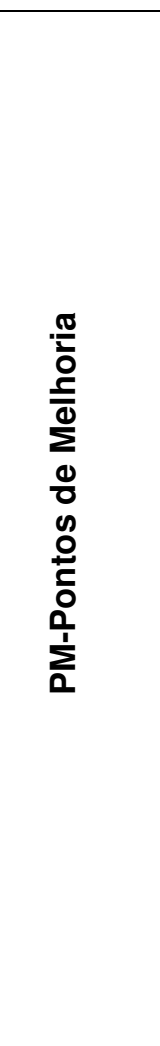 } & 1. Governança & $\begin{array}{l}\text { PM1a1- Modelos de governança } \\
\text { PM1a2- Apoio a MPEs } \\
\text { PM1 a3-Atuação reativa nas políticas setoriais. }\end{array}$ & $\begin{array}{l}\text { PM1b1-Maior participação do poder público local } \\
\text { PM1b2- Apoio a MPEs }\end{array}$ \\
\hline & 2. Estratégia & $\begin{array}{l}\text { PM2a1-Falta estratégias efetivas de internacionalização } \\
\text { PM2a2-Não oferecimento de serviços para as } \\
\text { empresas. } \\
\text { PM2a3-Não estruturação específica para atração de } \\
\text { empresas } \\
\text { PM2a4- Áreas temáticas tradicionais com } \\
\text { predominância de TIC. } \\
\text { PM2a5-Interacão entre os parques. }\end{array}$ & $\begin{array}{l}\text { PM2b1-Não existem processos para internacionalização. } \\
\text { PM2b2-Não oferecimento de serviços para as empresas. } \\
\text { PM2b3-Estratégia de atração de empresas somente na } \\
\text { promoção de projetos } \\
\text { PM2b4-Pouca participação nas estratégias locais. } \\
\text { PM2b5-Interação entre os Pólos. } \\
\text { PM2b6-Estratégias de operação da equipe de animação } \\
\text { com papéis pouco definidos. }\end{array}$ \\
\hline & 3. Infra-estrutura & $\begin{array}{l}\text { PM3a1-Instituições para formação de pessoas } \\
\text { PM3a2-Utilização da base de conhecimento de } \\
\text { instituições de C\&T. }\end{array}$ & $\begin{array}{l}\text { PM3b1-Espaço para incubação de empresas } \\
\text { PM3b2-Incentivo para redes de conhecimento e } \\
\text { informação }\end{array}$ \\
\hline & $\begin{array}{l}\text { 4. Universidade } \\
\text { Empresa }\end{array}$ & $\begin{array}{l}\text { PM4a1- aplicação de instrumentos de apoio. } \\
\text { PM4a2-melhor articulação para desenvolvimento de } \\
\text { projetos } \\
\text { PM4a3- atuação de doutores nas empresas } \\
\text { PM4a4-articulação entre empresas e base de C\&T para } \\
\text { projetos específicos. } \\
\text { PM4a5-sistematização de mapeamento de } \\
\text { competências de pesquisadores. } \\
\text { PM4a6-atuação reativa em relação aos organismos de } \\
\text { fomento. } \\
\text { PM4a7-Incentivar a presenca de institutos de pesquisa. }\end{array}$ & $\begin{array}{l}\text { PM4b1-Maiores incentivos e aproximação com } \\
\text { universidades. } \\
\text { PM4b2-Melhor aproveitamento dos recursos existentes. } \\
\text { PM4b3-Atuação do Pólo na orientação das pesquisas a } \\
\text { serem desenvolvidas. } \\
\text { PM4b4-Utilização de mecanismos para promoção } \\
\text { interação universidade-empresa. } \\
\text { PM4b5-Mecanismos de Proteção ao conhecimento } \\
\text { PM4b6- sistematização de mapeamento de competências } \\
\text { de pesquisadores }\end{array}$ \\
\hline
\end{tabular}


Com base no tratamento qualitativo dos pontos fortes e pontos de melhoria foi possível estabelecer um conjunto de fatores prioritários que são apresentadas na Tabela 6.11.2.

Tabela 6.11.2 - Relação Análise qualitativa e fatores prioritários

\begin{tabular}{|c|c|}
\hline $\begin{array}{c}\text { Analise } \\
\text { Qualitativa }\end{array}$ & Fatores Prioritários \\
\hline PF1a4, PF1a4, PM2b4, PF2a3 & 1. Articular o apoio do poder público local \\
\hline $\begin{array}{llll}\text { PF1a1, } & \text { PF1b1, } & \text { PF1a2, } & \text { PF1b4, } \\
\text { PM1a1, } & \text { PF1a5, } & \text { PF1a3, } & \text { PF2a2, } \\
\text { PM2b6 } & & & \end{array}$ & $\begin{array}{l}\text { 2. Desenvolver modelo de gestão que seja flexível para } \\
\text { a tomada de decisões rápidas }\end{array}$ \\
\hline $\begin{array}{llll}\text { PM4a1, PM4a2, } & \text { PM4a3, } & \text { PM4a4, } \\
\text { PM4a5, PM4a6, PM4a7, } & \text { PM4b1, } \\
\text { PM4b2, PM4b3, PM4b4, } & \text { PM4b5, } \\
\text { PM4b6, PM4b1, PM4b2, } & \text { PM4b3, } \\
\text { PF4b1, PF4b2, PF4b3, } & \text { PF4b4, } \\
\text { PF4b5, PM4b3, PF3b2. } & \end{array}$ & $\begin{array}{l}\text { 3. Articular com as Instituições de Ensino para orientar a } \\
\text { a base de C\&T Local }\end{array}$ \\
\hline $\begin{array}{l}\text { PF3a1, PM3b1, PM1b2, PM1a2, } \\
\text { PF3a1, PM2a2, PM2b2 }\end{array}$ & $\begin{array}{l}\text { 4. Apoiar as médias, micro e pequenas empresas e } \\
\text { empresas nascentes de todos os segmentos. }\end{array}$ \\
\hline $\begin{array}{l}\text { PM2b4, PF1a4, PM1b1, } \\
\text { PF2a3 }\end{array}$ & $\begin{array}{l}\text { 5. Participar das estratégias de desenvolvimento e } \\
\text { regional e local }\end{array}$ \\
\hline $\begin{array}{llll}\text { PM4b6, } & \text { PM3a2, } & \text { PM3b2, } & \text { PF3b3, } \\
\text { PF4a3, } & \text { PF4a2, } & \text { PF4b2, } & \text { PM4b5, } \\
\text { PF3a2 } & & & \end{array}$ & $\begin{array}{l}\text { 6. Promover estrutura para incentivar a ligação da base } \\
\text { do conhecimento com as empresas }\end{array}$ \\
\hline PM2b1, PM2a1, PF2b5 & $\begin{array}{l}\text { 7. Estabelecer canais para desenvolver o comércio } \\
\text { exterior }\end{array}$ \\
\hline PF1b2, PF1b4 & $\begin{array}{l}\text { 8. Comportar grandes empresas no modelo de gestão, } \\
\text { participando das definições Estratégicas. }\end{array}$ \\
\hline PF2b4, PF2b6, PM2a4, PM2a4 & 9. Contemplar diferentes áreas temáticas \\
\hline PM3b1, & 10. Criar novas empresas de base tecnológica \\
\hline PM1a3, & $\begin{array}{l}\text { 11. Desenvolver uma atitude pró-ativa em relação às } \\
\text { políticas industriais e setoriais. }\end{array}$ \\
\hline PF4a2, PF4b2, PF2b1, PF2b2 & 12. Incentivar a presença de doutores nas empresas \\
\hline PM4a7, PF4b5, PF2b1, PF2b2 & $\begin{array}{l}\text { 13. Desenvolver estruturas para compartilhamento de } \\
\text { conhecimentos e pesquisas, tais como laboratórios, } \\
\text { centros de pesquisa. }\end{array}$ \\
\hline PM3a1, PF3b2, PF2a1, PF2b1- & $\begin{array}{l}\text { 14. Prover mecanismos de formação de Recursos } \\
\text { Humanos. }\end{array}$ \\
\hline PM4a1, PM4b2, PM4a6, PM3b2, & 15. Utilizar-se dos mecanismos de apoio e incentivo. \\
\hline $\begin{array}{l}\text { PF3a3, PF3b4, PF3b1, } \text { PM2b3, } \\
\text { PM2a3. }\end{array}$ & 16. Atrair empresas para a região \\
\hline PM2b5, PM3a2, PM2a5 & 17. Desenvolver redes de conhecimento \\
\hline
\end{tabular}




\section{CAPÍTULO VII - PROPOSIÇÃO DE UMA ESTRUTURA CONCEITUAL DE AMBIENTE DE INOVAÇÃO PARA O MUNICÍPIO DE SOROCABA.}

Para o desenvolvimento da estrutura conceitual de ambiente de inovação para Sorocaba foi utilizado como insumos: i) as informações referentes às principais demandas relacionadas ao Sistema Local de Inovação de Sorocaba e as bases científicas e tecnológicas da cidade; ii) os fatores prioritários obtidos pela análise qualitativa dos modelos dos Pólos de Competitividade franceses e das experiências nacionais estudadas nesta pesquisa (Figura 7-1).

Considerando o Sistema Local de Inovação, as demandas são provenientes do processo de mapeamento das condições locais de Sorocaba realizado no Capítulo 4. Especificamente, a análise dos componentes do Sistema de Inovação de Sorocaba foi desenvolvida com base na teoria de sistema de inovação (capítulo 2), a qual propõe como elementos principais: as organizações, as instituições e a dinâmica de articulação.

Relacionado às características do Sistema Local de Inovação que de certa forma reproduz as características do Sistema de Inovação brasileiro, caracterizado como heterogêneo, são destacados os seguintes aspectos (Tabela 7.1).

Tabela 7.1- Características do sistema de Inovação de Sorocaba

\section{Característica}

a. Número reduzido de inovações de base tecnológica

b. Baixo volume de gastos privados em P\&D

c. Poucos doutores nas empresas

d. Pouca interação da academia com empresas

e. Desalinhamento entre formação profissional e necessidades do mercado

f. Base científica e tecnológica incipiente

g. Potencial de aumento dos incentivos locais

h. Potencial de aproveitamento dos incentivos existentes nas políticas setorias e industriais. 
No que tange aos fatores prioritários destacados no capítulo $\mathrm{VI}$, na Tabela 6.11.2, eles foram reduzidos por meio de análises qualitativas com base nos pontos fortes e pontos de melhoria das experiências analisadas (Pólos de Competitividade da França e Parques Tecnológicos no Brasil).

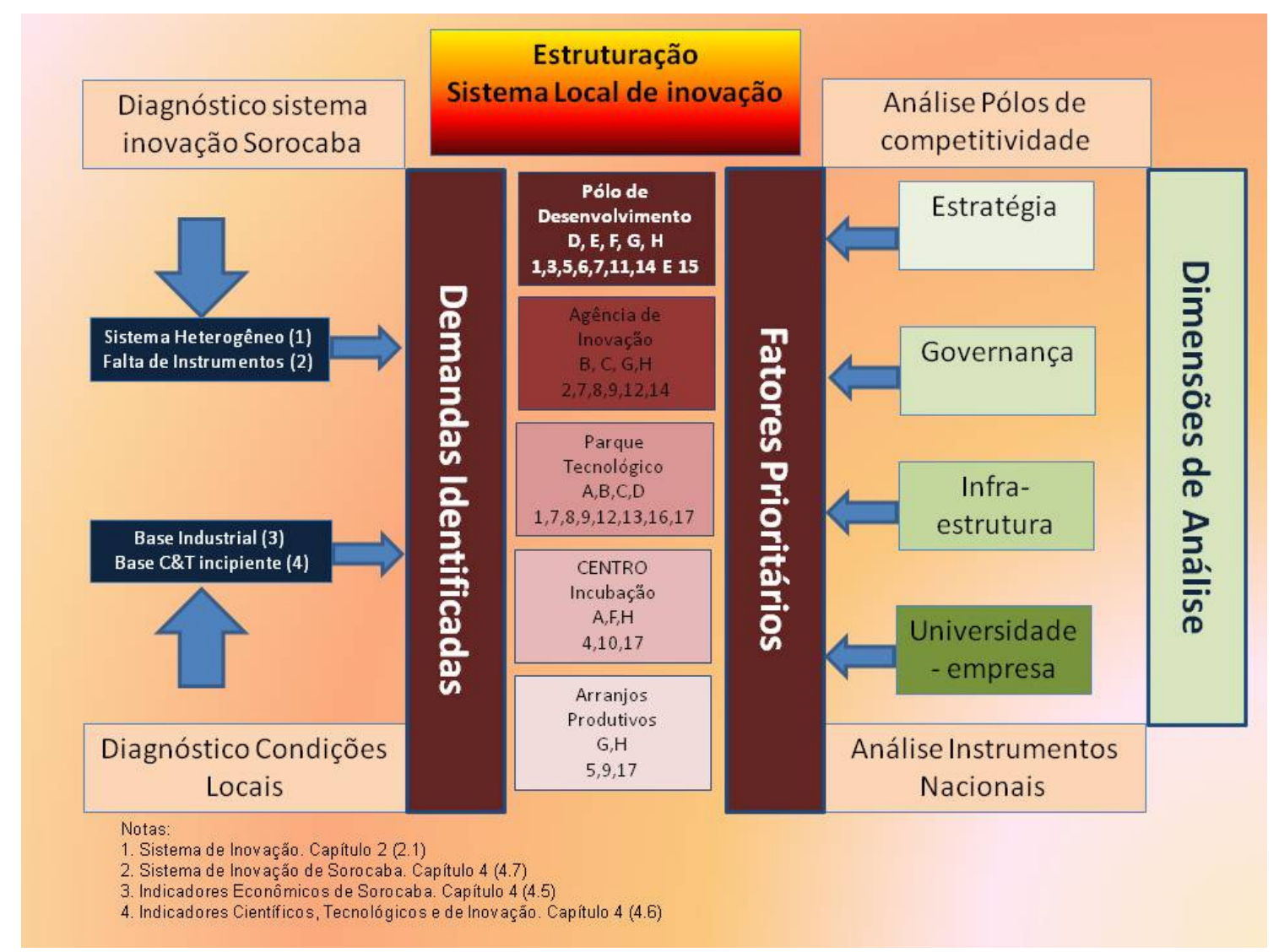

Figura 7-1: Estrutura Conceitual para a articulação do Sistema Local de Inovação.

A análise evidenciou que uma proposição baseada num instrumento único dificilmente permitiria abranger todas as necessidades e demandas levantadas.

Desta forma, optou-se per uma abordagem de característica sistêmica, com a proposição de instrumentos complementares e relacionados entre si, (conforme exposto na Figura 7-1), a qual aponta: i) os fatores desagregados pelos instrumentos que respondem as necessidades e demandas, ii) os diagnósticos que serviram de base para a definição de demandas e, iii) os critérios e dimensões para a definição dos fatores prioritários. Desta maneira, foram concebidos e estruturados os seguintes instrumentos, detalhados a seguir: 


\section{- Pólo de Desenvolvimento e Inovação de Sorocaba.}

O Pólo tem como principal missão ser um elemento operacional e articulador entre o poder público local, as entidades de ensino e pesquisa e as empresas; desta forma, busca fomentar a cultura da inovação, do conhecimento e do empreendedorismo sustentável para a região.

Idealiza-se uma estrutura concebida tendo como referência o programa nacional francês de Pólos de Competitividade; todavia, com escopo de atuação mais abrangente, de acordo com a realidade brasileira e alinhada com a dinâmica planejada do sistema de inovação local.

Desta forma, dada a característica de articulação e o importante papel de indução do poder público local (Fomento, Articulação e Organização), tornouse viável a proposição de uma estrutura de articulação altamente especializada dentro da administração pública, com papéis de gerenciamento das demandas e rápido direcionamento aos canais competentes.

A mesma prevê parcerias das instituições de ensino e pesquisa (Faculdades, Escolas, Institutos de Pesquisa), e da iniciativa privada (Empresas e Investidores). Estes protagonistas foram estimulados por um conjunto de políticas públicas, com o objetivo de potencializar as vocações locais e atrair novos investimentos para a região.

Outro aspecto pretendido de sua atuação é a organização dos requisitos e necessidades dos usuários, adequando a uma abordagem técnica por meio de programas e projetos. As suas linhas de ação, na perspectiva da estrutura desenhada, envolvem como eixos principais, descritos a seguir:

\section{Desenvolvimento e Inovação \& Comércio Exterior}

- Promover e estimular parcerias para apoiar a Agenda de Desenvolvimento Regional;

- Incrementar a competitividade das empresas instaladas no município de Sorocaba;

- Captar recursos financeiros e investimentos, nacionais e estrangeiros, de forma coordenada, para aplicação na criação e operação de ambientes produtivos e inovadores; 
- Identificar e induzir à formação de cadeias produtivas, de forma coordenada; estimular a cultura da exportação de bens, serviços, com valor agregado, entre as micro, pequenas e médias empresas de Sorocaba;

- Estimular e atrair missões internacionais de investidores;

- Estabelecer ações que visem à desburocratização e facilitação das exportações; desenvolver parcerias efetivas com órgãos públicos relacionados ao comércio exterior;

- Mapear, negociar e firmar convênios internacionais em políticas públicas de estímulo ao desenvolvimento baseado no conhecimento.

2. Capacitação Tecnológica, Capacitação em Gestão de Tecnologia e Inovação; Capacitação em Gestão

- Agir para fortalecer as atividades de pesquisa \& desenvolvimento \& inovação nas instituições públicas e privadas no município de Sorocaba;

- Fomentar o acesso a novas tecnologias no meio empresarial;

- Fomentar a transferência de tecnologia das instituições de pesquisa \& desenvolvimento para o setor produtivo;

- Incrementar as ações para capacitação em qualidade e produtividade, gestão de projetos, tecnologia de informação e inclusão digital;

- Incrementar as parcerias com as agências públicas e privadas visando a facilitação de acesso a novas linhas de crédito e financiamentos para as atividades de inovação tecnológica nas empresas

- Agir para capacitar o empreendedor em gestão de negócios;

- Capacitar em gestão de pessoas e em planejamento financeiro;

- Capacitar em planejamento de marketing;

- Incrementar as parcerias com agências públicas e privadas visando o atendimento ao empreendedor.

3. Apoio às Micro e Pequenas Empresas (MPE)

- Agir para facilitar a abertura e funcionamento de micro e pequenas empresas;

- Agir para facilitar e incentivar a participação das micro e pequenas empresas nas compras governamentais;

- Estimular a formação de mercados para produtos locais; 
- Facilitar o acesso ao crédito;

- Incentivar a formação de cooperativas e o associativismo;

- Fomentar a criação e o funcionamento de incubadoras de empresas;

- Organizar políticas de incentivo fiscal que apóiem as médias, micro e pequenas empresas;

- Promover a capacitação profissional e o empreendedorismo.

Para tal, envolve a mobilização de uma equipe de profissionais qualificados que devem ter as seguintes competências:

- Gestão de projetos, com competências para estruturar as idéias e demandas dos usuários e grupos de usuários dos serviços do Pólo;

- Gestão do conhecimento, permitindo trabalhar com processos de criação, validação, disseminação de conhecimentos;

- Tecnologia da informação, desenvolvendo processos de captura, tratamento armazenamento e distribuição de informações,

- Gestão da inovação, tratando de questões relacionadas a fomento, políticas públicas e outros e;

- Gestão de pessoas, para relacionamento no ambiente interno e externo.

O desenvolvimento desse instrumento permite responder às seguintes demandas A, D, E, F, G e H (vide Tabela 7.1) e fatores prioritários 1, 3, 5,6, 7, 11, 14. O Pólo tem papel decisivo na melhoria e orientação das entidades de ensino e pesquisa locais. 


\section{- Agência de Inovação}

Tem como papel ser um elemento articulador e executor das ações de inovação e desenvolvimento do Município, oferecendo dinamismo e velocidade às decisões e ações. Deve ser constituída por atores de diferentes esferas da sociedade, a saber: poder público, entidades de ensino e pesquisa, entidades de classe e representação de empresas.

Tem como principal característica a busca da flexibilidade operacional, e a sua atuação visa facilitar a operação de outros instrumentos, em seus propósitos, programas e projetos, tais como o Pólo de Desenvolvimento, o Parque Tecnológico e as Incubadoras.

A Agência de inovação, dada a sua característica jurídica, permite agilizar processos e estimula o dinamismo de relações de mercado e extramercado. Outro espectro da sua atuação está no incentivo e apoio às relações com órgãos de fomento, financiamento e incentivo.

As suas características são:

- Associação sem fins econômicos;

- Personalidade jurídica de direito privado;

- Constituída por tempo indeterminado;

- Autonomia administrativa e financeira;

- Regida por um Estatuto;

- Com representantes da Iniciativa Privada, de Governo e de entidades de ensino e pesquisa.

Os seus objetivos são:

- Estimular a melhoria da eficiência econômica das empresas;

- Melhorar a coordenação de ações entre os segmentos empresariais na região;

- Incentivar a cultura da inovação;

- Estimular o pensamento global; a promoção/facilitação de acesso, por parte do setor produtivo, às fontes de conhecimento/tecnologia;

- Promover serviços estratégicos de apoio à produção;

- Promover do desenvolvimento sustentável, conciliando o incremento da produtividade/competitividade com a preservação ambiental e a qualidade de vida; 
- Implantar, operacionalização e gerência técnica e administrativa de ambientes inovadores, visando materializar, oportuna, econômica e eficientemente, a inovação e o progresso tecnológico, por meio do apoio a empresas nascentes ou a empresas já existentes que necessitem atingir nível tecnológico e gerencial mais moderno e competitivo.

$O$ desenvolvimento desse instrumento permite responder as seguintes demandas B, C, G e H (vide Tabela 7.1) e fatores prioritários 2, 7, 8, 9 e 14. 


\section{- Parque Tecnológico}

O Parque tecnológico tem como funções principais oferecer um ambiente diferenciado para promover o desenvolvimento de Empresas de Base Tecnológica - EBT e acelerar o processo de transformação do conhecimento em riqueza.

Para tal, busca promover a interação entre as bases do conhecimento (universidades, centros de pesquisa, públicos e privados e institutos) com a base produtiva (empresas) contando com o apoio do poder público local, pela lógica da proximidade, a qual é um elemento facilitador para a gestão do conhecimento e seus processos de geração, codificação e disseminação entre outros.

Especificamente no Parque Tecnológico de Sorocaba pretende-se conceber um modelo de terceira geração (conforme exposto à página 70), o qual tem como característica o envolvimento com as diretrizes de políticas públicas locais para articulação dos instrumentos que buscam o desenvolvimento econômico e social sustentável.

O Parque Tecnológico de Sorocaba também deve estar atrelado a uma diretriz de qualificação e requalificação de áreas deprimidas, possibilitando um adensamento econômico e populacional dessas áreas. Sendo assim, deve ser um vetor para a promoção de políticas públicas de atração e manutenção de empresas de alta competitividade.

Para acelerar o desenvolvimento do Município, a Prefeitura de Sorocaba desenvolveu um Projeto de Lei de Incentivo ao Parque Tecnológico, denominado Parque Tecnológico Incentivado - PTI que prevê o ressarcimento de despesas decorrentes da instalação, implantação ou ampliação de empresas consideradas estratégicas para o desenvolvimento econômico e social no âmbito do PTI, mediante a inscrição fiscal mobiliária na Secretaria de Finanças.

No tocante a ocupação, o Parque Tecnológico deve prever a presença de: universidades, centros de pesquisa, incubadoras de empresas, centros empresariais, centros de serviços, empresas de base tecnológica e a presença de agentes de fomento/financiamento, ou de sua representação, e um Núcleo Gestor.

O estudo do contexto econômico e tecnológico, juntamente com o mapeamento dos atores envolvidos nos processos de inovação local e a infra- 
estrutura disponível, permitiu a este pesquisador desenvolver um modelo conceitual, com a apresentação de um grupo de requisitos, expostos a seguir:

- Envolvimento no contexto local e a indicação de um ambiente de inovação que seja aderente a características econômicas, tecnológicas, científicas, ambientais e de infra-estrutura locais.

- Análise dos efeitos sobre o ambiente social, o conjunto de variáveis que impactam o projeto, aspectos relacionados ao conjunto de atores e os efeitos sobre o sistema de animação local.

- Definição do Modelo de Ambiente de Inovação - com base no estudo do contexto científico e tecnológico e no potencial econômico (no qual a mesma atividade se destaca). Propõe-se o desenvolvimento de Parque Tecnológico, envolvendo toda a cadeia produtiva dos segmentos priorizados. Dentre as atividades, inclui-se o automobilístico, cujo setor de autopeças aparece com destaque conforme nos estudos apresentados no capítulo 4, especificamente no item 4.5, que trata dos indicadores econômicos e administrativos de Sorocaba. Outro fator deve-se a instalação da planta automobilística da empresa Toyota que será instalada nas proximidades do Parque Tecnológico.

- Requalificação local - o Projeto do Parque Tecnológico de Sorocaba (PTS) deve ser desenvolvido no contexto de uma política pública local/regional com efeitos sobre a sua área de influência e possibilitando contribuir para a requalificação da região administrativa de Sorocaba.

- Determinação das atividades prioritárias - etapa muito importante que consiste na determinação do foco do projeto do Parque Tecnológico, envolvendo o conjunto de atividades econômicas e plataformas tecnológicas e industriais que serão privilegiadas pelo habitat de inovação. Considerando a base industrial atual bastante concentrada na indústria metal-mecânica, e a possibilidade de desenvolver tecnologias com foco na aplicação do conhecimento tecnológico envolvendo atividades com alto potencial de desenvolvimento:

- Tecnologias para mineração com a presença da Empresa Metzo Minerais;

- Tecnologias para geração de energia eólica com as empresas Woben e Tecsis; 
- Tecnologia para comunicação (Flextronics),

- Tecnologia para manutenção de aeronaves (Dassault e Oceanair).

- Perspectiva estratégica, utilizar o Parque Tecnológico como âncora para a promoção da aproximação e articulação entre os atores do Sistema Local de Inovação, apoiando as empresas que são parceiras no projeto e buscando o suporte de organizações e agências de fomento, públicas e privadas, nacionais e internacionais.

Para viabilizar a proposição, mantendo a diretriz de impactar positivamente o Sistema Local de Inovação, torna-se desejável desenvolver as seguintes ações:

- Eixo de Apoio e parcerias: Mapear as autoridades locais, regionais e nacionais para apoiar o projeto e formar parcerias com stakeholders (partes interessadas) relevantes da base de C\&T\&I. Estabelecer as necessárias aproximações com outros empreendimentos ou iniciativas regionais.

- Eixo de sensibilização/promoção: Planejar o conjunto de ações para promoção do projeto e também para sensibilização das partes interessadas relevantes para o projeto, com a elaboração de um plano de divulgação e sensibilização com visitas, palestras e seminários, entre outras iniciativas. Devem ser previstas também as iniciativas para o estabelecimento de cooperação internacional.

- Eixo institucional: Apresentar os parceiros e a sua condição de influenciar as características do modelo de gestão. Análise dos fatores críticos de sucessos observar os seguintes aspectos críticos do projeto: o sistema de incentivos para as empresas; os espaços (áreas) para aglomeração de empresas; infraestrutura básica; gestão sócio-ambiental (sustentabilidade) e imagem urbanística; e foco de mercado.

Na Figura 7-2 são apresentados, de forma esquemática, os quatro eixos propostos para a articulação do Parque Tecnológico Incentivado de Sorocaba e respectivas ações, a saber: ensino e capacitação, pesquisa \& desenvolvimento \& inovação; articulação da dinâmica industrial local; articulação com organizações de fomento e financiamento. 


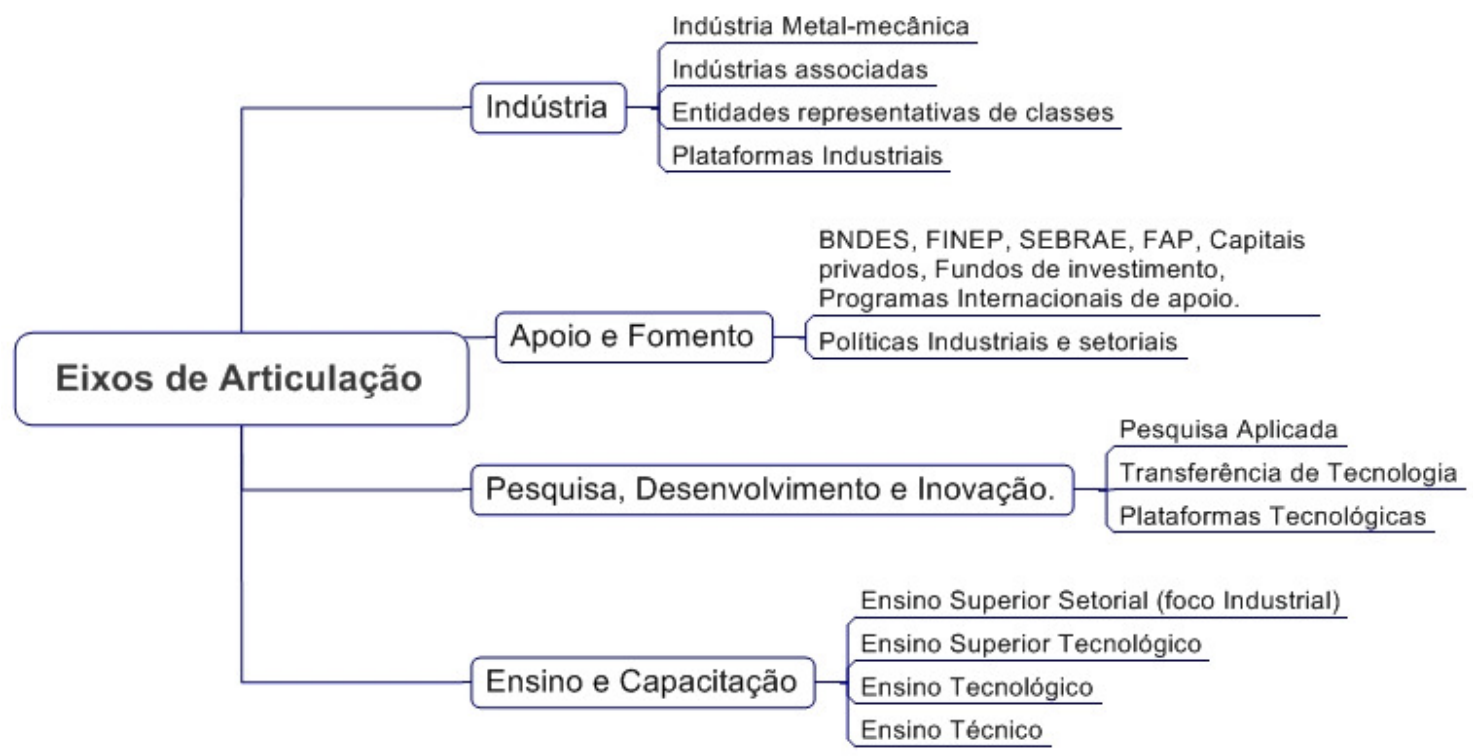

Figura 7-2: Articulação baseada em quatro eixos: ensino e capacitação; pesquisa \& desenvolvimento \& inovação; articulação da dinâmica da indústria local; articulação com organizações de fomento e financiamento.

O desenvolvimento desse instrumento permite responder as seguintes demandas A, B, C e D (vide Tabela 7.1) e fatores prioritários 1, 7, 8, 9, 12, 13, 16 e 17. 


\section{- Centro de Incubação}

Na perspectiva do desenvolvimento econômico de uma localidade, o papel do empreendedorismo inovador é relevante. No grupo de instrumentos viáveis, encontram-se as incubadoras de empresas, que podem ser definidas como um ambiente propício para a inovação, desenvolvido para abrigar e desenvolver empresas iniciantes de base tecnológica.

Estas se distinguem por serem intensivas na utilização de conhecimento, concorrem por meio da inovação, geram produtos de alto valor agregado, possuem processos intensivos em mão-de-obra qualificada e com baixo impacto ambiental.

A lógica de uma incubadora de base tecnológica está baseada na necessidade de oferecer suporte, sobretudo gerencial, aos empreendedores com perfil técnico e promover a socialização (troca de conhecimentos tácitos) pela interação e proximidade das empresas. Em linhas gerais, capacitando negócios para enfrentar a competição de mercado.

Considerando a proposição de criação e desenvolvimento de empresas tecnológicas, a estruturação do sistema de inovação de Sorocaba prevê o fortalecimento das atividades de incubação de empresas no Município, oferecendo condições diferenciadas para o desenvolvimento dessas empresas, a partir de uma forte atuação na academia local, a qual será o manancial de novos projetos para a região.

Essa atuação com a base de ciência e tecnologia local será estimulada pelo desenvolvimento de projetos e programas específicos que objetivem a articulação e incentivem 0 empreendedorismo inovador, envolvendo a participação de pesquisadores e discentes nas atividades e gestão de empresas, processo que foi estimulado na Lei no $10.973^{15}$, de 2 de dezembro de 2004.

As incubadoras de base tecnológica são espaços atrativos para os pesquisadores empreendedores com o objetivo de desenvolvimento de empresas. Sendo assim, nesses ambientes desenvolvem-se empresas iniciantes oriundas do

\footnotetext{
${ }^{15}$ LEI N. 10.973, DE 2 DE DEZEMBRO DE 2004. Dispõe sobre incentivos à inovação e à pesquisa científica e tecnológica no ambiente produtivo e dá outras providências.
} 
meio acadêmico e do meio empresarial oriundas de empresas maiores, (conhecidos como spin-offs).

A aproximação com bases de ciência e tecnologia é fundamental para dotar as empresas incubadas de alta qualificação técnica. Vislumbra-se fundamental prover iniciativas para fortalecer a aproximação.

A incubadora será um dos principais ativos do Parque Tecnológico e o desenvolvimento desse instrumento permite responder as seguintes demandas $A$, F, H (vide Tabela 7.1) e fatores prioritários 4, 10, 17. 


\section{- Arranjos Produtivos}

Considerando a definição das atividades prioritárias que serão desenvolvidas no Parque Tecnológico de Sorocaba e na sua área de influência que envolve o Município de Sorocaba e região, torna-se interessante propor dois movimentos: i) articular os principais arranjos produtivos existentes, buscando desenvolver a cooperação e aprendizagem entre os elos da cadeia, como por exemplo, a cadeia metal-mecânica, envolvendo os setores de auto-peças e máquinas pesadas; ii) estruturar arranjos em atividades estratégicas e intensivas em conhecimentos, com atividades com alto potencial de desenvolvimento como tecnologias para mineração com a governança da empresa Metzo Minerais, tecnologias para geração de energia eólica com governança das empresas Woben e Tecsis, tecnologia para comunicação com a Flextronics e tecnologias para manutenção de aeronaves com a presença da Dassault e Oceanair.

Projeta-se trabalhar com base no conceito de plataformas tecnológicas ${ }^{16}$, definidas aqui, como sistemas de governança em áreas temáticas para o desenvolvimento de tecnologias.

Desta forma, busca-se superar as limitações individuais dos atores num determinado elo de uma cadeia ou segmento para desenvolver inovações tecnológicas, buscando superá-las por meio de cooperação (ações conjuntas), para estimular o desenvolvimento de capacidades coletivas para empreender inovações.

O estudo das cadeias produtivas permitirá diagnosticar as principais lacunas de competências em determinados segmentos e atuar sobre eles, inclusive propondo o desenvolvimento de atividades complementares.

A articulação desses arranjos será proveniente da análise das condições locais do Município conjuntamente com a atuação do Pólo de Desenvolvimento e o $\operatorname{SEBRAE}^{17}$, entidade de apoio que possui um programa específico para o desenvolvimento de Arranjos Produtivos, com o objetivo de apoiar o desenvolvimento dos territórios. No Município de Sorocaba não possui nenhum arranjo produtivo estruturado.

\footnotetext{
${ }^{16}$ Programa Plataformas Tecnológicas. Relatório de atividades. Disponível em: www.ibp.org.br. Acesso em 04/03/2009 17 Serviço Brasileiro de Apoio as Micro e Pequenas Empresas. Disponível em: www.sebraesp.com.br. Acesso em: 04/03/2009.
} 
A concepção de estruturação envolve duas perspectivas:

i) Com base na dinâmica espontânea das atividades produtivas já existentes, com o papel de identificação e articulação dos arranjos existentes, os quais apresentam diferentes estágios de cooperação ente os agentes;

ii) Com base na dinâmica planejada, estimulando a cooperação e surgimento de arranjos com alto potencial tecnológico, em plataformas Tecnológicas identificadas como prioritárias pelos agentes de desenvolvimento econômico.

O desenvolvimento desse instrumento permite responder as seguintes demandas G, H (vide Tabela 7.1) e fatores prioritários 5, 9, 17. 


\subsection{Proposta de sistema de Inovação de Sorocaba}

A proposta de sistema de inovação para Sorocaba (Figura 7-3) está ancorada na necessidade de interação entre os atores do meio empresarial, da academia e do poder público.

Todavia essa interação não é espontânea e para estimular esse processo, a proposta prevê instrumentos específicos com finalidade de articulação na camada (2) do sistema, na qual serão trabalhados os diversos projetos para aproveitamento dos recursos de fomento dos diversos organismos federais, estaduais e municipais.

Também, serão acumuladas informações sobre o potencial científico e tecnológico das entidades de ensino, potencial das bases econômicas e serão promovidos sistemas de comunicação para interação dos atores.

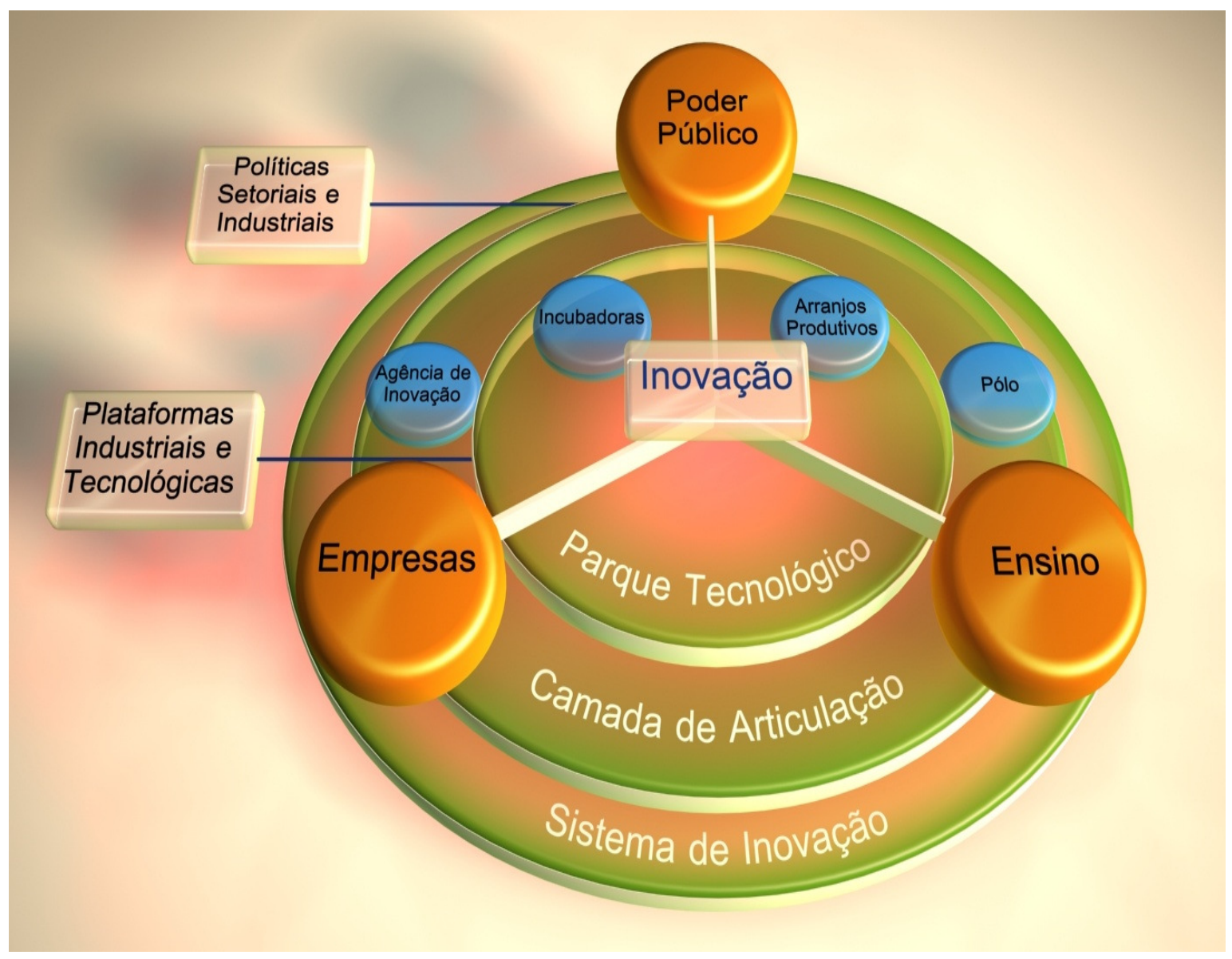

Figura 7-3: Estruturação do Sistema de Inovação de Sorocaba.

Especificamente, como instrumento, aparece o desenvolvimento do Pólo de Desenvolvimento e Inovação com a função de estimular as relações entre 
academia, pode público local e meio empresarial. Esse órgão tem como atividades e competências principal a gestão de projetos, oferecendo apoio para a obtenção de financiamentos nos órgãos em perspectivas federais, estaduais e internacionais. A governança do Pólo tem como base o poder público, no caso a prefeitura de Sorocaba.

$\mathrm{Na}$ proposta, outra estrutura com finalidade de articulação será a Agência de Inovação, constituída a partir da interação entre academia, pode público e empresas. Esse órgão de interesse público representa os anseios da sociedade e a sua estrutura operacional tem como característica a flexibilidade e facilidade operacional dos projetos envolvidos no sistema de inovação local.

$\mathrm{Na}$ camada (3), a estruturação comporta o Parque Tecnológico de Sorocaba com três objetivos principais, ser o meio indutor da transformação dos conhecimentos em valor econômico; requalificar o espaço, visto que o está alicerçado numa proposta de desenvolvimento local envolvendo o adensamento de áreas degradadas e; ser o vetor do desenvolvimento e inovação de Sorocaba e região.

O Parque Tecnológico de Sorocaba deve proporcionar o desenvolvimento de diferentes áreas do conhecimento com base na priorização de diferentes plataformas tecnológicas e industriais.

Envolve a priorização da vocação metal-mecânica e outras atividades com alto potencial de desenvolvimento como tecnologias para mineração, tecnologias para geração de energia eólica, tecnologia para informação e Comunicação - TIC e Tecnologias para manutenção de aeronaves.

Além desses, segmentos transversais intensivos em conhecimento e com alto potencial de futuro como nanotecnologia, novos materiais $e$ biotecnologia.

Estas plataformas serão compostas de diferentes ativos, tais como centros de pesquisa, centros de desenvolvimento, centros de formação, laboratórios, com a finalidade de desenvolver setores específicos.

Essa concepção implica no relacionamento com diferentes dinâmicas produtivas e setoriais, abrindo um espaço para a discussão de arranjos produtivos que serão discutidas e organizadas em duas perspectivas, dinâmicas 
espontâneas, as quais, já estão estabelecidas e dinâmicas planejadas em áreas que oferecem grandes oportunidades de desenvolvimento.

Outro ativo estratégico proposto é a incubadora de base tecnológica, promovendo o desenvolvimento de novas empresas intensivas em tecnologia e com dois papéis específicos: i) o papel de incentivar o empreendedorismo inovador e, ii) fomentar a inovação com o desenvolvimento de empresas intensivas em conhecimento e geradora de riquezas.

A seguir, na Tabela 7.2 serão apresentados os principais relacionamentos previstos entre os componentes no sistema proposto.

Tabela 7.2 - Relacionamento dos Ativos do Sistema de Inovação de Sorocaba.

\begin{tabular}{|c|c|c|c|c|c|}
\hline $\begin{array}{l}\text { Instrumentos } \\
\text { Demandas }\end{array}$ & $\begin{array}{c}\text { Pólo de } \\
\text { Desenvolvimento } \\
\text { e Inovação }\end{array}$ & $\begin{array}{l}\text { Agência de } \\
\text { Inovação }\end{array}$ & $\begin{array}{c}\text { Parque } \\
\text { Tecnológico }\end{array}$ & $\begin{array}{l}\text { Incubadoras } \\
\text { Tecnológicas }\end{array}$ & $\begin{array}{l}\text { Arranjos } \\
\text { Produtivos }\end{array}$ \\
\hline 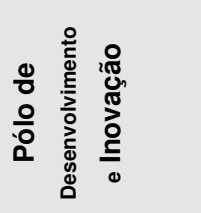 & & $\begin{array}{c}\text { Articulação via } \\
\text { poder público. } \\
\text { Projetos }\end{array}$ & $\begin{array}{l}\text { Demandas de } \\
\text { articulação e } \\
\text { indução. }\end{array}$ & $\begin{array}{l}\text { Demandas de } \\
\text { gestão, } \\
\text { articulação e } \\
\text { projetos. }\end{array}$ & $\begin{array}{c}\text { Demandas } \\
\text { de } \\
\text { articulação }\end{array}$ \\
\hline 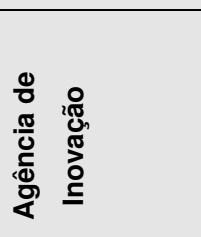 & $\begin{array}{c}\text { Apoio a Gestão } \\
\text { financeira dos } \\
\text { projetos. }\end{array}$ & & $\begin{array}{c}\text { Demandas de } \\
\text { apoio à Gestão do } \\
\text { Parque }\end{array}$ & $\begin{array}{l}\text { Apoio a Gestão. } \\
\text { Apoio a Gestão } \\
\text { financeira dos } \\
\text { projetos. }\end{array}$ & $\begin{array}{l}\text { Demandas } \\
\text { de operação } \\
\text { de projetos }\end{array}$ \\
\hline $\begin{array}{l}\text { 유 } \\
\frac{0}{0} \\
\frac{0}{0} \\
\frac{\delta}{0} \\
\frac{\Phi}{0} \\
\frac{0}{0} \\
0\end{array}$ & $\begin{array}{l}\text { Demandas } \\
\text { Tecnológicas }\end{array}$ & Projetos & & $\begin{array}{c}\text { Demandas de } \\
\text { Espaço e } \\
\text { fomento }\end{array}$ & $\begin{array}{c}\text { Demandas } \\
\text { de Espaço } \\
\text { para } \\
\text { organização } \\
\text { e ações de } \\
\text { fomento }\end{array}$ \\
\hline 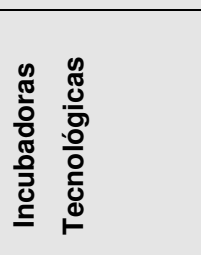 & $\begin{array}{l}\text { Demandas de } \\
\text { Projetos e } \\
\text { Necessidades } \\
\text { de Gestão }\end{array}$ & Projetos & $\begin{array}{l}\text { Desenvolvimento } \\
\text { de empresas de } \\
\text { base Tecnológica }\end{array}$ & & $\begin{array}{c}\text { Apoio a } \\
\text { empresas } \\
\text { iniciantes }\end{array}$ \\
\hline 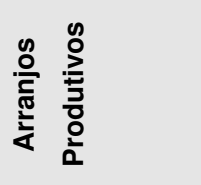 & $\begin{array}{l}\text { Articulação } \\
\text { inter-setorial, }\end{array}$ & Projetos & $\begin{array}{c}\text { Articulações } \\
\text { setoriais }\end{array}$ & $\begin{array}{c}\text { Demandas de } \\
\text { apoios setoriais }\end{array}$ & \\
\hline
\end{tabular}




\section{Método para validação da proposta}

O método utilizado para a validação tem como base o método dos incidentes críticos $^{18,}$ bastante utilizado na qualidade de serviços.

Esse método, de característica qualitativa, baseia-se no posicionamento do respondente em relação a um evento, situação ou incidente considerado crítico.

O documento foi estruturado para apresentar os pontos críticos da proposição e obter o posicionamento dos especialistas em relação às afirmativas apresentadas. Os especialistas selecionados para análise (maiores detalhes ver anexo D) foram:

O Professor Titular da Universidade de São Paulo Vahan Agopyan, também coordenador de Ciência e Tecnologia (C\&T) da Secretaria de Desenvolvimento do Estado de São Paulo.

O professor Marco Antonio Raupp, BSc em Física pela UFRGS, PhD em Matemática pela Universidade de Chicago e Livre Docente pela USP. Atualmente é Coordenador do Parque Tecnológico de São José dos Campos.

A seguir na Tabela 7.3 serão analisadas as afirmações e comentários:

Tabela 7.3 - Considerações dos especialistas.

\begin{tabular}{|c|c|}
\hline Afirmativa & Especialista A \\
\hline $\begin{array}{l}\text { 1. A proposta conceitual de estrutura do } \\
\text { sistema de inovação local, cujo aspecto } \\
\text { crítico é a articulação, pode contribuir para } \\
\text { promover a interação entre o setor público, } \\
\text { o setor privado e a universidade /centros de } \\
\text { pesquisa, com vista ao incremento da } \\
\text { competitividade no Município de Sorocaba }\end{array}$ & $\begin{array}{l}\text { A Figura 7-3 destaca bem as idéias do autor para o } \\
\text { sistema de inovação local, no entanto, a proposta } \\
\text { conceitual é bem ampla e sistêmica, baseada nas } \\
\text { experiências do exterior e no país. Acho muito importante } \\
\text { ter uma visão global e uma proposta ousada e completa, } \\
\text { no entanto não notei no texto uma orientação maior para a } \\
\text { sua implantação gradativa ou até parcial, conforme os } \\
\text { ditames políticos. É correto ter um sonho amplo, mas com } \\
\text { uma estratégia bem explicitada para a sua viabilização, } \\
\text { mesmo que parcial. } \\
\text { Logicamente, quase todas as estruturas previstas no } \\
\text { modelo já existem ou estão em implantação, mas a sua } \\
\text { correlação e articulação exigem ações concatenadas que } \\
\text { não estão explicitadas no texto. }\end{array}$ \\
\hline
\end{tabular}

18 Parasuraman, A., Zeithaml, V.A. \& Berry, L.L. (1985). "A conceptual model of service quality and its implication for future research", in Journal of Marketing, Vol.49, Autumn, pp.41-50. 


\begin{tabular}{l}
\hline \multicolumn{2}{c}{ Afirmativa } \\
\hline \\
\hline Brasil como um país com sistema de \\
inovação desarticulado, característica \\
também espelhada no Município de \\
Sorocaba.
\end{tabular}

Sendo assim, a proposta de um nível de específico de articulação, na qual foram apresentados como instrumentos específicos: o Pólo de Desenvolvimento e Inovação e a Agência de Inovação revertem essa situação numa perspectiva local.
Especialista A

A proposta é um grande avanço para a articulação do sistema de inovação do Município de Sorocaba. No entanto, na Figura 7-3, fiquei com uma dúvida de como a Agência de Inovação será o instrumento da camada 2. Mesmo a agência funcionando plenamente, atendendo os seus objetivos básicos, a interação academia - produção não é trivial, como todos nós sabemos e só a existência da Agência não garantirá essa interação, se não tivermos alguns instrumentos complementares para incentivar essa cooperação.

Da mesma forma, na camada 3, o parque tecnológico é o instrumento ideal para a estruturação do sistema municipal de inovação, mas da mesma forma que a Agência, necessita de incentivos complementares para a consecução dessa ação.

Nos exemplos que temos dos parques bem sucedidos, sempre se tem alguma ação efetiva que estimula o seu desenvolvimento, às vezes, por iniciativa governamental, outras vezes pelo empreendedorismo dos seus gestores e até por fatos externos.

3. Com base nas condições locais de Sorocaba, a estrutura do seu sistema de inovação e as experiências observadas o desenvolvimento de uma proposição baseada num instrumento único dificilmente permitiria abranger todas as necessidades e demandas levantadas, sendo viável a abordagem sistêmica que foi utilizada.

4. Dado o estudo das características locais que apresentam: base de C\&T incipiente e grande base industrial metal-mecânica e o sistema de inovação desarticulado, torna-se viável a construção de Plataformas Científicas e Tecnológicas no âmbito do Parque Tecnológico.

Esse movimento será positivo para
A abordagem sistêmica proposta pela Tese é o ponto central do trabalho e o que permite vislumbrar uma efetiva implementação do sistema de inovação no Município. Neste aspecto destaco as Figura 7-1 e Figura 7-3, como uma orientação eficaz para concretizar o objetivo. Nos comentários anteriores apenas destaquei a necessidade de prevermos a sua efetivação em etapas ou parcialmente. Novamente externo a minha preocupação de que se vai necessitar uma intensa tarefa de informação para mudança cultural, pois apenas por meio de políticas públicas não se garante o pleno uso das plataformas científicas. Temos experiências no país de recursos disponíveis, a custos subsidiados, no caso fora de parques ou APLs, que não são utilizados. Apenas 8 empresas (inclusive algumas públicas) respondem pela quase totalidade das pesquisas do IPT, não considerando os 


\begin{tabular}{|c|c|}
\hline Afirmativa & Especialista A \\
\hline $\begin{array}{l}\text { o desenvolvimento de novas } \\
\text { tecnologias, utilizando ativos existentes } \\
\text { e outros que possam ser criados ou } \\
\text { incrementados (centros de pesquisa, } \\
\text { centros de desenvolvimento, centros de } \\
\text { formação e laboratórios), por meio de } \\
\text { políticas públicas ou pela atração de } \\
\text { investimentos da iniciativa privada. }\end{array}$ & serviços rotineiros do Instituto. \\
\hline $\begin{array}{l}\text { 5. A proposta do Parque Tecnológico de } \\
\text { Sorocaba permite atender aos seus três } \\
\text { objetivos principais: } \\
\text { - Ser um dos meios de indução da } \\
\text { transformação de conhecimento em } \\
\text { valor econômico no contexto do sistema } \\
\text { local de inovação; } \\
\text { Requalificar o espaço, visto que está } \\
\text { alicerçado numa proposta de } \\
\text { desenvolvimento local envolvendo o } \\
\text { adensamento de áreas deprimidas; } \\
\text { Ser um dos vetores do desenvolvimento } \\
\text { e inovação de Sorocaba e região. }\end{array}$ & $\begin{array}{l}\text { Pela descrição do parque tecnológico (página } 246 \text { do } \\
\text { texto), como um parque da terceira geração, ele deve } \\
\text { atender a esses objetivos e exercer, ainda, o seu papel no } \\
\text { sistema, como a camada } 3 \text { da Figura } 7-3 \text {. }\end{array}$ \\
\hline
\end{tabular}

A Análise do especialista $B$ foi de concordância com as afirmativas expostas na Tabela 7.3 e a argumentação enfatizou a viabilidade da proposta e coerência com as experiências de outros ambientes nacionais e internacionais.

Com base na aceitação dos fatores críticos enunciados para os especialistas consultados e posterior concordância com os mesmos, pode-se considerar a aceitação da proposta do sistema de inovação de Sorocaba.

Como observação de forma genérica, foram mencionadas as dificuldades no processo de implantação, totalmente pertinente; argumenta-se, porém que, conceitualmente, a implantação do sistema deva ser iniciada pelas camadas de articulação envolvendo o Pólo de Inovação e a Agência de Inovação cujas correlações com os outros instrumentos estão explicitadas na Tabela 7.2.

Relacionado ao aspecto da operação da agência de inovação, existe a concordância, como sugerido na análise, com relação à dificuldade de aproximação entre empresas e setor acadêmico. Para superar esse aspecto, 
busca-se, por meio da priorização da articulação, desenvolver relações de confiança, as quais serão os elementos motivadores de novos acordos, facilitadas pela estrutura da agência que prevê sua composição por atores de diferentes instituições e com alta representatividade. Também, é importante ressaltar a importância da elaboração de instrumentos jurídicos voltados a metas e resultados.

No que tange especificamente, aos parques tecnológicos a estratégia da agência de inovação será replicada e incrementada pela formação de plataformas industriais com base nas potencialidades vocacionais e tecnológicas, com atividades com alto potencial de desenvolvimento.

Relacionado à estrutura sistêmica proposta, considera-se como essencial, dado o grande número de variáveis existentes em projetos com essa característica, as quais serão agrupadas em instrumentos específicos.

Para o desenvolvimento das plataformas científicas e tecnológicas, mesmo considerando a dificuldade natural da sua implantação, considera-se viável pelo esforço de articulação que envolverá o Pólo de Desenvolvimento e Inovação conjuntamente com outros atores como o Sebrae, Centro das Empresas do Estado de São Paulo e a própria Associação Comercial.

Finalizando, observa-se que o modelo de desenvolvimento do Parque Tecnológico pressupõe um aprofundamento sobre o movimento e condições locais para oferecer condições mais favoráveis para a população. 


\title{
8. CAPÍTULO VIII - CONCLUSÕES, COMENTÁRIOS E RECOMENDAÇÕES
}

\begin{abstract}
Para estimular a interação entre o setor público, o setor privado e a universidade /centros de pesquisa, com vistas ao incremento da competitividade considerando a experiência de um modelo desenvolvido num país com um sistema de inovação articulado e alicerçado em dinâmicas espontâneas versus o caso de uma localidade em um país caracterizado por um sistema de inovação heterogêneo com base numa dinâmica planejada, torna-se necessário a presença de uma forte governança local (município) para induzir a composição entre os vetores do desenvolvimento (empresas, academia, poder público). A abordagem deve proporcionar a aplicação de diferentes instrumentos, coerentes com a dinâmica do município, constituindo uma abordagem sistêmica que deve prever a utilização estratégica dos mesmos, com priorização dos elementos para os voltados para a articulação.
\end{abstract}

Cabe ressaltar que os estudos referentes a sistemas de inovação, especificamente no Brasil e Sorocaba, conjuntamente com a revisão na literatura sobre ambientes de inovação, a análise do contexto econômico e tecnológico local e o estudo de campo forneceram subsídios para o desenvolvimento de um conceito de articulação de ambientes de inovação para Sorocaba.

Inicialmente, a análise sobre os sistemas de inovação posicionou a importância da interação entre os sistemas científico-tecnológicos e o setor produtivo. O Brasil é caracterizado pela pouca interação entre esses atores. Considerando o estado de São Paulo, o estado mais desenvolvido no país, observa-se que o mesmo apresenta indicadores positivos quando comparado com as referências internacionais em termos de produção científica, todavia incipientes em termos de produção tecnológica, utilizando como aproximação, por exemplo, o número de patentes.

$\mathrm{Na}$ perspectiva de análise do sistema de inovação do Município de Sorocaba pelos resultados, este caracteriza-se por possuir uma base de C\&T 
incipiente, com uma produção científica limitada, mesmo panorama da produção tecnológica.

A análise do sistema de inovação local com base nos seus componentes principais - organizações, instituições (arcabouço institucional) e interações - evidencia um panorama de pouca articulação, com as organizações atuando de forma isolada, não existindo um agente indutor para a aproximação.

Nesse contexto surge a oportunidade de promover a interação entre a academia e as empresas por meio da indução do poder público, considerando a condição de promoção de políticas públicas na esfera da municipalidade.

As políticas públicas são operadas sob a forma de projetos, incluindo alguns com o objetivo específico de desenvolver inovação no setor produtivo, sendo viável o dinamismo de um instrumento com fins de articulação.

Nesse aspecto, são conhecidos os impactos do ambiente para desenvolvimento de atividades inovativas, visto que possibilitam a transmissão dos conhecimentos tácitos pela proximidade entre os atores. Essa importância do ambiente na promoção da inovação tecnológica constitui um dos principais pilares das leis de promoção de inovação no país, tanto no nível federal como no estado de São Paulo.

Para a promoção do ambiente entende-se necessário que o instrumento a ser desenvolvido seja aderente às condições específicas locais. Desta forma, foram analisadas as condições do município de Sorocaba, as relações contextuais e os diferentes modelos de ambientes de inovação, sendo que inicialmente foram abordados os arranjos produtivos locais - APL e os Parques Tecnológicos.

Os sistemas produtivos variam de acordo com o tipo de setor a ser explorado, podendo desenvolver atividades tradicionais ou consideradas inovativas sendo sensível aos níveis de intensidade tecnológica destas. A diagnose das atividades desenvolvidas na localidade permite observar as suas principais forças e debilidades, sendo um importante instrumento para a tomada de decisões.

A constituição de um arranjo produtivo pode ser planejada, porém, geralmente é espontânea, com o intuito de aproveitar as externalidades positivas de determinadas regiões e a sua maturidade varia de acordo com o nível de 
articulação entre os atores. No caso de Sorocaba observa-se que alguns segmentos apresentam uma alta concentração de atividades, caso específico do setor metal-mecânico.

Todavia, uma análise mais detalhada evidencia que a interação é bastante incipiente $e$, quando existente, está relacionada às transações de mercado. Esse panorama apresenta uma oportunidade de coordenação de ações que precisa ser desenvolvida; acredita-se que essas ações podem ser desenvolvidas no âmbito do Parque Tecnológico, conjuntamente com as plataformas tecnológicas e científicas a serem exploradas. Sendo assim, defendese a formulação de uma proposta que privilegie a adoção de plataformas industriais com base nas vocações identificadas e conjuntamente plataformas científicas e tecnológicas com base no desenvolvimento de áreas do conhecimento.

No que tange à aplicação de conhecimentos por meio da aproximação entre os atores oriundos da academia, poder público e empresas a forma mais evoluída de desenvolvimento são os parques tecnológicos.

No projeto de Sorocaba privilegia-se um projeto considerado de terceira geração, com maior inserção local e forte envolvimento com as políticas públicas, dado os impactos que apresentam para as suas áreas de influência. No caso de Sorocaba, o projeto está alicerçado no adensamento de uma área deprimida de cerca de vinte milhões de metros quadrados, permitindo qualificar o adensamento e desenvolver um contexto de externalidade positiva na área.

A necessidade de uma base científica e tecnológica implica na articulação com instituições de ensino, de formação, de fomento e de qualificação, aliados à presença de institutos de pesquisa e agentes de certificação; entendese necessária a articulação com a Entidade de Ciência e Tecnologia para a promoção da facilitação na obtenção de recursos para projetos.

A outra vertente relacionada à base produtiva (vocação de determinada área) será o diferencial na definição da necessidade e tipo de atuação do Parque Tecnológico que no caso sorocabano, pelas suas características, entende-se propício o desenvolvimento de um modelo multi-plataformas para diferentes tecnologias, envolvendo o potencial de tecnologias industriais consolidadas no 
Município como no caso metal-mecânico e também tecnologias com alto potencial de futuro como geração de energia (fontes alternativas) e biotecnologia.

No que concerne à área de influência, entende-se que devem existir políticas públicas que permitam direcionar as atividades de interesse do parque; para tal torna-se necessária a articulação com os agentes envolvidos e o alinhamento com os planos diretores e leis de zoneamento.

No processo de implementação desses ambientes, algumas variáveis são de extrema importância, como o modelo de governança em operação, o qual envolve a definição das linhas de decisão e responsabilidades, além de questões de financiamento, de coordenação e de papéis dos atores, sobretudo do poder público em suas diferentes esferas de atuação.

Para tal é importante desenvolver um organismo de gestão que permita flexibilidade para a operação e seja representativo dos anseios dos diferentes grupos. Nessa perspectiva, a formação de uma agência com a participação de diferentes atores da sociedade local e uma figura jurídica independente é favorável.

Outro aspecto a ser considerado, direciona para análise das empresas de base tecnológica iniciantes; estas são altamente dependentes de um apoio nos seus estágios iniciais de vida para o seu fortalecimento, dada a complexidade técnica dos seus produtos e processos. Surge a necessidade do desenvolvimento de incubadoras de base tecnológica, as quais devem ter como vertente bem definida a promoção de empresas de base tecnológica.

Em paralelo, o estudo conjuntamente com uma pesquisa sobre os ambientes de inovação possibilitou definir as principais dimensões que devem ser investigadas na análise desses ambientes: governança, estratégia, relação universidade e empresas e infra-estrutura. Essas dimensões serviram de base para o desenvolvimento de pesquisas em campo que apontaram as potencialidades e fragilidades do modelo francês dos Pólos de Competitividade e também dos parques tecnológicos brasileiros. Esse método permitiu levantar pontos fortes e pontos de melhoria desses modelos, os quais serviram de referência para a definição dos instrumentos.

Sendo assim, dada a complexidade existente no município observou-se que as demandas provenientes da análise das condições e dos fatores prioritários 
em relação às experiências analisadas não seriam sanadas com base na perspectiva de um único instrumento, necessitando da aplicação de vários numa base sistêmica, com relacionamento entre os instrumentos.

Foram propostas, então, três camadas com funcionalidades bem definidas: a camada de articulação envolvendo os pólos de competitividade e a agência de inovação, as quais são responsáveis pelo conjunto de articulações e formulação de projetos com atores internos e externos aos processos como investidores, organismos de apoio e fomento e sociedade; a camada do Parque Tecnológico, a qual envolve os arranjos produtivos e a incubadora de empresa, com base na proposta de desenvolvimento de plataformas industriais e plataformas de Ciência e Tecnologia para o desenvolvimento de segmentos de interesses e a camada de resultados, a camada de inovação.

Todas essas camadas são transversais ao eixo de articulação entre empresas, para as instituições de ensino e poder público constituído.

No que tange à tese entende-se que: i) os ambiente tem grande influência para o desenvolvimento de inovações, ii) que o poder público é um importante agente indutor do processo e iii) que a articulação entre o poder público, a academia e o tecido empresarial no caso do Município de Sorocaba passa pelo desenvolvimento de um sistema de inovação com a estruturação de instrumentos convergentes e complementares.

\section{Recomendações}

Considerando as limitações do estudo de utilizar como referência um modelo conceitual, observa-se um grande potencial para o desenvolvimento de outros estudos de caso com característica semelhante e utilizando de modelos reais em operação.

No aspecto da metodologia a definição das dimensões de estudo podem ser incrementadas e aprofundadas em outros temas, tais como propriedade intelectual, modelos de financiamentos e modelos de gestão. Da mesma forma, a abordagem de alguns temas tratados no presente estudo de forma mais genérica pode ser aprofundada, dado que esses temas apresentam potencial para futuras pesquisas, considerando, por exemplo, estratégia e governança. 
Na perspectiva do objeto do estudo, os ambientes de inovação, a literatura sobre os APL apresentam uma densidade de publicações avançada quando comparada com os parques tecnológicos, expondo uma oportunidade para futuras pesquisas sobre o tema.

Na perspectiva do Sistema Paulista de Parques Tecnológicos abre-se uma grande oportunidade para análises comparativas entre as experiências, considerando as vocações e plataformas a serem desenvolvidas. 
APÊNDICE A - QUESTIONÁRIO DE PESQUISA 


\title{
Présentation
}

\author{
Mesdames, Messieurs,
}

$\Rightarrow$ Cette recherche fait partie du développement de la Thèse de Doctorat de Devanildo Damião, sous la direction de la Professeur Désirée Zouain, coordinatrice de projets du Centre de Politique et Gestion Technologique de I'Université de São Paulo.

$\Rightarrow$ La contribution attendue avec cette étude consiste à comprendre, à partir de I'expérience française, comment les outils présents en systèmes d'innovation consolidés peuvent être répliqués, en tenant compte de I'investigation de structures qui mobilisent les facteurs-clés de la compétitivité - la connaissance et I'innovation, dans un pays développé avec un système d'innovation pleinement développé et mature comme le cas de la France ; et en tenant compte de la désarticulation présente dans les systèmes d'innovation hétérogènes, comme c'est le cas, au Brésil, d' une région déterminée (Sorocaba - São Paulo).

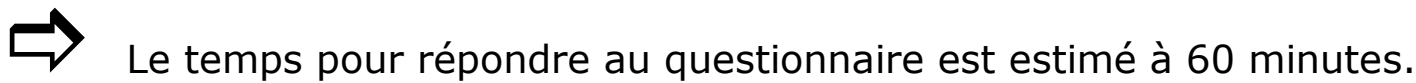

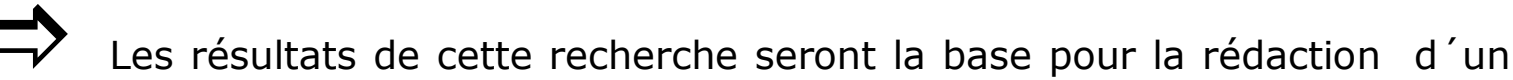
rapport analytique qui sera offert aux participants de l'enquête.

\section{Nous comptons sur votre collaboration et intérêt !}

Votre participation est fondamentale dans ce mouvement de rapprochement des liens de recherche et développement entre le Brésil et la France.

Contact avec Professeur Désirée Zouain, par téléphone: (+55 11) 3818-4011 (secrétaire Sonia) - Núcleo de Política e Gestão Tecnológica da Universidade de São Paulo - PGT/USP. Merci! 


\section{Instructions}

\section{Temps}

- Le temps pour répondre au questionnaire est estimé à 60 minutes.

- Nous vous prions de nous envoyer le questionnaire répondu jusqu' à $21 / 07 / 2008$.

\section{Questionnaire}

- Nous vous prions d'envoyer le questionnaire répondu par Email :

○ devan@usp.br

○ devanildo@gmail.com

- Vous pouvez aussi répondre le questionnaire on line au site http://www.damiao.pro.br/

- Réponses

- Nous vous prions d'utiliser directement le questionnaire pour répondre;

- Il n'existe pas des limites pour les tailles des réponses.

- Contact

- Si vous besoin des informations additionnels, Professeur Désirée Zouain est disponible par téléphone: (+55 11) 3818-4011 où Email (dzouain@uol.com.br) (Secrétaire : Mme. Sonia Vitorino) - Centre de Recherche en Politique et Gestion de la Technologie - Université de São Paulo, Brésil.

- Nous comptons sur votre collaboration et intérêt !

Votre participation est fondamentale dans ce mouvement de rapprochement des liens de recherche et développement entre le Brésil et la France. 


\section{Infrastructure}

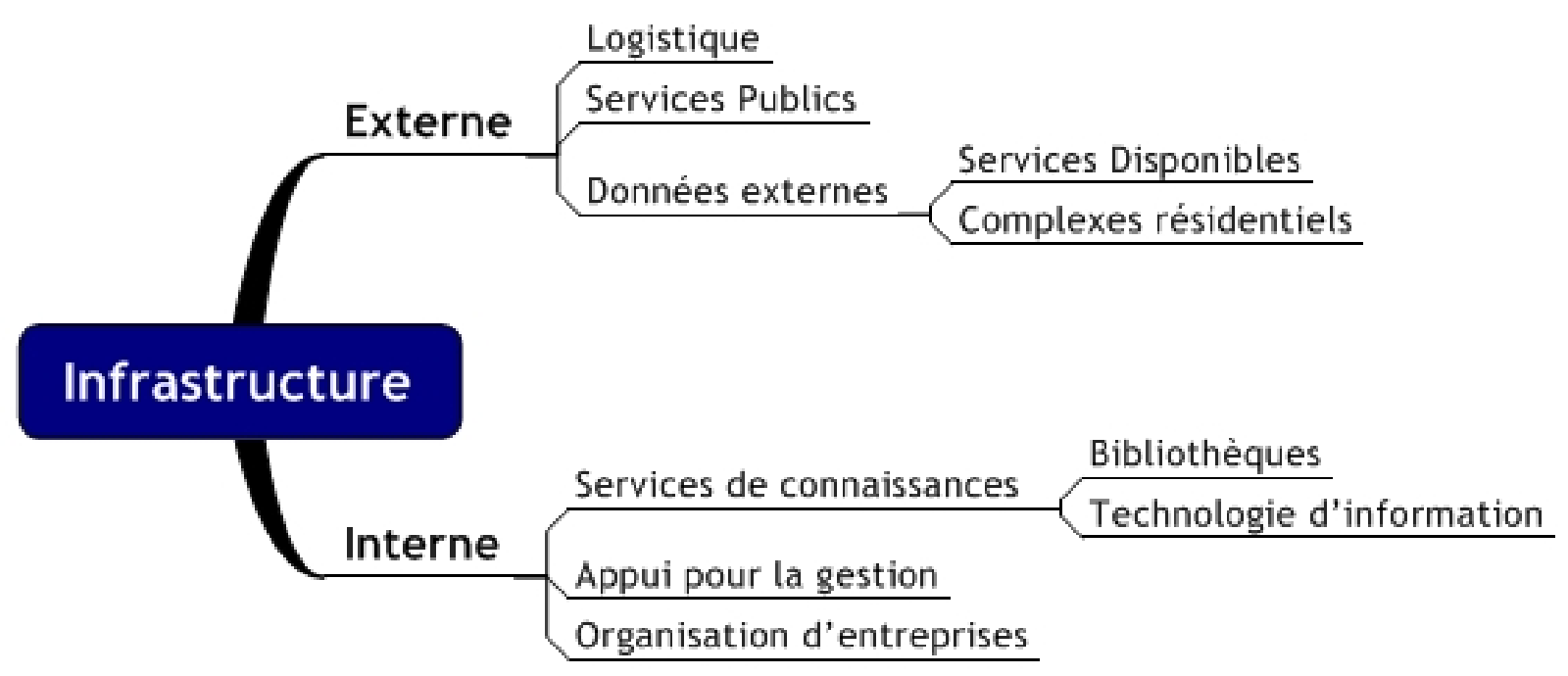

Dans cette étude seront traités:

En externe :

- tout ce qui concerne la logistique disponible locale, considérant les principales vois d'accès, aéroports, métro, et routes.

- Les principaux outils publics disponibles pour les personnes qui sont dans le pôle.

- Enfin, considérés comme données externes, seront analysés les complexes résidentiels ainsi que les services de commerce, tourisme et loisirs disponibles. 


\section{En interne :}

- tout ce qui concerne les services disponibles pour les entreprises présentes dans le pôle, comme les services de connaissance (ex: bibliothèques), la technologie d'information disponible, les laboratoires de recherche et de développement et la structure pour les communautés de pratique, les réseaux et les autres groupes.

- Aussi, les formes et les modèles d'appui à la gestion de l'entreprise, comme les formations, trainings, et conseils spécialisés.

- Enfin, la manière d'organisation des entreprises dans les pôles, prenant en compte les différentes structures de micro, petites, moyennes et grandes entreprises.

\section{Attentes vis-à-vis des réponses:}

1. La description des structures disponibles concernant la logistique externe du Pôle, englobant les transports et les services publics disponibles dans la localité où se situe le pôle. Aussi la description des complexes résidentiels pour le logement des employés.

2. Description des types d'organisation des entreprises présentes dans le Pôle : y a-t-il des pépinières ?, des groupements d'entreprises ? Quel est le détail relatif à la gouvernance?

3. Description des structures d'appui à la gestion du pôle, englobant l'édification de structures pour : certifications, propriété intellectuelle, commerce extérieur, et autres services.

4. Description de l'infrastructure de connaissance, dont les bibliothèques, les communautés de pratiques, la technologie de l'information (hardware, software, base de donnés et réseaux) et les laboratoires de recherche et développement. 


\begin{tabular}{|c|c|c|}
\hline A - Logistique & Noms & Localisation (distance du pôle) \\
\hline \multicolumn{3}{|l|}{ Axes routiers principaux } \\
\hline \multicolumn{3}{|l|}{ Principaux Aéroports } \\
\hline \multicolumn{3}{|l|}{ Gares/Lignes de Train } \\
\hline \multicolumn{3}{|l|}{$\begin{array}{l}\text { Stations/Lignes de } \\
\text { Métro }\end{array}$} \\
\hline Complexes résidentiels & & \\
\hline
\end{tabular}

Services Publics

\begin{tabular}{|c|c|c|c|}
\hline \multirow{5}{*}{\multicolumn{2}{|c|}{ 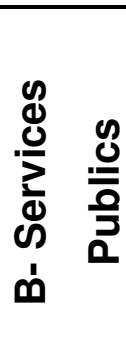 }} & Services publics (Hôpitaux, Postes de service, appuis) & Détails \\
\hline & & & \\
\hline & & & \\
\hline & & & \\
\hline & & & \\
\hline
\end{tabular}


Organisation

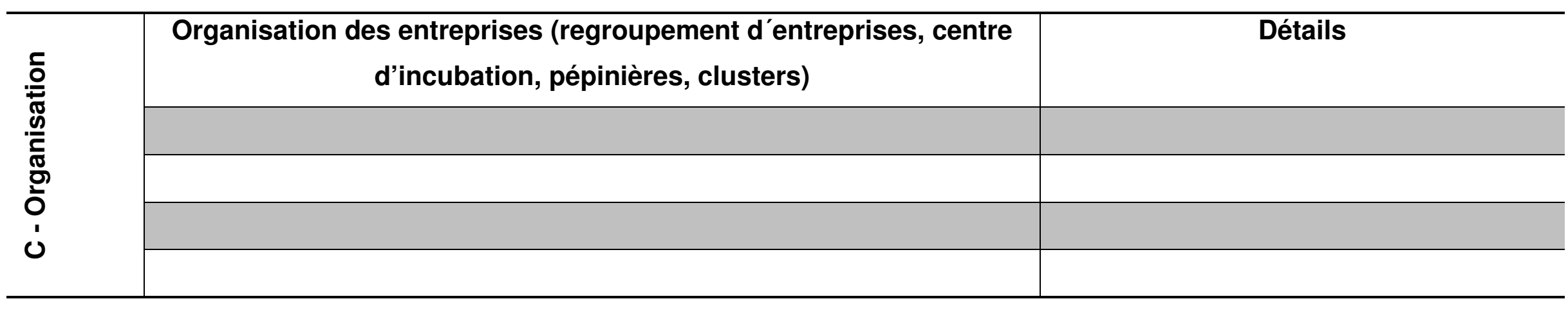

Appui à la Gestion

\begin{tabular}{|c|c|c|c|}
\hline \multirow{5}{*}{\multicolumn{2}{|c|}{ 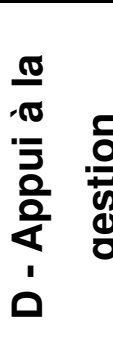 }} & Modalités & Détails \\
\hline & & & \\
\hline & & & \\
\hline & & & \\
\hline & & & \\
\hline
\end{tabular}


Services pour la connaissance

\begin{tabular}{|c|c|c|c|}
\hline \multirow{6}{*}{ 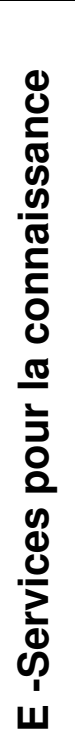 } & Modalités & Description & Détails \\
\hline & Bibliothèques & & \\
\hline & $\begin{array}{l}\text { Réseaux } \\
\text { (communautés) }\end{array}$ & & \\
\hline & $\begin{array}{l}\text { Technologie de } \\
\text { I'Information }\end{array}$ & & \\
\hline & Communautés & & \\
\hline & $\begin{array}{l}\text { Laboratoires de } \\
\text { R\&D }\end{array}$ & & \\
\hline
\end{tabular}




\section{Gouvernance}

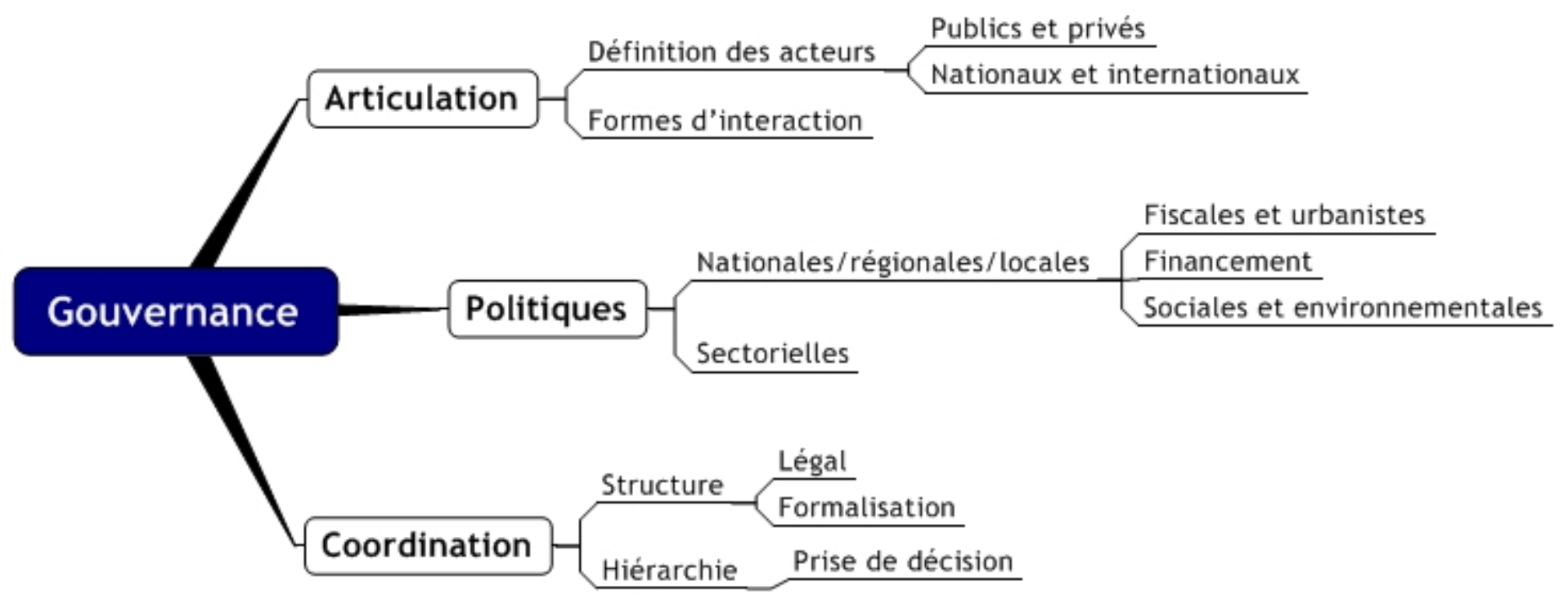

Pour cette étude, il est fait les définitions suivantes:

\section{ARTICULATION :}

DÉFINITION DES ACTEURS : identification/caractérisation des acteurs publics et privés impliqués dans les actions du Pôle (local, régional, national) ; identification / caractérisation des acteurs internationaux ;

CARACTERISTIQUES - étude et caractérisation des formes/procédures d'articulation (comment est réalisée l'articulation ?). 


\section{POLITIQUES :}

POLITIQUES LOCALES/REGIONALES/NATIONALES : étude et caractérisation des politiques locales et régionales d'appui aux actions du Pôle et ses participants, et articulateurs: politiques fiscales et urbanistes (d'attraction); de financement; sociales, environnementales; de développement local/régional.

POLITIQUES SECTORIELLES : étude et caractérisation de politiques sectorielles d'appui aux pôles

\section{COORDINATION :}

STRUCTURE : étude et caractérisation de la structure : forme juridique, degré de formalisation, organisation de l'articulation ; HIERARCHIE : étude et caractérisation du processus de prise de décision (stratégie)

\section{Attentes vis-à-vis des réponses:}

1. Comprend la caractérisation des acteurs présents dans le Pôle, la forme de l'interaction, ainsi que la participation dans les prises de décision.

2. En considérant les différentes sphères de participation, quel est le pouvoir d'influence des institutions.

3. Description des politiques fiscales, urbanistes, de financements, environnementaux et sociaux du pôle, concernant les sphères régionales, locales, gouvernementales et sectorielles.

4. Description de la structure hiérarchique du Pôle, incluant l'aspect juridique, la formalisation et la prise de décision. 
ARTICULATION :

- DEFINITION DES ACTEURS :

A. Identifier les acteurs du Pôle de Compétitivité, et quels sont les rôles de chacun dans le cadre du Pôle Technologique.

\begin{tabular}{l|l|l|l|l}
\hline \multicolumn{1}{c|}{ ACTEURS } & Public/Privé & $\begin{array}{c}\text { Fonction } \\
\text { Dans le Pôle }\end{array}$ & $\begin{array}{c}\text { Participation dans la } \\
\text { Gouvernance }\end{array}$ & \\
\hline ACADEMIQUE: & & & & \\
\hline GOUVERNEMENT: & & & & \\
\hline LOCAL/REGIONAL: & & & & \\
\hline NATIONAL: & & & & \\
\hline ENTREPRISES/SOCIÉTÉS & & & & \\
\hline PMES & & & & \\
\hline ACTEURS INTERNATIONAUX & & & & \\
\hline AUTRE REPRESENTATION & & & & \\
\hline
\end{tabular}


B. Pouvoirs de décisions académiques, des entreprises et des organismes publics

\begin{tabular}{l|l|l|l}
\hline \multicolumn{1}{c|}{ Acteurs } & Représentation & & Investissements \\
\hline Entreprises & & & \\
\hline PMEs & & & \\
\hline CYADT & & & \\
\hline ACADEMIQUE & & & \\
\hline GOUVERNEMENT: & & & \\
\hline
\end{tabular}




\section{Politique}

\begin{tabular}{l|l|l|l|l}
\hline \multicolumn{1}{c|}{ Politique } & Locale & Régionale & Nationale & Secteurs \\
\hline Fiscales & & & & \\
\hline Urbanistes & & & & \\
\hline Financement/Fonds & & & & \\
\hline Environnementales & & & & \\
\hline Sociales & & & & \\
\hline
\end{tabular}


D. Structure et hiérarchie du Pôle

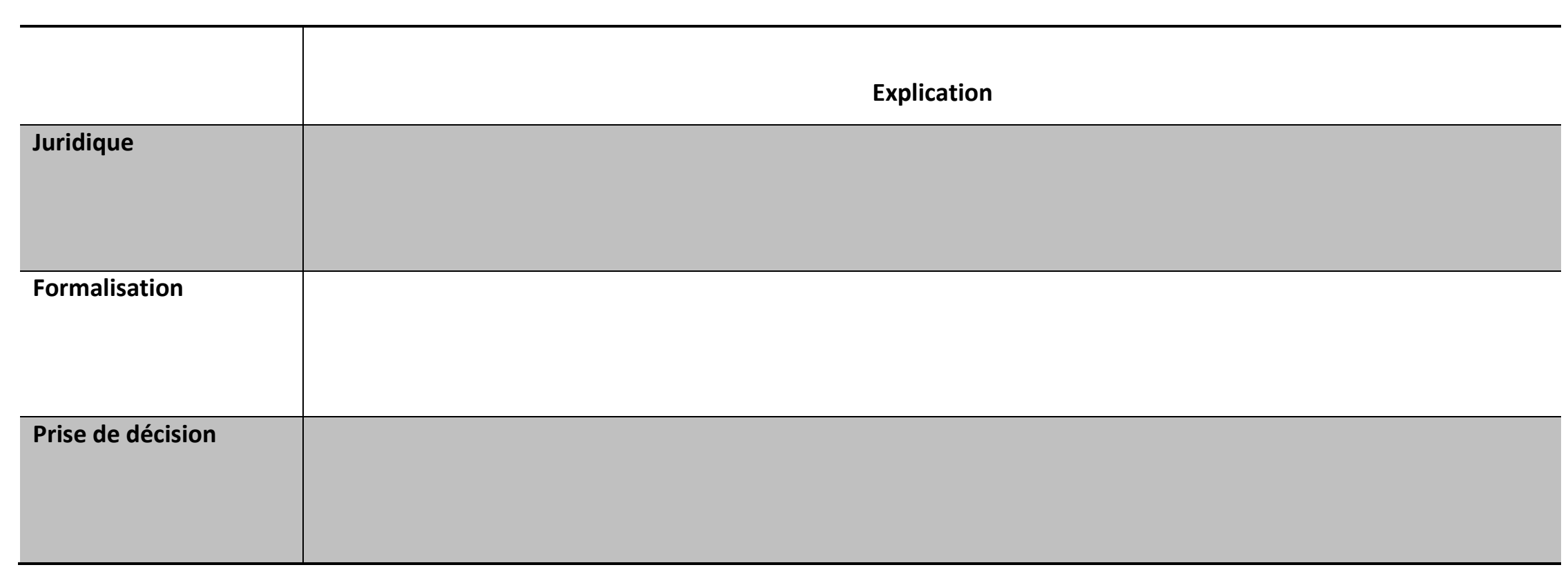




\section{Stratégies}

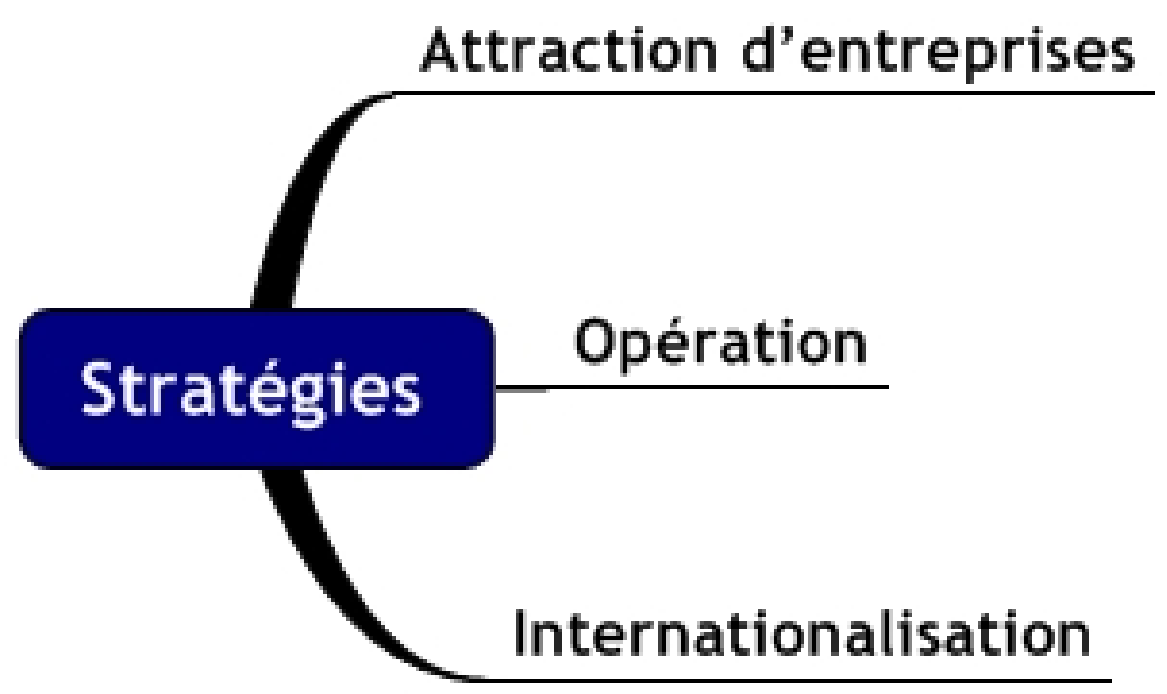

On définie les Stratégies comme l'ensemble des actions planifiées par les organismes compétents de gestion pour répondre aux contextes de développement du pôle.

Dans le cadre de ce travail, les stratégies ont été définies en trois axes, concernant :

- Stratégies d'internationalisation;

- Stratégies d'Opération ;

- Stratégies d'attraction des Entreprises. 


\section{Attentes vis-à-vis des réponses:}

1. Description des principales stratégies utilisées par le Pôle pour l'internationalisation, concernant les actions pour stimuler le commerce extérieur, les partenariats avec des entreprises internationales, la représentation internationale et d'autres.

2. Description des organismes respectifs et des structures administratives.

3. Explication détaillée en précisant comment se passe l'application de la stratégie. Par exemple, comment l'entreprise réussi à avoir un financement pour exporter, ou comment elle reçoit les formations nécessaires pour connaître les nouveaux marchés.

4. Comment sont développées les opérations des activités du Pôle? Qui fait quoi ? Comment ? Les éléments d'activités et d'attributions seront identifiés.

5. Comment sont développées les stratégies d'attraction d'entreprises ? Existe-t-il un organisme formel ? Et s'il y en a un, quelle est sa structure ? Les entreprises répondent-elles aux appels d'offre publics ? Sont-elles aidées en cela? 


\begin{tabular}{l|l|l|l}
\hline \multicolumn{1}{c|}{ Planning } & Description & Organisme Responsable & Application \\
\hline Internationalisation & & & \\
\hline & & & \\
\hline & & & \\
\hline & & & \\
\hline & & & \\
\hline & & & \\
\hline & & & \\
\hline & & & \\
\hline & & & \\
\hline & & & \\
\hline
\end{tabular}




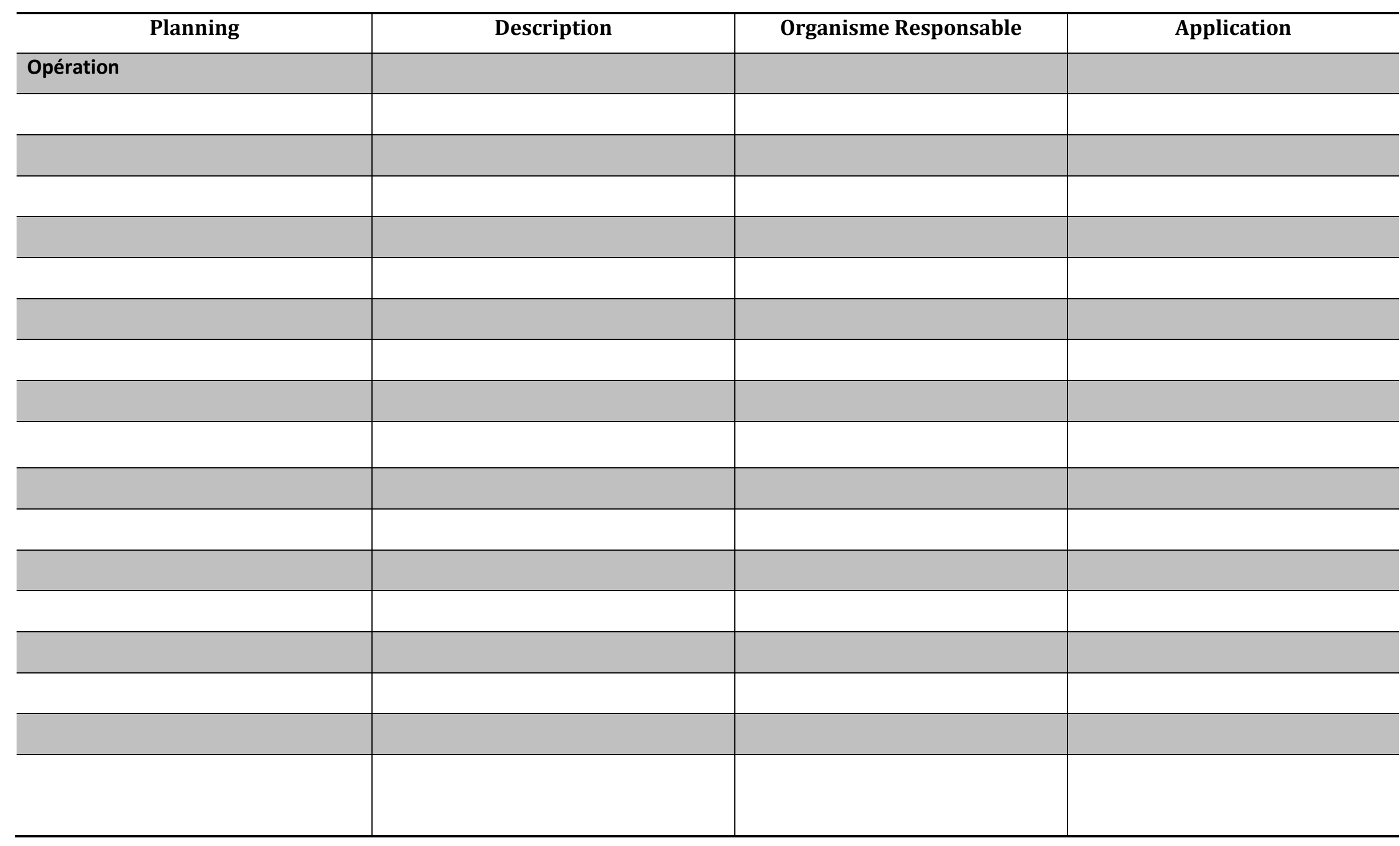




\begin{tabular}{|c|c|c|c|}
\hline Planning & Description & Organisme Responsable & Application \\
\hline \multicolumn{4}{|l|}{ Attraction d'entreprises } \\
\hline & & & \\
\hline & & & \\
\hline & & & \\
\hline & & & \\
\hline & & & \\
\hline & & & \\
\hline & & & \\
\hline & & & \\
\hline & & & \\
\hline & & & \\
\hline & & & \\
\hline & & & \\
\hline & & & \\
\hline & & & \\
\hline & & & \\
\hline & & & \\
\hline
\end{tabular}




\section{Relation Université-Entreprises}

Dans le cadre du projet, la relation université-entreprise sera traitée dans les perspectives suivantes : composition de la base de science et technologie, structures d'appui et mécanismes de financement.

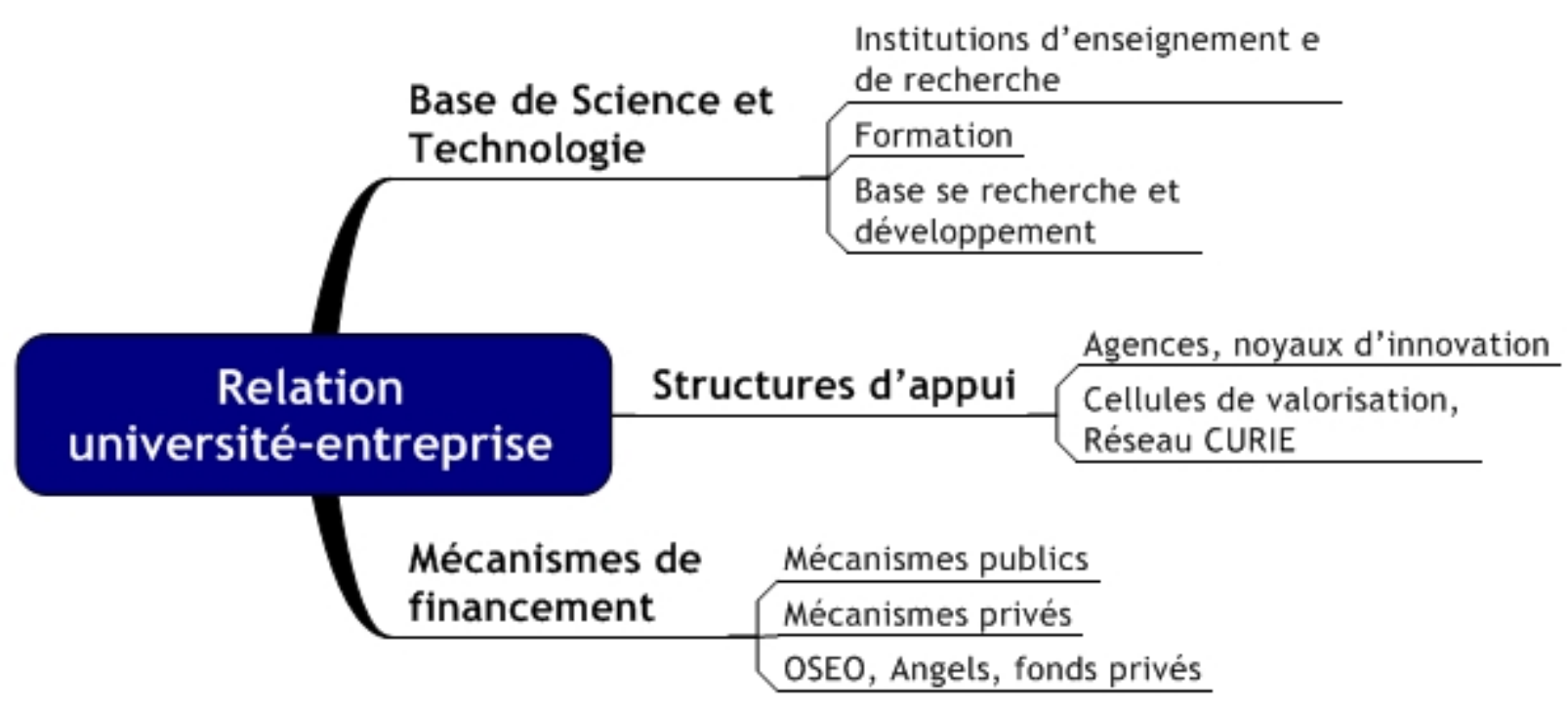


Pour la finalité de cette étude, il est fait les définitions suivantes :

\section{Base de Science et Technologie}

Définition des institutions d'enseignement et recherche présentes dans le Pôle, les mécanismes pour la formation de professionnels, et les bases présentes pour la recherche et le développement.

\section{Structure d'Appui}

Relatives aux instruments pour appuyer la relation université-entreprise, incluant les agences d'innovation, noyaux d'innovation, le modèle de cellules de valorisation, et la formation de réseaux.

\section{Mécanismes de financement}

Comprenant les fonds disponibles pour appuyer la relation, dans la perspective de possibles financements publics, privés, et l'implication d'organismes institutionnels.

\section{Attentes vis-à-vis des réponses:}

1. Description du contexte de sciences et technologie présent dans le Pôle, concernant les universités, les écoles techniques et autres, avec la spécialisation de chacune e leur représentativité académique, du point de vue du nombre de maîtres et docteurs.

2. Description des principaux mécanismes d'appui à la relation université-entreprise présents dans le Pôle, incluant organismes publics et privés.

3. Description des mécanismes d'appui segmentés par activités, comme : propriété intellectuelle, commerce extérieur, certifications, etc. 


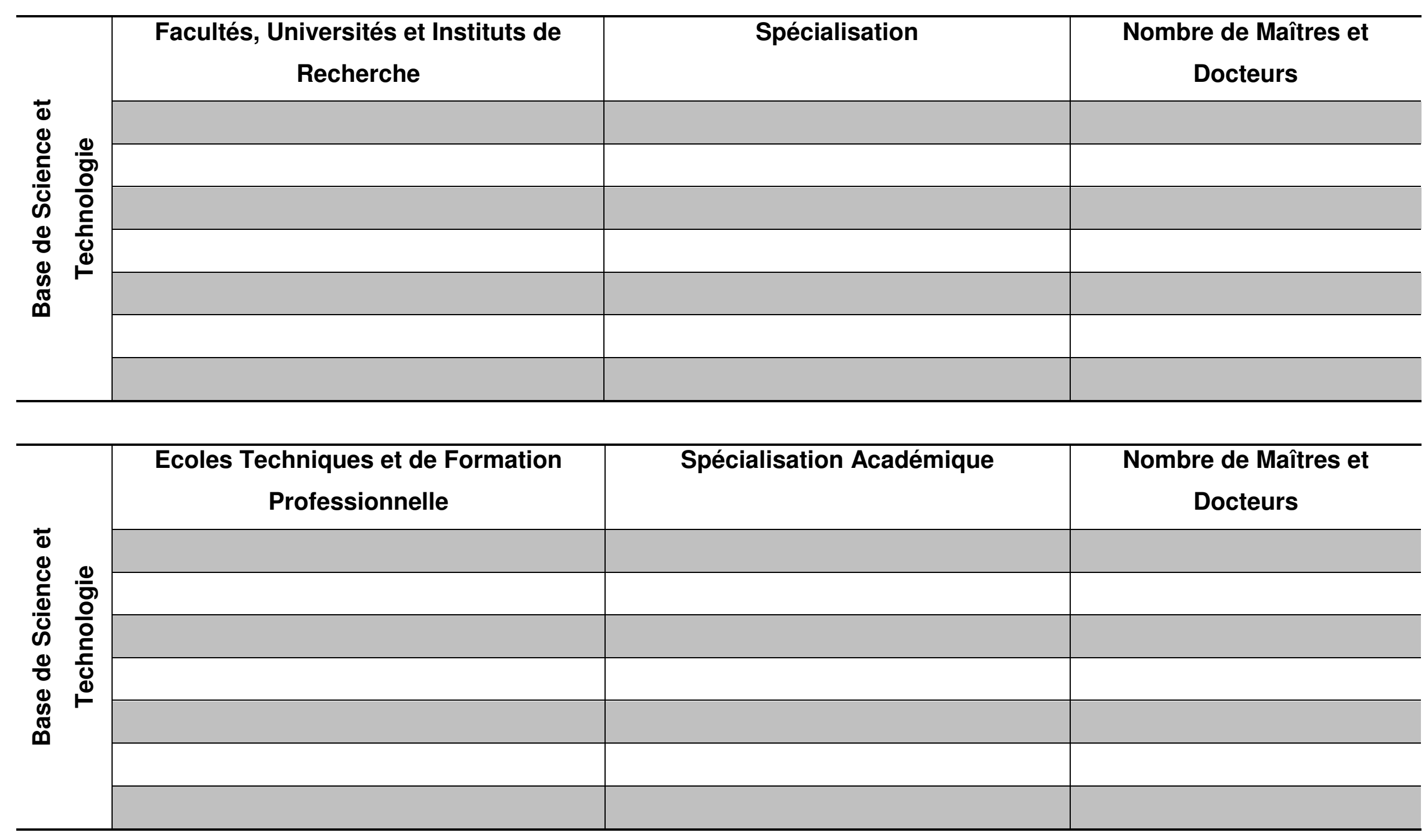


Autres Mécanismes

\begin{tabular}{l|l|l}
\hline & $\begin{array}{c}\text { Autres Mécanismes de Financement } \\
\text { (fondations, agences, associations } \\
\text { commerciales) }\end{array}$ & Détails de la Participation \\
\cline { 2 - 3 } & & \\
\hline & & \\
\hline & & \\
\hline
\end{tabular}


Mécanismes d'Appui

\begin{tabular}{|c|c|c|c|}
\hline \multirow{8}{*}{ 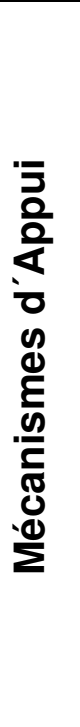 } & Type/Structure (centres, réseaux, etc.) & Modalités d'appui & $\begin{array}{c}\text { Secteurs (propriété } \\
\text { intellectuelle, commerce } \\
\text { extérieur, etc.) }\end{array}$ \\
\hline & & & \\
\hline & & & \\
\hline & & & \\
\hline & & & \\
\hline & & & \\
\hline & & & \\
\hline & & & \\
\hline
\end{tabular}


Mécanismes d'Appui

\begin{tabular}{|c|c|c|c|}
\hline \multirow{7}{*}{ 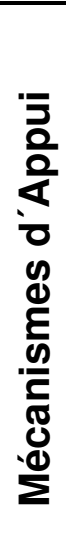 } & Cellules de Valorisation, Réseau CURIE & Modalité d'appui & Insertion \\
\hline & & & \\
\hline & & & \\
\hline & & & \\
\hline & & & \\
\hline & & & \\
\hline & & & \\
\hline & & & \\
\hline
\end{tabular}


Mécanismes de Financement

\begin{tabular}{|c|c|c|c|c|}
\hline \multirow{8}{*}{ 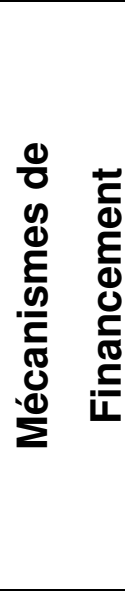 } & \multicolumn{2}{|c|}{ Publics } & \multirow[t]{2}{*}{ Valeurs } & \multirow[t]{2}{*}{ Période } \\
\hline & Nom & Modalité & & \\
\hline & & & & \\
\hline & & & & \\
\hline & & & & \\
\hline & & & & \\
\hline & & & & \\
\hline & & & & \\
\hline
\end{tabular}


Mécanismes de Financement

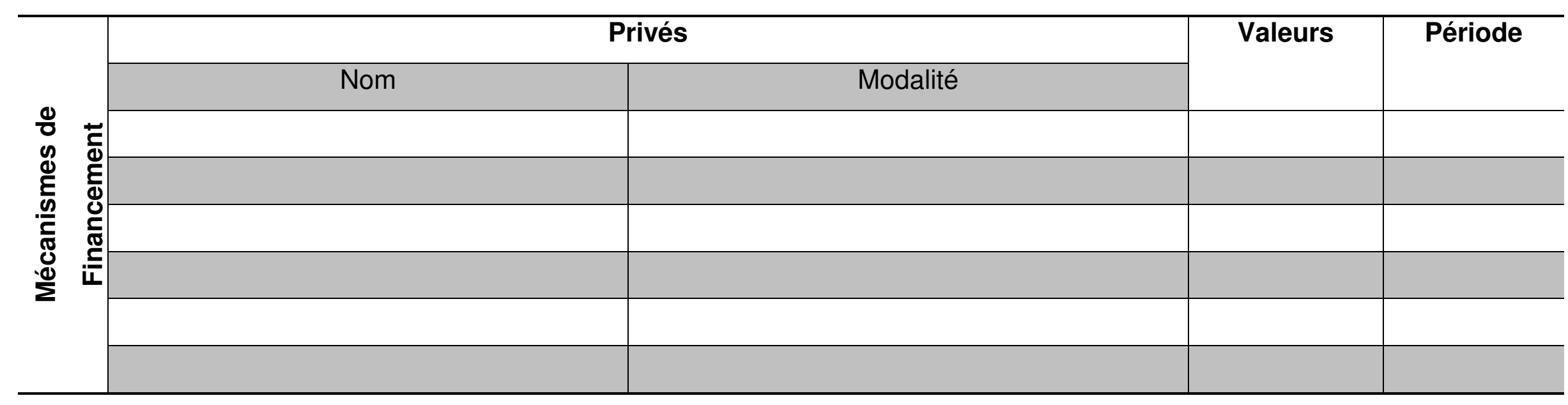


Mécanismes de Financement

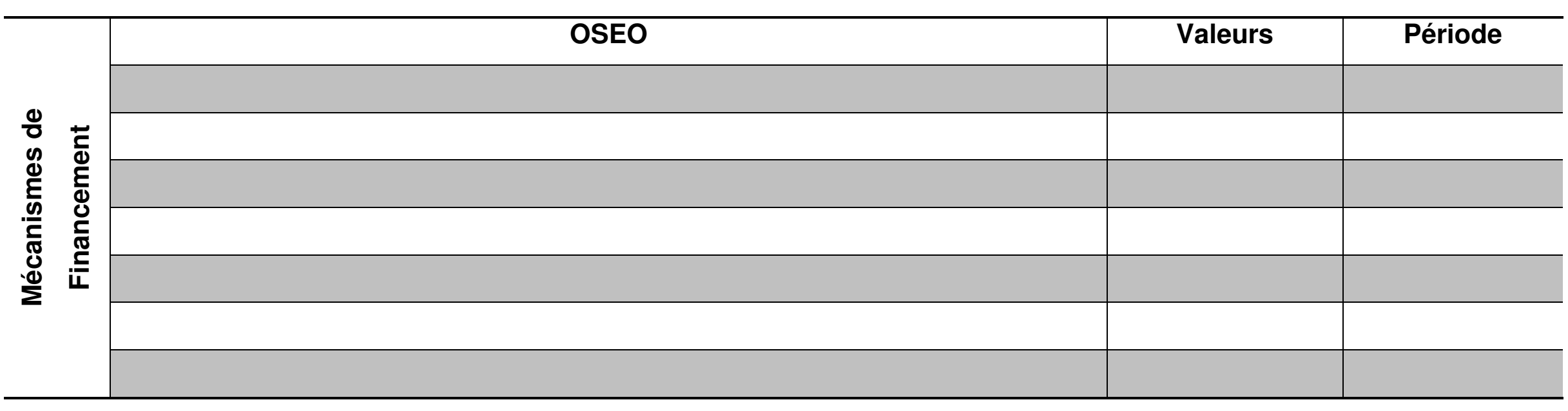


Apêndice B - Relatório de Pesquisa na França 


\section{Mission Pôles de Compétitivité en France}

\section{8 à 16 septembre 2008}

Relatório de Entrevistas

\section{Observatóire de pôles de Competitivité}
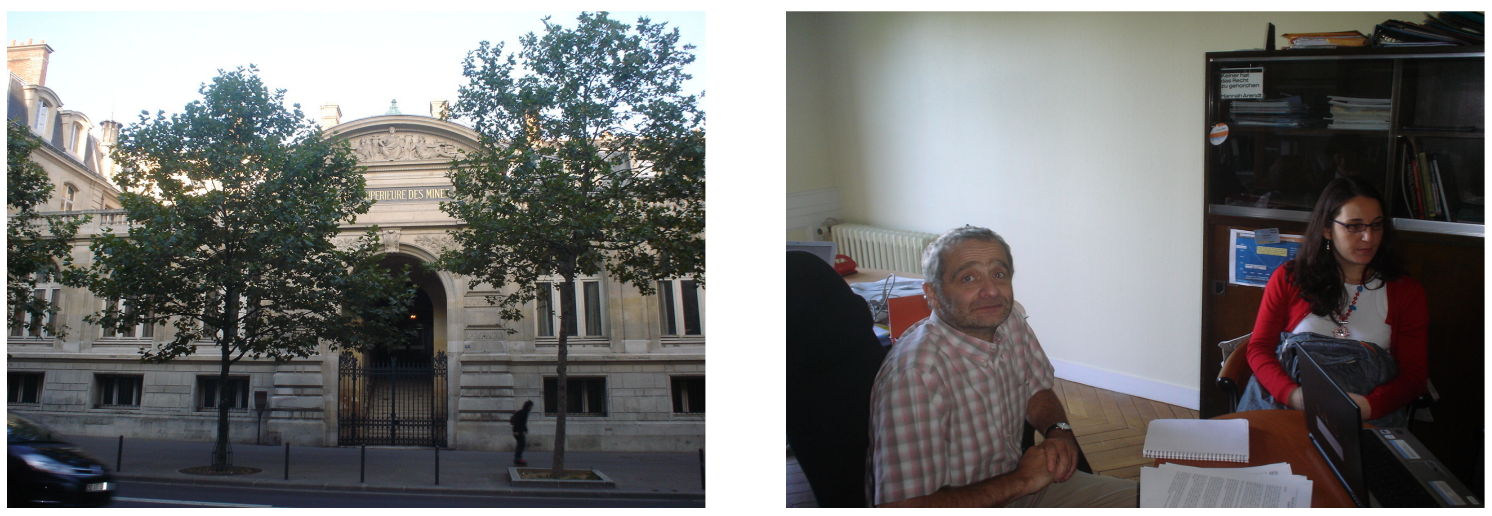

Pesquisadores:

Dra. Désirée Moraes Zouain - IPEN-USP/PGT-USP

Msc. Devanildo Damião - IPEN/PGT-USP 


\section{Contexto}

O relatório apresentado a seguir é parte da missão realizada na França para o desenvolvimento da pesquisa sobre Pólos de competitividade.

A entrevista realizada no dia dia 09/09/2008 tinha como objetivo evidenciar as principais observações realizadas pelo grupo de estudo da ècole de Mines, os entrevistados foram o Dr. Thierry Weil e a aluna de doutorado Stéphanie Fen Chong, o encontro ocorreu na Ecole de Mines.

A coleta de informações foi estruturada a partir de um questionário qualitativo com enfoque em quatro dimensões: infra-estrutura, governança, estratégias e relação universidade-empresa.

O observatório dos Pólos de competitividade é uma plataforma aberta Liderada pela Ecole des Mines de Paris, a pedido da Associação das Regiões de França, do servindo para o intercâmbio de informações e debates abertos a todos os envolvidos na vida pólos de competitividade, atuando direta ou indiretamente.

Os seus objetivos envolvem o aumento da interatividade entre os pólos e os atores das iniciativas pública, privada e acadêmica, servindo como uma plataforma que incentiva a disseminação dos conhecimentos entre os participantes.

No contexto do projeto de doutorado, a entrevista na École de Mines, tinha como objetivos específicos:

- Evidenciar uma análise dos Pólos numa perspectiva geral, ou seja, desenvolvida com base numa fonte que tem por finalidade olhar para o objeto de estudo como um conjunto de projetos e,

- Aferir a visão da academia nesse processo, considerando a Instituição e o papel de pesquisadores dos entrevistados.

A Escola de Minas foi fundada em 1783 com ênfase na mineração e na indústria de alta tecnologia e concentrava os temas de segurança pessoal e de planejamento econômico. Com o desenvolvimento econômico da região ela ampliou o seu escopo e hoje exibe competência nas áreas de engenharias e ciências econômicas e sociais. 


\section{Questionário}

$\Rightarrow$ Estratégia

\section{Descrição das principais estratégias utilizadas pelos pólos para Internacionalização, referentes às ações para estimular o comércio exterior, as parcerias com as empresas internacionais, a representação internacional e dos autores.}

A estratégia dos Pólos de competitividade deriva de uma abordagem de políticas públicas que tem como objetivo unificar as políticas territoriais e setoriais. $O$ escopo envolve a internacionalização dado que os Pólos recebem classificações e aportes de recursos de acordo com a característica do domínio setorial sendo eles: os pólos mundiais, os pólos de vocação mundial e os pólos nacionais.

O Estado financia por meio de diferentes órgãos os projetos desenvolvidos no Pólo, os quais envolvem centros de pesquisa e indústrias, os projetos com maior inserção internacional recebem mais recursos.

São observadas no conjunto dos Pólos algumas ações isoladas para internacionalização, todavia, ainda não estruturada, mas é uma diretriz que grande parte deve desenvolver uma verdadeira estratégia internacional.

Nessa perspectiva prevê-se um apoio mais direto das instituições de apoio para proporcionar melhores condições para internacionalização dos Pólos, está previsto o desenvolvimento de um Seminário para tratar do assunto em colaboração com o Departamento de Coordenação de inteligência econômica e de outros parceiros (UBIFRANCE, COFACE, OSEO).

Pretende-se apresentar as ofertas de serviços oferecidos pelo Ministério da Economia, da Indústria e do Trabalho e compartilhar as experiências de alguns Pólos e suas empresas no desenvolvimento internacional.

\section{Descrição dos organismos específicos e suas estruturas administrativas.}

Na perspectiva de uma análise global é fundamental ressaltar que os pólos de competividade derivam de políticas públicas estabelecidas pelo governo da França. 
O programa foi lançado em 2004 pelo próprio primeiro ministro, numa ação coordenada para trazer a competitividade da França a patamares anteriores, visto que se observava um declínio em termos de indicadores econômicos e científicos na sua performance.

O programa teve uma perspectiva interministerial, a sua orientação deriva de um grupo de trabalho Interministerial GTI, coordenado e envolvendo as agências do estado francês, sendo que a seguir serão descritas:

- Oseo, voltados ao apoio e financiamento de pequenas e médias empresas,

- ANR, Agência Nacional de Pesquisa.

- All - Agência de Inovação Industrial.

Os recursos são derivados de diversos ministérios, os quais contribuem para um fundo único, o Fundo Único da Inovação - FUI. A maior contribuição é do Ministério da Indústria, e envolve recursos de outros ministérios, a saber: Defesa, Interior, Planejamento Regional, Saúde, agricultura, Infraestrutura e Ministério da Pesquisa.

O GTI é coordenado pela DGE Direção Geral das Empresas do Ministério da Indústria e pela DIACT ("Délégation à l'Aménagement et à la Compétitivité des Territoires"), que é um serviço coordenado primeiro Ministro, com atribuições de planejamento territorial.

\section{Explicação detalhada e precisa de como é aplicada a estratégia.}

Para operacionalizar a estratégia dos pólos foi destinado um orçamento $€ 1,5$ bilhão, no período de 2006 a 2008.

A próxima etapa foi o lançamento de editais parametrizados para chamamento de projetos. Dentre os parâmetros estabelecidos para os projetos estava a determinação do período de vigência previsto para ocorrer entre 03 a 05 anos. Todavia, o principal fator era a necessidade de cooperação entre instituições de pesquisa básica e organizações de mercado.

Entre os critérios de seleção do caderno de especificação da chamada de projetos, quatro eram particularmente importantes:

- O detalhamento da estratégia de desenvolvimento econômico proposta pelo projeto;

- A visibilidade internacional do pólo;

- A parceria e o modo de governança;

- A criação de sinergia em matéria de P\&D e de inovação. 
Após um processo de seleção em diferentes esferas, são definidos os projetos aprovados, para a sua efetivação eles são coordenados na forma jurídica própria de Associações, que ressalvadas as peculariedades do sistema jurídico administrativo francês, tem similaridades com as nossas organizações sociais.

Outro fato interessante é que são destinados recursos para equipes operacionais, as chamadas equipes de animação, as quais geralmente são compostas de 05 a 10 profissionais com dedicação exclusiva.

\section{Como são desenvolvidas as operações das atividades do Pólo, Quem faz o que? Comentários? Os elementos das atividades e atribuição devem ser identificados.}

Os pólos contam com estruturas bastante enxutas, as atividades naturalmente são condicionadas a estrutura dos diferentes pólos, sendo que esses são derivados de esforços de cooperação entre as instituições de pesquisa e as empresas.

Pode-se observar que de forma geral, a principal atividade de um Pólo está relacionada à estruturação de um projeto para responder aos editais. Nessa perspectiva é fundamental que se tenha um mapeamento das competências na esfera acadêmica para compor o quadro de colaboradores dos projetos.

A estrutura administrativa permanente tem como função principal promover o desenvolvimento de parcerias e ações de acompanhamento para desenvolvimento e apresentação de projetos candidatos a financiamento governamental.

\section{Como são desenvolvidas as estratégias de atração de empresas? Existe um organismo formal? Em caso positivo, qual é a estrutura? As empresas respondem aos chamados públicos? São adicionadas em grupos? Elas se auto ajudam ?}

Apesar de ser muito importante para o país e também ser um dos motivos para o projeto de Póles de Competitivité, não existe formalmente um organismos para tratar de projetos de atração de empresas. A relação das empresas com o Pólo é oriunda das chamadas públicas que ocorrem nas quais são disponibilizados recursos aos melhores projetos. Considerando o aspecto de interação dos pólos não existem estruturas formais de interação. Sendo assim, os pólos com mais estrutura terão melhores condições para gerir os projetos e conseqüentemente desenvolver know- 
how para concorrer com maior possibilidade em novos projetos, na verdade, existe um ciclo vicioso, no qual é dado mais dinheiro para aqueles que são mais bem sucedidos.

\section{$\Rightarrow$ Governança}

\section{Envolve a caracterização dos atores presentes no Pólo, a forma de interação, também a participação das empresas nas decisões.}

Os Pólos são estruturados a partir de associações, sendo que essas prevêem a participação das empresas associadas no conjunto de decisões do Pólo, todavia, cabe destacar que existe uma diferenciação da participação das empresas, sendo que as grandes empresas pelo fato oferecer uma estrutura mais adequada para Pesquisa e Desenvolvimento tendem a exercer seu poder de governança. Logicamente, existem diferenças relacionadas às especificidades dos segmentos e da cadeia produtiva.

\section{Considerando as diferentes esferas de participação, definindo o poder de influência das instituições.}

Considerando as questões políticas dos pólos nota-se que as universidades e seus pesquisadores estão distantes das decisões estratégicas. A participação é bastante efetiva quando considerado o projeto numa perspectiva isolada, mas é limitada nos aspectos de reflexão sobre os dos pólos de competitividade, ou seja, participam de forma reativa respondendo a projetos específicos, mas não condicionada a uma discussão mais aprofundada sobre a determinação de vocações, ou participação em conselhos para análise da performance dos mesmos.

\section{Descrição das políticas fiscais, urbanísticas do pólo, considerando as esferas regionais, locais, governamentais e setoriais.}

É uma política dos pólos de competitividade aumentar a capilaridade, por meio da participação das regiões. A participação envolve diferentes formas, tais como: a adesão aos projetos de Pesquisa e Desenvolvimento que mesmo sendo apoiados parcialmente por outras instituições podem receber apoio, a participação na governança e no oferecimento de recursos e de estruturas de animação, além do oferecimento de recursos para internacionalização, como por exemplo: missões internacionais.

No escopo dos apoios regionais são contabilizadas diferentes foram de apoio, envolvendo os seguintes elementos: convites para apresentação de projetos, o contato com as empresas do 
setor de um pólo de competitividade e para incentivar as relações entre os diversos intervenientes ou despesas atribuídas à transferência de tecnologia.

A seguir tem-se um panorama dos recursos nos projetos desenvolvidos na região de lle de France:

\begin{tabular}{|c|c|c|c|c|}
\hline Anos & $\begin{array}{c}\text { Número de } \\
\text { projetos } \\
\text { selecionados FCE } \\
\text { FUI, Oséo) }\end{array}$ & $\begin{array}{l}\text { Total de Despesas } \\
\text { (milhões de euros) }\end{array}$ & $\begin{array}{c}\text { Subvenções } \\
\text { regionais } \\
\text { Projetos de P\&D } \\
\text { (milhões de euros) }\end{array}$ & $\begin{array}{c}\text { Subvenções } \\
\text { regionais } \\
\text { Governança } \\
\text { (milhões de euros) }\end{array}$ \\
\hline 2005 & $\begin{array}{l}12 \text { (Medicen, } \\
\text { System@tic, Cap } \\
\text { Digital) }\end{array}$ & 92 & 9 para 8 projetos & \\
\hline 2006 & 35 (5 pólos) & 255 & $\begin{array}{l}24,7 \text { para } 19 \\
\text { projetos }\end{array}$ & 0,750 para 05 pólos \\
\hline 2007 & 41 (6 pólos) & 402 & $\begin{array}{l}26,7 \text { para } 31 \\
\text { projetos }\end{array}$ & 1,158 para 7 pólos \\
\hline 2008 & $\begin{array}{l}56 \text { apresentados (7 } \\
\text { pólos) }\end{array}$ & 260 & 28 & 1,150 para 7 pólos \\
\hline Total & & & 88,4 & 3,058 \\
\hline
\end{tabular}

Tabela 01: Panorama dos incentivos em: lle de France. fonte: http://observatoirepc.org

Os incentivos fiscais são vultosos, cerca de 300 milhões de euros de incentivos fiscais (isenção do imposto para as empresas) e sociais (isenção das cotas sociais para os pesquisadores) e 400 milhões de euros em créditos de intervenção ministerial (divididos entre o ministério da indústria, da pesquisa e de planejamento territorial).

\section{Descrição da Estrutura hierárquica dos Pólos, incluindo os aspectos jurídicos, a formalização e o poder de decisão.}

Os Pólos são organizados como associações com uma lei específica para tratamento da mesma. Essa formalização de uma figura jurídica implica na estruturação de uma equipe para gerenciar o Pólo, essas equipes variam o seu tamanho de acordo com a complexidade do Pólo, todavia situam-se entre 05 a 15 pessoas.

O projeto para ser aceito necessita de participações da esfera acadêmica e do tecido empresarial, visto que as empresas podem se associar aos Pólos. Nessa perspectiva, uma crítica corrente é a supremacia das grandes empresas em vários pólos. Esse fato é facilmente explicado, visto que as grandes empresas apresentam estruturas para Pesquisa e Desenvolvimento enquanto que as pequenas apresentam uma séria de dificuldades, cujos dirigentes se vêm 
sobrecarregados ao tentar participar dos pólos em condições de equilíbrio com as grandes empresas.

\section{$\Rightarrow \quad$ Relação Universidade-empresa}

\section{Descrição do contexto científico e tecnológico presente nos pólos, envolvendo as universidades, escolas técnicas e outros, com a especialização de cada um e sua representatividade acadêmica, do ponto de vista do número de mestres e doutores.}

Considerando a perspectiva dos Pólos, a base de ciência e tecnologia está presente em todas as etapas de desenvolvimentos dos projetos. A presença da base de ciência e tecnologia envolve a mobilização de laboratórios, institutos de pesquisas e universidades e escolas. Os pólos quando são estruturados identificam as suas áreas de competências que estarão diretamente ligadas a sua condição de pesquisa, sendo que esta deriva da concentração de especialistas.

\section{Descrição dos principais mecanismos de apoio a relação universidades-empresa presente no Pólo, incluindo organismos públicos e privados.}

A estrutura da Célula de Valorização da Pesquisa não obteve a repercussão esperada nos projetos e foi reformulada, a sua evolução para tratar dos assuntos da relação UniversidadeEmpresa é o SAIC - SERVICO DE ATIVIDADES INDUSTRIAIS E COMERCIAIS, que também não estão obtendo aderências nos projetos dos Pólos.

As justificativas para a desmobilização dos serviços da Célula de Valorização da Pesquisa para integrá-lo a uma estrutura mais robusta são: a estrutura da Célula de Valorização foi criada prematuramente, pois os pesquisadores e a própria estrutura acadêmica não tinham uma cultura de desenvolvimento de pesquisa em colaboração com empresas.

No caso da École de Mines - que tem por modelo o MIT - Massachusetts Institute of Technology (EUA), guardadas as características francesas. Os professores podem ter uma remuneração complementar para a realização de pesquisas por meio do CNRS - Centre National de la Recherche Scientifique - que possue semelhanças com o CNPq).

Outro ponto de destaque é o sistema ARMINE que permite receber recursos para participação dos alunos e o pesquisador tem complementação financeira. A questão da governança universitária - evoluiu com a participação do poder local - em 2006 foram criadas as Fundações de Pesquisa (com renuncia fiscal dos empresários) e no ano seguinte (2007) foram realizadas alterações nas universidades, incentivando a figura do "chercheur entrepreneur". 
Também na França, o mecanismo de bolsas CIFRE (Conventions Industrielles de Formation par la Recherche) faz muito sucesso e é uma garantia do triunfo da cooperação Universidade-Empresa. Referem-se a Doutores que fazem suas teses de Doutorado em empresas, como funcionários da empresa orientados por um laboratório, sobre um tema de pesquisa escolhido pela empresa e pelo laboratório de comum acordo.

12. Descrição dos mecanismos de apoio segmentados por atividades, como: propriedade intelectual, comércio exterior, certificações de qualidade, etc.

Não existe uniformização em relação aos apoios disponibilizados aos Pólos, é disponibilizado de forma geral, o apoio do INPI - na questão da propriedade industrial, todavia é específico ao projeto.

O Ministério da Indústria estimula a organização desta atividade - principalmente no caso dos centros incubadores, que são instituições que atuam na formalização de projetos de base tecnológica. Atualmente, lançando um olhar sobre as universidades, observa-se que as mesmas não estão preparadas para lidar com o tema, considerando a sua baixa experiência industrial.

Os acordos de Propriedade intelectual entre os parceiros devem ser feito previamente ao pedido de financiamento dos projetos, a participação dos Pólos é totalmente consultiva, existe também o temor das pequenas empresas que apresentam dificuldades para fazer acordos de propriedade intelectual que Ihes sejam convenientes.

\section{$\Rightarrow$ Infra-estrutura}

13. A descrição das estruturas disponíveis relacionadas à logística externa do Pólo, envolvendo os transportes e serviços públicos disponíveis na localidade na qual se situa o Pólo. Também a descrição dos complexos residenciais para estadia dos empregados.

Diferentemente de outros ambientes de inovação, os pólos de competitividade, caracterizamse pelo papel de agenciador e em estruturas de cluster já existentes e não para promover a concentração territorial.

Basicamente atuam para promover a interação entre os atores, tendo como base projetos específicos, portanto atuam com base numa representação administrativa e não física, sendo 
assim a questão relacionada ao espaço tem pouca representatividade. De forma geral, os pólos são espaços situados em prédios oferecendo a estrutura para trabalhos administrativos

\section{Descrição dos tipos de organização de empresas presentes no Pólo: as incubadoras, os agrupamentos de empresas?}

A Base para o desenvolvimento dos Pólos de competitividade são os clusters de empresas, portanto, pressupõe-se que existe uma aglomeração em determinado domínio setorial que será o elemento desencadeador do desenvolvimento de projetos.

As empresas associadas formam um dos eixos básicos para a formação dos pólos juntamente com os laboratórios de pesquisa, em relação às características das empresas presentes, são observadas empresas de diferentes portes, os quais são determinadas pelas características das atividades desenvolvidas.

Considerando os ativos tais como incubadoras, é importante ressaltar inicialmente uma diferença conceitual entre os termos de incubação no Brasil e na França, os centros incubadores na França são caracterizados pelo desenvolvimento e articulação de projetos, ou seja, em fase embrionária. Os projetos que envolvem empresas constituídas são conhecidos como pepiniéres.

Dentro de sua estratégia de apoio à criação de empresas inovadoras, a França criou um modelo de trajetória de apoio para melhor identificar os atores e seus papéis. Esta trajetória genérica possui quatro fases, validação, pré-incubação, criação e desenvolvimento. Esse modelo permite distinguir a função da pré-incubação, conduzida pelas pré-incubadoras; a função de acompanhamento de empresas conduzida pelas incubadoras.

\section{Descrição das estruturas de apoio a gestão do Pólo, envolvendo edificações a edificação de estruturas para certificação, propriedade intelectual, comércio exterior e outros serviços.}

Atualmente nos Pólos não existem edificações específicas para apoios as empresas, na verdade, o escopo de atuação dos Pólos não prevê apoio as empresas associadas ao mesmo, todavia, estão focados nos projetos que serão submetidos.

Percebe-se também, que ainda existe espaço para melhorar as condições de controle dos projetos nos Pólos, a atuação das equipes de animação dos pólos é tímida no desenvolvimento dos mesmos. 
Em relação a propriedade intelectual o ministério da industria, disponibiliza um guia de propriedade intelectual para orientar os responsáveis pela animação do Pólo e disseminar os conhecimentos para os parceiros.

16. Descrição da estrutura de conhecimentos, com bibliotecas, comunidades de prática, tecnologia da informação (hardware, software, base de dados e pesquisa) e laboratórios de pesquisa e desenvolvimento.

De forma geral, a questão do compartilhamento é bastante tímida, quando considerada uma visão que não considera o desenvolvimento de um projeto específico. Alguns Pólos tomam a iniciativa de consultar as bases de dados mais relevantes para manter um cadastro que possibilite direcionar os associados. Todavia, de forma geral, a utilização de recursos e compartilhamento é determinada na elaboração dos projetos. 


\section{Mission Pôles de Compétitivité en France}

\section{8 à 16 septembre 2008}

\section{Relatório de Entrevistas}

\section{I-trans}
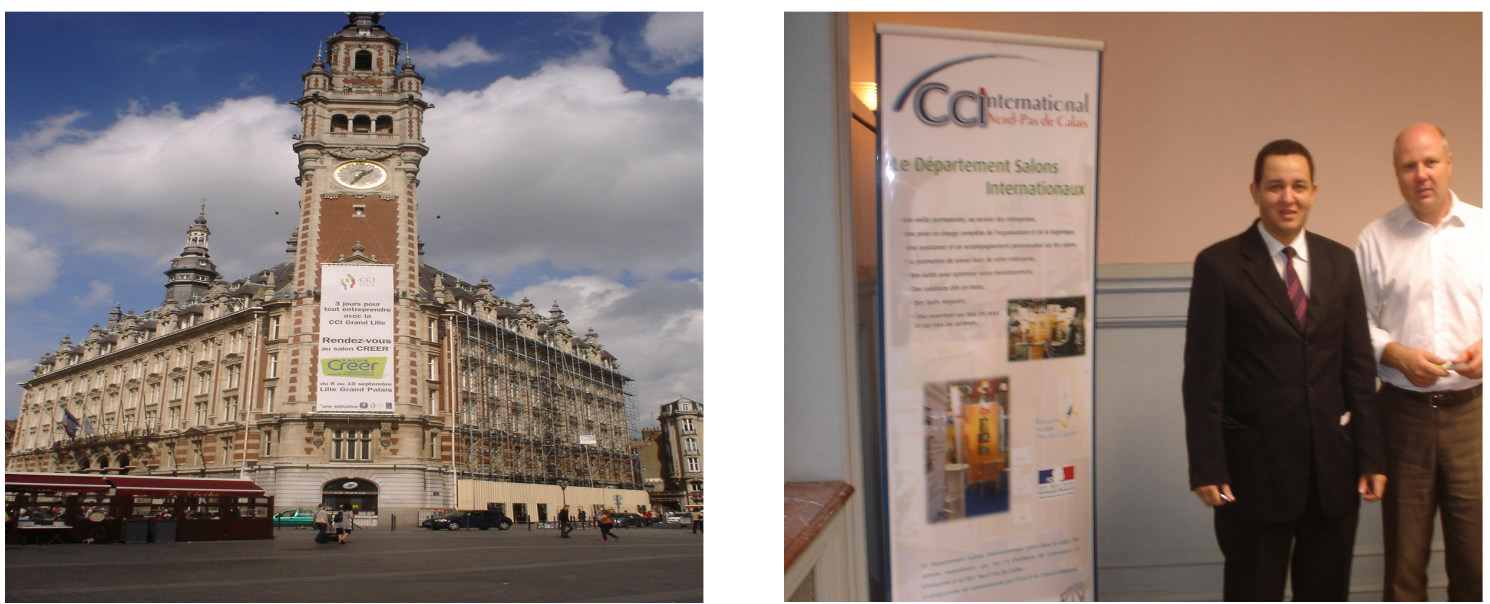

Pesquisadores:

Dra. Désirée Moraes Zouain - IPEN-USP/PGT-USP

Doutorando- Devanildo Damião - IPEN/PGT-USP 


\section{Contexto}

O relatório apresentado a seguir é parte da missão realizada na França para o desenvolvimento da pesquisa sobre Pólos de competitividade.

A entrevista realizada no dia 11/09/2008 tinha como objetivo colher as principais informações sobre o Pólo de competitividade foi o delegado Geral do Pólo, Jean-Pierre PROVO, o encontro ocorreu na Regional Chamber Of Commerce And Industry situada em Lille.

A coleta de informações foi estruturada a partir de um questionário qualitativo com enfoque em quatro dimensões: infra-estrutura, governança, estratégias e relação universidade-empresa.

\section{Apresentação do Pólo I-trans}

O I-trans é um Pólo de vocação mundial, reconhecido em 2005, nas regiões Nord-Pas-deCalais e Picardie, o pólo de competitividade - tem como objetivo desenvolver inteligência nos transportes.

O início do Processo deriva da criação de uma associação em Valencienes, que tinha como objetivo principal desenvolver solução para o transporte ferroviário e automobilístico considerando a vocação da região (Nord-Pas-de-Calais-Picardie) que concentra uma parcela significativa dos empregos nesses setores (250 mil empregos).

Com a instalação de dois importantes atores: a Agência Ferroviária Européia como o Estabelecimento Público de Segurança Ferroviária, a situação ficou bastante confortável para obter o credenciamento como Pólo de Competitividade obtido por meio da associação Transports Terrestres Promotion TTP Northern France que foi criada em 1991.

O Pólo de Competitividade reúne os principais atores da indústria, da pesquisa, e dos domínios ferroviários, automobilístico, logístico, dos sistemas de transporte terrestre inovadores situados na região de abrangência do Pólo.

Existem quatro domínios de atividade, os quais têm como objetivo o desenvolvimento durável/sustentável. 
- Transporte ferroviário - com foco na inter-operatividade (fazer com que um trem que anda/fabricado na França possa andar em qualquer outra parte da Europa);

- Automotivo - atuam em sistemas embarcados (usam as competências existentes localmente) - como no caso da Universidade de Compiénne.

- Logística - visam favorecer as trocas entre as plataformas logística-modais (transportes marítimos, ferroviários, automotivos) - isso faz com que todos os contratos aduaneiros sejam facilitados - eles não trabalham sobre os aspectos de engenharia (de transporte, etc) - trabalham nos processos, em sua otimização;

- Sistemas de transporte inteligentes - eles vão participar do Salão Internacional de Nova lorque em novembro deste ano - com os contatos prévios fazem toda a articulação para divulgar a capacitação da reunião.

O pólo quer ser o líder europeu em projetos, construção, manutenção, exploração de sistemas de transportes terrestres. Para isso investe amplamente em pesquisa e Desenvolvimento com estimativa de 50 milhões de euros até o final de 2010.

Principais características

\begin{tabular}{|c|c|}
\hline Setores & $\begin{array}{l}\text { Transporte ferroviário, automobilístico, logístico e sistemas } \\
\text { de transportes inteligentes. }\end{array}$ \\
\hline Regiões Principais & Norte de França (Nord-Pas-de-Calais and Picardy regions) \\
\hline Número de Empresas & $\begin{array}{l}46 \text { envovendo dentre outras: Alstom Transport, AMKEY } \\
\text { Management, Arcelor Altlantique et lorraine, Atos Worldline, } \\
\text { Bombardier Transport, Carbone lorraine, EGIS Mobilité, Faiveley } \\
\text { Transport, Federal Mogul, GECOM, Hutchinson, NFTlou, } \\
\text { OUTREAU Technologies, Railtech International, RATP, Renault, } \\
\text { Saint Gobain Sekurit, Siemens, SNCF, Direction de Lille, Valeo } \\
\text { Embrayages, Vistéon systèmes Intérieurs, Vossloh Cogifer }\end{array}$ \\
\hline Centros de Pesquisa & $\begin{array}{l}\text { Research organizations. } \\
\text { Centre National Recherche Scientifique (C.N.R.S.), CETIM, } \\
\text { CREPIM, CRITT M2A, IFTH, INERIS, Institut national de la } \\
\text { recherche dans les Transports (INRETS), INRIA, ONERA. } \\
6 \text { Educational establishments. } \\
\text { Ecole Centrale de Lille, ENSAIT, ENSAM, ENTE, ESC Lille, } \\
\text { ESIEE. } \\
\mathbf{8} \text { Research and educational establishments. } \\
\text { Ecole des Mines de Douai, Ecole Supérieur de Chimie de } \\
\text { Lille, ICAM, Université d'Artois, Université Picardie Jules Verne, }\end{array}$ \\
\hline
\end{tabular}




\begin{tabular}{|c|l|}
\hline & $\begin{array}{l}\text { Université Sciences et Technologies de Lille, Université } \\
\text { Technologique de Compiègne, Université de Valenciennes } \\
\text { Hainaut-Cambrésis }\end{array}$ \\
\hline $\begin{array}{c}\text { Número de Empregos } \\
\text { nas PMEs }\end{array}$ & $\begin{array}{l}\text { Extração de pedras para construção, construção de material } \\
\text { atividades } \\
\text { ferroviário rolante, engenharia e estudos técnicos, comércio de } \\
\text { detalhes em livros, jornais e papelaria, organização de } \\
\text { transportes internacionais. }\end{array}$ \\
\hline Projetos & $\begin{array}{l}53 \text { projets labellisés : 35 projets d'innovation, 15 projets de } \\
\text { recherche, 2 projets d'accompagnement et un projet global de } \\
\text { formation. }\end{array}$ \\
\hline
\end{tabular}




\section{Questionário}

$\Rightarrow$ Estratégia

\section{Descrição das principais estratégias utilizadas pelos pólos para Internacionalização, referentes às ações para estimular o comércio exterior, as parcerias com as empresas internacionais, a representação internacional e dos autores.}

O Pólo de competitividade i-trans é hoje um cluster com dimensão internacional, com projetos em conjunto com outros clusters europeus, pode-se citar o de Aix-la-Chapelle, Milão, Barcelona e Manchester - como também os clusters americanos e japoneses.

A estratégia de internacionalização passa pela presença nos principais eventos mundiais de transporte, como o Innotrans (International Trade Fair for Transport Technology Innovative Components, Vehicles, Systems) em Berlim e ITS em Londres - e no último Congresso Mundial de Pesquisa Ferroviária (Montreal, junho de 2006). Além disso, Lille foi a cidade escolhida para sediar, em 2011, esse mesmo Congresso Mundial.

Considerando as empresas, a taxa de exportação das empresas atinge quase $40 \%$, sendo que deste percentual as pequenas e médias empresas (aquelas com menos de 250 empregados), respondem por $21,7 \%$.

\section{Descrição dos organismos específicos e suas estruturas administrativas.}

A definição do Presidente do Pólo é atribuída ao C E S R (Comitê Econômico e Social da Região), na estrutura administrativa francesa, cada região tem um comitê (que se reporta ao Comitê Nacional). O Conselho Regional na região de Lille tem uma gande influência, pois reúne a indústria, os representantes políticos, a pesquisa e atores sociais (principalmente os sindicatos).

Considerando esse contexto, foi definido que o decisor do Pólo I-trans deveria ser o Presidente do CESR com a validação dos demas organismos.

\section{Explicação detalhada e precisa de como é aplicada a estratégia.}

As atividades do Pólo são baseadas na interação entre o tecido empresarial presente na sua localidade $e$ as instiuições que desenvolvem atividades de C\&T, dentro desse contexto, a estratégia de tornar a região como referência em transportes inteligentes é desenvolvida por meio de projetos.

Os projetos desenvolvidos estão inseridos em cinco grupos: 
1. Interoperabilidade Ferroviária - articulação em torno do projeto do trem de alta velocidade entre cidades.

2. Segurança e acústica dos equipamentos - desenvolver as competências necessárias para interagir com essas variáveis.

3. Frete intermodal - envolve a articulação dos atores para o desenvolvimento do sistema.

4. Informações aos passageiros - Prover informações e serviços aos pasageiros.

5. Guia Urbanos dos transportes - com o objetivo de oferecer maior comodidade e conforto aos passageiros.

\section{Como são desenvolvidas as operações das atividades do Pólo, Quem faz o que? Comentários? Os elementos das atividades e atribuição devem ser identificados.}

No pólo existe uma equipe permanente que desenvolve as operações do Pólo, essa equipe conta com 06 profissionais, com funções específicas. Para o desenvolvimento dos projetos, o Pólo conta com especialistas especialistas permanentes, os quais não são assalariados, mas trabalham nos projetos, por exemplo, as funções de o Diretor científico, Diretor científico adjunto e Responsável internacional.

Dentro da Estrutura organizacional do Pólo existe o Comitê de Programas, com designação de estudo de um tema específico sob a coordenação de um Coordenador, que é pesquisador especializado no tema, é importante frisar que eles não são pagos para fazer isso - eles têm suas atividades profissionais e se interessam no desenvolvimento da região.

\section{Como são desenvolvidas as estratégias de atração de empresas? Existe um organismo formal? Em caso positivo, qual é a estrutura? As empresas respondem aos chamados públicos? São adicionadas em grupos? Elas se auto ajudam ?}

O Pólo não atua diretamente e/ou formamelmente no processo de atração de empresas, considera-se importante a sua presença para fortalecimento da região, todavia não existem processos formais de atração de empresas na estrutura do Pólo. É importante ressaltar que existem outros organismos com essa finalidade como as associações comerciais, o pólo é articuldao com essas associações e auxilia no processo de atração de empresas, todavia, de maneira indireta. 


\section{Envolve a caracterização dos atores presentes no Pólo, a forma de interação, também a participação das empresas nas decisões.}

As regiões de Nord-Pas de Calais e de Picardie são reconhecidas pelas suas competências indústrias e científicas nos domínios de logística, domímio ferroviário, automobilístico e de sistemas de transportes inteligentes. Assim, empresas de reconhecimento mundial, Micro e pequenas empresas, laboratórios de pesquisa e ensaios (publicos e privados), pólos universitários especializados e escolas de engenharia uniram-se para desenvolver o Pólo.

A seguir são apresentados, alguns dados do Pólo.

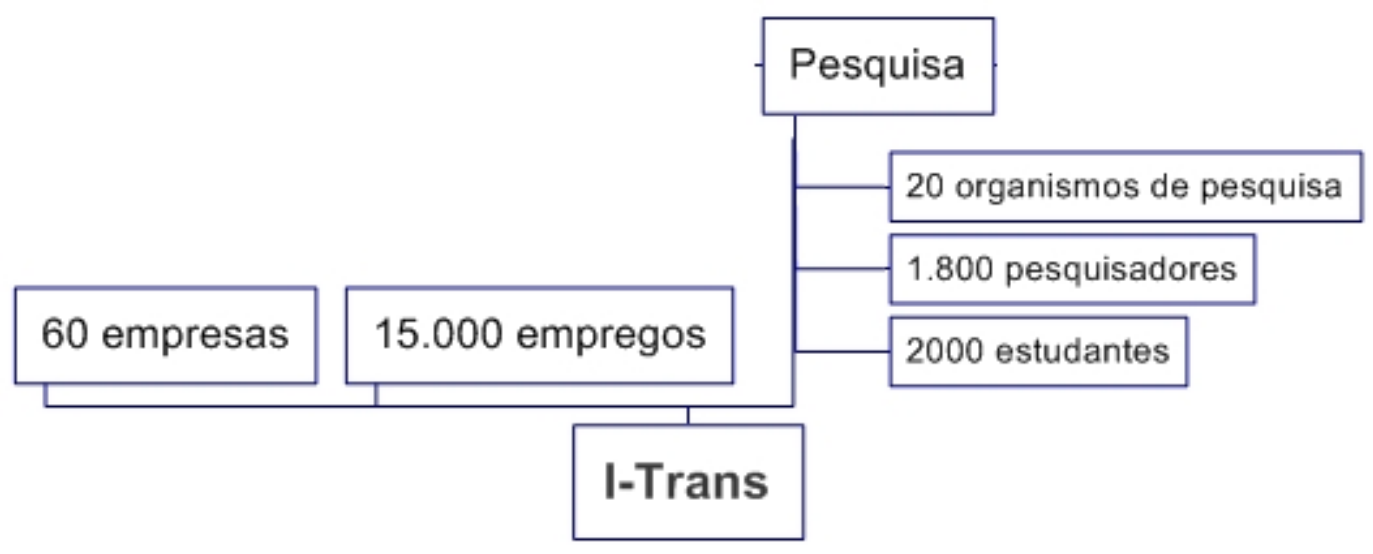

O Pólo reúne cerca de 50 empresas, entre as quais grandes nomes em material ferroviários (Alstom, Bomabardier), em equipamentos automotivos (Saint Gobain, Valéo, Visteon), essas participam ativamente das decisões no Pólo.

As Dez maiores empresas do Pólo são apresentadas a seguir: 


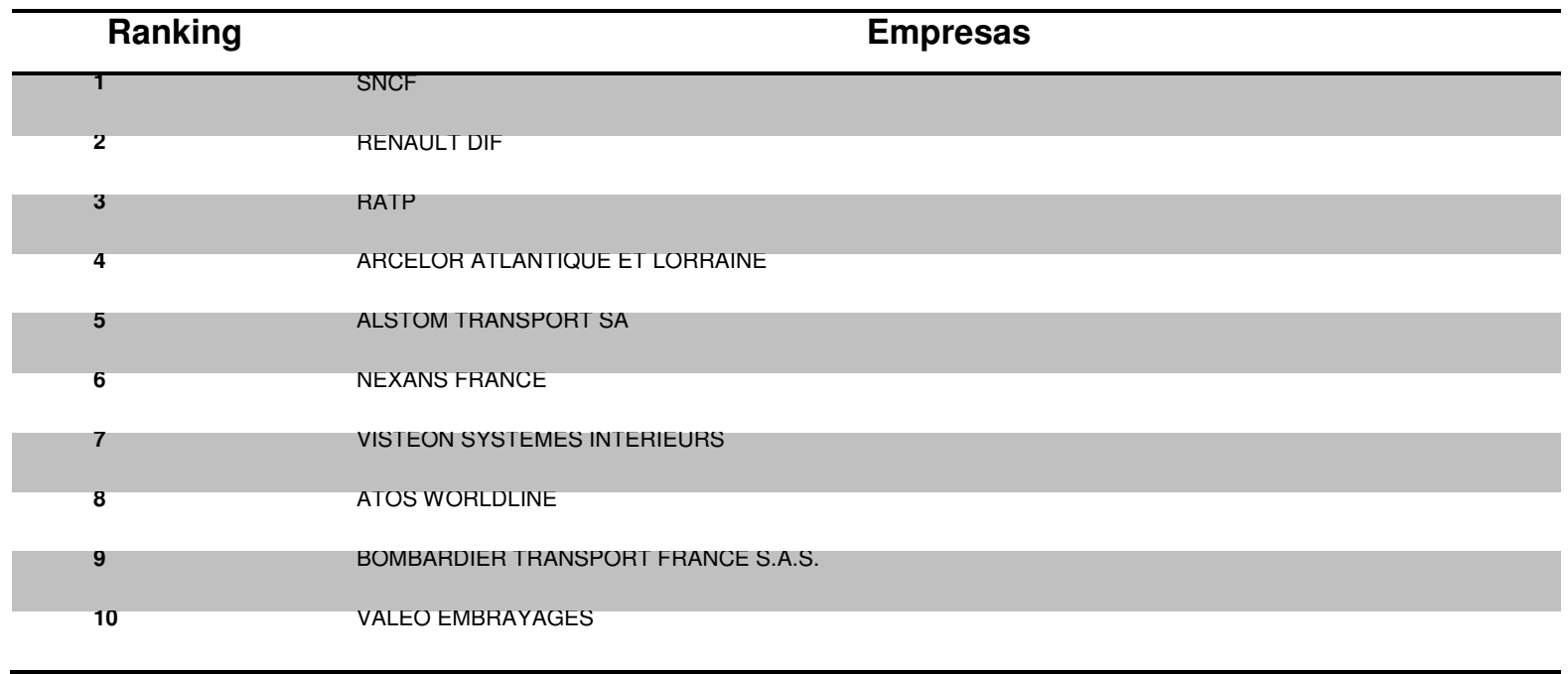

Figura 0-1: As Maiores Empresas da Pólo l-trans considerando o número de empregos.

Fonte: DGE / Sessi / Insee / Diact

\section{Considerando as diferentes esferas de participação, qual é o poder de influência das instituições.}

Contam com uma Associação responsável pela governança do Pólo, na verdade uma exigência de todos os pólos reconhecidos pelo governo francês. Esta associação conta com um órgão de direção, um Conselho de Administração e uma Assembléia geral.

A associação conta com um Comitê Diretivo - com a participação de representantes da própria Associação, do Estado, da Coletividade Local e do Departamento (no caso as Regiões são: Nord Pas de Calais e Picardie - incluindo 5 departamentos, com representação de várias cidades e comunidades). Além desses representantes do setor público são importantes os representantes industriais da região (alguns atuam como líderes importantes e de articulação como ALSTOM e Bombardier) ou são representados por associações profissionais (por exemplo, associações de industriais do setor ferroviário. É bom ressaltar a importância dos líderes públicos que participam fortemente na vida financeira do Pólo (incluindo o desenvolvimento dos projetos).

\section{Descrição das políticas fiscais, urbanísticas do pólo, considerando as esferas regionais, locais, governamentais e setoriais.}

Os políticos interferem diretamente de duas maneiras: no financiamento do Pólo e o financiamento de projetos (em parte pelo Estado francês, pelos departamentos, pelas coletividades). Todos esses projetos são colaborativos, por exigência, necessariamente devem prover representações industriais e de um organismo de pesquisa - esta é a condição inicial para a submissão de um projeto. 
Considerando a representação de parceiros públicos, são observados:

- Estado, por meio de diferentes serviços externos;

- Conselhos regionais (2)

- Conselhos Gerais (2)

- Comunidades (11)

9. Descrição da Estrutura hierárquica dos Pólos, incluindo os aspectos jurídicos, a formalização e o poder de decisão.

De acordo com as diretrizes expostas para estruturação dos Pólos, os mesmos devem ser formalizados por meio de Associações.

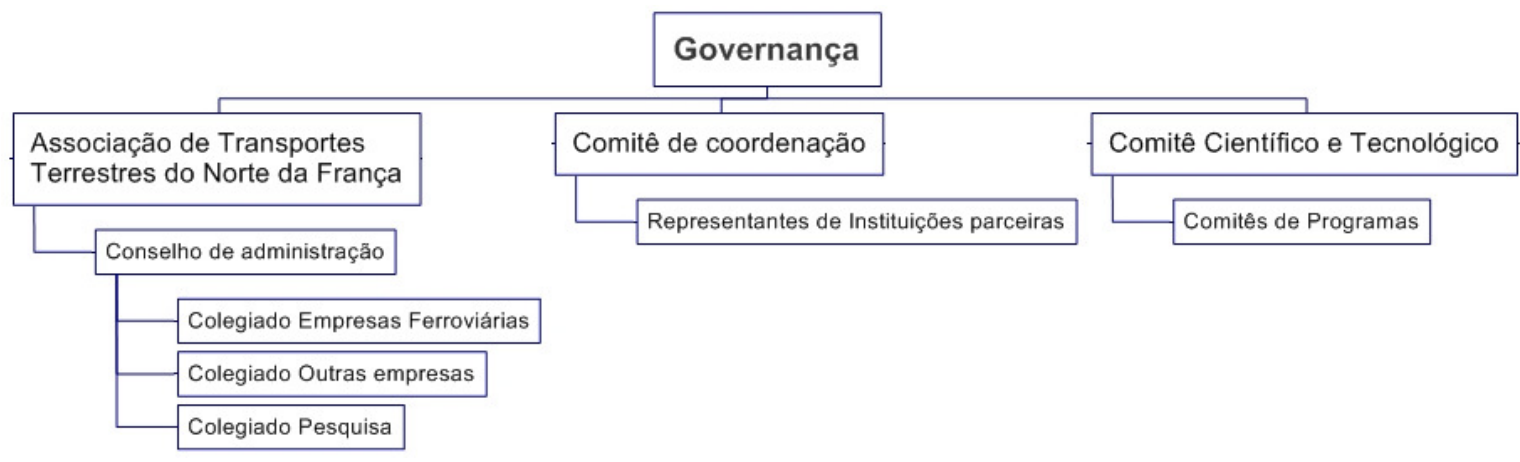

A estrutura do Pólo I-trans envolve um conselho de administração, com representações de empresas e pesquisa, um comitê de coordenação e um comitê tecnológico e científico. 
$\Rightarrow$ Relação Universidade-empresa

\section{Descrição do contexto científico e tecnológico presente nos pólos, envolvendo as universidades, escolas técnicas e outros, com a especialização de cada um e sua representatividade acadêmica, do ponto de vista do número de mestres e doutores.}

As entidades de pesquisas têm uma participação importante: as Escolas, Universidades que compõem o Groupement Régional de La Recherche Corporative, a qual é uma estrutura típica do caso de Lille, que permite o alinhamento da pesquisa com o desenvolvimento da indústria da região.

Podem ser citadas algumas instituições acadêmicas, tais como o CETIM, CETMEF, CNRS, CREPIM, CRITT M2A, École Supérieure de Chimie de Lille, Ecole Centrale de Lille, Ecole des Mines de Douai, ENSAM, ESIEE, GRRT, ICAM, IFTH, INERIS, INRETS Villeneuve d'Ascq, INRIA, ONERA, Université d'Artois, Univers itéde Picardie Jules Vernes, Université des Sciences et Technologies de Lille, Université de Valenciennes et du Hainaut Cambrésis, Université Technologique de Compiègne.

Especificamente, no caso das universidades, elas vislumbram uma oportunidade de dirimir as dificuldades financeiras pela comercialização de serviços de pesquisa para as industriais. A operação do processo inicia-se por meio de um diagnóstico desenvolvido pelas Universidades de Lille, que tem como objetivo evidenciar as capacidades de cada universidade e seus laboratórios, permitindo uma maior agilidade para identificar competências que atendam a solicitação de especialistas para as necessidades industriais.

Os especialistas detentores de know-how no desenvolvimento de projetos aumentam a possibilidade de submissão de projetos vencedores, considerando a perspectiva concorrencial presente na realidade francesa.

\section{Descrição dos principais mecanismos de apoio a relação universidades-empresa presente no Pólo, incluindo organismos públicos e privados.}

Especificamente, no contexto do Pólo não existe repercussão específica de um instrumento ou mecanismo na interação universidades-empresas. É condição para elaboração do projeto que exista a presença de empresas e universidades em conjuntos, sendo assim, o Pólo estimula essa interação. As universidades são motivadas a participar do processo pela possibilidade de alcançar melhores condições financeiras. 
12. Descrição dos mecanismos de apoio segmentados por atividades, como: propriedade intelectual, comércio exterior, certificações de qualidade, etc.

Considerando os mecanismos de apoio, nota-se que a estrutura do Pólo é dirigida para apoiar o desenvolvimento dos projetos, sendo possível obter informações nos instrumentos de divulgação tais como mídia e portal (de como se montar um projeto de inovação). Todavia, não existem mecanismos e processos para apoiar especificamente atividades nas empresas, tais como certificações, propriedade intelectual, comércio exterior. A propriedade intelectual é vislumbrada na perspectiva do projeto e na sua conformação.

Os serviços oferecidos são:

- Suporte a formalização de projetos;

- Presenças de experts internacionais, analisando a viabilidade de projetos numa perspectiva mundial;

- Mapeamento de parceiros de confiança

- A assistência para mobilização de fundos públicos para financiamento;

- Assistência tecnológica em parceira com instituições.

- Disponibilidade de organismos de propriedade industrial. 
$\Rightarrow$ Infra-estrutura

13. A descrição das estruturas disponíveis relacionadas à logística externa do Pólo, envolvendo os transportes e serviços públicos disponíveis na localidade na qual se situa o Pólo. Também a descrição dos complexos residenciais para estadia dos empregados.

O Pólo se situa numa região com vocação industrial, região que abriga grandes empresas do setor automobilístico, e de logística, a região apresenta boas condições em termos de disponibilidade de serviços públicos e condições de moradias para os empregados no Pólo.

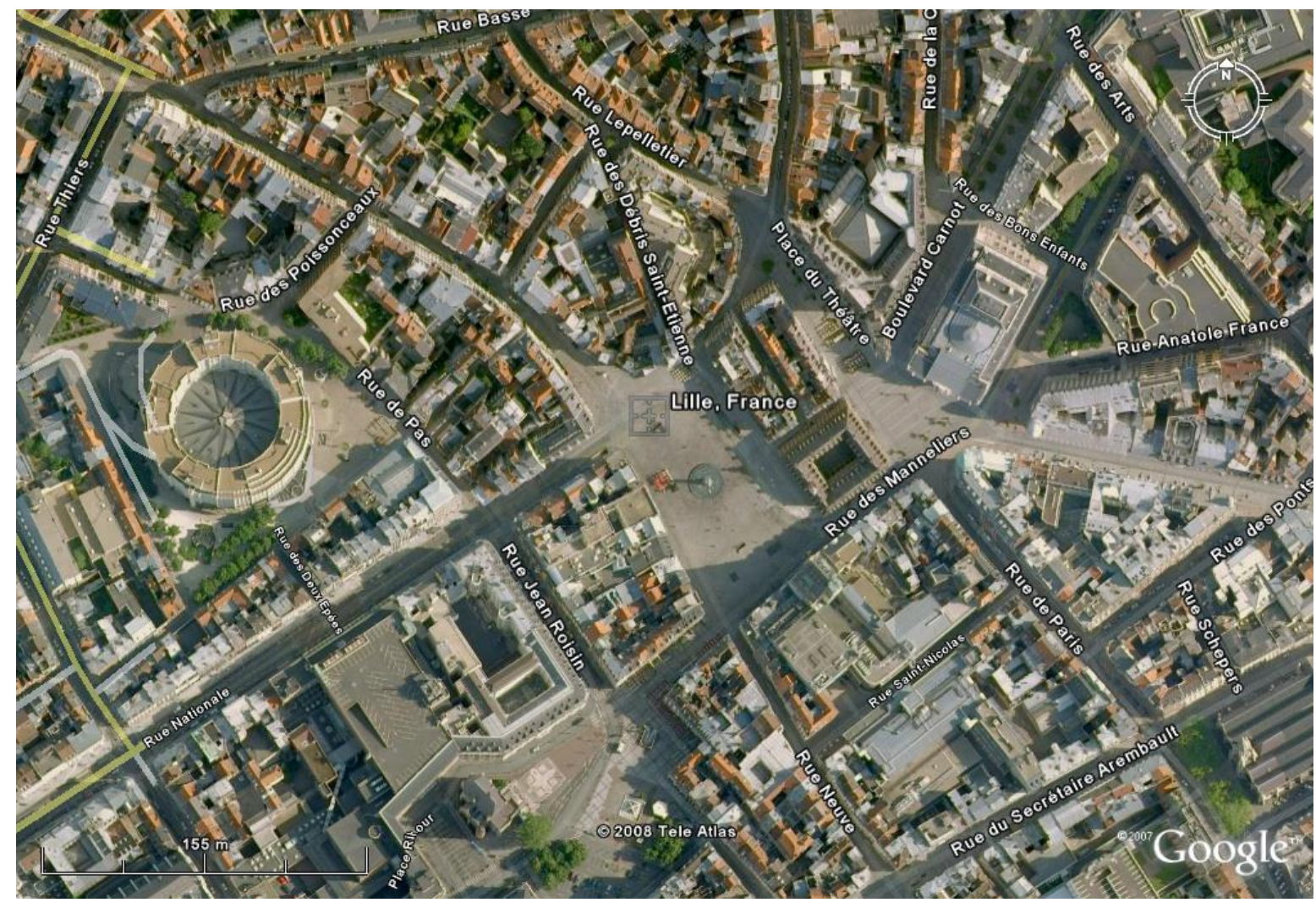

14. Descrição dos tipos de organização de empresas presentes no Pólo: as incubadoras, os agrupamentos de empresas?

A concentração de empresas é a base para o desenvolvimento do Pólo, sendo que a especificidade do segmento econômico é o determinante na definição dos Pólos. Nas estratégias do Pólo está inserido o apoio as PMEs com 24 empresas atuantes no Pólo. 
Relacionado às estruturas como o Centro Incubador, dada a convergência de objetivos, existe o apoio para o seu desenvolvimento, todavia não existe uma governança direta do Pólo, todavia uma abertura para ações em conjunto.

15. Descrição das estruturas de apoio a gestão do Pólo, envolvendo edificações a edificação de estruturas para certificação, propriedade intelectual, comércio exterior e outros serviços.

O Pólo funciona com uma estrutura enxuta e tem o papel de articulador e apoio para os associados, sendo assim não desenvolveu uma estrutura física para lidar com determinadas funções e operações para as empresas.

16. Descrição da estrutura de conhecimentos, com bibliotecas, comunidades de prática, tecnologia da informação (hardware, software, base de dados e pesquisa) e laboratórios de pesquisa e desenvolvimento.

Não foi desenvolvido nenhum tipo de estrutura do conhecimento específica para o Pólo, sendo que a consulta a base de dados e outras informações acontecem no âmbito das instituições presentes nos projetos que são desenvolvidos. 


\section{Mission Pôles de Compétitivité en France}

08 à 16 septembre 2008

\section{Relatório de Entrevistas}

Medicen Paris Region
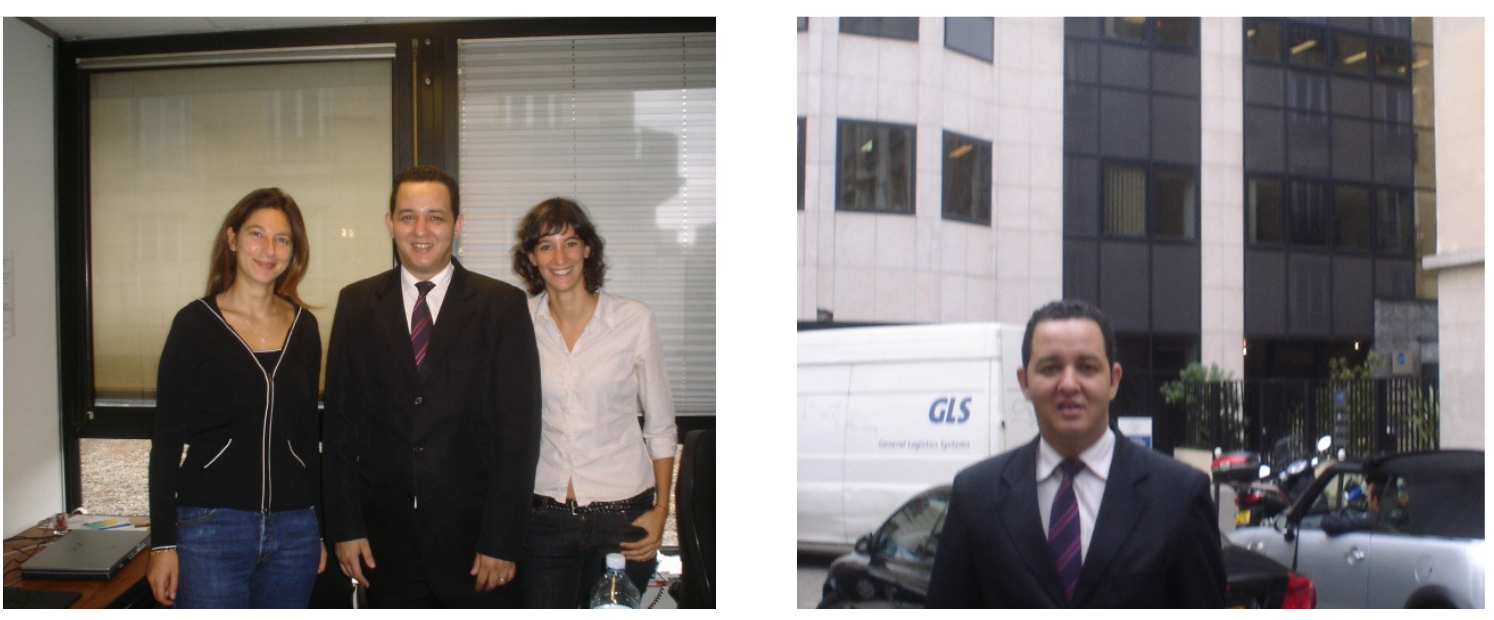

Pesquisadores:

Dra. Désirée Moraes Zouain - IPEN-USP/PGT-USP

Doutorando- Devanildo Damião - IPEN/PGT-USP 


\section{Contexto}

O relatório apresentado a seguir é parte da missão realizada na França para o desenvolvimento da pesquisa sobre Pólos de competitividade.

A entrevista realizada no dia 12/09/2008 tinha como objetivo colher as principais informações sobre o Pólo de competitividade. As entrevistadas foram as gerentes de projetos: Céline Griener e Agnès De Simone, o encontro aconteceu no escritório administrativo do Pólo em Paris, na região 75015.

A coleta de informações foi estruturada a partir de um questionário qualitativo com enfoque em quatro dimensões: infra-estrutura, governança, estratégias e relação universidade-empresa.

\section{Apresentação do Médicen}

O Medicen Paris Region é um pólo de competitividade mundial, estruturado num clusters que envolve os atores na área de saúde como hospitais, a industria farmaceutica e as universidades e pequenas empresas de produtos médicos, contando com especialistas em ciências da vida e tratamento da saúde.

Localizado numa região central da Europa, a lle-de-France é uma região líder na Europa e a região no mundo em termos de capacidade e desenvolvimento de pesquisa (estima-se 126.000 pessoas atuando com atividades de pesquisa)

O orçamento para custear a estrutura do Pólo custa ceca de 1 milhão de euros por anos, as atividades de Pesquisa e Desenvolvimento estão avaliadas em 260 milhões de euros por um período de 03 anos. 
Principais Caracteristicas

\begin{tabular}{|c|c|}
\hline Setores & $\begin{array}{l}\text { Oncologia, doenças do sistema } \\
\text { infecciosas, terapias moleculares e eluro, doenças } \\
\text { farmacêuticas e imagens médicas. }\end{array}$ \\
\hline Regiões Principais & Ile de France \\
\hline $\mathbf{N}$ & $\begin{array}{l}\text { 99, envolvendo dentre outras: Novo Nordisk, Novartis, Philips } \\
\text { Medical Systems, Sanofi-Aventis, Servier, Siemens, Sun } \\
\text { Microsystems, Zeiss, Cap Gemini, Danone, General Electric } \\
\text { Healthcare, GlaxoSmithKline, Harrison Clinical Research, } \\
\text { Chemunex, Denoyelle, Hamamatsu, Medasys-Hitachi, Ipsen }\end{array}$ \\
\hline Centros de Pesquisa & $\begin{array}{l}\text { 20, envolvendo Centos de pesquisa e sentros de formação, } \\
\text { por exemplo, Pasteur Institute, the Evry Génopole and the Atomic } \\
\text { Energy Center (CEA) biotechnologies labs. }\end{array}$ \\
\hline Númerc & pregos \\
\hline $\begin{array}{l}\text { Principais } \\
\text { das }\end{array}$ & $\begin{array}{l}\text { Neurociência, Oncologia, Doenças infecciosas, Imagens } \\
\text { biomédicas, Medicina molecular e celular, ciências e tecnologias } \\
\text { do medicamento. }\end{array}$ \\
\hline Projetos & $\begin{array}{l}\text { De Setembro de } 2005 \text { a Abril de } 2007 \text {, o Pólo credenciou } 19 \\
\text { projetos colaborativos de P\&D, dos quais } 18 \text { receberam } \\
\text { financiamento público. }\end{array}$ \\
\hline
\end{tabular}




\section{Questionário}

\section{$\Rightarrow$ Estratégia}

\section{Descrição das principais estratégias utilizadas pelos pólos para Internacionalização, referentes às ações para estimular o comércio exterior, as parcerias com as empresas internacionais, a representação internacional e dos autores.}

O Pólo de competitividade tem como prioridade trazer competitividade a região e atratividade internacional considerando terapias inovativas de alto nível, criando ocupações de alta especialização em ciências da vida.

O ministério das finanças organiza missões coletivas internacionais, de acordo com regiões que despertam interesses, no ano passado foram organizadas missões para a India, Israel, USA e Japão.

O roteiro das visitas inclui as incubadoras, os clusters locais, também é organizada uma feira de negócios, na qual as empresas do pólo podem expor os seus produtos e desenvolver parceiros internacionais. Uma experiência de sucesso foi o convênio firmado com um pólo da Hungria.

O custo das missões é atrativo para as empresas, considerando a possibilidade de novos negócios internacionais, como ponto de controle da efetividade da missão, é desenvolvida uma avaliação para registrar os resultados positivos.

Relacionado às exportações, a taxa de exportações de empresas associadas no Pólo é de $29 \%$, sendo que $13 \%$ são MPEs.

\section{Descrição dos organismos específicos e suas estruturas administrativas.}

O conceito de competitividade do Pólo é desenvolvido com a idéia de adicionar valor ao negócio, sendo que esses são desdobrados em alguns objetivos, tais como:

- Fortalecer a indústia local, formada por empresas de inovação em biotecnologia e empresas farmacêuticas, serviços médicos, manufaturas de provedores de serviços afins, com a criação de empregos qualificados.

- Desenvolver a base científica nos setores público e privado, por meio do fortalecimento dos projetos internacionais colaborativos. 
- Facilitar o acesso para os participantes dos projetos de infra-estrutura adequada (equipamentos, informação e serviço).

- Suportar o desenvolvimento de parcerias e ativas colaborações, entre empresas e organizações de pesquisa e capacitação.

- Construir um reservatório de competências, com o encontro das necessidades das empresas e instituições de pesquisa.

- Melhorar o ambiente de sucesso financeiro dos projetos, colaborando com empresas iniciantes e buscando financiamentos

- Provendo alta visibilidade internacional.

\section{Explicação detalhada e precisa de como é aplicada a estratégia.}

A base de atuação do Pólo Medicen é o desenvolvimento de projetos que envolvem diferentes atores: Grandes empresas, Médias e pequenas empresas, Insituições de Pesquisa, Centros de P\&D de empresas, hospitais com o objetivo de gerar inovações. A equipe de animação do Medicen faz a articulação entre os atores para desenvolvimento dos projetos.

A atuação do Medicen Paris é focada em 06 áreas, sendo três áreas terapêuticas e três tenológicas:

- Doenças do sistema nervoso

- Oncologia

- Doenças infecciosas

- Terapias genéticas e Moleculares

- Imagens biomédicas

- Projetos drogas científicas e tecnológicas.

\section{Como são desenvolvidas as operações das atividades do Pólo, Quem faz o que? Comentários? Os elementos das atividades e atribuição devem ser identificados.}

Considerando a estrutura operacional do pólo, observa-se que a equipe administrativa (animação) é composta de 07 pessoas. Elas estão distribuídas entre pessoas que atuam diretamente nos projetos e cuidam da parte de relações internacionais e de comunicação. Também existe os responsáveis pela parte administrativa envolvendo a gestão do pólo e da parte de contabilidade. Observa-se uma lacuna existente relacionada a um profissional com perfil para trabalhar a questão das Médias e Pequenas empresas e projetos temáticos. 


\section{Como são desenvolvidas as estratégias de atração de empresas? Existe um organismo formal? Em caso positivo, qual é a estrutura? As empresas respondem aos chamados públicos? São adicionadas em grupos? Elas se auto ajudam?}

Relacionada a atratividade de empresas, considera-se que o fortalecimento da região será o vetor de atratividade de empresas, todavia inexistem processos e estruturas específicas para esse tema. As empresas de diversos portes são acionadas para participar de projetos específicos que oferecem boas condições de rentabilidade. As missões internacionais podem ser consideradas como um elemento de atratividade, outro aspecto refere-se a busca de parcerias com outras instituições, como outros pólos de saude. Atualmente, são desenvolvidos projetos cooperativos com com empresas de outros pólos. 
6. Envolve a caracterização dos atores presentes no Pólo, a forma de interação, também a participação das empresas nas decisões.

O Pólo reúne cerca de 73 empresas, as dez maiores empresas do Pólo são apresentadas a seguir:

\begin{tabular}{ll}
\hline Ranking & \multicolumn{1}{c}{ Empresas } \\
\hline 1 & SANOFI-AVENTIS RECHERCHE ET DÉVELOPPEMENT \\
2 & LABORATOIRE GLAXOSMITHKLINE \\
3 & GE MEDICAL SYSTEMS \\
4 & LFB S.A. \\
5 & BIO RAD \\
6 & GUERBET \\
7 & CIS BIO INTERNATIONAL \\
8 & INSTITUT DE RECHERCHES SERVIER \\
9 & SIEMENS MEDICAL SOLUTIONS FRANCE \\
10 & LABORATOIRES INNOTHERA \\
\hline
\end{tabular}

Figura 0-2: As Maiores Empresas da Pólo I-trans considerando o número de empregos.

Fonte: Sources : Sessi - recensement auprès des pôles, Insee Ficus 2005

7. Considerando as diferentes esferas de participação, qual é o poder de influência das instituições.

No modelo de organização do pólo de Competitividade Medicen observa-se o domínio de uma governança estruturada nas empresas, as quais são privilegiadas nas decisões de representatividades. As empresas são os atores que possuem maior poder na escolha da estrutura de administração dos Pólos.

A associação contempla membros ordinários e honorários, os quais são pessoas altamente qualificadas nomeadas pelo corpo de diretores. Os membros ordinários são divididos em colégios eleitorais específicos:

- Colégio eleitoral de pequenas empresas

- Colégio eleitoral de grandes empresas 
- Colégio Eleitoral da academia e pesquisa

- Colégio Eleitoral de representações do estado, região e corpo de governo local com as agências de desenvolvimento e autoridades locais.

\section{Descrição das políticas fiscais, urbanísticas do pólo, considerando as esferas regionais, locais, governamentais e setoriais.}

O Pólo não trata de questões fiscais e urbanísticas, esses elementos são tratados em outras esferas administrativas como as comunidades e regiões. Como o Pólo trabalha a partir de um pressuposto que já existe uma aglomeração e uma base científica local, a questão urbanística não é tratada nesse momento. As políticas fiscais são importantes e relevantes, todavia, tratadas numa esfera coletiva dos pólos e não numa perspectiva isolada.

\section{Descrição da Estrutura hierárquica dos Pólos, incluindo os aspectos jurídicos, a formalização e o poder de decisão.}

De acordo com as diretrizes expostas para estruturação dos Pólos, os mesmos devem ser formalizados por meio de Associações não lucrativas. A estrutura do Pólo é definida pela representação das empresas (divididas em dois grupos de acordo com o seu porte), Universidades, autoridades locias e regionais e hospitais. e instituições de pesquisa.

As decisões e ações estão distribuídas por uma estrutura que contempla a assembléia geral, o corpo de diretores e o corpo executivo, além da equipe de animação. 


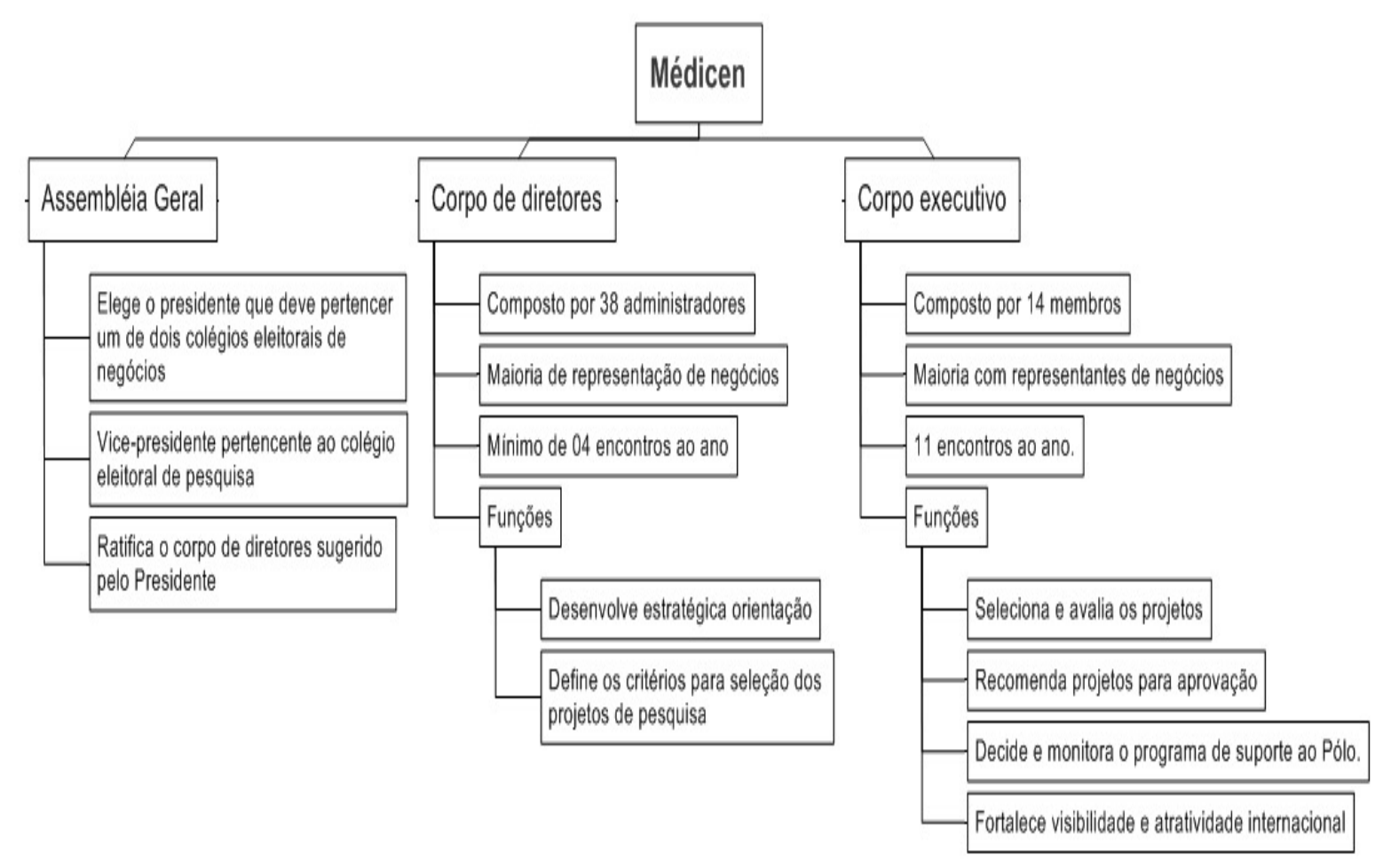

\section{$\Rightarrow$ Relação Universidade-empresa}

\section{Descrição do contexto científico e tecnológico presente nos pólos, envolvendo as} universidades, escolas técnicas e outros, com a especialização de cada um e sua representatividade acadêmica, do ponto de vista do número de mestres e doutores.

Considerando as instituições presentes no Pólo são identificadas como instituições de pesquisa:

CEA - Commissarait à l'Energie Atomique, INSERM - Institut National de la Santé et de la Recheche Medicale, CNRS - Centre National de la Recherche Scientifique, Pasteur Institute, Curie Institute, Gustave Roussy Institute Cancer Cluster, French public hospital network (Assistance Publique Hôpitaux de Paris), INRA, INRIA, Maison-Alfort Veterinary School

Também estão presentes 09 universidades que oferecem cursos completos em biologia e cursos relacionados a Ciências. Também encontram-se 02 escolas superiores e Escolas de Engenharia.

Paris V, VI, XI, XII, XIII Universities, Evry University, Versailles University, Cergy University, Cachan and Ulm Higher Schools, INAPG, Ecole Central de Paris school, Ecole des Mines de Paris school, IBPI, ESPCI 
Os pólos para articular essa relação desenvolve e organiza eventos, como almoços e cafés para articular pesquisas, a estratégia é mais dirigida a animação de redes, outra estratégia é a elaboração de comitês temáticos para desenvolver os projetos que necessitam ser colaborativos.

\section{Descrição dos principais mecanismos de apoio a relação universidades-empresa presente no Pólo, incluindo organismos públicos e privados.}

O Pólo não faz uso do modelo de células de valorização na relação com as universidades e institutos de pesquisas, também não utiliza-se de outros instrumentos com essa finalidaade, a relação ocorre na perspectiva do projeto para qualificá-lo.

A melhoria no relacionamento com as universidades não é priorizado no Pólo não existe uma diretriz que indique essa necessidade, o papel do Pólo é de mediador das relações, eventualmente o grupo de animação do pólo participa de reuniões mais não existe nada sistematizado, depende das caracterísiticas de cada pessoa.

\section{Descrição dos mecanismos de apoio segmentados por atividades, como: propriedade intelectual, comércio exterior, certificações de qualidade, etc.}

Os pólos de forma geral ao desenvolverem as suas atividades relacionadas a questão dos contratos lidam com o aspecto da propriedade intelectual, visto que trabalham e desenvolvem projetos para inovação, na formalização dos contratos é necessário o acordo a priori de como serão trabalhadas as relações de propriedade. Os acordos, via de regra são complexos, demandando um tempo considerável, principalmente na questão da propriedade intelectual, sendo que as questões de direitos e exclusividades são muito difíceis de resolver.

\section{$\Rightarrow$ Infra-estrutura}

13. A descrição das estruturas disponíveis relacionadas à logística externa do Pólo, envolvendo os transportes e serviços públicos disponíveis na localidade na qual se situa o Pólo. Também a descrição dos complexos residenciais para estadia dos empregados.

O Pólo se situa numa região central na lle de France, região que abriga empresas de diferentes portes. Cerca de $90 \%$ das empresas francesas especializadas em experimentos clínicos 
estão localizadas na lle de France e são suportadas por redes de grandes hospitais do mundo: o Sistema Frances de Hospitais Públicos (Assistance Publique-Hôpitaux de Paris AP-HP).

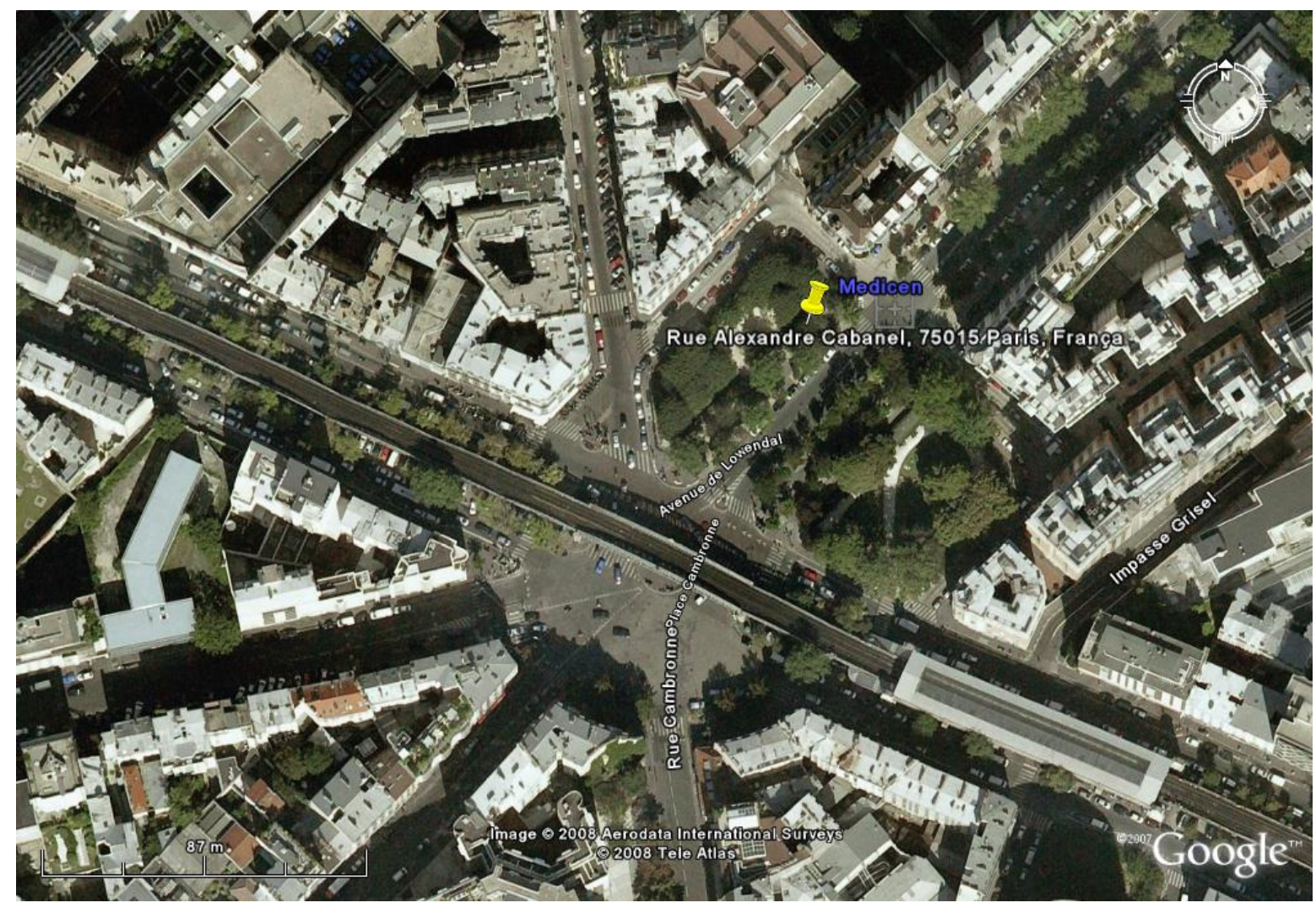

\section{Descrição dos tipos de organização de empresas presentes no Pólo: as incubadoras, os agrupamentos de empresas?}

Estão presentes no Pólo diferentes tipos de empresas, o porte varia de pequenas e médias a grandes empresas. Considerando as pequenas e médias empresas podem ser citadas: Anaconda Pharma, ABS Science, Agilent, Ariana Pharmaceuticals, Affymetrix, Bioalliance Pharma, Biospace, Bioprotein Technologies, Cell Tissues Progress, Cytomics, Diverchem, Echosens, Eucodys, Geneware, Genescore, Genzyme/Myosix, Integraren, Helios Biosciences.

Também existem grandes empresas líderes que exercem liderança nos seus campos, tais como: Novo Nordisk, Novartis, Philips Medical Systems, Sanofi-Aventis, Servier, Siemens, Sun Microsystems, Zeiss, Cap Gemini, Danone, General Electric Healthcare, GlaxoSmithKline, Harrison Clinical Research, Chemunex, Denoyelle, Hamamatsu, Medasys-Hitachi, Ipsen. 
No aspecto das incubadoras, atualmente tem de 5 a 10 incubadores que estão associadas ao polo e trabalham numa estratégia comum, como por exemplo as incubadoras localizadas no Genopole.

\section{Descrição das estruturas de apoio a gestão do Pólo, envolvendo edificações a edificação de estruturas para certificação, propriedade intelectual, comércio exterior e outros serviços.}

O Pólo funciona com uma estrutura enxuta e tem o papel de articulador e apoio para os associados, sendo assim não desenvolveu uma estrutura física para lidar com determinadas funções e operações para as empresas.

Sendo assim, é sua finalidade prover boas condições para o desenvolvimento dos projetos e permitir o compartilamento de uma estrutura de qualidade para os participantes, todavia, não são desenvolvidas estruturas específicas para essa finalidade, todavia, é vislumbrada a otimização do espeço existente no contxto de um projeto.

\section{Descrição da estrutura de conhecimentos, com bibliotecas, comunidades de prática, tecnologia da informação (hardware, software, base de dados e pesquisa) e laboratórios de pesquisa e desenvolvimento.}

Não foi desenvolvido nenhum tipo de estrutura do conhecimento específica para o Pólo, sendo que a consulta a base de dados e outras informações acontecem no âmbito das instituições presentes nos projetos que são desenvolvidos.

O Pólo trabalha para oferecer o compartilhamento de base de dados, para permitir que a pesquisa tenha mais subsídios teóricos para a sua exeucução. 


\section{Mission Pôles de Compétitivité en France}

08 à 16 septembre 2008

\section{Relatório de Entrevistas \\ Cap digital}
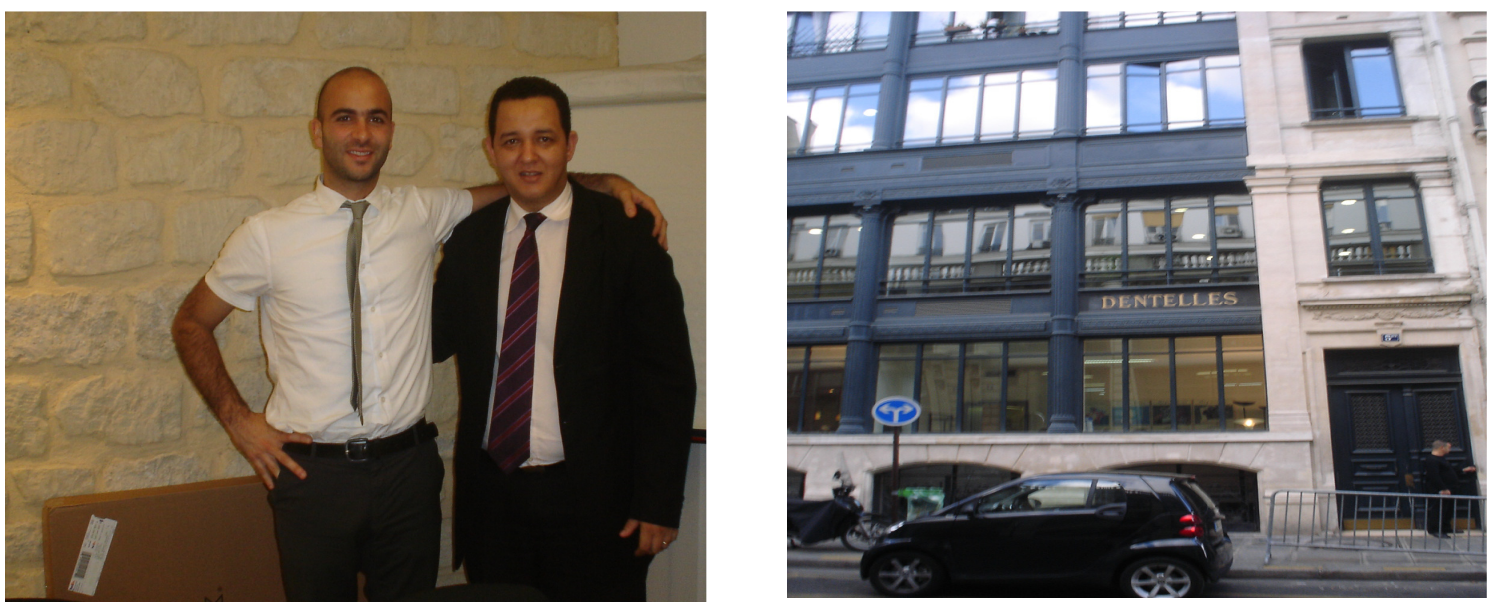

Pesquisadores:

Dra. Désirée Moraes Zouain - IPEN-USP/PGT-USP

Doutorando- Devanildo Damião - IPEN/PGT-USP 


\section{Contexto}

O relatório apresentado a seguir é parte da missão realizada na França para o desenvolvimento da pesquisa sobre Pólos de competitividade.

A entrevista realizada no dia 12/09/2008 tinha como objetivo colher as principais informações sobre o Pólo de competitividade. O entrevistado foi o gerente de projetos: Eduardo Oliveira, o encontro aconteceu no escritório administrativo do Pólo em Paris, na região 75002.

A coleta de informações foi estruturada a partir de um questionário qualitativo com enfoque em quatro dimensões: infra-estrutura, governança, estratégias e relação universidade-empresa.

\section{Apresentação do CAP DIGITAL}

O Cap Digital é um Pólo de vocação mundial que trabalha os setores de imagem e multimídia, com base em três eixos:

- desenvolvimento estratégico consistente com amplo plano de desenvolvimento de toda a região,

- fortes parcerias público-privadas;

- concentração de indústrias baseadas em alto nível de conhecimento.

O Cap Digital faz a interface entre as tecnologias digitais e seis setores estratégicos firmemente enraizados na região de Paris: conhecimentos em engenharia, patrimônio digital, imagens, sons e interatividade, videogames, educação digital e serviços e práticas.

Apesar de recente, com cerca de dois anos e meio de atuação, o pólo já registra excelentes resultados: ao todo, são 330 membros - o que inclui mais de 270 pequenas e médias empresas, 20 grandes empresas, 37 instituições públicas, universidades, centros de pesquisa e centros de formação, entre outros - e 140 projetos credenciados.

A iniciativa já movimentou 213 milhões de euros em investimentos privados e 148 milhões em financiamento público. Existe bastante similaridade com a realidade nacional, entre elas: a característica das empresas, a maioria pequenas e médias, a subcapitalização (capital insuficiente por parte dessas empresas) e o grande potencial criativo e artístico. 
Principais Caracteristicas

\begin{tabular}{|c|c|}
\hline Setores & $\begin{array}{l}\text { Tecnologia de informação e comunicação e conteúdos } \\
\text { digitais }\end{array}$ \\
\hline Regiões Principais & Ile de France \\
\hline Número de Empresas & $\begin{array}{l}\text { Total de } 250 \text { empresas, sendo mais de } 30 \text { empresas com } \\
\text { reputação global: Lagardère Interactive, Editis, France Télécom, } \\
\text { EADS, Thalès, TF1, Canal+, Sagem, Motorola, Eurodisney, } \\
\text { Europacorp, SFP, TSF. } \\
\quad 200 \text { altamente dinâmicas pequenas e médias empresas : } \\
\text { Attitude Studio, Akkana, Odile Jacob Multimédia, Sinequa, } \\
\text { Exalead, Pertimm, Eclair, Mac Gull Line, Mikros, Capital Games, } \\
\text { Silicon Sentier e inúmeras outras pequenas e médias empresas. }\end{array}$ \\
\hline Centros de Pesquisa & $\begin{array}{l}50 \text { dentre outros: INA, French Documentation Office } \\
\text { (Documentation Française), IRCAM, CNC, BDIC, etc. }\end{array}$ \\
\hline Número de Empregos & 169399 empregos \\
\hline Principais atividades & 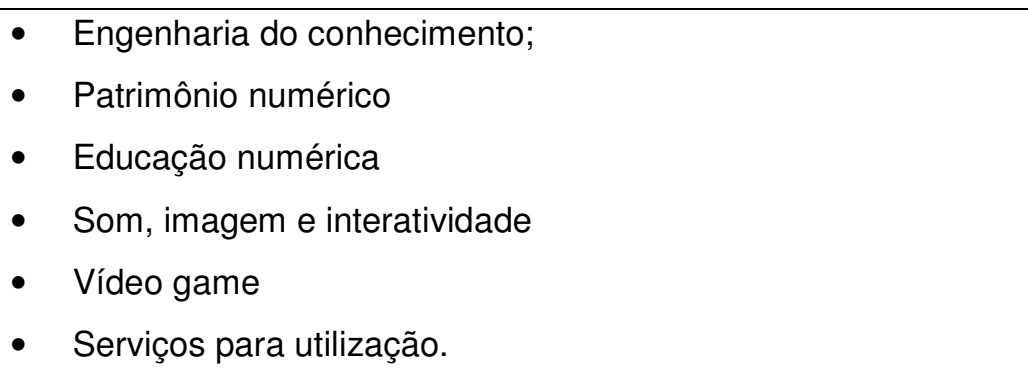 \\
\hline Projetos & - Foram desenvolvidos 16 projetos de P\&D. \\
\hline
\end{tabular}




\section{Questionário}

\section{$\Rightarrow$ Estratégia}

\section{Descrição das principais estratégias utilizadas pelos pólos para Internacionalização, referentes às ações para estimular o comércio exterior, as parcerias com as empresas internacionais, a representação internacional e dos autores.}

O Cap digital foi desenvolvido no âmbito de um internacional networking de clusters, com foco no mercado internacional estimado em 300 bilhões de euros. Estrategicamente está focado em:

- Participar de programas europeus em ICT como EUREKA e IST;

- Desenvolver parceria com clustes da california, onde está sediada Hollywood;

- Parceria com o cluster de Seul, mercado com grande nivel de penetração de internet banda larga no mundo e também um dos locais que abrigam grande potencial para desenvolvimento de vídeo-games.

Atualmente desenvolve vários projetos que são financiados pela comunidade européia, dedicando para isso um profissional dedicado a formação de cooperações internacionais.

Alguns mercados são considerados de grande interesse como Japão, Coréia, EUA, Canadá e China, sendo países incentivados oficialmente pelo Ministério da Indústria, sendo buscadas parcerias. O Cap Digital no seu grupo de animação tem um profissional que trata de cooperações internacionais, inclusive com um foco no mercado europeu.

O Cap Digital atua no segmento de conteúdo digital, Digital Content - cinema, games, música, internet, serviços por telefone celular. Essas áreas pemitem muitas inovações incrementais, relacionadas as áreas de desenvolvimento e menos pesquisa, atuar nesse mercado pressupõe agilidade e forte interação com o mercado para oferta de novos serviços, a internet é uma plataforma para vários serviços.

O desenvolvimento de projetos tecnológicos conjuntos, no âmbito do pólo, caso do CAP DIGITAL, permite uma relação de confiança que facilita a estruturação de parcerias.

\section{Descrição dos organismos específicos e suas estruturas administrativas.}

O Cap Digital possue uma governança bem definida que não implica na grande necessidade espacial em termos de espaços para desenvolvimento das suas atividades. O funcionamento da estrutura do Cap Digital prevê uma estrutura de animação composta de 10 pessoas assalariadas, sendo uma delas uma estagiária para tratar de questões administrativas. 


\section{Explicação detalhada e precisa de como é aplicada a estratégia.}

O estado francês lança anualmente um edital, para conceder financiamentos a projetos apresentados por pólos de diversos setores. A partir daí, os atores de cada pólo dos diferentes setores se reuniram e começaram a trabalhar de forma conjunta, elaborando projetos de interesse de cada pólo, para concorrer a estes recursos. Para o desenvolvimento, existe um processo que passa pela interação entre o atores, com o compartilhamento das suas respectivas visões tecnológicas, da identificação de problemas, conhecimento e acesso aos modelos de financiamento.

\section{Como são desenvolvidas as operações das atividades do Pólo, Quem faz o que? Comentários? Os elementos das atividades e atribuição devem ser identificados.}

A estrutura operaconal do pólo participa do Comitê Executivo, sendo que a sua estrutura conta com membros permanentes que dirigem e gerenciam as atividades principais do Pólo. As funções são de um CEO, Chief Executive Officer, que é reponsável pelas decisões no contexto geral do Pólo, também participam gerentes de Pesquisa e desenvolvimento, gerentes de pesquisa de pesquisa e prjetos educacionais, Gerente de proejtos de Comunicação e assistentes de escritório.

\section{Como são desenvolvidas as estratégias de atração de empresas? Existe um organismo formal? Em caso positivo, qual é a estrutura? As empresas respondem aos chamados públicos? São adicionadas em grupos? Elas se auto ajudam?}

Considerando a perpsectiva regional, observa-se na região de lle-de-France por meio das autoridades e necessidade de atração de empresas estrangeiras. $O$ tratamento desa questão fica no âmbito dos relacionamentos internacionais que são desenvolvidos por um dos membros da equipe de animação. É importante ressaltar que esse processo não está estruturado, na verdade, as atividades são desenvolvidas na perspectiva de apresentar o Pólo de forma geral e nesse contexto evidenciar as suas condições diferenciadas. 
6. Envolve a caracterização dos atores presentes no Pólo, a forma de interação, também a participação das empresas nas decisões.

As empresas participam das decisões nos Pólos por meio da estrutura hierárquica que prevê os diferentes conselhos, com reuniões para tomadas de decisões e estratégias. O pólo digital pela característica da atividade desenvolvida pressupõe uma forte interação com o mercado, sendo caracteriado como um cluster de negócios.

A seguir seguem as principais empresas que participam do Pólo Digital:

\begin{tabular}{ll}
\hline Ranking & \multicolumn{1}{c}{ Empresas } \\
\hline 1 & FRANCE TELECOM \\
2 & CIE IBM FRANCE \\
3 & THALES COMMUNICATIONS S.A. \\
4 & 164 CENTELEC SAS \\
5 & SOCIETE FRANCAISE DU RADIOTELEPHONE -SFR \\
6 & TELEVISION FRANCAISE 1 \\
7 & SONY FRANCE SA \\
8 & HACHETTE LIVRE \\
9 & MICROSOFT FRANCE \\
10 & MOTOROLA SAS \\
\hline
\end{tabular}

Figura 0-3: As Maiores Empresas da Pólo I-trans considerando o número de empregos.

Fonte: Sources : Sessi - recensement auprès des pôles, Insee Ficus 2005

7. Considerando as diferentes esferas de participação, qual é o poder de influência das instituições.

Formalmente o organismo máximo de decisões do pólo permite a participação de todos os segmentos na sua composição. A prática permite observar que dada a característica temática do pólo e suas estratégias, as empresas tendem a ter uma maior participação, visto que o segmento de tecnologia da Informação é bastante dinâmico e exige respostas rápidas.

8. Descrição das políticas fiscais, urbanísticas do pólo, considerando as esferas regionais, locais, governamentais e setoriais. 
Especificamente no caso da indústria de games, a França busca maior competitividade territorial, pois não é competitiva nesse momento, assim estão incentivando essa atividade com uma política de isenção de impostos, financiamentos e incentivos urbanísticos. Algumas empresas franceses, saíram da França para o Canadá que oferecia melhores condições tributárias.

Os conselhos regionais e distritais como o IDF desenvolvem um papel importante no financiamento dos projetos. As autoridades locais privilegiam projetos com apelo para o desenvolvimento nos seus territórios.

\section{Descrição da Estrutura hierárquica dos Pólos, incluindo os aspectos jurídicos, a formalização e o poder de decisão.}

Cap Digital é uma associação não lucrativa, financiada em duas partes nas quais, $20 \%$ são recursos provenientes pelos membros anuais e $80 \%$ por representações de responsáveis do estado e regionais:

- Estado: DRIRE, ANS

- Regional: Conselho Geral do Haut des Seine, Conselho geral Seine- Saint Dênis, Conselho Geral Seine-Marne, Departement de Paris, Departement Val d'oise, Conselho Geral Departament Val-de-Marne, Conselho geral Yvelines 78. 


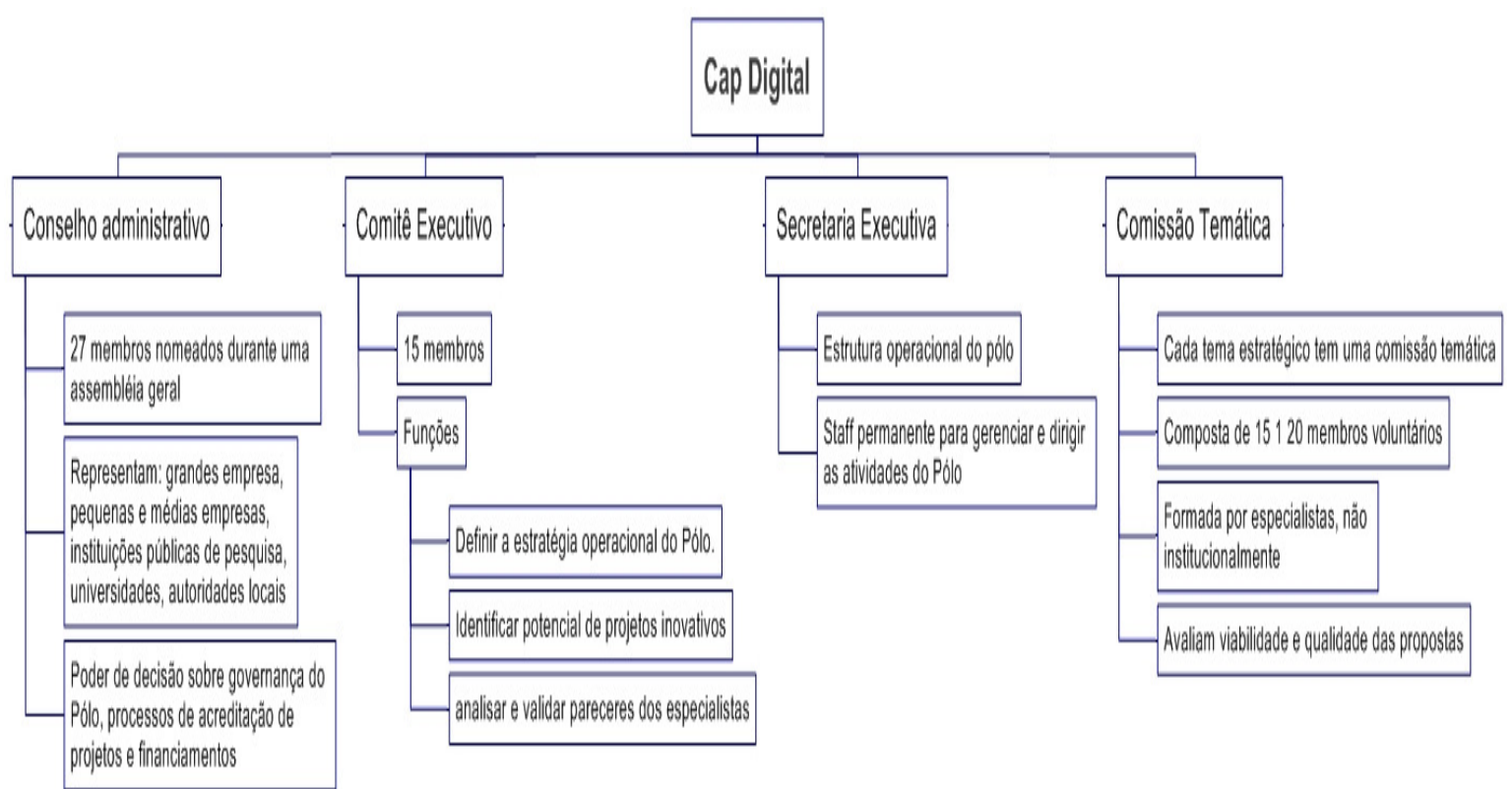

$\Rightarrow$ Relação Universidade-empresa

10. Descrição do contexto científico e tecnológico presente nos pólos, envolvendo as universidades, escolas técnicas e outros, com a especialização de cada um e sua representatividade acadêmica, do ponto de vista do número de mestres e doutores.

Estão presentes nos Pólos 50 laboratórios de pesquisa como o INA, Escritório de Documentação Francês, o IRCAM, o CNC, BDIC.

No aspecto de capacitação estão presentes universidades e escolas especializadas como a Paris VI University, Paris XIII University, CNAM, GET (ENST, INT) Les Gobelins School.

\section{Descrição dos principais mecanismos de apoio a relação universidades-empresa presente no Pólo, incluindo organismos públicos e privados.}

$\mathrm{Na}$ criação do Pólo, havia um plano inicial com a intenção da parceria com as células de valorização das universidades, porém isso não funcionou. Essa área de valorização não está resolvida nas universidades, existem conflitos que geram problemas.

Outro aspecto que provoca distanciamento é visão dos pesquisadores em relação as empresas, via de regra, a empresa ainda é mal vista pelos pesquisadores. 
12. Descrição dos mecanismos de apoio segmentados por atividades, como: propriedade intelectual, comércio exterior, certificações de qualidade, etc.

Considerando a questão da Propriedade intelectual, as regras são bem rígidas, principalmente nos contratos franceses ou europeus. O Pólo não atua nesta área. Apenas informalmente dada a experiência adquirida nos projetos, o grupo de aniimação faz algumas orientações de caráter consultivo. O tema é importante e demanda atenção, todavia é tratado na perspectiva das empresas. Referente a processos de qualidade, a participação é indireta, sendo tratada pelas próprias empresas, no tocante ao comércio exterior o pólo atua como articulador para que as empresas desenvolvam contatos e apresentem produtos e processos, assim como desenvolvam parcerias. as regras são bem rígidas neste caso - nos contratos franceses ou europeus. Não assumem responsabilidades nesse contexto. Cada empresa é independente neste item. 
13. A descrição das estruturas disponíveis relacionadas à logística externa do Pólo, envolvendo os transportes e serviços públicos disponíveis na localidade na qual se situa o Pólo. Também a descrição dos complexos residenciais para estadia dos empregados.

O Pólo se situa numa região central na lle de France, região que abriga empresas de diferentes portes, com uma grande concentração de empresas especializadas no segmento multimídia, audio-visual, efeitos especiais ou video-gamos, empresas de distribuição e edição, grupos industriais e laboratórios de pesquisas.

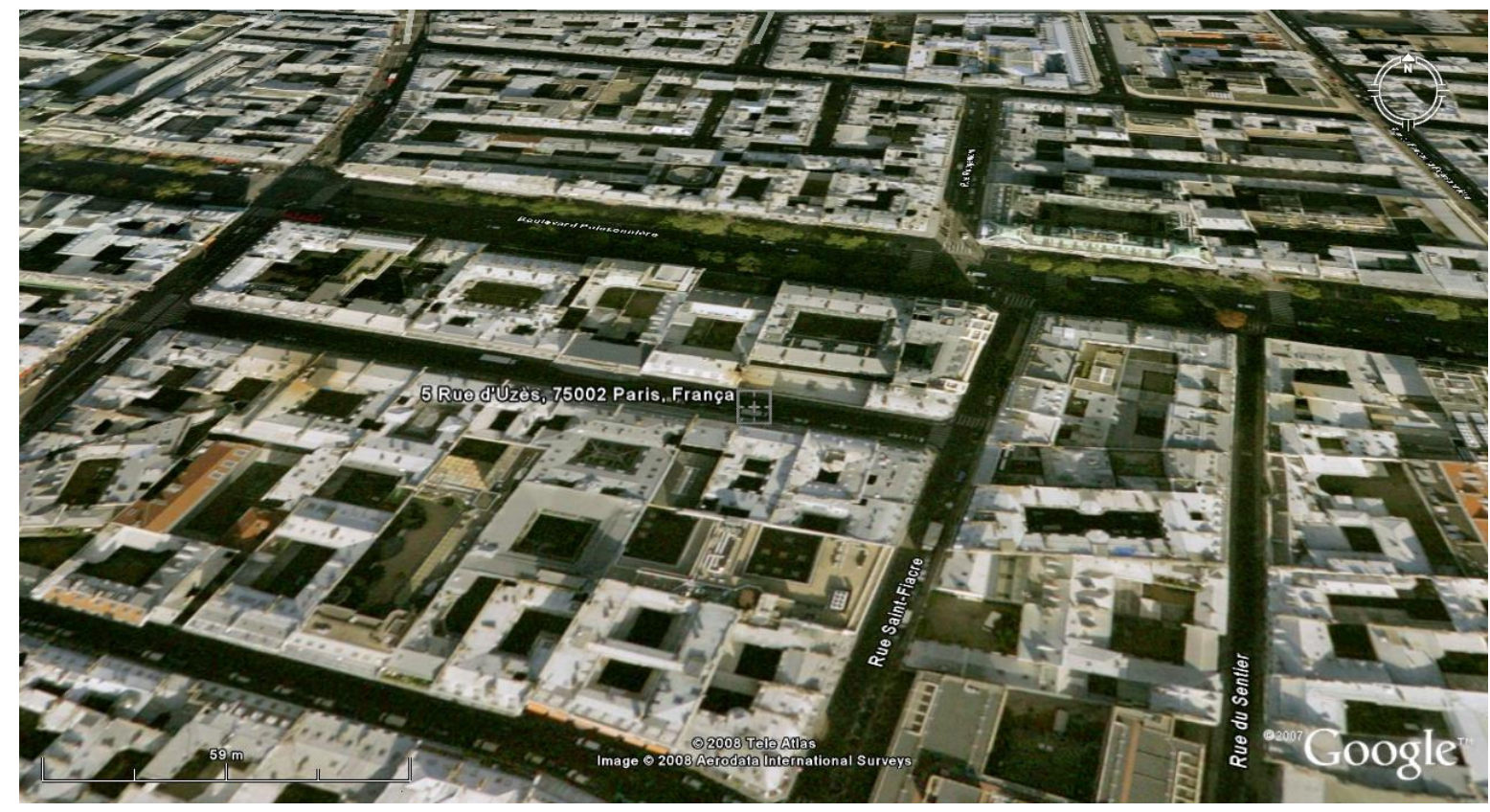

A produção doméstica da França está concentrada na lle de France, com mais de $75 \%$ da produção, segmentando por setores menores $65 \%$ das companhias de vídeo game, acima de $80 \%$ de folmes e produção audio visual e $91 \%$ das atividades de animação. 


\section{Descrição dos tipos de organização de empresas presentes no Pólo: as incubadoras, os agrupamentos de empresas?}

Eles não têm nenhuma relação com incubadoras mas tem empresas que estão relacionadas ao Pólo que estão incubadas. A Prefeitura de Paris está lançando um edital e eles vão se candidatar para tentar ter uma incubadora na área de tecnologia da informação e comunicação (vão fazer um consórcio com o Systematic, que é outro pólo que trata do segmento de Tecnologia da Informação).

\section{Descrição das estruturas de apoio a gestão do Pólo, envolvendo edificações a edificação de estruturas para certificação, propriedade intelectual, comércio exterior e outros serviços.}

O Pólo funciona com uma estrutura enxuta e tem o papel de articulador e apoio para os associados, sendo assim não desenvolveu uma estrutura física para lidar com determinadas funções e operações para as empresas.

Sendo assim, é sua finalidade prover boas condições para o desenvolvimento dos projetos e permitir o compartilamento de uma estrutura de qualidade para os participantes, todavia, não são desenvolvidas estruturas específicas para essa finalidade, todavia, é vislumbrada a otimização do espeço existente no contexto de um projeto.

\section{Descrição da estrutura de conhecimentos, com bibliotecas, comunidades de prática, tecnologia da informação (hardware, software, base de dados e pesquisa) e laboratórios de pesquisa e desenvolvimento.}

Considerando o compartilhamento de base de dados, o Pólo não disponibiliza nenhuma, a sua atuação limita-se a direcionar a necessidade de tilização a possíveis ofertas, ou seja, existe um mapeamento das ofertas de base de dados e essas são indicadas para o desenvolvimento de projetos específicos. Inexiste comunidades de práticas para troca de infomações entre os membros. As instituições de pesquisa e desenvolvimento possuem sua própria estrutura, as quais disponibilizam para os participantes dos projetos. 
Mission Pôles de Compétitivité en France

08 à 16 septembre 2008

Relatório de Entrevistas

ASTech
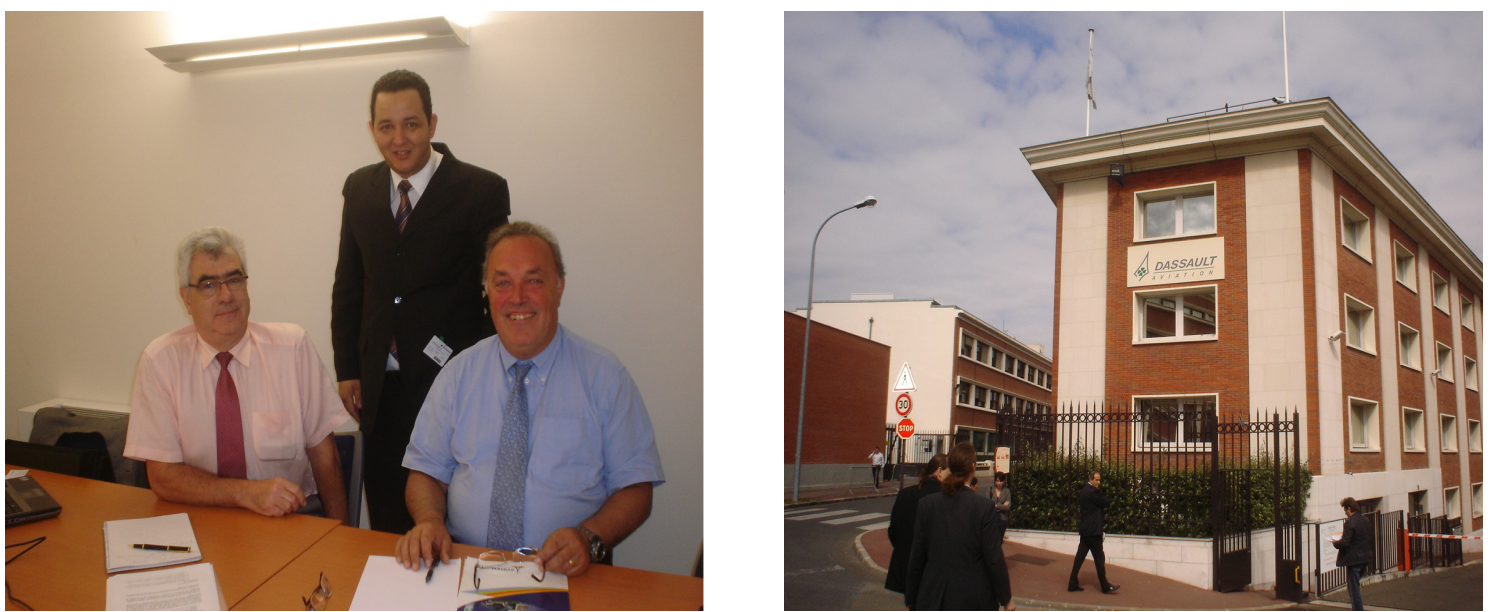

Pesquisadores:

Dra. Désirée Moraes Zouain - IPEN-USP/PGT-USP

Doutorando- Devanildo Damião - IPEN/PGT-USP 


\section{Contexto}

O relatório apresentado a seguir é parte da missão realizada na França para o desenvolvimento da pesquisa sobre Pólos de competitividade.

A entrevista realizada no dia 15/09/2008 tinha como objetivo colher as principais informações sobre o Pólo de competitividade. Os entrevistados foram o diretor Geral: Gérard Laruelle e o Vice Presidente Gérard Poirier, o encontro aconteceu na Empresa DASSAULT AVIATION (92214- Saint Cloud)

A coleta de informações foi estruturada a partir de um questionário qualitativo com enfoque em quatro dimensões: infra-estrutura, governança, estratégias e relação universidade-empresa.

\section{Apresentação do ASTech}

Considerando o domínio aeronáutico e espacial, a França é um líder mundial. Especificamente, a região da lle de France contribui para esta liderança nas áreas de aviação de negócios, transporte espacial, motor e equipamentos, graças a presença da indústria que é competitiva globalmente e seus parceiros.

Essa atividade intensiva em conhecimento foi desenvolvida com a presença de centros de excelência e centros de pesquisa que contribuam para desenvolvimento de toda a indústria francesa aeroespacial, fato que justifica a atuação do Pólo ASTech nessa região.

O Pólo é complementar a outros Pólos que desenvolvem atividades como $p$ AESE que abrange aviação comercial, satélites, estudos atmosféricos e sistemas embarcados e o Pégase da região Côte d'Azur (PACA) centrada em helicópteros. Além disso, o Paris ASTech Região tem uma Sistema de pólos complementares tecnologicamente o System@atic e o MOV'EO.

O Pólo tem duas missões principais, a primeira missão do pólo é prover projetos, por meio da articulação entre academia e iniciativa privada, a segunda é fortalecer o setor Aeroespacial na lle de France. 
Principais Caracteristicas

\begin{tabular}{|l|l|}
\hline Setores & $\begin{array}{l}\text { Aviação de negócios } \\
\text { Transporte espacial } \\
\text { Equipamentos e Motorização }\end{array}$ \\
\hline Regiões Principais & Ile de France \\
\hline Número de Empresas & Total de 60 empresas. \\
\hline Centros de Pesquisa & 15 centros de pesquisa e mais 20 centros de formação. \\
\hline Número de Empregos & 100.000 empregos na área de lle de France \\
\hline Principais atividades & Propulsão \\
& Materiais \\
& Energia a bordo \\
& Arquitetura de Veículos \\
\hline Projetos & THERMELEC - Management Thermique pour Electroniques \\
& de puissance embarquées; \\
& SEFORA - Smart Ema for operations in Rough \\
& Athmospheres Actionneur Életrique Intelligent \\
& Environnements Sévères. \\
& REBECCA - Reduction du Bruit Moteur avion par des \\
& Concepts technologiques Avancés. \\
& Tosca - Technologies pour l'opérabilité des Systèmes \\
& d'injection sur Chambres Aéronautiques. \\
\hline
\end{tabular}




\section{Questionário}

\section{$\Rightarrow$ Estratégia}

\section{Descrição das principais estratégias utilizadas pelos pólos para Internacionalização, referentes às ações para estimular o comércio exterior, as parcerias com as empresas internacionais, a representação internacional e dos autores.}

O foco dos pólos é a organização local/regional buscando aumentar a competitividade de determinada atividade setorial. Especificamente, a indústria aeroespacial precisa trabalhar em escala global, fato que demanda a inserção em mercados internacionais, os grandes grupos que atuam no Pólo ASTech, atuam em mercados bem estabelecidos internacionalmente.

O Pólo ASTech, é relativamente novo, com 18 meses de vida, nas propostas para seleção dos pólos, um dos critérios está focado na formalização de uma estratégia para internacionalização.

Como ações efetivas, pode-se citar a participação na missão para Pequim com duas pequenas empresas, uma que já tinha negócios lá e outra que gostaria de abrir este mercado, a embaixada facilitou os contatos. Todavia, ainda é notória a necessidade de avançar nessa área.

\section{Descrição dos organismos específicos e suas estruturas administrativas.}

A estrutura administrativa do pólo propõe grupos diferentes referentes a tomada de decisões, com grupos estratégicos para formular a mesma e grupos executivos que desenvolvem a operação. A estrutura está descrita na figura: 


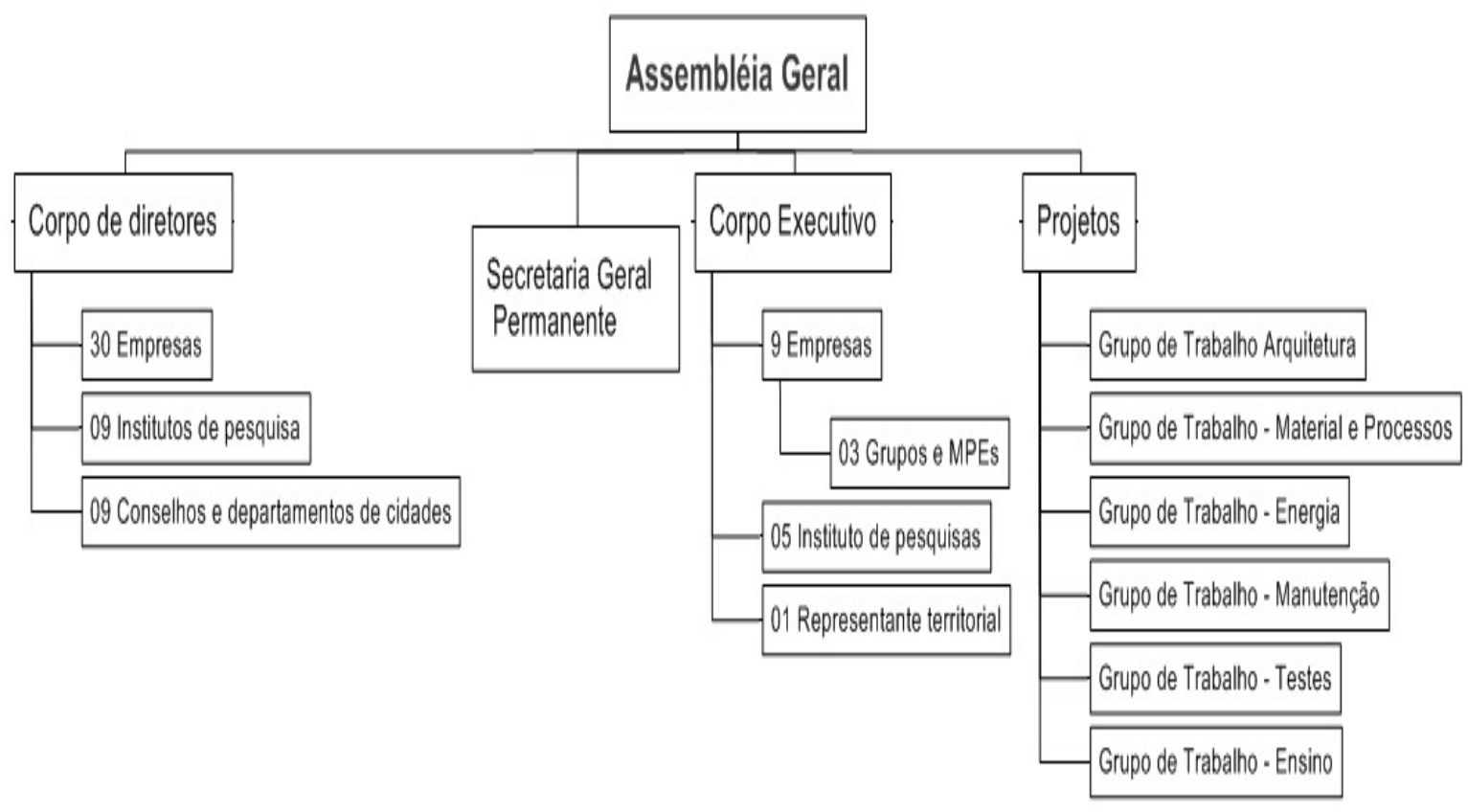

\section{Explicação detalhada e precisa de como é aplicada a estratégia.}

O Pólo tem duas missões principais que são desenvolver projetos de relevância e prover competitividade para o setor Aeroespacial. As atividades básicas do Pólo estão relacionadas com o desenvolvimento de projetos, para isso, atualmente conta com uma equipe de animação de quatro pessoas que vai aumentar para sete, sendo uma delas o diretor Laruelle, essa equipe é assalariada.

$\mathrm{Na}$ atuação com as para as PMEs, eles oferecem serviços de organização para montar projetos de pesquisa, financiamentos, de forma geral ajudam a empresa se organizar para que possam participar dos projetos.

\section{Como são desenvolvidas as operações das atividades do Pólo, Quem faz o que? Comentários? Os elementos das atividades e atribuição devem ser identificados.}

A figura jurídica do Pólo é uma associação que está estruturada em colégios com diferentes representações, a missão e objetivos da associação são:

- Organizar e assegurar a governança do Pólo;

- Assegurar a animação tecnológica a cada temática;

- Seleção de projetos cooperativos a montante consistente com os objetivos definidos; 
- Estabelecer uma relação permanente e duradoura com os financiadores na facilitação, avaliação e análise dos projetos de pesquisa colaborativos e desenvolver ações para mobilizar o apoio dos mesmos;

- Envolver os principais parceiros do pólo, notadamente as PME inovadoras e outors organismos que representam o pólo nos projetos de cooperação.

- Promover a execução conjunta com o seu centro operacional ambiente;

- Promover visibilidade ao Pólo;

- Apresentar relatórios sobre a adequação, eficiência e eficácia das ações.

A associação possuí um corpo de Diretores com representaçãoes da academia, empresas e entidades locais, essa associação define as estratégias para o Pólo, abaixo encontra-se um corpo executivo que tem por finalidade operar as atividades do Pólo, esse corpo conta com uma equipe de animação (secretariado executivo), que vai aumentar para cerca de 7 pessoas de forma que possam atuar de forma mais específica.

As atividades de pesquisa são conduzidas por especialistas alocados em grupos de trabalhos técnicos.

\section{Como são desenvolvidas as estratégias de atração de empresas? Existe um organismo formal? Em caso positivo, qual é a estrutura? As empresas respondem aos chamados públicos? São adicionadas em grupos? Elas se auto ajudam?}

O processo de atração de empresas, atualmente fica na esfera de tratativas do governo. As estâncias de governo das cidades têm instrumentos adequados para atrai empresas, como estímulos fiscais e urbanísiticos. A ARD (representação coletiva territorial) para a região parisiense possui políticas para atrair as empresas para a região e as ajudam a atuar no exterior. Outra estrutura, todavia de característica setorial, a SYMPAV - sindicato misto aeronáutico, também desenvolve ações para atração de empresas, além das agências de desenvolvimento, . Na cidade de Paris existe o Paris Dévélopement (Agência de Desenvolvimento de Paris). 


\section{Governança}

6. Envolve a caracterização dos atores presentes no Pólo, a forma de interação, também a participação das empresas nas decisões.

As empresas participam das decisões nos Pólos por meio de representações na Associação e nos diferentes conselhos, que desenvolvem reuniões para tomadas de decisões e definição de estratégias. Na sua estrutura de associação, existe a figura do colégio de negócios que é representado por empresas, especificamente, na sua estrutura administrativa a representação das empresas está em diversas esferas, tais como no corpo de diretores, diretores executivos e demais organismos.

A seguir seguem as principais empresas que participam do Pólo:

\begin{tabular}{ll}
\hline & Empresas \\
\hline & DASSAULT AVIATION \\
& EADS-Astrium \\
SNECMA Engenharia Aérea & Landing Gears \\
& Messier-Bugatti \\
& Messier-dowt \\
& Thales AES \\
& SAGEM DS \\
& Goodrich \\
Hispano-Suiza
\end{tabular}

Figura 0-4: Empresas do Pólo ASTech. 


\section{Considerando as diferentes esferas de participação, qual é o poder de influência das instituições.}

A associação que administra o Pólo tem colégios em diferentes setores, sendo negócios, científico e de representação cívil, no seu desdobramento administrativo, observa-se que a maior parcela de diretores é representativa do tecido empresarial. A lógica para isso, encontra-se no segmento de atividade desenvolvido, caracterizado pela governança da cadeia produtiva por grandes empresas, especificamente a Dassault e a EADS - Astrium e a Safram.

\section{Descrição das políticas fiscais, urbanísticas do pólo, considerando as esferas regionais, locais, governamentais e setoriais.}

A organização do polo de competitividade não participa da formulação de políticas, todavia atua na interface com os representantes regionais e locias departamentais no que concerne aos subsídios de projetos de pesquisa e a ajuda para o funcionamento do pólo (para pagar a equipe, por exemplo). Na formulação de políticas a atuação é da Camara de Comércio, a qual tem conhecimento das demandas do Pólo.

\section{Descrição da Estrutura hierárquica dos Pólos, incluindo os aspectos jurídicos, a formalização e o poder de decisão.}

O Pólo está estruturado com a formalização de uma associação. A associação é constituída por pessoas física ou sociedades divididas em três esferas:

- O colégio de negócios.

- O colégio dos órgãos e instituições públicas de pesquisa, ensino superior e de pesquisa.

- O colégio local.

Os membros são divididos em quatro categorias:

1. Membros fundadores: os membros que iniciaram o projeto, ou seja, Safran, Dassault Aviation, a $\quad$ Astrium $\quad$ Space $\quad$ Transportation (ex: EADS-ST), o Centro Nacional d'Etudes Spatiales (CNES), o National Estudos e Pesquisas Aeroespaciais (ONERA), o Centro Nacional de Recherche Scientifique (CNRS) e da Ecole des Mines de Paris, acompanhada pelo seu advogado SOFRED e da Agência Regional Desenvolvimento lle-de-France, 
2. Membros Ordinários: são membros da associação admitidos em conformidade com os princípios definidos, nomeados para a participação em projetos de cooperação.

3. Membros associados: as comunidades locais que contribuam para apoiar o desenvolvimento do pólo.

4. Membros convidados: elas contribuem para o financiamento ou o desenvolvimento do Pólo, como Prefeitura da Região e as agências de desenvolvimento econômica e financeira, envolvidas na governança do pólo sem voz e sem participação nas cotas de direitos.

\section{$\Rightarrow$ Relação Universidade-empresa}

\section{Descrição do contexto científico e tecnológico presente nos pólos, envolvendo as} universidades, escolas técnicas e outros, com a especialização de cada um e sua representatividade acadêmica, do ponto de vista do número de mestres e doutores.

O pólo participa apenas da negociação, na questão de buscar parceiros para desenvolver os projetos, ou seja, somente na perspectiva da articulação, não atua na questão de contratação.

O grande trabalho do Pólo é na animação temática. Cada um dos domínios temáticos dos pólos é animado por técnicos especializados (geralmente professores). Eles atuam na organização de reuniões periódicas para discutir Road maps, discussão dos projetos, gargalos de projetos - essas atividades não são formalizadas.

O governo Francês determinou que as Universidades devem ampliar as receitas oriundas de outras fontes, não somente as públicas, esse aspecto foi importante pois motivou as universidades a desenvolverem parcerias e trabalhos conjunto.

\section{Descrição dos principais mecanismos de apoio a relação universidades-empresa presente no Pólo, incluindo organismos públicos e privados.}

Não são utilizados e desenvolvidos mecanismos e instrumentos específicos para o relacionamento universidade-empresas. O Pólo articula o relacionamento das entidades, todavia não participa das negociações entre universidades e pesquisadores. Observa-se que existe uma demanda das universidades para participar dos projetos, sendo notada inclusive um aspecto de competição entre elas. 
12. Descrição dos mecanismos de apoio segmentados por atividades, como: propriedade intelectual, comércio exterior, certificações de qualidade, etc.

Considerando a questão da propriedade intelectual, o Pólo não atua diretamente, a sua atuação é indicativa na perspectiva de direcionar os participantes dos projetos para o site do governo francês que desenvolveu uma metodologia para auxílio. Observa-se em outros pólos que a prática de oferecer especialistas em Propriedade Intelectual pela coordenação dos pólos. Todavia, existe uma sensibilização que para alavancar a competitividade da indústria francesa nesse sgmento será necessário oferecer alguns serviços para as PMEs.

Infra-estrutura

13. A descrição das estruturas disponíveis relacionadas à logística externa do Pólo, envolvendo os transportes e serviços públicos disponíveis na localidade na qual se situa o Pólo. Também a descrição dos complexos residenciais para estadia dos empregados.

A importância setorial do setor aeroespacial em lle-de-França é uma realidade no mundo todo, sendo que a região será reforçada pela presença de seu Núcleo de Competitividade, Paris ASTech Região. Os grandes grupos como Dassault Aviation, Safran, Astrium, CNES, a ESA (European Space Agency), transformam o ambiente da lle-de-França num ambiente amplamente favorável na aventura aeroespacial. 


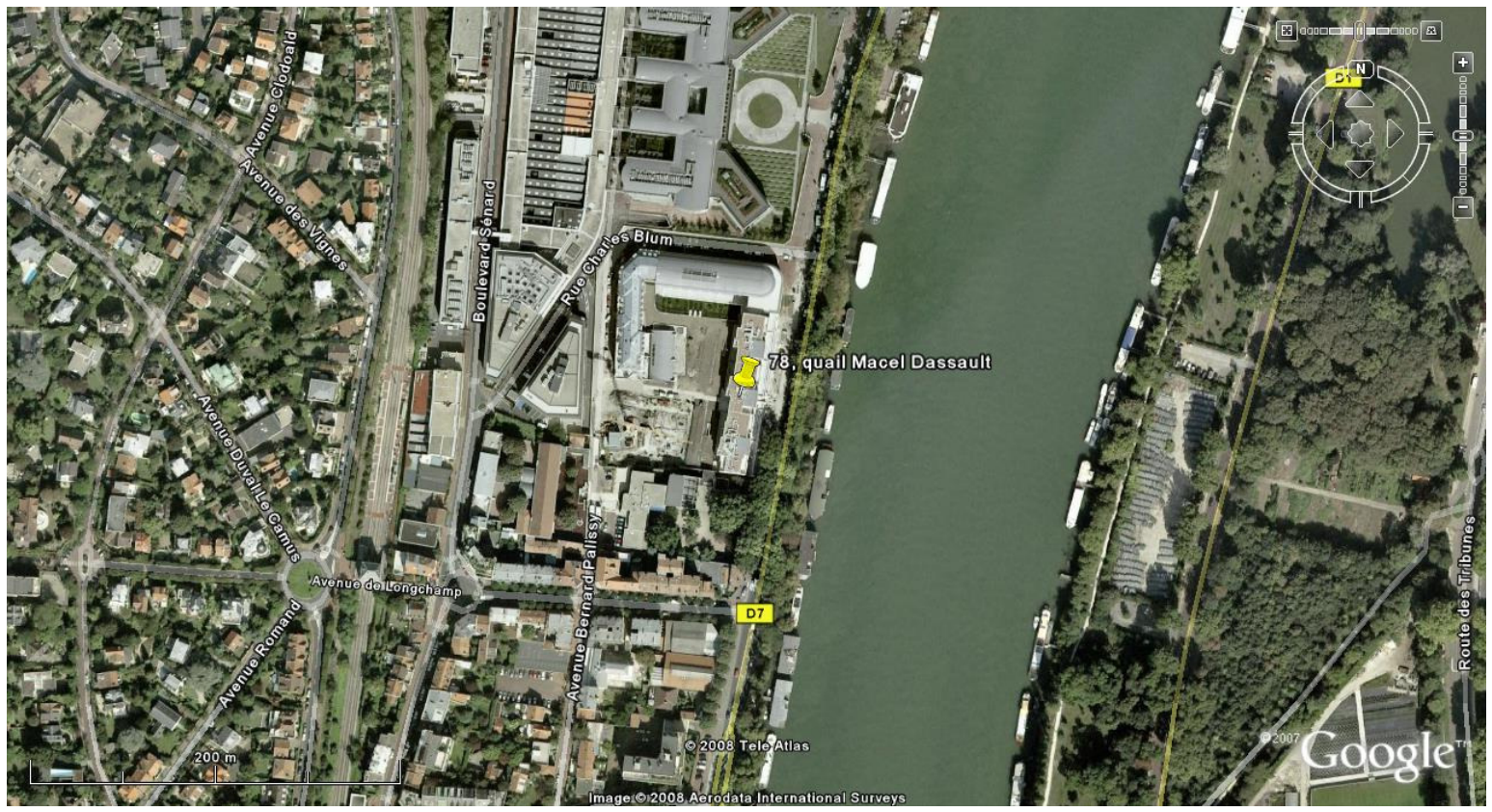

\section{Descrição dos tipos de organização de empresas presentes no Pólo: as incubadoras, os agrupamentos de empresas?}

Relacionado ao centro incubador, o Astech não trabalha com as incubadoras, no entanto, em criar alguma estrutura mais específica para as necessidades das empresas integrantes do pólo. Todavia, um dos principais objetivos do Pólo é a de ajudar as PMEs, inserindo-as em projetos em colaboração, tais como projetos financiados ppor órgãos externos como FUI, ANR, FP, que permitirá melhorar o estágio da indústria aeroespacial francesa.

Os níveis de excelência esperado pelos principais investidores internacionais exigem a necessidade de preparar as PMEs, a fim de satisfazer as exigências de competitividade tecnológica (processo industrial competitivo), qualidade (do produto, mas também no tempo) técnica (habilidades dos empregados e subcontratados) e de competitividade económica.

\section{Descrição das estruturas de apoio a gestão do Pólo, envolvendo edificações a edificação de estruturas para certificação, propriedade intelectual, comércio exterior e outros serviços.}

O Pólo funciona com uma estrutura enxuta e tem o papel de articulador e apoio para os associados, sendo assim não desenvolveu uma estrutura física para lidar com determinadas funções e operações para as empresas. 
16. Descrição da estrutura de conhecimentos, com bibliotecas, comunidades de prática, tecnologia da informação (hardware, software, base de dados e pesquisa) e laboratórios de pesquisa e desenvolvimento.

O acesso aos instrumentos do conhecimento, são possibilitados no desenvolvimento dos projetos, a participação nos projetos permite o acesso as informações que estão armazenadas em bancos de dados, bibliotecas e outros. O pólo ASTech Paris utiliza-se de ferramentas de rede de conhecimentos, ferramentas tecnológicas e inteligência competitiva para a proposição e desenvolvimento de projetos que envolvam os avanços tecnológicos em parceria com os atores (PMEs ou grandes empresas) e laboratórios de pesquisa. 


\section{Mission Pôles de Compétitivité en France}

\section{8 à 16 septembre 2008}

\section{Relatório de Entrevistas}

System@tic
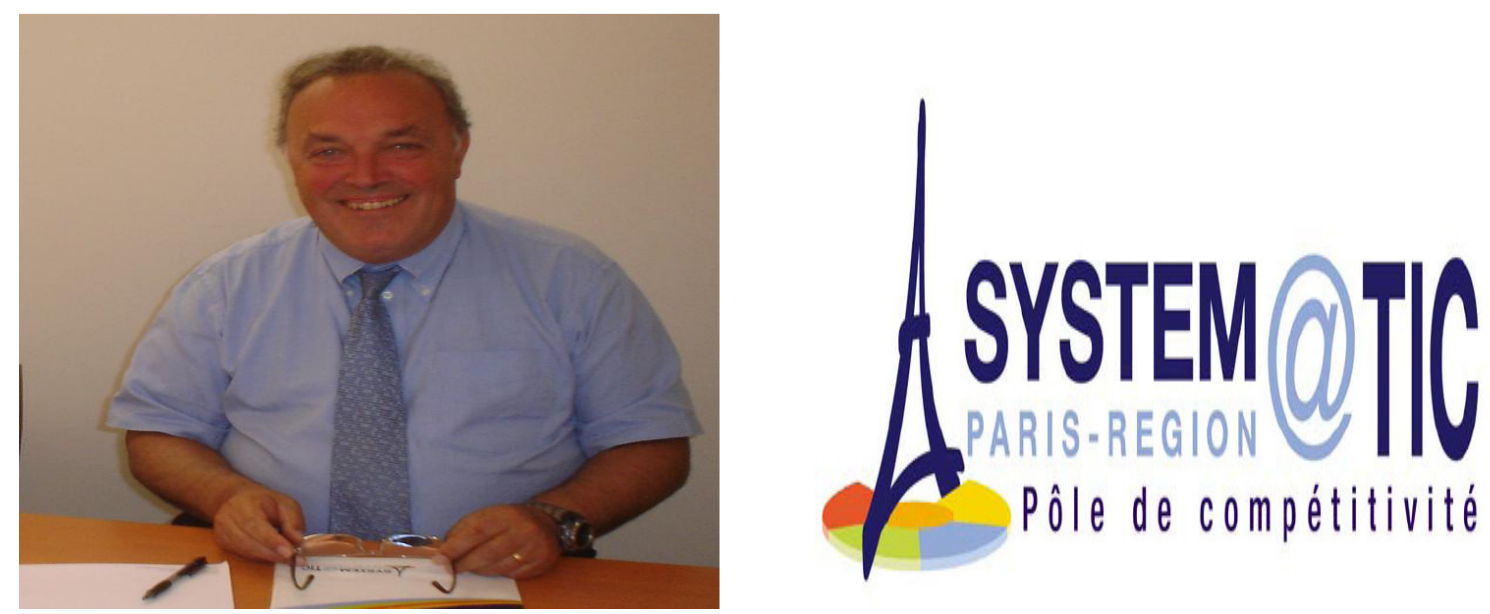

Pesquisadores:

Doutorando- Devanildo Damião - IPEN/PGT-USP

Dra. Désirée Moraes Zouain - IPEN-USP/PGT-USP 


\section{Contexto}

O relatório apresentado a seguir é parte da missão realizada na França para o desenvolvimento da pesquisa sobre Pólos de competitividade.

A entrevista realizada no dia 15/09/2008 tinha como objetivo colher as principais informações sobre o Pólo de competitividade System@tic. O entrevistado foi o Presidente para o domínio Systems Design e Development Tools Presidente Gérard Poirier, o encontro aconteceu na Empresa DASSAULT AVIATION (92214- Saint Cloud)

A coleta de informações foi estruturada a partir de um questionário qualitativo com enfoque em quatro dimensões: infra-estrutura, governança, estratégias e relação universidade-empresa.

\section{Apresentação do System@tic}

É um Pólo mundial, localizado na Região de lle de France, focado em sistemas eletrônicos complexos, com utilização no direcionamento, supervisão, regulação e controle de instalações sofisticadas. Abrange atividades de comércio, finanças, saúde, segurança, transporte e energia.

O Pólo posiciona-se como líder industrial nas áreas de soluções para conceitos, gestão e manutenção de sistemas computacionais complexos, em 4 mercados-alvo, descritos na seqüência:

- Telecomunicações;

- Automotiva e Transporte,

- Segurança e Defesa,

- Ferramentas de Projetos e desenvolvimento de sistemas.

Os seus objetivos principais do Pólo são:

- Desenvolver a atividade econômica e o emprego;

- Criar industriais e empresas de serviços: definir o objetivo de quinze com elevado potencial de crescimento por ano;

- Seleção de pesquisadores, atraindo especialmente os centros de $P$ \& $D$ empresas internacionais neste domínio: recrutamento objetivo de 4000 cientistas por ano. 
Principais Características

\begin{tabular}{|c|c|}
\hline Setores & $\begin{array}{l}\text { Controle de tecnologias-chave (óptica, eletrônica e software) } \\
\text { e sistemas complexos nos seguintes temas: } \\
\text { - Telecomunicações; } \\
\text { - } \quad \text { Automóveis \& Transporte; } \\
\text { - Segurança e Defesa; } \\
\text { - } \quad \text { Ferramentas de desenho e desenvolvimento de sistemas; } \\
\text { - Software Livre }\end{array}$ \\
\hline Regiões Principais & Ile de France \\
\hline Número de Empresas & $\begin{array}{l}\text { Total de } 180 \text { empresas, } 100 \text { MPEs } \\
\text { Grandes empresas - Alcatel, Altis Semiconductor, Bull, } \\
\text { Cegelec, Dassault Avion, EADS, EDF, France Telecom, } \\
\text { Motorola, Renault, Sagem, Thales, Valeo. } \\
\text { MPEs - Adise SAS, Aevix, Amesim, Bertin Technologies, } \\
\text { CAPS Entreprise, CGG, CIMPA, Comsis, Cril Telecom Software } \\
\text { SA, Esterel Technology, ESI Group, Euraltech, GridXpert, } \\
\text { Haption, Ilog, Intercontrole, Kylia, M2M, N2soft, Newphenix, } \\
\text { Ommic, Picogiga SAS, Pyramis, Resonate, Samtech, Softeam, } \\
\text { Trialog, Trusted Logic, Vecsys, Virtools }\end{array}$ \\
\hline Centros de Pesquisa & $\begin{array}{l}134 \text { centros de pesquisa e mais } 44 \text { centros de formação. } \\
\text { CNES (Centre National des Etudes Spatiales - Space } \\
\text { Research Center), Ecole Centrale Paris, Polytechnique, HEC, } \\
\text { INRIA (French National Institute for Research in Computer } \\
\text { Science and Control), Supelec (Electrical Engineering and } \\
\text { Computer Science), etc. }\end{array}$ \\
\hline Número de Empregos & 706270 empregos na área de lle de France \\
\hline Principais atividades & $\begin{array}{ll} & \text { Sistemas embarcados } \\
\text { - } & \text { Infra-estrutura distribuída } \\
\text { - } & \text { Interface humana } \\
\text { - } & \text { Softwares } \\
\text { - } & \text { Eletrônica } \\
\text { - Otica }\end{array}$ \\
\hline Projetos & $\begin{array}{l}\text { Foram desenvolvidos } 93 \text { projetos, dentro de } 5 \text { atividades } \\
\text { principais distribuídas nos grupos de Trabalho: } \\
\text { Automotivo e Transporte; Free \& Open Source Software; } \\
\text { Segurança \& Defesa; Projeto de sistemas e Desenvolvimento de } \\
\text { ferramentas, Telecomunicações. }\end{array}$ \\
\hline
\end{tabular}

Figura 0-5: Características do Pólo 
O system@tic foi um dos primeiros pólos a ser criado, o mesmo conta atualmente com 101 projetos de pesquisa nos cinco grupos temáticos nos quais está organizado, com foco em inovações de ruptura que possam representar um referencial para as empresas em termos de mercado.

\section{Questionário}

\section{$\Rightarrow$ Estratégia}

\section{Descrição das principais estratégias utilizadas pelos pólos para Internacionalização, referentes às ações para estimular o comércio exterior, as parcerias com as empresas internacionais, a representação internacional e dos autores.}

O desenvolvimento do Pólo responde a uma necessidade de dotar as regiões francesas de maior competitividade, para tal, foram traçadas metas, as quais são destacadas:

- Atrair capital e talento para a região de Paris;

- Ajudar os laboratórios e as empresas a exportarem os seus produtos e patentes;

- Enfrentar o desafio da crescente competição global:

- Os grandes integradores de sistemas (E.U.A., Europa, Ásia);

- Desenvolvimento de softwares de baixo custo (China, Índia, África do Norte)

- Novos players no domínio dos sistemas incorporados (China, Índia, etc.)

Confrontado com os seus concorrentes internacionais, o System@tic desfruta de visibilidade e atratividade para a Região, em parte devido:

- Forte rede industrial e presença de líderes do mundo acadêmico;

- Uma comunidade científica dedicada às questões abrangidas pelo Pólo;

- Série de programas acadêmicos do mundo, proporcionando a captação de estudantes estrangeiros;

- Presença de um líder europeu do mercado regional no domínio dos sistemas complexos;

- Equipamentos de cálculo intensivo únicos na Europa;

- Cooperação entre os membros do Pólo e os seus parceiros europeus;

- Visibilidade internacional dos seus membros através dos centros de investigação situados no exterior (China, E.U.A., Índia, etc.);

- Notoriedade e atratividade de Paris;

- Conexões com outros conglomerados nacionais e internacionais; 
Com o intuito de reforçar a competitividade européia e para implementar programas complementares de $\mathrm{P} \& \mathrm{D}$, é necessário ligar o sistema francês com iniciativas européias, sendo que alguns membros do Pólo já estão envolvidos em redes européias, tais como as plataformas tecnológicas européias (ARTEMIS eMobility, etc.) e agregados EUREKA (ITEA MEDEA +, etc.) Além disso, alguns membros também estão envolvidos em programas de $P \& D$ da Comissão Européia (Programa-Quadro de IDT).

O Pólo pretende desenvolver parcerias com outros pólos e clusters europeus ,para alcançar este objetivo, atualmente conta com estas cooperações existentes entre alguns dos seus membros e estas redes européias.

O alemão SafeTRANS cluster na área da segurança embarcados em sistemas de transportes, o System@tic e o juntamente com a AESE tem desenvolvido uma parceria estratégica para a instalação do Instituto Europeu para a Complex Embedded Systems Engineering (EICOS), no âmbito do ARTEMIS.

Outra parceria desenvolvida é com a com a holandesa Point-Um, a qual é um cluster centrado em sistemas integrados e micro-nano tecnologia..

\section{Descrição dos organismos específicos e suas estruturas administrativas.}

A estrutura administrativa do pólo propõe grupos diferentes referentes à tomada de decisões, com grupos específicos. O Processo de trabalho envolve passos e metodologias desde a geração da idéia até o desenvolvimento completo do relatório de proposta, necessitando uma intensa interação com as equipes do Pólo. 


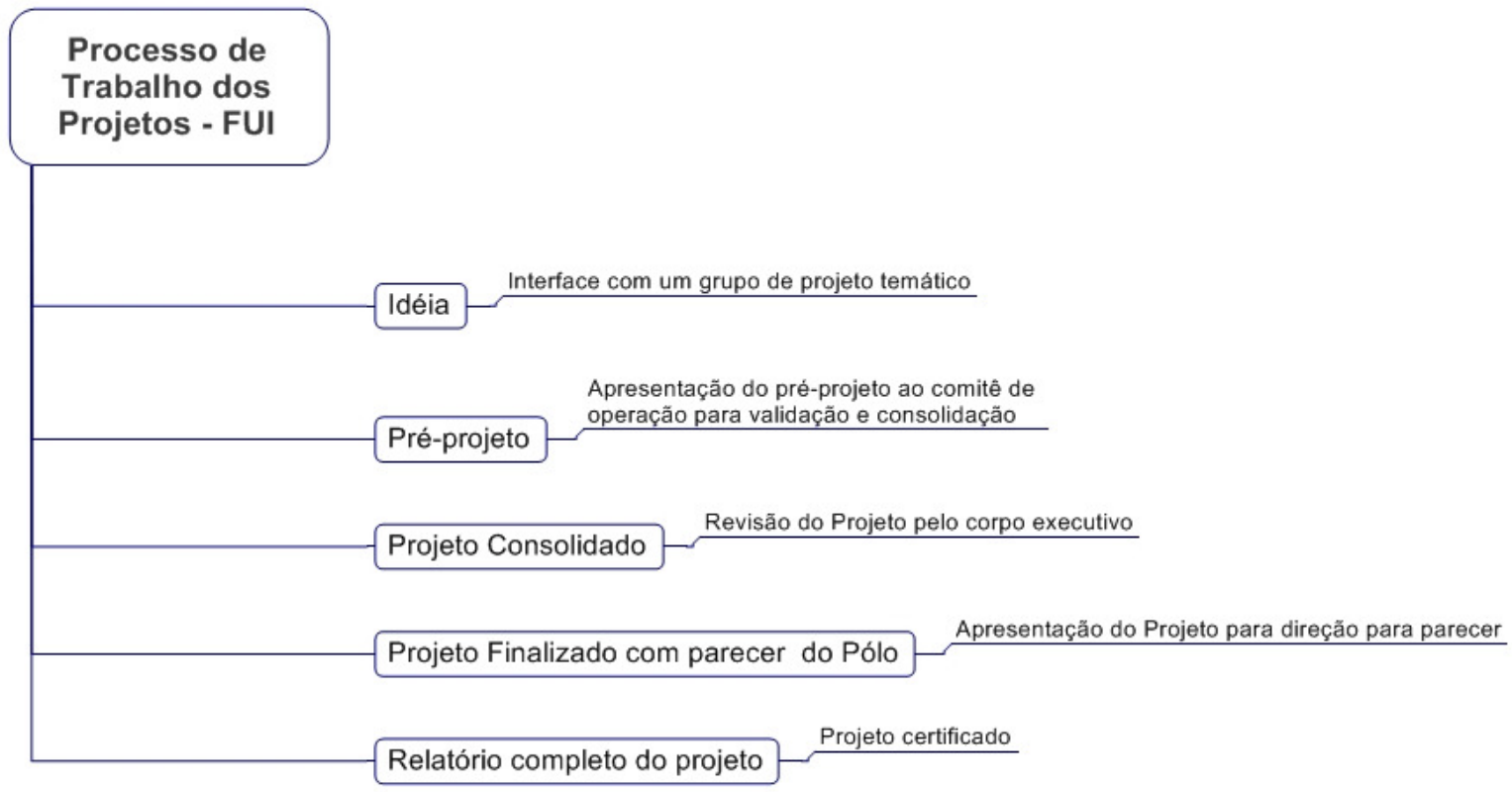

Figura 0-6: Processos para projetos do Fundo Único Interministerial.

\section{Explicação detalhada e precisa de como é aplicada a estratégia.}

A estrutura operacional do Pólo é desenvolvida pela Secretaria Permanente, a qual é um grupo formado por 13 profissionais com um orçamento de 1,7 milhões de Euros anuais, provenientes de $40 \%$ do estado, $40 \%$ de coletividades territoriais e $20 \%$ dos membros da Associação.

As atividades da Secretaria são descritas a seguir:

- Organização da Governança

- Animação de grupos temáticos e compartilhamento da visão estratégica;

- Rapidez e certificação de trabalhos de P\&D

- Promoção e visibilidade do Pólo;

- Apoio as PMEs;

- Parcerias no nível europeu e internacional;

- Inteligência Econômica;

- Desenvolvimento de competências.

4. Como são desenvolvidas as operações das atividades do Pólo, Quem faz o que? Comentários? Os elementos das atividades e atribuição devem ser identificados. 
A figura jurídica do Pólo é uma associação que está estruturada administrativamente em colégios com diferentes representações. A estrutura de trabalho dos Pólos são os projetos.

Para desenvolver projetos com boas perspectivas de alcançar financiamentos existe a necessidade de dotá-los com alto padrão de qualidade, incluindo especialistas em diferentes temas. No caso do presente Pólo são: automobilístico e transportes, telecomunicações, segurança e defesa e instrumentos de concepção e desenvolvimento de sistemas.

Cabe a um grupo específico do pólo fazer um mapa de pesquisadores com potencial de integrar os projetos, ou seja, promover a animação do pólo, interagir com a comunidade, integrar novos parceiros, definir roadmaps estratégicos, e a emergência dos projetos de Pesquisa e Desenvolvimento - P\&D.

\section{Como são desenvolvidas as estratégias de atração de empresas? Existe um organismo formal? Em caso positivo, qual é a estrutura? As empresas respondem aos chamados públicos? São adicionadas em grupos? Elas se ajudam?}

O Pólo vem atraindo empresas em diversos segmentos, sendo que no contexto das PMEs, o número de empresas tem crescido de forma mais acelerada desde a inauguração.

O percentual de crescimento das PMEs situa-se na faixa de $68 \%$ em três anos, evidenciando a alta atratividade que o Pólo apresenta, considerando as grandes empresas, o crescimento é menor, todavia, altamente relevante na perspectiva de ser atrativo, proporcionando a adesão de 19 novas empresas.

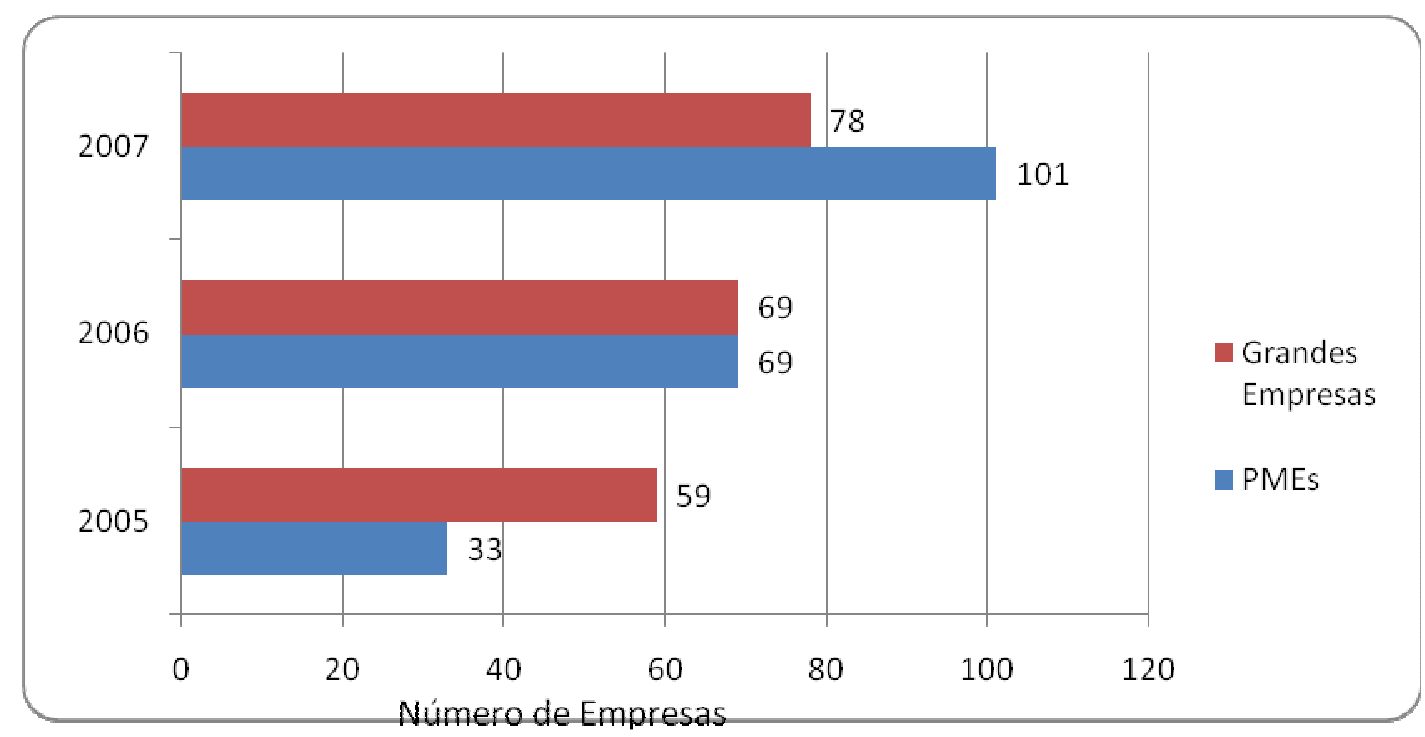

Figura 0-7: Número de Empresas no Pólo 


\section{Envolve a caracterização dos atores presentes no Pólo, a forma de interação, também a participação das empresas nas decisões.}

O Pólo System@tic prevê em seu estatuto que a presidência do Pólo sempre será ocupada por um industrial, fato que garante a visão da indústria presente nas decisões estratégicas. A governança do Pólo prevê a representatividade de diversas esferas da sociedade, a seguir serão nomidas as representação:

Grandes empresas: Airbus, Alcatel $\square$ Lucent, ALSTOM Transport, Altis Semiconductor, ARCHOS, Arc Informatique, Atos Origin, Axlog, AXORYS, Bertin Technologies, Bull, CIMPA, Compagnie Générale de Géophysique, CS, Dassault Aviation, Dassault Systèmes, Delphi, Draka Comteq, EADS, EDF, ESG France, ESI Group, France Telecom, Freescale Semiconductor, Frontoo, Fujitsu Systems Europe, Gemalto, Hispano Suiza, HP, ILOG, IMAGINE, ISIS $\square$ MPP, Johnson Controls, Martec, MBDA, Messier $\square$ Dowty, Motorola, NetTest, Oberthur Card Systems, Open CASCADE, Picogiga International, PSA, RATP, Renault, Renault Trucks, SAFRAN, Siemens VDO Automotive, SNCF, SNECMA, SODERN, STMicroeletronics, SVS, TDF, Thales, Thomson, United Monolithic Semiconductors, Valeo, Virtools, Visteon, etc.

\section{Pequenas e Médias Empresas:}

3S PHOTONICS, Adise, Aonix, APPEDGE, ARION, Arithmetic Components, Artenum, Arteris, ATEJI, AUD'System, BluWan, Cabinet Bensoussan, CAPS Entreprise, Cepid Infrared Systems, CityPassenger, COMSIS, Cryptolog International, CYBEL, Deveryware, Dictao, Distene, DOTMOBIL, E $\square$ Blink, Egide, Egylis, ELAPSE, Entr'ouvert, ERCOM, ESO Technologies, Esterel Technologies, Eurobios, EURODECISION, EVITECH, FOR SUP, GTI6, Haption, HGH Systèmes Infrarouges, idCAD Consulting, Intempora, KarmicSoft, Knowledge Inside, Kylia, LASCOM, Legos, LHERITIER, LOGILAB, LS TELECOM SAS, Lyria, M2000, m2m, MASA Group, MEDIT, MondiTech, N2NSOFT, NewPhenix, Nomia, Obeo, OMMIC, Open Wide, Oxalya, PDF Solutions, PragmaDev, PrismTech, PY AUTOMATION, REALVIZ, Resonate MP4, Samtech, Scaleo Chip, Science Pratique, SEQUANS Communications, SERMA Ingénierie, SESTREAM, Sherpa Engineering, Sinovia, SISPIA, Softeam, Spring Technologies, STAR $\square$ APIC, SYSTEREL, SYSTREL, TechViz, Tiga Technologies, TNI $\square$ Software, Transatel, TRIALOG, Trusted Logic, ValoTec, VECSYS, VIERLING Communication, VirtualLogix, Webdyn, etc.

\section{Representações Locias, regionais, nacionais e de Estado}

Urban communities of Arc $\square$ de $\square$ Seine, Cergy $\square$ Pontoise, Hauts de Bièvres, Plateau de Saclay, Saint $\square$ Quentin $\square$ en $\square$ Yvelines, Seine $\square$ Essonne, Versailles $\square$ Grand Parc and Arpajonnais ; the City of Paris ; Local Governments of 5 Essonne, Hauts $\square$ de $\square$ Seine, Val d'Oise and Yvelines ; Regional Government of Paris/lle $\square$ de $\square$ France ; the State Governement.

\section{Cantros de Pesquisa e Estabelecimentos de Educação Superior}


CEA, CNAM, CNES, CNRS, CSTB, Digiteo Labs, Ecole Centrale Paris, Ecole des Mines de Paris, ENS de Cachan, Ecole Polytechnique, ENSAM, ENSEA, ENSTA, Genopole®, GET/INT, Groupe HEC, IFP, INRETS, INRIA, Institut d'Optique Graduate School, Léonard de Vinci Engineering School, ONERA, PRES UniverSud Paris, Supélec, Teratec, Université de Cergy $\square$ Pontoise, Université d'Evry Val d'Essonne, Université Paris Dauphine, Université Pierre et Marie Curie, Université Paris 7 $\square$ Denis Diderot, Université Paris $\square$ Sud 11, Université Paris 12 Val de Marne, Université de Technologie de Compiègne, Université de Versailles Saint $\square$ Quentin $\square$ en $\square$ Yvelines.

\section{Entidades de desenvolvimento econômico}

Agence pour l'Economie en Essonne (Agency for the Economy in Essonne); Agence Régionale de Développement (Paris Region Economic Development Agency); Comité d'Expansion Economique du Val d'Oise (Val d'Oise Economic Expansion Committee); Caisse des Dépôts et Consignations d'lle-de-France (Consignments and Loan Fund of the Paris Region); Chambre Régionale de Commerce et d'Industrie d'lle-de-France (Regional Chamber of Commerce and Industry); the Essonne, Paris and Yvelines-Val d'Oise chambers of Commerce and Industry; OSEO (institution supporting SMEs); National Research Agency.

A seguir um descritivo das 10 maiores empresas, considerando o critério de número de funcionários.

\begin{tabular}{ll}
\hline & \\
\hline 1 & SNCF \\
2 & FRANCE TELECOM \\
3 & EDF \\
4 & PSA-DAF \\
5 & RENAULT DIF \\
6 & REGIE AUTONOME DES TRANSPORTS PARISIENS \\
7 & RENAULT TRUCKS \\
8 & SNECMA MOTEURS \\
9 & DASSAULT AVIATION \\
10 & ALCATEL CIT \\
\hline
\end{tabular}

Figura 0-8: Principais Empresas do Pólo System@aric

FONTE: Sessi - recensement auprès des pôles, Insee Ficus 2005

7. Considerando as diferentes esferas de participação, qual é o poder de influência das instituições. 
A governança do Pólo está estruturada para receber participações de diferentes setores e assim aumentar a sua competitividade. Atualmente a diretoria consta de 46 membros, distribuídos de acordo com a

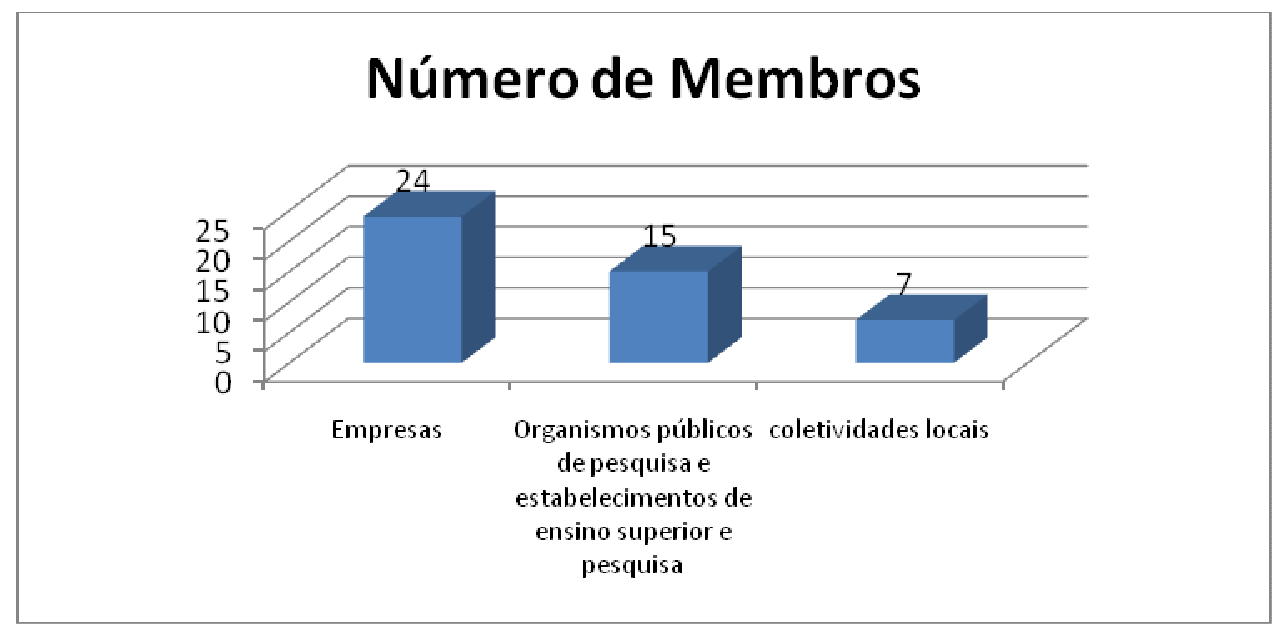

Figura 0-9: Número de membros no corpo de diretores.

\section{Descrição das políticas fiscais, urbanísticas do pólo, considerando as esferas regionais, locais, governamentais e setoriais.}

O Pólo Systema@tic é um Pólo com alta representatividade na região de lle de France, gozando de alto prestígio e com atuação, no Pólo estão presentes 12 coletividades territorias, representando a região de lle de France, cinco departamentos franceses e seis comunas de aglomeração.

Considerando que o Pólo foi estruturado a partir da existência de um forte cluster na região de Ile de France, na perspectiva local, não ocorreu grandes arranjos em termos de incentivos, todavia numa perspectiva de estado, o grande motor para o seu desenvolvimento são os recursos advindos dos Fundos Únicos Interministeriais, da Agência Nacional de Pesquisa e da OSEO.

\section{Descrição da Estrutura hierárquica dos Pólos, incluindo os aspectos jurídicos, a formalização e o poder de decisão.}

A figura jurídica do Pólo é identica os dos demais, ou seja, é uma associação sem fins lucrativos. $O$ arranjo administrativo envolve a formação de colégios que representam diferentes tipos de atores, a estrutura envolve um comitê de coordenação com representações científicas e de finanças, 


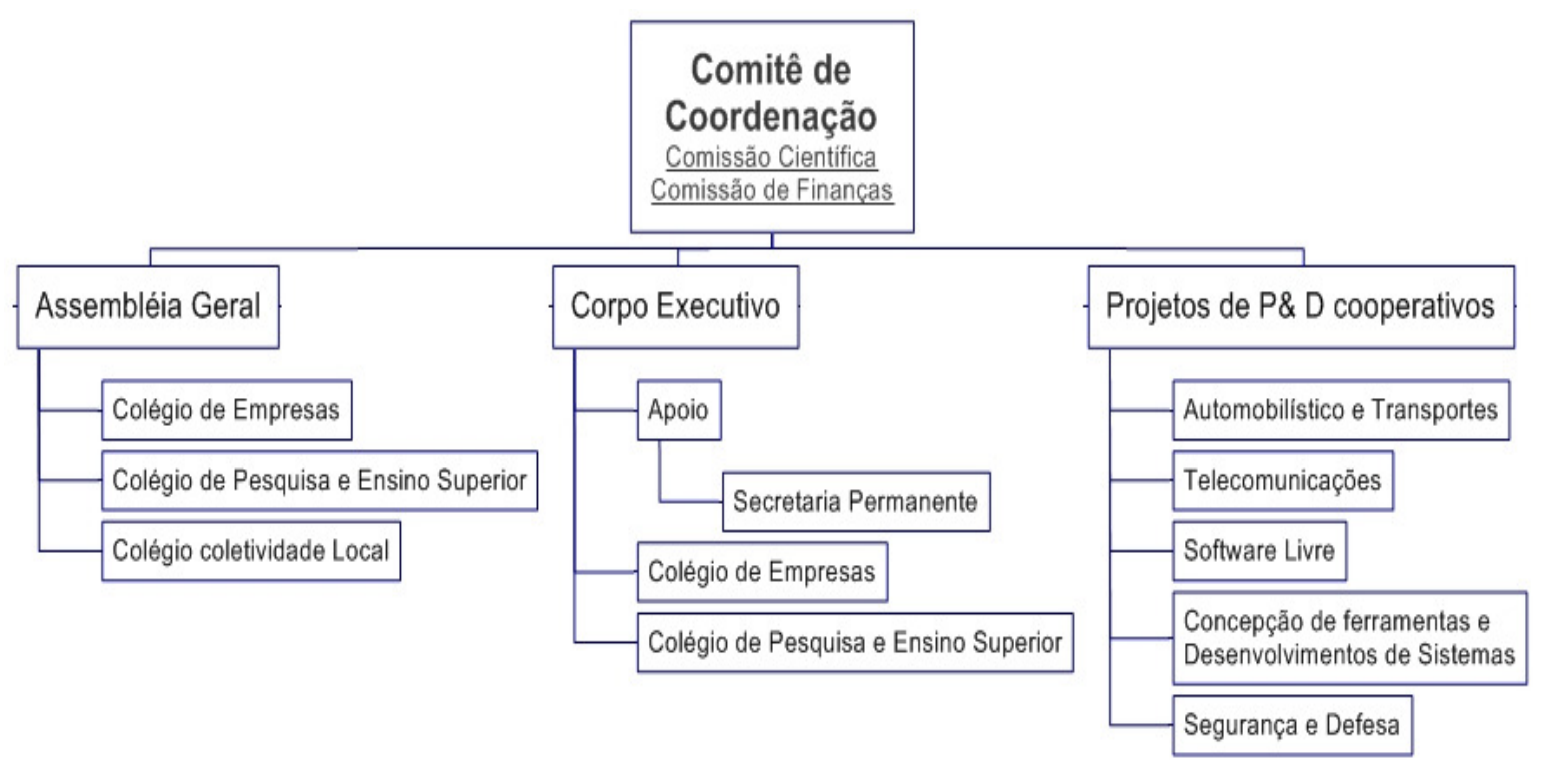

Figura 0-10: Organograma do Pólo.

\section{$\Rightarrow$ Relação Universidade-empresa}

10. Descrição do contexto científico e tecnológico presente nos pólos, envolvendo as universidades, escolas técnicas e outros, com a especialização de cada um e sua representatividade acadêmica, do ponto de vista do número de mestres e doutores.

O pólo participa apenas da negociação, na questão de buscar parceiros para desenvolver os projetos, ou seja, somente na perspectiva da articulação, não atua na questão de contratação.

Atualmente são 140 estabelecimentos de pesquisa e laboratórios públicos, isso é fruto de uma evolução dado que em 2005 eram 129, no ano de 2006 ocorreu um aumento de 4\%, então o número aumentou para 134. Estima-se que aproximadamente 3.000 pessoas irão trabalhar nos projetos de P\&D a cada ano.

11. Descrição dos principais mecanismos de apoio a relação universidades-empresa presente no Pólo, incluindo organismos públicos e privados. 
Não são utilizados e desenvolvidos mecanismos e instrumentos específicos para o relacionamento universidade-empresas. O Pólo articula o relacionamento das entidades, todavia não participa das negociações entre universidades e pesquisadores. Observa-se que existe uma demanda das universidades para participar dos projetos, sendo notada inclusive um aspecto de competição entre elas.

12. Descrição dos mecanismos de apoio segmentados por atividades, como: propriedade intelectual, comércio exterior, certificações de qualidade, etc.

Em linhas gerais, a atuação dos Pólos situa-se no contexto dos projetos, sendo que os processos de qualidade e certificações são desenvolvidos pelas próprias empresas. No tocante as PMEs, a atuação da equipe de animação do Pólo é mais aprofundada, procurando dotar as organizações de melhores condições para que possam integrar os projetos, todavia, a participação é indireta com orientações e busca de soluções de financiamentos, etc.

Considerando a questão da propriedade intelectual, os participantes dos projetos são orientados a consultar os documentos disponibilizados pelo Ministério no tocante a essas questões.

$\Rightarrow$ Infra-estrutura

13. A descrição das estruturas disponíveis relacionadas à logística externa do Pólo, envolvendo os transportes e serviços públicos disponíveis na localidade na qual se situa o Pólo. Também a descrição dos complexos residenciais para estadia dos empregados.

A região é uma das mais desenvolvidas na europa e no mundo, com cerca de região 320000 empregados (não incluindo as atividades de P\&D do setor público) que trabalham neste campo na lle-de-França, a região apresenta um perfil de maõ-de-obra altamente qualificada e um potencial de pesquisa de 3000 cientistas por ano.

A região é altamente desenvolvida, oferecendo os recursos de infra-estrutura para empresas, pesquisadores e demais parceiros. 


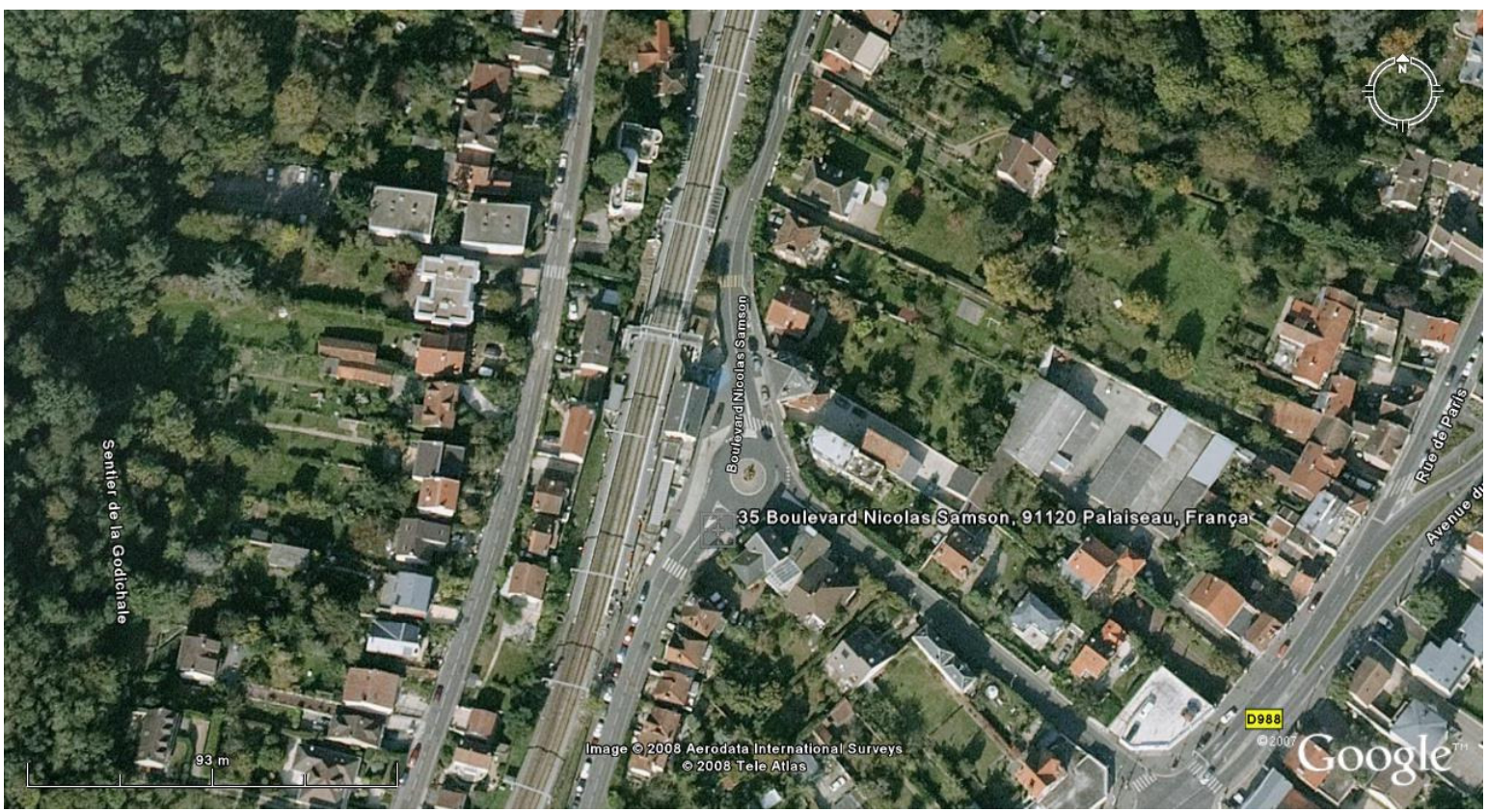

Figura 0-11: Mapa da região do Pólo System@tic.

\section{Descrição dos tipos de organização de empresas presentes no Pólo: as incubadoras, os agrupamentos de empresas?}

O Pólo não atua diretamente na gestão de incubadoras ou pepiniéres, todavia, algumas empresas desses ambientes participam dos projetos dos Pólos.

As PMEs participam dos grupos temáticos e dos projetos desenvolvidos no âmbito do Pólo, que oferece um percentual de $16 \%$ de subvenção para as mesmas, além disso, várias ações do Pólo visam fortalecer as PMEs, promovendo encontros com investidores, apoiando o desenvolvimento de uma escola dedicada, fortalecendo o desenvolvimento de manifestos de apoio, etc.

15. Descrição das estruturas de apoio a gestão do Pólo, envolvendo edificações a edificação de estruturas para certificação, propriedade intelectual, comércio exterior e outros serviços.

O Pólo funciona com uma estrutura enxuta e tem o papel de articulador e apoio para os associados, sendo assim não desenvolveu uma estrutura física para lidar com determinadas funções e operações para as empresas. 
16. Descrição da estrutura de conhecimentos, com bibliotecas, comunidades de prática, tecnologia da informação (hardware, software, base de dados e pesquisa) e laboratórios de pesquisa e desenvolvimento.

O Compartilhamento das estruturas de conhecimentos, laboratórios e de Tecnologia da Informação, basicamente ocorrem no âmbito dos projetos, o Pólo articula as parcerias para o desenvolvimento dos projetos.

Uma importante ação do Pólo é o desenvolvimento de mapas de competências no nível individual e coletivo, fato que proporciona promover um ambiente de trocas de conhecimentos e recursos, dado que no contexto do projeto, os participantes precisam saber quem sabe o quê? 
Apêndice C - Relatórios das Visitas Nacionais 


\section{Relatório de Visita}

\section{PORTO DIGITAL}
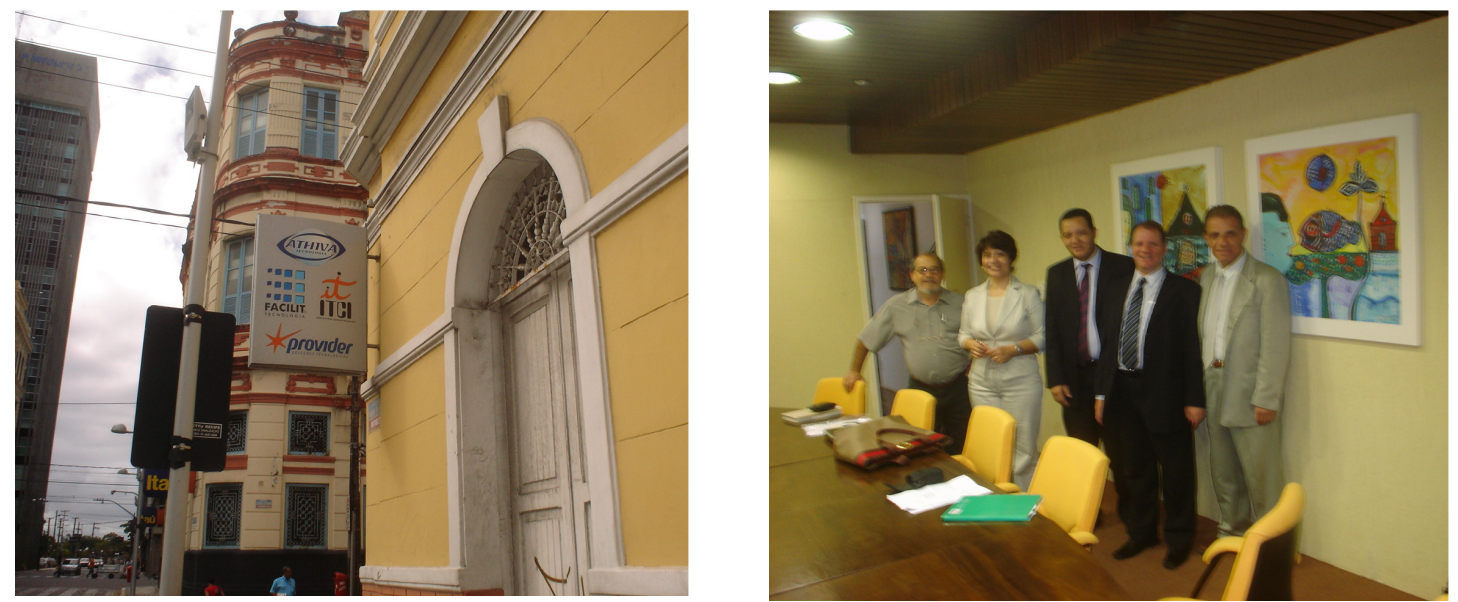

Coordenação:

Dra Désirée Moraes Zouain - IPEN-USP/PGT-USP

Pesquisadores:

Msc. Devanildo Damião - Doutorando - PGT-USP/UNIFIG

Wazdat de Oliveira - Secretaria de Desenvolvimento de Guarulhos Marcelo Chueiri - AGENDE Guarulhos 


\section{Contexto}

O relatório apresentado a seguir é parte integrante do Projeto de Políticas Públicas do Município de Guarulhos para o desenvolvimento de um ambiente social e tecnológico a ser consolidado, tendo como âncora um ambiente de inovação.

A coleta de informações foi estruturada a partir de um questionário qualitativo com enfoque em quatro dimensões: infra-estrutura, governança, estratégias e interações inerentes ao habitat de inovação do PORTO DIGITAL em Recife/PE.

O questionário foi aplicado na visita técnica desenvolvida na cidade de Recife, em viagem realizada entre os dias 30/07, 31/07 e 01/08/2008, e os entrevistados foram: Sr Aurélio Molina Diretor de Inovação e Competitividade Empresarial e Sr Marcos Suassuna - Consultor Especial.

\section{Questionário $\Rightarrow$ Governança}

\section{Qual é a estrutura de governança do PORTO DIGITAL? (tomada de decisão)}

O PORTO DIGITAL surgiu em julho de 2000, com um projeto de desenvolvimento do sistema de inovação local, com crescimento econômico por meio de investimentos públicos e participação da iniciativa privada e universidades.

O intuito de produzir conhecimento localmente e exportar serviços de valor agregado para o mundo. Para implantar o modelo de governança e os projetos estruturadores, foi criado o Núcleo de Gestão do PORTO DIGITAL - NGPD.

Está localizado no Recife Antigo, pois existe a perspectiva de revitalizar uma área que foi muito importante para a cidade como legado cultural.

O Parque tem a concepção de Parque aberto com a estratégia de povoar o bairro com novas empresas.

Os recursos iniciais de $\mathrm{R} \$ 33$ milhões vieram do Governo do Estado, destinados a criar a infra-estrutura e as condições necessárias para a implantação e operação do PORTO DIGITAL, que tem como missão inserir Pernambuco no cenário tecnológico mundial. Para implantação do Parque foram realizados diversos investimentos, entre eles, recuperação de prédios e cabeamento com fibra ótica.

Em oito anos de operação, o PORTO DIGITAL já transferiu para o Bairro do Recife quatro mil postos de trabalho, atraindo dez empresas de outras regiões do País e quatro multinacionais, abrigando, ainda, quatro centros de tecnologia. 


\section{Qual é a figura jurídica que administra o PORTO DIGITAL? (grau de formalidade)}

Para implantar o modelo de governança e os projetos estruturadores, foi criado o Núcleo de Gestão do PORTO DIGITAL (NGPD), associação civil sem fins lucrativos, qualificada como Organização Social (OS). Criado em dezembro de 2000, o NGPD tem como propósito estruturar e promover a gestão auto-sustentada de um ambiente de negócios de classe mundial.

O Conselho de administração conta com 19 membros, sendo 40\% do setor público e $60 \%$ privado.

O NGPD também desenvolve projetos de capacitação para jovens e fornece ferramentas para promover a inclusão social da comunidade do Pilar, situada ao norte do Bairro do Recife.

\section{Quais são os atores da iniciativa privada, pública e da academia que formam o PORTO DIGITAL? (representatividade $x$ articulação)}

O processo de desenvolvimento do Porto Digital contou com atores de diferentes esferas, pelo lado da Academia a UFP - a Universidade Federal de Pernambuco foi a grande responsável pelo desenvolvimento da competência local em Tecnologia da Informação. Pelo lado do Poder público, a esfera do Estado de Pernambuco colaborou significativamente com investimento inicial de 33 milhôes (fruto da privatização da Copel) que proporcionou o desenvolvimento dos fundos de capital humano e de capital de risco. No nível municipal, a aprovação de condições fiscais favoráveis foi o alicerce para a atração de empresas, além do oferecimento de infra-estrtura favorável.

As ações foram coordenadas pelo NGPD que estruturou as ferramentas, as leis e os incentivos para que as empresas se instalassem no PORTO DIGITAL.

Também, foram executadas obras civis de recuperação de imóveis históricos, além da articulação de implantação e operação dos fundos de investimento em Capital Humano (FCH) e Capital de Risco (FCR).

$\mathrm{Na}$ segunda fase de atuação, o NGPD atua para o desenvolvimento contínuo do ambiente de negócios, realizando acordos de cooperação técnica, transferência tecnológica, incentivando ainda a integração entre empresas, e promovendo no âmbito nacional e internacional a imagem do Arranjo Produtivo Local como uma ilha de excelência na área de TIC.

\section{Quais são as empresas âncoras do PORTO DIGITAL? (lideranças do tecido empresarial)}


Atualmente, o PORTO DIGITAL conta com cento e quinze instituições entre empresas de TIC, serviços especializados e órgãos de fomento. A maior empresa localizada no Porto Digital fatura 100 milhões de reais ano. Também é importante salientar que os grandes players da Tecnologia da Informação como Motorola, Microsoft, IBM estão presente no Porto Digital, porém, com diferentes modelos de associação, muitas vezes para desenvolver tecnologias específicas como o JAVA ou a linguagem XML.

Como empresas de sucesso pode-se citar o exemplo de duas que desenvolveram softwares de gestão hospitalr como a IB informática e a WF informática.

Outras âncoras (organizações que lideram um ou vários aspectos relacionados à liderança, definição e execução de políticas setoriais, excelência na produção, concepção de idéias fundamentais para o ecossistema) no PORTO DIGITAL estão representadas abaixo, segundo o seu papel institucional:

\section{SECTMA}

A Secretaria de Ciência, Tecnologia e Meio Ambiente (SECTMA) é o órgão do Governo do Estado de Pernambuco responsável pela definição e desenvolvimento da Política Estadual de Ciência e Tecnologia. O PORTO DIGITAL é uma das ações definidas nesta política e a SECTMA foi o primeiro e principal investidor público no Sistema Local de Inovação PORTO DIGITAL. Seu papel articulador e fomentador das ações de ciência e tecnologia fazem da sectma uma importante âncora do PORTO DIGITAL. A secretaria ocupa um imóvel de destaque no Bairro do Recife. Erguido na primeira metade do século 20, o casarão possui 1.740 metros quadrados de área restaurados pelo PORTO DIGITAL. Foram investidos R\$2,5 milhões para instalar a Sectma no centro histórico da cidade.

\section{C.E.S.A.R}

Concebido para promover a transferência tecnológica entre universidade, mercado e sociedade, o Centro de Estudos e Sistemas Avançados do Recife (CESAR) é uma das âncoras do PORTO DIGITAL. Associado ao Centro de Informática da UFPE, a instituição desenvolve soluções tecnológicas e estrutura unidades de negócios. O CESAR foi berço de dezenas de empresas, entre elas a InForma Software, o Radix e a Vanguard. No PORTO DIGITAL, o CESAR ocupa um antigo armazém localizado em frente à Praça Tiradentes, com uma área de 2.000 metros quadrados preparada para abrigar mais de 300 profissionais. Os investimentos utilizados na transferência do CESAR para o Bairro do Recife foram de $R \$ 2$ milhões.

\section{$\underline{\text { Cln }}$}

Inovação, Excelência e Criatividade fazem do Centro de Informática da UFPE um dos melhores centros acadêmicos de informática da América Latina. O Cln tem 30 anos de 
funcionamento e oferece curso de bacharelado em ciência da computação, disponibilizando 100 vagas por ano. Hoje atuam no corpo docente do CIn 46 doutores. Estão matriculados no Centro cerca 123 alunos de mestrado, 65 alunos de doutorado e 165 de especialização. Diversas empresas do PORTO DIGITAL nasceram a partir de projetos de alunos do CIN.

\section{SOFTEX}

O Softex Recife - Centro de Tecnologia de Software para Exportação do Recife - é uma sociedade civil sem fins lucrativos, criada em 8 de novembro de 1994 que tem sua origem vinculada ao Programa Softex2000. O SoftexRecife tem hoje cerca de 50 empresas associadas e atua em parceria com o PORTO DIGITAL incentivando projetos de desenvolvimento de software para exportação. http://www. /softexrecife.br

\section{C.A.I.S do Porto}

A incubadora de empresas do PORTO DIGITAL está estruturada como um microsistema local de inovação, em funcionamento no edifício sede do PORTO DIGITAL. Reúne em um mesmo ambiente físico um conjunto diverso de instituições e normas que, articuladas, promovem inovação e impulsionam negócios. O C.A.I.S do Porto não é apenas uma incubadora, pois abriga também empresas consolidadas. O objetivo é que a experiência de mercado já experimentada por essas empresas possam ser compartilhadas com os novos empreendedores. O C.A.I.S do Porto também abriga atividades de capacitação, treinamento, assessorias e desenvolvimento empresarial. Possui ainda um moderno centro de convenções com capacidade para até 100 pessoas.

\section{$\Rightarrow$ Infra-estrutura}

\section{Incubadoras no PORTO DIGITAL? (aspectos da inovação)}

O PORTO DIGITAL tem duas incubadoras, atuando em modelos diferenciados. A do C.E.S.A.R funciona como unidades de negócios dentro da empresa. Sete desses projetos já fizeram spin-off, conquistando o mercado nacional de TIC. Entre algumas a Tempest, a ecapture, Neurotech, Qualiti e Vanguard.

O C.A.I.S do Porto é a incubadora de empresas de TIC que começou a atuar em abril de 2003 e é onde está a sede do PORTO DIGITAL. Anima, Daccord, Jynx, Globaltech, Fabrik e Whitec ocupam módulos empresariais e infra-estrutura de ponta, como rede wi-fi. O espaço tem ainda um centro de eventos, salão para eventos, salas de reuniões.

Apesar do pouco tempo de funcionamento, o C.A.I.S do Porto já conseguiu realizar o spinoff da Tempest, empresa do setor de segurança e um dos cases de sucesso do PORTO DIGITAL .

Hoje 10 empresas de portes diferenciados fazem parte da incubadora, com projetos que vão do desenvolvimento de jogos a softwares para a área musical. 
Possuem uma rede da incubadoras, a INCUBANET, que reúne incubadoras sociais, de cooperativas, de projetos e tem processos tipo "garage" para jovens empreendedores.

\section{Qual é a área total do PORTO DIGITAL? E quais os seus ativos?}

O PORTO DIGITAL está situado no sítio histórico do Bairro do Recife, acrescentando ao projeto a componente de revitalização urbana. O bairro possui infra-estrutura adequada para a instalação de empresas de TIC por dispor de excelente estrutura de serviços e de telecomunicações.

Atualmente, contam com três prédios administrados pelo NGPD e um quarto prédio em andamento que abrigará um Centro de Tecnologia da Informação. A maior parte dos prédios do Bairro do Recife foi tombada como patrimônio histórico.

A Prefeitura é responsável pela recuperação dos prédios e instalação de infra-estrutura adequada para o empreendimento.

Números do PORTO DIGITAL: 100 hectares; 107 organizações; 3,6 mil empregos; 8 km de fibra ótica; $26 \mathrm{~km}$ de dutos.

\section{Quais são as principais atividades desenvolvidas no PORTO DIGITAL? (grau de diversificação)}

Em oito anos de atuação, o PORTO DIGITAL se consolidou com os investimentos realizados na melhoria dos processos de desenvolvimento de sotfware e com a instalação de dezenas de empresas vindas de outras regiões da Região Metropolitana do Recife, de outros estados e até de outros países.

Entre os segmentos de TIC, destacam-se as produções de softwares para gestão, soluções para o sistema financeiro e de saúde, games, softwares para o setor de segurança, sistemas para gerenciamento de tráfego e transporte, usabilidade de software e soluções integradas para desenvolvimento de portais, extranets e intranets.

O cluster é composto, em sua maioria, por pequenas e médias empresas, porém multinacionais como IBM, Motorola, Samsung e Microsoft também estão presentes no PORTO DIGITAL. A IBM transferiu para a ilha a sua sede regional.

A Motorola e a Samsung têm uma parceria com o C.E.S.A.R para desenvolvimento de softwares embarcados para celular.

Já a Microsoft está presente no Centro de Pesquisa XML, que funciona há dois anos no CAIS do Porto, resultado de uma parceria com o PORTO DIGITAL, Fisepe, HP, Qualiti, C.E.S.A.R, e o CIN, com o objetivo de desenvolver tecnologia para a plataforma XML. 


\section{Brazil Test Center}

O C.E.S.A.R e o Centro de Informática, CIn - UFPE são parceiros da Motorola em uma iniciativa que faz do Brasil o único centro mundial de verificação e integração de testes de software para celulares da marca. O projeto também conta com a participação do Instituto Eldorado, de Campinas, e da Universidade Federal de Santa Catarina, além da própria equipe de pesquisa e desenvolvimento da Motorola em Jaguariúna (SP).

\section{Como o órgão gestor administra os processos relacionados à gestão do conhecimento, propriedade intelectual, qualidade, etc? (coordenação).}

Dentro da perspectiva do projeto a proximidade é a base para a extrapolação do conhecimento, sendo que expontaneamente são trocados conhecimentos a cada momento pelos colaboradores das várias empresas locadas no Porto Digital. O modelo do Porto Digital está inserido numa perspectiva de dotar a organização de autonomia para as decisões relacionadas a operação dos seus processos, o NGPD atua para o desenvolvimento contínuo do ambiente de negócios, realizando acordos de cooperação técnica, transferência tecnológica, incentivando ainda a integração entre empresas Em projetos específicos de exportação de software desenvolveu parceria com a APEX e o SEBRAE para adequação de empresas para a exportação de produtos e serviços.

\section{$\Rightarrow$ Estratégia}

\section{Quais são as atividades econômicas que são privilegiadas no PORTO DIGITAL?}

Tecnologia da informação é uma vocação acadêmica de Recife, fruto de anos de estudos e pesquisa desenvolvidas no âmbito da UFP e, portanto, a principal atividade desenvolvida pelo PORTO DIGITAL. Atualmente, a cidade conta com trinta e cinco faculdades privadas formando profissionais na área de informática. O Centro de Informática conta com mais de quarenta doutores atuando em seus projetos.

\section{Quais são os principais objetivos a médio e longo prazo?}

O PORTO DIGITAL tem como objetivos, entre outras coisas, verificar como poderiam contribuir mais para os projetos e atividades dos empreendedores que não são da área de Tl e também como implementar uam política de responsabilidade social na qual os empresários possam participar sem a necessidade de envolver a equipe do PD que é limitada. 
Pretendem também ampliar o número de pessoas treinadas para atender ás necessidades das empresas, a fim de também abrir oportunidades nas favelas e outras áreas da ilha. Nesta empreitada contam o apoio do Governo do Estado (bolsas auxílio) e buscam também apoio dos empresários da região.

Também está no escopo de objetivos da equipe do Porto Digital o processo de valorização e desenvolvimento da marca Porto Digital, como um selo de qualidade para as empresas.

\section{$\Rightarrow$ Interações e relação Universidade- empresa}

\section{Qual a relação do PORTO DIGITAL com o poder público? Existem ações elaboradas com o poder público para manter o PORTO DIGITAL competitivo e em expansão? Quais? (políticas públicas)}

O projeto do Porto Digital não é considerado um projeto de governo, todavia um projeto de estado. A sua importância foi assimilada pela sociedade, que considera importante a imagem de Pernambuco atrelada ao desenvolvimento de tecnologia. Também é importante ressaltar que hoje as atividades desenvolvidas no Porto Digital correpondem a 3,8\% do PIB Estadual. Cabe aa lembrança que o governo do Estado de Pernambuco investiu $\mathrm{R} \$ 33$ milhões, no início do projeto, sendo que $\mathrm{R} \$ 14$ milhões estão sendo diretamente executados pelo NGPD.

O restante dos recursos está sendo executado por órgãos do governo como Facepe (Fundação de Amparo à Ciência e Tecnologia de Pernambuco), AD-Diper (Agência de Desenvolvimento de Pernambuco) e Sectma (Secretaria de Tecnologia, Ciência e Meio Ambiente).

Profissionais do setor produtivo, governos, universidades e outras representações da sociedade possuem função deliberativa e de fiscalização no que diz respeito ao estabelecimento de objetivos, metas e diretrizes para o funcionamento do PORTO DIGITAL. A composição do conselho é formada por $37 \%$ de representantes de governos; $21 \%$ do setor produtivo; $11 \%$ de universidades; $16 \%$ de organizações não governamentais e $16 \%$ de representantes de outros setores da sociedade.

\section{PARCEIROS:}

\section{FINEP}

A Financiadora de Estudos e Projetos (FINEP),empresa pública vinculada ao Ministério da Ciência e Tecnologia (MCT), e o PORTO DIGITAL são parceiros na implementação do Programa Juro Zero. O PORTO DIGITAL teve sua proposta aprovada no dia 13 de dezembro de 2004 e está atualmente ajustando sua proposta ao escopo do programa. A finalidade do Programa Juro Zero é estimular a capacidade inovadora das micro e pequenas empresas 
brasileiras nos aspectos comerciais, de processo ou de produtos/serviços, por meio de financiamento de longo prazo e com juro real zero.

\section{SEBRAE}

O Sebrae, Serviço Brasileiro de Apoio às Micro e Pequenas Empresas, desenvolve diversas parcerias institucionais com o PORTO DIGITAL. Entre algumas, o Projeto para Exportação de Software (PSI), e o de financiamento de APLs que foi submetido ao BID. A parceria também envolve a participação das empresas em rodadas de negócios e feiras promovidas pelo Sebrae.

\section{ASSESPRO}

Associação das Empresas de Tecnologia da Informação, Software e Internet Regional (Assespro Regional), a Assespro atua em todo o Brasil. Na Regional Nordeste, a Assespro tem trabalhado para aproximar os empresários de investidores e para a formação de consórcios entre empresas de atividades complementares. Em parceria com o PORTO DIGITAL e o Softex, a Assespro também tem atuado fortemente na aprovação de leis que incentivem e fortaleçam o mercado de Tecnologia da Informação e Comunicação.

\section{$\underline{\text { ITPO }}$}

O Escritório de Promoção de Investimentos e Tecnologia do Recife (Investment and Technology Prommotion Office) faz parte da rede de promoção de negócios da Organização das Nações Unidas para O Desenvolvimento Industrial (UNIDO). O ITPO Recife é o único escritório nas Américas que se une a uma rede de outros 14 escritórios em países da Europa e Ásia.

\section{Há vínculos econômicos / tecnológicos com outras regiões do país, ou mesmo com o exterior? (parcerias/cooperação)}

Pernambuco é um dos principais centros de pesquisa e desenvolvimento do Brasil. Um dos fatores determinantes da viabilidade do PORTO DIGITAL é o número de faculdades de ciência da computação. O Centro de Informática da UFPE é um dos mais antigos do País e está entre os cinco melhores da América Latina.

O PORTO DIGITAL tem parcerias estabelecidas com multinacionais como a Borland e a Sun. O C.E.S.A.R é o único Centro Mundial de Excelência na Plataforma Java em toda a América Latina. E o Recife está entre os maiores pólos de desenvolvimento na linguagem Java do Brasil, de acordo com a Borland.

\section{Instituto Nokia}

Recife sedia o Instituto Nokia de Tecnologia (INdT), uma das três unidades de desenvolvimento da Nokia no Brasil. No INdT funciona um centro mundial de desenvolvimento de aplicativos da Nokia, dedicado à criação de aplicativos em plataformas de código aberto 
como Linux e Java. O objetivo dessa iniciativa, de acordo com a empresa finlandesa, é tornar o Brasil um ponto de referência no desenvolvimento de aplicativos para smartphones.

\section{Considerando a experiência do modelo teórico adotado no PORTO DIGITAL, quais são os requisitos fundamentais necessários para a transformação de agentes públicos e privados (Estado, Instituições Acadêmicas x Empresas) em Parques Tecnológicos?(Estudo de Caso)}

O desenvolvimento do Porto Digital obedeceu a uma lógica que combinou a vocação tecnológica co a necessidade de requalificação de uma determinada área. O detalhamento dessa iniciativa permite observar as estratégias essenciais para a sua consolidação: povoar o Bairro do Recife; qualificar e fortalecer as empresas; fomentar novos empreendimentos; implementar políticas de inclusão social; conquistar credibilidade; acessar mercados; modelar negócios; participação efetiva do Governo do Estado e da Prefeitura no Conselho de Administração.

Considerando essa experiência, podem-se destacados dois aspectos: 1. a viabilidade de utilizar o desenvolvimento de um Parque Tecnológico como um instrumento de políticas pública; 2. A necessidade de interação entre os atores.

14. Ainda de que forma as possíveis assimetrias inter-atores dos PTs podem afetar negativamente o desenvolvimento do Parque (sua organização produtiva, as relações com os demais agentes locais/ regionais)? (cultura, linguagem, canais de acesso)

O modelo do Porto Digital caracterizado como um Parque Tecnológico Urbano e Aberto pressupõe uma articulação bem desenvolvida com os poderes públicos, principalmente o local (nível de municipalidade). Portanto, um ponto crítico de sucesso do projeto é a articulação política. Considerando esse aspecto e as características de Recife pode-se relativizar o peso desse ponto crítico de sucesso por dois aspectos a saber: 1. A representatividade da Universidade Federal de Pernambuco no planejamento das políticas locais, inclusive de representantes ocupando funções de assessoria no município e estado; 2. O modelo de gestão do NPGD que prevê representações das entidades públicas. 


\section{Relatório de Visita}

\section{Fundação CERTI e SAPIENS Parque}
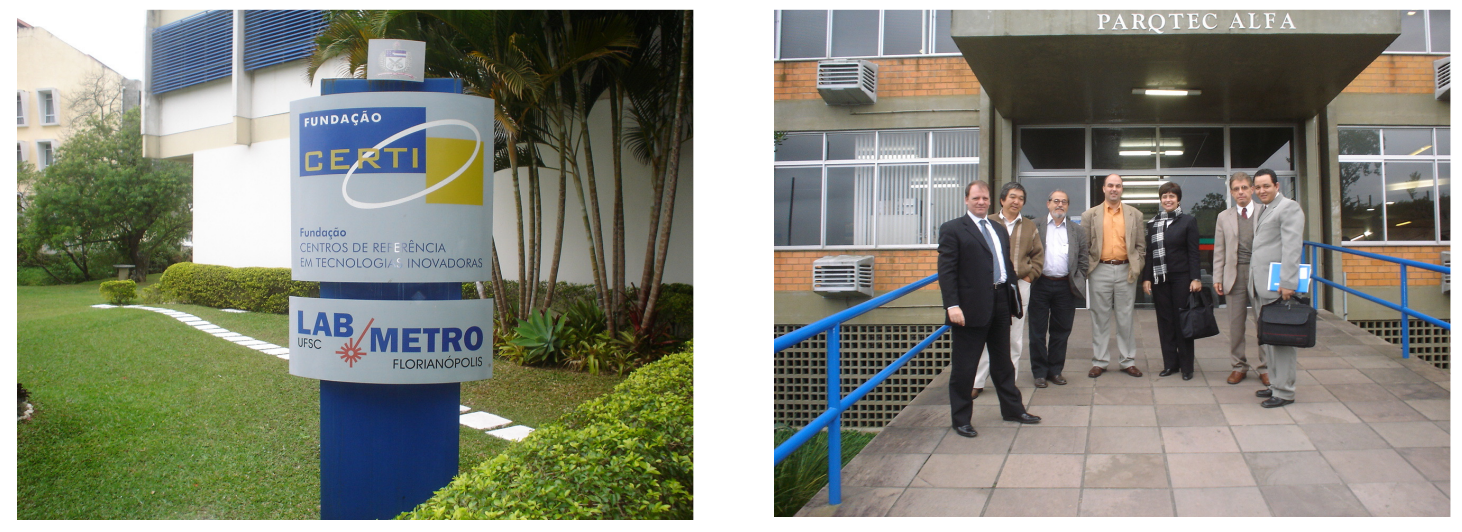

Coordenação:

Dra Désirée Moraes Zouain - IPEN-USP/PGT-USP

Pesquisadores:

Msc. Devanildo Damião - Doutorando - PGT-USP/UNIFIG

Wazdat de Oliveira - Secretaria de Desenvolvimento de Guarulhos Marcelo Chueiri - AGENDE Guarulhos 


\section{Contexto}

O relatório apresentado a seguir é parte integrante do Projeto de Políticas Públicas do Município de Guarulhos para o desenvolvimento de um ambiente social e tecnológico a ser consolidado, tendo como âncora um ambiente de inovação.

A coleta de informações foi estruturada a partir de um questionário qualitativo com enfoque em quatro dimensões: infra-estrutura, governança, estratégias e interações inerentes ao habitat de inovação da Fundação CERTI, da Incubadora de Empresas CELTA (Centro Empresarial para Laboração de Tecnologias Avançadas) e do Sapiens Parque.

O questionário foi aplicado na visita técnica desenvolvida na cidade de Florianópolis no dia 13 de agosto de 2008 e os entrevistados foram: Sr. José Eduardo Azevedo Fiates Superintendente de Inovação da Fundação CERTI, Sr. Tony Chierighini - Gerente de Negócios da Incubadora CELTA e o Sr. Leandro Carioni - Gerente Executivo do Sapiens Parque.

\section{Questionário}

$\Rightarrow$ Governança

\section{Qual é a estrutura de governança da Fundação CERTI e do SAPIENS Parque? (tomada de decisão)}

A Fundação CERTI (Centros de Referência em Tecnologias Inovadoras) é uma instituição sem fins lucrativos, de pesquisa e desenvolvimento tecnológico, com foco na inovação em negócios, produtos e serviços no segmento de tecnologia da informação e coordena todas as atividades relacionadas aos Parques Tecnológicos em Florianópolis: incluindo ALFA, SAPIENS e demais ativos.

A Instituição foi criada em 1984, a partir do Laboratório de Metrologia do Departamento de Engenharia Mecânica da Universidade Federal de Santa Catarina (UFSC), com a participação de diversas empresas, incluindo empresas paulista do setor mecânico e também dos governos federal e estadual.

A Fundação conta com duzentos profissionais, especializados em Universidades do Brasil e do exterior que possuem amplo know-how em suas áreas de atuação, e desenvolvem projetos para grandes, médias e pequenas empresas. Os valores destes projetos variam de $\mathrm{R} \$ 500$ mil a 1 milhão de reais. 
A sede da CERTI funciona desde 1990 em prédio próprio localizado no campus da UFSC, o trabalho da CERTI é realizado por intermédio de sete Centros, sendo cinco deles denominados CRITs - Centro de Referência em Tecnologias Inovadoras, com competências tecnológicas específicas e equipes de colaboradores próprios. Mais de 600 empresas e instituições de todo o Brasil beneficiam-se, anualmente, dos serviços tecnológicos, dos projetos de melhoria de processos, dos desenvolvimentos de produtos inovadores e dos empreendimentos tecnológicos desenvolvidos pelos Centros da Fundação CERTI.

Os cinco atuais CRITs são: CME - CRIT em Dispositivos Meca-Opto-Eletrônicos; CMI CRIT em Soluções de Metrologia e Instrumentação; CPC - CRIT em Sistemas Produtivos Cooperativos; CAI - CRIT em Ambientes de Inovação; e CCD - CRIT em Soluções de Convergência Digital.

Os outros dois Centros da CERTI são: CIENCIA - Centro Incubador de Empreendimentos, Novos Conhecimentos e Idéias Avançadas e CELTA - Centro Empresarial para Laboração de Tecnologias Avançadas

A Fundação também possui dois Institutos associados: um localizado em Manaus Instituto CERTI Amazonas (ICA); e outro localizado em Brasília para atender projetos de convergência digital - Instituto Sapientia (IS); e um Laboratório: o LABelectron - que é mantido com acordos de cooperação técnico-científica, baseados na Lei de Informática, com as empresas ALCATEL e MEGAFLEX SUL.

O Sapiens foi constituído como uma empresa com representação de diferentes atores entre os quais: a própria Fundação Certi, o governo do Estado de Santa Catarina. Também é importante ressaltar que os projetos são estruturados com base na formação de empresas de propósito Específicos - SPE.

\section{Quais são os atores da iniciativa privada, pública e da academia que formam o SAPIENS? (representatividade $x$ articulação)}

O empreendimento foi idealizado pela Fundação Centro de Referências em Tecnologias Inovadoras (CERTI) e apoiado pelo Governo do Estado de Santa Catarina. O Sapiens está inserido em uma estratégia de desenvolvimento tecnológico regional que envolve outros projetos como a incubadora Celta, o ParqTec Alfa, o laboratório-escola LABelectron e outras iniciativas do sistema local de inovação. Atualmente, integra os governos municipal, estadual e federal, sendo o principal parceiro, o governo do estado por meio da CODESC e da SC Parcerias - uma empresa criada para gerir os projetos de parceria público-privada.

A Sapiens Parque S.A. está promovendo também parcerias com universidades, centros de pesquisa e desenvolvimento, laboratórios e outras organizações que busquem um ambiente de inovação para criar novas tecnologias e conhecimentos. O Sapiens será um local para atrair talentos e instituições de referência no mundo acadêmico, empresarial e terceiro setor. 
O Sapiens Parque é um parque de inovação concebido para promover o desenvolvimento de segmentos econômicos que já são vocações de Florianópolis, como o turismo, a tecnologia, o meio-ambiente e serviços especializados.

A denominação Sapiens origina-se de "Sapientia" (sabedoria) e de "Homo Sapiens" (ser humano) e é composto por quatro grandes áreas que estruturam a sua concepção inovadora: Experientia, Scientia, Artis e Gens.

O Sapiens Parque incorpora conceitos e diretrizes presentes nos mais ousados e inovadores projetos do mundo nesta área, como a economia da experiência, a sociedade do conhecimento, o desenvolvimento sustentável, a convergência digital e a das ciências e tecnologias, a globalização econômica e a adoção de um ciclo contínuo de inovação.

\section{Quais são as empresas âncoras do SAPIENS? (lideranças do tecido empresarial)}

Tona-se necessário informar que o Parque Sapiens é uma empresa criada para a gestão dos ativos do parque tecnológico, atualmente em fase de desenvolvimento.

Não existe no momento uma empresa com o domínio de uma cadeia de valor que possa ser considerado o papel clássico de âncora. Entretando no momento encontra-se em desenvolvimento a produção de filmes de animação com a mobilização de tecnologia e conhecimentos locais para produções cinematrográficas internacionais.

O Parque Alpa abriga a grande empresa nacional que surgiu a partir de ambientesde inovação, a BEMATEC que fatura 250 milhões de reais/ano.

Ademais, cabe ressaltar que O SAPIENS Parque está dividido em nove grandes empreendimentos, dos quais sete já está em operação e dois em fase de desenvolimento, a saber:

a) Em operação:

a.1.: Comunidade SAPIENS - Objetiva a inclusão e a capacitação dos moradores e empreendedores do Norte da llha, além de cooperar no crescimento da economia da região.

a.2.: Roteiro Gastronômico - Doze restaurantes do entorno do Sapiens Parque participam do projeto Roteiro Gastronômico Norte da llha. O objetivo é aumentar o fluxo de clientes e turistas nestes restaurantes.

a.3.: Escola Sapiens - Foi criada dentro de conceito de ser uma escola das escolas, onde rofessores e alunos da Rede Pública de Ensino de Santa Catarina participam de programas de capacitação nas áreas de tecnologia da informação, arte e sustentabilidade, para a produção de conteúdos educativos e culturais, utilizando equipamentos cedidos pela Sun Microsystems. 
a.4.: Sapiens Circus - Plataforma itinerante em formato de domo, com $145 \mathrm{~m} 2$, que utiliza soluções tecnológicas para acelerar o processo de aprendizado através de experiências memoráveis.

a.5.: Quinta das Artes - Por meio do projeto Artesanato Sapiens, foi criada a "Associação Quinta das Artes" e seu showroom, na sede do Parque.

a.6.: Trilha do Rio do Braz - Passarelas, pontes, placas informativas e uma torre de 10 metros proporcionam uma visão privilegiada do Parque Natural Sapiens e uma verdadeira imersão na natureza local.

a.7.: Telecentro e Biblioteca SESI - O Sapiens Parque, em parceria com o Sesi/SC, está construindo uma biblioteca, que funcionará também como telecentro, para os moradores da região. Por meio do empreendimento, a comunidade terá acesso a diversos cursos de aperfeiçoamento e serviços públicos, via internet.

b) Em desenvolvimento:

b.1.: Centro de Eventos e Cultura - Pretende ser o palco dos grandes espetáculos em Florianópolis.

b.2.: Jardim Botânico - O Sapiens Parque está desenvolvendo o primeiro Jardim Botânico de Santa Catarina, com 323,7 mil m², coordenado pela Fapesc e Epagri com a parceria da ACIF e Floram.

\section{$\Rightarrow$ Infra-estrutura}

\section{Incubadoras na CERTI, relato sobre a a Incubadora Celta e a pré-incubadora Ciência? (aspectos da inovação)}

\section{INCUBADORA CELTA}

CELTA (Centro Empresarial para Laboração de Tecnologias Avançadas) - é um centro da Fundação CERTI sem personalidade jurídica, com um Conselho de Administração que está subordinado ao Conselho Curador da Fundação CERTI; o presidente do Conselho de Administração é o Prefeito de Florianópolis, entre outras entidades locais importantes que participam (sistema FIESC, Fundação CERTI, SEBRAE, representante dos empresários do CELTA) - contam com duas grandes universidades (UFSC e a UDESC - estado).

O CELTA, a incubadora da CERTI, surgiu em 1986, em resposta aos anseios de desenvolvimento da capital catarinense, de viabilizar um promissor setor econômico, aproveitando os talentos e o conhecimento gerados pela UFSC (Universidade Federal de Santa Catarina). A Incubadora nasceu num prédio alugado, na Trindade - Florianópolis, com área para empreendimentos de hum mil e duzentos metros quadrados a $2 \mathrm{~km}$ do campus da UFSC. O prédio é hoje ocupado por empresas do condomínio da ACATEL e da incubadora Midi-Tecnológico (do SEBRAE). 
O CELTA atualmente instalado em um prédio com dez mil e quinhentos metros quadrados, distante $4 \mathrm{~km}$ do campus da UFSC, mantém trinta e oito empresas de base tecnológica que geram 785 empregos diretos e, no ano de 2005, o faturamento das incubadas alcançou aproximadamente $\mathrm{R} \$ 40$ milhões.

A incubadora já colocou no mercado quarenta e três novas empresas que hoje faturam $R \$$ 780 milhões, considerado o maior volume de faturamento de empreendimentos nascidos em incubadoras do país. Nos últimos três anos o CELTA liberou doze empresas.

O CELTA não tem nenhum convênio financeiro para se manter - é auto-sustentado. No início o governo do estado bancava $1 / 3$ das despesas, porém tinham muita dificuldade de receber. Portanto, em 1992 travaram todos os débitos, continuaram ainda pedindo recursos para o governo até 1994. Depois disso, não solicitam mais recursos.

A matéria prima do processo da incubadora é o Plano de Negócio das empresas. O processo de incubação dura de dois a cinco anos. Para a empresa entrar no Parque Tecnológico ou na incubadora passa por um processo que se inicia com um Plano de Negócios (tecnologia-mercado-finanças); passa pela avaliação, e então, compra um terreno no parque ou aluga (pois no momento não há mais espaço para venda); e por último passa pelo processo de incubação.

Oferecem serviços gerais e de suporte estratégico (apoio na busca de financiamento, elaboração de projetos especiais, intermediações e contatos estratégicos). Também serviços de suporte ao desenvolvimento empresarial (acompanhamento/assessoria em MKT e finanças; assessoria em gestão da qualidade total; apoio à participação em eventos, feiras e congressos; treinamento a novos empreendedores; banco de assessores/consultores especializados; banco de recursos humanos especializados). Serviço de Suporte Tecnológico (locação de equipamentos, busca de informações tecnológicas, acesso facilitado a laboratórios especializados, registro de marcas e patentes, busca de parcerias e assessorias, apoio no cadastramento e homologação de produtos e processos).

Para ter acesso ao CELTA a empresa interessada deve configurar-se como Empresa de Base Tecnológica, nas áreas de interesse do CELTA, a saber: Instrumentação, Telecomunicações, Automação, Eletrônica, Mecaoptoeletrônica, Microeletrônica, Informática ( Incluindo hardware e software), Mecânica de Precisão.

\section{Alguns números interessantes do CELTA:}

- 1200 planos de negócios já recebidos e já foram aprovados até hoje 90 planos.

- 38 empresas incubadas (sendo 29 criadas a partir da UFSC).

- Faturamento no ano passado cerca de 40 milhões de reais e das graduadas passou de 1 bilhão de reais. Postos de trabalho só no prédio da incubadora: 785 .

- 42 planos de negócio sendo avaliados. 
- Orçamento da incubadora: $\mathrm{R} \$ 880$ mil por ano. O custo real (econômico) é 1 milhão trezentos e setenta e cinco mil reais (considerando o uso do prédio - que não paga; o uso de laboratórios da universidade - que não paga).

\section{PRÉ-INCUBADORA CIENCIA}

A pré-cincubadora CIENCIA é uma iniciativa da Fundação CERTI, que tem como finalidade apoiar a transformação de pesquisas, especialmente aquelas realizadas no meio acadêmico, em futuros negócios.

O apoio a estas iniciativas será feito desde a identificação de idéias e oportunidades com real potencial de valor, até a confecção de um primeiro plano de negócio mostrando a sua possibilidade de geração de empresa a ser incubada preferencialmente no CELTA.

A sustentabilidade inicial desta iniciativa, será primeiramente bancada pelos diferentes CRITs da Fundação CERTI. Na medida do interesse e necessidade, buscar-se-á apoiar a busca de projetos específicos para as agências de fomento (FAPESC, SEBRAE, FINEP etc.), afim de finalizar o produto/processo objeto de pré-incubação.

A Fundação CERTI, alocará uma estrutura de pessoal e física para a pré-incubadora, oferecendo apoio técnico e juridico aos empreendedores, prevendo-se também, a contratação de serviços especializados para situações específicas que se mostrarem necessárias.

A pré-incubadora CIENCIA funciona com uma estrutura mínima (uma sala com telefone e computador) que serve como ponto de referência na Fundação CERTI. Esta estrutura permite aos futuros empreendedores, se reunirem e debaterem suas propostas de negócio, sempre com a participação e orientação do CERTI, coordenada pelo CIENCIA.

A CERTI apoiará preferencialmente as propostas que estejam alinhadas com os interesses de seus centros e plataformas e que possam ser incubadas no CELTA ou implantadas no SAPIENS PARQUE.

\section{Qual é a área total do SAPIENS? E quais os seus ativos?}

Sapiens em Números:

- Área total = 4,5 milhões m2 (445 hectares)

- Potencial Máximo Construtivo = 1,2 milhões m2

- TO (Taxa de Ocupação $)=11 \%$

- IA (Índice de Aproveitamento) = 25\%

- Horizonte de Implantação = 15 a 20 anos

- Arrecadação de Impostos na fase de implantação = R $\$ 1,1$ bilhão

- $\quad$ Capital da Sapiens Parque S.A. = R\$228.817.602,00

- Investimento em infra-estrutura (5 fases do projeto) $=\mathrm{R} \$ 417.189 .000,00$ 
- Investimento em edificações comerciais e empresariais $=\mathrm{R} \$ 1.350 .000 .000,00$

- Investimento em Projetos nas Áreas Social e Ambiental $=\mathrm{R} \$ 150.000 .000,00$

- Investimento em Projetos Tecnológicos e Científicos $=\mathrm{R} \$ 250.000 .000,00$

- Investimentos relativos à infra-estrutura e projetos sociais no entorno do Sapiens Parque $=R \$ 150.000 .000,00$

- Investimento Total (20 anos) $=\mathrm{R} \$ 2.317 .189 .000,00$

- Área Natural Preservada $=2.000 .000 \mathrm{~m}^{2}$ (mais de $50 \%$ total)

- Total de empregos diretos (nas 5 fases de implantação) = Cerca de 30 mil

\section{Quais são as principais atividades desenvolvidas no SAPIENS? (grau de diversificação)}

$\mathrm{Na}$ criação do Sapiens Parque buscou-se empreender algo importante para a região, o estado e o país; integrar de forma inovadora e pragmática conhecimento/tecnologia \& ser humano/sociedade; desenvolver e implementar um empreendimento de referência, diferenciado e especial; assegurar que o projeto tenha sustentabilidade e alto retorno/valorização.

Realizou-se uma pesquisa internacional de experiências de sucesso e a partir disso concebeu-se a cidade de Florianópolis como uma região empreendedora, inovadora - por meio de engenharia reversa criaram o conceito de "Parque de Inovação" - uma plataforma estratégica, institucional e operacional para promover e abrigar empreendimento, projetos e outras iniciativas visando transformar Florianópolis numa Região Empreendedora e inovadora líder na Economia do Conhecimento e referência em Desenvolvimento Sustentável.

As atividades desenvolvidas englobam os seguintes setores: turismo, serviços do conhecimento, tecnologia. O Sapiens está dividido em quatros grandes núcleos: núcleo chave SCIENTIA - C\&T\&I - reserva de 300 a 400 mil metros quadrados para trazer centros de pesquisa para FLORIANÓPOLIS; núcleo ARTIS - formação de pessoas na área de arte e cultura, cinema, música, artes plásticas e design; núcleo GENS - promoção do desenvolvimento sustentável - parques, etc..; núcleo EXPERIENTIA - museu de ciência \& tecnologia + parque temático + laboratório de $\mathrm{P} \& \mathrm{D}$ + show room.

\section{Como o órgão gestor administra os processos relacionados à gestão do conhecimento, propriedade intelectual, qualidade, etc? (coordenação).}

Pode-se dizer que praticamente todas as empresas estão situadas no Parque Tecnológico Alfa, em duas modalidade: incubadora de empresas e condomínio de empresas. $O$ aspecto do processo de gestão é realizado com controles avaliativos, sendo que é política da direção que as empresas apresentem lucratividade e busquem a sua sustentação financeira. 
São oferecidas assessorias em gestão da qualidade total; apoio à participação em eventos, feiras e congressos; treinamento a novos empreendedores; banco de assessores/consultores especializados; banco de recursos humanos especializados). Serviço de Suporte Tecnológico (locação de equipamentos, busca de informações tecnológicas, acesso facilitado a laboratórios especializados, registro de marcas e patentes, busca de parcerias e assessorias, apoio no cadastramento e homologação de produtos e processos).

O processo de acompanhamento das empresas envolve diretrizes para atuação no mercado, ajudando a empresa a se situar e conseguir desenvolver produtos e serviços atrativos, consequentemente com qualidade. As empresas são assistidas em aspectos que envolvem a necessidade de proteção do conhecimento, a gestão do conhecimento ainda não recebe um tratamento direcionado.

\section{Qual é a figura jurídica que administra o SAPIENS? (grau de formalidade), explicar a relação da fundação CERTI e do SAPIENS.}

A estrutura do parque tecnológico Sapiens é desenvolvido a partir de uma empresa. A sua estrutura acionária apresenta - 60\% propriedade da CODESC; a Fundação CERTI - 6,5\% (integralização do capital intelectual); Sapientia 0,6\%.

Existe um acordo de acionista leonino em favor da Fundação CERTI - têm um forte poder de veto ( 5 dos 7 membros do Conselho de Administração).

Procuraram um modelo que desse estabilidade de governança (no caso sendo a Fundação CERTI a gestora). Procuraram uma estrutura que $93 \%$ da companhia é de propriedade do governo - o governo do estado capitaliza todos os benefícios e visibilidade.

\section{$\Rightarrow$ Estratégia}

\section{Quais as atividades econômicas que são privilegiadas no SAPIENS?}

O Sapiens especificamente encontra-se em fase de desenvolvimento, as atividades desevolvidas no momento com maior relevância são relacionadas com a produção de filmes de animação com a aplicação de tecnologia de Tecnologia de Informação e Comunicação - TIC, envolvendo o trabalho com massas especiais.

O Sapiens propõe a ser um ambiente diferenciado, fugindo do tradicional modelo de priorização de um único segmento e avançando sobre aspectos culturais e ligados a vocação turística da llha. 


\section{Quais são os principais objetivos a médio e longo prazo?}

$\mathrm{Na}$ verdade, como tem poucas vantagens de localização, o Parque tem que buscar outros diferenciais. Segundo FIATES: "Temos que criar um ambiente muito mais ousado que o atual, para fazer o diferencial e sair do modelo bonsai."

Estimativa de Resultados para o ano 2020:

- 30 mil postos de trabalho

- 1,2 milhões de metros quadrados construídos

- $\mathrm{R} \$ 1,3$ bilhões de investimentos nos empreendimentos

- $\mathrm{R} \$ 150$ milhões de investimento na infra-estrutura básica

- 400 empresas inovadoras

- $\mathrm{R} \$ 1,5$ bilhões/ano de receitas das empresas

- $\mathrm{R} \$ 450$ milhões/ano em impostos

- Entre 20 e 40 mil empregos indiretos

$\Rightarrow$ Interações e relação Universidade-empresas

11. Qual a relação do SAPIENS com o poder público? Existem ações elaboradas com

o poder público para manter o SAPIENS competitivo e em expansão? Quais? (políticas públicas)

A Fundação CERTI tem sido útil para o governo, de forma geral. No entanto, estão convencidos que devem ter duas entidades no Parque Tecnológico: uma .com e uma .org. A entidade .org oficialmente vai desempenhar as funções mais técnico-científicas. Ambas com uma governança integrada, porém com as especificidades resguardadas. Determinados segmentos da sociedade civil ainda não atuam bem ou aceitam bem o "S.A.".

Fizeram visitas e negociações do país e no exterior para atrair empresas para a região. $\mathrm{Na}$ maioria, as empresas não querem entrar em um "empreendimento pequeno" - o tipo de empresas que estão atraindo em termos de empresas âncora (como a SIEMENS) preferem estruturas maiores. Estão tentando inclusive desenvolver projetos mais vultuosos, inclusive negociação com bancos privados - que pretendem instalar uma base operacional no Parque, por exemplo.

\section{Há vínculos econômicos / tecnológicos com outras regiões do país, ou mesmo com o exterior? (parcerias/cooperação)}

LABELECTRON - Laboratório fábrica de desenvolvimento e testes de produtos e processos eletrônicos (com o apoio da ALCATEL para a sua implantação) - algumas empresas de São Paulo também utilizam a planta (inclusive a TOSHIBA de São Paulo) - eles criaram uma empresa que gerencia este laboratório fábrica como empresa privada $-25 \%$ do tempo do laboratório é dedicado às universidades para o desenvolvimento de novos produtos e tecnologia. Isto porque as empresas não conseguem tempo em sua produção para fazer 
prototipagem, assim apóiam as pequenas e médias empresas, que são as mais atingidas com este problema.

Estão junto do MCT criando uma rede em outras cinco cidades para a criação de laboratórios semelhantes. Tem uma design-house para atender as pequenas empresas (não fazem chips - que faz isso é o CIENTEC no Rio Grande do Sul - fizeram uma parceria com eles).

13. Considerando a experiência do modelo teórico adotado no SAPIENS, quais são os requisitos fundamentais necessários para a transformação de agentes públicos e privados (Estado Instituições Acadêmicas $x$ Empresas) em Parques Tecnológicos?(Estudo de Caso)

Breve relato cronológico:

1960 - Criação da Univ Fed de Santa Catarina

1962 - Implantação da Escola de Engenharia Industrial da UFSC

1974 - Convênio de Cooperação Brasil Alemanha

1984 - Criação da Fundação CERTI (convênio CNPq)

1986 - Criação da ACATE (condomínio industrial de informática)

1986 - Criação da Incubadora Empresarial Tecnológica e do Condomínio Empresarial de Informática

1991 - Institucionalização do Tecnópolis

1993 - Inauguração do Parqtec ALFA

1995 - Inauguração do CELTA

2002 - Criação do LabElectron

2002 - Criação do SAPIENS Parque S.A.

Com a criação da UFSC em 1960 - foi criada uma área de tecnologia - de engenharia industrial (por não ter indústria em Florianópolis - foram criadas algumas práticas - como professores com dedicação integral e com doutorado no exterior e com uma cultura de trabalho com interação com empresas). Uma geração depois (24 anos depois) foi criada a fundação CERTI - para intensificar a relação com empresas. Desafio - como absorver a mão-de-obra qualificada que saía da universidade? Criado na época o condomínio industrial de informática e a incubadora. Em 1991 evoluiu para o modelo de Tecnópolis (ação estruturante: Parque Tecnológico ALFA - 1993); Em 1995, o CELTA passa a operar em prédio próprio sendo uma unidade da Fundação CERTI; em 2001 quando o ALFA estava ocupado, começaram o projeto do SAPIENS (março/2006).

A primeira área que deu origem a fundação - metrologia e instrumentação (totalmente credenciada na Rede Brasileira de Calibração e na Rede Européia de Calibração - trabalham principalmente com grandezas mecânicas): ensaios e testes de confiabilidade, medições automatizadas, medições padrões,etc... - garantia de qualidade e processos produtivos (fazem 
desde o projeto de fábrica, implementação desistemas de garantia de qualidade e estruturação de processo produtivo).

Metodologia> SINAPSE - sistema que integra a criação e desenvolvimento de empresas desde a universidade até o mercado. Criaram uma empresa de venture também (CVenture).

\section{Ainda de que forma as possíveis assimetrias inter-atores dos PTs podem afetar negativamente 0 desenvolvimento do Parque (sua organização produtiva, as relações com os demais agentes locais/ regionais)? (cultura, linguagem, canais de acesso)}

A llha de Florianópolis tradicionalmente nunca foi um local atrativo para as empresas, sendo que a estrutura de governo sempre demandou esforço para alterar esse contexto. $O$ trabalho da Fundação Certi, a qual está inserida no contexto da Universidade Federal de Florianópolis, com o projeto com o projeto do Parque Alfa começou a alterar esse quadro, levando a uma aproximação maior com o poder público em nívei estaduais e municipais. Hoje os órgãos de governo são importantes atores nos projetos desenvolvidos no ambito da Fundação Certi, tornando-se sócios e dividindo riscos de investimentos. Esse movimento tende a tornar O Parque Sapiens como ponto de atração de empresas em diversos segmentos, sobretudo, aqueles relacionados a vocação naural da llha.

PARQUE TECNOLÓGICO ALFA - ocupado por empresas que faturam já em nível de mercado - tem concentração em tecnologia da informação e comunicação, mas não têm restrição de setor. A empresa precisa ter atividades que a infra-estrutura existente seja suficiente.

A partir do final do ano 2000, o SAPIENS nasceu por discussões sobre como iriam sobreviver no mundo globalizado - competição acirrada.

A grande empresa nacional que surgiu a partir de parque tecnológico é a BEMATEC (fatura 250 milhões de reais). O comportamento, neste setor, é o do tipo "bonsai".

O objetivo é sair desta situação - para um sistema mais equilibrado com empresas pequenas, mas também com empresas com maior relevância (com impactos significativos de visibilidade, agentes econômicos, agentes sociais).

Como Florianópolis é pequena esses empreendimentos já são relevantes para a sociedade local (turismo e tecnologia).

Mapearam 30 localidades em Florianópolis e optaram por uma determinada área (que é de uma vez e meia a área do centro de Florianópolis). A área era do governo do estado (com um projeto de parques temáticos, etc..). Por questões ambientais, o máster plan foi especialmente desenvolvido. Foi feito um trabalho para o desenvolvimento deste parque desde 2001 (incluindo consultorias internacionais). Estão instalados, atualmente, no marco zero - antiga casa da fazendo (que depois da década de 60 foi convertida em colonia penal agrícola - que 
foi desativada). Têm cerca de 100 pessoas trabalhando lá. Em função do plano diretor somente prédios de 4 pavimentos. Projetaram 4 lagos artificiais (para material de aterro) - o projeto está servindo como uma melhoria urbanística para a região.

O projeto foi licenciado em 4 fases, para que ao longo de 20 anos o empreendimento esteja todo implantado.

Não terá ocupação residencial, pois não há demanda. É uma região de sazonalidade (principalmente paulistas) - os turistas preferem hotéis e pousadas. No entorno existem 20 milhões de área com potencial residencial. Foi também uma estratégia, pois o empreendimento foi declarado de utilidade pública - o que facilitou as licenças ambientais. A área era de rural urbana e o plano diretor foi alterado em 2003 para serviços especiais, institucional, parque tecnológico. Foi criada uma lei específica para a área do Parque Tecnológico. Essas alterações deram uma valorização de quase 50 milhões de reais na área.

Eles conceberam o projeto como empresa - eles não doam área para empresários, eles vendem áreas - é um empreendimento imobiliário. Foi a melhor solução. É uma empresa S.A. (com a controladora sendo uma empresa de economia mista) - o patrimônio foi integralizado para a empresa. O capital social da empresa hoje é 230 milhões de reais (210 milhões foram integralizados pelo governo do estado - no valor da área). Todo o dinheiro colocado pelo estado foi por integralização. 


\section{Relatório de Visita TECNOPUC}

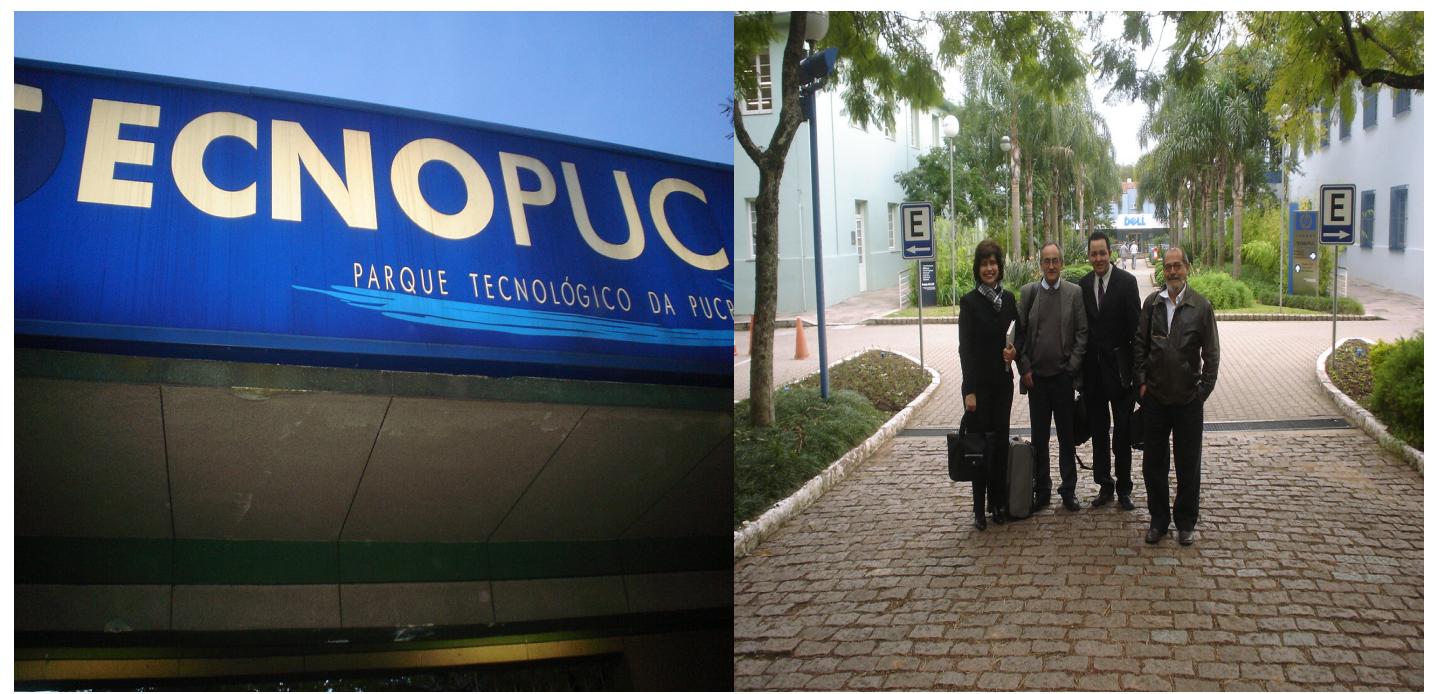

Coordenação:

Dra Désirée Moraes Zouain - IPEN-USP/PGT-USP

Pesquisadores:

Msc. Devanildo Damião - Doutorando - PGT-USP

Dr. Carlos Alberto Graça - PGT-USP/Torricelli

Wazdat de Oliveira - Secretaria de Desenvolvimento de Guarulhos 


\section{Contexto}

O relatório apresentado a seguir é parte integrante do Projeto de Políticas Públicas do Município de Guarulhos para o desenvolvimento de um ambiente social e tecnológico a ser consolidado, tendo como âncora um ambiente de inovação.

A coleta de informações foi estruturada a partir de um questionário qualitativo com enfoque em quatro dimensões: infra-estrutura, governança, estratégias e interações inerentes ao habitat de inovação TECNOPUC-RS.

O questionário foi aplicado na visita técnica desenvolvida na cidade de Porto Alegre nos dias 25 e 26 de junho de 2008 e os entrevistados foram: Sr Edemar de Paula - Gestor de Relacionamento TECNOPUC, Sra. Gabriela Cardozo Ferreira - Coordenadora INOVAPUC, Sr Vicente Zanella - Coordenador Acadêmico RAIAR, Sra. Marli Elizabeth Ritter dos Santos Coordenadora ETT.

\section{Questionário $\Rightarrow$ Governança}

\section{Qual é a estrutura de governança do TECNOPUC? (tomada de decisão)}

O Parque Científico e Tecnológico TECNOPUC foi criado em agosto de 2003 pela Universidade PUCRS (Pontifícia Universidade Católica do Rio Grande do Sul), que é dirigida pelos irmãos maristas e cujo atual reitor, irmão Joaquim Clotet, acredita muito na relação Universidade - Empresa e no empreendedorismo. A PUCRS tem mais de vinte e seis mil estudantes nos seus cinqüenta cursos de graduação, e mais de cinco mil estudantes divididos entre os cento e quinze cursos de pós-graduação lato-sensu e os quarenta e um cursos de pós-graduação strictu-sensu. Atualmente, a PUCRS é uma das primeiras colocadas no ranking de universidades privadas e grupos de pesquisa do país.

Em meados da década de 90, ao realizar seu planejamento estratégico para os anos futuros, a PUCRS definiu que iniciaria um movimento importante em prol da ciência e da tecnologia e da busca por uma aproximação Universidade - Empresa e que, entre outras metas, teria próximo ao ano de 2000 um total de hum mil mestres e doutores. Hoje esse número já foi ultrapassado e a Universidade conta com cerca de hum mil e oitocentos e cinqüenta professores, dentre os quais, $85 \%$ são mestres e doutores.

Assim, surgiu o TECNOPUC que é estritamente PUC, está diretamente ligado aos departamentos de pós-graduação da Universidade, e foi criado com o objetivo de interagir o conhecimento de base, desenvolvido a partir da pesquisa na Universidade - PUC, com o tecido 
empresarial que possui o mercado para vender o produto resultante da aplicação prática desse conhecimento.

Outro elemento indutor do processo foi o Porto Alegre TECHNOPOLE, cuja equipe treinada por pesquisadores franceses, realizava projetos locais envolvendo a UFRS (Universidade Federal do Rio Grande do Sul), a UNISINOS (Universidade do Vale do Rio dos Sinos) e a PUCRS, nos quais identificavam necessidades das pequenas empresas e buscavam soluções em parceria com grupos das Universidades. O Porto Alegre TECHNOPOLE está desativado, mas existe o interesse na região em reativá-lo, considerando as ações positivas geradas e o nível de articulação feita no passado que gerou casos de sucesso, como por exemplo, a instalação da Motorola P\&D no Brasil. Atualmente, a UFRS, a UNISINOS e a PUCRS não têm projetos em comum, nem parcerias.

O Modelo de governança do TECNOPUC está baseado no modelo americano de Parques Tecnológicos que surgiram a partir das Universidades.

A estrutura de governança do TECNOPUC é formada por um Comitê Gestor interno à Universidade, do qual fazem parte os pró-reitores de Pesquisa e Pós-Graduação-PRPPG (Presidente), Extensão-PROEX, Administração e Finanças-PROAF, Procuradoria JurídicaPROJUR e a Direção da Agência de Gestão Tecnológica-AGT.

O TECNOPUC tem uma grande infra-estrutura instalada dentro da PUCRS que abriga também estudantes de mestrado e doutorado do exterior.

No processo de desenvolvimento e expansão do Parque, realizou-se uma importante aproximação com os fabricantes de equipamentos de informática DELL Computadores do Brasil e HP (Hewlett-Packard Development Company), a qual propiciou o início da utilização da Lei de Informática e dos Fundos Setoriais de Ciência e Tecnologia para ampliação de material permanente no Parque.

\section{Qual é a figura jurídica que administra o TECNOPUC? (grau de formalidade), a AGT desenvolve esse papel?}

O TECNOPUC, bem como, a AGT (Agência de Gestão Tecnológica), a Incubadora Raiar, o ETT (Escritório de Transferência de Tecnologia) e os outros organismos associados ao funcionamento do TECNOPUC, estão subordinados à pró-reitoria de pesquisa da PUCRS, cujo atual pró-reitor é o Professor Dr. Jorge Audy.

Os profissionais que atuam nestas instituições são funcionários da PUCRS, alguns com carreira de docente e outros estagiários. As Instituições funcionam como um departamento da Universidade e não têm personalidade jurídica.

Por sua vez, a gestão dos seus projetos é realizada pelo meio da AGT (Agência de Gestão Tecnológica) que curiosamente é um departamento mais antigo que o próprio TECNOPUC. 
A AGT que é um departamento da pró-reitoria da Pós-graduação da PUC, e é responsável por toda interação universidade $X$ empresas. Conta com uma equipe de 13 membros para atuação como elo no processo de interação Universidade-Empresa, viabilizando e estimulando a criação de Projetos conveniados com atores do tecido empresarial e/ou governo, articulando as necessidades do mercado com as competências existentes na Universidade.

Tida como o órgão gestor do TECNOPUC, hierarquicamente vinculado à Pró-Reitoria de Pesquisa e Pós-Graduação (PRPPG), que dá a orientação macro, cabendo a AGT a responsabilidade pela execução das políticas definidas pelo seu Comitê Gestor.

Desta forma, a AGT pode ser entendida como o instrumento pelo qual o Comitê Gestor (Governança), coordena e articula as diferentes áreas da PUC com atores internos e externos em diferentes aspectos de negócios ligados à dinâmica inovativa que acontece no Parque.

O Conselho Gestor do TECNOPUC é formado por órgãos internos da PUCRS, não houve interesse deles em agregar outros atores.

Embora a estrutura física e de profissionais seja totalmente dependente da Universidade, existe uma agilidade na execução das atividades e prestação de serviços, justificada principalmente pelo comprometimento de todos os departamentos da PUCRS e também pelo fato de ser uma Universidade privada.

Atualmente, a AGT gerencia 93 projetos e a equipe ainda não consegue atuar de forma pró-ativa, respondendo por enquanto somente às demandas espontâneas. No entanto, existe uma expectativa de modificar isto, elaborando um planejamento que possa detectar, entre outros, potenciais no mercado e também riscos e problemas dos projetos.

A Universidade ainda não tem benefícios financeiros diretos com o TECNOPUC, mas sim, benefícios indiretos gerados pela maior atração de novos alunos pagantes, pelas oportunidades detectadas no TECNOPUC e na evolução dos grupos de pesquisa (atualmente têm reconhecimento da CAPES - Coordenação de Aperfeiçoamento de Pessoal de Nível Superior - com conceito quatro na Pós-Graduação - Mestrado e Doutorado - em Ciências da Computação), financiamento de bolsas de empresas, etc.

AGT: A Agência de Gestão Tecnológica - AGT - criada em dezembro de 1999 pela Reitoria da PUCRS, como desdobramento do que previa seu planejamento estratégico, tem o objetivo de centralizar em um único órgão as atividades de apoio a execução de projetos de P\&D desenvolvidos em regime de cooperação com empresas. Atualmente, a AGT faz toda gestão da relação Universidade-Empresa, intermediando a relação entre os pesquisadores e entidades públicas e privadas, visando à melhoria da qualidade do ensino, da pesquisa e da extensão na PUCRS.

O coordenador de gestão do programa na AGT é o Professor Dr. Marcelo Blois Ribeiro e os projetos somente são aprovados se existir o envolvimento de alunos e gerar benefícios para 
a Universidade no âmbito do avanço de conhecimentos e/ou aumento de equipamentos. Recentemente, há também a participação do governo em alguns dos projetos.

\section{Quais são os atores da iniciativa privada, pública e da academia que formam o TECNOPUC? (representatividade $x$ articulação)}

O TECNOPUC como observado anteriormente está estruturado no binômio, universidade $X$ empresas, contando com uma grande universidade, dotada de vários Institutos e Unidades Acadêmicas de Pesquisa, e empresas de diferentes portes que vieram a se estabelecer no parque. Conta também com incubadoras de empresas que abrigam spin-offs, de projetos acadêmicos e de empresas localizadas no TECNOPUC, bem como empresas start-ups de alunos oriundos de cursos oferecidos pela PUC.

Em relação ao aspecto de participação das organizações públicas e privadas de desenvolvimento científico, ela é indireta e ocorre por meio de financiamentos das agências de fomento (FAPERS, FINEP, CNPq, SEBRAE, ANPROTEC, FIERGS e outros), com apoio a projetos específicos.

A estrutura de gestão estratégica do parque, conforme discutido acima está ligada aos departamentos de Pós-graduação da Universidade (Reitorias), e tem na AGT a gestão operacional que comanda a articulação entre atores multi-setoriais.

\section{Quais são as empresas âncoras do TECNOPUC? (lideranças do tecido empresarial)}

Atualmente, o TECNOPUC possui quarenta e duas empresas instaladas, entre as quais, HP, DELL, MICROSOFT- Centro de Treinamento, STEFANINI, DBSERVER, TLANTIC Empresa do Grupo SONAE, DATACOM, INPAR, e também oito instituições, tais como, ASSESPRO, SOFTSUL, CEITEC, AJE, PMI, ABINEE/RS, FUNDAÇÃO PENSAMENTO DIGITAL.

As âncoras empresariais do TECNOPUC são: DELL que emprega cerca de quatrocentas pessoas e a HP com cerca de quinhentas pessoas. Essas empresas desenvolvem atividades de pesquisa e desenvolvimento dentro do Campus da PUC, principalmente no desenvolvimento de softwares. É importante frisar que essas empresas geram por meio de sua atuação os spin-offs (surgimento de outras empresas a partir delas). Possui também a presença de laboratórios de pesquisa da Microsoft.

Merece destaque o alinhamento dentre as tecnológicas desenvolvidas no Parque e as necessidades de mercado que as empresas âncoras sinalizam, levando a uma gestão compartilhada entre o pesquisador e o executivo da empresa parceira.

Existem também sete Centros de Pesquisa da PUCRS localizados no TECNOPUC que contam com parcerias de empresas, em projetos de pesquisa cooperativa, envolvendo atualmente sessenta pesquisadores em cinqüenta projetos de P\&D. Os Centros são: Centro de 
Pesquisa em Nanotecnologia, Centro de Pesquisa em Biologia Molecular e Funcional, Centro de Pesquisa em Energia Solar Fotovoltaica, Centro de Pesquisa de Radiação e Energia, Centro de Pesquisa em Energia Elétrica, Centro de Pesquisas da Petrobras e Centro de Pesquisa de Farmácia.

Contam com mais de duas mil e quatrocentas pessoas envolvidas nos trabalhos, das quais cento e sessenta e duas cursam mestrado e doutorado pagos pelas empresas em que trabalham, além de duzentas e duas bolsas de graduação, proporcionadas pelo fundo arrecadado pelo TECNOPUC para apoio à graduação.

\section{$\Rightarrow$ Infra-estrutura}

\section{Qual é o papel da Raiar, existem outras incubadoras no TECNOPUC? (aspectos da inovação)}

A PUCRS no sentido de cumprir sua missão de criar uma comunidade de pesquisa e inovação interdisciplinar por meio da colaboração entre academia, empresas e governo visando aumentar a competitividade dos seus atores e melhorar a qualidade de vida de suas comunidades, possui quatro principais operações em seu campus: o TECNOPUC, A AGT, O ETT e a RAIAR.

Um dos quesitos que contribuíram para o sucesso do TECNOPUC foi o fato de que eles dispõem de estrutura física para oferecer às empresas. Assim, as empresas podem pagar para usar o espaço, que é exclusivo do TECNOPUC, delimitado por portarias cujo acesso é feito por identificação pessoal, e ainda usufruir de serviços diversos disponíveis no campus da Universidade, favorecendo a integração com as diferentes atividades da PUCRS.

INCUBADORA RAIAR: A Incubadora foi inaugurada em novembro de 2003, é um dos ativos do TECNOPUC, e possui três campi: Porto Alegre, Viamão e Uruguaiana. É um espaço para o aluno empreendedor a partir do seu projeto de pesquisa. Abriga empresas spin-offs que surgiram de projetos acadêmicos e demandas das empresas âncoras e possui infra-estrutura e processo de incubação bem estruturado com acompanhamento de resultados por meio de painel de indicadores tipo BSC. O faturamento das empresas da incubadora alcançou $R \$$ 4.250.000,00 em 2007. Possui dezoito empresas incubadas.

Dados recentes da ANPROTEC (Associação Nacional de Entidades Promotoras de Empreendimentos Inovadores) mostram que o Brasil já ultrapassou o número de quatrocentas incubadoras e que a maioria está concentrada nas regiões sul e sudeste do país.

Uma das atuais preocupações da RAIAR é incentivar a venda de produtos integrados, ou seja, proporcionar aos clientes soluções sistêmicas e não apenas parte das soluções. Eles sabem que precisam oferecer soluções integradas, trabalhando seus produtos de forma que os 
mesmos tenham melhor condição de competir no mercado. Pretendem inclusive incentivar a articulação entre as empresas incubadas, a fim de as mesmas possam propor soluções conjuntas para o mercado.

INFRA-ESTRUTURA: A RAIAR foi criada após o Parque Tecnológico, no contra-fluxo do processo observado na maioria dos casos, pois ela veio com a demanda gerada a partir da necessidade de atender aos alunos da PUCRS, que apoiados por bolsas corporativas tinham interesse em criar empresas baseadas em seus projetos de pesquisa. E assim a Incubadora surgiu ocupando um prédio do dormitório dos sargentos no antigo quartel.

Com o tempo, a Incubadora passou a receber não somente os alunos, mas também spinout das empresas instaladas no Parque, como HP e DELL. Um exemplo citado foi o caso da empresa que testa softwares, como os da HP, que começou com quatro funcionários instalados na Incubadora e atualmente conta com mais de cinqüenta colaboradores que testam softwares não somente para empresas do Brasil, mas também para empresas do exterior. Esse caso acabou atraindo o interesse de outras empresas para incubar novos projetos na RAIAR.

Ainda no primeiro ano de existência, a Incubadora verificou que tinha uma demanda muito grande de projetos, sendo necessário inclusive dividir os projetos entre o campus de Viamão e o campus de Uruguaiana. Nessa unidade de Uruguaiana existe um diferencial que é uma parceria estabelecida entre a PUCRS, que oferece o know-how e faz a gestão da Incubadora; a Associação Comercial que oferece o espaço físico e a Prefeitura que apóia institucionalmente o projeto.

Atualmente, a Incubadora conta com uma equipe de treze profissionais, sendo que cinco pessoas estão envolvidas diretamente na gestão da incubadora e oito pessoas são bolsistas e estagiários para apoio às atividades gerais e das empresas incubadas relacionadas às suas especialidades de estudo. Sempre que necessário, são contratados consultores técnicos para auxiliar em situações específicas, tais como, temas de exportação, etc.

PROCESSO DE INCUBACÃO: A Incubadora parte do princípio de que deve dar apoio ao empreendedor naquilo com que ele não sabe lidar, ou seja, principalmente na gestão do negócio, pois normalmente o empreendedor é um profissional que vem de uma área mais técnica, de pesquisa e desenvolvimento e não está acostumado com a linguagem administrativa e comercial do negócio.

A incubação divide-se em cinco etapas principais, sendo que as etapas 2, 3 e 4 devem acontecer em aproximadamente três meses e a etapa 5 pode durar até doze meses, são elas:

ETAPA 1: Pesquisa e decisão sobre o nome da empresa e marca

ETAPA 2: Plano de Negócios - nesta fase incluem-se também os casos de custos da embalagem, manual, impostos, etc., além do trabalho de identidade visual da empresa e divulgação junto a imprensa. Vale a pena destacar que a Incubadora conta com programadores 
visuais e assessoria de imprensa, a qual já conquistou credibilidade junto a mídia, transformando a Incubadora em fonte de informações para compor pautas jornalísticas.

ETAPA 3: Conceituação e elaboração do mix de marketing - nesta fase a Incubadora auxilia o empresário a entender melhor como seu produto pode ser apresentado ao mercado, as características de destaque, os pontos fortes e fracos, enfim, o empresário começa a entender a realidade do posicionamento de seu produto no mercado.

ETAPA 4: Elaboração de Plano Financeiro

ETAPA 5: Acompanhamento - A Incubadora pretende que a empresa incubada seja modelada no primeiro ano de incubação, concomitante, existe um trabalho de busca de qualificações específicas que atendam às necessidades dos incubados. A Incubadora não realiza treinamentos abertos com temas genéricos. A equipe da RAIAR busca temas específicos para treinamentos que realmente possam agregar conhecimento, a partir da identificação de problemas e dificuldades de cada empresa.

SISTEMA DE ACOMPANHAMENTO DAS ETAPAS: A Incubadora possui um sistema simples de acompanhamento e registro das informações geradas pelas empresas, durante estas etapas citadas anteriormente, o qual é gerido por uma equipe de oito profissionais. No entanto, os documentos formais de acompanhamento ainda são gerados em papel, processo que eles pretendem melhorar. Com este acompanhamento eles dizem "tirar um retrato" da RAIAR de seis em seis meses.

COMPROMISSO ENTRE A INCUBADORA E OS INCUBADOS: É importante destacar que existe um compromisso das empresas incubadas em fornecer dados reais e completos para a Incubadora, incluindo informações financeiras, a fim de que a Incubadora possa, a partir dos dados, elaborar relatórios para o acompanhamento individual e coletivo das empresas. As empresas incubadas que não fornecem dados não recebem liberação para execução de serviços, tais como, elaboração de banners, material promocional, etc. São realizadas reuniões semanais que enfatizam também a conscientização dos incubados sobre a importância em cumprir os compromissos com a Incubadora.

PÓS-INCUBACCÃO: Na última etapa da incubação, a RAIAR prepara a empresa incubada e o plano de negócios para submeter-se ao capital de risco, ou então, para buscar um financiamento, etc. Existe também um apoio no momento da empresa tornar-se independente e buscar um espaço físico fora da Incubadora. Como a empresa incubada passa por várias etapas e vai conquistando essa independência, pagando suas despesas, entre outras coisas, a pós-incubação não é uma etapa traumática, pois a empresa que chega no momento de sair está madura e com uma visão realista do mercado que vai encontrar fora da Incubadora e da Universidade. 
Por enquanto, não existem documentos formais tratando da relação da pós-incubação, mas a Incubadora já atua nesta etapa com aquelas empresas que desejam manter um a relação com a Incubadora.

\section{PRÁTICA INTERESSANTE:}

ANIVERSÁRIOS DA INCUBADORA: Em cada aniversário da Incubadora realizam-se eventos que privilegiam um tema específico, por exemplo, no segundo aniversário o tema foi "As pessoas nas Empresas"; no terceiro aniversário: "Os frutos da RAIAR" - neste caso as mais de trinta empresas apresentaram seus projetos; no quarto aniversário o tema foi "Ganhando o cliente" - em que foram abordadas ações para atrair e manter os clientes.

NÚMEROS DA INCUBADORA: Contabilizam cento e treze propostas recebidas e trinta e nove empresas selecionadas nas áreas de informática, engenharia, saúde, telecomunicações e tecnologia da informação.

As empresas incubadas já lançaram cinqüenta e cinco novos produtos e vinte novos serviços no mercado.

Houve um grande aumento no número de bolsistas atuando nas empresas.

RATEIO DOS CUSTOS: A participação financeira da PUCRS na gestão da RAIAR vai tornando-se menor, pois a Incubadora a cada ano que passa vai à busca de uma situação de menor dependência financeira, contando com a contribuição das taxas pagas pelas empresas incubadas e graduadas.

AÇÕES ESTRATÉGICAS PARA 2008: Implantação de um sistema de BSC (Balanced Scorecard), que está em andamento, e tem como perspectiva financeira a captação de recursos e subsídio da entidade gestora, para tanto, criaram quatorze indicadores e respectivas metas. $\mathrm{E}$ também dar continuidade ao processo do registro da marca.

\section{Qual é a área total do TECNOPUC? E quais os seus ativos?}

A área total do TECNOPUC está em 5,4 hectares (ha) com uma área construída de dezoito mil metros quadrados que será dobrada com a construção do novo prédio que se encontra em obras. A sua estrutura física é composta de prédios e edificações espalhadas pela área do TECNOPUC, onde são identificados a incubadora de empresas, os condomínios empresariais, os laboratórios de P\&D das empresas das empresas âncoras. Também estão presentes representantes de entidades de classe como ABINEE, ASSESPRO, SOFTSUL, CEITEC, PMI e outras, totalizando 08 instituições.

Os colaboradores das empresas do TECNOPUC podem usufruir dos mesmos espaços, facilidades e oportunidades que são oferecidas aos alunos da PUCRS, tais como, livre acesso à Biblioteca, Centro Esportivo, Estacionamento, etc. 
O investimento das empresas inclui um valor de locação pelo espaço físico utilizado, uma taxa de rateio das despesas de manutenção externa do Parque, valores referentes aos projetos de pesquisa de interesse das partes, além dos valores de energia elétrica, telecomunicações, instalações lógicas e benfeitorias feitas na unidade.

A previsão de expansão do TECNOPUC compreende na FASE II - ampliação de dois mil e quatrocentos metros quadrados para a área de TIC, além do prédio que já está em construção para abrigar o Portal PUC com dezoito mil metros quadrados; e na FASE III - a utilização completa do prédio de um antigo Seminário na cidade de Viamão, localizada a doze quilômetros da PUCRS.

\section{Quais são as principais atividades que são desenvolvidas no TECNOPUC? (grau de diversificação)}

As principais áreas de concentração das atividades das empresas são: tecnologia da informação e comunicação (TIC), eletroeletrônica, energia e física, biotecnologia. $\mathrm{Na}$ área de biotecnologia existe uma grande expectativa de sucesso em um projeto envolvendo um laboratório de controle de qualidade de insumos importados para a elaboração de vacinas e remédios que já conta com recursos da FINEP (Financiadora de Estudos e Projetos do Ministério da Ciência e Tecnologia) e com parceria com a ANVISA (Agência Nacional de Vigilância Sanitária) e no qual já foram investidos $\mathrm{R} \$ 5$ milhões na compra de equipamentos.

\section{Como o órgão gestor administra os processos relacionados à gestão do conhecimento, propriedade intelectual, qualidade, etc. (coordenação).}

A gestão da proteção da propriedade intelectual, basicamente marcas, registro de propriedade intelectual (patentes, softwares), gestão do conhecimento, estão a cargo do Escritório de Transferência Tecnológica-ETT, atuando como órgão de apoio à AGT, na medida em que todas as questões que passam pela AGT são respaldadas pelo ETT.

ESCRITÓRIO DE TRANSFERÊNCIA DE TECNOLOGIA: O ETT foi criado em março de 2005 e é considerado uma experiência recente da Universidade. Está ligado à reitoria de pesquisa de pós-graduação e localiza-se no Parque Tecnológico. Surgiu a partir da necessidade de proteger o patrimônio intelectual da Universidade e promover a transferência dos resultados de pesquisa ao setor produtivo, buscando fortalecer e ampliar a inserção da PUCRS na sociedade.

O ETT faz registro da propriedade intelectual, transferência de tecnologia e capacitação de recursos humanos neste temas. A prioridade dos trabalhos é dada à comunidade universitária, mas também presta serviços para as empresas que estão no espaço da Universidade, como as empresas da Incubadora RAIAR. No caso da Incubadora, quatro empresas já tiveram suas marcas registradas. 
As ações do ETT estão respaldadas em dois objetivos institucionais principais: estabelecer e promover, em consonância com a PRPPG, a política institucional de propriedade intelectual e transferência de tecnologia; e implementar e divulgar os procedimentos necessários à proteção da propriedade intelectual dos resultados de pesquisa realizada nas diferentes unidades da Instituição, bem como os relacionados à transferência de tecnologia através da comercialização de ativos, protegidos ou não, de propriedade da PUCRS.

No que se refere à capacitação de recursos humanos, tem um importante papel de multiplicador dos conceitos de propriedade intelectual, a partir de cursos e seminários que são ministrados, por exemplo, em parceria com o INPI (Instituto Nacional da Propriedade Industrial), o IEL (Instituto Euvaldo Lodi) e o Escritório Americano de Patentes.

A atuação do ETT está diretamente ligada à AGT, todos os projetos que passam pela AGT, mesmo aqueles que não caracterizam proteção à propriedade intelectual, têm o parecer do ETT. E o trabalho tem como princípio o fato de que como os direitos de propriedade intelectual vão ser divididos entre os parceiros, devem ser estabelecidos antes do início do desenvolvimento e da relação.

O ETT conta com seis profissionais de formação variada, a fim de oferecer melhor suporte às demandas.

SIGILO: A manutenção do sigilo é de responsabilidade do coordenador do projeto. O ETT fornece um termo de confidencialidade. São assinados também acordos de confidencialidade antes de iniciadas as relações com as empresas, algumas vezes estes acordos são assinados ainda na fase de prospecção ou captação de projetos

O ETT NÃO TEM AUTONOMIA COM RELAC̄ÃO À PROCURADORIA JURÍDICA: A PUCRS é uma entidade sem fins lucrativos, filantrópica e tem uma instituição mantenedora, 0 que a faz ter uma estrutura bastante complexa, que precisa cumprir uma série de legislações. Um dos procuradores jurídicos está alocado na AGT e é o primeiro interlocutor do ETT. E no ETT existe um advogado que auxilia nas tratativas jurídicas para elaboração de documentos formais. Assim, o documento chega à AGT já bastante avançado, o que facilita muito a tramitação. As questões de maior complexidade jurídica, como por exemplo, os contratos de licenciamento, têm processos mais demorados e são encaminhados à Procuradoria Jurídica da Universidade - Projur.

RESULTADOS: Entre os anos de 2002 e 2006 depositaram vinte patentes, mas no ano de 2007, depositaram dez patentes, assim, o ETT vem conquistando resultados muito significativos. No final do mês de maio de 2008, firmaram o primeiro contrato de licenciamento com um laboratório farmacêutico, e a PUCRS ficou com 52\% da planta que está sendo desenvolvida. O ETT tem também uma patente que, embora não esteja licenciada oficialmente, já permitiu captar projetos na ordem de $\mathrm{R} \$ 30$ milhões. As patentes têm uma grande importância para dar visibilidade da expertise dos pesquisadores e estão disponíveis na página do ETT na internet no item catálogo de patentes. 
A PUCRS tem submetido patentes a uma Feira de Tecnologia dos EUA que este ano aconteceu em Boston. Este evento reúne empresas e tecnologias de universidades do mundo inteiro. As grandes empresas têm espaço para apresentação dos seus portfólios, interesses e estratégias. O feedback obtido é muito importante, pois as patentes são submetidas a um comitê de julgamento que dá um retorno com informações sobre o real valor das patentes analisadas.

\section{$\Rightarrow$ Estratégia}

\section{Quais são as atividades econômicas que são privilegiadas no TECNOPUC?}

O TECNOPUC nasceu de uma idéia: Qual é o destino das pesquisas realizadas na Universidade - PUC? No início do século XXI, a Reitoria criou o TECNOPUC com a finalidade de assumir um novo papel na sociedade.

Essa idéia inovadora atraiu o poder público, empresas de base tecnológicas e deu sentido à aplicação prática do conhecimento desenvolvido na Universidade.

Considerando que o TECNOPUC é o espaço mais visível para fora da PUC-RS, muito embora existam internamente outras instituições importantes, deve-se reconhecer, também, tal feito como uma fantástica estratégia de marketing, através do efeito catalisador na conquista de novos alunos.

As atividades econômicas têm como âncora, pesquisas que possam gerar novas tecnologias nas áreas citadas no item 07 , e, que possam gerar valor para a sociedade.

\section{Quais são os principais objetivos a médio e longo prazo?}

A visão do TECNOPUC é ser em 2010 a referência nacional e internacional pela relevância das pesquisas com a marca da inovação.

O grande desafio do TECNOPUC está na operacionalização da Rede INOVAPUC. Tal rede congrega o conjunto de atores, ações e mecanismos relativos ao processo de inovação e empreendedorismo da PUCRS. Considerando que a PUC tem procurado responder a demandas de seus parceiros do tecido empresarial e instituições existentes, e por isso é uma referência nacional, os gestores do TECNOPUC esperam através dessa rede de cooperação inter-organizacional reunir grupos de empresas e unidades de pesquisas multi-setoriais potencializando as competências da Universidade, e a consagração do TECNOPUC. 


\section{$\Rightarrow$ Interações e relação Universidade- empresas}

11. Qual a relação do TECNOPUC com o poder público? Existem ações elaboradas com o poder público para manter o TECNOPUC competitivo e em expansão? Quais? (políticas públicas)

Conforme já discutido o TECNOPUC é estritamente PUC. A relação do TECNOPUC com o Poder Público está circunscrita a questões de desenvolvimento científico, quando as agências de fomento, dão apoio através de financiamentos a projetos específicos. Inexiste qualquer participação do poder público em ações ligadas aos destinos do TECNOPUC.

12. Há vínculos econômicos / tecnológicos com outras regiões do país, ou mesmo com o exterior? (parcerias/cooperação)

A pesquisa constatou que até o presente momento o TECNOPUC desenvolveu orientação estratégica e programas de ação voltados exclusivamente para a sua existência interna. Parcerias e programas de cooperação ocorrem no âmbito do Parque com empresas lá residentes e empresas externas, notadamente, a Petrobrás.

Todavia, embora esteja na orientação macro da Reitoria criar através do efeito transbordamento do Parque, os vínculos internacionais ainda são incipientes, sendo que atualmente podem ser categorizados a parceria com Taiwan e o processo de negociação com o Panamá; no plano nacional inexistem programas de pesquisas conjuntas com outros estados.

13. Considerando a experiência do modelo teórico adotado no TECNOPUC, quais são os requisitos fundamentais necessários para a transformação de agentes públicos e privados (Estado Instituições Acadêmicas x Empresas) em Parques Tecnológicos?(Estudo de Caso)

Podem ser listados os seguintes elementos:

$\Rightarrow$ A Universidade tem que ter áreas de Pesquisa como resposta a uma demanda da sociedade, com características de bens de mercado;

$\Rightarrow$ As empresas devem perceber aplicação direta - incentivos econômicos dessas pesquisas no seu negócio; 
$\Rightarrow A$ formação de parcerias - Cooperação Interorganizacional - Universidade $x$ Empresas x Governo, nas quais se perceba uma relação de vantagens mútuas, a partir do compartilhamento de competências entre os parceiros;

$\Rightarrow$ Orientação estratégica com foco no mercado, e Capacidade de Gestão na coordenação e articulação dos atores;

$\Rightarrow$ A importância da participação de órgãos governamentais para financiar pesquisas, pois os resultados das parcerias contribuem para 0 desenvolvimento econômico local e regional.

\section{Ainda de que forma as possíveis assimetrias entre atores dos PTs podem afetar negativamente o desenvolvimento do Parque (sua organização produtiva, as relações com os demais agentes locais/ regionais)? (cultura, linguagem, canais de acesso)}

Dentro do contexto do TECNOPUC a questão é suavizada dada a participação de apenas dois atores no processo (Universidade e empresas), sendo que existe uma tendência natural ao alinhamento de projetos conjuntos pelo fato das empresas reconhecerem as atividades de pesquisa e desenvolvimento da Universidade como importantes para o seu processo de inovação em produtos e processos para o mercado. Outro aspecto de relevância é o fato da participação dos corpos discentes e docentes nos processos de pesquisa.

REDE INOVAPUC: A INOVAPUC, que surgiu a partir de um grupo de trabalho criado no ano de 2005, é a REDE que congrega o conjunto de atores, ações e mecanismos relativos ao processo de inovação e empreendedorismo da PUCRS. Atua como uma assessoria da pró-reitoria de pesquisa e teve seu início oficializado no ano de 2006, com o objetivo de promover o processo de inovação e empreendedorismo na Universidade, articulando, para tal, todos os atores envolvidos no ensino, pesquisa e extensão.

A REDE promove um esforço multidisciplinar para buscar soluções e oferecer respostas às demandas da sociedade em termos de desenvolvimento econômico, social, ambiental e cultural, baseada nos conceitos de: Universidade empreendedora e empreendedorismo.

A INOVAPUC articula dois atores principais: o Núcleo Acadêmico, que representa as vinte e três unidades acadêmicas, os Institutos de Pesquisa da PUCRS e o Museu de Ciência e Tecnologia, e as Unidades Periféricas, que são os mecanismos institucionais mais voltados à interação com a sociedade, como o TECNOPUC, a 
AGT, O ETT, o Centro de Inovação em parceria com a Microsoft, o núcleo empreendedor, o Instituto Idéia de Pesquisa e Desenvolvimento, o LABELO Laboratório especializado em eletroeletrônica e as próprias empresas do Parque Tecnológico.

O funcionamento da REDE inclui Reuniões mensais dos gestores e Fórum com todos os participantes das unidades realizado quatro vezes por ano. O Fórum funciona como uma oportunidade de apresentação de todos os projetos, cujos problemas são discutidos em conjunto.

A INOVAPUC pretende principalmente ajudar a gerar um fluxo maior no processo de inovação e empreendedorismo, o intuito é de que aquilo que é criado pela academia possa evoluir dentro do campus da PUCRS como uma empresa incubada ou por meio da comercialização de tecnologia, etc. Para isso, a existência da várias unidades que objetivam dar apoio neste processo, tais como, o ETT e o IDÉIA.

IDÉIA: É um Instituto de P\&D, dirigido por um dos professores da PUCRS, que oferece suporte técnico ao pesquisador, como, apoio à captação de recursos em agências de fomento; laboratórios especializados em ótica, física e micro-eletrônica que prestam serviços à pesquisa na Universidade para elaboração de protótipos; incubação de projetos de pesquisa por meio de edital no qual os pesquisadores da PUCRS se candidatam. Atualmente, sua equipe está trabalhando em um projeto de relação Universidade-Empresa em que as empresas entram com sua demanda por meio do Instituto Idéia, o qual identifica os pesquisadores mais adequados para a área de atuação, promove o encontro de todos e apóia o desenvolvimento dos projetos.

NÚCLEO EMPREENDEDOR: Tem o objetivo de dar suporte ao processo de empreendedorismo em capacitação, programas de apoio de desenvolvimento, e eventos. O foco do Núcleo são os alunos da PUCRS. Foi criado recentemente e ainda está em fase de formatação e adequação. O destaque de trabalho do Núcleo foi a realização do Torneio Empreendedor, no qual os alunos apresentavam um plano de negócios para a criação de uma empresa. A premiação do Torneio incluía um valor em dinheiro e também a pré-habilitação para a incubadora RAIAR. O Torneio proporcionou também um curso de elaboração de plano de negócios e privilegiava as equipes multidisciplinares. 


\section{Relatório de Visita}

\section{Parque Tecnológico de São José dos Campos}
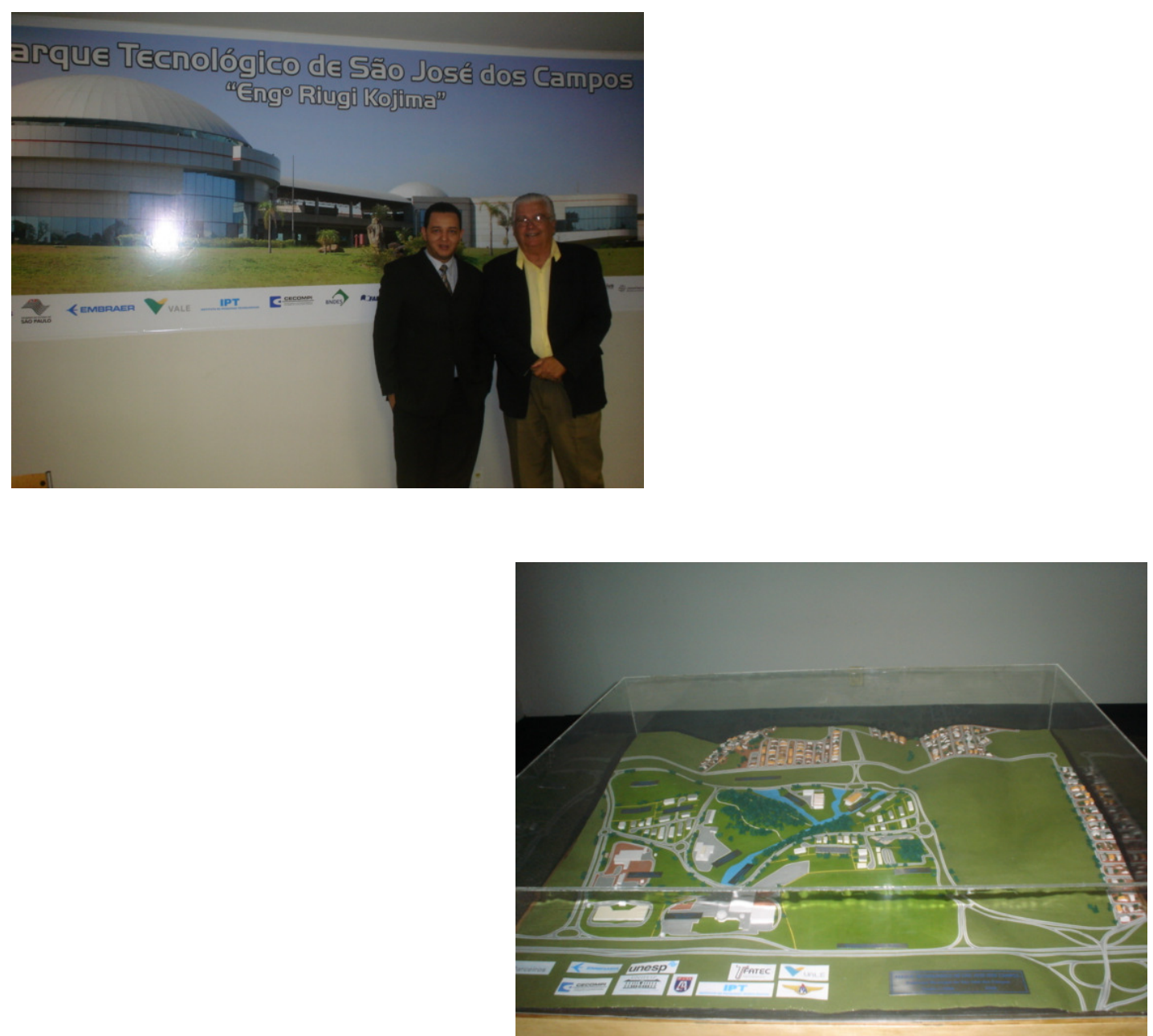

Pesquisador:

Msc. Devanildo Damião - Doutorando - PGT-USP 


\section{Contexto}

O relatório apresentado a seguir foi desenvolvido no contexto de visitas técnicas ao Parque Tecnológico de São José dos Campos ocorridas nos meses de abril e maio de 2009.

A coleta de informações foi estruturada a partir de um questionário qualitativo com enfoque em quatro dimensões: infra-estrutura, governança, estratégias e interações inerentes ao habitat de inovação do Parque Tecnológico de São José dos Campos

O questionário foi aplicado na visita técnica desenvolvida na cidade nos dias 18 de abril e 15 de junho de 2009 e os entrevistados foram: Dr. Marco Antonio Raupp - diretor do Parque Tecnológico e Angela Tornelli - Secretaria de assuntos estratégicos da Prefeitura Municipal de São José dos Campos.

\section{Questionário $\Rightarrow$ Governança}

1. Qual é a estrutura de governança do Parque Tecnológico de São José dos Campos? (tomada de decisão)

A base de governança do Parque Tecnológico de São José tem a Prefeitura Municipal como grande fomentador e órgão de apoio nos estágios iniciais do projeto.

Como ações podem ser citadas, a formação da equipe técnica e a aquisição do prédio no qual o Núcleo do Parque Tecnológico está instalado que custou 6 milhões de dólares.

O modelo de gestão do Parque está concebido com base em dois organismos, a URBAM, que é um órgão da administração Pública sendo um gestor imobiliário responsável pelas negociações envolvendo o espaço.

Em relação a entidade gestora, está sendo constituída a APTSJC, a Associação Parque Tecnológico de São José dos Campos, órgão responsável pela gestão dos ativos e também pela articulação externa. A Incubadora de Negócios sediada no Parque Tecnológico de São José dos Campos,é gerenciada pelo Cecompi.

\section{Qual é a figura jurídica que administra o Parque Tecnológico de São José dos Campos? (grau de formalidade). \\ O Parque é uma PPP (parceria público-privada), visto que envolve atividades de agentes} públicos, em níveis federal, estadual e municipal; e privados. Relacionado a figura jurídica, o Parque Tecnológico de SJC está no processo de transição de um organismo da Prefeitura para uma Organização Social, sendo constituída a APTSJC, a Associação Parque Tecnológico de São José dos Campos que é uma OS - Organização Social. 
No aspecto da Governança imobiliária, o papel é exercido pelo URBAM, que é um órgão da administração Pública.

3. Quais são os atores da iniciativa privada, pública e da academia que formam o Parque Tecnológico de São José dos Campos? (representatividade $\mathrm{x}$ articulação)

O poder público está representado nas três esferas de governo. A Prefeitura de SJC como enfatizado anteriormente tem um importante papel para o desenvolvimento do Parque. $O$ governo do Estado por meio do sistema paulista de Parques Tecnológicos e da FAPESP Fundo de amparo à pesquisa no Estado de São Paulo são outros atores de destaque. O Governo Federal participa de forma mais indireta por meio de apoio dos órgão como FINEP e BNDES. Relacionado as empresas elas evidenciam seus apoios por meio dos projetos desenvolvidos nos centros de tecnologia. Podem ser citadas a EMBRAER, A VALE, a Petrobrás como importantes parceiros. No aspecto acadêmico temos a FATEC - Faculdade de Tecnologia com um Campus no Núcleo do Parque Tecnológico, A Universidade Estadual de São Paulo - UNESP, A UNIFESP - Universidade Federal de São Paulo, o Serviço de Nacional de Aprendizagem Industrial - Senai e outras instituições que estão alocadas em projetos específicos como o ITA, a Universidade de São Paulo e outras.

Segue a relação dos financiamentos compromissados por fontes:

- PMSJC - 31,3 Milhões de Reais

- Gov. Est. SP - 17,2 Milhões de Reais

- BNDES - 112,6 Milhões de Reais

- Embraer - 45,5 Milhões de Reais

- Vale - 112 Milhões de Reais

- Sygma - 11 Milhões de Reais

4. Quais são as empresas âncoras do Parque Tecnológico de São José dos Campos? (lideranças do tecido empresarial)

Relacionado as empresas elas evidenciam seus apoios por meio dos projetos desenvolvidos nos centros de tecnologia como ocorre com a EMBRAER, A VALE, a Petrobrás, sendo importantes parceiros. A empresa Sygma investiu $R \$ 11$ milhões em projetos.

\section{$\Rightarrow$ Infra-estrutura}

5. Qual é o papel da Incubadora de projetos, existem outras incubadoras no Parque Tecnológico de São José dos Campos? (aspectos da inovação).

A Incubadora de Negócios de São José dos Campos diferentemente da maioria das incubadoras do País é uma Incubadora de negócios, não de empresas, oferecendo aos empreendedores apoio para desenvolver suas atividades e estruturar novos negócios que visam a inovação e inserção no mercado. 
Dentro da incubadora os empreendedores têm acesso à infra-estrutura operacional que oferece condições apropriadas para desenvolver negócios com sucesso, além de serviços especializados de consultorias: gestão empresarial e orientação mercadológica. Entretanto, o diferencial da incubadora joseense está na pré-incubação, que não abriga empresas já formadas, mas sim projetos e idéias que possuem viabilidade técnica e potencial para vencer no mercado.

Entre os serviços oferecidos pela incubadora estão: a disponibilização de espaço físico, consultoria para a criação e funcionamento de empresa, apoio durante a elaboração do plano de negócios, identificação de fontes de financiamento e apoio na participação de feiras.

\section{Qual é a área total do Parque Tecnológico de São José dos Campos? E quais os seus ativos?}

O Parque Tecnológico de SJC trabalha com o conceito de um Núcleo e uma área de influência no entorno que foi transformada numa Zona Especial de Tecnologia, a ZEPTEC que compreende uma área de 12,5 milhões de metros quadrados.

Especificamente, o Núcleo do Parque tecnológico possuí área de 1 milhão de metros quadrados e área construída de 30 mil metros quadrados. Os seus principais ativos são os Centros de Desenvolvimento de Tecnologia, a Incubadora de Idéias, os auditórios de 800 e 300 lugares e o Centro de Inovação da Microsoft (Microsoft Innovation Center) - MIC.

\section{Quais são as principais atividades que são desenvolvidas no Parque Tecnológico de São José dos Campos? (grau de diversificação) \\ Apesar da grande vocação da cidade de São José dos Campos está relacionada a indústria aeroespacial, o Parque Tecnológico busca a diversificação das suas atividades, sendo que estão sendo estruturados três Centros de desenvolvimento, o Centro de Desenvolvimento de Tecnologia Aeronáutica - CDTA, Centro de Desenvolvimento Tecnológico em Energia - CDTE e o Centro de Desenvolvimento de Tecnologias da Informação - CDTI.}

\section{Como o órgão gestor administra os processos relacionados à gestão do conhecimento, propriedade intelectual, qualidade, etc. (coordenação).}

No âmbito da Incubadora de empresas existe a figura de uma organização do terceiro setor, sem fins lucrativos tendo como figura jurídica a denominação de Organização Social. $O$ Cecompi (Centro Para a Competitividade e Inovação do Cone Leste Paulista) foi criado em outubro de 2004, sendo um organismo de articulação entre o Poder Público, Instituições de Ensino e Pesquisa e Iniciativa Privada. 
Na perspectiva do Parque Tecnológico, também é uma organização social, a entidade gestora, está sendo constituída a APTSJC, a Associação Parque Tecnológico de São José dos Campos, órgão responsável pela gestão dos ativos, serviços e administração dos serviços, e também pela articulação externa.

\section{$\Rightarrow$ Estratégia}

9. Quais são as atividades econômicas que são privilegiadas no Parque Tecnológico de São José dos Campos?

O Parque Tecnológico tem como princípio ser um parque generalista, atualmente as principais atividades econômicas privilegiadas estão relacionadas com o setor aeroespacial, o setor de desenvolvimento de energias e o setor de Tecnologia da Informação.

\section{Quais são os principais objetivos a médio e longo prazo?}

Busca-se o desenvolvimento dos centros de desenvolvimento e também o aumento do adensamento de empresas tecnológicas na área Especial de Tecnologia do Parque Tecnológico.No futuro, serão implantados pequenos condomínios industriais, os campi da Unifesp (Universidade Federal de São Paulo), Unesp (Universidade Estadual de São Paulo), além de uma unidade do Senai.

\section{$\Rightarrow$ Interações e relação Universidade- empresas}

\section{Qual a relação do Parque Tecnológico de São José dos Campos com o poder público? Existem ações elaboradas com o poder público para manter o Parque Tecnológico de São José dos Campos competitivo e em expansão? Quais? (políticas públicas)}

A relação com a Prefeitura Municipal é intensa, pode-se considerar a Prefeitura Municipal de São José dos Campos como a grande indultora do projeto do Parque Tecnológico. O apoio financeiro da Prefeitura que possibilitou o desenvolvimento dos estágios iniciais do projeto, inclusive adquirindo o prédio da empresa Solectron que foi adaptado para o Parque Tecnológico. 
O papel da PMSJC é crucial, sendo articulador e atrator de novos investimentos públicos e privados para o benefício do desenvolvimento das empresas, do emprego qualificado e da sociedade

\section{Há vínculos econômicos / tecnológicos com outras regiões do país, ou mesmo com o exterior? (parcerias/cooperação)}

Dentro do contexto do estado de São Paulo, existe um sistema de parques tecnológicos, nos quais existe a interação com as iniciativas de outras cidades. No aspecto internacional são desenvolvidas parcerias para o desenvolvimento de projetos específicos. Observa-se um grande espaço a ser desenvolvido no tocante a relações internacionais. O desenvolvimento das tecnologias privilegiadas envolvem a articulação com diversas redes no âmbito nacional e internacional.

\section{Considerando a experiência do modelo teórico adotado no Parque Tecnológico de São José dos Campos, quais são os requisitos fundamentais necessários para a transformação de agentes públicos e privados (Estado Instituições Acadêmicas $x$ Empresas) em Parques Tecnológicos?(Estudo de Caso)}

Fica bem evidenciada no projeto a necessidade de articulação e interação com todos os organismos que tem influência nesses projetos. A governança em projetos com essa característica deve inicilamente pertencer a um organismo de alta representatividade como a Prefeitura, para ter legitimidade na relação com os outros atores. A exploração dos recursos disponibilizados pelos organismos de fomento e apoio no país constituí uma iportante fonte de receita para dar sustentabilidade ao projeto.

14. Ainda de que forma as possíveis assimetrias entre atores dos PTs podem afetar negativamente o desenvolvimento do Parque (sua organização produtiva, as relações com os demais agentes locais/ regionais)? (cultura, linguagem, canais de acesso)

As assimetrias são naturais em projetos com esse nível de complexidade, e podem ser um grande entrave para o desenvolvimento desses projetos. Nessa perspectiva, o papel de articulação é de fundamental importância para alinhamento das expectativas e da comunicação entre os atores. No caso de São José dos Campos, a Governança dsenvolvidas nos estágios iniciais pela Prefeitura, ajudou a fortalecer a credibilidade no projeto, facilitando o acesso aos demais parceios. 
As assimetrias exploradas na perspectiva de acelerar o processo de inovação e ambiente organizacional é um importante instrumento para o desenvolvimento de melhorias. 
Apêndice D - Questionário para validação 


\section{Documento para Validação}

Objetivo:

Captar a análise de especialistas no tema de forma a validar a base conceitual da proposta apresentada.

Método:

O método utilizado para a validação tem como base o método dos incidentes críticos19, bastante utilizado na qualidade de serviços.

De característica qualitativa, baseia-se no posicionamento do respondente em relação a um evento, situação ou incidente considerado crítico.

O documento foi estruturado para apresentar os pontos críticos da proposição e obter o posicionamento dos especialistas em relação às afirmativas apresentadas.

Vahan Agopyan - Graduado em Engenharia Civil pela Escola Politécnica da Universidade de São Paulo (1974), mestrado em Engenharia Urbana e de Construções Civis pela Escola Politécnica da Universidade de São Paulo (1978) e doutorado em Engenharia Civil pela University of London King's College (1982). Atualmente é Professor Titular de Materiais e Componentes de Construção Civil da Escola Politécnica da Universidade de São Paulo, Vice Presidente do CIB International Council for Research and Innovation in Building and Construction, Membro do Conselho Superior da FAPESP - Fundação de Amparo à Pesquisa do Estado de São Paulo, Presidente do Conselho de Superior do IPEN - Instituto de Pesquisas Energéticas e Nucleares, Conselheiro de diversas instituições como o IPT - Instituto de Pesquisas Tecnológicas do Estado de São Paulo, IE - Instituto de Engenharia, IMT - Instituto Maua de Tecnologia. Desde fevereiro de 2008 é o Coordenador de Ciência e Tecnologia da Secretaria do Desenvolvimento do Estado de São Paulo. Foi Diretor da Escola Politécnica da USP, Diretor Presidente do IPT e representante de área na CAPES, e como tal, membro do Conselho Superior da Agência. Tem experiência na área de Construção Civil, com ênfase em Materiais e Componentes, atuando principalmente com materiais reforçados com fibras. Mais recentemente, dedica-se aos estudos da qualidade e sustentabilidade da Construção Civil. É Comendador da Ordem Nacional do Mérito Científico, Eminente Engenheiro do Ano, Personalidade da Tecnologia e Cidadão Paulistano. (Texto informado pelo autor - extraído do Lattes).

Marco Antonio Raupp - Matemático, doutorado pela University of Chicago (1971). Atual Presidente da Sociedade Brasileira para o Progresso da Ciência - SBPC e, em parceria com o Governo do Estado de São Paulo e Governo Municipal de São José dos Campos, Coordena o Núcleo do Parque Tecnológico de São José dos Campos em São Paulo. Foi Diretor do Instituto Nacional de Pesquisas Espaciais INPE e Diretor do Laboratório Nacional de Computação Científica LNCC/MCT. Na pesquisa, trabalha em Análise Numérica. (Texto informado pelo autor - extraído do Lattes).

\footnotetext{
${ }^{19}$ Parasuraman, A., Zeithaml, V.A. \& Berry, L.L. (1985). "A conceptual model of service quality and its implication for future research”, in Journal of Marketing, Vol.49, Autumn, pp.41-50.
} 
$1^{a}$ Afirmação.

A proposta conceitual de estrutura do sistema de inovação local, cujo aspecto crítico é a articulação, pode contribuir para promover a interação entre o setor público, o setor privado e a universidade /centros de pesquisa, com vista ao incremento da competitividade no Município de Sorocaba.

( ) Concordo

( ) Não Concordo. Justifique.

$2^{a}$ Afirmação.

A teoria do sistema de inovação trata o Brasil como um país com sistema de inovação desarticulado, característica também espelhada no Município de Sorocaba.

Sendo assim, a proposta de um nível de específico de articulação (Documento para validação, Figura 6), na qual foram apresentados como instrumentos específicos: o Pólo de Desenvolvimento e Inovação e a Agência de Inovação revertem essa situação numa perspectiva local.

( ) Concordo

( ) Não Concordo. Justifique.

$3^{a}$ Afirmação.

Com base nas condições locais de Sorocaba, a estrutura do seu sistema de inovação e as experiências observadas o desenvolvimento de uma proposição baseada num instrumento único dificilmente permitiria abranger todas as necessidades e demandas levantadas, sendo viável a abordagem sistêmica que foi utilizada.

( ) Concordo

( ) Não Concordo. Justifique?

4a Afirmação.

Dado o estudo das características locais que apresentam: base de C\&T incipiente e grande base industrial metal-mecânica e o sistema de inovação desarticulado, torna-se viável a construção de Plataformas Científicas e Tecnológicas no âmbito do Parque Tecnológico.

Esse movimento será positivo para o desenvolvimento de novas tecnologias, utilizando ativos existentes e outros que possam ser criados ou incrementados 
(centros de pesquisa, centros de desenvolvimento, centros de formação e laboratórios), por meio de políticas públicas ou pela atração de investimentos da iniciativa privada.

( ) Concordo

( ) Não Concordo. Justifique?

$5^{a}$ Afirmação.

A proposta do Parque Tecnológico de Sorocaba permite atender aos seus três objetivos principais:

- Ser um dos meios de indução da transformação de conhecimento em valor econômico no contexto do sistema local de inovação;

- Requalificar o espaço, visto que está alicerçado numa proposta de desenvolvimento local envolvendo o adensamento de áreas deprimidas;

- Ser um dos vetores do desenvolvimento e inovação de Sorocaba e região.

( ) Concordo

( ) Não Concordo. Justifique? 
E. APÊNDICE E- CARACTERÍSTICAS DE SOROCABA 


\section{Planejamento do Município}

São apresentados os principais programas da Secretaria do Desenvolvimento Econômico (SEDE) para os anos de 2006 a 2009, que estão detalhados no Plano Plurianual do Município de Sorocaba.

Tabela 0.1- Extrato do Plano Plurianual do município de Sorocaba

\begin{tabular}{c|l|l|l}
\hline $\begin{array}{c}\text { Program } \\
\text { a }\end{array}$ & \multicolumn{1}{|c|}{ Detalhamento } & \multicolumn{1}{c}{ Objetivo } & \multicolumn{1}{c}{ Ações } \\
\hline 6.009 & $\begin{array}{l}\text { Desenvolvimento } \\
\text { local. }\end{array}$ & $\begin{array}{l}\text { Atração de novas } \\
\text { empresas. }\end{array}$ & $\begin{array}{l}2355 \text { - Criação de sistema de } \\
\text { - divulgaça do município. } \\
2356-\text { Realização de eventos } \\
\text { e seminários no município. } \\
2402-\text { Manutenção dos } \\
\text { serviços administrativos. }\end{array}$ \\
\hline 6.010 & $\begin{array}{l}\text { Fortalecimento do } \\
\text { empreendedorismo } \\
\text { local. }\end{array}$ & $\begin{array}{l}\text { Ampliar a } \\
\text { sustentabilidade e a } \\
\text { competitividade das } \\
\text { empresas locais. }\end{array}$ & $\begin{array}{l}2232-\text { Manutenção do } \\
\text { sistema de informação. }\end{array}$ \\
\hline 6.011 & $\begin{array}{l}\text { Fortalecimento do } \\
\text { desenvolvimento } \\
\text { regional. }\end{array}$ & $\begin{array}{l}\text { Fomentar a } \\
\text { organização da } \\
\text { economia regional. }\end{array}$ & $\begin{array}{l}\text { 2357 - Organização de } \\
\text { eventos de âmbito regional } \\
\text { com entidades } \\
\text { representativas, órgãos } \\
\text { públicos e privados. }\end{array}$ \\
\hline
\end{tabular}

Fonte: Prefeitura de Sorocaba. Plano Plurianual do Município 2006 a 2009. Lei 7586.

Várias iniciativas possuem objetivos identificados com o crescimento da indústria local e conseqüentemente crescimento econômico, em concordância com o sistema local de inovação.

- Núcleo de Planejamento Urbano da Prefeitura de Sorocaba - Nuplan

O Núcleo de Planejamento Urbano da Prefeitura de Sorocaba - Nuplan é formado por uma equipe de profissionais que reúne, entre outros, engenheiros e arquitetos, especializados em áreas como: plano diretor, agronomia, sistema viário, recursos hídricos, patrimônio histórico, uso de solo e trânsito, entre outras.

Os profissionais foram selecionados nos quadros da Prefeitura das Secretarias: Habitação Urbanismo e Meio Ambiente (Sehaum), Obras e InfraEstrutura Urbana (Seobe) e de Transportes (Setran) - da Empresa de Desenvolvimento Urbano e Social (Urbes) e do Serviço Autônomo de Água e Esgoto (Saae).

Esta equipe técnica tem como missão principal, estudar e planejar as diretrizes para políticas de desenvolvimento sustentável para a cidade de Sorocaba. A Nuplan, órgão coordenado pela Sehaum, tem a responsabilidade de utilizar os 
recursos disponíveis para avaliar ações e transformar esses dados em informação e planos para a administração.

- Centro de Desenvolvimento de Empreendedorismo Social e Parcerias Cedemp

O Centro de Desenvolvimento de Empreendedorismo Social e Parcerias - Cedemp é um Programa de Governo da Secretaria de Parcerias (Separ) que compreende a promoção do autoconhecimento e capacitação aos parceiros associados para fomentar o empreendedorismo social e empresarial, fornecendo informações técnicas e jurídicas à comunidade.

A Secretaria de Parcerias (Separ) foi criada para estabelecer mecanismos de integração entre o serviço público municipal, empresas, ONGs (Organizações Não-Governamentais) e instituições, promovendo projetos e programas que beneficiam os cidadãos sorocabanos.

\section{Infra-estrutura do Município de Sorocaba}

Serão destacados a seguir alguns dos elementos da infra-estrutura do Município:

- Energia Elétrica e Combustíveis

Refletindo o crescimento da cidade, o consumo de energia elétrica industrial tem aumentado acentuadamente em Sorocaba na última década, esse crescimento foi atendido pela infra-estrutura elétrica, cuja capacidade instalada é de 350 mil KVA, dos quais somente 200 mil KVA estão em uso. A cidade tem uma Estação de Transmissão e quatro subestações retransmissoras e a responsabilidade do serviço é da CPFL (Companhia Piratininga de Força e Luz).

A presença de três refinarias de petróleo instaladas num raio de 100 quilômetros da cidade facilita o acesso aos combustíveis usados pelas empresas locais para aquecimento - óleo diesel, óleo pesado e gás engarrafado. A disponibilidade passou a ser ainda maior com a entrada em funcionamento do gasoduto Brasil-Bolívia.

Atualmente, o setor elétrico brasileiro é bastante dependente de fontes hídricas; a tendência é evoluir no sentido de diminuir esta dependência. O parque elétrico nacional é composto por $84 \%$ de geradores hídricos, e o Governo Federal projeta para 2023 um cenário no qual a matriz elétrica contará com uma participação de aproximadamente $70 \%$ dessa fonte, pois espera-se o aumento da participação de outras fontes, como o gás natural e o carvão.

- Recursos Hídricos

O Rio Sorocaba, um privilégio natural da cidade, é a principal fonte de recursos hídricos do Município, afluente da margem esquerda do Rio Tietê, possui 
180 quilômetros de extensão e em linha reta 227 quilômetros (considerando seu leito em seu trajeto natural) e apresenta uma vazão de 13 metros cúbicos por segundo (regularmente). A bacia hidrográfica do Sorocaba, que está passando por um grande projeto de despoluição, é fundamental para a economia da região.

O abastecimento de água é realizado por três mananciais, as Represas do Clemente, Itupararanga e a de Ipaneminha, que juntas correspondem a $85 \%$ do total captado. Os 15\% restantes ficam a cargo do córrego Piragibu-Mirim e de 22 poços tubulares profundos distribuídos pela cidade.

Considerando a distribuição de água potável e rede coletora de esgoto, Sorocaba é a cidade paulista que apresenta um dos melhores índices que chegam a $99 \%$ no que tange a distribuição de água potável e $96 \%$ da rede coletora de esgoto. A sistemática de coleta, tratamento e distribuição de água é um dos mais modernos, sendo reforçado no abastecimento da zona industrial por poços artesianos. A distribuição mensal de quase 4,5 milhões de metros cúbicos de água é garantida por cerca de 1,8 milhões de metros lineares de canos e tubos.

Para recuperar a bacia do rio Sorocaba, principal recurso hídrico da região, o município está investindo na construção de emissários coletores de esgoto e de estações de tratamento.

A qualidade das águas da bacia Rio Sorocaba tem sido monitorada pela CETESB (Companhia de Tecnologia de Saneamento Ambiental) através de 09 pontos de amostragens, dos quais 08 deles se encontram distribuídos desde a sua nascente até a confluência com o rio Tietê, e 01 ponto no Ipaneminha.

Em maio de 2005, de acordo com dados da Prefeitura, foi colocada em operação a Estação de Tratamento de Esgoto - ETE-S1, uma importante estação de tratamento de esgoto, com capacidade de 1,50 metros cúbicos por segundo, que trouxe uma significativa melhora na qualidade da água do Rio Sorocaba, que foi comprovada pela CETESB em relatório de situação publicado em 2007. Essa ETE situa-se à montante do ponto estudado e trata o equivalente a aproximadamente $60 \%$ da carga de esgoto doméstico da cidade de Sorocaba.

Outro dado importante, que terá influência direta sobre a qualidade das águas, é que o município de Sorocaba está executando mais cinco ETEs, no planejamento plurianual de Sorocaba, com início de operação previsto para os próximos 18 meses, alcançando um grau de tratamento dos esgotos domésticos próximo a $100 \%$.

- Rodovias

Para conectar-se à cidade de São Paulo, considerado o maior centro econômico da América Latina, distante 90 quilômetros, Sorocaba utiliza-se de duas grandes rodovias do Estado: a Rodovia Presidente Castello Branco (SP 280) e a 
Rodovia Raposo Tavares (SP-270). O Sistema Castello-Raposo integra as rodovias Castello Branco, Raposo Tavares, Senador José Ermírio de Moraes (Castelinho), além da rodovia Dr. Celso Charuri, beneficiando mais de dois milhões de habitantes, moradores da região. Essas rodovias constituem a principal ligação entre a Capital e o Oeste paulista, sendo administradas pela empresa Viaoeste responsável pela operação de 168 quilômetros de rodovias por onde trafegam diariamente mais de 500 mil veículos. A ViaOeste faz parte, desde março de 2005, do sistema da Companhia de Concessões Rodoviárias - CCR20.

Por sua localização geograficamente estratégica, a cidade oferece ainda outras vantagens para empresas que precisam contar com uma eficiente logística de transportes. Considerando outros eixos viários importantes, como as rodovias SP-308 (Açúcar), SP-330 (Anhangüera), SP-250 (Bandeirantes), BR-116 (Régis Bittencourt), SP-079 (Santos Dumont), SP-065 (D. Pedro), Sorocaba fica bem próxima do segundo maior pólo de desenvolvimento do Estado, formando um triângulo com as cidades de Campinas e São Paulo.

- Formas de Acesso

Na Tabela 0.2 são apresentadas as principais vias de acesso a Sorocaba, considerando as localidades do entorno e os principais pólos de desenvolvimento do Estado de São Paulo.

Tabela 0.2 - Principais vias de acesso para Sorocaba.

\begin{tabular}{ll}
\hline DE... & ACESSO \\
\hline \hline São Paulo / Itu / Campinas & Rod. Castelo Branco (SP 280) \\
\hline \hline Araçoiaba / Itapetininga / Alumínio & Rod. Raposo Tavares (SP 270) \\
\hline \hline Itu & Rod. Sorocaba - Itu (SP 79) \\
\hline \hline & Rod. Emerenciano Prestes de Barros \\
\hline \hline & (SP 97) \\
\hline & Salto de Pirapora / Votorantim / \\
Piedade & Rod. João Leme dos Santos (SP 264) \\
\hline $\begin{array}{l}\text { Fonte: Dados disponíveis em: http://www.viaoeste.com.br/concessionaria/sobrea/. } \\
\text { Acesso em 17/04/2008. }\end{array}$
\end{tabular}


- Hidrovias

A cidade de Sorocaba está muito próxima ao terminal da Hidrovia TietêParaná (Figura 0-1), localizado a 80 quilômetros, em Conchas. Ressalta-se a importância do Sistema Hidroviário Tietê-Paraná, com 2.400 quilômetros de vias navegáveis, de Piracicaba e Conchas (ambos em São Paulo) até Goiás e Minas Gerais (ao norte) e Mato Grosso do Sul, Paraná e Ciudad Del Este no Paraguai (ao sul). Esse Sistema liga os cinco dos maiores estados produtores de soja do Brasil.

A Hidrovia Tietê-Paraná é conhecida como a "Hidrovia do MERCOSUL". No trecho no Estado de São Paulo, a Hidrovia Tietê-Paraná possui 800 quilômetros de vias navegáveis, dez reservatórios, dez barragens, 23 pontes, 19 estaleiros e 30 terminais intermodais de cargas. Sua infra-estrutura é administrada pelo Departamento Hidroviário - DH que transformou o modal em uma alternativa econômica para o transporte de cargas, além de propiciar o re-ordenamento da matriz de transportes da região centro-oeste do Estado e impulsionar o desenvolvimento regional de cidades como Barra Bonita e Pederneiras.

O deslocamento trimodal - rodovia, hidrovia e ferrovia - , que realiza o trajeto Rio Verde-São Simão (GO) de caminhão, São Simão-Pederneiras (SP) pela hidrovia, e Pederneiras-Santos pelo modal ferroviário, tem um custo total de R\$ 50,74 por tonelada de soja.

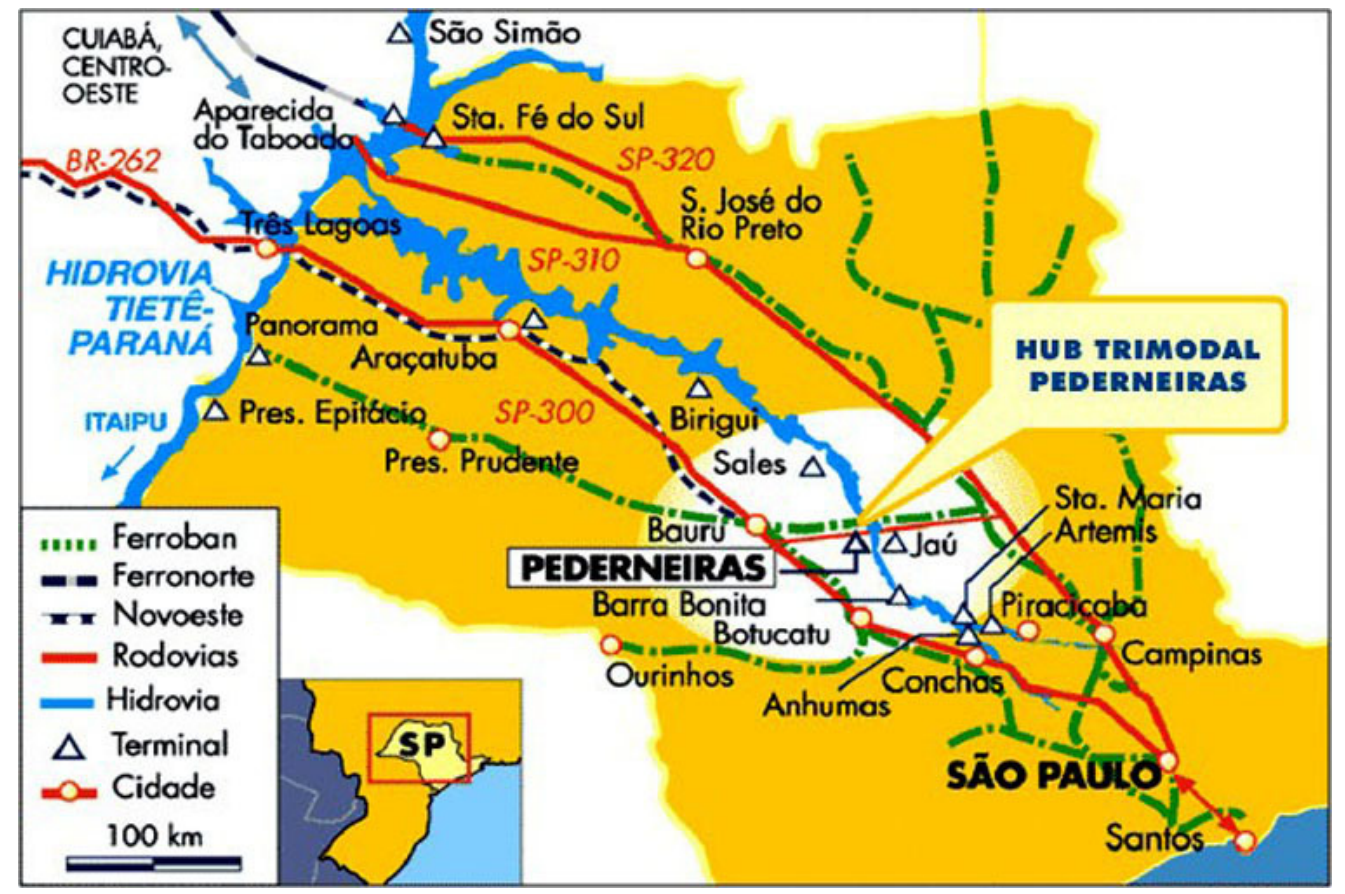

Figura 0-1: Hidrovia Tietê-Paraná (adaptado da fonte)

Fonte: Disponível em: http://jaufatosefotos.br.tripod.com/hidroviatieteparana.htm.

Acesso em: 17/04/2008. 
- Aeroportos

Em 1965, foi inaugurado o aeroporto "Bertrand Luiz Leupolz" (vide Figura 0-2) localizado em Sorocaba, situado a cerca de 60 quilômetros do aeroporto de Viracopos (Campinas/SP), a 100 quilômetros do Aeroporto de Congonhas (São Paulo/SP) e a 120 quilômetros do Aeroporto de Cumbica (Guarulhos/SP), três dos principais aeroportos do país.

O Aeroporto está recebendo melhoramentos contando já com o novo terminal de passageiros e uma pista com extensão atual de 1.420 metros. Existe a previsão da ampliação da pista do aeroporto de Sorocaba, para torná-lo uma alternativa ao transporte de cargas expressas. Há ainda vôos diários realizados pela empresa Ocean Air com destino a Congonhas (São Paulo/SP), e cidades dos Estados de Santa Catarina, Rio Grande do Sul e Minas Gerais.

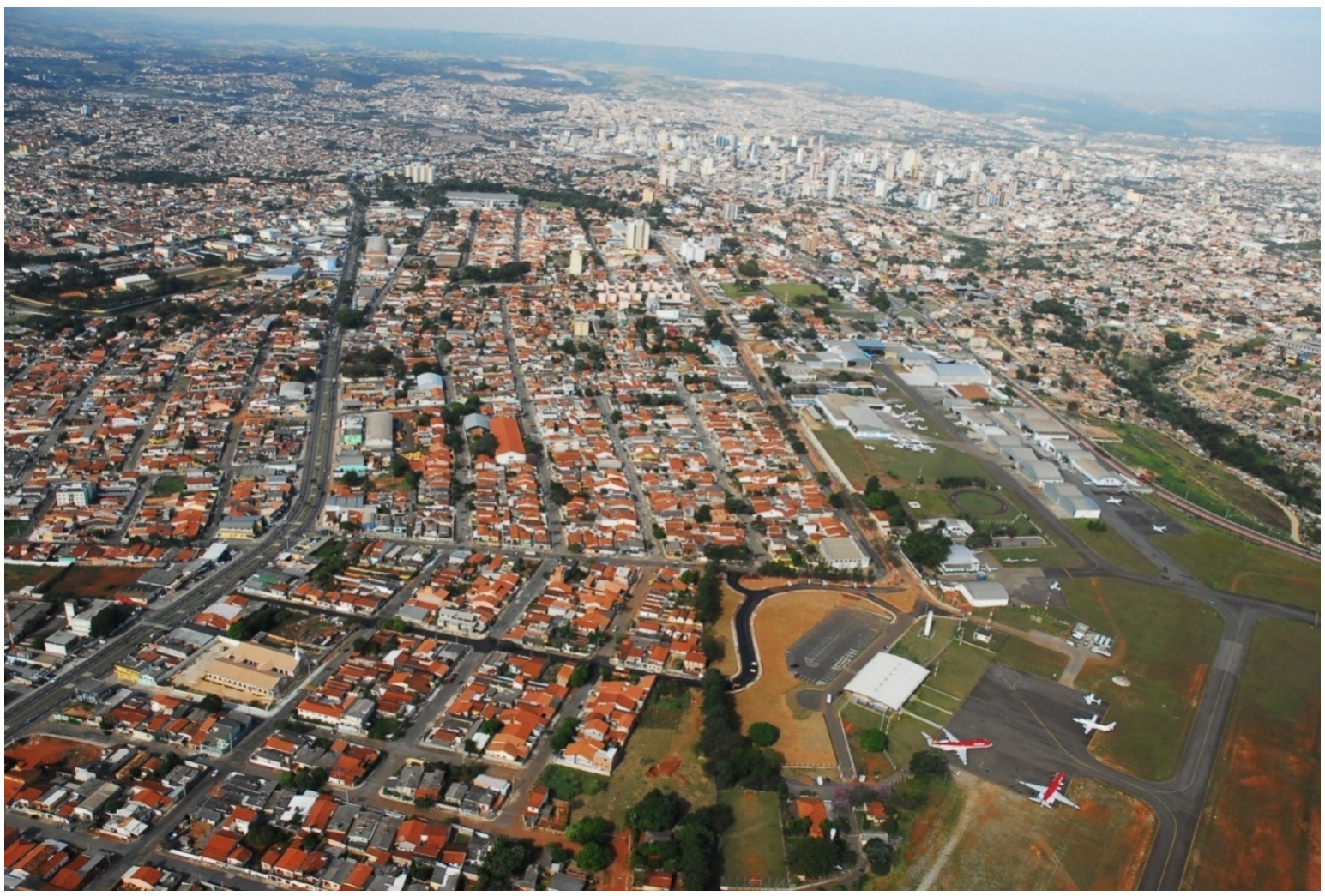

Figura 0-2: Aeroporto Estadual de Sorocaba.

Fonte: DAESP: Disponível em: www.daesp.sp.gov.br. Acesso em: 04 de janeiro de 2008.

O Aeroporto constitui-se no maior Pólo de Manutenção de aviação executiva no país, essa dinâmica levou a formação de uma importante aglomeração com o estabelecimento de empresas e hangares com mais de vinte empresas, dentre elas líderes de mercado como a OceanAir, Dassault Falcon Jet do Brasil, Jet aviation e Alliance jet. 
Desta forma, mesmo sem ter vôos regulares, o aeroporto de Sorocaba registra um movimento operacional de aeronaves acima do aeroporto de Viracopos, em Campinas/SP, que conta com vôos domésticos e internacionais. Na média mensal, são 4.500 pousos e decolagens em Sorocaba contra 2.119 em Campinas, perfazendo uma diferença superior ao dobro de operações por mês.

De acordo com as estatísticas do Departamento Aeroviário do Estado de São Paulo - DAESP (2007), o aeroporto local registrou a passagem de 40.503 aeronaves, 44.496 embarques e desembarques de passageiros, e mais de 100 mil toneladas de cargas.

Para efeito de comparação, em Campinas, segundo a Infraero (Empresa Brasileira de Infra-Estrutura Aeroportuária), em 2007 o aeroporto registrou 29.226 aeronaves com o número de passageiros de mais de um milhão e volume de cargas, ficou em torno de 238.043 mil toneladas de cargas

O aeroporto de Congonhas, em São Paulo/SP, registrou em 2007, 205.130 aeronaves, 15 milhões de passageiros e 35 mil toneladas de cargas. $O$ aeroporto de Cumbica, em Guarulhos/SP, teve um movimento de 18,8 milhões de passageiros, 424 mil toneladas de cargas e quase 188 mil aeronaves no mesmo período. (INFRAERO, 2008).

\section{- Ferrovias}

A ferrovia que corta a cidade de Sorocaba, com linhas da Ferrovia dos Bandeirantes S/A (Ferroban), antiga Ferrovia Paulista S/A, liga a cidade ao porto de Santos (167 quilômetros), um dos mais importantes do país. Essa linha conecta-se também aos principais ramais férreos do país, sendo, portanto uma alternativa ao transporte de carga para qualquer ponto do Brasil, chegando até a Argentina e Bolívia.

De fato, a questão dos serviços logísticos, incluindo os internacionais, consiste em aspecto estratégico importante para empresas, sendo que Sorocaba tem situação privilegiada quanto ao modal ferroviário.

Nesse sentido, vale destacar o exemplo da empresa América Latina Logística - ALL que apresenta diversas soluções integradas para as necessidades dos diversos clientes, com interesses também em Sorocaba.

A ALL dispõe de serviços logísticos internacionais, com origem e destino no Brasil, Argentina e Chile (Figura 0-3), em diversos segmentos, incluindo o automotivo, siderúrgico, químico, alimentos, entre outros. De acordo com as soluções requeridas por seus clientes, a empresa pode oferecer serviços de transporte, armazenagem, distribuição e consolidação/desconsolidação de cargas. A sua frota é composta de 960 locomotivas, mais de 27.000 vagões, além de 160 
carretas bimodais que trafegam em ferrovias e rodovias, também a sua capacidade de operação envolve mais de 1.800 veículos.

Uma forma moderna e econômica de transporte de produção, viabilizada pela ALL, consiste no Transporte Intermodal de Contêineres, realizado sem contato direto com a carga nas trocas de um meio de transporte para outro, com várias vantagens, entre elas: redução do tempo de manipulação de carga, mais segurança e rapidez no transporte e menores riscos de danos aos produtos. No Brasil, o maior centro produtivo do MERCOSUL, a ALL dispõe de dez terminais intermodais de contêineres localizados nas cidades de: Tatuí e Paulínia (São Paulo), Cascavel, Guarapuava e Curitiba (Paraná), Marcelino Ramos e Lages (Santa Catarina), Esteio (Rio Grande do Sul). Estão para serem inaugurados também os terminais de Araraquara (São Paulo), Alto Araguaia (Mato Grosso), Passo Fundo (Rio Grande do Sul) e Telêmaco Borba (Paraná).

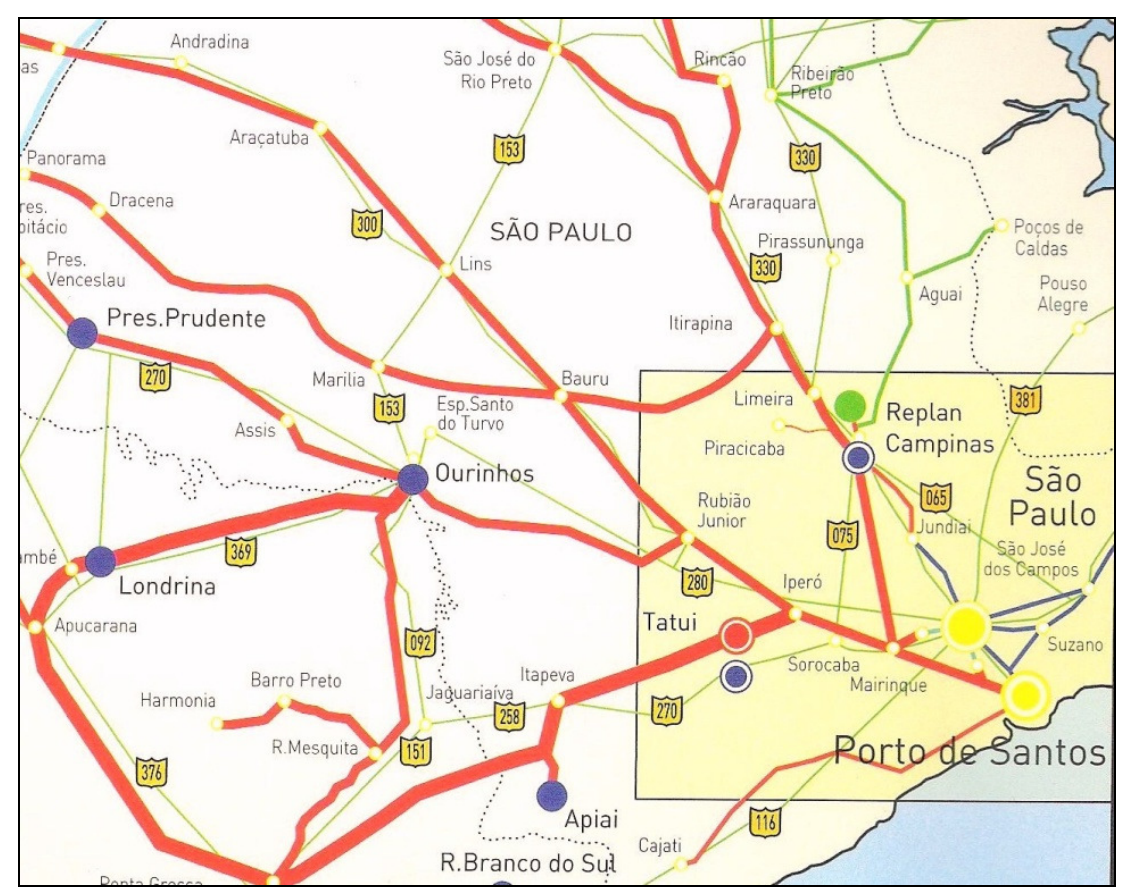

Figura 0-3: Malhas da Empresa América Latina Logística.

Disponível em: http://www.all-logistica.com/. Acesso em 24/04/2008.

Um dos casos mais interessantes da ALL a destacar, no interesse deste estudo, consiste na operação de transferência de peças e componentes provenientes de uma montadora localizada em São José dos Pinhais, para a unidade de Córdoba na Argentina, sendo que Sorocaba é um dos pontos de articulação das cargas, na direção RUMO SUL desta operação, a saber na Tabela 0.3 
Tabela 0.3 - Logística de cargas.

\begin{tabular}{l|l}
\hline 160 & SÃO JOSÉ DOS CAMPOS X ROSÁRIO \\
\hline 12 & MOGI DAS CRUZES X BUENOS AIRES OU GENERAL RODRIGUEZ \\
\hline 8 & SOROCABA X BUENOS AIRES OU GENERAL RODRIGUEZ \\
\hline 7 & $\begin{array}{l}\text { SOROCABA (MATRIMET) } \\
\text { RODRIGUEZ }\end{array}$ \\
\hline 9 & GUENOS AIRES OU GENERAL \\
\hline 6 & GRAVATAÍ X BUENOS AIRES OU GENERAL RODRIGUEZ \\
\hline 2 & SÃO CAETANO DO SUL X ROSÁRIO \\
\hline 204 & TOTAL \\
&
\end{tabular}

- Terminal Alfandegário

A Estação Aduaneira do Interior (EADI) (Figura 0-4) é um terminal alfandegário "porto seco" de uso público destinado à movimentação e armazenagem de mercadorias importadas ou exportadas.

A EADI tem como função principal o desembaraço de todos os serviços aduaneiros, a cargo da Secretaria da Receita Federal, inclusive os de processamento de despacho aduaneiro de importação e exportação (conferência e desembaraço aduaneiros), permitindo, assim, a sua interiorização.

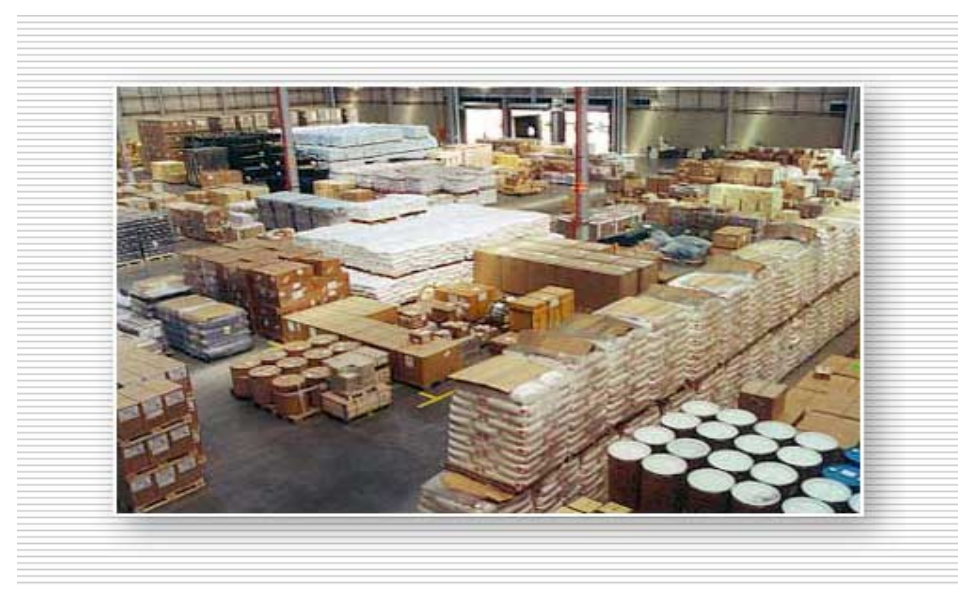

Figura 0-4: Terminal Aurora EADI Fonte : EADI

Sorocaba foi escolhida para abrigar o porto seco devido a sua infraestrutura de serviços, parque industrial, malha rodoviária e localização geográfica. A estação encontra-se a apenas 80 quilômetros do aeroporto de Viracopos (Campinas/SP), a 160 quilômetros do Porto de Santos e a 90 quilômetros do terminal de Conchas da Hidrovia Tietê-Paraná. 
A estação está localizada na região industrial de Sorocaba, numa área de 70 mil metros quadrados, tem 25 mil metros de construção, um galpão de 5.200 metros quadrados com 17 metros livres de pé direito, destinado à estocagem vertical com a utilização de paletes. Na área externa, com 15 mil metros quadrados, cinco mil metros quadrados são utilizados para a estocagem de contêineres. Dispõe ainda de uma área administrativa totalmente informatizada que abriga posto da Receita Federal, um posto do Banco do Brasil, uma sala de apoio a despachantes, boxes para uso de clientes e um restaurante.

- Responsabilidade Ambiental

A sociedade de Sorocaba acredita na importância do crescimento sustentado e com responsabilidade ambiental, assim, investe na formação da conscientização ambiental com diversos tipos de programas, cursos e treinamento, dentre os quais se destacam:

- Programa Município Verde: Um protocolo de adesão ao Programa Município Verde foi assinado pelo Prefeito, em que foi firmada uma parceria entre a Prefeitura de Sorocaba e a Secretaria do Meio Ambiente do Governo do Estado de São Paulo de acordo com as dez diretivas para a conquista da certificação de município verde na gestão ambiental compartilhada: Esgoto Tratado; Lixo mínimo; Recuperação de Mata Ciliar; Arborização Urbana; Educação Ambiental; Habitação Sustentável; Uso da Água; Poluição do Ar; Estrutura Ambiental; Conselho Municipal.

- Semana do Meio Ambiente: Tem como objetivo demonstrar a população como a natureza possui mecanismos perfeitos de funcionamento e equilíbrio, ilustrando a importância do aquecimento natural do planeta para a manutenção da biodiversidade e a reflexão por intermédio de oficinas práticas.

- Cursos de Férias nos Parques: Tranzôo Pimpolhos, Tranzôo, "Observando e Curtindo a Natureza" Parque Água Vermelha. Cursos de férias realizados nos meses de janeiro e julho para crianças e adolescentes, com o objetivo de utilizar o tempo livre em atividades saudáveis, divertidas e ao mesmo tempo educativas; através de ações individuais e coletivas; formando agentes multiplicadores da Educação Ambiental. 
- Cursos nos Parques: Tranzôo Família e "Melhor Idade". Realização de atividades saudáveis, divertidas e educativas; buscando aliados para conservação e preservação do meio ambiente.

- Clubes Ecológicos nos Parques: Reunião semanal de crianças e adolescentes para discutir temas e propor ações para ajudar na preservação ambiental.

- Transclubes - Curso de férias do Clube Ecológico (crianças de 07 a 18 anos) que tem como objetivo proporcionar atividades gratuitas divertidas e educativas, formar multiplicadores em Educação Ambiental, incentivar práticas de cidadania e respeito ao Meio Ambiente, unindo os clubes dos Parques para aprendizados e interação dos jovens.

- Programas de estágios e voluntariado: Os participantes aprendem a transmitir informações aos visitantes do Zôo e dar apoio na execução de eventos.

- Zooterapia: A Equipe do Zôo visitam o setor de internamento infantil de hospitais públicos, creches de crianças com necessidades especiais, orfanatos e asilos, levando momentos de entretenimento, distração e ânimo para pessoas em variados estados de saúde física e psicológica, que podem resultar em melhoria da qualidade de vida.

- Dia do Rio Sorocaba: Conscientizar sobre a importância do Rio Sorocaba e envolver a população e os alunos das Escolas Municipais em prol das atitudes positivas que irão favorecer todo o meio ambiente.

- Semana da Árvore: Oficinas práticas e distribuição de mudas para divulgar e incentivar o cidadão Sorocabano a participar da Campanha de arborização urbana, bem como alertá-lo para as causas e as conseqüências do aquecimento global e atitudes que podem ajudar.

- Workshop de enriquecimento Ambiental: Proporcionar aos animais de cativeiro, a possibilidade de terem um comportamento o mais próximo possível do que exibem em seu meio natural, e que retrate condições de bem estar satisfatórias, através de capacitação de profissionais da área. 


\section{Principais Serviços públicos e privados}

Empresas de diversas áreas, principalmente nos setores de hotelaria e lazer, escolheram a cidade de Sorocaba para a implantação de novos projetos, devido às condições e às oportunidades oferecidas pelo mercado local.

Em pesquisa realizada junto aos dez principais hotéis da cidade constatou-se a vocação do município de Sorocaba para o turismo de negócios. Hoje a cidade conta com aproximadamente trinta hotéis para turismo e negócios, além de um Hotel-Fazenda e três SPA, que oferecem uma completa infra-estrutura para a realização de palestras, reuniões de negócios, convenções e eventos tanto para as empresas instaladas em Sorocaba, como também para as empresas de São Paulo que buscam opções diferenciadas para a realização dos seus eventos.

Sorocaba oferece ainda, uma ampla opção de estabelecimentos como restaurantes, bares, casas noturnas, boates, cinemas, casas de shows e clubes.

- Coleta de Lixo

A coleta de lixo domiciliar atende a população em quase $100 \%$. Os diferentes tipos de lixos são tratados de forma especial; os detritos recolhidos são depositados no Aterro Sanitário Municipal, enquanto os resíduos sólidos vão para uma área especial no aterro, que mantém monitoramento permanente. A Prefeitura possui também o "Programa Cidade Super Limpa", que visa melhorar a qualidade de vida da população por intermédio de ações pioneiras da Prefeitura em parceria com a população, a fim de tornar a cidade de Sorocaba uma referência de limpeza em todo o Brasil. As principais ações deste Programa são: Ecopontos para retirada de entulho, implementação de mais lixeiras na cidade, contêineres em todos os bairros para um bom acondicionamento do lixo e agilização com a coleta mecanizada, coleta de material reciclável realizada por cooperativas, fiscalização intensa para que terrenos permaneçam limpos e ações educativas nas escolas.

- Telefonia

O segmento de comunicação também se expandiu com aumento do número de terminais telefônicos fixos instalados na cidade que dobrou em menos de uma década. As empresas com demandas cada vez maiores nesse segmento têm sido atendidas por meio da utilização da infra-estrutura instalada.

- Hospitais

O município apresenta um bom sistema de saúde com a presença de 12 (doze) hospitais particulares que disponibilizam 2.300 (dois mil e trezentos) leitos, 
atendendo a um vasto conjunto de doenças e com serviços especializados em diversas áreas.

$\mathrm{Na}$ Tabela 0.4 é apresentada a descrição do atendimento em hospitais particulares e na Tabela 0.5 do hospital público, as tabelas foram validadas pela Dra. Sônia Maria de Andrade Siqueira Diretora da Vigilância Sanitária Regional de Sorocaba em entrevista.

Tabela 0.4 - Descrição e especialidades dos hospitais particulares de Sorocaba.

\begin{tabular}{|c|c|c|c|c|}
\hline \multicolumn{2}{|c|}{$\begin{array}{l}\text { No de Hospitais } \\
\text { Particulares: }\end{array}$} & $\begin{array}{l}\text { No de } \\
\text { Leitos }\end{array}$ & $\begin{array}{l}\text { Atendimento } \\
\text { s Prestados }\end{array}$ & Serviços: \\
\hline \multirow[t]{3}{*}{1} & \multirow{3}{*}{$\begin{array}{l}\text { Hospital } \\
\text { Modelo de } \\
\text { Sorocaba } \\
\text { Intermédica } \\
\text { Sistema de } \\
\text { saúde - S/A. }\end{array}$} & \multirow[t]{3}{*}{92} & $\begin{array}{l}\text { Atendimento } \\
\text { Ambulatorial }\end{array}$ & \multirow{3}{*}{ 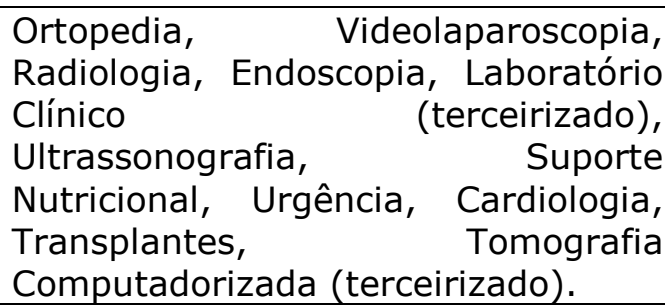 } \\
\hline & & & Internação & \\
\hline & & & $\begin{array}{l}\text { Urgência } \\
\text { Emergência }\end{array}$ & \\
\hline \multirow[t]{2}{*}{2} & \multirow{2}{*}{$\begin{array}{l}\text { Hospital } \\
\text { Psiquiátrico } \\
\text { Jardim das } \\
\text { Acácias } \\
\text { (ASSOCIAÇÃO } \\
\text { PROTETORA } \\
\text { DOS INSANOS } \\
\text { DE } \\
\text { SOROCABA) }\end{array}$} & \multirow[t]{2}{*}{300} & $\begin{array}{l}\text { Atendimento } \\
\text { Ambulatorial }\end{array}$ & \multirow[t]{2}{*}{$\begin{array}{l}\text { Atenção Psicossocial, Cuidados } \\
\text { Prolongados. }\end{array}$} \\
\hline & & & Internação & \\
\hline \multirow[t]{3}{*}{3} & \multirow{3}{*}{$\begin{array}{l}\text { Hospital } \\
\text { Mental de } \\
\text { Sorocaba }\end{array}$} & \multirow[t]{3}{*}{400} & $\begin{array}{l}\text { Atendimento } \\
\text { Ambulatorial }\end{array}$ & \multirow[t]{3}{*}{ Fisioterapia, Atenção Psicossocial. } \\
\hline & & & $\begin{array}{l}\text { Internação - } \\
\text { SADI }\end{array}$ & \\
\hline & & & SADT & \\
\hline \multirow[t]{2}{*}{4} & \multirow{2}{*}{$\begin{array}{l}\text { Hospital } \\
\text { Samaritano de } \\
\text { Sorocaba }\end{array}$} & \multirow[t]{2}{*}{127} & Internação & \multirow{2}{*}{ 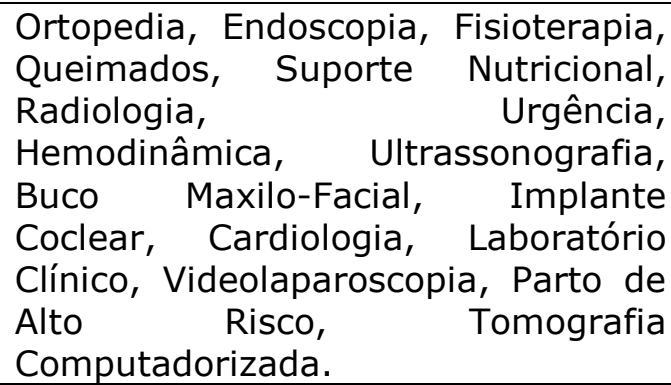 } \\
\hline & & & $\begin{array}{l}\text { Urgência } \\
\text { Emergência }\end{array}$ & \\
\hline \multirow[t]{3}{*}{5} & \multirow{3}{*}{$\begin{array}{l}\text { GPACI } \\
\text { Hospital } \\
\text { Sarina Rolim } \\
\text { Caracante - } \\
\text { Grupo de } \\
\text { Pesquisa e } \\
\text { Assistência ao } \\
\text { Câncer Infantil } \\
\text { Assistência ao } \\
\text { Câncer Infantil }\end{array}$} & \multirow[t]{3}{*}{21} & $\begin{array}{l}\text { Atendimento } \\
\text { Ambulatorial }\end{array}$ & \multirow{3}{*}{$\begin{array}{lr}\text { Radiologia, } & \text { Fisioterapia, } \\
\text { Hemoterapia, } & \text { Cardiologia, } \\
\text { Laboratório Clínico, Quimioterapia. }\end{array}$} \\
\hline & & & Internação & \\
\hline & & & SADT & \\
\hline 6 & Hospital Santa & 142 & Atendimento & Ultrassonografia, \\
\hline
\end{tabular}




\begin{tabular}{|c|c|c|c|c|}
\hline \multicolumn{2}{|c|}{$\begin{array}{c}\text { No de Hospitais } \\
\text { Particulares: }\end{array}$} & \multirow[t]{4}{*}{$\begin{array}{l}\text { No de } \\
\text { Leitos }\end{array}$} & \multirow{3}{*}{$\begin{array}{l}\begin{array}{c}\text { Atendimento } \\
\text { s Prestados }\end{array} \\
\text { Ambulatorial } \\
\text { Internação }\end{array}$} & Serviços: \\
\hline & \multirow[t]{3}{*}{ Lucinda } & & & \multirow{3}{*}{ 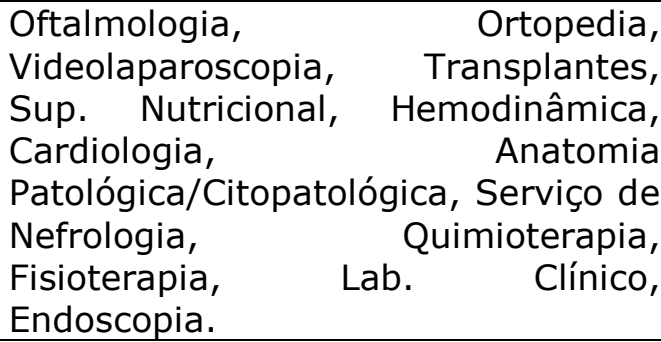 } \\
\hline & & & & \\
\hline & & & SADT & \\
\hline \multirow[t]{4}{*}{7} & \multirow[t]{4}{*}{$\begin{array}{l}\text { Santa Casa de } \\
\text { Sorocaba }\end{array}$} & \multirow[t]{4}{*}{279} & $\begin{array}{l}\text { Atendimento } \\
\text { Ambulatorial }\end{array}$ & \multirow{4}{*}{ 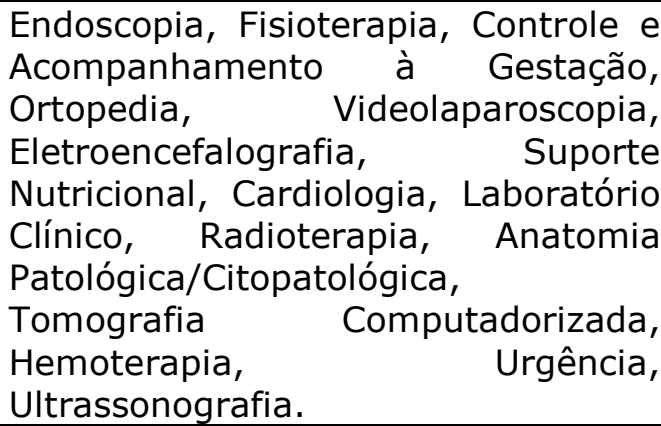 } \\
\hline & & & Internação & \\
\hline & & & SADT & \\
\hline & & & $\begin{array}{l}\text { Urgência } \\
\text { Emergência }\end{array}$ & \\
\hline \multirow[t]{4}{*}{8} & \multirow{4}{*}{$\begin{array}{l}\text { Hospital } \\
\text { Oftalmológico } \\
\text { de Sorocaba }\end{array}$} & \multirow[t]{4}{*}{26} & Atendimento & \multirow{4}{*}{$\begin{array}{l}\text { Transplantes, } \\
\text { Audiologia/Otologia, } \\
\text { Ultrassonografia, } \\
\text { Laboratório Clínico }\end{array}$} \\
\hline & & & Ambulatorial & \\
\hline & & & Internação & \\
\hline & & & SADT & \\
\hline \multirow[t]{4}{*}{9} & \multirow{4}{*}{$\begin{array}{l}\text { Hospital } \\
\text { Unimed de } \\
\text { Sorocaba }\end{array}$} & \multirow[t]{4}{*}{91} & $\begin{array}{l}\text { Atendimento } \\
\text { Ambulatorial }\end{array}$ & \multirow{4}{*}{$\begin{array}{l}\text { Tranplantes (renal, córnea, fígado, } \\
\text { cardíaco), Cuidados Prolongados } \\
\text { Oncologia/Osteomuscular/Neurologia } \\
\text { /Pneumologia, Suporte Nutricional, } \\
\text { Fisioterapia, Ortopedia, } \\
\text { Videolaparoscopia, Transplantes, } \\
\text { Parto de Alto Risco, Hemoterapia, } \\
\text { UTI Móvel, Anatomia } \\
\text { Patológica/Citopatológica, } \\
\text { Laboratório Clínico, Quimioterapia, } \\
\text { Cirurgia Bariátrica, Ultrassonografia, } \\
\text { Urgência, Cardiologia. }\end{array}$} \\
\hline & & & Internação & \\
\hline & & & SADT & \\
\hline & & & $\begin{array}{l}\text { Urgência } \\
\text { Emergência }\end{array}$ & \\
\hline \multirow[t]{3}{*}{10} & \multirow{3}{*}{$\begin{array}{l}\text { Hospital } \\
\text { Evangélico de } \\
\text { Sorocaba }\end{array}$} & \multirow[t]{3}{*}{62} & $\begin{array}{l}\text { Atendimento } \\
\text { Ambulatorial }\end{array}$ & \multirow{3}{*}{$\begin{array}{l}\text { Endoscopia, Ortopedia cirúrgica, } \\
\text { Videolaparoscopia, Fisioterapia, } \\
\text { Radiologia, Laboratório Clínico, } \\
\text { Ultrassonografia, Cardiologia, } \\
\text { Anatomia Patológica/Citopatologia, } \\
\text { Ginecologia }\end{array}$} \\
\hline & & & Internação & \\
\hline & & & SADT & \\
\hline \multirow[t]{2}{*}{11} & \multirow{2}{*}{$\begin{array}{l}\text { Hospital } \\
\text { Psiquiátrico } \\
\text { Vera Cruz }\end{array}$} & 536 & $\begin{array}{l}\text { Atendimento } \\
\text { Ambulatorial }\end{array}$ & \multirow[t]{2}{*}{ Atenção Psicossocial } \\
\hline & & & Internação & \\
\hline \multirow[t]{2}{*}{12} & \multirow{2}{*}{$\begin{array}{l}\text { Instituto } \\
\text { Psiquiátrico } \\
\text { Professor } \\
\text { André Teixeira } \\
\text { Lima }\end{array}$} & \multirow[t]{2}{*}{243} & $\begin{array}{l}\text { Atendimento } \\
\text { Ambulatorial }\end{array}$ & \multirow[t]{2}{*}{ Atenção Psicossocial } \\
\hline & & & Internação & \\
\hline
\end{tabular}

Fonte: DATASUS - Banco de dados do sistema ùnico de Saúde. Disponível em: http://cnes.datasus.gov.br/Index.asp?Configuracao $=1280 \&$ bro=Microsoft\%20Inter net\%20Explorer Acesso em 02/10/2008 
O Conjunto Hospitalar de Sorocaba é uma estrutura pública que oferece atendimento à população em várias especialidades médicas, disponibilizando 450 leitos, incluindo atendimento de emergência, atendimento ambulatorial, internações. Na Tabela 0.5 encontra-se a descrição do atendimento público em Sorocaba.

Tabela 0.5 - Características do Hospital Público de Sorocaba.

\begin{tabular}{|c|c|c|c|c|}
\hline \multicolumn{2}{|c|}{$\begin{array}{l}\text { No de Hospitais } \\
\text { Públicos: }\end{array}$} & $\begin{array}{l}\text { No de } \\
\text { Leitos }\end{array}$ & $\begin{array}{c}\text { Atendimentos } \\
\text { Prestados: }\end{array}$ & Serviços: \\
\hline \multirow[t]{4}{*}{1} & \multirow[t]{4}{*}{$\begin{array}{l}\text { Conjunto } \\
\text { Hospitalar de } \\
\text { Sorocaba }\end{array}$} & \multirow[t]{4}{*}{449} & $\begin{array}{l}\text { Atendimento } \\
\text { Ambulatorial }\end{array}$ & \multirow{4}{*}{ 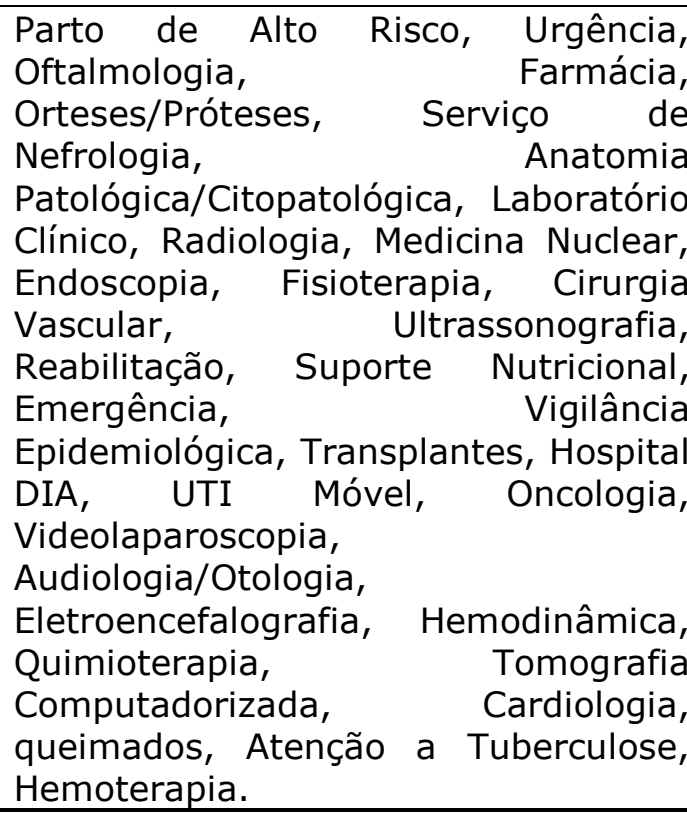 } \\
\hline & & & Internação & \\
\hline & & & SADT & \\
\hline & & & $\begin{array}{l}\text { Urgência } \\
\text { Emergência }\end{array}$ & \\
\hline
\end{tabular}

Fonte: DATASUS - Banco de dados do sistema ùnico de Saúde. Disponível em: http://cnes.datasus.gov.br/Index.asp?Configuracao $=1280 \&$ bro $=$ Microsoft $\% 20$ Inter net\%20Explorer Acesso em 02/10/2008

- Lazer e Cultura

A cidade de Sorocaba apresenta diversas opções de entretenimento, incluindo: mais de cinqüenta restaurantes de diferentes culinárias, entre as quais, típica brasileira, alemã, italiana, japonesa, chinesa, árabe e argentina; fast-food; pizzarias; casas noturnas (seis destinadas ao público adulto e uma destinada ao público adolescente) e bares.

Existem duas Bibliotecas Municipais, dois Museus e dois Teatros disponíveis à população, a saber: a Biblioteca "Jorge Guilherme Senger", a Biblioteca Infantil "Renato Sêneca de Sá Fleury", o Museu da Estrada de Ferro Sorocabana, o Museu Histórico Sorocabano, o Teatro Municipal "Teotônio Vilela", com capacidade para 439 pessoas e o Teatro SESI "Armando Pannunzio", com capacidade para 280 pessoas. A população pode desfrutar também dos treze parques naturais e dez centros esportivos da cidade. 
○ Hotéis

As viagens de negócio e lazer representam um setor de grande importância econômica no mundo. Sorocaba, pelo seu conjunto de características históricas e econômicas, tornou-se uma cidade atrativa para investimentos de redes hoteleiras nacionais e internacionais, que impulsionam fortemente o setor.

A cidade conta, atualmente, com aproximadamente trinta hotéis para turismo e negócios, além de um Hotel-Fazenda e três SPA (Spa Med Campus, o São Pedro Spa Médico e o Spa Sorocaba) que oferecem uma completa infra-estrutura para a realização de palestras, reuniões de negócios, convenções e eventos, tanto para as empresas instaladas em Sorocaba, como também para as empresas de São Paulo que buscam opções diferenciadas para a realização dos seus eventos. Na Tabela 0.6 são apresentados alguns dos principais hotéis da cidade com distribuição de unidades habitacionais (UH's) e número de leitos disponíveis.

Tabela 0.6 - Hotéis, Leitos e Unidades Habitacionais em Sorocaba.

\begin{tabular}{l|c|c}
\hline \multicolumn{1}{c|}{ Nome } & No UH's & Leitos \\
\hline Nacional Inn & 96 & 192 \\
\hline Cardum Hotel & 60 & 118 \\
\hline Chamonix & 110 & 230 \\
\hline Grand Hotel Royal & 84 & 168 \\
\hline Hotel Ibis & 112 & 126 \\
\hline Inter Plaza Hotel & 59 & 118 \\
\hline Ipanema & 54 & 105 \\
\hline Milano & 24 & 41 \\
\hline Pitangueiras & 43 & 86 \\
\hline Salima's & 70 & 162 \\
\hline Scarpelli & 16 & 33 \\
\hline Shelton Inn & 125 & 250 \\
\hline Sorocaba Park Hotel & 100 & 214 \\
\hline Transamérica Flat-The First & 150 & 300 \\
\hline Tropeiro Plaza & 40 & 96 \\
\hline Villa Centralle & 98 & 150 \\
\hline
\end{tabular}

Fonte: Desenvolvido a partir do Sorocaba Convention \& Visitors Bureau

Disponível em http://www.sorocababureau.com.br/. Acesso em 10/12/2008 


\section{GLOSSÁRIO}

AÇÕES ESTRATÉGICAS - Ações (medidas) que objetivam a exploração de oportunidades potencialmente geradoras de resultados.

FINEP - Estabelecimento de Programas e Ações Estratégicas. IN: NORMA N-PDEM/03.00/1999.Rio de Janeiro

AGENTES DE DESENVOLVIMENTO - são os diversos organismos públicos e privados que promovem ações de fomento em áreas de atuação afins ou complementares àquelas que são objeto de ação da FINEP: agências de fomento nacionais e internacionais, bancos de desenvolvimento, fundações de amparo à pesquisa, sistema CNI, IEL, sistema SEBRAE, organizaçõees setoriais de apoio técnico, gerencial ou comercial, instituições financeiras e gestores de fundos de investimento, sindicatos e associações de classe.

Política Operacional FINEP

AQUISIÇÃO DE TECNOLOGIA E KNOW-HOW INTANGÍVEL- Aquisição externa de tecnologia na forma de patentes, invenções não patenteadas, licenças, comunicações de know-how, marcas registradas, desenhos, padrões e serviços de computador ou outros serviços científicos e técnicos relacionados com a implantação das Inovações PPT, mais a aquisição de software em pacotes que não estejam classificados em outra parte.

OECD. Oslo Manual. Paris, OCDE/Eurostat, 1997, cap.3, pag.10-12.

AQUISIÇÃO DE TECNOLOGIA TANGÍVEL - Aquisição de maquinaria e equipamentos com desempenho tecnológico aperfeiçoado (incluindo software integrado) ligada às inovações tecnológicas de produtos ou processos implantadas pela empresa.

OECD. Oslo Manual. Paris, OCDE/Eurostat, 1997, cap.3, pag.10-12.

ARRANJO PRODUTIVO LOCAL - aglomeração de empresas definida por critérios imultaneamente regionais e setoriais. A ação de fomento em arranjos produtivos locais busca a construção de economias externas a cada empresa e internas à aglomeração. Assim, as ações da FINEP priorizam 0 apoio a projetos cujos resultados produzam externalidades com aproveitamento coletivo.

Política Operacional FINEP

CADEIA PRODUTIVA - Conjunto de atividades econômicas que se articulam progressivamente desde o início da elaboração de um produto ( inclui as matérias primas, máquinas e equipamentos, produtos intermediários...) até o produto final, a distribuição e comercialização. Ministério do Desenvolvimento, Indústria e Comércio - MDIC

CAPACITAÇÃO TECNOLÓGICA- Significa a aquisição de capacidade de inovar, através principalmente do domínio das tecnologias em uso. É o estágio prévio e necessário para a ocorrência da inovação. Deve ser o objetivo principal da política tecnológica no que se refere às empresas. Não significa substituição de importação de tecnologia, envolvendo em geral, pelo contrário, compra de tecnologia de origem externa em condições de efetiva absorção. A capacitação tecnológica é também condição importante para a interação frutífera entre empresas e centros de P\&D.

GUIMARÃES, Fábio Celso de Macedo Soares. A Política de Incentivo à Inovação. Rio de Janeiro. FINEP, 2000.

CHAMADAS PÚBLICAS - Potítca de Fomento com seleção por meio de um processo de competição aberto ao público. Em geral, visam promover projetos cooperativos em determinada área do conhecimento ou atividades consorciadas entre empresas e instituições de pesquisa, com o objetivo de desenvolver uma inovação.

Política Operacional FINEP

CIÊNCIA - Conjunto organizado dos conhecimentos relativos ao universo, envolvendo seus fenômenos naturais, ambientais e comportamentais. A geração do conhecimento científico se 
faz através da pesquisa ou investigação científica, seguindo as etapas do método ou metodologia científica.

LONGO, W.P. Conceitos Básicos sobre Ciência e Tecnologia. Rio de Janeiro, FINEP, 1996. V.1.

OECD. Frascati Manual. Paris, OCDE, 1993, cap.2, pag.29

CLUSTERS - Empresas e/ ou instituições que interagem entre si, gerando e capturando sinergias, com potencial de atingir crescimento contínuo superior a uma simples aglomeração econômica, geograficamente próximas e pertencentes a um setor específico. Os Clusters se caracterizam pelos seguintes benefícios potenciais:

MCKINSEY \& COMPANY. Desenvolvimento dos programas de Ação para o "Cluster" de Biotecnologia em Belo Horizonte: Projeto Cresce Minas. Belo Horizonte, FIEMG/CIEMG/SESI/SENAI/IEL 1999. 163p.

COMPETITIVIDADE- No sentido estrito significa a capacidade de competir. No passado recente tem substituído a palavra "desenvolvimento" nos documentos de política econômica, sobretudo as industrial e tecnológica. Normalmente tem sido interpretada como a capacidade que os produtos gerados internamente têm de competir com seus similares produzidos no exterior, tanto no que se refere à importação como à exportação. No curto prazo a competitividade se traduz em preços, e é influenciada sobretudo pelas políticas cambial, fiscal e monetária e pelo crescimento econômico, já que este gera modernização. No longo prazo ela reflete a qualidade e a confiabilidade dos produtos, em geral expressas no prestígio da marca. A política de inovação é eficaz e decisiva para a competitividade apenas no longo prazo. GUIMARÃES, Fábio Celso de Macedo Soares. A Política de Incentivo à Inovação. Rio de Janeiro. FINEP, 2000.

DESENVOLVIMENTO DE PRODUTO- O desenvolvimento de um novo produto requer pesquisa, planejamento cuidadoso, controle meticuloso e, mais importante, o uso de métodos sistemáticos. Os métodos sistemáticos de projeto exigem uma abordagem interdisciplinar, abrangendo métodos de marketing, engenharia de métodos e a aplicação de conhecimentos sobre estética e estilo. A interação entre ciências sociais, tecnologia e arte aplicada não é tarefa fácil, mas a necessidade de inovação exige que ela seja tentada. $O$ desenvolvimento de novos produtos é um problema multifatorial: o sucesso ou fracasso depende de muitos fatores, tais como: simpatia dos consumidores, aceitação dos distribuidores, facilidade de fabricação, durabilidade e confiabilidade do produto. Portanto, o desenvolvimento de um produto é o sucesso de transformar uma idéia sobre um produto em um conjunto de instruções para a sua fabricação. Em cada etapa, devem ser abordados maiores detalhes do projeto. Os riscos e incertezas vão se reduzindo à medida que as decisões vão sendo tomadas. O processo de desenvolvimento de um produto envolve as etapas:

BAXTER, Mike . Projeto de Produto: guia prático para o desenvolvimento de novos produtos. Trad. Itiro lida. São Paulo, Editora Edgard Blucher Ltda., 1998.

DIFUSÃO TECNOLÓGICA - Processo de propagação de uma inovação técnica entre usuários potenciais ( adoção de uma nova técnica) e seu melhoramento e adaptação contínua. Os processos de inovação e difusão, particularmente de novas tecnologias, são interdependentes e se determinam simultaneamente estimulados pela interação usuários/produtor.

MARTíNEZ, Eduardo \& ALBORNOZ, Mário. Indicadores de ciência y tecnología: Estado del arte y perspectivas. Caracas, Unesco, 1998.

EMPRESA DE ALTA TECNOLOGIA - Unidades de negócios produtoras de bens e serviços, cuja competitividade depende do projeto, desenvolvimento e produção de novos produtos ou processos inovadores, através da aplicação sistemática e intensiva de conhecimentos científicos e tecnológicos.

MARTíNEZ, Eduardo \& ALBORNOZ, Mario. Indicadores de ciencia y tecnología: Estado del arte y perspectivas. Caracas, Unesco, 1998.

EMPRESA DE BASE TECNOLÓGICA - Empresa de qualquer porte ou setor que tenha na inovação tecnológica os fundamentos de sua estratégia competitiva. Esta condição será considerada atendida pelas empresas que apresentam pelo menos duas das seguintes características:

a) desenvolvam produtos ou processos tecnologicamente novos ou melhorias tecnológicas significativas em produtos ou processos existentes. $\mathrm{O}$ termo produto se aplica tanto a bens como a serviços;

b) obtêm pelo menos $30 \%$ (trinta por cento) de seu faturamento, considerando-se a média mensal dos últimos doze meses, pela comercialização de produtos protegidos por patentes ou direitos de autor, ou em processo de obtenção das referidas proteções; 
c) encontram-se em fase pré-operacional e destinam pelo menos o equivalente a $30 \%$ (trinta por cento) de suas despesas operacionais, considerando-se a média mensal dos últimos doze meses, a atividades de pesquisa e desenvolvimento tecnológico;

d) não se enquadram como micro ou pequena empresa e destinam pelo menos $5 \%$ (cinco por cento) de seu faturamento a atividades de pesquisa e desenvolvimento tecnológico;

e) não se enquadram como micro ou pequena empresa e destinam pelo menos $1,5 \%$ (um e meio por cento) de seu faturamento a instituições de pesquisa ou universidades, ao desenvolvimento de projetos de pesquisa relacionados ao desenvolvimento ou ao aperfeiçoamento de seus produtos ou processos;

f) empregam, em atividades de desenvolvimento de software, engenharia, pesquisa e desenvolvimento tecnológico, profissionais técnicos de nível superior em percentual igual ou superior a $20 \%$ (vinte por cento) do quantitativo total de seu quadro de pessoal;

g) empregam, em atividades de pesquisa e desenvolvimento tecnológico, mestres, doutores ou profissionais de titulação equivalente em percentual igual ou superior a $5 \%$ (cinco por cento) do quantitativo total de seu quadro de pessoal.

Política Operacional FINEP

EMPRESAS NASCENTES DE BASE TECNOLÓGICA ("START UP") - Empresa cuja estratégia empresarial e de negócios é sustentada pela inovação e cuja base técnica de produção está sujeita a mudanças freqüentes, advindas da concorrência centrada em esforços continuados de pesquisa e desenvolvimento tecnológico. Principais características das empresas nascentes de base tecnológica:

1. Em estruturação empresarial ("quase-empresa"),

2. Sem posição definida no mercado;

3. Inseridas ou não em incubadoras;

4. Que buscam oportunidades em nichos de mercado com produtos/serviços inovadores e de alto valor agregado.

FINEP. Superintendência de Estudos e Estratégias Setoriais . Categorização das Empresas Clientes Finep. Rio de janeiro, 2000.

ENGENHARIA - Faz a concepção da produção de bem ou de serviço, estuda sua viabilidade técnica e econômica, projeta e implanta as instalações físicas e, conforme o caso, também as opera.

LONGO, W.P. Conceitos Básicos sobre Ciência e Tecnologia. Rio de Janeiro, FINEP, 1996. V.1.

ESTUDO DE VIABILIDADE - Investigação de projetos técnicos propostos, usando as técnicas pré-existentes, a fim de fornecer informações complementares antes da decisão quanto à implementação. No campo das ciências sociais, os estudos de viabilidade constituem-se em investigações sobre as características sócio-econômicas e as implicações decorrentes de situações específicas, ( p.ex. um estudo sobre a viabilidade de implantação de um complexo petroquímico numa certa região).

OECD. Frascati Manual. Paris, OCDE, 1993, cap.2, pag.29

FOMENTO DIRETO - é a ação sistemática de agências de fomento científico e tecnológico na busca de oportunidades para promover a inovação junto a empresas e organizações públicas e privadas de pesquisa.

Política Operacional - FINEP

GESTÃO TECNOLÓGICA - Aplicação das técnicas de gestão em apoio a processos de inovação tecnológica. Integra princípios e métodos de gestão (administração), avaliação, economia, engenharia, informática e matemática aplicada. Na Gestão Tecnológica se identificam necessidades e oportunidades tecnológicas e se planejam, desenham, desenvolvem e implantam soluções tecnológicas. Constituem um processo de administração das atividades da pesquisa tecnológica e da transferência dos seus resultados às unidades produtivas. O que é importante para a competitividade (e a produtividade) é a capacidade de demarcar os desenvolvimentos tecnológicos (inovação, progresso técnico) dentro de uma estratégia da empresa.

MARTíNEZ, Eduardo \& ALBORNOZ, Mario. Indicadores de ciencia y tecnología: Estado del arte y perspectivas. Caracas, Unesco, 1998. 
IMPACTO AMBIENTAL - Qualquer alteração no sistema físico, químico, biológico, cultural e sócio-econômico que possa ser atribuída a atividades humanas relativas às alternativas em estudo para satisfazer as necessidades de um projeto.

CANTER, L. Environmental impact assessment. Oklahoma, McGraw Hill Inc., 1977, 331p.

INCUBADORA DE EMPRESAS - Uma incubadora de empresas é um ambiente flexível e encorajador onde é oferecida uma série de facilidades para o surgimento e crescimento de novos empreendimentos. Além da assessoria na gestão técnica e empresarial da empresa, a incubadora oferece a infra-estrutura e serviços compartilhados necessários para 0 desenvolvimento do novo negócio, como espaço físico, salas de reunião, telefone, fax, acesso à internet, suporte em informática, entre outros. Dessa forma, as incubadoras de empresas geridas por órgãos governamentais, universidades, associações empresariais e fundações são catalisadoras do processo de desenvolvimento e consolidação de empreendimentos inovadores no mercado competitivo. Com base na utilização do conhecimento profissional e prático, os principais objetivos de uma incubadora de empresas estão na produção de empresas de sucesso e na criação de uma cultura empreendedora.

FINEP - 2009

INFRA-ESTRUTURA DE P\&D - Conjunto de condições materiais de apoio e instalações físicas para implementação de atividades de pesquisa e desenvolvimento (equipamentos e laboratórios de P\&D, instituições de P\&D, etc).

MINISTÉRIO DA CIÊNCIA E TECNOLÓGIA - MCT. Conceitos (Glossário). 1997.

INOVAÇÃO - É a introdução no mercado de produtos, processos, métodos ou sistemas não existentes anteriormente ou com alguma característica nova e diferente da até então em vigor. GUIMARÃES, Fábio Celso de Macedo Soares. FINEP. Rio de Janeiro, 2000.

INOVAÇÃO DE PROCESSO TECNOLÓGICO- É a adoção de métodos de produção novos ou significativamente melhorados, incluindo métodos de entrega dos produtos. Tais métodos podem envolver mudanças no equipamento ou na organização da produção, ou uma combinação dessas mudanças, e podem derivar do uso de novo conhecimento. Os métodos podem ter por objetivo produzir ou entregar produtos tecnologicamente novos ou aprimorados, que não possam ser produzidos ou entregues com os métodos convencionais de produção, ou pretender aumentar a produção ou eficiência na entrega de produtos existentes. Em algumas indústrias de serviço, a distinção entre processo e produto pode ser nebulosa. Por exemplo, uma mudança de processo em telecomunicações para introdução de uma rede inteligente pode permitir a oferta ao mercado de um conjunto de novos produtos, tais como espera de chamada ou visualização da chamada. Para um melhor entendimento sugerimos consultar o Manual Oslo.

OECD. Oslo Manual. Paris, OCDE/Eurostat, 1997, cap.3, pag.51.

INOVAÇÃO INCREMENTAL- É a introdução de qualquer tipo de melhoria em um produto, processo ou organização da produção dentro de uma empresa, sem alteração na estrutura industrial.

LEMOS C., Inovação na Era do Conhecimento. IN: Parcerias Estratégicas, ํo8, maio, 2000, MCT.

INOVAÇÃO RADICAL- É a introdução de um novo produto, processo ou forma de organização da produção inteiramente nova. Este tipo de inovação pode representar uma ruptura estrutural com o padrão tecnológico anterior, originando novas indústrias, setores ou mercados.

LEMOS C., Inovação na Era do Conhecimento. IN: Parcerias Estratégicas, ํo8, maio, 2000, MCT

PARQUES TECNOLÓGICOS - "Parques-tecnológicos" são iniciativas planejadas que visam criar condições favoráveis para que as tecnologias desenvolvidas nas universidades e institutos de pesquisa e desenvolvimento sejam transferidas para o setor de produção, via pesquisadores que criam ou participam da criação de empresas com o emprego das tecnologias geradas. Os importantes elementos para a caracterização dos parques tecnológicos seriam, portanto, o seu caráter planificado e presença de empresas nascentes criadas a partir de tecnologias geradas nas instituições de P\&D.

FREEMAN ,C. e PEREZ ,C., in Technical Change and Economic Theory. London, 1988.

PESQUISA - É uma atividade realizada com o objetivo de produzir novos conhecimentos, geralmente, envolvendo experimentação. Na maior parte das vezes, é utilizada para designar 
atividades que poderiam ser denominadas de censo, levantamento de dados ou coleta de informações. Três categorias podem ser distinguidas no âmbito da pesquisa: Pesquisa Básica, Pesquisa Aplicada, Desenvolvimento Experimental

LONGO, W.P. Conceitos Básicos sobre Ciência e Tecnologia. Rio de Janeiro, FINEP, 1996. V.1.

PESQUISA E DESENVOLVIMENTO - P\&D - É O trabalho criativo e empreendido em base sistemática com vistas a aumentar o estoque de conhecimento, incluindo o conhecimento do homem, da cultura e da sociedade, e ao uso desse estoque para perscrutar novas aplicações. Política Operacional - FINEP

PÓLO TECNOLÓGICO/TECNÓPOLIS - São grandes áreas com infra-estrutura necessária para unidades produtivas que realizam atividades de baixa ou grande escala, baseadas em pesquisa e desenvolvimento tecnológico. Nessas áreas, são oferecidos serviços que facilitam a obtenção de recursos tecnológicos e humanos de alto nível, acesso a centros de investigações, bibliotecas e serviços de documentação especializada e de contratação de projetos tecnológicos.

ANPROTEC. Parques Tecnológico.

PROPRIEDADE INTELECTUAL - A propriedade, no seu sentido lato, é o poder irrestrito de uma pessoa sobre um bem. A propriedade dos bens imateriais é regida por regras específicas constituindo o Direito de Propriedade Intelectual. A propriedade é irrestrita quando não está condicionada a parâmetros que a restrinjam ou limitem. É restrita quando fica condicionada a certas prerrogativas, principalmente, ligadas ao tempo e ao espaço. A propriedade intelectual pode ser conceituada como o direito de uma pessoa sobre um bem imaterial. As regras, ou leis, que disciplinam esse direito, comumente, estabelecem as relações de dependência entre a propriedade de bem imaterial e alguns parâmetros. A propriedade intelectual está voltada para o estudo das concepções inerentes aos bens tangíveis que, de modo geral, podem ser enquadrados nas categorias: artísticas, técnicas e científicas. As criações artísticas englobam as obras literárias, escritas ou orais; as obras musicais, cantadas ou instrumentadas; as obras estéticas bidimensionais (desenhos, pinturas, gravuras, litografias, fotografias, etc.) ou tridimensionais (esculturas e obras de arquitetura). As criações técnicas referem-se às invenções. As regras de propriedade, ou de proteção, estão dispostas nas leis de patentes estabelecidas pelas nações, as quais, não obstante adotarem um consenso universal, amoldam-se aos interesses específicos de cada nação. As concepções científicas são, por essência as descobertas nos diversos campos da física, da química, da biologia, da astronomia, etc. A descoberta não é passível de ser protegida. $O$ autor de uma descoberta não faz jus à sua propriedade: quando muito é agraciado pelas academias de ciência. $O$ fato pode ser interpretado por não se considerar a descoberta como a criação de algo novo. Trata-se, isto sim, de um fenômeno natural, ignorado até então. O autor teve o mérito de antecipar a sua revelação, ou conhecimento à humanidade. Trata-se de um descobridor, não de um criador; não tendo pois direito de propriedade. A propriedade intelectual procura regular as ligações do autor, ou criador, com o bem imaterial. Estabelece as regras de procedimento para a obtenção do privilégio, bem como a atuação das autoridades que intervêm nessa matéria.

DI BLASI, Clésio Gabriel. A propriedade Industrial. Rio de Janeiro, Editora Guanabara Dois S.A., 1982.

PROSPEÇÃO TECNOLÓGICA - São "tentativas sistemáticas para observar, a longo prazo, o futuro da ciência, a tecnologia, a economia e a sociedade, com o propósito de identificar as tecnologias emergentes que provavelmente produzirão os maiores benefícios econômicos e/ou sociais" -

OCDE

SERVIÇOS TÉCNICOS ESPECIALIZADOS - Referem-se aos serviços laboratoriais de aferição e calibração, dosagens, determinações e testes de desempenho para qualificação de produtos e processos industriais, padronizados e fundamentados em normas técnicas ou procedimentos sistematizados. MINISTÉRIO DA CIÊNCIA E TECNOLOGIA - MCT.

SISTEMA DE INOVAÇÃO - É um conjunto de instituições distintas que conjuntamente e individualmente contribuem para o desenvolvimento e difusão de tecnologias. Tal noção envolve, portanto, não apenas empresas mas, principalmente, instituições de P\&D, de financiamento, de governo, etc.

CASSIOLATO, J. E. \& LASTRES, H. M., IN: Parcerias Estratégicas, ํo8, maio/2000, MCT. 
START-UP CAPITAL - É o capital fornecido para a empresa iniciar suas atividades como, por exemplo, o aluguel de sua sede, a aquisição de equipamentos e instalações e a contratação de pessoal.FINEP. Projeto Inovar

TECNOLOGIA - "Tecnologia é o conjunto ordenado de conhecimentos empregados na produção e comercialização de bens e serviços, e que está integrada não só por conhecimentos científicos - provenientes das ciências naturais, sociais, humanas, etc. - , mas igualmente por conhecimentos empíricos que resultam de observações, experiência, atitudes específicas, tradição (oral ou escrita), etc.

Sábato 1972 


\section{REFERÊNCIAS BIBLIOGRÁFICAS}

1. ALBUQUERQUE. E. M.; BAESSA. A. R.; KIRDEIKAS. J.C.V.; SILVA. L. A.; RUIZ. R. M. Produção Científica E Tecnológica das Regiões Metropolitanas Brasileiras. R. Economia contemporânea. Rio de Janeiro, 9(3): pp. 615-642, set./dez. 2005.

2. ALBUQUERQUE. E. M. Immature systems of innovation: introductory notes about a comparison between South Africa, India, Mexico and Brazil based on science and technology statistics. Texto para discussão. Belo Horizonte: UFMG/Cedeplar, 2003. Disponível em http://www.cedeplar.ufmg.br. Acesso em 01/12/2008.

3. ALLEN, J. Third Generation Science Parks. Manchester Science Parks - Battelle Memorial Institute, 2007. Disponível em http://www.batelle.org. Acesso em 02/03/2008.

4. ALMEIDA, S. Dinâmica Industrial e cumulatividade Tecnológica. 2003. Dissertação de Mestrado. Universidade Federal do Rio de Janeiro UFRJ.

5. ALVES-MAZZOTTI. A J. Uso e abuso dos estudos de caso. Cadernos de Pesquisa, v. 36, n. 129, set./dez. 2006.

6. AMSDEN, A. The rise of "the rest": challenges to the West from late-industrializing economies. Oxford: Oxford University, 2001.

7. ANPROTEC: SEMINÁRIO INTERNACIONAL DA ANPROTEC 2006. Apresentação: Modelos dos Eixos estratégicos. SANZ, L. Minas Gerais, 2006.

8. ANPROTEC. Parques Tecnológicos no Brasil. Estudo, Análise e Proposições. Disponível em: www.anprotec.org.br. Acesso em 22/12/2008.

9. ANPROTEC 2008. Portifólio de Parques Tecnológicos no Brasil. Versão de trabalho. Dezembro de 2008. Disponível em: www.anprotec.org.br. Acesso em 22/12/2008.

10. ANPROTEC: Panorama Anual 2005. Disponível em http://www.anprotec.org.br. Acesso em 01/10/2008.

11. AURP - Association of University Research Parks. Profile 2003. Disponível em http://www.aurp.net/. Acesso em 12/12/2007.

12. ARBACHE, J. S. Inovações Tecnológicas e Exportações afetam o tamanho e a produtividade das firmas manufatureiras? evidências para o Brasil. In: DE NEGRI, J. A.; SALERNO, M. S. (Org.). Inovações, padrões tecnológicos e desempenho das firmas industriais brasileiras. Brasília: IPEA, 2005. 
13. ARI, M. Administração José Crespo Gonzales: 1969-1973. Sorocaba, SP: do autor, coleção: Sorocaba em tempo de Desenvolvimento, 2006.

14. ASHEIM, B. T.; ISAKSEN, A. Regional Innovation Systems: The Integration of Local 'Sticky' and Global 'Ubiquitous' Knowledge. Journal of Technology Transfer, 27, pp. 77-86, 2002.

15. AUDRETSCH, D. B.; THURIK, A. R. What's new about the new economy? Sources of growth in the managed and entrepreneurial economies. Industrial and Corporate Change 10 (1): 267-315, mar. 2001.

16. BATTELLE MEMORIAL INSTITUTE. Characteristics and trends in North American Research Parks: 21st Century Directions. United States of America, 2007. Disponível em http://www.batelle.org. Acesso em 02/03/2008.

17. BÊRNI, D. A . Técnicas de pesquisa em economia. Editora Saraiva. São Paulo: 2002.

18. BORRAS, S. System of Innovation theory and the European Union. Science and Public Policy, v. 31. n. 6. December 2004.

19. BRISOLA, S.; CORDER, S.; GOMES, E.; MELLO, D. As relações universidade-empresa-governo: Um estudo sobre a Universidade Estadual de Campinas. Educação \&Sociedade, ano XVIII, n. 61, DEZEMBRO/97

20. BRUNET, M. O modelo francês de inovação tecnológica: dos Parques Tecnológicos aos Pólos de Competitividade. Working Paper. Consulado da França em São Paulo, 2007.

21. CASAROTTO, F.N. Instrumentos de Integração e governança em Aglomerações Competitivas, Universidade Federal De Santa Catarina. Disponível em: http://www.ucdb.br/coloquio/arquivos/Casarotto.pdf. Acesso em 05/01/2009.

22. CASSIOLATO, J. E. e LASTRES, L. M. M. sistemas de inovação: políticas e perspectivas, Parcerias Estratégicas, Centro de Estudos Estratégicos, Brasília, n. 8. pp 237-255, Maio, 2000.

23. CASSIOLATO, J. E.; LASTRES, H. M. M. O foco em arranjos produtivos e inovativos locais de micro e pequenas empresas. In: Lastres, H. M. M.; Cassiolato, J. E.; Maciel, M. L. (orgs.), Pequenas empresas : cooperação e desenvolvimento local. Relume Dumará Editora, julho, 2003.

24. CASSIOLATO, J. E.; SZAPIRO, M. Aglomerações e sistemas produtivos e inovativos locais: em busca de uma caracterização voltada ao caso brasileiro. Rio de Janeiro: UFRJ. Instituto de Economia Industrial, mar. 2002, 36p.

25. CRESWELL, J. Research design: qualitative and quantitative approaches. Thousand Oaks: Sage Publications, 1994. 
26. DAGNINO, R. A relação universidade-empresa no brasil e o argumento da hélice tripla. Revista brasileira de Inovação. v. 2 n. 2 julho / dezembro 2003

27. DARMON, D. Pôles de compétitivité : des accélérateurs d'innovation. Annales du bâtiment et des travaux publics. (fra). $N^{\circ} 3$, .- pp. 5-11. Juin 2006

28. EDQUIST, C.Reflections on the systems of innovation approach. Science and Public Policy. v. 31, n. 6. December 2004.

29. EISENHARDT. K. Building theories from case study research. Academy of Management Review., v. 14. n. 04. P. 532-550. 1989.

30. ESTATUTO SOCIAL da Agência de Desenvolvimento e Inovação de Sorocaba - INOVA, elaborado pela Dr. Désirée Zouain em 08/05/2007. Documento dísponel na INOVA.

31. ETZKOWITZ, H.; Entrepreneurial science in the academy: a case of transformation of norms", In Social Problems, v.36, n.1, p.14-29, fev., 1989.

32. FELDMAN, M. The geography of innovation. Netherlands: Kluwer Academic Publishers, 1994.

33. FELDMAN, M. P., FLORIDA, R. The geographic sources of innovation: technological infrastructure and product innovation in the United States. Annals of the Association of American Geographers, v. 84, n. 2, p. 210-229, June 1994.

34. FIGLIOLI, A. Perspectivas de financiamentos de Parques Tecnológicos: um estudo comparativo. Dissertação de Mestrado. Universidade de São Paulo, 2007.

35. FREEMAN, C. The National System of Inovation in Historical Perspective. Cambridge Journal of Economics, v. 19, n 1, pp.5-24, 1995.

36. FUNDAÇÃO DE AMPARO À PESQUISA DO ESTADO DE SÃO PAULO PROGRAMA DE PESQUISA EM POLÍTICAS PÚBLICAS Projeto: Modelo Conceitual de Ambiente de Inovação para o Município de Guarulhos RELATÓRIO FINAL - FASE I - PROCESSO № 2007/55126-8180.

37. FUNDAÇÃO DE AMPARO À PESQUISA DO ESTADO DE SÃO PAULO - FAPESP. Indicadores de ciência, tecnologia e inovação em São Paulo: 2004. Organização de Francisco Romeu Landi. São Paulo: Fapesp, 2004.

38. FURTADO, J. Limites e possibilidades do Brasil nas configurações produtivas globalizadas uma análise apoiada em diversas cadeias. III Relatório Parcial de Pesquisa. Geein/DE/Unesp e Ipea, 2000. 
39. FURTADO, A. D. QUADROS, R. Padrões de intensidade tecnológica da indústria brasileira um estudo comparativo com os países centrais. São Paulo em perspectiva, v. 19, n. 1, p. 70-84, jan./mar. 2005.

40. GEREFFI, G. Competitividade e redes na cadeia produtiva do vestuário na américa do norte. Revista latino-americana de estudos do trabalho, v. 4, n. 6,1998, p. $101-27$

41. GILSING, V. Cluster governance: How clusters can adapt and renew over time. Working Paper, prepared for the DRUID PhD-conference, Copenhagen, January 2000. Erasmus universituy, depto. of business studies, Rotterdam, 2000.

42. GONÇALVES, E. Firma e território: três ensaios sobre inovação em ambientes periféricos. 2007. TESE (doutorado). CEDEPLAR. Universidade Federal de Minas Gerais.

43. GRAÇA, C.A. Governança e Inovação Tecnológica em Apls: "Um Estudo De Caso no do APL Calçadista de Birigüi (SP), (anos 1990 2000"). 2007. Tese de Doutorado, Universidade de São PAulo.

44. HART, C. Doing a Literarure Review. London: sage, 1998.

45. IASP (International Association of Science Parks) The IASP in a few slides. Disponível em http://www.iasp.ws. Acesso em 13/10/2008.

46. IASP Survey on STPs (2004/2004) - Worldwide statistics about Science \& Technology Parks: facts \& figures. Disponível em http://www.iasp.ws/publico/index. Acesso em 13/08/2006.

47. IASP Survey on STPs (2007/2007) - Worldwide statistics about Science \& Technology Parks: facts \& figures. Disponível em http://www.iasp.ws/publico/index. Acesso em 13/10/2008.

48. IPEA. Identificação, mapeamento e caracterização estrutural de Arranjos produtivos locais no brasil. Org: SUZIGAN, W. IPEA. Relatório Consolidado, 2006.

49. KANG. B. A Study on the Establishing Development Model for Research Parks. Journal of Technology Transfer, 29, 2; ABI/INFORM Global. Apr 2004

50. KYSIAK, R. United States Research Parks in a Down Economy: Retrenching And Changes. Evanston: northwestern university, 2004.

51. LARÉDO, P.; MUSTAR, P. Innovation and research policy in France (1980-2000) or the disappearance of the Colbertist state. Research Policy. 31 (2002)

52. LIU, X., WHITE, S. Comparing Innovation Systems: A Framework and Application to China's Transitional Context. Research Policy, v. 30, n. 7, pp. 1091-1114(24). August 2001. 
53. LUNARDI, M. E. Parques tecnológicos: estratégias de localização em Porto Alegre, Florianópolis e Curitiba. Curitiba: Edição do autor, 1997, p. 16.

54. LUNDVALL, B.A. User-producer Relationships and National System of Inovation. In: Lundvall, B-A. (org.), National System of Innovation: Towards a Theory of Innovation and Interactive Learning. Londres: Printer, 1992.

55. LUNDVALL, B.A. National Innovation Systems-Analytical Concept and Development Tool. Industry and Innovation; v.14, n.1; ABI/INFORM Global, Feb 2007;

56. MALERBA, F. Sectoral system and Innovation and Technology Policy. Revista Brasileira de Inovação. V. 2 n. 2 Julho / Dezembro 2003

57. MATIAS-PEREIRA, J., KRUGLIANZSKAS, I. Gestão de inovação: a lei de inovação tecnológica como ferramenta de apoio às políticas industrial e tecnológica do brasil. Rae-eletrônica, v. 4, n. 2, art. 18, jul./dez. 2005.

58. MEREDITH, J. Building operations management theory through case and field research. Journal of Operations Management. 16. P. 441-454. 1998.

59. MEYER, R.M.P. Atributos da Metrópole Moderna. São Paulo Perspectiva. vol.14 no.4 São Paulo Oct./Dec. 2000

60. MOBIT - Plano de Mobilização Brasileira pela Inovação Tecnológica. ABDI/CEBRAP. Workshop de apresentação e discussão de resultados. Produto 5: Relatórios de Viagem (Reino Unido, França, Finlândia e Japão) com os resultados dos trabalhos de campo no exterior. 2007

61. MOBIT - Plano de Mobilização Brasileira pela Inovação Tecnológica. ABDI/CEBRAP. Relatório Final do Projeto. 2007

62. MOWERY, D. C.; ROSENBERG, N. Trajetórias da inovação. Tradutor: Marcelo Knobel. Campinas, SP: Editora Unicamp, 2005.

63. NELSON, R. (ed.) National innovation systems: a comparative analysis. New York, Oxford: Oxford University, 1993.

64. OCDE. Manual de Oslo: proposta de diretrizes para coleta e interpretação de dados sobre Inovação tecnológica. Brasília: OCDE, FINEP, 2004.

65. Parasuraman, A., Zeithaml, V.A. \& Berry, L.L. A conceptual model of service quality and its implication for future research. Journal of Marketing, Vol.49, Autumn, pp.41-50. 1985

66. PATTON, M. Q. Qualitative Evaluation and Research Methods. California: sage publications, 1990. 
67. PIORE, M. J.; SABEL, C. The Second Industrial Divide: Possibilities for Prosperity. New York: Book, 1984.

68. PINTEC, Pesquisa de Inovação Tecnológica 2005. Disponível em http://www.pintec.ibge.gov.br. Acesso em: 08/12/2008.

69. PLONSKI, G.A. Cooperação universidade-empresa: um desafio gerencial complexo. RAUSP. V.. 34, n. 4, p. 5-12, 1999.

70. PLONSKI, G. A. SEMINÁRIO PROJETO FAPESP: Modelo de Ambiente de Inovação para o Município de Guarulhos. Apresentação: Movimento dos Parques tecnológicos. São Paulo FEA/USP, 2008.

71. PORTER, M. E. A Vantagem Competitiva das nações. Campus, Rio Janeiro, Campus, 1989

72. POSSA, M. Concorrência Schumpeteriana. In: KUPLER, D; HASENCLEVER, L. (orgs). Economia Industrial: Fundamentosnteóricos e práticos no Brasil. Rio de Janeiro: Campus, 2002.

73. PROJETO EUROBRASIL 2000. Texto de referência em planejamento e gestão territorial. Ministério de planejamento, orçamento e gestão, Brasília, 2006. Disponível em: http://www. planejamento.gov.br. Acesso em 12/09/2008.

74. QUADROS, R.; BRISOLLA, S.; FURTADO, A.; BERNARDES, R.. Força e fragilidade do sistema de inovação paulista. São Paulo Perspectiva. (online). v. 14, n. 3, pp. 124-141. 2000.

75. RAPINI, M. S. Interação universidade-empresa no Brasil: evidências do diretório dos grupos de pesquisa do CNPq. Estud. Econ. v. 37, n. 1, p. 211233, janeiro-março 2007

76. RICHARDSON, G.B. The organization of industry. Economic journal, n. 82, p. 883-896, 1972.

77. REDESIST. Rede de Pesquisas Sistemas e Arranjos Produtivos e Inovativos Locais. Disponível em: http://www.redesist.ie.ufrj.br/. Acesso em: 01/10/2008.

78. SCHUMPETER, J.A. Teoria do Desenvolvimento Econômico. Editora Fundo de Cul tura, Rio de Janeiro, 1961.

79. SCHUMPETER, J. A. Teoria do desenvolvimento econômico: uma investigação sobre lucros, capital, crédito, juro e o ciclo econômico. São Paulo: abril cultural, 1982

80. SILVA, M. M.; CAMPANÁRIO, M. A.; ROVAI, R. L.; COSTA, T. R. Entendendo as dimensões críticas do progresso técnico. In: RUIZ, M. S.; MACHADO, E. L. (org). Observatório de Tecnologia e Inovação: a experiência paulista no período de 2002 a 2005. São Paulo: IPT, Instituto de Pesquisas Tecnológicas do Estado de São Paulo, 2006. 
81. SOUZA, Nali de Jesus de. Teoria dos Pólos, Regiões Inteligentes e Sistemas Regionais de Inovação. Análise. Porto Alegre v. 16 n. 1 p. 87-112 jan./jul. 2005.

82. STRAFORINI, R. No Caminho das Tropas. Sorocaba: TCM comunicação, 2001

83. SUZIGAN, W.; GARCIA, R.; FURTADO, J. Governança em sistemas de MPMEs em clusters industriais. In: LASTRES, H.; CASSIOLATO, J.E.; MACIEL,M.L. (orgs.) Pequena Empresa: cooperação e desenvolvimento local. Rio de Janeiro: Relume Dumará, 2003, 556 p. (pág. 63-83).

84. SUZIGAN, W., FURTADO, J.; GARCIA, R.; SAMPAI, S. E. K. Inovação e conhecimento: indicadores regionalizados e aplicação a São Paulo. In: XXXII encontro nacional de economia, da Anpec - Associação Nacional de Centros de Pós-graduação em Economia. João Pessoa, Dezembro, 2004.

85. TIGRE, P. B. Gestão da Inovação. A economia da Tecnologia no Brasil. Rio de Janeiro: Elsevier, 2006.

86. VARGAS, M. Proximidade Territorial, aprendizado e inovação: Um estudo sobre a dimensão local dos processos de capacitação inovativa em arranjos e sistemas produtivos locais, 2002. Tese (Doutorado) Universidade Federal do Rio de Janeiro.

87. VEDOVELLO, C. A., JUDICE, V.M.M., MACULAN, A.M.D. Revisão Crítica às abordagens a parques tecnológicos: alternativas interpretativas às experiências brasileiras recentes. RAI - Revista de Administração e Inovação. São Paulo: NPGT-USP, v.3 n.2 p.103-118, 2006.

88. VIOTTI, E. B.; BAESSA, A. R.; KOELLER, P. Perfil da Inovação na Indústria Brasileira: uma comparação internacional. In: DE NEGRI, J. A.; SALERNO, M. S. (Org.). Inovações, padrões tecnológicos e desempenho das firmas industriais brasileiras. Brasília: IPEA, 2005.

89. VOSS, C. TSIKRIKTSIS, N,. FROHLICH, M.; Case research in operations management. International journal of operation \& production management, v. 22. N.02.. Pags 195-209. 2002

90. ZOUAIN, D. M. Parques Tecnológicos - Propondo um modelo conceitual para regiões urbanas - $O$ Parque Tecnológico de São Paulo. 2003. Tese (Doutorado), Instituto de Pesquisas Energéticas e Nucleares IPEN/USP, São Paulo.

91. ZOUAIN, D. M.; DAMIAO, D.; CATHARINO, M. Urban Technology Parks Model as instrument of Public Policies for regional/local development: Technology Park of Sao Paulo. XXII IASP - WORLD CONFERENCE ON SCIENCE AND TECHNOLOGY PARKS. Proceedings, 2006.

92. YIN, R. K. Case Study Research, Beverly Hills: Sage Publications, 1994. 
93. YIN, R. K. Case Study Research: Design and Methods. London: Sage, 1984.

94. YIN, R. K.; Applications Of Case Study Research. Thousand Oaks, California: Sage Publications. 1993.

95. YIN, R. K. Estudo de Caso Planejamento e Metodos. 3.ed. Porto Alegre: Bookman, 2005.

96. WILLIAMSON, O. The Economic Institutions Of Capitalism. New York: the free press. 1985

97. WRIGHT, J. T. C.; GIOVINAZZO, R. Delphi-uma ferramenta de apoio ao planejamento prospectivo. Caderno de Pesquisas em Administração.

Fia/Fea/USP. São Paulo: v. 01, n. 12, p.54-65, 2000.

Fontes Eletrônicas

100. ANDREW. Disponível em http://www.andrew.com - Acesso em 15/11/2007.

101. CONSELHO NACIONAL DE DESENVOLVIMENTO CIENTÍFICO E TECNOLÓGICO - CNPq. Disponível em http://www.cnpq.br - Acesso em 14/07/2007.

102. DAESP - Disponível em: www.daesp.sp.gov.br. acesso em 10 de fevereiro de 2008

103. DATASUS - Disponível

em:http://cnes.datasus.gov.br/Index.asp?Configuracao=1280\&bro=Microsoft $\% 2$ OInternet\%20Explorer Acesso em 02/10/2008.

104. DRAKTEL. Disponível em http://www.draktel.com.br - Acesso em 15/11/2007.

105. EADI. Disponível em http://www.eadiaurora.com.br/sorocaba - Acesso em 15/11/2007.

106. EMPRESA PAULISTA DE PLANEJAMENTO METROPOLITANO EMPLASA. Disponível em < http://www.emplasa.sp.gov.br >- Acesso em 14/07/2007.

107. FACENS - Disponível em : http://www.facens.br/ acesso em 10 de fevereiro de 2008

108. FADI - Disponível em: http://www.fadi.br/ acesso em 10 de fevereiro de 2008. 
109. FATECSOROCABA- Disponível em http://www.fatecsorocaba.edu.br/ acesso em 10 de fevereiro de 2008.

110. FINANCIADORA DE ESTUDOS E PROJETOS - FINEP. Disponível em http://www.finep.gov.br/ >- Acesso em 13/07/2007.

\section{FUNDAÇÃO DE AMPARO À PESQUISA DO ESTADO DE SÃO}

PAULO - FAPESP. Disponível em < http://www.fapesp.br/ >- Acesso em 13/07/2007. [33] A dimensão regional das atividades de C\&T\&I no Estado de São Paulo. Capítulo 09. Disponível em < http://www.fapesp.br/indicadores >-Acesso em 13/07/2007.

112. IBCT - Instituto Brasileiro de Informação em Ciência e Tecnologia. Disponível em: http://prossigas.ibct.br. Acesso em 10/04/2009.

113. IBGE. PINTEC - Pesquisa de inovação Tecnológica. Disponível em www.pintec.ibge.gov.br. Acesso em 10/10/2008

114. IHARA. Disponível em < http://www.ihara.com.br/ > - Acesso em 15/11/2007.

115. INEP-Disponível em: http://www.educacaosuperior.inep.gov.br. Acesso em 10 de fevereiro de 2008

116. INFRAERO - Disponível em: www.infraero.gov.br, Acesso em 10/10/2008.

117. INSTITUTE FOR SCIENTIFIC INFORMATION - ISI. National citation report. Disponível em: <http://www.isinet.com/rsg/ncr/>. Acesso em: fev. 2007.

118. INSTITUTO DE PESQUISAS ECONÔMICAS APLICADAS - IPEA.

Disponível em < http://www.ipea.gov.br_- Acesso em 03/02/2008.

119. JARAGUA. Disponível em < http://www.jaraguaequipamentos.com > Acesso em 15/11/2007.

120. LES PÓLES DE COMPETITIVITE. Disponível em: www.competitivite.gouv.fr Acesso em 21/02/2007.

121. KYOCERA. Disponível em < http://www.kyocera-yashica.com.br/ > Acesso em 15/11/2007.

122. MAPA DO MUNICÍPIO DE SOROCABA - IBGE - Instituto Brasileiro de Geografia e Estatística. Disponível em < http://mapas.ibge.gov.br > - Acesso em 10/07/2007.

123. METALAC. Disponível em < http://www.metalac.com.br/ > - Acesso em 15/11/2007.

124. METSO. Disponível em < http://www.metsominerals.com > - Acesso em 15/11/2007. 
125. MINISTÉRIO DA CIÊNCIA E TECNOLOGIA - MCT. Indicadores da Produção Científica. Disponível em: <www.mct.gov.br> Acesso em: fev. 2008.

126. NIPRO. Disponível em < http://www.nipro.com/ > - Acesso em $15 / 11 / 2007$.

127. PONTIFÍCIA UNIVERSIDADE CATÓLICA. Disponível em < http://www.sorocaba.pucsp.br/ > - Acesso em 13/07/2007.

128. Programa Plataformas Tecnológicas - IBP. Relatório de atividades.

Disponível em: www.ibp.org.br. Acesso em 04/03/2009

129. SEADE - Fundação Sistema Estadual de Análise de Dados. Disponível em < http://www.seade.gov.br/ > - Acesso em 15/11/2007.

130. SERVIÇOS - Relação de Empresas. Disponível em < http://www.sorocaba.sp.gov.br > - Acesso em 04/07/2007.

131. SOROCABA BUREAL - Disponível em:

http://www.sorocababureau.com.br/. Acesso em: 10/12/2008.

132. SOROCABA - História. Disponível em < http://www.sorocaba.sp.gov.br > - Acesso em 04/07/2007.

133. SOROCABA - Dados Gerais. Disponível em < http://www.sorocaba.sp.gov.br > - Acesso em 04/07/2007.

134. SOROCABA - Conheça Sorocaba. Disponível em < http://www.sorocaba.sp.gov.br > - Acesso em 04/07/2007.

135. SPLICE. Disponível em < http://www.splice.com.br/ > - Acesso em 15/11/2007.

136. TELCON. Disponível em < http://www.telcon.com.br/ > - Acesso em $15 / 11 / 2007$.

137. TURISMO - Como chegar. Disponível em < http://www.sorocaba.sp.gov.br > - Acesso em 04/07/2007.

138. UNISO - Disponível em http://www.uniso.br/ acesso em 10 de fevereiro de 2008

139. UNIVERSIDADE FEDERAL DE SÃO CARLOS. Disponível em < http://www.ufscar.br/ > - Acesso em 13/07/2007.

140. UNIVERSIDADE DE SOROCABA. Disponível em < http://www.uniso.br/ > - Acesso em 22/08/2007.

141. UNIVERSIDADE ESTADUAL PAULISTA. Disponível em < http://sorocaba.unesp.br/ > - Acesso em 22/08/2007. 
142. UNIVERSIDADE PAULISTA. Disponível em < http://www5.unip.br/ > Acesso em 13/07/2007.

143. ZF DO BRASIL. Disponível em < http://www.zf.com.br/ > - Acesso em $15 / 11 / 2007$. 